PAULO HENRIQUE RIBEIRO

\title{
CONTRIBUIÇÃO AO BANCO DE DADOS BRASILEIRO PARA APOIO À AV ALIAÇÃO DO CICLO DE VIDA: FERTILIZANTES NITROGENADOS
}

São Paulo 2009 
PAULO HENRIQUE RIBEIRO

\section{CONTRIBUIÇÃO AO BANCO DE DADOS BRASILEIRO PARA APOIO À AV ALIAÇÃO DO CICLO DE VIDA: FERTILIZANTES NITROGENADOS}

Tese apresentada à Escola

Politécnica da Universidade de São

Paulo para obtenção do título de Doutor em Engenharia

São Paulo 
PAULO HENRIQUE RIBEIRO

CONTRIBUIÇÃO AO BANCO DE DADOS BRASILEIRO PARA APOIO À AV ALIAÇÃO DO CICLO DE VIDA: FERTILIZANTES NITROGENADOS

Tese apresentada à Escola

Politécnica da Universidade de São

Paulo para obtenção do título de

Doutor em Engenharia

Área de Concentração:

Engenharia Química

Orientador:

Prof. Dr. Gil Anderi da Silva

São Paulo 


\section{FICHA CATALOGRÁFICA}

Ribeiro, Paulo Henrique

Contribuição ao banco de dados brasileiro para apoio a avaliação do ciclo de vida: fertilizantes nitrogenados / P.H. Ribeiro.

-- São Paulo, 2009.

$341 \mathrm{p}$.

Tese (Doutorado) - Escola Politécnica da Universidade de São Paulo. Departamento de Engenharia Química.

1. Fertilizantes 2. Gestão ambiental 3. Prevenção de perdas I. Universidade de São Paulo. Escola Politécnica. Departamento de Engenharia Química II. t. 
RIBEIRO, Paulo Henrique. Contribuição ao banco de dados brasileiro para apoio à avaliação do ciclo de vida: fertilizantes nitrogenados. São Paulo, 2009. (Doutorado) Escola Politécnica, Universidade de São Paulo, São Paulo, 2009.

\section{ERRATA}

\begin{tabular}{|c|c|c|c|}
\hline PÁGINA & LINHA & ONDE SE LÊ & LEIA-SE \\
\hline 04 & $14^{\underline{a}}$ & drasticamente & significativamente \\
\hline 05 & $13^{\mathrm{a}}$ & organismos & espécies \\
\hline 05 & $23^{a}$ & encontrar maneira & encontrar uma maneira \\
\hline 11 & $12^{\mathrm{a}}$ & antes de estes & antes destes \\
\hline 18 & $9^{\underline{a}}$ & tem sido um dos & tem sido uma das \\
\hline 18 & $23^{\mathrm{a}}$ & Ao longo dos amos & Ao longo dos anos \\
\hline 22 & $16^{\mathrm{a}}$ & Associação Brasileria & Associação Brasileira \\
\hline 23 & $17^{\mathrm{a}}$ & para o cicio de vida & para o ciclo de vida \\
\hline 25 & $20^{\mathrm{a}}$ & publicadas & produzidas \\
\hline 29 & $29^{\underline{a}}$ & com uma das & como uma das \\
\hline 35 & $2^{\mathrm{a}}$ & na elaboração de este & na elaboração deste \\
\hline 36 & $8^{\underline{a}}$ & aos resultados de este & aos resultados deste \\
\hline 66 & $9^{\mathrm{a}}$ & Os principais softwares & Alguns softwares \\
\hline 73 & $24^{\underline{a}}$ & $\begin{array}{c}\text { instituições } \\
\text { governamentais }\end{array}$ & $\begin{array}{l}\text { instituições governamentais } \\
\text { e privadas }\end{array}$ \\
\hline 89 & $18^{\mathrm{a}}$ & econômico de estes & econômico destes \\
\hline 94 & $14^{\underline{a}}$ & baseada & baseadas \\
\hline 99 & $20^{\mathrm{a}}$ & $\begin{array}{c}\text { Caso seja significativa, } \\
\text { segue-se }\end{array}$ & $\begin{array}{c}\text { Caso seja significativa, } \\
\text { maior que } 5 \% \text { (usualmente), } \\
\text { segue-se }\end{array}$ \\
\hline 101 & $5^{\mathrm{a}}$ & perdas de estes & perdas destes \\
\hline 102 & $7^{\underline{a}}$ & $\begin{array}{l}\text { considerados no estudo } \\
\text { foram são: }\end{array}$ & $\begin{array}{l}\text { considerados no estudo } \\
\text { foram: }\end{array}$ \\
\hline 102 & $19^{\mathrm{a}}$ & em critério físico. & em critério físico (massa). \\
\hline 104 & $13^{\mathrm{a}}$ & década de 50 & década de 1950 \\
\hline 104 & $15^{\mathrm{a}}$ & década de 60 & década de 1960 \\
\hline 106 & $1^{\mathrm{a}}$ & década de 80 & década de 1980 \\
\hline 106 & $5^{a}$ e $9^{a}$ & década de 90 & década de 1990 \\
\hline 138 & $5^{\mathrm{a}}$ & em termo de nitrogênio & em termos de nitrogênio \\
\hline 140 & $10^{\mathrm{a}}$ & $\begin{array}{l}\text { fornecer o nutriente } \\
\text { nitrogênio }(\mathrm{N}) \text { ao solo. }\end{array}$ & $\begin{array}{l}\text { produzir o nutriente } \\
\text { nitrogênio }(\mathrm{N}) \text {. }\end{array}$ \\
\hline 145 & $2^{\mathrm{a}}$ & de este documento e & deste documento é \\
\hline 150 & $24^{\mathrm{a}}$ & Por meio desta estapa & Por meio desta etapa \\
\hline 185 & $1^{\underline{a}}$ & no escopo de este & no escopo deste \\
\hline 189 & $12^{a}$ & são necessários 1.083 kg & são necessários $1.083 \mathrm{k}$ \\
\hline
\end{tabular}




\begin{tabular}{|c|c|c|c|}
\hline & & & de resíduo asfáltico \\
\hline 191 & $23^{a}$ & 54,54 toneladas & 54,54 toneladas de petróleo \\
\hline 192 & $25^{\underline{a}}$ & 110,8 toneladas & 110,8 toneladas de petróleo \\
\hline 192 & $27^{\underline{a}}$ & 54,54 toneladas & 54,54 toneladas de petróleo \\
\hline 198 & $24^{a}$ & vem atendo & vem atendendo \\
\hline 201 & $8^{\underline{a}}$ & de este estudo forma & deste estudo foram \\
\hline 202 & $16^{\mathrm{a}}$ & somente essas & somente essas três \\
\hline 206 & $26^{a}$ & 46 & 53 \\
\hline 274 & $1^{\underline{a}}$ & uncertaity & uncertainty \\
\hline 290 & $4^{\mathrm{a}}$ & $\begin{array}{c}110,8 \text { t de petróleo } \\
\text { consumido no Brasil (para } \\
\text { a nafta) }\end{array}$ & $\begin{array}{c}110,8 \text { t de petróleo } \\
\text { consumido no Brasil (para a } \\
\text { nafta necessária à } \\
\text { produção de caprolactama) }\end{array}$ \\
\hline 290 & $4^{\underline{a}}$ & $\begin{array}{c}54,54 \text { t de petróleo } \\
\text { consumido no Brasil (para } \\
\text { a nafta) }\end{array}$ & $\begin{array}{c}54,54 \text { t de petróleo } \\
\text { consumido no Brasil (para a } \\
\text { nafta necessária à } \\
\text { produção de acrilonitrila) }\end{array}$ \\
\hline 290 & $4^{\mathrm{a}}$ & $\begin{array}{c}2,29 \text { t de petróleo } \\
\text { consumido no Brasil (para } \\
\text { a nafta) }\end{array}$ & $\begin{array}{l}2,29 \text { t de petróleo } \\
\text { consumido no Brasil (para a } \\
\text { nafta necessária à } \\
\text { produção de MMA) }\end{array}$ \\
\hline 291 & $4^{\underline{a}}$ & $\begin{array}{c}187.407 \text { t.km (para a } \\
\text { nafta) }\end{array}$ & $\begin{array}{l}187.407 \text { t.km (para a nafta } \\
\text { necessária à produção de } \\
\text { caprolactama) }\end{array}$ \\
\hline 291 & $4^{\mathrm{a}}$ & 92.249 t.km (para a nafta) & $\begin{array}{l}92.249 \text { t.km (para a nafta } \\
\text { necessária à produção de } \\
\text { acrilonitrila) }\end{array}$ \\
\hline 291 & $4^{\underline{a}}$ & 3.874 t.km (para a nafta) & $\begin{array}{c}3.874 \text { t.km (para a nafta } \\
\text { necessária à produção de } \\
\text { MMA) }\end{array}$ \\
\hline 292 & $4^{\underline{a}}$ & $\begin{array}{l}\text { Refino de } 110,8 \text { t de } \\
\text { petróleo (para a nafta) }\end{array}$ & $\begin{array}{c}\text { Refino de 110,8 t de } \\
\text { petróleo (para a nafta } \\
\text { necessária à produção de } \\
\text { caprolactama) }\end{array}$ \\
\hline 292 & $4^{\mathrm{a}}$ & $\begin{array}{l}\text { Refino de } 54,54 \text { t de } \\
\text { petróleo (para a nafta) }\end{array}$ & $\begin{array}{c}\text { Refino de } 54,54 \text { t de } \\
\text { petróleo (para a nafta } \\
\text { necessária à produção de } \\
\text { acrilonitrila) }\end{array}$ \\
\hline 292 & $4^{\mathrm{a}}$ & $\begin{array}{l}\text { Refino de } 2,29 \text { t de } \\
\text { petróleo (para a nafta) }\end{array}$ & $\begin{array}{l}\text { Refino de } 2,29 \text { t de petróleo } \\
\text { (para a nafta necessária à } \\
\text { produção de MMA) }\end{array}$ \\
\hline
\end{tabular}




\section{DEDICATÓRIA}

Aos meus pais e familiares, por suas existências. 


\section{AGRADECIMENTOS}

Ao meu amigo e orientador Prof. Dr. Gil Anderi da Silva pela confiança, incentivo e doação de seus conhecimentos e experiências, que contribuíram para minha formação acadêmica.

Aos meus pais (Sérgio e Arlette) e familiares (Ana Paula e Sueli) pela compreensão e apoio.

Ao amigo e Prof. Dr. Luiz A. Kulay pela contribuição no projeto.

Ao Prof. Dr. Tah W. Song pelas sugestões extremamente valiosas.

Aos amigos Laércio, Eduardo, Alex e Juliana do GP2 da EPUSP pelo companheirismo.

Aos amigos Fúlvia, Fernanda, Rita, Marcelo, Isabella, Paulo, Vera, Rocio, Jesus e Glorys do DEQ da EPUSP pelo estímulo e colaboração constantes.

A Professora. Dra. Patrícia H. L. dos Santos Matai pelo incentivo.

Aos colegas funcionários Antonio Carlos, Elisete, Graça, Alexandre, Maria Lúcia, Fátima, Terezinha, Tereza e Caio do DEQ da EPUSP pelo auxílio prestado desde meu ingresso na pós-graduação. 
"Mil cairão ao teu lado e dez mil à tua direita, mas não chegará a ti”. (Salmo 91 verso 7 ) 


\section{RESUMO}

A principal limitação da Avaliação do Ciclo de Vida (ACV) é a necessidade da coleta de um elevado número de dados representativos para a região em estudo. Esta limitação pode ser contornada pela construção de bancos de dados regionais, ou seja, de inventários de elementos que são comuns aos ciclos de vida de inúmeros produtos. Entre esses elementos encontram-se os fertilizantes químicos. Nesse contexto este trabalho de doutorado apresenta uma contribuição ao banco de dados brasileiro para apoio aos estudos de ACV, qual seja: os inventários do ciclo de vida da uréia; do nitrato de amônio e do sulfato de amônio adequados às condições brasileiras. Para a elaboração dos inventários foi necessário obter o perfil detalhado do setor de fertilizantes nitrogenados no país. Em seguida, efetuou-se a identificação e quantificação das entradas de recursos naturais e das disposições de rejeitos associados ao ciclo de vida dos fertilizantes estudados. Por fim, fez-se uma discussão dos principais aspectos ambientais associados à produção dos três fertilizantes no Brasil. Os dados obtidos no inventário da uréia revelaram 45 aspectos ambientais. No que diz respeito às emissões atmosféricas, verificou-se que o dióxido de carbono foi responsável por $98,3 \%$ do total e em relação aos efluentes líquidos, os compostos nitrogenados corresponderam a $73,5 \%$ do total. Quanto ao inventário do nitrato de amônio, foram encontrados 42 aspectos ambientais. Verificou-se que o dióxido de carbono foi responsável por $79 \%$ do total de emissões atmosféricas e que em relação aos efluentes líquidos, os compostos nitrogenados corresponderam a $25,3 \%$ do total. O inventário do sulfato de amônio revelou a existência de 46 aspectos ambientais. Concluiu-se que o dióxido de carbono contribuiu por $99 \%$ do total de emissões e que os compostos nitrogenados e de enxofre foram responsáveis, respectivamente, por $5 \%$ e $41 \%$ do total de efluentes líquidos gerados. A partir dos resultados deste trabalho torna-se possível identificar oportunidades para a melhoria de desempenho ambiental dos processos industriais analisados. 
Palavras-chave: Avaliação do ciclo de vida. Fertilizantes nitrogenados. Gestão ambiental. Prevenção da poluição. 


\begin{abstract}
The main limitation of Life Cycle Assessment (LCA) is the necessity for collection a large number of representative data for the region under study. This limitation can get rounded by the construction of regional databases, or inventories of elements that are common to the life cycle of many products. Among these elements are the chemical fertilizers. In this context is inserted this doctorate thesis which presents a contribution to the Brazilian database for support LCA studies which is: the life cycle inventories of urea, ammonium nitrate and ammonium sulfate for the Brazilian conditions. For the elaboration of inventories was necessary to get the detailed profile of nitrogen fertilizers industry in Brazil. Following, the quantified identification of the natural resources inputs and the waste dispositions associated to the fertilizers life cycle referred in this study is made. Finally, there was a discussion of main environmental aspects associated to production of the three fertilizers in Brazil. Data from urea inventory showed 45 environmental aspects. With regard to air emissions, it was found that carbon dioxide was responsible for $98.3 \%$ of the total and for the liquid effluents, the nitrogen compounds accounted for $73.5 \%$ of the total. As ammonium nitrate inventory, were found 42 environmental aspects. It was found that carbon dioxide was responsible for $79 \%$ of total emissions and in relation to liquid effluents, the nitrogen compounds accounted for $25.3 \%$ of the total. The ammonium sulfate inventory revealed the existence of 46 environmental aspects. It was concluded that carbon dioxide contributed by $99 \%$ of total emissions and the sulfur and nitrogen compounds were responsible, respectively, for $5 \%$ and $41 \%$ of all liquid effluents generated. From the results of this study becomes possible to identify opportunities for improving the environmental performance of industrial processes analyzed.
\end{abstract}

Keywords: Life cycle assessment. Nitrogen fertilizers. Environmental management. Pollution prevention. 


\section{SUMÁRIO}

DEDICATÓRIA

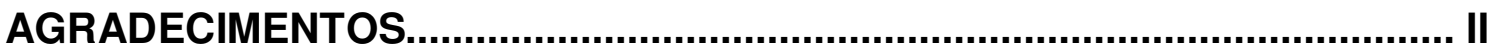

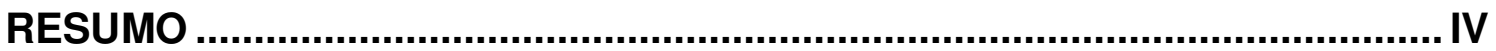

ABSTRACT

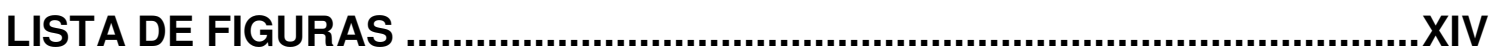

LISTA DE TABELAS ................................................................................

LISTA DE ABREVIATURAS E SIGLAS....................................................XX

LISTA DE COMPOSTOS QUÍMICOS ...................................................... XXV

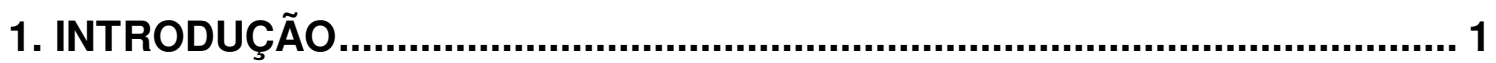

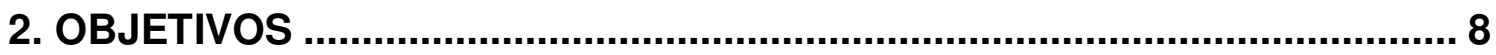

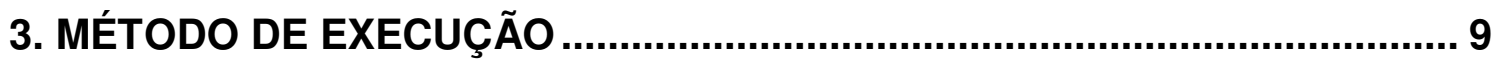

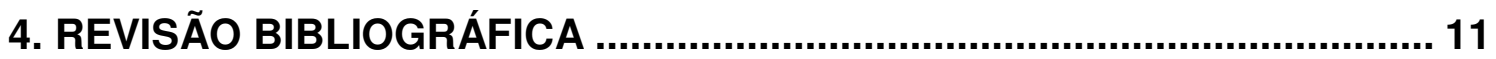

4.1. Avaliação do Ciclo de Vida (ACV) ........................................... 11

4.1.1. Conceito de ciclo de vida e definição de Avaliação do Ciclo de

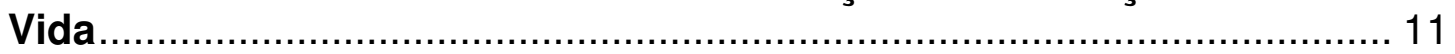

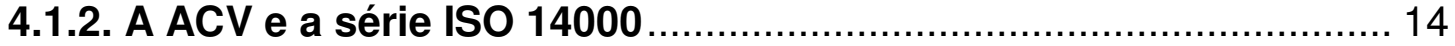

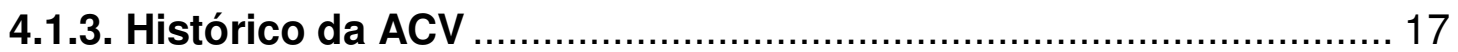

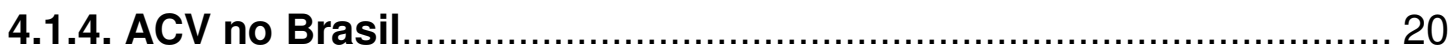

4.1.4.1. Estudos acadêmicos de ACV publicados no Brasil...................... 24

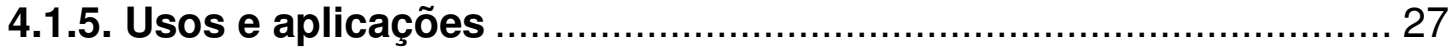

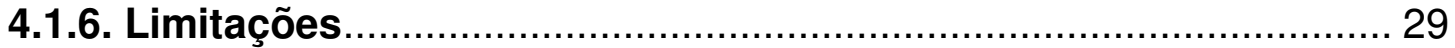

4.1.7. Considerações sobre a metodologia de ACV ............................. 32

4.1.8. Método da ISO de execução da ACV ......................................... 35

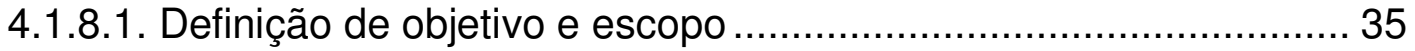

4.1.8.2. Inventário de ciclo de vida (ICV) ........................................... 43 
4.1.8.2.1. Preparação para coleta de dados ....................................... 45

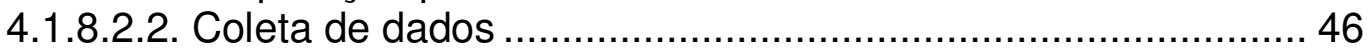

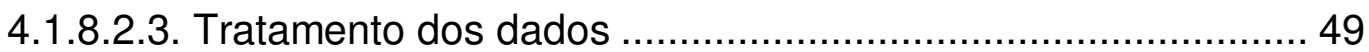

4.1.8.2.4. Refinamento das fronteiras do sistema .............................. 52

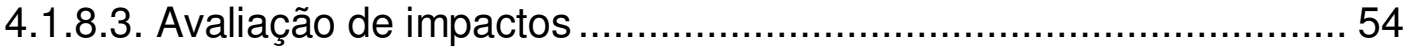

4.1.8.3.1. Métodos para avaliação de impactos .................................. 57

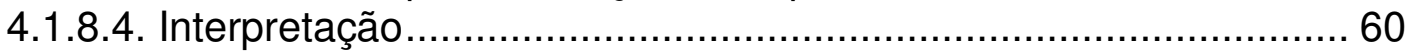

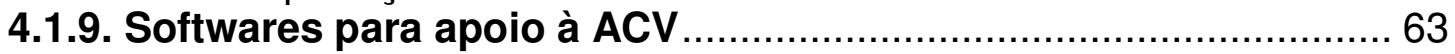

4.1.10. Bancos de dados para suporte da ACV ................................ 71

4.1.11. Estudos recentes publicados sobre a técnica............................ 82

4.1.12. ACV simplificada ............................................................. 94

4.1.13. Incertezas em estudos de ACV .......................................... 96

4.1.14. Estudos sobre produtos do setor de fertilizantes nitrogenados

4.2. Setor de Fertilizantes no Brasil ................................................... 104

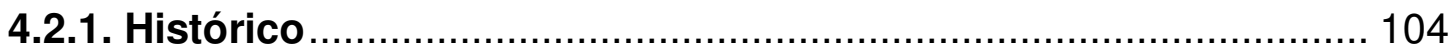

4.2.2. Produção e importações.............................................................. 111

4.2.3. Consumo de fertilizantes no país ........................................... 118

4.3. Indústria brasileira de fertilizantes nitrogenados.......................... 120

4.3.1. Principais insumos materiais .................................................. 120

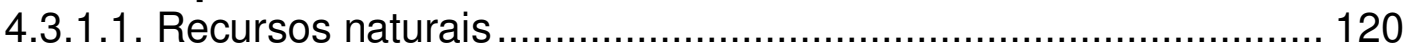

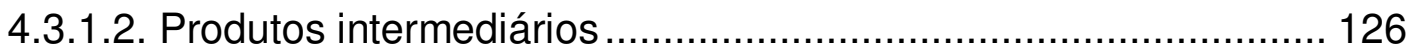

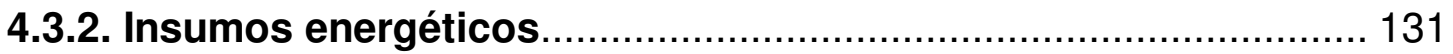

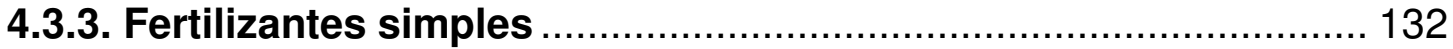

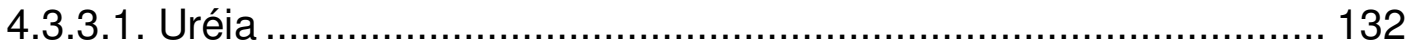

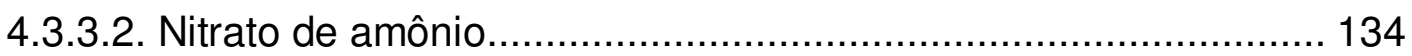

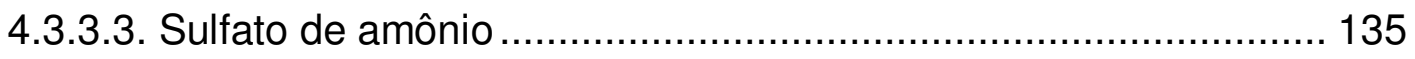

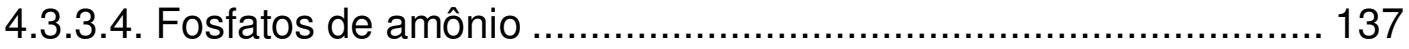

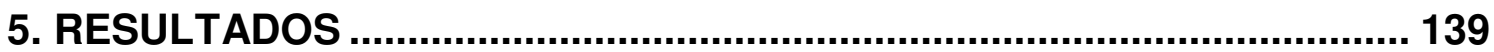

5.1. Definição de objetivo e escopo.................................................. 139

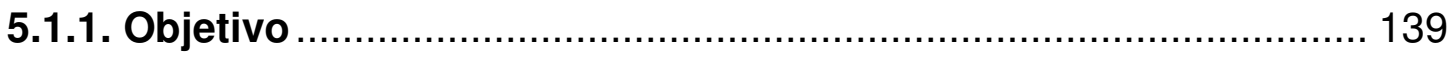

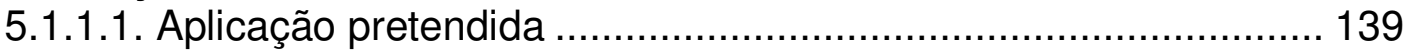

5.1.1.2. Razões para condução do estudo ......................................... 139

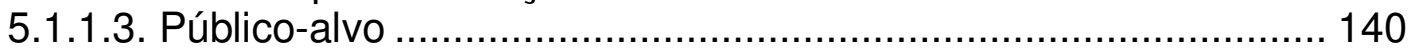

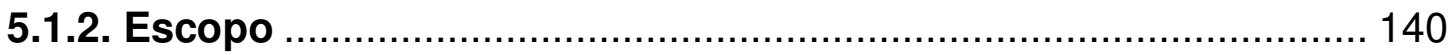

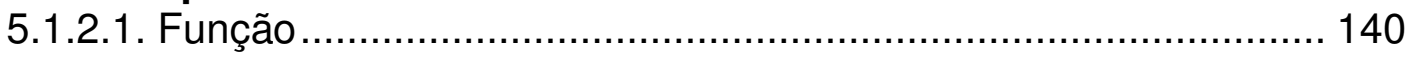

5.1.2.2. Unidade funcional e fluxos de referência ................................ 140

5.1.2.3. Fronteiras iniciais dos sistemas ............................................... 141

5.1.2.4. Definição dos sistemas de produto ........................................... 141

5.1.2.4.1. Sistema de produto da uréia ............................................. 142

5.1.2.4.2. Sistema de produto do nitrato de amônio.............................. 143

5.1.2.4.3. Sistema de produto do sulfato de amônio ............................ 145 
5.1.2.4.4. Descrição dos subsistemas .............................................. 147

5.1.2.5. Procedimento de alocação .................................................. 179

5.1.2.6. Tipos de impacto e metodologia de avaliação de impacto........... 180

5.1.2.7. Requisitos de qualidade dos dados ....................................... 180

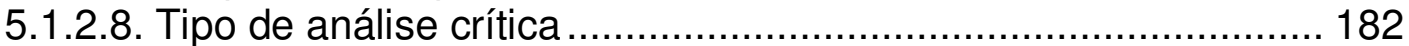

5.1.2.9. Tipo e formato do relatório final ........................................... 182

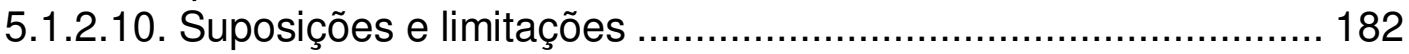

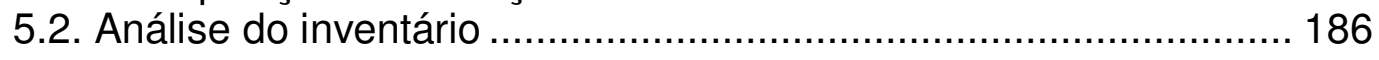

5.2.1. Inventário de ciclo de vida do subsistema do petróleo consumido no Brasil ................................................................................. 187

5.2.2. Inventário de ciclo de vida do transporte marítimo de petróleo importado para o Brasil .............................................................. 193 5.2.3. Inventário de ciclo de vida do subsistema de refino do petróleo 198 5.2.4. Inventário consolidado das produções de gás combustível de refinaria, de resíduo asfáltico e de nafta .......................................... 200 5.2.5. Inventário de ciclo de vida do subsistema geração e distribuição de energia elétrica no Brasil......................................................... 202 5.2.6. Inventário de ciclo de vida da extração e beneficiamento de gás natural 204

5.2.7. Inventário de ciclo de vida da geração de energia térmica através da queima de gás natural .......................................................... 207 5.2.8. Inventário de ciclo de vida do subsistema de separação criogênica do ar. 209

5.2.9. Inventário de ciclo de vida do subsistema da produção de amônia pelo processo de reforma catalítica de gás natural com vapor de água 211

5.2.10. Inventário de ciclo de vida do subsistema da produção de amônia pelo processo de oxidação parcial de resíduo asfáltico …................... 213 5.2.11. Inventário de ciclo de vida do subsistema da produção de amônia pelo processo de reforma catalítica de gás de refinaria com vapor de água. 216

5.2.12. Inventário do subsistema da produção de uréia ...................... 218

5.2.13. Inventário do subsistema da produção de ácido nítrico............ 220

5.2.14. Inventário do subsistema da produção de nitrato de amônio... 222 5.2.15. Inventário do subsistema da produção de ácido sulfúrico ........ 223 5.2.16. Inventário do subsistema da produção de sulfato de amônio via

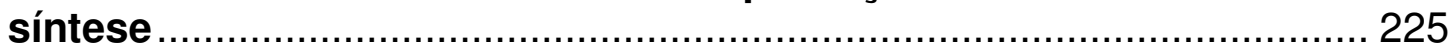

5.2.17. Inventário do subsistema da produção de benzeno ….............. 226

5.2.18. Inventário do subsistema da produção de ciclohexano ............ 228

5.2.19. Inventário do subsistema da produção de propeno .................. 229 5.2.20. Inventário do subsistema das produções de caprolactama e sulfato de amônio.......................................................................... 231 5.2.21. Inventário do subsistema da produção de ácido cianídrico...... 233 
5.2.22. Inventário do subsistema das produções de acrilonitrila e sulfato de amônio 235

5.2.23. Inventário do subsistema das produções de metacrilato de metila e sulfato de amônio 237

5.2.24. Inventário consolidado da uréia produzida pela Petrobras/Fafen 239

5.2.25. Inventário consolidado da uréia produzida pela Fosfertil S. A. 240 5.2.26. Inventário consolidado da uréia adequada às condições brasileiras 241

5.2.27. Inventário consolidado do nitrato de amônio adequado às condições brasileiras............................................................... 242 5.2.28. Inventário consolidado do sulfato de amônio produzido pelo processo de síntese pela Unigel S. A. 243

5.2.29. Inventário consolidado do sulfato de amônio produzido pelo processo de síntese pela Bunge fertilizantes S. A. 244 5.2.30. Inventário consolidado do sulfato de amônio obtido como subproduto da produção de caprolactama pela Braskem S. A............ 245 5.2.31. Inventário consolidado do sulfato de amônio obtido como subproduto da produção de acrilonitrila pela Unigel S. A.................... 246 5.2.32. Inventário consolidado do sulfato de amônio obtido como subproduto da produção de metacrilato de metila pela Unigel S. A. ... 247 5.2.33. Inventário consolidado do sulfato de amônio adequado às condições brasileiras 249

6. DISCUSSÃO DOS RESULTADOS, CONCLUSÕES E RECOMENDAÇÕES 251

7. REFERÊNCIAS BIBLIOGRÁFICAS 256

GLOSSÁRIO 280

ANEXO A - ESTUDOS ACADÊMICOS DE ACV PUBLICADOS NO BRASIL 282

APÊNDICE A1 - INVENTÁRIOS DO SUBSISTEMA DE PETRÓLEO A SER CONSUMIDO NO BRASIL NAS PRODUÇÕES DE RESÍDUO ASFÁLTICO, GÁS DE REFINARIA E NAFTA. 290

APÊNDICE A2 - INVENTÁRIOS DO SUBSISTEMA DE TRANSPORTE MARÍTIMO DE PETRÓLEO IMPORTADO NECESSÁRIO ÀS PRODUÇÕES DE RESÍDUO ASFÁLTICO, GÁS DE REFINARIA E NAFTA. 291 
APÊNDICE A3 - INVENTÁRIOS DO SUBSISTEMA DE REFINO DO PETRÓlEO PARA AS PRODUÇÕES DE RESÍDUO ASFÁLTICO, GÁS DE REFINARIA E NAFTA. 292

APÊNDICE A4 - INVENTÁRIO CONSOLIDADO DA PRODUÇÃO 730,2 KG DE GÁS DE REFINARIA. 293

APÊNDICE A5 - INVENTÁRIO CONSOLIDADO DA PRODUÇÃO DE 1.083 KG DE RESÍDUO ASFÁLTICO. 295

APÊNDICE A6 - INVENTÁRIO CONSOLIDADO DA PRODUÇÃO DE 11,78 TONELADAS DE NAFTA 297

APÊNDICE A7 - INVENTÁRIO CONSOLIDADO DA PRODUÇÃO DE 5,798 TONELADAS DE NAFTA 299

APÊNDICE A8 - INVENTÁRIO CONSOLIDADO DA PRODUÇÃO DE 121,8 KG DE NAFTA 301

APÊNDICE A9 - INVENTÁRIOS DO SUBSISTEMA DE EXTRAÇÃO E BENEFICIAMENTO DE GÁS NATURAL 303

APÊNDICE A10 - INVENTÁRIO DO SUBSISTEMA DE GERAÇÃO DE ENERGIA TÉRMICA PROVENIENTE DA COMBUSTÃO DO GÁS NATURAL 304

APÊNDICE A11 - INVENTÁRIO DO SUBSISTEMA DE SEPARAÇÃO CRIOGÊNICA DE 11,73 KG DE AR. 305

APÊNDICE A12 - INVENTÁRIOS DO SUBSISTEMA DA PRODUÇÃO DE AMÔNIA POR REFORMA CATALÍTICA DE GÁS NATURAL 306

APÊNDICE A13 - INVENTÁRIO DO SUBSISTEMA DA PRODUÇÃO DE 1,217 TONELADAS DE AMÔNIA POR OXIDAÇÃO PARCIAL DE RESÍDUO ASFÁLTICO 307

APÊNDICE A14 - INVENTÁRIO DO SUBSISTEMA DA PRODUÇÃO DE 1,217 TONELADAS DE AMÔNIA, POR REFORMA CATALÍTICA DE GÁS DE REFINARIA, COM FATOR DE ALOCAÇÃO DE 46,3\% 308 
APÊNDICE A15 - INVENTÁRIO DO SUBSISTEMA DA PRODUÇÃO DE 2,17 TONELADAS DE URÉIA.

APÊNDICE A16 - INVENTÁRIO DO SUBSISTEMA DA PRODUÇÃO DE 2,25 TONELADAS DE ÁCIDO NÍTRICO

APÊNDICE A17 - INVENTÁRIO DO SUBSISTEMA DA PRODUÇÃO DE 2,941 TONELADAS DE NITRATO DE AMÔNIO

APÊNDICE A18 - INVENTÁRIO DO SUBSISTEMA DA PRODUÇÕES DE 840 KG E 3,5 TONELADAS DE ÁCIDO SULFÚRICO.

APÊNDICE A19 - INVENTÁRIO DO SUBSISTEMA DA PRODUÇÃO DE 4,717 TONELADAS DE SULFATO DE AMÔNIO VIA SÍNTESE. 313

APÊNDICE A20 - INVENTÁRIO DO SUBSISTEMA DAS PRODUÇÕES DE 68,86 KG E 6,66 TONELADAS DE BENZENO. 314

APÊNDICE A21 - INVENTÁRIO DO SUBSISTEMA DA PRODUÇÃO DE 5,936 TONELADAS DE CICLOHEXANO

APÊNDICE A22 - INVENTÁRIO DO SUBSISTEMA DAS PRODUÇÕES DE 91,58 KG E 4,359 TONELADAS DE PROPENO. 316

APÊNDICE A23 - INVENTÁRIO DO SUBSISTEMA DA PRODUÇÃO DE 2,62 TONELADAS DE CAPROLACTAMA E 4,717 TONELADAS DE SULFATO DE AMÔNIO 317

APÊNDICE A24 - INVENTÁRIO DO SUBSISTEMA DA PRODUÇÃO DE 3,232 TONELADAS DE ÁCIDO CIANÍDRICO

APÊNDICE A25 - INVENTÁRIO DO SUBSISTEMA DA PRODUÇÃO DE 29,48 TONELADAS DE ACRILONITRILA E 4,717 TONELADAS DE SULFATO DE AMÔNIO 319

APÊNDICE A26 - INVENTÁRIO DO SUBSISTEMA DA PRODUÇÃO DE 1,57 TONELADAS DE MMA E 4,717 TONELADAS DE SULFATO DE AMÔNIO 320

APÊNDICE B1 - INVENTÁRIO CONSOLIDADO DA URÉIA PRODUZIDA PELA PETROBRAS/FAFEN. 
APÊNDICE B2 - INVENTÁRIO CONSOLIDADO DA URÉIA PRODUZIDA PELA FOSFERTIL 323

APÊNDICE B3 - INVENTÁRIO CONSOLIDADO DA URÉIA ADEQUADA ÀS CONDIÇÕES BRASILEIRAS. 325

APÊNDICE B4 - INVENTÁRIO CONSOLIDADO DO NITRATO DE AMÔNIO ADEQUADO ÀS CONDIÇÕES BRASILEIRAS 327

APÊNDICE B5 - INVENTÁRIO CONSOLIDADO DO SULFATO DE AMÔNIO PRODUZIDO PELO PROCESSO DE SÍNTESE PELA UNIGEL .

APÊNDICE B6 - INVENTÁRIO CONSOLIDADO DO SULFATO DE AMÔNIO PRODUZIDO PELO PROCESSO DE SÍNTESE PELA BUNGE FERTILIZANTES 331

APÊNDICE B7 - INVENTÁRIO CONSOLIDADO DO SULFATO DE AMÔNIO OBTIDO COMO SUBPRODUTO DA PRODUÇÃO DE CAPROLACTMA PELA BRASKEM.

APÊNDICE B8 - INVENTÁRIO CONSOLIDADO DO SULFATO DE AMÔNIO OBTIDO COMO SUBPRODUTO DA PRODUÇÃO DE ACRILONITRILA PELA UNIGEL 336

APÊNDICE B9 - INVENTÁRIO CONSOLIDADO DO SULFATO DE AMÔNIO OBTIDO COMO SUBPRODUTO DA PRODUÇÃO DE MMA PELA UNIGEL339

APÊNDICE B10 - INVENTÁRIO CONSOLIDADO DO SULFATO DE AMÔNIO ADEQUADO ÀS CONDIÇÕES BRASILEIRAS 


\section{LISTA DE FIGURAS}

Figura 1: Ciclo de vida de um produto ou serviço (adaptado de SILVA, 2003). 12

Figura 2: Estrutura de uma ACV segundo SETAC (adaptado da fig. 1 de

CONSOLI et al., 1993)................................................................... 32

Figura 3: Estrutura de uma ACV segundo UNEP (UNEP, 1996) .................... 33

Figura 4: Estágios de uma ACV segundo ISO (adaptado da fig. 1 da norma ISO

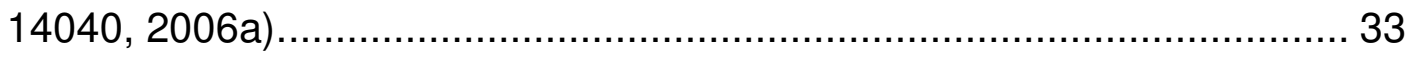

Figura 5: Descrição conceitual de processo elementar (adaptado da fig.3 da ISO 14040, 2006a). 39

Figura 6: Procedimentos simplificados para a etapa de análise do inventario (adaptado da fig. 1 da ISO 14044, 2006b). 44

Figura 7: Fases da avaliação de impactos (adaptado da fig.4.5 de CHEHEBE,

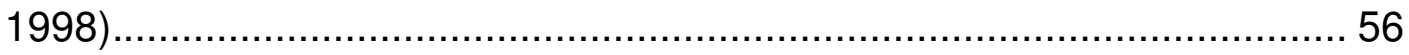

Figura 8: Representação de banco de dados (RIBEIRO, 2004) ..................... 71

Figura 9: Estrutura do setor de fertilizantes no Brasil em 2007 (ANDA, 2008).

Figura 10: Modelo representativo da uréia produzida no Brasil..................... 142

Figura 11: Modelo representativo do nitrato de amônio produzido no país. ... 144

Figura 12: Modelo representativo do sulfato de amônio produzido no país.... 146

Figura 13: Diagrama de blocos simplificado das operações de refino do petróleo (GARCIA, 2002). 152

Figura 14: Diagrama de blocos do subsistema de beneficiamento de gás natural adequado às condições brasileiras (GARCIA, 2002).....

Figura 15: Diagrama de blocos do subsistema de produção de amônia pelo processo de reforma catalítica com vapor de água (CEKINSKI et al., 1990).

Figura 16: Diagrama de blocos do subsistema de produção de amônia pelo processo de oxidação parcial (CEKINSKI et al., 1990). 161 
Figura 17: Diagrama de blocos do subsistema de produção de uréia pelo processo de reciclo total (CEKINSKI et al., 1990). 163

Figura 18: Diagrama de blocos do subsistema de geração, distribuição e importação de energia elétrica no Brasil (COLTRO; GARCIA; QUEIROZ, 2003) 164

Figura 19: Diagrama de blocos do subsistema de produção de ácido nítrico pelo processo de monopressão (CEKINSKI et al., 1990). 167

Figura 20: Diagrama de blocos do subsistema da produção de nitrato de amônio (CEKINSKI et al., 1990). 169

Figura 21: Diagrama de blocos do subsistema da produção de ácido sulfúrico pelo processo de dupla absorção (CEKINSKI et al., 1990). 172

Figura 22: Diagrama de blocos do subsistema da produção de sulfato de amônio pelo processo de síntese (CEKINSKI et al., 1990). 174 


\section{LISTA DE TABELAS}

Tabela 1: Dissertações e teses de ACV publicadas por ano no Brasil (CAPES, 2008; DEDALUS, 2008; SABER, 2008)............................................. 24

Tabela 2: Dissertações e teses de ACV publicadas no Brasil por instituições acadêmicas (CAPES, 2008; DEDALUS, 2008; SABER, 2008). 26

Tabela 3: Exemplo de função, unidade funcional e fluxo de referência (adaptado

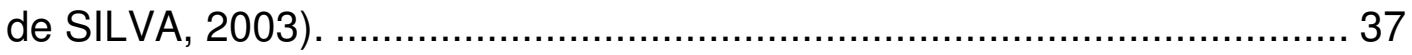

Tabela 4: Tipos de estudos de ACV (RIBEIRO, 2004)................................. 37

Tabela 5: Exemplo de aplicação de fatores de alocação em massa (adaptado de BORGES, 2004)................................................................. 40

Tabela 6: Exemplo de folha de coleta de dados (adaptado do quadro 3.1 de CHEHEBE, 1998). 48

Tabela 7: Parâmetros típicos do inventário de ciclo de vida de um produto (adaptado da tabela 1, p. 21 de MOURAD; GARCIA; VILHENA, 2002).... 53

Tabela 8: Endereços eletrônicos dos métodos de AICV disponíveis (LIFE

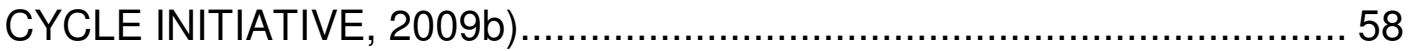

Tabela 9: Softwares de apoio à ACV (USEPA 2007; EPLCA 2007; CURRAN,

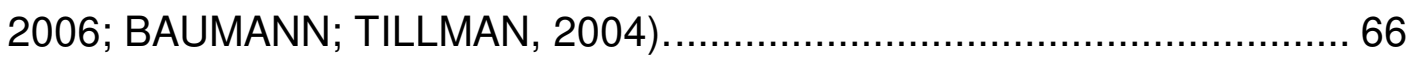

Tabela 10: Bancos de dados de ICVs nacionais disponíveis em 2006 (CURRAN, 2006).

Tabela 11: Bancos de dados de organizações industriais disponíveis em 2006 (CURRAN, 2006). 77

Tabela 12: Matriz de qualidade dos dados (FRISCHKNECHT et al., 2007).... 98

Tabela 13: Fatores de incerteza aplicados à pontuação pela qualidade do dado

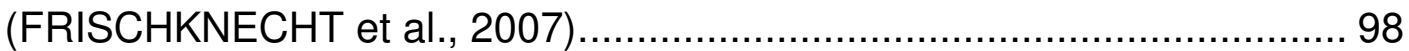

Tabela 14: Empresas do setor de fertilizantes simples no Brasil (ABIQUIM,

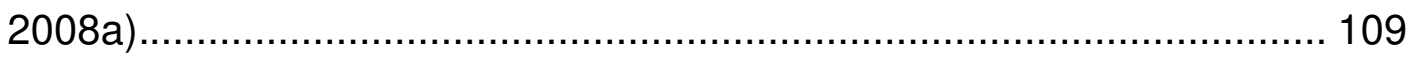

Tabela 15: Consumo mundial de fertilizantes por país no ano de 2007 (ANDA, 2008) 
Tabela 16: Balanço brasileiro de fertilizantes em 2007 (ANDA, 2008). 113

Tabela 17: Produção nacional de fertilizantes em 2007 (ANDA, 2008) 114

Tabela 18: Consumo de fertilizantes, por cultura, no Brasil no ano de 2007 (ANDA, 2008). 118

Tabela 19: Consumo de fertilizantes por região brasileira em 2007 (ANDA, 2008). 118

Tabela 20: Composição aproximada do gás natural empregado pela PETROBRAS / FAFEN (SAC PETROBRAS/FAFEN, 2005) 122

Tabela 21: Produtores de amônia do setor de fertilizantes no Brasil *(ANDA, 2008); **(ABIQUIM, 2008a). 128

Tabela 22: Empresas produtoras de uréia no Brasil *(ANDA, 2008); **(QUÍMICA INDUSTRIAL, 2004). 133

Tabela 23: Principais dados para o nitrato de amônio produzido no Brasil (ANDA, 2008). 135

Tabela 24: Relação de empresas produtoras de sulfato de amônio no Brasil *(ANDA, 2008); **(ABIQUIM, 2008a). 136

Tabela 25: Relação de produtores de MAP no Brasil *(ANDA, 2008); **(ABIQUIM, 2008a)

Tabela 26: Distância e participação na importação brasileira dos países exportares de petróleo para o Brasil *(PORTWORLD, 2008); **(MDIC, 2008c)

Tabela 27: Inventário de ciclo de vida do petróleo consumido no Brasil (VIANNA, 2006). 188

Tabela 28: Dados da refinaria REPAR para o ano de 2007 (1) ANP, 2008c; (2)

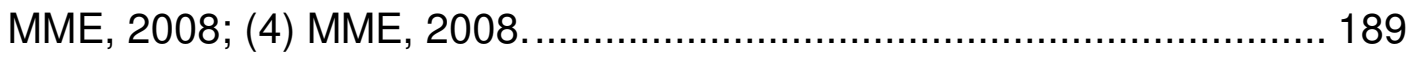

Tabela 29: Dados da refinaria RPBC para o ano de 2007 (1) ANP, 2008c; (2)

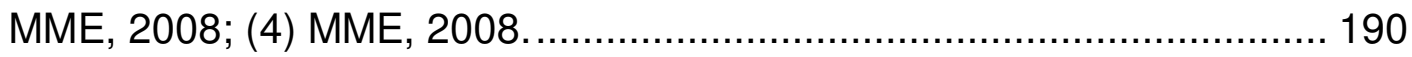

Tabela 30: Dados da refinaria RLAM para o ano de 2007 (1) ANP, 2008c; (2) MME, 2008; (4) MME, 2008. 192 
Tabela 31: Inventário de ciclo de vida de dados brutos do transporte marítimo de 1 t.km de petróleo importado (PRé-CONSULTANTS, 2006a).

Tabela 32: Inventário de ciclo de vida das produções de óleo diesel e óleo combustível pesado (PRé-CONSULTANTS, 2006b; PRé-CONSULTANTS, 2006c).

Tabela 33: Inventário de ciclo de vida do transporte marítimo de $1 \mathrm{t} . \mathrm{km}$ de petróleo importado. 196

Tabela 34: Inventário do subsistema do refino de $1 \mathrm{t}$ de petróleo (VIANNA, 2006)

Tabela 35: Inventário de ciclo de vida da geração e distribuição de 1 GJ de energia elétrica no Brasil (COLTRO; GARCIA; QUEIROZ, 2003). 203

Tabela 36: Inventário de ciclo de vida para $1 \mathrm{~kg}$ de gás natural beneficiado (SILVA; RIBEIRO; KULAY, 2006). 205

Tabela 37: Inventário de ciclo de vida da geração de $38 \mathrm{MJ}$ de energia térmica através da combustão de gás natural (PRé Consultants, 2006d). 208

Tabela 38: Inventário de ciclo de vida para a separação criogênica de $1 \mathrm{~kg}$ de ar (FOSFERTIL, 2005; ECOINVENT CENTRE, 2004a)........................... 210

Tabela 39: Inventário do subsistema da produção de $1 \mathrm{~kg}$ de amônia por reforma catalítica de gás natural com vapor de água (SAC PETROBRAS/FAFEN, 2005; ECOINVENT CENTRE; 2004b)............... 212

Tabela 40: Inventário do subsistema da produção de $1 \mathrm{~kg}$ de amônia por oxidação parcial (FOSERTIL, 2005; ECOINVENT CENTRE, 2004c)...... 215

Tabela 41: Inventário do subsistema da produção de $1 \mathrm{~kg}$ de amônia por reforma catalítica de gás combustível de refinaria com vapor de água (FOSFERTIL S. A., 2005; ECOINVENT CENTRE, 2004b).................... 217

Tabela 42: Inventário do subsistema da produção de $1 \mathrm{~kg}$ de uréia (FOSFERTIL, 2005; PRé Consultants, 2006e)..................................... 219

Tabela 43: Inventário do subsistema da produção de $1 \mathrm{~kg}$ de ácido nítrico (FOSFERTIL, 2005; ECOINVENT CENTRE, 2004d). 221 
Tabela 44: Inventário do subsistema da produção de $1 \mathrm{~kg}$ de nitrato de amônio (FOSFERTIL, 2005; ECOINVENT CENTRE, 2004e)............................ 223

Tabela 45: Inventário do subsistema da produção de 1 tonelada de ácido

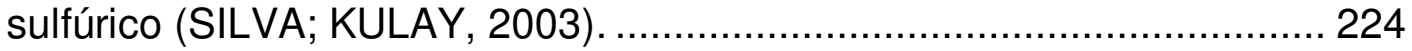

Tabela 46: Inventário do subsistema da produção de $1 \mathrm{t}$ de sulfato de amônio (UNIGEL, 2006; ECOINVENT CENTRE, 2004e) ................................. 226

Tabela 47: Inventário do subsistema da produção de $1 \mathrm{~kg}$ de benzeno (PRé

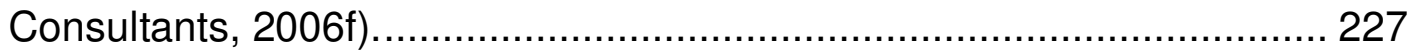

Tabela 48: Inventário do subsistema da produção de $1 \mathrm{~kg}$ de ciclohexano (PRé

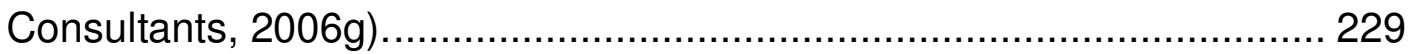

Tabela 49: Inventário do subsistema da produção de $1 \mathrm{~kg}$ de propeno (PRé

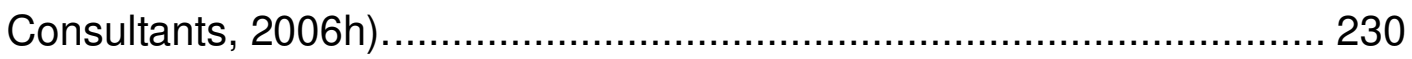

Tabela 50: Inventário do subsistema da produção de $1 \mathrm{~kg}$ de caprolactama (BRASKEM, 2008; PRé Consultants, 2006i)....................................... 232

Tabela 51: Inventário do subsistema da produção de $1 \mathrm{~kg}$ de ácido cianídrico (UNIGEL, 2006; ECOINVENT CENTRE, 2004f). 234

Tabela 52: Inventário do subsistema da produção de $1 \mathrm{~kg}$ de acrilonitrila (UNIGEL, 2006; PRé Consultants, 2006j)........................................... 236

Tabela 53: Inventário do subsistema da produção de $1 \mathrm{~kg}$ de metacrilato de metila (UNIGEL, 2006; PRé Consultants, 2006k). 238 


\section{LISTA DE ABREVIATURAS E SIGLAS}

ABC: Activity Based Costing

ABCV: Associação Brasileira de Ciclo de Vida

ABIPTI: Associação Brasileira das Instituições de Pesquisa Tecnológica

ABIQUIM: Associação Brasileira da Indústria Química

ABNT: Associação Brasileira de Normas Técnicas

ACV: Avaliação do Ciclo de Vida

AICV: Avaliação de Impactos do Ciclo de Vida

AMA: Associação dos Misturadores de Adubo

ANDA: Associação Nacional para Difusão de Adubos

ANP: Agência Nacional do Petróleo, Gás Natural e Biocombustíveis

APME: Association of Plastics Manufactures in Europe

ARAFERTIL: Araxá Fertilizantes e Produtos Químicos S. A.

atm: Atmosfera

BA: Bahia

BAHIAGÁS: Bahia Gás S. A.

BEES: Building for Environmental and Economic Sustainability

${ }^{\circ} \mathrm{C}$ : Graus Celsius

CCV: Custeio do Ciclo de Vida

CEMPRE: Compromisso Empresarial Para Reciclagem

CETEA: Centro de Tecnologia de Embalagem

Cia: Companhia

$\mathrm{Cl}^{\circ}$ : Íon Cloreto

CN: Íon Cianeto

COV: Compostos Orgânicos Voláteis

CVRD: Companhia Vale do Rio Doce

DAP: Fosfato de Diamônio

DBO: Demanda Bioquímica de Oxigênio

DNPM: Departamento Nacional de Produção Mineral 
DQO: Demanda Química de Oxigênio

EDIP: Environmental Design of Industrial Products

EFMA: European Fertilizer Manufacturers Association

ELCD: European Reference Life Cycle Data System

EPA: Environmental Protection Agency

EPS: Environmental Priority Strategies

FAFEN: Fábrica de Fertilizantes Nitrogenados do Nordeste

FAPESP: Fundação de Amparo à Pesquisa do Estado de São Paulo

FIA: Fundação Instituto de Administração

FMP: Termofosfato Magnesiano Fundido

FOSFERTIL: Fertilizantes Fosfatados S. A.

g: Grama

GANA: Grupo de Apoio à Normalização

GCV: Gestão do Ciclo de Vida

GEMIS: Global Emission Model for Integrated Systems

GJ: Giga Joule

GLP: Gás Liquefeito de Petróleo

GN: Gás Natural

GO: Goiás

GOIÁSFERTIL: Goiás Fertilizantes S. A.

GP2: Grupo de Prevenção da Poluição

GREET: Greenhouse gases, Regulated Emissions, and Energy use in

Transportation

GSA: Global Scope Assessment

$\mathbf{H}^{+}$: Íon Hidrogênio

IAP: Indústria Agropecuária Paulista S. A.

IBICT: Instituto Brasileiro de Ciência e Tecnologia

ICC: Indústria Carboquímica Catarinense

ICV: Inventário de Ciclo de Vida

IFA: International Fertilizer Industry Association 
Inc.: Incorporation

IPT: Instituto de Pesquisas Tecnológicas do Estado de São Paulo

ISO: International Organization for Standardization

ITAL: Instituto Técnico de Alimentação

JEPIX: Japan Environmental Policy Priorities Index

K: Potássio

kg: Quilograma

km: Quilômetro

kcal: Quilocaloria

LCA: Life Cycle Assessment

LCC: Life Cycle Costing

LCI: Life Cycle Inventory

LCSA: Life Cycle Sustainability Assessment

LIME: Life Cycle Impact Assessment Method based on Endpoint modeling

Ltd.: Limitada

$\mathbf{m}^{3}$ : Metro Cúbico

MAP: Fosfato de Monoamônio

MCT: Ministério da Ciência e Tecnologia

MDIC: Ministério do Desenvolvimento, Indústria e Comércio Exterior

METAGO: Metais de Goiás S. A.

MG: Minas Gerais

MJ: Mega Joule

MMA: Metacrilato de Metila

MME: Ministério de Minas e Energia

MRI: Midwest Research Institute

N: Nitrogênio

$\mathrm{Na}^{+}$: Íon Sódio

NBR: Norma Brasileira

NIST: National Institute for Standards and Technology

$\mathrm{NO}_{3}{ }^{-}$: Íon Nitrato 
N-P-K: Nitrogênio-Fósforo-Potássio

NREL: National Renewable Energy Laboratory

ONGs: Organizações não-governamentais

P: Fósforo

PETROBRAS: Petróleo Brasileiro S. A.

PETROFERTIL: Petrobras Fertilizantes S. A.

PETROMISA: Petrobras Mineiração S. A.

PNFCA: Plano Nacional de Fertilizantes e Calcário Agrícola

PNUMA: Programa das Nações Unidas para o Meio Ambiente

PR: Paraná

REPAR: Refinaria Presidente Getúlio Vargas

RLAM: Refinaria Landulpho Alves de Mataripe

RPBC: Refinaria Presidente Bernardes

RS: Rio Grande do Sul

S: Enxofre

S. A.: Sociedade Anônima

SAC: Serviço de Atendimento ao Cliente

SALCA: Swiss Agricultural Life Cycle Assessment

SC: Subcomitê

$\mathrm{SD}_{\text {g95: }}$ : Grau de Incerteza

SE: Sergipe

SERGÁS: Sergipe Gás S. A.

SETAC: Society of Environmental Toxicology and Chemistry

SIACESP: Sindicato das Indústrias de Adubos e Corretivos Agrícolas do Estado de São Paulo

SIMPRIFERT: Sindicato de Matérias-Primas para Fertilizantes

SP: São Paulo

SSP: Superfosfato Simples

t: Tonelada Métrica

TC: Technical Committee 
t.km: Tonelada Quilômetro

TRACI: Tool for the Reduction and Assessment of Chemical and other Environmental Impacts

TRANSPETRO: Petrobras Transporte S. A.

TSP: Superfosfato Triplo

UnB: Universidade de Brasília

U. F.: Unidade Funcional

UFSC: Universidade Federal de Santa Catarina

UNEP: United Nations Environment Programme

UNICAMP: Universidade Estadual de Campinas

UPGNs: Unidades de Processamento de Gás Natural

U. S.: United States

USDOE: United States Department of Energy

USEPA: United States Environmental Protection Agency

US\$: United States Dollars

USP: Universidade de São Paulo

UTFPR: Universidade Técnica Federal do Paraná

XIX: Dezenove

$\mathbf{X X}$ : Vinte

WISARD: Waste Integrated Systems Assessment for Recovery and Disposal 


\section{LISTA DE COMPOSTOS QUÍMICOS}

$\mathrm{CH}_{4}$ : Metano

$\mathrm{C}_{2} \mathrm{H}_{6}$ : Etano

$\mathrm{C}_{3} \mathrm{H}_{6}$ : Propileno ou Propeno

$\mathrm{C}_{3} \mathrm{H}_{8}$ : Propano

$\mathrm{C}_{3} \mathrm{H}_{6} \mathrm{O}$ : Acetona

$\mathrm{C}_{6} \mathrm{H}_{6}$ : Benzeno

$\mathrm{C}_{6} \mathrm{H}_{12}$ : Ciclohexano

CyHx: Hidrocarboneto

$\mathrm{C}_{2} \mathrm{H}_{3} \mathrm{CN}$ : Acrilonitrila

$\mathrm{C}_{3} \mathrm{H}_{6} \mathrm{CNOH}$ : Acetona cianidrina

$\mathrm{C}_{4} \mathrm{H}_{6} \mathrm{ONH}_{2} \mathrm{HSO}_{4}$ : Sulfato de metacrilamida

$\mathrm{C}_{6} \mathrm{H}_{11} \mathrm{NO}$ : Caprolactama

$\mathrm{C}_{6} \mathrm{H}_{10} \mathrm{NOH}$ : Oxima de ciclohexanona

$\mathrm{C}_{6} \mathrm{H}_{10} \mathrm{O}$ : Ciclohexanona

$\mathrm{C}_{5} \mathrm{H}_{8} \mathrm{O}_{2}$ : Metacrilato de metila

$\mathrm{CH}_{3} \mathrm{OH}$ : Metanol ou Álcool metílico

CO: Monóxido de carbono

$\mathrm{CO}_{2}$ : Dióxido de carbono

$\mathrm{CO}\left(\mathrm{NH}_{2}\right)_{2}$ : Uréia

$\mathrm{H}_{2}$ : Hidrogênio

HCN: Cianeto de hidrogênio ou Ácido cianídrico

$\mathrm{HNO}_{3}$ : Ácido nítrico

$\mathrm{H}_{2} \mathrm{O}$ : Água

$\mathrm{H}_{2} \mathrm{~S}$ : Sulfeto de hidrogênio

$\mathrm{H}_{2} \mathrm{SO}_{4}$ : Ácido sulfúrico

KCl: Cloreto de potássio

$\mathrm{MgCl}_{2}$ : Cloreto de magnésio

$\mathbf{N}_{\mathbf{2}}$ : Nitrogênio 
$\mathrm{NaCl}$ : Cloreto de sódio

$\mathrm{NaNO}_{3}$ : Nitrato de sódio

$\mathrm{NH}_{3}$ : Amônia

$\mathrm{NH}_{2} \mathbf{C O}_{2} \mathbf{N H}_{4}$ : Carbamato de amônio

$\mathrm{NH}_{2} \mathrm{OH}$ : Hidroxilamina

$\mathrm{NH}_{4} \mathrm{H}_{2} \mathrm{PO}_{4}$ : Fosfato de monoamônio

$\left(\mathrm{NH}_{4}\right)_{2} \mathrm{HPO}_{4}$ : Fosfato de diamônio

$\mathrm{NH}_{4} \mathrm{HSO}_{4}$ : Bissulfato de amônio

$\mathrm{NH}_{4} \mathrm{NO}_{3}$ : Nitrato de amônio

$\left(\mathrm{NH}_{4}\right)_{2} \mathrm{SO}_{4}$ : Sulfato de amônio

$\mathrm{N}_{2} \mathrm{O}$ : Óxido nitroso

NO: Monóxido de nitrogênio

$\mathrm{NO}_{2}$ : Dióxido de nitrogênio

NOx: Óxidos de nitrogênio

$\mathrm{O}_{2}$ : Oxigênio

Pt: Platina

Rh: Ródio

$\mathrm{SO}_{2}$ : Dióxido de enxofre

$\mathrm{SO}_{3}$ : Trióxido de enxofre

SOx: Óxidos de enxofre

$\mathrm{V}_{2} \mathrm{O}_{5}$ : Pentóxido de vanádio 


\section{INTRODUÇÃO}

O solo pode ser entendido como o meio no qual as culturas desenvolvem-se para alimentar a população mundial. Entender a fertilidade do solo é compreender a necessidade básica para a produção vegetal. As plantas alimentam-se dos nutrientes que o solo fornece e dos fertilizantes aportados.

Dezoito elementos químicos são chamados essenciais para o crescimento das plantas. De acordo com a legislação brasileira, em Decreto que aprova o Regulamento da Lei número 6.894 de 16 de dezembro de 1980 (Decreto número 4.954 de 14 de janeiro de 2004), eles são divididos em dois grupos principais: os não-minerais e os minerais. Os nutrientes não minerais são: o carbono, o hidrogênio e o oxigênio. Os nutrientes minerais são divididos em três grupos: macronutrientes primários (nitrogênio $-\mathrm{N}$, fósforo $-\mathrm{P}$ e potássio - K); macronutrientes secundários (cálcio, magnésio e enxofre); e micronutrientes (boro, cloro, cobalto, cobre, ferro, manganês, molibdênio, silício e zinco).

Os fertilizantes minerais estão definidos na legislação brasileira (Decreto número 4.954 de 14 de janeiro de 2004) como "produto de natureza fundamentalmente mineral, natural ou sintético, obtido por processo físico, químico ou físico-químico, fornecedor de um ou mais nutrientes de plantas".

Antes da existência desses fertilizantes, as principais fontes de nutrientes para as plantas eram através de fertilizantes denominados orgânicos, tais como: esterco de animais, cinzas, farinha de peixes, farinha de ossos, entre outros resíduos orgânicos.

Com o aumento da população e a crescente necessidade de produzir mais alimentos, foram, então, desenvolvidos os fertilizantes minerais ou químicos. Muitos pesquisadores afirmam que se os fertilizantes orgânicos tivessem seu valor apenas pelos conteúdos de N-P-K, não há dúvida que há muito já teriam sido abandonados e inteiramente substituídos pelos minerais. 
Diante desse cenário, o que podemos notar ao longo dos anos é um enorme crescimento no consumo de fertilizantes químicos em todo o mundo, acompanhado pelo desenvolvimento de processos de fabricação e de produtos fertilizantes.

O Brasil, por exemplo, é um dos poucos países do mundo com enorme potencial para aumentar a sua produção agrícola, seja pelo aumento de produtividade ou pela expansão da área plantada. Com um clima diversificado, chuvas regulares, energia solar abundante e quase $13 \%$ de toda a água doce disponível no planeta, o país tem 388 milhões de hectares de terras agricultáveis férteis e de alta produtividade, dos quais 90 milhões ainda não foram explorados; se constituindo em um dos líderes mundiais na produção e exportação de vários produtos agropecuários (MAPA, 2009).

No ano de 2007 constatou-se que o Brasil foi o quarto maior consumidor mundial de fertilizantes, correspondendo a aproximadamente 25 milhões de toneladas de produtos fertilizantes. Contudo, o país produziu naquele ano apenas $36 \%$ do necessário ao seu consumo em termos de produtos fertilizantes (ANDA, 2008).

Os nutrientes primários (N-P-K) geralmente tornam-se deficientes no solo antes dos demais, porque as plantas os usam em quantidades relativamente grandes. Os demais nutrientes, apesar da importância biológica, não têm expressão econômica na indústria de fertilizantes, nem valorização comercial significativas, por serem utilizados em quantidades bem menores (ANDA, 2009).

Face ao exposto, a indústria de fertilizantes minerais (ou químicos) se dividiu em três setores, de acordo com a espécie do principal nutriente que contém: fertilizantes nitrogenados, fertilizantes fosfatados e fertilizantes potássicos. Esses setores industriais produzem os fertilizantes minerais simples, que segundo a legislação brasileira (Decreto número 4.954 de 14 de janeiro de 2004) são "produtos formados, fundamentalmente, por um composto 
químico, contendo um ou mais nutrientes de plantas". A partir dos fertilizantes simples são feitas as misturas e/ou produtos granulados de formulação N-P-K.

Apesar de pesquisadores, empresas e os próprios agricultores já terem comprovado cientificamente que o uso eficiente dos fertilizantes minerais contribui para aumento da produtividade agrícola, por outro lado existem dúvidas no que se refere ao consumo de recursos naturais e à geração de rejeitos (emissões atmosféricas, efluentes líquidos e resíduos sólidos) ao longo de suas cadeias produtivas.

Diante de tais dúvidas e aproveitando a experiência do Prof. Dr. Gil Anderi da Silva adquirida ao longo de mais de trinta anos junto ao setor de fertilizantes, optou-se por realizar o trabalho de doutorado voltado à produção de fertilizantes no Brasil.

Em 1998, foi implementado no Departamento de Engenharia Química da Escola Politécnica da Universidade de São Paulo (USP) o Grupo de Prevenção da Poluição (GP2) que tem se dedicado a estudos abordando a problemática ambiental sob o ponto de vista da prevenção da poluição. Atualmente, a principal linha de atuação do grupo está direcionada à Avaliação do Ciclo de Vida (ACV) de bens e serviços, sob a coordenação do Prof. Dr. Gil Anderi da Silva. O objetivo do grupo é proporcionar as condições necessárias para que estudos de ACV possam ser conduzidos no país, tais como: a divulgação da metodologia de execução dessa técnica, a contribuição para o desenvolvimento metodológico adequado para as condições locais e a disponibilização de informações através da criação de um banco de dados brasileiro para apoio à ACV.

A ACV é uma técnica da gestão ambiental utilizada para avaliar o desempenho ambiental de um produto ou serviço ao longo de todo o seu ciclo de vida. O ciclo de vida é o conjunto de etapas encadeadas e sucessivas que incluem: a obtenção dos recursos naturais; as etapas de transformação necessárias à fabricação do produto principal (o qual é o objeto de estudo); uso; distribuição e disposição final do produto no meio ambiente. 
De um modo simplista, podemos dizer que a execução de um estudo de ACV compreende a identificação e quantificação das interações do ciclo de vida do produto ou serviço com o meio ambiente (aspectos ambientais) e a avaliação dos potenciais impactos associados a essas interações. Entende-se por aspectos ambientais, todas as correntes de matéria e energia que saem do meio ambiente para o sistema em estudo e todas as correntes (de matéria e energia) que saem do sistema e vão para o meio ambiente.

Devido à elevada quantidade de dados necessários para a elaboração de um estudo dessa natureza e sabendo que esses dados devem ser representativos para a região que se pretende analisar, é imprescindível que um banco de dados regional esteja disponível.

Em razão do número de informações representativas contidas em um banco de dados, podemos afirmar que sua disponibilização reduzirá drasticamente o consumo de tempo e de recursos necessários para os estudos de ACV.

Um banco de dados para apoio aos estudos da técnica da ACV deve conter informações representativas e de consumo de materiais e de energia, de emissões atmosféricas, de efluentes líquidos e de resíduos sólidos para elementos comuns a vários outros ciclos de vida. Esses elementos comuns, para efeito de banco de dados, são divididos em quatro categorias: materiais; energia; atividades de transporte e gerenciamento de resíduos.

Nesse contexto está inserido este trabalho de doutorado que pretende contribuir para a consolidação de um banco de dados brasileiro através dos fertilizantes, uma vez que estes se constituem em um dos elementos comuns a vários outros ciclos de vida.

Considerando que o GP2 já possui trabalhos realizados para fertilizantes fosfatados produzidos no país; quais sejam, superfosfato simples - SSP (KULAY, 2000), superfosfato triplo - TSP e termofosfato magnesiano fundido FMP (KULAY, 2004) e também para um fertilizante potássico (cloreto de 
potássio - KCl) (SILVA; RIBEIRO; KULAY, 2006), optou-se então pela elaboração de um estudo voltado aos fertilizantes nitrogenados no Brasil.

O nitrogênio é um elemento fundamental para a vida dos organismos vivos. Para as plantas, exerce um papel vital. O solo, em particular, deve conter compostos nitrogenados, para possibilitar o bom desenvolvimento das plantas.

$\mathrm{O}$ nitrogênio ocorre na forma de $\mathrm{N}_{2}$ no ar, na forma de proteínas em todos os seres vivos e no solo, na forma de sais e de outros compostos (MALAVOLTA, 1981).

$\mathrm{O}$ ar atmosférico contém grande quantidade de nitrogênio molecular. $\mathrm{O}$ nitrogênio molecular $\left(\mathrm{N}_{2}\right)$ é um gás incolor, inodoro, não-inflamável e não tóxico. Os vegetais, na realidade, estão imersos em nitrogênio. No entanto, o nitrogênio atmosférico é quimicamente pouco reativo, encontrando-se em uma forma que poucos organismos utilizam-no como nutriente (IFA, 2009a). Assim é necessário, portanto, transformá-lo em formas assimiláveis às plantas. Embora alguns microrganismos possam assimilar o nitrogênio da atmosfera, transformando-o em substâncias aproveitáveis pelas plantas, na agricultura em geral esse elemento é fornecido na forma de alguns compostos químicos, os quais passaram a ser a principal forma de fixar o nitrogênio e torná-lo disponível para os vegetais.

Até o final do século XIX, o nitrogênio era obtido a partir de sais, como o nitrato de sódio $\left(\mathrm{NaNO}_{3}\right)$, e de excremento de aves. Entretanto, era claro que essas fontes não poderiam suprir a demanda mundial futura.

Nessas circunstâncias, os químicos se dedicaram a encontrar maneira econômica de converter o nitrogênio atmosférico em composto nitrogenado que pudesse ser usado como fertilizante agrícola, ou seja, em uma forma que fosse útil à fixação pelas plantas. A pouca reatividade do nitrogênio parecia obstáculo insuperável (MALAVOLTA, 1981).

Contudo, em 1909, o engenheiro químico alemão Fritz Haber (18861934) descobriu que a justa combinação de catalisador, temperatura e pressão, 
propiciava a reação com bons rendimentos, entre o nitrogênio $\left(N_{2}\right)$ e o hidrogênio $\left(\mathrm{H}_{2}\right)$ para formar a amônia $\left(\mathrm{NH}_{3}\right)$ (IFA, 2009a).

A fixação do nitrogênio atmosférico foi desenvolvida para uso industrial e comercializada por Carl Bosch (1874-1940) em 1910 através do processo que ficou conhecido como Haber-Bosch. A primeira instalação industrial para produzir amônia foi construída na Alemanha para a empresa química alemã BASF por Fritz Haber e Carl Bosch, tendo começado a funcionar em 1913 (MALAVOLTA, 1981).

O processo Haber-Bosch é de tal importância para a humanidade que continua, até os dias atuais, a ser a única descoberta química reconhecida através de dois prêmios Nobel de química: Fritz Haber em 1918, e Carl Bosch em 1931 (IFA, 2009a).

Dado o teor do nutriente nitrogênio $(N)$ contido nos fertilizantes nitrogenados, decidiu-se realizar o trabalho de doutorado para a uréia (46\% de $\mathrm{N})$, nitrato de amônio (34\% de $\mathrm{N}$ ) e sulfato de amônio ( $21,2 \%$ de $\mathrm{N})$. Esses três produtos foram responsáveis, no ano de 2007 , por $76 \%$ de toda a produção de fertilizantes nitrogenados no Brasil em termos de toneladas do nutriente nitrogênio (ANDA, 2008).

Face ao contexto apresentado, este trabalho apresenta uma contribuição ao banco de dados brasileiro para apoio a estudos de ACV, qual seja, os inventários do ciclo de vida de fertilizantes nitrogenados para as condições brasileiras.

De modo simplificado, podemos dizer que para a elaboração do inventário foram coletadas informações para se obter um perfil detalhado do setor de fertilizantes nitrogenados no Brasil. Em seguida, realizou-se a identificação quantificada das entradas de recursos naturais (materiais e energéticos) e das disposições de rejeitos (materiais e energéticos) associadas aos ciclos de vida, do berço ao portão da fábrica, dos três fertilizantes estudados. Concluindo, foi efetuada uma discussão dos principais aspectos 
ambientais associados à obtenção de recursos naturais e às etapas de fabricação dos fertilizantes nitrogenados no Brasil. 


\section{OBJETIVOS}

O trabalho de doutorado visa identificar e quantificar os aspectos ambientais associados aos processos de fabricação de fertilizantes nitrogenados simples no Brasil, utilizando a técnica da ACV, os quais serão apresentados de acordo com os requisitos para o desenvolvimento da técnica em questão na forma de um inventário do ciclo de vida.

Como produto imediato e decorrente de este esforço de pesquisa o presente estudo tem por objetivo complementar, porém não menos importante, contribuir na composição do banco de dados brasileiro em apoio aos estudos de ACV. 


\section{MÉTODO DE EXECUÇÃO}

O trabalho de doutorado foi estruturado em termos de sua condução em três etapas, a saber:

I. Revisão bibliográfica: visa fornecer o estado da arte sobre os temas a serem tratados e foi executada através da consulta a livros, publicações especializadas, artigos científicos, normas técnicas e demais publicações disponíveis. A internet também constituiu um papel importante nesta etapa, pois, permitiu o acesso a um grande número de informações. Esta primeira etapa do trabalho foi organizada em três vertentes:

a) avaliação do ciclo de vida (ACV)

Nesse item do trabalho estudaram-se: o conceito de ciclo de vida e a definição de Avaliação do Ciclo de Vida; um breve histórico sobre os estudos realizados; o desenvolvimento da metodologia de execução da técnica de ACV; uma descrição de seus usos e aplicações, bem como, da importância e das limitações dessa ferramenta da gestão ambiental e a metodologia de execução da mesma; de bancos de dados e softwares disponíveis para suporte da técnica; além dos estudos acadêmicos publicados no país e dos estudos recentes publicados sobre a técnica.

b) perfil da indústria brasileira de fertilizantes simples

Constam desta vertente: um breve histórico do setor de fertilizantes no Brasil; o desempenho do setor de fertilizantes frente à indústria química nacional; a distribuição do consumo de fertilizantes no país; as empresas do setor no que se refere à composição acionária, aos produtos e às unidades industriais; a produção nacional de fertilizantes nitrogenados, fosfatados e potássicos e a dependência das importações. 
c) fertilizantes nitrogenados produzidos atualmente no Brasil

Foram abordados neste item, da pesquisa bibliográfica, assuntos que dizem respeito aos fertilizantes nitrogenados produzidos atualmente no país tais como: o número de empresas do setor, suas participações no mercado regional, a localização das unidades de produção, os insumos utilizados, os processos de fabricação e os fornecedores de insumos; além das importações do setor.

II. Elaboração de inventários do ciclo de vida de fertilizantes nitrogenados brasileiros: uma vez conhecidos os sistemas de produto a serem estudados, com base na pesquisa anterior, esta segunda etapa do trabalho constitui-se, basicamente, da identificação e quantificação de todos os aspectos ambientais associados aos sistemas dos produtos fertilizantes estudados. A coleta dos dados necessários para a elaboração dos inventários foi constituída, essencialmente, através do contato com empresas brasileiras do setor de fertilizantes nitrogenados.

III. Análise e discussão dos resultados obtidos na etapa anterior. 


\section{REVISÃO BIBLIOGRÁFICA}

\subsection{Avaliação do Ciclo de Vida (ACV)}

\subsubsection{Conceito de ciclo de vida e definição de Avaliação do Ciclo de Vida}

Produtos e serviços têm por função original preencher lacunas no padrão de qualidade de vida da sociedade. No mérito mais específico dessa abordagem, o cumprimento de determinada função por um bem está associado ao atendimento de uma necessidade social, ou à identificação de uma oportunidade de aproveitamento do mesmo.

Dentro de um conceito amplo, o atendimento de certa função por um produto compreende a produção de este último. Para tanto, seus componentes e materiais constituintes devem ser processados previamente a esta produção; assim como, os materiais e componentes antes de estes.

Esta leitura se propaga ao longo dos diversos elos da cadeia produtiva até a obtenção, junto ao meio ambiente dos recursos necessários a tais processamentos. Por outro lado, esgotado o uso para o qual o produto foi concebido, este será disposto no meio ambiente na forma de rejeito. Desta sucessão interconectada de estágios decorre o conceito de ciclo de vida (representado na figura 1).

SILVA (2006) apresenta o conceito de ciclo de vida como "conjunto de todas as etapas necessárias para que um produto cumpra sua função, desde a obtenção dos recursos naturais usados na sua fabricação até sua disposição final após o cumprimento da função". 


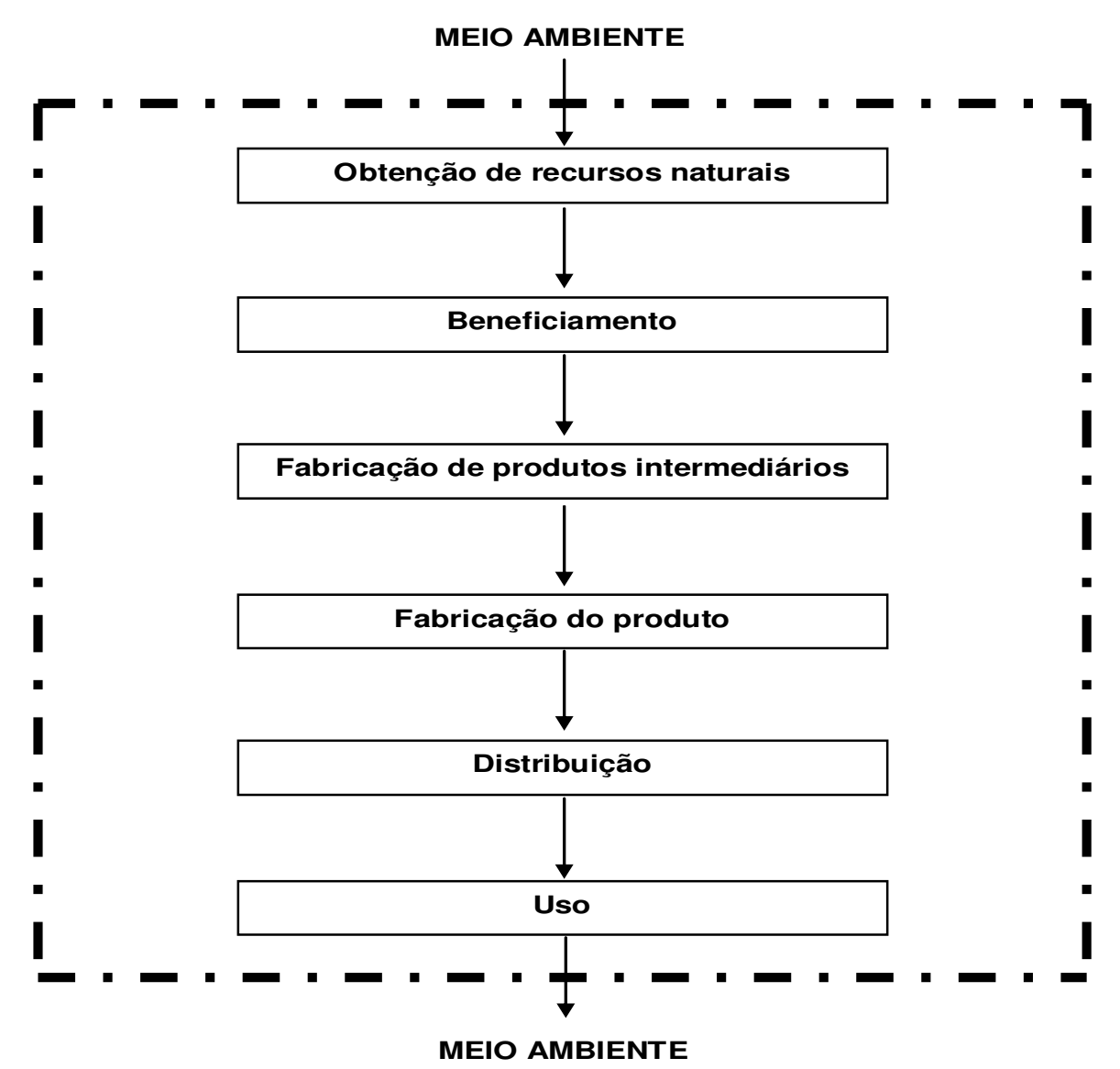

Figura 1: Ciclo de vida de um produto ou serviço (adaptado de SILVA, 2003).

Vários autores (FAVA et al., 1991; CONSOLI et al., 1993; JENSEN et al., 1997; CHEHEBE, 1998; GRAEDEL, 1998) descrevem a ACV como sendo um instrumento de avaliação do impacto ambiental associado a um produto ou processo cuja abrangência compreende etapas que vão desde a retirada das matérias-primas elementares da natureza que entram no sistema produtivo (berço) à disposição do produto final após uso (túmulo).

SILVA (2006) define a Avaliação do Ciclo de Vida (ACV), de forma bem apropriada, como "uma técnica utilizada para avaliar o desempenho ambiental de produtos e serviços ao longo de todo o seu ciclo de vida, desde a obtenção dos recursos naturais até a disposição final, passando por todos os elos industriais da cadeia produtiva e pela distribuição e uso dos mesmos". 
Ainda de acordo com SILVA (2006), a ACV é uma técnica que permite a identificação quantificada das interações do ciclo de vida do produto com o meio ambiente e a avaliação dos impactos ambientais associados a essas interações. 


\subsubsection{A ACV e a série ISO 14000}

Até o ano de 2005 as normas publicadas sobre a técnica da Avaliação do Ciclo de Vida, pela International Organization for Standardization (ISO), foram:

a) ISO 14040 - Environmental management - Life cycle assessment - Principles and framework (1997).

b) ISO 14041 - Environmental management - Life cycle assessment - Goal and scope definition and inventory analysis (1998).

c) ISO 14042 - Environmental management - Life cycle assessment - Life cycle impact assessment (2000).

d) ISO 14043 - Environmental management - Life cycle assessment - Life cycle interpretation (2000).

De acordo com FINKBEINER et al. (2006), em dezembro de 2003 foi criado um grupo de trabalho com mais de cinqüenta especialistas internacionais para comandar a revisão das normas da série ISO 14040. Os principais objetivos do grupo foram:

- aperfeiçoar as normas, com a responsabilidade de deixar seus termos obrigatórios e conteúdos técnicos sem modificações, exceto para erros e inconsistências. As ações para correção de erros e inconsistências resultaram nas inclusões das definições de produto e processo, na adição dos princípios da ACV, e em esclarecimentos sobre as fronteiras do sistema e revisão crítica;

- reunir todos os itens obrigatórios em uma única norma (ISO 14044), fixando a estrutura de objetivo e escopo, inventário, avaliação de impacto e interpretação como capítulos separados; e

- manter a ISO 14040 como um documento modelo, mas transferindo todos os itens obrigatórios para a nova norma, dando a ISO 14040 a obrigação de seguir as exigências da nova norma, que será o principal documento para os praticantes da ACV. 
Como resultado, o grupo de estudo desenvolveu duas novas normas em substituição às anteriores (ISO 14040/41/42/43) que foram publicadas internacionalmente pela ISO em 2006, quais sejam:

a) ISO 14040 - Environmental management - Life cycle assessment Principles and framework (2006a). Apresenta a definição dos principais termos e descreve os princípios gerais para as etapas de definição de objetivo e escopo, análise do inventário, avaliação de impactos e interpretação. Apresenta a necessidade e os requisitos para revisão crítica externa e descreve critérios para elaboração dos relatórios de estudos da técnica. Contudo, a norma não descreve a técnica da ACV em detalhes nem especifica metodologias para as etapas individuais da ACV; e

b) ISO 14044 - Environmental management - Life cycle assessment Requirements and guidelines (2006b). Especifica requisitos e diretrizes para estudos de ACV incluindo as quatro etapas da técnica; bem como, o relatório a revisão critica; limitações da técnica e a relação entre as etapas da ACV.

Essas normas podem ser adquiridas através da internet no endereço: www.iso.org.

Publicada também no ano de 2006 a norma ISO 14025 (ISO, 2006c) estabelece os requisitos para obtenção de rótulos ambientais do tipo III sendo que um desses requisitos é a existência de estudo de ACV para o produto. Segundo a norma (ISO, 2006c), declarações (rótulos) ambientais do tipo III apresentam informações quantificadas sobre o ciclo de vida de um produto para permitir comparações entre produtos que desempenham a mesma função.

A série ISO 14040 também contém três relatórios técnicos, que ainda estão em vigor, exemplificando a aplicação das normas relativas à ACV:

a) ISO 14047 - Environmental management - Life cycle assessment - Illustrative examples on how to apply ISO 14042 (2001);

b) ISO 14048 - Environmental management - Life cycle assessment - Data documentation format (2002); e 
c) ISO 14049 - Environmental management - Life cycle assessment - Examples for the application of ISO 14041 to goal and scope definition and inventory analysis (2000). 


\subsubsection{Histórico da ACV}

Conforme CHEHEBE (1998), a crise do petróleo no início da década de 70 do século $X X$ alertou os países desenvolvidos para a necessidade da melhor utilização de seus recursos naturais e racionalização do consumo de fontes energéticas esgotáveis.

Ainda no início da década de 70 do século XX, estudos publicados em The Limits to Growth (MEADOWS et al., 1972) e em A Blueprint for Survival (GOLDSMITH et al., 1972) resultaram em previsões dos efeitos do crescimento da população mundial sobre a demanda de recursos materiais e energéticos finitos. As previsões para o rápido esgotamento dos combustíveis fósseis e as alterações climáticas estimularam estudos mais detalhados em relação ao consumo de recursos energéticos esgotáveis. Durante este período, alguns estudos foram realizados para estimar os custos e as implicações ambientais de fontes alternativas de energia (USEPA, 2006).

Em 1969 a Coca-Cola Company encomendou um estudo ao Midwest Research Institute (MRI) para estimar os efeitos ambientais do uso de diferentes tipos de embalagens para refrigerantes. Este trabalho vem a ser aprimorado em 1974 pelo MRI, por encomenda da Environmental Protection Agency (EPA), e se torna o primeiro modelo do que conhecemos hoje como Avaliação de Ciclo de Vida (JENSEN et al., 1997). Os primeiros estudos baseados nesta metodologia visavam prioritariamente estimar o consumo energético dos processos e produtos em questão.

Posteriormente na Europa foi desenvolvido um procedimento similar chamado Ecobalance, que a partir de 1985 torna-se uma referência obrigatória para as empresas da área alimentícia, para o monitoramento do consumo de matérias primas e energia, além da geração de resíduos na fabricação de seus produtos (CHEHEBE, 1998).

Em 1991 o Ministério de Meio Ambiente da Suíça contratou um abrangente estudo sobre materiais para embalagens que gerou um banco de 
dados referencial para outros estudos, inclusive a versão do primeiro software para ACV, o Ökobase I (CHEHEBE, 1998).

Nos anos de 1991 e 1993 foram lançadas pela Society of Environmental Toxicology and Chemistry (SETAC) as respectivas publicações sobre a execução da técnica da ACV: "Technical framework for life cycle assessment" de FAVA et al. (1991) e "Guidelines for life cycle assessment: a code of practice" de CONSOLI et al. (1993). A SETAC é uma sociedade profissional de indivíduos e grupos para estudos de problemas ambientais. Sua fundação para educação ambiental tem sido um dos maiores responsáveis pelo desenvolvimento da técnica da ACV. Muitos dos conceitos desenvolvidos na SETAC foram adotados pela ISO na tentativa de padronizar o método de execução da técnica da ACV.

Segundo SONNEMANN; CASTELLS; SCHUHMACHER (2004), a partir de 1993, com a criação do Comitê Técnico TC 207 da ISO, em especial o subcomitê SC05, a ISO iniciou o processo de elaboração das normas sobre ACV, dividindo o trabalho entre cinco grupos: WG 1 - ISO 14040 (princípios gerais), WG 2 e WG 3 - ISO 14041 (análise do inventário), WG 4 - ISO 14042 (avaliação de impactos) e WG 5 - ISO 14043 (interpretação).

No início de 1996 é lançada a primeira publicação do periódico bimestral "The international journal of life cycle assessment" inteiramente dedicado à técnica da ACV (BAUMANN; TILLMAN, 2004). O periódico se constitui em uma importante referência para quem quiser acompanhar as tendências do desenvolvimento da ACV. Ao longo dos amos, artigos e comentários sobre a metodologia da técnica, estudos de caso e informações sobre eventos têm sido publicados.

Ainda no ano de 1996 ocorreu o lançamento da publicação "Life cycle assessment: what it is and how to do it' pela UNEP (United Nations Environment Programme). Desde então, a UNEP estabeleceu um grupo de trabalho que tem seus esforços voltados ao estudo do ciclo de vida de produtos (UNEP, 1996). 
Em junho de 1997 a primeira norma da ISO sobre ACV (ISO 14040) foi publicada internacionalmente. Outras normas lançadas pela ISO foram: ISO 14041 em 1998, ISO 14042 e ISO 14043 em 2000 (BAUMANN; TILLMAN, 2004).

Em abril de 2002 teve início a parceria internacional da UNEP com a SETAC denominada "The Life Cycle Initiative" (A Iniciativa do Ciclo de Vida) com o objetivo principal de disseminar o conceito de ciclo de vida ao redor do mundo. Os objetivos específicos são: coletar e disseminar informação de casos de sucesso no "Life Cycle Thinking" (Pensamento do Ciclo de Vida); compartilhar o conhecimento da interface entre a ACV e outras ferramentas; identificar as melhores práticas de indicadores e estratégias de comunicação para a gestão do ciclo de vida; prover a base para capacitação; expandir a disponibilidade de dados e métodos da técnica de ACV; e facilitar o uso da informação e dos métodos baseados no ciclo de vida. Para alcançar esses objetivos, três programas foram lançados: Gestão do Ciclo de Vida (GCV), Inventário do Ciclo de Vida (ICV) e Avaliação de Impactos do Ciclo de Vida (AICV) (LIFE CYCLE INITIATIVE, 2009a). 


\subsubsection{ACV no Brasil}

SILVA; KULAY (2006) mencionam que a primeira atividade relacionada à Avaliação de Ciclo de Vida (ACV) no Brasil se deu, em 1994, com a criação do Grupo de Apoio à Normalização (GANA) junto à Associação Brasileira de Normas Técnicas (ABNT) para viabilizar a colaboração do Brasil no comitê técnico TC 207 da ISO, criado um ano antes. A criação do GANA incluiu o subcomitê de ACV SC 05.

Com base nos trabalhos do referido comitê técnico, no ano de 1998, foi publicado o primeiro livro brasileiro sobre ACV intitulado "Análise do Ciclo de Vida de Produtos: ferramenta gerencial da ISO 14000" de José Ribamar Chehebe (CHEHEBE, 1998).

Ainda no ano de 1998, sob a coordenação do Prof. Dr. Gil Anderi da Silva, foi criado o Grupo de Prevenção da Poluição (GP2) junto ao Departamento de Engenharia Química da Escola Politécnica da USP. O grupo, atuante até hoje, tem se dedicado a estudos abordando a problemática ambiental sob o ponto de vista da prevenção da poluição.

Atualmente, a principal linha de atuação do grupo está direcionada à Avaliação do Ciclo de Vida de bens e serviços. As atividades do GP2 têm se concentrado no desenvolvimento de uma metodologia de execução adequada às condições brasileiras e na construção de um banco de dados regional. Desde sua criação o grupo publicou diversos artigos em eventos e periódicos nacionais e internacionais. Até o presente momento, além de outros projetos que se encontram em execução, uma tese de doutorado e doze dissertações de mestrado já foram concluídas.

O Centro de Tecnologia de Embalagem (CETEA) do Instituto Técnico de Alimentação (ITAL), em parceira com um consórcio de associações e empresas e com o apoio da Fundação de Amparo à Pesquisa do Estado de São Paulo (FAPESP), desenvolveu, no período entre 1997 e 2000, o projeto "Análise de Ciclo de Vida de Embalagens para o Mercado Brasileiro". Esse projeto teve por 
objetivo a condução de estudos de ACV para 13 sistemas de embalagem, considerando a realidade tecnológica e os recursos disponíveis no país.

A partir do ano de 1999 o GANA foi sucedido pelo Comitê Brasileiro de Gestão Ambiental (CB 38) da ABNT. O CB 38 tem no SC 05 o grupo encarregado das normas relativas à ACV no país (SILVA; KULAY, 2006).

Em novembro de 2001 é lançada pela ABNT a tradução da primeira norma da ISO da série 14040 (NBR ISO 14040), fazendo com que empresas e instituições brasileiras passassem a ter interesse pela ACV e utilizassem, desde então, essa ferramenta como uma técnica para avaliação de seus processos produtivos sob o ponto de vista ambiental.

No ano de 2002 se deu o lançamento da publicação "Avaliação do Ciclo de Vida: princípios e aplicações" do CETEA/CEMPRE visando traduzir e ilustrar os conceitos, aplicações e restrições dos estudos de ACV.

Em vista da importância e do crescimento rápido da ACV, foi criada em 29 de novembro de 2002, na cidade do Rio de Janeiro, a Associação Brasileira de Ciclo de Vida (ABCV) para divulgar e desenvolver o uso da técnica da ACV no país. Nesse contexto, dois aspectos são prioridades para a Associação:

a) promover a consolidação de uma metodologia para a ACV, compatível com a realidade brasileira; e

b) executar a construção de um banco de dados brasileiro para apoiar estudos da técnica.

A ABCV tem como entidades fundadoras: empresas; órgãos de classe; universidades; instituições do governo; entidades de pesquisas e ONGs.

Durante 0 ano de 2004 foram publidadas, pela ABNT, duas normas de gestão ambiental relativas à ACV: NBR ISO 14041 (Definição de objetivo e escopo e análise de inventário) e NBR ISO 14042 (Avaliação do impacto do ciclo de vida).

Em novembro de 2004, na cidade de São Paulo, foi realizado o evento "Estratégias para a consolidação da ACV no Brasil" organizado pela ABCV e pelo Instituto EKOS Brasil. Nesse evento, que contou com a participação de 
membros da indústria (Nestlé, Petrobras, Basf, Natura, entre outras), academia (USP, UnB, UFSC, etc.), governo (Ministério da Ciência e Tecnologia - MCT) e órgãos de consultoria (Geoclock Consultoria Ltda.), se deu a criação de um projeto para a construção do banco de dados brasileiro em apoio aos estudos da técnica. $O$ projeto brasileiro envolve três requisitos essenciais: a capacitação de recursos humanos no que se refere à $\mathrm{ACV}$; a disponibilidade de dados genuinamente brasileiros para compor o banco de dados; e o comprometimento de segmentos econômicos.

$A$ criação da $A B C V$, bem como do projeto de construção do banco de dados brasileiro surgem em um momento extremamente apropriado, pois, condizem com a atual manifestação das autoridades brasileiras, das áreas governamental e econômica, que têm demonstrado a necessidade do Brasil se capacitar no uso da técnica, para não perder espaço no mercado internacional.

No ano de 2005 outra norma de gestão ambiental relativa à ACV, NBR ISO 14043 (Interpretação do ciclo de vida), teve sua publicação efetuada pela ABNT. Nesse mesmo ano foi lançado, pela Associação Brasileria das Instituições de Pesquisa Tecnológica (Abipti), o livro "Avaliação do Ciclo de Vida: a ISO 14040 na América Latina" sob a organização do Prof. Armando Caldeira Pires da Universidade de Brasília que reuniu onze combinações de situações que abordaram a aplicação da metodologia de ACV em estudos de caso característicos de países latino-americanos (PIRES, PAULA, VILLAS BOAS; 2005).

Foi realizada em fevereiro de 2007, na cidade de São Paulo, a "Conferência Internacional de Avaliação de Ciclo de Vida - CILCA 2007" que objetivou facilitar a troca de experiências e conhecimentos e consolidar $\mathrm{O}$ conceito de ciclo de vida e o gerenciamento do ciclo de vida na América Latina, integrando essa região com outras onde a técnica da ACV está mais avançada.

$O$ evento contou com minicursos, palestras e apresentações de trabalhos técnicos divididos em dez temas. Foram gerados, para a Conferência, 81 trabalhos que tiveram a seguinte distribuição entre os temas: três trabalhos em 
análise de ecoeficiência; oito em bancos de dados; sete sobre ecodesign e rotulagem; dez em energia; nove em estudos de caso; dez sobre gestão por meio da abordagem de ciclo de vida; doze em metodologia de ACV; seis em responsabilidade social; seis em softwares; e dez sobre sustentabilidade.

Ainda em 2007, foi lançado o livro "Ciclo de vida de embalagens para bebidas no Brasil" de Renata B. G. Valt que trata de um estudo de ACV de embalagens PET, de alumínio e de vidro para refrigerantes (VALT, 2007).

Ao final do mês de outubro de 2008, na cidade de Curitiba (PR), ocorreu o "Primeiro Congresso Brasileiro em Gestão do Ciclo de Vida - I CBGCV" visando propiciar um ambiente para o intercâmbio de conhecimento, voltado para a integração de conceitos, métodos e técnicas para incluir os aspectos ambiental, econômico e sócio-cultural no ciclo de vida de produtos, processos e serviços, entre pesquisadores, representantes de instituições públicas e de diversos segmentos industriais.

$O$ congresso contou com minicursos relacionados às ferramentas computacionais de apoio à ACV, à introdução a gestão do ciclo de vida e ao design para o cicio de vida; palestras e apresentações de trabalhos nos seguintes temas: avaliação do ciclo de vida de produtos, processos e serviços; projeto para o ciclo de vida; ecodesign; aplicação da gestão do ciclo de vida nos setores de energia, construção e transporte; sustentabilidade no ciclo de vida; gestão do ciclo de vida e indicadores de sustentabilidade. 


\subsubsection{Estudos acadêmicos de ACV publicados no Brasil}

Com o intuito de verificar os trabalhos acadêmicos de ACV produzidos no país, realizou-se uma pesquisa em três bancos de dados, a saber: banco de dados bibliográficos da Universidade de São Paulo (DEDALUS, 2008); biblioteca digital de teses e dissertações da Universidade de São Paulo (SABER, 2008); e banco de teses da Coordenação de Aperfeiçoamento de Pessoal de Nível Superior (CAPES, 2008).

A pesquisa efetuada contabilizou trabalhos cujos resumos mencionam 0 emprego da técnica da ACV nos mesmos.

Com base no levantamento de informações da pesquisa, foram encontrados 111 trabalhos acadêmicos assim distribuídos: 87 dissertações de mestrado e 24 teses de doutorado. Constatou-se que 32 trabalhos se dedicaram ao estudo das etapas de execução da técnica da ACV e 79 trabalhos foram voltados a estudos de caso envolvendo materiais e energia. As dissertações e teses produzidas no país obedeceram à distribuição apresentada na tabela 1, a seguir.

\begin{tabular}{|c|c|c|c|}
\hline Ano & $\begin{array}{c}\text { Número de } \\
\text { dissertações }\end{array}$ & Número de teses & $\begin{array}{c}\text { Total de trabalhos } \\
\text { publicados }\end{array}$ \\
\hline 1997 & - & 01 & 01 \\
\hline 1998 & 03 & - & 03 \\
\hline 1999 & 02 & - & 02 \\
\hline 2000 & 03 & 01 & 04 \\
\hline 2001 & 02 & 02 & 04 \\
\hline 2002 & 05 & 01 & 06 \\
\hline 2003 & 11 & 05 & 16 \\
\hline 2004 & 16 & 05 & 21 \\
\hline 2005 & 10 & 03 & 13 \\
\hline 2006 & 09 & 02 & 11 \\
\hline 2007 & 25 & 04 & 29 \\
\hline 2008 & 01 & - & 01 \\
\hline Total & $\mathbf{8 7}$ & $\mathbf{2 4}$ & $\mathbf{1 1 1}$ \\
\hline
\end{tabular}

Tabela 1: Dissertações e teses de ACV publicadas por ano no Brasil (CAPES, 2008; DEDALUS, 2008; SABER, 2008). 
Conforme os dados mostrados na tabela 1 o período com maior número de publicações foi o biênio 2006/2007. Esse fato evidencia que o acesso à informação sobre a técnica ACV está mais fácil e que o interesse pela técnica aumentou significativamente em relação aos anos anteriores.

Nesta pesquisa verificou-se também que os trabalhos acadêmicos brasileiros contemplam diversos segmentos produtivos, tais como: petroquímico; químico; construção civil; automobilístico; agrícola; metalúrgico e eletrônico.

Percebeu-se que desde a publicação das normas ISO sobre ACV e também com a criação da $\mathrm{ABCV}$ diversos trabalhos foram voltados a produtos que são comuns ao ciclo de vida de inúmeros outros produtos, visando contribuir para a consolidação do banco de dados brasileiro, tais como: energia; fertilizantes; combustíveis; além de materiais metálicos, poliméricos e cerâmicos.

No que diz respeito às dissertações de mestrado encontradas a USP é a instituição que conta com maior número de publicações, totalizando 28 trabalhos. De acordo com a pesquisa constatou-se que a maior produção da USP, com 13 dissertações, está concentrada no Departamento de Engenharia Química da Escola Politécnica devido à existência do Grupo de Prevenção da Poluição (GP2), o qual possui 12 dissertações publicadas.

Conforme pode ser observado na tabela 2 , a pesquisa ainda revelou que em relação às teses de doutorado a USP também se destaca com maior numero de trabalhos, sendo este igual a oito publicações. A Universidade Estadual de Campinas (UNICAMP) vem a seguir com quatro teses. 


\begin{tabular}{|l|c|c|c|}
\hline \multicolumn{1}{|c|}{ Instituição } & $\begin{array}{c}\text { Número de } \\
\text { dissertações }\end{array}$ & $\begin{array}{c}\text { Número } \\
\text { de teses }\end{array}$ & Total \\
\hline Universidade de São Paulo & 28 & 8 & 36 \\
\hline Universidade Federal do Rio Grande do Sul & 6 & - & 6 \\
\hline Universidade Federal de Santa Maria & 5 & - & 5 \\
\hline Universidade Estadual de Campinas & 3 & 4 & 7 \\
\hline Universidade Federal do Rio de Janeiro & 3 & 3 & 6 \\
\hline Universidade Federal de Santa Catarina & 4 & 2 & 6 \\
\hline Instituto de Pesquisas Tecnológicas do Estado de & & & \\
\hline São Paulo & 4 & - & 4 \\
\hline Universidade Federal do Paraná & 3 & 1 & 4 \\
\hline Universidade Federal da Bahia & 3 & - & 3 \\
\hline Universidade Regional de Blumenau & 3 & - & 3 \\
\hline Universidade de Brasília & 3 & - & 3 \\
\hline Universidade Federal do Espírito Santo & 2 & - & 2 \\
\hline Universidade Federal Fluminense & 2 & 1 & 3 \\
\hline Universidade Metodista de Piracicaba & 2 & - & 2 \\
\hline Universidade Federal de São Carlos & 1 & 1 & 2 \\
\hline Universidade Federal de Minas Gerais & 1 & 1 & 2 \\
\hline Universidade de Caxias do Sul & 1 & - & 1 \\
\hline Universidade Tecnológica Federal do Paraná & 2 & - & 2 \\
\hline Pontifícia Universidade Católica do Rio de Janeiro & 1 & - & 1 \\
\hline Universidade de Taubaté & 1 & - & 1 \\
\hline Universidade Federal de Itajubá & 2 & - & 2 \\
\hline Universidade Federal de Viçosa & 1 & 1 & 2 \\
\hline Universidade Estadual de São Paulo & 1 & - & 1 \\
\hline Centro Universitário do Instituto Mauá de Tecnologia & 1 & - & 1 \\
\hline Universidade Paulista & 1 & - & 1 \\
\hline Centro Federal de Educação Tecnológica Celso Suckow da & 1 & - & 1 \\
\hline Fonseca (CEFET/RJ) & 1 & - & 1 \\
\hline Universidade de Santa Cruz do Sul & 1 & - & 1 \\
\hline Universidade do Estado de Santa Catarina & $\mathbf{8 7}$ & 2 & 2 \\
\hline Universidade Federal do Pará & $\mathbf{2 4}$ & $\mathbf{1 1 1}$ \\
\hline Total & 2 & & \\
\hline
\end{tabular}

Tabela 2: Dissertações e teses de ACV publicadas no Brasil por instituições acadêmicas (CAPES, 2008; DEDALUS, 2008; SABER, 2008).

As informações complementares sobre os trabalhos encontrados estão organizadas em uma tabela, no anexo $\mathrm{A}$, ao final de este documento. 


\subsubsection{Usos e aplicações}

Segundo UNEP (1996) os usuários primários da ACV são: indústrias e outras empresas comerciais; governos nacionais e locais, órgãos reguladores nacionais e intergovernamentais; organizações não governamentais (como grupos ambientais, sindicatos, organizações de consumidores e organizações comerciais); e consumidores.

As aplicações industriais da ACV citadas em UNEP (1996) são: a indicação de pontos fortes e fracos do produto na busca de sua melhoria; o projeto de produtos; a formulação da política da companhia; o atendimento à legislação e as informações do produto para questões de marketing.

De acordo com a mesma referência, a ACV pode ser utilizada pelo governo para rotulagem ambiental; como subsídios e taxações em favor da produção mais limpa e em políticas gerais como na determinação de combustíveis para a geração de eletricidade e meios de transporte.

No que dizem respeito às organizações não-governamentais (ONGs), os estudos de ACV podem ser utilizados por estas para gerar informações aos consumidores e para buscar uma base técnica de apoio a discussões públicas e debates (UNEP, 1996).

Para CONSOLI et al. (1993) o uso da ACV, por uma organização industrial, pode ser dividido em interno e externo.

Como usos internos destacam-se: o planejamento estratégico ou desenvolvimento de estratégias ambientais; o projeto de produtos e processos, visando otimizações; a identificação de oportunidades de melhorias ambientais; dar suporte ao estabelecimento de procedimentos ou especificações de compras; e auditorias ambientais e minimização de rejeitos. Como usos externos, são citados: o marketing ou suporte a declarações ambientais específicas; certificações; educação pública e comunicação; definição de políticas; e dar suporte ao estabelecimento de procedimentos ou especificações de compras (CONSOLI et al., 1993). 
Segundo CHEHEBE (1998), a ACV pode ser usada para: identificar oportunidades de melhoria dos aspectos ambientais de produtos em vários pontos de seu ciclo de vida; avaliar a tomada de decisão na indústria, assim como nas organizações governamentais e não governamentais (planejamento estratégico, projeto de produto ou processo); selecionar indicadores relevantes de desempenho ambiental, incluindo técnicas de medição; e promover marketing institucional e de produto.

SILVA; KULAY (2006) mencionam que a ACV é uma técnica que proporciona informações sobre as interações que ocorrem entre as etapas que constituem o ciclo de vida de um produto ou serviço e o meio ambiente. Assim sendo, a realização de um estudo de ACV tem como aplicações: fornecer uma imagem de quaisquer interações existentes com o meio ambiente; comparar o desempenho ambiental de produtos ou serviços que cumprem uma mesma função; identificar oportunidades para melhorias de desempenho ambiental, tais como o projeto de novos produtos, a reavaliação de produtos existentes, a busca de novos insumos e formas de energia alternativas; e elaboração de rótulos e declarações ambientais, quando o estudo for efetuado confrontando o desempenho ambiental de produtos contra um padrão preestabelecido.

Para MOURAD; GARCIA; VILHENA (2002), a ACV é uma metodologia importante por se constituir em uma ferramenta que trata com clareza e objetividade de questões ambientais complexas, tais como: o gerenciamento de recursos naturais; a identificação dos pontos críticos de um determinado produto ou serviço ao longo do ciclo de vida; a otimização de um produto ou serviço sistemas de produtos; o desenvolvimento de novos serviços e produtos; e definição de parâmetros para atribuição de rótulo ambiental a um determinado produto. 


\subsubsection{Limitações}

Neste este item apresenta-se uma relação de limitações citadas por alguns autores de publicações sobre ACV.

A falta de conhecimento do conceito de ciclo de vida pelas partes potencialmente interessadas e a indisponibilidade de fontes de informações específicas e confiáveis para a realização do estudo são apontadas como limitações da técnica por SILVA; YOKOTE; RIBEIRO (2002). De acordo com os autores, as principais razões para a persistência de este último problema são: sigilo de dados pelos proprietários; falta de atratividade para as organizações coletarem dados e, principalmente, o custo.

Assim como CURRAN (1996), GUINÉE et al. (2001) também ressaltam a indisponibilidade de dados para apoio, ou seja, de dados prontamente acessíveis como limitação da técnica da ACV. Muito embora bancos de dados tenham sido desenvolvidos em diversos países e o formato dos dados nestes contidos estarem sendo normalizado, os dados apresentam-se muitas vezes obsoletos, incomparáveis, ou de qualidade desconhecida.

Ainda em GUINÉE et al. (2001) é levantada a observação de que a ACV avalia potenciais de impactos ambientais, porque os mesmos não são especificados no tempo e no espaço e são freqüentemente relacionados para uma unidade funcional. Assim, não se tem certeza do instante, local da ocorrência e grandeza do impacto ambiental.

Para CHRISTIANSEN et al. (1997) e SILVA; KULAY (2006) a ACV requer uma grande quantidade de dados, resultando em elevado consumo de tempo e de recursos. Do mesmo modo, em pesquisa apresentada em UNEP (1999) foi revelado que o custo; a complexidade de execução e as incertezas sobre o resultado são os principais desestímulos para adoção de estudos de ACV.

CHEHEBE (1998) e SILVA (2006) destacam a dependência geográfica com uma das principais limitações da ACV. Os autores mencionam que as 
informações necessárias para o inventário, a seleção de categorias de impacto e a escolha de fatores de caracterização e de ponderação na etapa de AICV, devem ser específicas (representativas) ou para as condições técnicas, ambientais e geográficas da região onde está sendo executado o estudo.

Conforme destacado por SILVA (2006), o fato de um estudo de ACV necessitar da obtenção de grande quantidade de informações representativas pode ser solucionado com a disponibilização de um banco de dados regional.

A norma ISO 14040 (ISO, 2006a) considera que os principais problemas estão voltados às decisões subjetivas, ou seja, à natureza da seleção feita em um estudo de ACV. Segundo a norma (ISO, 2006a), a escolha dos limites do sistema, a seleção da origem e da idade dos dados e a escolha das categorias de impacto podem ser subjetivas, levando a uma perda do caráter objetivo da técnica.

Outra limitação importante da técnica é mencionada por SILVA (2006); qual seja, a ausência de uma metodologia universal consolidada, em particular no que se refere: à definição de procedimentos para a prática da técnica; à padronização da terminologia e do formato dos dados; e ao estabelecimento de restrições e cuidados necessários quando da realização de estudos comparativos que serão disponibilizados ao público. De acordo com a norma ISO 14040 (ISO, 2006a), não há, até o momento, um método de execução considerado como padrão.

MOURAD; GARCIA; VILHENA (2002) abordam como limitação a necessidade de combinação da ACV com outros instrumentos de análise. De fato, recentemente os estudos de ACV têm se dedicado à inclusão de aspectos sociais, à inclusão de aspectos econômicos e à análise de riscos de acidentes, fornecendo assim subsídios mais completos para o gerenciamento ambiental e à tomada de decisões.

Para MILLET et al. (2007), os modelos de sistemas de produtos elaborados por praticantes da técnica da ACV representam uma simplificação do sistema real. Tal fato, segundo os autores, pode causar a exclusão de 
alguns aspectos ambientais e até de processos importantes para o estudo, afetando assim seus resultados e suas conclusões.

MILLET et al. (2007) comentam o fato da técnica da ACV introduzir o conceito de unidade funcional, o qual está diretamente relacionado com a função do produto. Para os autores, a função de um produto não pode ser reduzida para a expressão de uma única especificação de uso. De fato, estudos mais detalhados em relação à unidade funcional demonstram que a definição da função de um produto necessita da identificação de uma complexa lista de requerimentos. Segundo REAP et al. (2008), a seleção adequada de uma unidade funcional é de extrema importância, pois, diferentes unidades funcionais podem levar a resultados diferentes para um mesmo sistema de produto.

Para contornar as limitações citadas são necessárias algumas ações fundamentais:

- padronização da metodologia e estabelecimento de critérios rígidos que disciplinem a forma como estudos dessa natureza devem ser conduzidos e levados ao conhecimento público;

- desenvolvimento de bancos de dados e de métodos de AICV regionais e confiáveis, bem como suas incorporações em softwares; e

- divulgação da técnica de ACV como ferramenta de gestão ambiental mostrando sua importância, usos e aplicações com o intuito de atrair e incentivar empresas, associações e governo a coletarem e disponibilizarem informações ambientais sobre pordutos e serviços. 


\subsubsection{Considerações sobre a metodologia de ACV}

Esta ferramenta de gestão ambiental é feita, basicamente, através da identificação dos aspectos ambientais (correntes de matéria e de energia que entram e emissões atmosféricas, efluentes líquidos, resíduos sólidos e emissões não materiais que saem do sistema de produto) de cada etapa do ciclo de vida do produto, seguida da avaliação dos potenciais impactos ambientais associados a estes aspectos.

Existem três métodos principais de execução de um estudo ACV: o método estabelecido pela SETAC em 1993 (CONSOLI et al., 1993), o da UNEP em 1996 e mais recente, o método recomendado pela norma ISO 14040 (2006a). Nas figuras 2, 3 e 4 a seguir, encontra-se a representação gráfica dos três métodos.

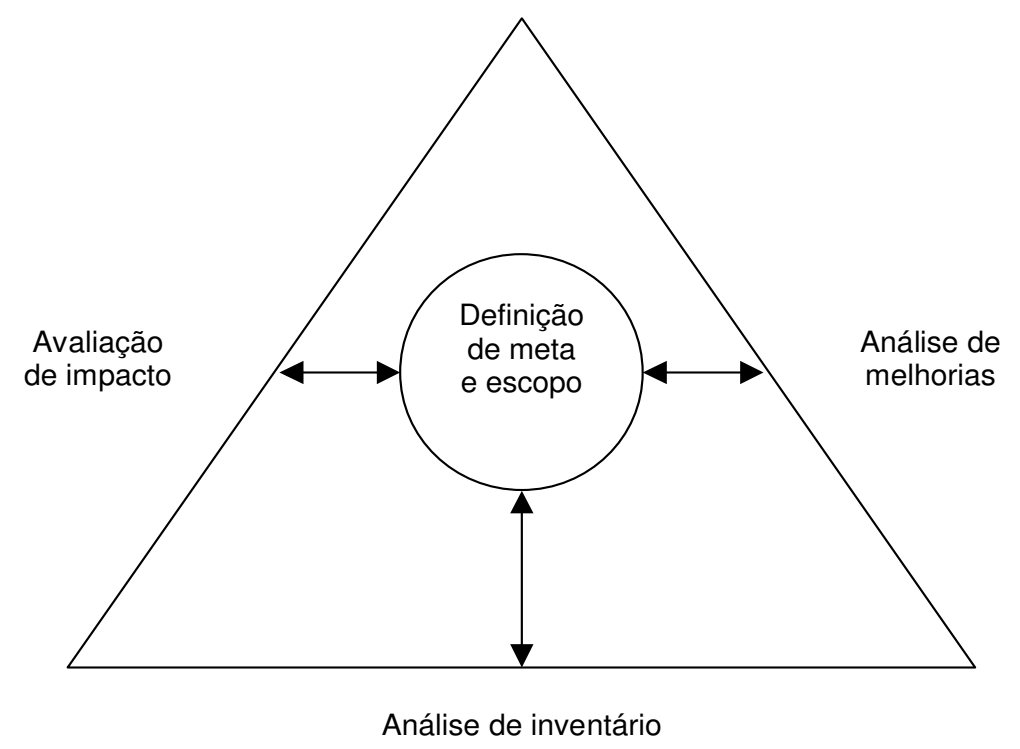

Figura 2: Estrutura de uma ACV segundo SETAC (adaptado da fig. 1 de CONSOLI et al., 1993). 


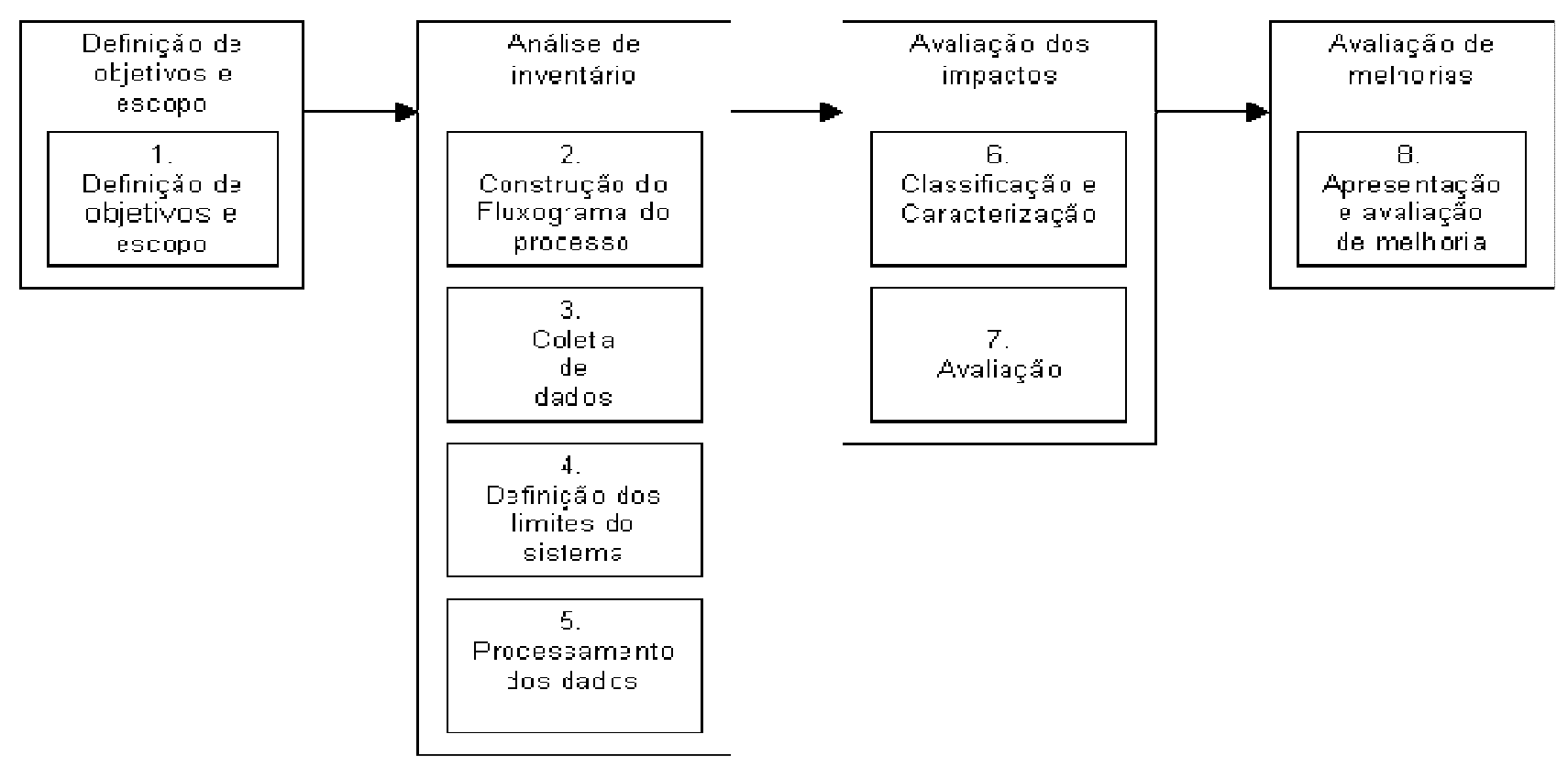

Figura 3: Estrutura de uma ACV segundo UNEP (UNEP, 1996).

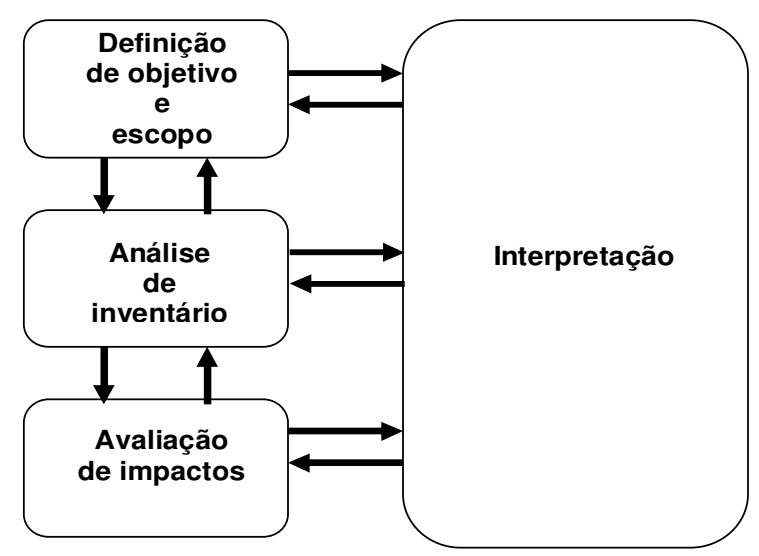

Figura 4: Estágios de uma ACV segundo ISO (adaptado da fig. 1 da norma ISO 14040, 2006a).

As duplas setas entre as fases indicam a natureza iterativa da Avaliação do Ciclo de Vida.

A partir da observação da representação gráfica das metodologias de execução de $A C V$, tanto a estrutura da norma ISO quanto à da SETAC, 
mostram o caráter iterativo de execução da ACV, através da colocação de setas em ambos os sentidos, ou seja, conforme vai se progredindo no estudo, é possível voltar em algum ponto anterior para verificar se as metas estão sendo atingidas ou se os dados coletados são adequados ao trabalho. Apesar de não estar explícito na estrutura da UNEP, também existe na mesma o caráter iterativo de um estudo de ACV, conforme se verifica ao se estudar a publicação.

Basicamente, todos os métodos citam quatro etapas principais de execução para ACV: definição de meta e escopo, análise de inventário, avaliação de impactos e avaliação de melhorias ou interpretação. Todas as etapas de cada um dos métodos são semelhantes, diferenciando-se por algumas tarefas que são realizadas ora numa etapa em uma metodologia, ora em outra etapa conforme a fonte estudada.

Um exemplo de tarefa onde este comportamento ocorre é a determinação do fluxograma do processo a ser estudado, que segundo a norma ISO, deve ser especificado durante a etapa de definição das metas e escopo, enquanto que segundo a SETAC e a UNEP, tal tarefa deverá ser realizada na etapa seguinte, ou seja, na análise de inventário.

$\mathrm{Na}$ metodologia de execução de ACV apresentada neste trabalho, prefere-se determinar o fluxograma ainda na etapa de definição de meta e escopo, pois assim ficará mais claro que dados serão realmente necessários, otimizando o tempo de coleta de dados. 


\subsubsection{Método da ISO de execução da ACV}

Neste item apresenta-se a metodologia adotada na elaboração de este trabalho e recomendada pelas normas ISO 14040 (ISO 2006a) e ISO 14044 (ISO, 2006b). O método de execução descrito nas normas citadas foi empregado neste trabalho por ser considerado o de melhor estrutura para a condução de estudos de ACV e também, por este ter sido atualizado recentemente.

A norma ISO 14040 descreve os princípios e a estrutura para se conduzir e relatar estudos de ACV e inclui certos requisitos mínimos (ISO, 2006a). Ainda de acordo com a norma (ISO, 2006a), a ACV é realizada através de quatro etapas (figura 5): definição de objetivo e escopo; análise do inventário; avaliação de impactos; e interpretação. A seguir passam a ser reportados brevemente os conteúdos de cada uma destas etapas.

\subsubsection{Definição de objetivo e escopo}

Conforme a norma (ISO, 2006a), nesta fase, a razão principal para a condução do estudo, sua abrangência e limites, a unidade funcional, a metodologia e os procedimentos considerados necessários para a garantia da qualidade do estudo e que deverão ser adotados são definidos.

Durante o processo de definição dos objetivos de uma ACV, devem ser avaliados fatores como as expectativas quanto às conclusões do estudo, assim como, os custos e o tempo de duração envolvidos no mesmo.

É importante ressaltar o caráter preliminar de tais definições, pois a ACV é uma ferramenta iterativa e faz parte de sua metodologia a revisão, quando necessária, do planejamento inicial (ISO, 2006b).

De uma forma simplificada a norma ISO 14040 (ISO, 2006a) estabelece que o conteúdo mínimo do escopo de um estudo de ACV deve referir-se às suas três dimensões: onde iniciar e parar o estudo do ciclo de vida (a extensão 
da ACV), quantos e quais subsistemas incluir (a largura da ACV), e o nível de detalhes do estudo (a profundidade da ACV). Estabelece, ainda que tais dimensões devem ser definidas de forma compatível e suficiente para atender o estabelecido nos objetivos do estudo.

De acordo com a ISO 14044 (ISO, 2006b), a etapa de definições é constituída por:

I. objetivo do estudo: deve, de modo inequívoco, estabelecer o uso que se pretende dar aos resultados de este, a motivação para realizá-lo e seu públicoalvo; e

II. escopo do estudo: deve identificar e definir o objeto de análise e limitá-lo para incluir o que é significativo.

Segundo a norma ISO 14044 (ISO, 2006b), o escopo do estudo deve considerar e descrever claramente os itens a seguir:

a) função: define a que se presta o produto ou serviço no contexto em que este será analisado.

b) unidade funcional (U. F.): é a unidade de medida da função anteriormente estabelecida. Deve prover uma referência para a qual as quantificações das entradas e saídas do sistema (aspectos ambientais) serão normalizadas. No caso do estudo envolver dois ou mais produtos, estes só poderão ser comparados se desempenharem a mesma função.

c) fluxo de referência: consiste na quantidade de produto necessária para exercer a função na medida (quantidade) estabelecida por uma unidade funcional. Para a determinação do fluxo de referência deve-se conhecer, preliminarmente, o desempenho (técnico) dos produtos a serem comparados. A tabela 3 apresenta um exemplo do estabelecimento de função, unidade funcional e fluxo de referência. 


\begin{tabular}{|c|c|c|c|c|}
\hline Produto & Função & $\begin{array}{c}\text { Unidade } \\
\text { funcional }\end{array}$ & $\begin{array}{c}\text { Desempenho } \\
\text { dos produtos }\end{array}$ & $\begin{array}{c}\text { Fluxo de } \\
\text { referência }\end{array}$ \\
\hline $\begin{array}{c}\text { Xícara de } \\
\text { plástico }\end{array}$ & $\begin{array}{c}\text { Servir doses } \\
\text { de café }\end{array}$ & $\begin{array}{c}1000 \text { doses de } \\
\text { café }\end{array}$ & 1 dose / xícara & 1000 xícaras \\
\hline $\begin{array}{c}\text { Xícara de } \\
\text { louça }\end{array}$ & $\begin{array}{c}\text { Servir doses } \\
\text { de café }\end{array}$ & $\begin{array}{c}1000 \text { doses de } \\
\text { café }\end{array}$ & 100 doses / xícara & 10 xícaras \\
\hline
\end{tabular}

Tabela 3: Exemplo de função, unidade funcional e fluxo de referência (adaptado de SILVA, 2003).

d) fronteiras iniciais do sistema de produto: para que um estudo de ACV possa se tornar eficiente em termos de custo e de tempo, devem ser estabelecidas fronteiras do sistema, tanto com o meio ambiente como com outros sistemas. A definição das fronteiras do estudo representa a delimitação da sua abrangência, considerando diversas dimensões.

De acordo com TILLMAN; BAUMANN (1995), estas são:

- fronteiras em relação ao sistema natural: são os limites que indicam onde seu ciclo de vida se inicia e termina, em relação ao meio natural. As opções de fronteira variam de acordo com o tipo de estudo de ACV a realizar, conforme representado na tabela 4 :

\begin{tabular}{|l|l|}
\hline \multicolumn{1}{|c|}{ Tipo de estudo de ACV } & \multicolumn{1}{c|}{$\begin{array}{c}\text { Etapas do ciclo de vida } \\
\text { consideradas }\end{array}$} \\
\hline Cradle to grave (do berço ao túmulo) & Todas. \\
\hline $\begin{array}{l}\text { Cradle to gate (do beç̧o ao portão da } \\
\text { fábrica) }\end{array}$ & $\begin{array}{l}\text { Extração e beneficiamento de recursos } \\
\text { naturais; fabricação dos produtos } \\
\text { intermediários e fabricação do produto } \\
\text { principal, o qual é o objeto de estudo. }\end{array}$ \\
\hline $\begin{array}{l}\text { Gate to grave (do portão da fábrica ao } \\
\text { túmulo) }\end{array}$ & $\begin{array}{l}\text { Distribuição, uso e disposição final do } \\
\text { produto. }\end{array}$ \\
\hline
\end{tabular}

Tabela 4: Tipos de estudos de ACV (RIBEIRO, 2004).

- fronteiras em relação a outros sistemas: em geral, cada sistema de produto tem associado uma rede de outros sistemas, como produção de insumos, obtenção de matérias-primas, subprodutos gerados, etc. Deve-se delimitar dentro desta rede quais processos serão ou não estudados, sob a pena de estarmos tentando abranger um universo demasiadamente amplo; 
- fronteiras geográficas: definem onde cada processo será considerado como realizado, uma vez que cada localidade possui características que podem fazer o resultado se tornar inadequado.

- fronteira temporal: considera o momento para o qual os dados levantados terão validade, ou seja, se será estudada uma situação atual, passada ou ainda cenários de futuro;

- fronteiras tecnológicas: representam o nível tecnológico ao qual os dados do estudo correspondem.

- fronteiras de bens de capital: determinam se serão incluídos ou não no estudo as infra-estruturas necessárias para a realização dos processos (edifícios das fábricas, estradas, etc).

Este estabelecimento de fronteiras em geral se inicia com uma visão geral do sistema de produto, usualmente representada através de um fluxograma de processos.

A partir da opinião de especialistas e da sensibilidade do realizador do estudo, defini-se uma primeira fronteira. Esta, dependendo das conclusões do inventário, poderá ou não ser alterada (WENZEL; HAUSCHILD; ALTING, 2000).

Após a definição das fronteiras do sistema, devem-se estabelecer os processos elementares que compõe o sistema. Entende-se por processo elementar o menor elemento, considerado na etapa de análise do inventário do ciclo vida, para o qual dados de entrada e saída são quantificados (ISO, 2006a).

Os processos elementares (figura 5) são conjuntos formados pelas operações e atividades contidas no sistema e são agrupadas por fronteiras próprias. As ligações entre os processos elementares são realizadas por correntes internas de matéria e energia. 


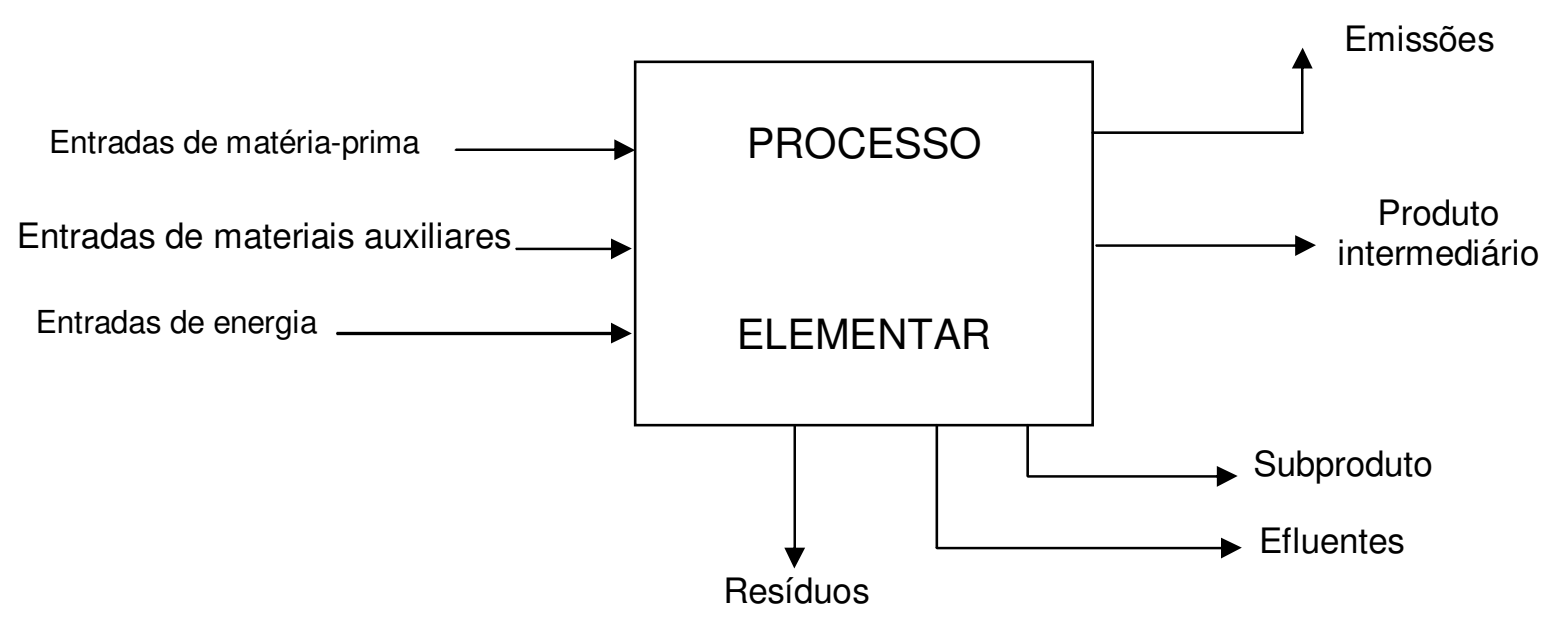

Figura 5: Descrição conceitual de processo elementar (adaptado da fig.3 da ISO 14040, 2006a).

e) sistema de produto: consiste no conjunto de processos elementares, que desempenha uma ou mais funções previamente definidas e que modela o ciclo de vida de um produto.

f) procedimento de alocação: diversos processos possuem mais de uma saída de interesse para o sistema produtivo. Além de poder haver mais de um produto, pode-se gerar subprodutos, que são incorporados a processos através de reuso ou reciclagem. Uma vez que todos estes são resultados de interesse para o sistema de produto, é justo que cada um seja responsável por parte do conjunto de aspectos ambientais do sistema. Para isso desenvolve-se o procedimento de alocação, que busca criar um método de distribuição das contribuições aos impactos entre os diferentes resultados do sistema (WENZEL; HAUSCHILD; ALTING, 2000). A cada produto ou subproduto atribuise então uma parcela dos aspectos que o sistema possui até o momento de sua geração. Essa ação consiste, então, na aplicação de um fator que distribua os aspectos ambientais para cada um dos produtos gerados. O fator de alocação pode ser baseado em critérios físicos, como massa ou energia, ou em critérios econômicos, como o valor de mercado dos produtos. 
A título de exemplificação, a tabela 5 mostra os resultados da aplicação de fatores de alocação, baseada em critério físico (massa), para a obtenção de $1 \mathrm{~kg}$ de cloro $\left(\mathrm{Cl}_{2}\right)$ gerado pelo processo denominado diafragma. Esse processo gera, além do cloro, outros dois produtos: o hidróxido de sódio $(\mathrm{NaOH})$ e o hidrogênio $\left(\mathrm{H}_{2}\right)$.

\begin{tabular}{|l|c|c|}
\hline \multicolumn{1}{|c|}{ Produto } & Massa (kg) & Fator de alocação (\%) \\
\hline Cloro $\left(\mathrm{Cl}_{2}\right)$ & 1 & $\frac{1}{2,1517} \times 100=46,5$ \\
\hline Hidróxido de sódio $(\mathrm{NaOH})$ & 1,123 & $\frac{1,123}{2,1517} \times 100=52,2$ \\
\hline Hidrogênio $\left(\mathrm{H}_{2}\right)$ & 0,0287 & $\frac{0,0287}{2,1517} \times 100=1,3$ \\
\hline Total & $\mathbf{2 , 1 5 1 7}$ & $\mathbf{1 0 0 , 0}$ \\
\hline
\end{tabular}

Tabela 5: Exemplo de aplicação de fatores de alocação em massa (adaptado de BORGES, 2004).

De acordo com os fatores de alocação apresentados na tabela 5, teremos a seguinte distribuição: $46,5 \%, 52,2 \%$ e 1,3\% dos aspectos ambientais atribuídos ao cloro, hidróxido de sódio e hidrogênio, respectivamente.

g) categorias de impacto e metodologia para avaliação de impacto: para que seja dada seqüência ao estudo após o inventário, é necessário definir as categorias de impacto, os indicadores de categoria e a metodologia para a avaliação dos impactos ambientais. Categoria de impacto é a classe que representa as questões ambientais relevantes às quais os resultados da análise do inventário podem ser associados. Sua definição deve ser particular para cada estudo e de acordo com seu propósito específico. O indicador de categoria de impacto consiste na representação quantificável de uma categoria de impacto.

Segundo FAVA et al. (1998) não existe uma série de categorias de impacto predeterminadas certas ou como padrão.

De acordo com SILVA; KULAY (2006) as categorias de impacto usualmente selecionadas são as seguintes: aquecimento global (também 
conhecido por efeito estufa, é provocado pelo acúmulo de gases, na atmosfera, que retêm parte da radiação solar); acidificação (aumento do teor de acidez do solo, do ar ou da água); eutrofização (provocada pelo acúmulo dos nutrientes nitrogênio e fósforo nos corpos d água e nos solos); toxicidade (resultante da disposição de rejeitos tóxicos no meio ambiente); consumo de recursos naturais (materiais e enrgéticos); redução da camada de ozônio (redução da quantidade de ozônio presente na estratosfera); e formação fotoquímica de ozônio (formação de ozônio nas camadas baixas da atmosfera).

h) requisitos de qualidade dos dados: devem ser definidos de forma a possibilitar que o objetivo e o escopo do estudo sejam alcançados. Esses requisitos especificam as características dos dados necessários para o estudo e devem envolver:

- cobertura relacionada ao tempo: considera a idade desejada para os dados e o período mínimo de tempo sobre o qual os dados devem ser coletados;

- cobertura geográfica: corresponde à área geográfica na qual os dados dos processos elementares devem ser coletados para satisfazer o objetivo do estudo;

- cobertura tecnológica: representa o nível tecnológico ao qual os dados do estudo correspondem (exemplos: dados de processo específicos de uma única companhia; dados de processo de várias companhias com mesma tecnologia; dados de várias companhias com diferentes tecnologias de fabricação do produto em estudo; etc.);

- precisão: medida da variabilidade dos dados para cada categoria de dados;

- completeza (C): porcentagem de dados primários relatados em relação aos dados potenciais existentes para cada categoria de dados em um processo elementar;

$$
C=\frac{\text { Número de dados primários de um processo elementar }}{\text { Número total de dados de um processo elementar }} \times 100
$$


- representatividade: avaliação qualitativa do grau em que o conjunto de dados reflete a população real de interesse, isto é, uma avaliação qualitativa do espaço geográfico, da cobertura tecnológica e do período de tempo, definidos pela meta e escopo do estudo;

- consistência: avaliação qualitativa de quanto uniforme a metodologia do estudo é aplicada aos vários componentes da análise;

- reprodutibilidade: avaliação qualitativa da extensão em que as informações sobre os dados e sobre a metodologia permitem que um consultor independente reproduza os resultados relatados no estudo;

- fonte dos dados.

Deve ser considerada também a natureza dos dados, ou seja, se os dados foram medidos, calculados, estimados ou obtidos de fontes publicadas (ISO, 2006b).

i) tipo de revisão crítica, se necessário: deve-se determinar o modo de condução e o responsável por esta revisão, que deve ser realizada ao final do estudo para verificação de sua qualidade (ISO, 2006b).

j) tipo e formato do relatório final: segundo a norma ISO 14044 (2006b), os resultados de uma ACV devem ser relatados ao público alvo de forma fiel, completa e exata, e o tipo e formato de este relatório devem ser definidos na etapa de definição do escopo.

k) suposições; e

I) limitações. 


\subsubsection{Inventário de ciclo de vida (ICV)}

Conforme a norma ISO 14044 (ISO, 2006b) a etapa anterior de definições provê um plano inicial para a condução do estudo. Esta etapa, de ICV, se refere por sua vez à coleta de dados e procedimentos de cálculos para quantificar as entradas de recursos naturais (materiais e energéticos) e as saídas (rejeitos materiais e energéticos) de um sistema de produto (ISO, 2006b). É importante verificar que a construção do ICV é iterativa e considerando que o conhecimento que se tem do sistema aumenta conforme se obtém dados, deve-se proceder sempre que necessário a novas definições de objetivo e escopo.

Das quatro etapas que constituem a metodologia de um estudo de ACV, a elaboração do ICV é a mais dispendiosa em termos de tempo e de recursos financeiros.

A norma ISO 14044 (2006b) estabelece procedimentos de forma mais detalhada para a execução da etapa de análise de inventário (figura 6). 


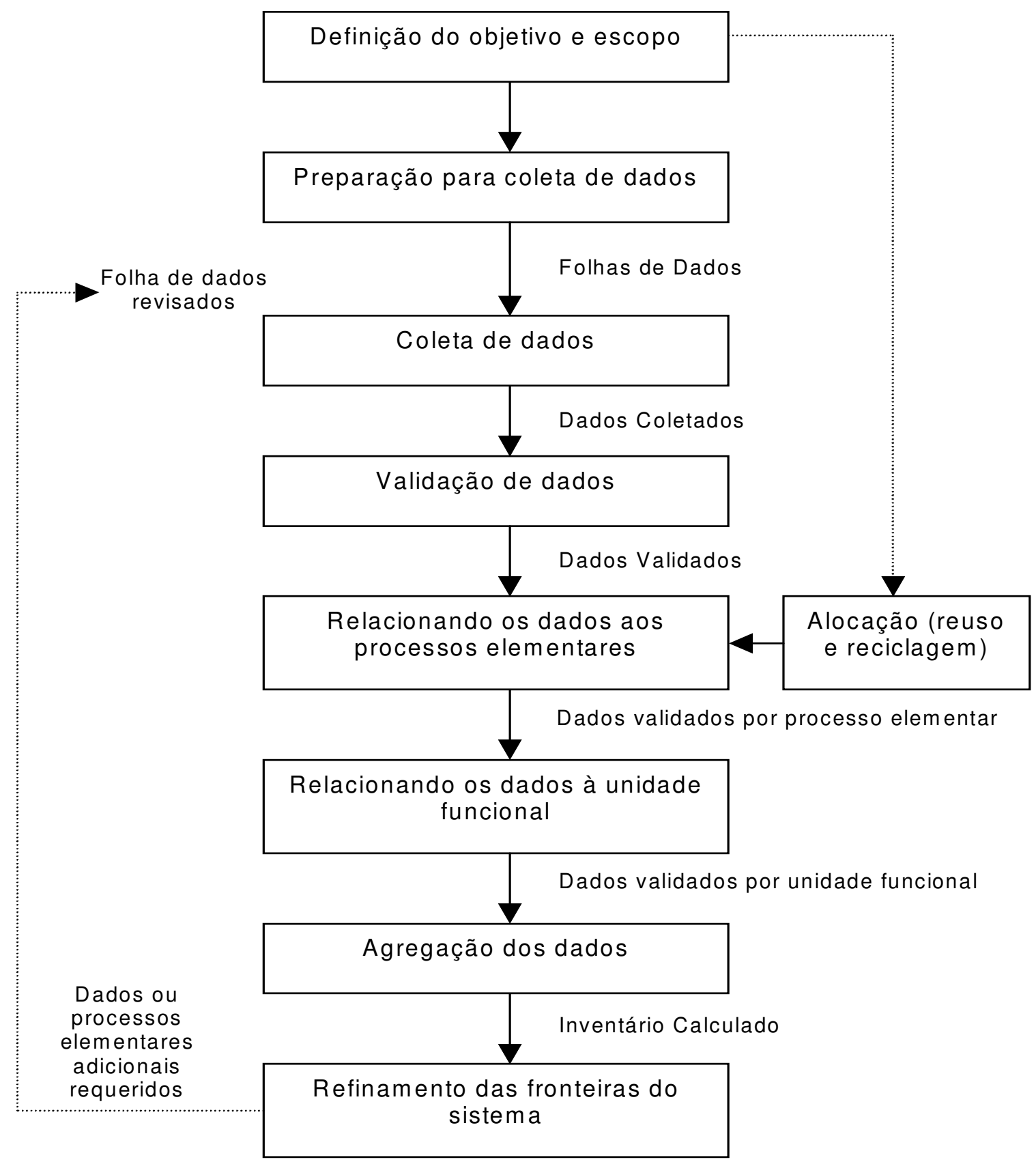

Inventário Completado

Figura 6: Procedimentos simplificados para a etapa de análise do inventario (adaptado da fig. 1 da ISO 14044, 2006b). 
De acordo com a norma (ISO, 2006a), o inventário deve ser constituído dos procedimentos a seguir.

\subsection{Preparação para coleta de dados}

Segundo a norma ISO 14044 (ISO, 2006b) os dados devem ser coletados para cada processo elementar constante das fronteiras do sistema. A etapa de definições fornecerá tanto a relação de estes processos como a identificação dos dados que devem ser obtidos.

Uma vez que esses processos podem estar bastante distribuídos, é recomendável que se sigam algumas etapas para garantir a uniformidade e consistência do sistema modelado. Estas incluem:

a) construção de fluxogramas dos processos elementares, incluindo suas interrelações: o objetivo da elaboração de um fluxograma é permitir uma visão global do sistema e das relações dele com o meio ambiente e com outros sistemas. O nível de detalhamento de um fluxograma é determinado pelos objetivos do estudo. Além do fluxograma do sistema, devem também ser elaborados fluxogramas individuais para cada processo elementar;

b) descrição de cada processo e listagem dos dados a estes associados;

c) determinação das unidades de medida;

d) determinação dos métodos de coleta e cálculo para cada categoria de dado: a qualidade dos dados e informações pode afetar diretamente os resultados de um estudo de ACV. Desta forma, em muitas situações torna-se difícil definir quais dados serão de fato considerados no estudo. Para orientar essa seleção, são propostos critérios de qualidade de dados relacionados a tempo, abrangência geográfica e tecnologia; e

e) provisão de instruções para documentação de casos especiais e irregularidades. 


\subsection{Coleta de dados}

É a tarefa que mais apresenta dificuldades para o estudo, devido ao elevado consumo de tempo e custo necessários para obtenção das informações e à possível indisponibilidade de fontes de informações específicas e confiáveis. Este problema, no entanto pode ser minimizado, principalmente através da criação de banco de dados com os resultados de estudos já realizados. A adoção desta prática leva, progressivamente, à redução do tempo e custo de obtenção das informações necessárias.

Uma observação importante é que na fase de coleta deve-se verificar se os dados obtidos provêm da região onde está sendo feito o estudo ou se os dados são compatíveis com as condições técnicas e ambientais da região.

De acordo com WENZEL; HAUSCHILD; ALTING (2000), um procedimento para coleta de dados pode ser realizado através de revisão bibliográfica (normas e literaturas técnicas, licenças e estatísticas ambientais, bancos de dados de ACV, etc.), aplicação de questionários específicos, cálculos teóricos a partir de modelos ou medições de campo;

Segundo pesquisadores do CETEA, a fase de coleta de dados pode ser constituída dos seguintes procedimentos: definição do objeto de estudo; definição das etapas do sistema; elaboração do fluxograma para as etapas a serem incluídas no estudo; identificação e caracterização das empresas fabricantes (produção, localização, participação no mercado, etc.); seleção das empresas (representativas) para a coleta de dados; estabelecimento de contato com as empresas; conseguir aprovação das empresas para a coleta de dados; estabelecer acordos de confidencialidade com as empresas; definição dos questionários e discussão; coleta de dados pelas próprias empresas e; avaliação dos questionários pelos executantes do estudo.

As principais dificuldades que podem existir para a fase de coleta de dados estão relacionadas a seguir: elevado número de empresas; empresas contatadas individualmente (elevado consumo de tempo); informações 
solicitadas são consideradas confidenciais; muitos dados não estão disponíveis na forma desejada; dificuldade na obtenção dos dados por processo elementar; e demora no retorno dos questionários (na média, período maior que seis meses).

O formulário de coleta de dados é recurso usado para que o registro das informações levantadas ocorra de maneira organizada. Um formulário de coleta corresponde a uma tabela (tabela 6) onde serão listados e quantificados os aspectos ambientais de cada processo elementar, na forma de correntes de entrada e saída e incluindo suas unidades. As correntes de entrada compreendem recursos materiais e energéticos, enquanto que as correntes de saída são compostas pelo produto, por subprodutos e pelos rejeitos gerados no sistema. 


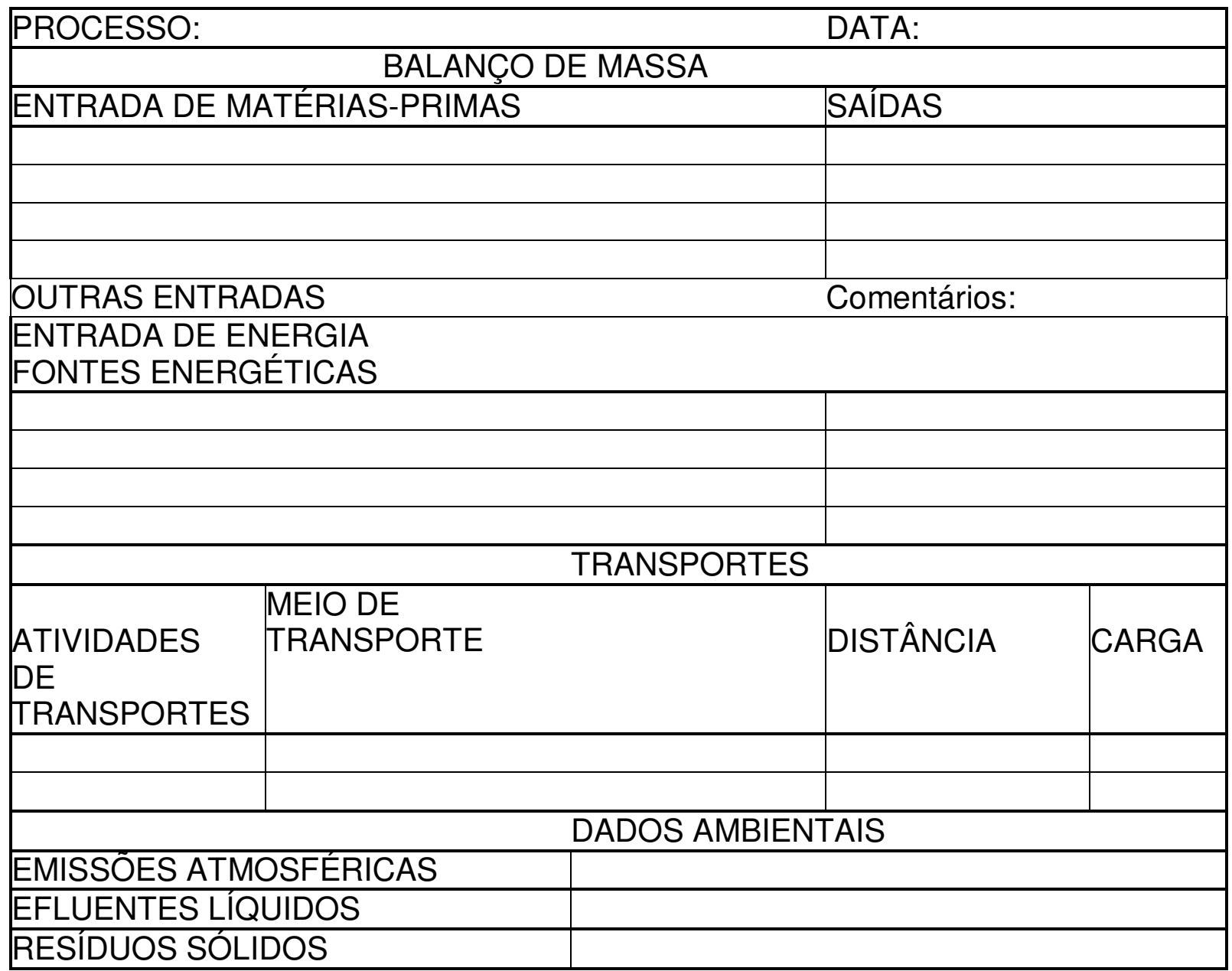

Tabela 6: Exemplo de folha de coleta de dados (adaptado do quadro 3.1 de CHEHEBE, 1998). 


\subsection{Tratamento dos dados}

Após coletar os dados é necessário que sejam feitos cálculos, com o intuito de adequar os dados obtidos aos processos unitários e à unidade funcional e avaliar sua qualidade (ISO, 2006b). De acordo com a norma (ISO, 2006b), o tratamento dos dados envolve os itens comentados a seguir.

a) validação dos dados: envolve verificações do tipo de balanços de massa e energia, análises comparativas, etc. A intenção de estes procedimentos é detectar ainda numa fase inicial quaisquer irregularidades existentes. Deve-se também determinar o que será feito na ausência do dado desejado;

b) adequação dos dados aos processos elementares: significa transpor os dados obtidos na coleta à base unitária do processo, fazendo tanto as necessárias alocações como a conversão de unidades;

c) alocação: é a repartição dos fluxos de entrada ou de saída de um processo ou sistema de produto entre o sistema de produto sob estudo e um ou mais diferentes sistemas de produto (ISO, 2006b).

Segundo WENZEL; HAUSCHILD; ALTING (2000), quando um sistema provê mais do que um serviço (sistema multifuncional), deve-se realizar uma alocação das entradas e saídas. Da mesma forma, a norma ISO 14044 (ISO, 2006b) recomenda que na existência de múltiplos produtos saindo de um sistema, os fluxos de materiais e de energia; assim como as liberações ao ambiente, precisam ser alocadas aos diferentes produtos.

Conforme a ISO 14044 (2006b), a alocação deve ser feita de acordo com os seguintes princípios: (i) identificação dos processos compartilhados entre os co-produtos e atribuição das cargas ambientais seguindo os procedimentos de alocação; (ii) a soma das entradas e saídas alocadas de uma unidade de processo deve ser igual às entradas e saídas do processo elementar antes da 
alocação; e (iii) quando vários critérios de alocação forem aplicáveis, deve ser conduzida uma análise de sensibilidade entre as alternativas. Seguindo os princípios destacados, os seguintes procedimentos devem ser aplicados:

- sempre que possível, a alocação deve ser evitada, pois os critérios, apesar de serem técnicos, acrescentam subjetividade ao estudo. Para evitar a alocação, citam-se duas maneiras: (i) divisão do processo elementar a ser alocado em dois ou mais subprocessos, seguido pela coleta dos dados para esses subprocessos. Dessa forma poderemos saber, por exemplo, quais entradas e saídas estão relacionadas com cada produto; e (ii) expansão das fronteiras inicialmente definidas para o sistema de produto de tal forma que os coprodutos fiquem incluídos nas novas fronteiras.

- se a alocação não pode ser evitada, as entradas e saídas do sistema devem ser divididas entre seus diferentes produtos ou funções de modo a refletir a relação física entre eles;

- se alocações por critérios físicos não são possíveis, deve-se procurar outro critério que reflita as relações entre eles, como o valor econômico de mercado, por exemplo.

Os princípios de alocação e procedimentos mencionados pela norma (ISO, 2006b) anteriormente também se aplicam às situações de reuso e reciclagem. De acordo com a norma (ISO, 2006b) o reuso e a reciclagem podem, em alguns casos, implicar o compartilhamento das entras e saídas associadas aos processos elementares e podem alterar, em usos subseqüentes, as propriedades dos materiais.

Pode-se separar a reciclagem em dois tipos distintos: ciclo aberto e ciclo fechado. A reciclagem com ciclo aberto ocorre nos casos em que um determinado rejeito de um sistema de produto é utilizado por outro sistema de produto. Um procedimento de alocação de ciclo aberto é aplicado nos casos onde houver mudança nas propriedades inerentes ao material reciclado. Os procedimentos de alocação mencionados anteriormente devem ser utilizados 
como base para alocação: propriedades físicas; valor econômico; ou o número de usos subseqüentes do material reciclado.

No que diz respeito à reciclagem com ciclo fechado, esta ocorre quando um ou mais materiais secundários retornam ao mesmo sistema de produto e também quando um produto final é reutilizado sem deixar o sistema. Nenhuma alocação é necessária desde que todas as entradas e saídas sejam normalizadas em relação à mesma unidade funcional.

d) adequação dos dados à unidade funcional e agregação: para que possamos realizar cálculos sobre todo o sistema devemos transformar os valores obtidos para cada processo, já transformados para a base unitária, a uma mesma base de cálculo referente ao fluxo de referência, o que é feito através da sua conversão à unidade funcional. Além disso, devemos agregar os dados obtidos, sendo o nível de agregação dependente da meta do estudo. 


\subsection{Refinamento das fronteiras do sistema}

Como o ICV é um processo iterativo, ao longo do qual se vai progressivamente obtendo maior conhecimento sobre o objeto da análise, a norma ISO 14044 (ISO, 2006a) recomenda que as fronteiras do sistema sejam revistas, identificando necessidades de novos refinamentos e dados adicionais.

Devem ser realizadas análises de sensibilidade quando necessário, de modo a avaliar: a exclusão de aspectos ambientais ou de processos elementares que não sejam significantes; e a inclusão de aspectos ambientais ou de novos processos elementares que sejam julgados relevantes. O resultado obtido com o refinamento das fronteiras do sistema deve ser justificado e documentado.

Ao final desta etapa de inventário o que se pretende obter é uma planilha de aspectos ambientais quantificados para cada processo em separado. Como exemplo, a tabela 7 apresenta alguns parâmetros típicos do inventário de ciclo de vida de um produto ou serviço. 


\begin{tabular}{|c|c|c|}
\hline & Unidade & Quantidade / U. F. \\
\hline \multicolumn{3}{|l|}{ ENERGIA (entrada) } \\
\hline \multicolumn{3}{|l|}{ Hidrelétrica } \\
\hline \multicolumn{3}{|l|}{ Térmica } \\
\hline \multicolumn{3}{|l|}{ Total } \\
\hline \multicolumn{3}{|l|}{ RECURSOS NATURAIS (entrada) } \\
\hline \multicolumn{3}{|l|}{ Água } \\
\hline \multicolumn{3}{|l|}{ Carvão } \\
\hline \multicolumn{3}{|l|}{ Gás natural } \\
\hline \multicolumn{3}{|l|}{$\begin{array}{l}\text { Petróleo } \\
\text { RESÍDUOS SÓLIDOS (saída) }\end{array}$} \\
\hline \multicolumn{3}{|l|}{ RESÍDUOS SÓLIDOS (saída) } \\
\hline \multicolumn{3}{|l|}{$\begin{array}{l}\text { Resíduo tóxico } \\
\text { Resíduo de processo industrial }\end{array}$} \\
\hline Resíduo de processo industrial & & \\
\hline \multicolumn{3}{|l|}{ EMISSÓES ATMOSFÉRICAS (saída) } \\
\hline \multicolumn{3}{|l|}{ Materiais particulados } \\
\hline \multicolumn{3}{|l|}{ Dióxido de carbônico $\left(\mathrm{CO}_{2}\right)$} \\
\hline \multicolumn{3}{|l|}{ Monóxido de carbono (CO) } \\
\hline \multicolumn{3}{|l|}{ Metano $\left(\mathrm{CH}_{4}\right)$} \\
\hline \multicolumn{3}{|l|}{ Óxidos de enxofre $\left(\mathrm{SO}_{x}\right)$} \\
\hline \multicolumn{3}{|l|}{$\begin{array}{l}\text { Compostos orgânicos voláteis (COV) } \\
\text { EFLUENTES LíQUIDOS (saída) }\end{array}$} \\
\hline \multirow{2}{*}{\multicolumn{3}{|c|}{$\begin{array}{l}\text { EFLUENTES LIQQUIDOS (saída) } \\
\text { DBO }\end{array}$}} \\
\hline DBO & & \\
\hline \multicolumn{3}{|l|}{ DQO } \\
\hline \multicolumn{3}{|l|}{ Sólidos suspensos } \\
\hline \multicolumn{3}{|l|}{ Sólidos solúveis } \\
\hline \multicolumn{3}{|l|}{ Metais pesados } \\
\hline Óleos e gorduras & & \\
\hline
\end{tabular}

Tabela 7: Parâmetros típicos do inventário de ciclo de vida de um produto (adaptado da tabela 1, p. 21 de MOURAD; GARCIA; VILHENA, 2002).

Os resultados do ICV listam a utilização dos recursos naturais e energéticos e as emissões para o ar, água e solo; porém, nenhuma avaliação dos riscos a saúde ou de qualquer tipo de impacto provocado ao meio ambiente decorrente desse fato é realizada. 


\subsubsection{Avaliação de impactos}

A Avaliação de Impactos do Ciclo de Vida (AICV) tem como propósito avaliar os potenciais impactos ambientais dos aspectos coletados e quantificados no inventário, além de fornecer subsídios para a etapa de interpretação (ISO, 2006a).

A estrutura metodológica e científica desta etapa da ACV ainda está em desenvolvimento, e nenhuma metodologia é aceita de forma geral (ISO, 2006a). No entanto, de acordo com a norma ISO 14044 (ISO, 2006b), a AICV é composta de elementos obrigatórios e opcionais, da seguinte forma:

a) elementos obrigatórios

- seleção de categorias de impacto, indicadores de categorias e modelos de caracterização: a seleção deve levar em consideração os aspectos ambientais quantificados no inventário do ciclo de vida e deve ser justificada e consistente com a etapa de definição de objetivo e escopo do estudo.

- classificação: consiste no relacionamento qualitativo dos aspectos identificados na etapa do inventário com as categorias de impacto às quais estes contribuem.

- caracterização: consiste na quantificação da classificação, ou seja, na determinação numérica de qual é a contribuição de cada aspecto a cada categoria de impacto. Nesta fase são aplicados fatores de caracterização para converter os resultados do inventário do ciclo de vida correspondentes para a unidade comum do indicador de categoria de impacto. $\mathrm{O}$ indicador de categoria é uma representação quantificada de uma categoria de impacto.

Ao final da caracterização procura-se obter um valor total de contribuição daquele ciclo de vida para cada categoria de impacto. Esse resultado muitas vezes já é o suficiente para os propósitos da ACV, uma vez que permite 
conhecer, dentro das hipóteses admitidas, as contribuições do ciclo de vida do produto para as categorias de impacto.

b) elementos opcionais

- normalização: tem por objetivo prover uma melhor avaliação dos resultados da caracterização, calculando quanto os valores encontrados representam dentro de um valor de referência para cada categoria de impacto.

- agrupamento: é uma reordenação da apresentação das categorias de impacto. Basicamente, segundo a norma ISO 14044 (ISO, 2006b), há duas maneiras de realizar este processo: ordenar as categorias em uma base nominal (ex. através de características como efeito local, regional ou global); ou hierarquizar as categorias segundo uma ordem de importância de acordo com seus valores.

- valoração (ou ponderação): as categorias de impacto são somadas entre si, de acordo com uma escala de importância para o meio ambiente previamente definida, buscando-se um indicador único de desempenho ambiental para o produto ou serviço (MOURAD; GARCIA; VILHENA, 2002). Todo o problema ambiental é ponderado de acordo com sua importância. $O$ fator de ponderação difere de país para país (ou dentro do próprio país), em função das diferenças nas condições locais (CHEHEBE, 1998).

Um esquema simplificado das fases da avaliação de impactos é apresentado na figura 7 . 


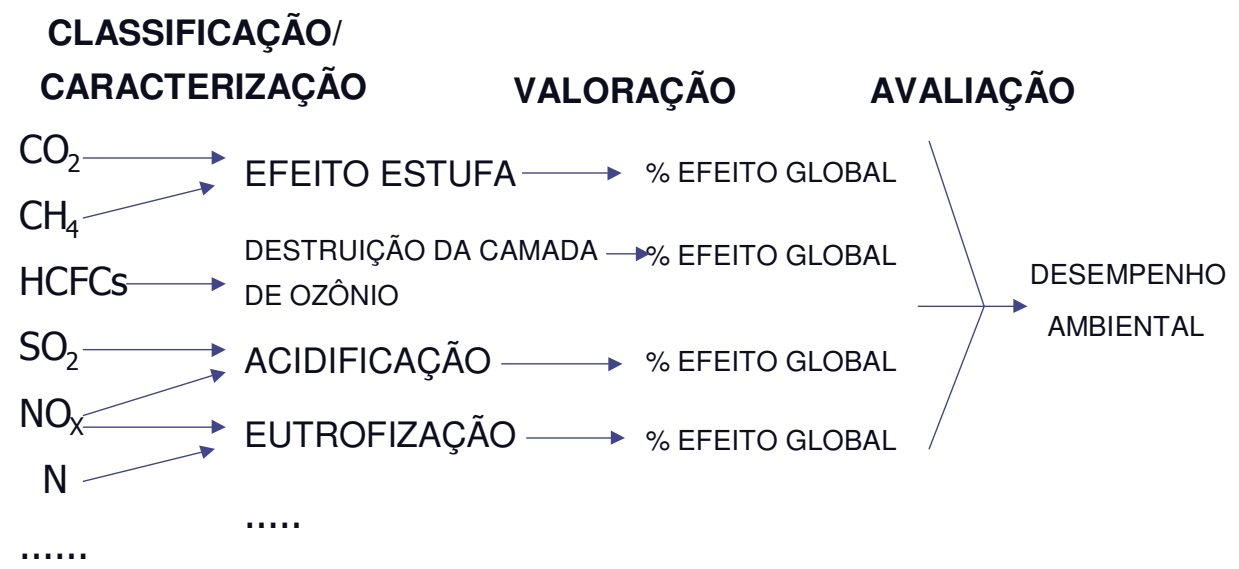

Figura 7: Fases da avaliação de impactos (adaptado da fig.4.5 de CHEHEBE, 1998). 


\subsection{Métodos para avaliação de impactos}

Para a realização da AICV existem diversas metodologias em diferentes estágios de desenvolvimento. Não há, até o momento, um método considerado como único ou mais apropriado.

De acordo com MELO; LEÃO; SOUZA (2008) ao longo do desenvolvimento da ferramenta de ACV, várias metodologias de AICV surgiram e hoje são, pelo menos, onze métodos distintos que se apresentam em três grandes grupos: o Norte Americano, o Europeu e o Japonês.

Informações obtidas junto à LIFE CYCLE INITIATIVE (2009b) revelaram que as metodologias identificadas de avaliação de impacto ambiental aplicáveis na ACV foram as desenvolvidas pelos seguintes países: Dinamarca - EDIP (Environmental Design of Industrial Products); Suíça - IMPACT 2002+, CML (Center for Environmental Science), Ecolndicator99 e Ecoscarcity Method (Ecopoints); Suécia - EPS (Environmental Priority Strategies); Canadá - LUCAS (A New LCIA Method Used for a Canadian-Specific Context); Estados Unidos TRACI (Tool for the Reduction and Assessment of Chemical and other Environmental Impacts); Japão - LIME (Life Cycle Impact Assessment Method based on Endpoint modeling) e JEPIX (Japan Environmental Policy Priorities Index); e Alemanha - Handbook on LCA.

Conforme MELO; LEÃO; SOUZA (2008) todas as metodologias são baseadas nas recomendações da norma ISO 14044 e nas publicações da SETAC. As metodologias existentes diferem no que diz respeito: a região considerada; ao nível de caracterização na cadeia de causa-efeito; às categoriais de impacto consideradas e aos modelos de caracterização; aos métodos e fatores de normalização e de ponderação.

A seguir a tabela 8 apresenta o endereço eletrônico dos métodos de AICV existentes. 


\begin{tabular}{|l|c|}
\hline \multicolumn{1}{|c|}{ Método de AICV } & Endereço eletrônico \\
\hline Eco-indicator 99 & http://www.pre.nl/eco-indicator99/ \\
\hline EDIP97 & http://ipt.dtu.dk/ mic/EDIP97 \\
\hline EDIP2003 & http://ipt.dtu.dk/ mic/EDIP2003 \\
\hline EPS 2000d & http://eps.esa.chalmers.se/ \\
\hline Handbook on LCA & http://www.leidenuniv.nl/cml/ssp/projects/lca2/lca2.html \\
\hline IMPACT 2002(+) & http://www.epfl.ch/impact \\
\hline LIME & http://www.jemai.or.jp/lcaforum/index.cfm \\
\hline SWISS ECOSCARCITY & http://www.e2mc.com/BUWAL297\%20english.pdf \\
\hline JEPIX & www.jepix.org \\
\hline TRACl & http://epa.gov/ORD/NRMRL/std/sab/iam_traci.htm \\
\hline
\end{tabular}

Tabela 8: Endereços eletrônicos dos métodos de AICV disponíveis (LIFE CYCLE INITIATIVE, 2009b).

Segue um breve comentário dos principais métodos segundo USEPA (2009).

Eco-Indicator 99, desenvolvido por "PRé Consultants", é um método de avaliação de impactos com etapas claramente detalhadas. Oferece uma forma de medir vários impactos ambientais e mostra o resultado final em um único indicador. Consiste basicamente em um conjunto de modelos para as categorias de impacto pré-determinadas pelo método. Esse conjunto de modelos consolida as diversas categorias de impacto em três categorias de danos: saúde humana, qualidade do ecossistema e recursos. Um relatório contendo uma descrição completa da metodologia, bem como uma visão geral de todos os fatores de caracterização podem ser acessados no endereço eletrônico fornecido na tabela 8.

O método para avaliação de impactos do ciclo de vida denominado IMPACT 2002(+) foi desenvolvido na Suíça e fornece fatores de caracterização para quase 1500 diferentes resultados de inventários de ciclo de vida. Este método foi implementado no banco de dados suíço de ACV denominado Ecoinvent.

O software EPS 2000 Design System foi elaborado por "Assess Ecostrategy Scandinavia AB". O EPS (Environmental Priority Strategies) é um software de avaliação de impacto do ciclo de vida para o desenvolvimento de 
produtos sustentáveis. Uma versão demo pode ser encomendada a partir do endereço fornecido na tabela 8.

A ferramenta computacional TRACI - Tool for the Reduction and Assessment of Chemical and other Environmental Impacts - foi elaborada pela "United States Environmental Protection Agency" e permite a análise do potencial de impactos associados à utilização de matérias-primas e à liberação de produtos químicos resultantes de processos envolvidos na produção de um produto. O software completo e o manual do usuário pode ser acessado a partir do endereço fornecido na tabela 8.

O método Swiss Ecoscarcity às vezes conhecido por "Swiss Ecopoints" permite uma ponderação comparativa e agregação de várias intervenções ambientais por meio da utilização de fatores. O método fornece fatores de ponderação para emissões atmosféricas, efluentes líquidos e resíduos sólidos; bem como, para a utilização dos recursos energéticos. Os fatores foram originalmente desenvolvidos para a Suíça. O método foi publicado pela primeira vez na Suíça em 1990.

JEPIX - Japan Environmental Policy Priorities Index - é método desenvolvido e aplicado pela "JEPIX Fórum", uma iniciativa voluntária de várias organizações privadas e pessoas envolvidas com contabilidade ambiental, gestão ambiental e avaliação de impactos do ciclo de vida. Foi inspirado no método suíço EcoScarcity e é considerado como um complemento aos atuais métodos de AICV. Desde 2003 cerca de 40 empresas japonesas (incluindo Komatsu, Canon, TEPCO, Suntory, Fuji Film, All Nippon Airways, J-Power, etc.) estão aplicando este método para avaliar e comunicar os seus dados de desempenho ambiental e para conduzir estudos de ACV de produtos e serviços.

O método alemão para avaliação de impactos "Handbook on LCA" apresenta fatores de caracterização para mais de 1500 diferentes resultados de inventários, o que pode ser acessado no endereço eletrônico fornecido na tabela 8. 


\subsubsection{Interpretação}

O objetivo desta etapa é combinar, resumir e discutir resultados do estudo (ISO 14043, 2000b), com o intuito de obter fundamentos para conclusões e recomendações que satisfaçam os objetivos inicialmente propostos. Além disso, tem a função de desenvolver uma apresentação dos resultados na forma de um relatório consistente e transparente. Para efetuar a interpretação são necessários quatro tipos de informação (ISO 14043, 2000b): os resultados das etapas anteriores; escolhas metodológicas (critérios de alocação, estabelecimento das fronteiras, escolha das categorias de impacto, etc); juízos de valores admitidos e relação dos envolvidos, seus interesses e obrigações.

De acordo com a ISO 14044 (2006b), existem três elementos básicos na interpretação:

a) identificação dos temas de relevância: consiste na identificação dos pontos mais relevantes do estudo que, segundo a norma, podem ser: aspectos do inventário ou suas categorias; categorias de impacto e processos unitários ou atividades.

b) avaliações: esta parte do estudo tem como função determinar a confiabilidade nos resultados, incluindo os temas e a relevância identificada anteriormente. Os resultados devem ser apresentados de forma clara e compressível ao usuário determinado para o estudo. De acordo com a ISO 14044 (2006b), pode-se descrever cada uma de suas etapas como segue:

- análise de completeza: tem como objetivo verificar se todas as informações relevantes e dados necessários estão disponíveis e completos. Pode resultar na adição de comentários extras ao relatório do estudo, ou mesmo a revisão do ICV ou do AICV;

- análise de sensibilidade: tem como objetivo avaliar a confiabilidade final dos resultados e conclusões, determinando quanto estes são afetados pelas 
incertezas dos dados, métodos de alocação, cálculos dos indicadores, etc. Esta avaliação deve levar em conta as hipóteses e simplificações feitas na etapa de definições, as análises de sensibilidade e incerteza já realizadas nas etapas de ICV e AICV e também a opinião de especialistas na área e experiências anteriores;

- análise de consistência: avalia o quanto das hipóteses, métodos e dados obtidos são consistentes com as definições iniciais. Verificam-se, por exemplo, as diferenças de qualidade de dados entre as diferentes etapas do ciclo de vida, se houve consideração de variações temporais/espaciais, se a aplicação de alocação e o estabelecimento de fronteiras foram adequados e se os elementos da avaliação de impacto estão de acordo com o que foi estabelecido no início.

c) conclusões, limitações e recomendações: tem como objetivo estabelecer conclusões e recomendações e identificar limitações para os usuários do estudo. Estas ações devem ser feitas como segue (ISO, 2006b):

- conclusões: devem ser estabelecidas de modo iterativo com outros elementos da etapa de interpretação, considerando sempre as definições iniciais;

- recomendações: sempre que apropriado à meta e ao escopo estabelecidos, devem ser feitas recomendações aos tomadores de decisão que irão utilizar os resultados da ACV. Estas devem ser baseadas nos resultados do estudo e justificadas de modo a refletir as conseqüências lógicas e razoáveis de estes; além disso, deve através do relatório, fornecer uma visão transparente e completa do estudo.

Uma vez que já se tenha considerado o estudo terminado, seus resultados devem ser relatados ao público-alvo de forma fiel, completa e exata. O tipo e formato de este relatório devem ser definidos na etapa de definições do estudo. Os resultados, dados, métodos, suposições e limitações devem ser apresentados com detalhe suficiente para permitir ao leitor compreender as complexidades inerentes a um estudo de ACV (ISO, 2006b). 
Apenas como última observação, a norma ISO 14040 (ISO, 2006a) ainda requer após o término do estudo a condução de uma verificação denominada de revisão crítica.

Revisão crítica é uma técnica para verificar se um estudo de ACV satisfez os requisitos da norma quanto à metodologia, aos dados, à interpretação e ao relatório. Deve ser definido no escopo do estudo se e como será conduzida a revisão crítica, assim como quem a conduzirá (ISO, 2006a).

A norma ISO 14040 (2006a) menciona que uma revisão crítica pode facilitar o entendimento e aumentar a credibilidade de estudos de ACV.

Para a norma ISO 14044 (ISO, 2006b) o processo de revisão crítica deve assegurar que:

- os métodos usados para conduzir uma ACV são consistentes com as normas ISO da série 14040;

- os métodos usados para conduzir uma ACV são científica e tecnicamente válidos;

- os dados usados são apropriados e razoáveis em relação ao objetivo do estudo;

- as interpretações refletem as limitações identificadas e o objetivo do estudo;

- o relatório final do estudo é transparente e consistente.

Em geral, revisões críticas de uma ACV são opcionais e conforme a norma ISO 14044 (ISO, 2006b), essas análises podem ser conduzidas por:

- um especialista interno, da própria empresa ou instituição que está realizando o estudo de ACV; um especialista externo; partes interessadas, ou seja, um especialista independente externo é selecionado pelo solicitante original do estudo para agir como coordenador de uma comissão de revisão crítica de pelo menos três membros.

Uma revisão crítica deve ser conduzida para estudos de ACV usados para fazer uma afirmação comparativa que é disponibilizada ao público (ISO, 2006b). 


\subsubsection{Softwares para apoio à ACV}

A ACV é uma ferramenta complexa que requer o envolvimento de um número elevado de dados, bem como um alto consumo de tempo e recursos.

Inseridos nesse contexto, dispõem-se de uma grande variedade de softwares para auxiliar na condução de estudos de ACV, os tornado possíveis de serem realizados e garantindo cálculos e conclusões de maior confiança.

MARIOTONI; CUNHA; BAPTISTELA (2007) comentam que os softwares são ferramentas computacionais que facilitam o gerenciamento dos dados envolvidos nos estudos das seguintes formas:

- disponibilizam bancos de dados que reduzem consideravelmente o tempo necessário para a coleta das informações;

- realizam avaliação de impactos e interpretação;

- são atualizados regularmente acompanhando o desenvolvimento da técnica da ACV; e

- apresentam os resultados de uma forma facilitada através de gráficos e tabelas.

Com todas essas vantagens torna-se imprescindível a utilização de um software para a condução de uma ACV.

De acordo com BENJAMIN (2001) aspectos como os financeiros, atualizações previstas da ferramenta, suporte técnico, compatibilidade com outras ferramentas, idioma, tamanho do banco de dados, possibilidade de edição dos dados originais e inclusão e documentação de novos dados devem ser considerados na escolha do software adequado.

Foi realizada uma pesquisa com o intuito de verificar os softwares de apoio a ACV disponíveis atualmente no mercado. A pesquisa que permitiu obter uma relação de softwares foi obtida de quatro fontes, a saber: BAUMANN \& TILLMAN (2004); CURRAN (2006); EPLCA (2007); e USEPA (2007).

Conforme pode ser observado na tabela 9, foram encontrados 35 softwares sendo a maioria, ou seja, 29 softwares desenvolvidos por países 
europeus. Os países europeus com mais softwares desenvolvidos são Alemanha e Holanda com sete cada um. O número elevado de softwares europeus confirma o fato de que os países desse continente estão muito avançados no uso da técnica da ACV. Assim sendo, pode-se concluir que esse número elevado é devido ao interesse e preocupação das organizações européias em contribuir com estudos de ACV, fornecendo dados para que os mesmos se tornem de representativos e de boa qualidade.

Os softwares têm origem e propósitos diferentes e estão apresentados a seguir na tabela 9. 


\begin{tabular}{|c|c|c|c|}
\hline Nome & Endereço na internet & Fornecedor & $\begin{array}{l}\text { País de } \\
\text { origem }\end{array}$ \\
\hline $\begin{array}{l}\text { 1. AIST-LCA } 4 \\
\text { (JEMAI-LCA) }\end{array}$ & http://unit.aist.go.jp/lca-center/english/theme.html & AIST & Japão \\
\hline 2. BEES 3.0 & http://www.bfrl.mist.gov/oae/software/bees.html & $\begin{array}{c}\text { National Institute for } \\
\text { Standards and Technology } \\
\text { (NIST) }\end{array}$ & $\begin{array}{l}\text { Estados } \\
\text { Unidos }\end{array}$ \\
\hline $\begin{array}{l}\text { 3. Boustead } \\
\text { Model } 5.0\end{array}$ & http://www.boustead-consulting.co.uk/products.htm & Boustead Consulting Limited & Reino Unido \\
\hline 4. CMLCA 4.2 & $\begin{array}{l}\text { http://www.liedenuniv.nl/interfac/cml/ssp/software/cmlca/index. } \\
\qquad \mathrm{html}\end{array}$ & $\begin{array}{c}\text { Centre of Environmental } \\
\text { Science (CML) - Leiden } \\
\text { University }\end{array}$ & Holanda \\
\hline 5. ECO-it 1.3 & http://www.pre.nl/eco-it/default.htm & PRé Consultants B. V. & Holanda \\
\hline 6. EcoScan 3.0 & http://www.ind.tno.nl/en/product/ecoscan/ & TNO Industrial Technology & Holanda \\
\hline 7. EIME 2.4 & http://www.codde.fr/eng/eime/licences.htm & CODDE & França \\
\hline 8. eiolca.net & www.eiolca.net & $\begin{array}{l}\text { Carnegie Mellon University - } \\
\text { Green Design Institute }\end{array}$ & $\begin{array}{l}\text { Estados } \\
\text { Unidos }\end{array}$ \\
\hline 9. EMIS & www.carbotech.ch & Carbotech & Suíça \\
\hline $\begin{array}{l}10 . \\
\text { Environmental } \\
\text { Impact Estimator }\end{array}$ & http://www.athenasmi.ca/tools/ & $\begin{array}{l}\text { ATHENATM Sustainable } \\
\text { Materials Institute }\end{array}$ & Canadá \\
\hline $\begin{array}{l}\text { 11. EPS } 2000 \\
\text { Design System }\end{array}$ & http://www.assess.se/ & $\begin{array}{l}\text { Assess Ecostrategy } \\
\text { Scandinavia } A B\end{array}$ & Suécia \\
\hline 12. eVerdEE 2.0 & www.ecosmes.net & $\begin{array}{l}\text { ENEA - Italian National } \\
\text { Agency for New Technology, } \\
\text { Energy and the Environment }\end{array}$ & Itália \\
\hline 13. GaBi 4.2 & http://www.gabi-software.com/ & $\mathrm{PE}$ International GmbH & Alemanha \\
\hline 14. GEMIS 4.4 & http://www.oeko.de/service/gemis/en/index.htm & Öko-Institut & Alemanha \\
\hline 15. Green-E 1.0 & http://www.ecointesys.ch/green-e & $\begin{array}{l}\text { Ecointesys - Life Cycle } \\
\text { Systems }\end{array}$ & Suíça \\
\hline 16. GREET 1.7 & http://www.transportation.anl.gov/software/GREET/index.html & $\begin{array}{l}\text { The U.S. Department of } \\
\text { Energy's Office of } \\
\text { Transportation Technologies }\end{array}$ & $\begin{array}{l}\text { Estados } \\
\text { Unidos }\end{array}$ \\
\hline $\begin{array}{l}\text { 17. IDEMAT } \\
2005\end{array}$ & http://www.io.tudelft.nl/research/dfs/idemat/index.htm & $\begin{array}{l}\text { Delft University of } \\
\text { Technology }\end{array}$ & Holanda \\
\hline $\begin{array}{l}\text { 18. KCL-ECO } \\
4.0\end{array}$ & http://www.kcl.fi/eco & $\begin{array}{c}\text { Ou Keskuslaboratorio- } \\
\text { Centrallaboratorium } \mathrm{Ab}, \mathrm{KCL}\end{array}$ & Finlândia \\
\hline $\begin{array}{l}\text { 19. LCA - } \\
\text { Evaluator } 2.0\end{array}$ & http://greendeltatc.com/index.php?id=112 & GreenDeltaTC GmbH & Alemanha \\
\hline 20. LCAiT 4 & http://www.Icait.com/ & CIT Ekologik & Suécia \\
\hline 21. LCAPIX & http://www.kmlmtd.com/index.htm & KM Limited & $\begin{array}{l}\text { Estados } \\
\text { Unidos }\end{array}$ \\
\hline 22. LEGEP 1.2 & www.legep.de & LEGEP Software GmbH & Alemanha \\
\hline 23. MIET & http://www.leidenuniv.nl/cml/ssp/software/miet/index.html & $\begin{array}{l}\text { Centre of Environmental } \\
\text { Science (CML) }\end{array}$ & Holanda \\
\hline $\begin{array}{l}\text { 24. Modular } \\
\text { MSWI Model } 1.0\end{array}$ & http://greendeltatc.com/index.php?id=39 & GreenDeltaTC GmbH & Alemanha \\
\hline 25. REGIS 2.3 & www.sinum.com & Sinum AG & Suíça \\
\hline 26. SimaPro 7 & www.pre.nl & Pré Consultants B. V. & Holanda \\
\hline $\begin{array}{l}\text { 27. SPOLD Data } \\
\text { Exchange }\end{array}$ & http://lca-net.com/spold/ & $\begin{array}{l}\text { Society for Promotion of } \\
\text { Life-cycle Assessment } \\
\text { Development (SPOLD) }\end{array}$ & Dinamarca \\
\hline 28. TEAM $^{\mathrm{TM}} 4.5$ & http://www.ecobalance.com/uk_team.php & $\begin{array}{l}\text { Pricewaterhouse Coopers } \\
\text { Ecobilan Group }\end{array}$ & França \\
\hline 29. TESPI & http://www.ecosmes.net/tespi/login2 & $\begin{array}{l}\text { ENEA - Italian National } \\
\text { Agency for New Technology, } \\
\text { Energy and the Environment }\end{array}$ & Itália \\
\hline 30. trainEE & http://greendeltatc.com/index.php?id=36 & GreenDeltaTC GmbH & Alemanha \\
\hline
\end{tabular}




\begin{tabular}{|c|c|c|c|}
\hline 31. Umberto $5 . .5$ & www.umberto.de & $\begin{array}{l}\text { Institute for Environmental } \\
\text { Informatics, Hamburg GmbH }\end{array}$ & Alemanha \\
\hline 32. Verdee & www.ecosmes.net & $\begin{array}{c}\text { ENEA - Italian National } \\
\text { Agency for New Technology, } \\
\text { Energy and the Environment }\end{array}$ & Itália \\
\hline $\begin{array}{l}\text { 33. USES-LCA } \\
2.0\end{array}$ & $\begin{array}{l}\text { http://www.ru.nl/environmentalscience/research/life_cycle/multi } \\
\text { media_toxic }\end{array}$ & $\begin{array}{l}\text { Radboud University } \\
\text { Nijmegen }\end{array}$ & Holanda \\
\hline 34. WISARD 4.0 & http://www.ecobalance.com/uk_wisard.php & $\begin{array}{l}\text { Pricewaterhourse Coopers } \\
\text { Ecobilan Group }\end{array}$ & França \\
\hline 35. WRATE & www.environment-agency.gov.uk/wrate & U.K. Environment Agency & Reino Unido \\
\hline
\end{tabular}

Tabela 9: Softwares de apoio à ACV (USEPA 2007; EPLCA 2007; CURRAN, 2006; BAUMANN; TILLMAN, 2004).

Os principais softwares para apoio à ACV segundo USEPA (2009) estão comentados resumidamente a seguir:

a) BEES 3.0 - desenvolvido pelo "National Institute for Standards and Technology (NIST) Building and Fire Research Laboratory". Este software (BEES - Building for Environmental and Economic Sustainability) pode ser usado para avaliar o desempenho ambiental e econômico de produtos de construção civil. Visa dar apoio à tomada de decisão de designers, construtores e fabricantes de produtos. Inclui dados de desempenho ambiental e econômico de 65 produtos. O software pode ser acessado no endereço eletrônico fornecido na tabela 9;

b) The Boustead Model 5.0 - Elaborado pela "Boustead Consulting". É um extenso banco de dados, que contém informações ambientais para combustíveis e energia, materiais, resíduos sólidos, efluentes líquidos e emissões atmosféricas. Também inclui um software que permite ao usuário manipular os dados no banco de dados e selecionar um método adequado a apresentação dos dados a partir de uma série de opções;

c) CMLCA - Criado pelo "Centre of Environmental Science (CML)" da Leiden University. Chain Management by Life Cycle Assessment (CMLCA) é uma ferramenta computacional que se destina a apoiar as etapas da metodologia de execução da ACV. O programa pode ser acessado no site fornecido na tabela 9 
d) ECO-it 1.3 - desenvolvido por PRé Consultants. ECO-it contém informações ambientais para materiais comumente utilizados, tais como: metais, plásticos, papel e vidro; bem como, para a produção desses materiais, para atividades de transporte, energia e tratamento de resíduos processuais. Calcula a carga ambiental de um produto e mostra as partes do produto que mais contribuem. Uma versão demo pode ser acessada no site fornecido na tabela 9;

e) GaBi 4 Software System and Databases - desenvolvido por PE Europe $\mathrm{GmbH}$ e IKP University of Stuttgart. Ferramenta computacional que apresenta versões para diferentes usos para avaliar aspectos ambientais, sociais e econômicos associados ao ciclo de vida de um produto ou serviço. Contém abrangente banco de dados com cobertura mundial, bem como dados do ecoinvent. Oferece auxílio para administrar grande quantidade de dados e modelar ciclo de vida de produtos. Uma versão demo está disponível para acesso público;

f) GEMIS (Global Emission Model for Integrated Systems) - desenvolvido por Öko-Institut. GEMIS é um programa computacional de ACV e de banco de dados para energia, materiais e atividades de transporte. $O$ banco de dados do GEMIS oferece informações sobre combustíveis fósseis, renováveis, produção de energia térmica e de eletricidade, materiais e transportes. Pode ser obtido gratuitamente a partir do site apresentado na tabela 9;

g) GREET Model - desenvolvido pelo "The U.S. Department of Energy's Office of Transportation Technologies fuel-cycle model called GREET (Greenhouse gases, Regulated Emissions, and Energy use in Transportation)". Permite aos usuários avaliar diferentes combinações de motores e de combustíveis; 
h) IDEMAT 2005 - pela Delft University of Technology. IDEMAT é uma ferramenta para seleções de materiais em processo de concepção. Ela fornece um banco de dados com informações técnicas sobre materiais e processos produtivos que permitem ao usuário comparar informações. Uma versão demo está disponível no endereço eletrônico fornecido na tabela 9;

i) KCL-ECO 4.0 - por KCL. Pode ser usado para aplicar a ACV em sistemas complicados com vários processos e fluxos. Inclui avaliação de impacto (caracterização, normalização e ponderação) e funções gráficas. Uma versão demo está disponível no site fornecido na tabela 9;

j) LCAiT 4 - elaborado por CIT Ekologik. Desde 1992, LCAit tem sido utilizada para a avaliação ambiental de produtos e processos. Inclui avaliação de impactos com fatores de caracterização e de ponderação;

k) LCAPIX - desenvovlvido por KM Limited. O software combina ACV e custeio ABC (Activity Based Costing) para ajudar as empresas a garantir a conformidade ambiental, garantindo simultaneamente rentabilidade sustentada. Permite uma avaliação quantitativa que pode indicar o potencial ônus de qualquer produto. Uma versão demo está disponível no site fornecido na tabela 9;

I) REGIS - elaborado por Sinum. Ferramenta computacional para a melhoria do desempenho ambiental das empresas de acordo com a ISO14031. Uma versão demo está disponível no site fornecido na tabela 9;

m) SimaPro 7 - desenvolvido por PRé Consultants. É uma ferramenta profissional de ACV que contém os seguintes métodos de avaliação de impacto: CML 1992, CML 2 baseline 2000, Eco-indicator 95, Eco-indicator 99, Ecopints 97, EDIP/UMIP 96 e EPS2000. Este software apresenta ainda os seguintes 
bancos de dados: BUWAL250 (248 processos de fabricação), Danish Food data (500 produtos), Dutch input output data (195 processos de fabricação), ecoinvent data (2700 sistemas de produtos), ESU-ETH data (1100 processos de fabricação e 1100 sistemas de produtos), Franklin USA data (78 processos de produção incluindo energia e atividades de transporte), IDEMAT (508 inventários de materiais), Industry data (74 processos de fabricação), IOdatabase for Denmark 1999 (750 materiais) e USA input output data (481 processos de fabricação). Esta ferramenta pode ser editada e expandida sem limitação. Pode comparar e analisar o desempenho ambiental de produtos e serviços com ciclos de vida bem complexos. Uma versão demo está disponível no site fornecido na tabela 9 ;

n) SPOLD Data Exchange Software - elaborado pela The Society for Promotion of Life-cycle Assessment. Este software é utilizado para criar, editar, importar e exportar dados no formato SPOLD'99. Ele pode ser acessado no site fornecido na tabela 9;

o) TEAM ${ }^{\mathrm{TM}}$ - desenvolvido pelo "Pricewaterhouse Coopers Ecobilan Group". TEAM $^{\text {TM }} 3.0$ é uma ferramenta profissional para a avaliação ambiental e econômica do ciclo de vida de produtos e serviços. Contém um detalhado banco de dados contendo mais de 600 processos com abrangência mundial. Permite ao usuário construir bancos de dados e calcular inventários de ciclo de vida de sistemas complexos. Uma versão demo está disponível a partir do site fornecido na tabela 9;

p) Umberto - criado pelo "Institute for Environmental Informatics" de Hamburg. Software de gestão ambiental que serve para visualizar fluxogramas de materiais e energia. Os principais objetivos de sua utilização nas empresas são detectar pontos cruciais para otimização dos processos no sistema de 
produção, reduzir os recursos de materiais e energia e minimizar as quantidades de emissões poluentes e, como conseqüência, reduzir os custos; e

q) WISARD'M - desenvolvido pelo "Pricewaterhourse Coopers Ecobilan Group". WISARD (Waste Integrated Systems Assessment for Recovery and Disposal) é uma ferramenta computacional de ACV para ajudar na tomada de decisões e avaliar as opções políticas relativas à eliminação dos resíduos domésticos. 


\subsubsection{Bancos de dados para suporte da ACV}

Um banco de dados (representação na figura 8) é constituído por diversas bases de dados que contêm informações de caráter ambiental sobre a produção de bens de consumo, sobre a disponibilização de recursos energéticos e ainda, sobre a realização de serviços. Essas bases, nada mais são que o inventário do ciclo de vida de elementos comuns a vários outros ciclos de vida. Como exemplos desses elementos comuns, podemos citar: materiais (poliméricos, metálicos, cerâmicos, combustíveis, fertilizantes, entre outros); energia (térmica, elétrica, etc.); atividades de transporte (rodoviário, ferroviário, marítimo, etc.) e gerenciamento de resíduos.

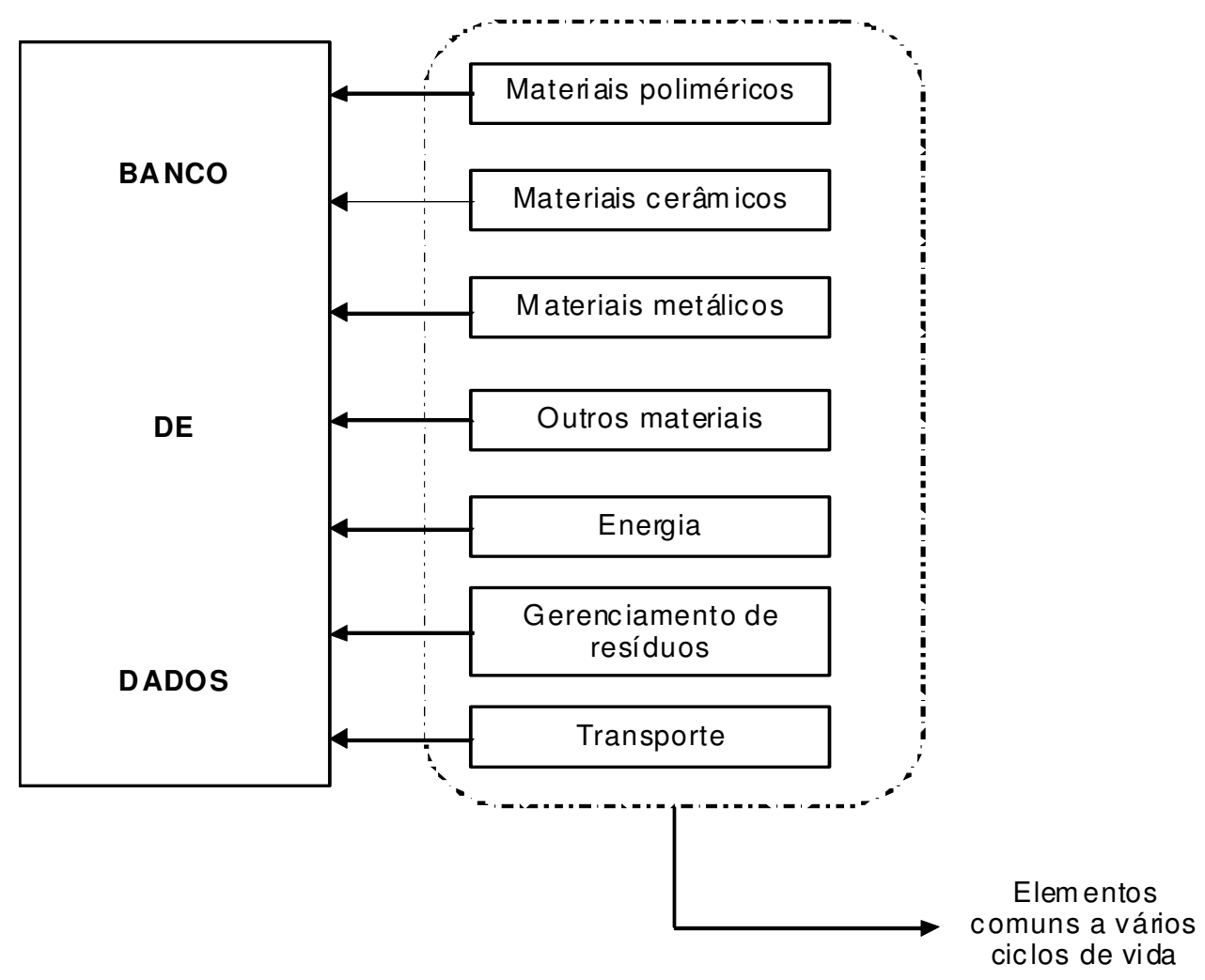

Figura 8: Representação de banco de dados (RIBEIRO, 2004). 
O uso de banco de dados contendo as informações citadas anteriormente se faz necessário para auxiliar a execução dos estudos de ACV, uma vez que esses estudos dependem de um elevado número de dados representativos para a região que se pretende analisar. Desse modo, o uso de um banco de dados abreviará em muito o consumo de tempo e de recursos necessários para a realização dos estudos da técnica no que diz respeito à coleta e tratamento das informações. Caso contrário, o estudo se tornaria tão lento e impreciso que estaria obsoleto antes mesmo de se terminar o tratamento dos dados.

A incorporação de um banco de dados em um software que permita a edição das informações nele contidas de modo que o executante possa atualizar, modificar e adequar as mesmas da melhor forma possível para seu estudo, também auxiliará em muito os praticantes de ACV.

Considerando o caráter regional que um banco de dados possui e a inexistência de uma metodologia universal consolidada para execução de estudos de ACV, é importante lembrar que deve existir compatibilidade entre as diversas bases de dados que constituem um banco de dados.

Um projeto de construção de um banco de dados regional deve envolver requisitos básicos, tais como: a capacitação de recursos humanos no que se refere à técnica $\mathrm{ACV}$; o comprometimento de segmentos econômicos; o estabelecimento em conjunto pelas partes envolvidas de regras comuns para princípios de modelagem dos sistemas de produtos (p. ex. escopos geográfico, técnico e temporal, critérios de exclusão, critérios de alocação); a adoção de um formato para a documentação dos dados; a disponibilidade de dados genuinamente brasileiros para compor o banco de dados; e a uniformização da caracterização, normalização e valoração de impactos ambientais para a região.

Contudo, a construção de um banco de dados só é possível caso exista uma combinação de esforços, através da composição de grupos de trabalho 
regionais, envolvendo os diversos setores interessados: empresas, associações, academia, governo e sociedade.

Tomando-se como exemplo o Ecoinvent, um banco de dados de ICVs deve possuir como estrutura básica os seguintes componentes: uma base de dados central onde estarão todos os inventários e metodologias de avaliação de impacto ambiental; um método de cálculo para aperfeiçoar os conjunto de dados obtidos pelas instituições; um editor para criar, mudar, completar ou apagar conjuntos de dados obtidos pelas bases de dados locais; uma ferramenta administrativa para auxiliar na análise dos dados; uma ferramenta de pesquisa dos ICVs disponíveis via internet para membros sócios; um formato para os dados de inventários que seja de preferência de acordo com as especificações da ISO/TR 14048, visto que está sendo discutida a possibilidade de criação de um formato único para forma dos dados de inventário; e implementações e atualizações através da utilização de bases de dados locais como por exemplo o Gabi, SimaPro, etc (FRISCHKNECHT et al., 2005).

Foi efetuada uma pesquisa com o intuito de verificar a situação atual dos bancos de dados de Inventários de Ciclo de Vida (ICVs) disponíveis no mundo. Verificou-se que os países mais adiantados no uso da técnica da ACV estão investindo significativamente na construção de seus bancos de dados regionais. Como exemplo podemos citar: U.S. LCI Database; German Network on LCI Data; National LCA Project in Japan - The LCA Data Library; Ecoinvent - a Web-based LCA Database (Swiss Federal Institute of Technology).

A seguir são apresentados na tabela 10 os bancos de dados de instituições governamentais encontrados na pesquisa. 


\begin{tabular}{|c|c|c|}
\hline Nome & Endereço na internet & $\begin{array}{c}\text { Região } \\
\text { dos dados }\end{array}$ \\
\hline $\begin{array}{l}\text { 1. Australian Life } \\
\text { Cycle Inventory } \\
\text { Data Project }\end{array}$ & http://www.cfd.rmit.edu.au/programs/life_cycle_assessment/life_cycle_inventory & Austrália \\
\hline 2. BUWAL 250 & http://www.umwelt-schweiz.ch/buwal/eng & Suíça \\
\hline $\begin{array}{l}\text { 3. Canadian Raw } \\
\text { Materials } \\
\text { Database }\end{array}$ & http://crmd.uwaterloo.ca/ & Canadá \\
\hline 4. DuboCalc & http://www.rws.nl/rws/bwd/home/www/cgi-bin/index.cgi?site=1\&doc=1785 & Holanda \\
\hline $\begin{array}{l}\text { 5. Dutch Input } \\
\text { Output }\end{array}$ & www.pre.nl & Holanda \\
\hline 6. ecoinvent & www.ecoinvent.ch & $\begin{array}{l}\text { Mundial/Eu } \\
\text { ropa/Suícca }\end{array}$ \\
\hline 7. EDIP & www.lca-center.dk & Dinamarca \\
\hline 8. Franklin US LCI & www.pre.nl & $\begin{array}{l}\text { Estados } \\
\text { Unidos }\end{array}$ \\
\hline $\begin{array}{ll}9 . & \text { German } \\
\text { Network on Life } \\
\text { Cycle Inventory } \\
\text { Data }\end{array}$ & www.lci-network.de & Alemanha \\
\hline 10. ITRI Database & http://www.itri.org.tw & Taiwan \\
\hline $\begin{array}{l}\text { 11. IVAM LCA } \\
\text { Data }\end{array}$ & www.ivam.uva.nl & Holanda \\
\hline $\begin{array}{lr}12 . & \text { Japan } \\
\text { National } & \text { LCA } \\
\text { Project } & \\
\end{array}$ & http://www.jemai.or.jp/english/lca/project.cfm & Japão \\
\hline 13. Korean LCl & http://www.kncpc.re.kr & Coréia \\
\hline 14. LCA Food & www.Icafood.dk & Dinamarca \\
\hline 15. SPINE@CPM & www.globalspine.com & Mundial \\
\hline $\begin{array}{lr}16 . & \text { Swiss } \\
\text { Agricultural } & \text { Life } \\
\text { Cycle Assessment } \\
\text { Database } \\
\text { (SALCA) }\end{array}$ & www.reckenholz.ch/doc/en/forsch/control/bilanz/bilanz.html & Suíça \\
\hline $\begin{array}{l}\text { 17. Thailand LCI } \\
\text { Database Project }\end{array}$ & www.mtec.or.th & Tailândia \\
\hline $\begin{array}{l}\text { 18. U.S. LCI } \\
\text { Database Project }\end{array}$ & www.nrel.gov/lci & $\begin{array}{l}\text { Estados } \\
\text { Unidos }\end{array}$ \\
\hline
\end{tabular}

Tabela 10: Bancos de dados de ICVs nacionais disponíveis em 2006 (CURRAN, 2006).

Os principais bancos de dados da tabela 10 estão comentados a seguir segundo USEPA (2009):

a) Ecoinvent - este banco de dados suíço apresenta dados de inventário para: geração, transmissão e distribuição de eletricidade de 25 países europeus; centrais elétricas; combustíveis e derivados de petróleo; energia (nuclear, 
hidroelétrica, eólica, solar e biomassa); abastecimento de combustível e geração de energia térmica; materiais de construção; produtos químicos orgânicos e inorgânicos; metais; madeira; papel; produtos agrícolas; serviços de transporte (aéreo, ferroviário, marítimo, lacustre e rodoviário); e gerenciamento de resíduos sólidos (reciclagem, incineração e aterros sanitários). Os dados são baseados na produção e situação de abastecimento no ano $2000 \mathrm{com}$ abrangência mundial e européia. Os bens de capital (estradas, meios de transporte, centrais elétricas, rede elétrica e instalações químicas) são constantemente incluídos. Apresenta mais de 2700 dados no formato EcoSpold. Além disso, contém os seguintes métodos de AICV: CML 2001, Eco-indicador 99, the ecological scarcity method 1997, EDIP 1997, EPS 2000 e Impact 2002(+);

b) IVAM LCA Data 4.0 - desenvolvido por IVAM University of Amsterdam bv. É um banco de dados utilizado para avaliação ambiental do ciclo de vida. Constitui-se em uma compilação de várias bases de dados bem conhecidas, tais como: APME (plásticos e outros produtos químicos); BUWAL e ETH 96. Apresenta dados para mais de 300 materiais e para cerca de 1300 processos, incluindo processos de geração de energia e atividades de transporte. $O$ banco de dados é particularmente abrangente para os setores de construção civil, de produção alimentar e de gerenciamento de resíduos sólidos. Este banco de dados está adaptado para o software SimaPro;

c) SPINE@CPM - desenvolvido por CPM (Competence Centre for Environmental Assessment of Product and Material Systems) na Chalmers University of Technology. O SPINE@CPM é um banco de dados elaborado na Suécia proveniente de uma colaboração entre indústria e academia. Este banco de dados contém cerca de 500 inventários do ciclo de vida no formato de dados estabelecido pela norma ISO/TS 14048. Apresenta informações detalhadas sobre atividades de transportes, geração de energia, produção de materiais 
(poliméricos, metálicos, fertilizantes, entre outros) e gerenciamento de resíduos sólidos. O banco de dados dispõe ainda de três modelos para avaliação de impactos: EPS, EDIP e Eco-indicador. O banco de dados pode ser acessado a partir do endereço eletrônico fornecido na tabela 10;

d) US Life Cycle Inventory Database - elaborado por Athena Sustainable Materials Institute. O "United States LCI Database" é um projeto com parcerias públicas e privadas que teve por objetivo desenvolver um banco de dados de inventários do ciclo de vida para materiais e processos. A principal razão para a sua elaboração era a ausência de ICVs com dados consistentes e transparentes para os Estados Unidos e o Canadá. Esta iniciativa vem sendo desenvolvida por pesquisadores do National Renewable Energy Laboratory (NREL) em conjunto com especialistas da técnica da ACV. Os inventários disponibilizados até o momento apresentam dados de acordo com o formato estabelecido pela norma ISO/TS 14048, também compatível com o formato Ecospold. Os dados podem ser importados para diversos softwares de ACV; e

e) EDIP Database - criado pela LCA Center of Denmark. O banco de dados foi elaborado visando dar assistência a empresas que necessitam de avaliações ambientais através da ACV. Este banco de dados possui ICVs de acordo com o formato dos dados do software Gabi.

A seguir a tabela 11 apresenta os banco de dados existentes de organizações industriais. 


\begin{tabular}{|l|c|c|}
\hline \multicolumn{1}{|c|}{ Nome } & Endereço na internet & $\begin{array}{c}\text { Região } \\
\text { dos dados }\end{array}$ \\
\hline $\begin{array}{l}\text { 1. American Iron and } \\
\text { Steel Institute (AISI) }\end{array}$ & www.steel.org/ & $\begin{array}{c}\text { Estados } \\
\text { Unidos }\end{array}$ \\
\hline $\begin{array}{l}\text { 2. American Plastics } \\
\text { Council (APC) }\end{array}$ & $\begin{array}{c}\text { http://americanplasticscouncil.org/ } \\
\text { http://www.americanchemistry.com/plastics/ } \\
\text { Unidos }\end{array}$ \\
\hline $\begin{array}{l}\text { 3. EDP-Norway } \\
\text { 4. European Aluminium } \\
\text { Association (EAA) }\end{array}$ & $\begin{array}{c}\text { Noruega e } \\
\text { Europa }\end{array}$ \\
\hline $\begin{array}{l}\text { 5. European Copper } \\
\text { Institute (ECI) }\end{array}$ & www.epd.norge.no & Europa \\
\hline $\begin{array}{l}\text { 6. European Federation } \\
\text { of Corrugated Board } \\
\text { Manufacturers (FEFCO) }\end{array}$ & www.copper-life-cycle.org & Europa \\
\hline $\begin{array}{l}\text { 7. Internacional Iron and } \\
\text { Steel Institute (IISI) }\end{array}$ & www.fefco.org & Europa \\
\hline $\begin{array}{l}\text { 8. Internacional Stainless } \\
\text { Steel Forum (ISSF) }\end{array}$ & www.worldsteel.org & Mundial \\
\hline $\begin{array}{l}\text { 9. KCL EcoData } \\
\text { 10. Nickel Institute }\end{array}$ & www.worldstainless.org & Mundial \\
\hline $\begin{array}{l}\text { 11. PlasticsEurope Eco- } \\
\text { profiles (antiga APME) }\end{array}$ & http://www.nickelinstitute.org/index.cfm/ci_id/114.htm & Finlandês \\
\hline $\begin{array}{l}\text { 12. Volvo EPDs } \\
\text { whw.plasticseurope.org }\end{array}$ & Europa \\
\hline
\end{tabular}

Tabela 11: Bancos de dados de organizações industriais disponíveis em 2006 (CURRAN, 2006).

Conformem mostram as tabelas 10 e 11 , a grande maioria dos bancos de dados encontrados foi desenvolvida por países europeus, os quais já lidam com ACV há muitos anos. O resumo da situação por regiões mundiais é apresentado a seguir.

I. África: segundo CURRAN (2006) sendo a África do Sul um grande exportador de insumos materiais, a procura de outros países por dados de ICVs desse país está aumentando significativamente. Contudo, as indústrias e o governo do país têm demonstrado pouco interesse no assunto e ainda não se deram conta dos benefícios que os estudos de ACV podem trazer. CURRAN (2006) ainda afirma que o pouco interesse das indústrias e do governo e a baixa capacitação em ACV é muito comum nos países em desenvolvimento. 
II. Ásia: de acordo com informações obtidas de CURRAN (2006), identificou-se nesse continente a necessidade de se desenvolver um banco de dados público de ACV contendo informações aplicáveis a essa região. No ano de 2000, a Associação Japonesa de Gestão Ambiental para a Indústria (JEMAI) lançou um projeto em parceria com os países da Austrália, Indonésia, Coréia, Malásia, Cingapura, Taiwan e Tailândia para trocar informações e disponibilizar dados de ICVs para energia e alguns insumos materiais comuns a diversos ciclos de vida. No Japão, o progresso em relação à ACV foi significativamente motivado pelo Projeto Nacional de ACV criado pelo Ministério da Indústria e Comércio Exterior (MITI) em outubro de 1998. O projeto é administrado pela JEMAI e conta com a participação da indústria, governo, instituições de pesquisa e academia. Os dados de ICVs para a produção média japonesa de vários materiais foram coletados pos associações industriais do país. Dados coletados junto à CURRAN (2006) permitiram constatar que o banco de dados está disponível na internet e pode ser utilizado mediante o pagamento de uma taxa.

Com o suporte do Ministério do Comércio, Indústria e Energia (MOCIE) e do Ministério do Meio Ambiente (MOE) a Coréia desenvolveu o projeto de construção de um banco de dados de ICVs para o país. Atualmente o banco de dados é utilizado para o Programa Coreano de Declaração Ambiental do tipo III (CURRAN, 2006).

Em Taiwan foi conduzido, pelo Instituto de Pesquisa Tecnológica Industrial (ITRI), um projeto para desenvolver um banco de dados contendo ICVs. O projeto contou com o apoio financeiro do Ministério de Assuntos Econômicos do país. Os dados estão disponíveis na internet para acesso público.

CURRAN (2006) comenta que na Índia, a Sociedade Indiana de Avaliação do Ciclo de Vida (ISLCA) tem atuado por vários anos com o intuito de capacitar recursos humanos e despertar o interesse em ACV no país.

Desde o ano de 2000, segundo CURRAN (2006), diversos projetos de ACV têm sido conduzidos na Tailândia por diversas universidades e pelo 
Instituto do Meio Ambiente da Tailândia. Na China está sendo desenvolvido um banco de dados nacional. Na Malásia os esforços estão concentrados na elaboração de um ICV para a produção de eletricidade. Alguns estudos de caso têm sido realizados em Cingapura e na Indonésia. Contudo, CURRAN (2006) verificou que o uso da ACV não se encontra muito difundido nesses dois países.

III. Austrália: na Austrália, de acordo com CURRAN (2006), institutos de pesquisas, consultores, especialistas e associações industriais têm desenvolvido um banco de dados para apoio aos estudos de ACV. No projeto denominado "Dados de Inventários de Ciclo de Vida Australianos", foram disponibilizadas informações de caráter técnico e ambiental para: vários tipos de plásticos; vidro; alumínio; aço; concreto; eletricidade; combustíveis; e meios de transporte.

IV. Europa: sendo o centro de informações sobre ACV desde o final da década de 80 , muitos bancos de dados distintos têm sido desenvolvidos em países desse continente. CURRAN (2006) afirma que os bancos de dados disponíveis são muito diversificados e, por conta disso, apresentam pouca harmonização entre si dado ao grande número de fontes de dados envolvidas e de países com características diferentes.

Conforme CURRAN (2006), em países como Alemanha, Suécia e Suíça, que têm atuado na elaboração de bancos de dados por muitos anos, o desafio atual é integrar e assegurar compatibilidade e permutabilidade entre uma variedade extensa de bancos de dados.

$\mathrm{Na}$ Alemanha, por exemplo, desde 2001 os trabalhos estão concentrados junto ao governo federal para prover continuamente a atualização e revisão dos dados de ICVs. Na Suécia o banco de dados denominado SPINE@CPM foi publicado em 1998 e desde então se encontra disponível na internet. Segundo CURRAN (2006) todos ICVs contidos no banco de dados são bem 
documentados e tem sido revisados no que diz respeito à transparência e à compreensibilidade.

No ano de 2001 o Instituto Federal Suíço de Tecnologia (ETH), principal instituo de pesquisas em ACV, junto a outras repartições federais suíças fundaram o ecoinvent Centre, o centro suíço para ICVs, que estabeleceu um banco de dados contendo: combinações de dados de eletricidades de 25 países europeus; usinas de geração de energia elétrica; combustíveis e combustão; materiais de construção; produtos químicos básicos inorgânicos e orgânicos; metais; serviços de transporte; serviços de gerenciamento de resíduos; e produtos agrícolas (EPLCA, 2007). Segundo CURRAN (2006), a transparência no relato dos dados é a principal característica do banco de dados suíço.

V. América do Norte: o projeto de criação do banco de dados canadense para materiais foi iniciado há mais de 10 anos. Tornou-se publicamente disponível entre os anos de 2001 e 2004. CURRAN (2006) verificou que o banco de dados contém ICVs que foram feitos para os seguintes materiais: aço; alumínio; vidro; plásticos; papel e madeira. Os dados foram providos por associações industriais. Teve início em 2001, nos Estados Unidos, um projeto colaborativo para desenvolver e disponibilizar ao público um banco de dados para a realidade do país. CURRAN (2006) informa também que o projeto teve suporte financeiro da Administração de Serviços Gerais (GSA) e do Departamento de Energia dos Estados Unidos (DOE). De acordo com CURRAN (2006), o banco de dados, já concluído, apresenta informações de ICVs coletados sob os contextos "gate-to-gate" e "cradle-to-gate" de um número considerável de fontes. O banco de dados é de responsabilidade do Laboratório Nacional de Energia Renovável (NREL) e está disponível na internet. O México iniciou atividades para desenvolver seu banco de dados nacional e obteve o primeiro auxílio financeiro em 2002 para coletar dados de eletricidade e metais. Assim, o auxílio estendeu-se para outras categorias de dados importantes, tais como: 
combustíveis; produtos químicos; materiais de construção; e tratamento de rejeitos (CURRAN, 2006).

VI. Américas Central e do Sul: um projeto de desenvolvimento de um banco de dados para ACV para as condições argentinas foi lançado na Universidade Tecnológica Nacional de Mendoza. A Colômbia também iniciou atividades voltadas para a construção de seu banco de dados nacional. No Chile, estudos estão sendo realizados para a obtenção de dados representativos de eletricidade para o país (CURRAN, 2006). A partir da realização do evento "Estratégias para a consolidação da ACV no Brasil”, em 2004, o Brasil lançou o projeto de construção de seu banco de dados. O projeto conta com o apoio do Ministério de Ciência e Tecnologia (MCT); além de diversas indústrias, de órgãos de consultoria e de universidades (SILVA, 2006). Segundo SILVA; KULAY (2006), o projeto de construção do banco de dados brasileiro está em andamento. Os autores destacam que o banco de dados brasileiro deve ter um caráter regional, ou seja, deve representar de maneira fiel e adequada as características do setor produtivo brasileiro. O caráter regional também deverá ser considerado para a etapa de avaliação de impactos, visto que grande parte dos softwares existentes contém métodos (para avaliação de impactos) baseados em problemas ambientais europeus. A gestão do projeto está a cargo do Instituto Brasileiro de Ciência e Tecnologia (IBICT) do MCT, enquanto que a área de informatização do banco de dados está sob as responsabilidades da Universidade de Brasília (UnB) e do IBICT. No que se refere à execução dos inventários, esta será elaborada por três núcleos de pesquisa especializados e coordenados por professores doutores nas seguintes instituições acadêmicas: UnB, Universidade de São Paulo (USP) e Universidade Técnica Federal do Paraná (UTFPR). Inicialmente o projeto optou por delimitar o escopo da elaboração dos inventários para os setores de energia, combustíveis e transporte (FERREIRA et al., 2007). 


\subsubsection{Estudos recentes publicados sobre a técnica}

Com o objetivo de verificar o estado da arte da técnica da ACV no mundo, efetuou-se uma pesquisa por meio do portal SpringerLink Database (2008) no principal periódico da técnica, qual seja, The International Journal of Life Cycle Assessment, entre os anos de 2005 e 2008 e, também em artigos publicados nos anais de dois congressos internacionais sobre ACV.

Com base nessa pesquisa, foi possível verificar que os estudos publicados recentemente, de ACV, têm se dedicado a três assuntos principais: inclusão de aspectos sociais; inclusão de aspectos econômicos; e regionalização da metodologia de execução da etapa de Avaliação de Impactos do Ciclo de Vida (AICV).

A seguir são apresentados comentários sobre alguns desses estudos que tiveram o intuito de buscar atualizações e melhorias na metodologia de execução da técnica.

\subsubsection{Inclusão de aspectos sociais}

Para que a ACV permita uma avaliação da sustentabilidade de um produto ou serviço, alguns estudos têm apresentado a necessidade de inclusão de indicadores sociais na ACV.

A inclusão de aspectos sociais em estudos de ACV objetiva que as empresas possam conduzir seus negócios de maneira socialmente responsável, fornecendo informação dos potenciais impactos sociais sobre as pessoas, causados pelas atividades do ciclo de vida de seus produtos.

Como demonstração da importância de este tópico, a Iniciativa do Ciclo de Vida (Life Cycle Initiative) do Programa das Nações Unidas para o Meio Ambiente (PNUMA) e a SETAC mantém como um de seus principais esforços, a inclusão de indicadores sociais nos estudos de ACV. 
A necessidade de aprimoramento social dentro das empresas aumenta cada vez mais, devido ao acompanhamento que elas sofrem pela mídia.

Para avaliação da responsabilidade social utilizam-se indicadores sociais que são dados estatísticos e retratam a situação social de uma determinada empresa, de um estado ou até mesmo de uma nação. O uso de indicadores sociais propicia que as empresas percebam o seu valor e reconheçam seu desempenho.

Avaliação social é vista por alguns autores e organizações como um complemento para ACV e determinação do custo do ciclo de vida como um terceiro componente de medição da prática do desenvolvimento sustentável.

UGAYA; MACHADO; JUNIOR (2005), no artigo "Avaliação social do ciclo de vida: estudos de caso" realizaram dois estudos de caso, sendo que em cada um deles uma indústria diferente foi investigada. Nessas indústrias os autores procuraram dados como: a geração de empregos; características das pessoas que ocupam cargos; renda; investimentos nos trabalhadores e em ações sociais e informações sobre a segurança do trabalho, tais como: efeitos, causas e freqüências de acidentes.

De acordo com os autores a inclusão de indicadores sociais nos estudos de ACV pode ser efetuada em três etapas:

a) definir os indicadores mais apropriados para o estudo;

b) coletar os dados da empresa para cada unidade de processo já definida, por meio de entrevistas e questionários; e

c) analisar as respostas obtidas e verificar ocorrências de semelhanças ou diferença em todo o processo e emitir um parecer.

UGAYA; JUNIOR (2007) no artigo intitulado "Incorporação de indicadores sociais na avaliação de ciclo de vida" mencionam a importância e a necessidade de inclusão de indicadores sociais em estudos de ACV.

Os autores comentam que a necessidade de aprimoramento social dentro das empresas aumenta cada vez mais, devido ao acompanhamento que elas sofrem pela mídia. De acordo com os mesmos, para avaliação da 
responsabilidade social utilizam-se indicadores sociais que são dados estatísticos e retratam a situação social de uma determinada empresa, de um estado ou até mesmo de uma nação. O uso de indicadores sociais propicia que as empresas percebam o seu valor e reconheçam seu desempenho (UGAYA; JUNIOR, 2007).

No artigo "A framework for social life cycle impact assessment" os autores DREYER; HAUSCHILD; SCHIERBECK (2006) afirmam que a inclusão de aspectos sociais, em estudos de ACV, visa que as empresas possam conduzir seus negócios de maneira socialmente responsável, fornecendo informação dos potenciais impactos sociais causados pelas atividades do ciclo de vida de seus produtos ou serviços.

O artigo de DREYER; HAUSCHILD; SCHIERBECK (2006) apresenta um método para definir as questões para categorias de impactos obrigatórios de ACV social. Para os autores, a ACV social diz respeito aos impactos causados nas pessoas e, assim sendo, o foco deve ser nas atividades do ciclo de vida que afetam negativamente as pessoas. A análise deve ser feita em unidades de processo, uma vez que a maioria dos impactos sobre as pessoas depende das condições físicas dos processos industriais.

O artigo sugere uma base para determinação de parâmetros de avaliação social de uma empresa em todos os estágios do ciclo de vida, exceto na etapa de uso. Na etapa de uso do produto, os impactos causados sobre as pessoas não podem ser relacionados diretamente a uma ou mais empresas e sim, relacionados diretamente ao uso do produto. A definição dos parâmetros de avaliação deve-se iniciar com a identificação do que é mais valioso para a sociedade. A escolha dos parâmetros de avaliação não deve ser baseada na disponibilidade dos dados.

Em uma ACV social, as atividades de uma empresa podem resultar em impactos positivos (injeção de capital na comunidade local, no caso de países em desenvolvimento; criação de empregos; etc.), bem como impactos negativos 
(condições inadequadas de trabalho; exploração de recursos naturais locais; etc.).

De acordo com os autores, em uma ACV social os indicadores de categorias são desenvolvidos para medir os impactos sociais diretamente na empresa. Os impactos na ACV social dependem muito da região geográfica. Isso significa que o indicador é determinado não apenas pelo comportamento da empresa, mas também pelos riscos locais que a conduta da empresa irá provocar na região.

O artigo "Societal LCA methodology and case study" de HUNKELER (2006) apresenta uma metodologia para avaliação social do ciclo de vida, acompanhada de um estudo de caso que compara dois detergentes.

Para o autor a avaliação social do ciclo de vida assume que um ICV já está disponível ou que este será obtido e aplica as mesmas fronteiras do sistema; a mesma unidade funcional e o mesmo inventário que um estudo de ACV convencional.

O autor comenta ainda que para uma ACV social, além dos aspectos ambientais tradicionais do sistema de produto, as horas de trabalho se constituem em uma informação muito relevante. De acordo com o autor, para uma ACV social, os dados do ICV devem ser convertidos uma base comum. $\mathrm{O}$ número de horas de mão-de-obra é um exemplo dessa base.

O artigo "Methodologies for social life cycle assessment" de JORGENSEN et al. (2008) apresenta uma revisão da literatura sobre métodos de execução de um estudo de Avaliação Social do Ciclo de Vida. A revisão bibliográfica efetuada pelos autores descreve o método de execução conforme os requisitos propostos pelo programa Iniciativa do Ciclo de Vida da UNEP/SETAC. Tais requisitos são similares àqueles estabelecidos na norma ISO 14040 para um estudo de Avaliação Ambiental do Cicio de Vida. Desse modo e de acordo com a pesquisa feita por JORGENSEN et al. (2008) um estudo de Avaliação Social do Ciclo de Vida é divido em quatro etapas: definição de objetivo e escopo, análise do inventário, avaliação de impactos e 
interpretação. No referido artigo apenas a etapa de interpretação não foi estudada.

Para a primeira etapa, em particular no que se refere à definição de objetivo, os autores identificaram duas classes, a saber: comparação de produtos, serviços ou companhias; e identificação de melhorias de produtos ou serviços.

Ainda sobre a primeira etapa, especificamente para a definição de escopo, quatro itens foram destacados pelos autores: origem dos impactos sociais; alocação; estabelecimento das fronteiras do sistema de produto; e seleção de indicadores sociais.

No que diz respeito à origem dos impactos sociais, de acordo com 0 artigo de JORGENSEN et al. (2008), DREYER; HAUSCHILD; SCHIERBECK (2006) e SPILLEMAECKERS et al. (2004) apud JORGENSEN et al. (2008) concordam que a maioria dos impactos sociais não tem relação com os processos produtivos, mas com o comportamento ou conduta das empresas responsáveis por tais processos.

Sobre a alocação DREYER; HAUSCHILD; SCHIERBECK (2006) apud JORGENSEN et al. (2008) propõem que uma parte da quantidade total de impactos gerados no sistema de produto pelas atividades da empresa deve ser alocada ao produto ou serviço em análise e que essa parte da quantidade total a ser alocada seja determinada pela contribuição da empresa em toda a cadeia produtiva do produto ou serviço. O fator de alocação pode ser baseado, por exemplo, no número de horas de mão-de-obra utilizadas.

Quanto ao estabelecimento de fronteiras do sistema, para DREYER; HAUSCHILD; SCHIERBECK (2006) apud JORGENSEN et al. (2008) se o objetivo do estudo for auxiliar a tomada de decisões na indústria, deve-se incluir as etapas do ciclo de vida onde há participação da empresa responsável pelo produto ou serviço em análise. Por outro lado, SCHMIDT et al. (2004) apud JORGENSEN et al. (2008) concordam que se o objetivo do estudo for comparação de produtos e se impactos relevantes forem identificados em todas 
as partes da cadeia produtiva, será necessária a inclusão de todas as etapas do ciclo de vida desses produtos. WEIDEMA (2005) apud JORGENSEN et al. (2008) defende a necessidade de aplicação dos requisitos estabelecidos na norma ISO 14044, ou seja, que a exclusão de uma etapa do ciclo de vida, ou de uma unidade de processo, ou ainda de quantidades de entrada e saída só será permitida caso não ocorram alterações significantes nas conclusões finais do estudo.

No que se refere à seleção de indicadores sociais, JORGENSEN et al. (2008) se basearam em onze artigos para citar alguns exemplos de indicadores quantitativos e qualitativos divididos em quatro classes conforme segue:

a) diretos humanos: mão-de-obra infantil; trabalhos forçados; liberdade para negociação salarial e para associação sindical; discriminação;

b) condições de trabalho dos empregados: salários por hora, regularidade de pagamento, contratos de trabalho, benefícios, incluindo auxílio familiar; condições físicas e psicológicas de trabalho, acidentes, distância até o local de trabalho; treinamento e educação dos funcionários;

c) sociedade: corrupção, fraudes, estabelecimento ilegal de preços de venda, violação dos direitos de propriedade; criação de empregos, atendimento aos fornecedores, investimentos em pesquisa e desenvolvimento, em infra-estrutura e em programas de educação para a comunidade local; aceitação e imagem perante a comunidade local; e

d) responsabilidade sobre o produto: informação completa do produto aos usuários e clientes; e comunicações ao mercado.

Para a segunda etapa de um estudo de Avaliação Social do Ciclo de Vida, denominada Análise de Inventário, DREYER; HAUSCHILD; SCHIERBECK (2006) e SPILLEMAECKERS et al. (2004) apud JORGENSEN et al. (2008) consideram que os impactos sociais são resultados da conduta da empresa e que essa conduta tem forte influência na região, fazendo com que os dados a serem coletados sejam específicos para a empresa em questão. 
A próxima etapa do estudo, denominada Avaliação de Impactos, envolve a classificação das informações contidas no inventário em categorias de impactos; além da caracterização, normalização e valoração desses impactos. Para a classificação, JORGENSEN et al. (2008) sugerem que esta ação seja feita por meio de informações obtidas através de funcionários, consumidores e da comunidade local. Por fim os autores comentam que até o presente os estudos dedicados à caracterização, normalização e valoração ainda são muito superficiais. 


\subsubsection{Inclusão de aspectos econômicos}

HUNKELER; REBITZER (2005) comentam, no artigo "The future of life cycle assessment', a respeito da necessidade de inclusão de aspectos econômicos e sociais em estudos de ACV. Os autores definem Custeio do Ciclo de Vida (CCV) como uma avaliação de todos os custos associados a todas as etapas do ciclo de vida de um produto ou serviço. Essa definição também tem sido adotada pelo grupo de trabalho europeu da SETAC em LCC (Life Cycle Costing).

Segundo HUNKELER; REBITZER (2005) um estudo de CCV tem as mesmas fronteiras do sistema e a mesma unidade funcional que um estudo de ACV tradicional.

WANG; HUA (2007) propõem, no artigo "Global scope assessment: a novel method and its application to chinese paper industry", um método denominado Global Scope Assessment (GSA) utilizado para avaliar o consumo de recursos naturais e a disposição de rejeitos no meio ambiente, combinando a técnica da ACV e a economia ambiental.

De acordo com o artigo, o método GSA baseia-se nos resultados de um estudo de ICV e no correspondente tratamento econômico de estes. As etapas de avaliação de impactos e de interpretação da técnica da ACV não são consideradas no método.

Para a etapa de economia ambiental, os autores sugerem diferentes métodos de avaliação monetária dos quais pode se escolhido o mais seguro e completo. 


\subsubsection{Necessidade de regionalização dos métodos de avaliação de impactos do ciclo de vida}

Quanto aos esforços voltados à regionalização da metodologia de execução de AICV, alguns artigos recentes foram selecionados para constituir esta pesquisa.

No artigo "A life cycle impact assessment method for the Brazilian context' elaborado por SOUZA; SOARES; SOUSA (2007), os autores comentam que a etapa de AICV é altamente dependente das condições de uma região e que atualmente os métodos de AICV são específicos para países da Europa Ocidental, para o Japão e também para os Estados Unidos.

Devido a relevâncias ambientais distintas de impactos locais e regionais e condições econômicas, existe uma necessidade de se desenvolver um método de AICV direcionado às condições ambientais brasileiras (SOUZA; SOARES; SOUSA, 2007).

Os autores afirmam que mediante a identificação e análise de métodos de AICV já existentes, observa-se a necessidade de selecionar categorias de impacto específicas, associadas aos principais problemas ambientais do país. O resultado esperado é reduzir incertezas nos estudos de ACV feitos no Brasil.

Conforme os autores, o Brasil encontra alguns problemas com a aplicação de metodologias de AICV:

a) algumas categorias de impacto, tais como: uso da terra, disposição de resíduos e consumo de recursos abióticos são normalmente omitidos nas metodologias atuais de AICV. Contudo, essas categorias são de muita importância para a avaliação ambiental da realidade brasileira;

b) no que se refere à etapa de caracterização, os fatores e os modelos atuais não podem ser apropriados para aplicação no Brasil;

c) na fase de normalização, é importante enfatizar a ausência de fatores. Em geral, os fatores de normalização só estão disponíveis para as cinco regiões 
federais brasileiras (sul, sudeste, centro-oeste, norte e nordeste) e para grandes áreas metropolitanas;

d) aspectos culturais, sociais e econômicos podem influenciar a etapa de ponderação.

Segundo os autores, de acordo com as condições ambientais brasileiras, no mínimo onze categorias de impacto podem ser propostas para o país: mudança climática; depleção da camada de ozônio; depleção de recursos abióticos; acidificação; eutrofização; formação de oxidante fotoquímico; ecotoxicidade; toxicidade humana; consumo de água; uso da terra; e disposição de resíduos.

Os autores propõem uma ferramenta para um método brasileiro de AICV que consiste basicamente na caracterização dos resultados de emissões em onze categorias de impacto diferentes. Devido à ausência de dados demográficos e de emissões, os autores comentam que a legislação brasileira e valores padrões devem ser usados como valores de referência para a fase de normalização. O método de ponderação (ou valoração) é baseado em decisão multicriteriosa auxiliada por painel de especialistas.

$\mathrm{O}$ artigo "The Life Cycle Impact Assessment (LCIA) and some important considerations to Brazil' de PEGORARO; GOEDKOOP; UGAYA; TADANO (2007) apresenta algumas considerações para o desenvolvimento de um método de AICV para o Brasil. Os autores comentam sobre o fato da etapa de AICV precisar ser estimulada no Brasil, devido ao país possuir específicas condições tecnológicas, geográficas e culturais.

No texto "Emergence and Future of Life Cycle Impact Assessment: good science comes from good people" de JOLLIET (2006) o autor provê seu ponto de vista a respeito do que foi efetuado nas últimas décadas sobre a etapa de AICV e também discute desafios futuros. 


\subsubsection{Ferramentas que usam a ACV}

A Análise de Eco-eficiência é uma ferramenta, desenvolvida pela BASF em 1996 em conjunto com a consultoria Roland Berger, que visa avaliar o desempenho ambiental de produtos, processos e serviços, de forma integrada com uma avaliação econômica. O desempenho ambiental dessa análise é obtido por meio da técnica da ACV e em seguida, de uma avaliação simplificada de riscos dos acidentes para cada uma das opções a serem comparadas. $O$ desempenho econômico é obtido através do levantamento de custos que ocorrem durante todo o ciclo de vida do produto. Através da ferramenta são obtidos índices ambientais e econômicos que são relacionados de uma forma que ambos os desempenhos tenham os mesmos pesos no resultado final (VIANNA, 2006).

A ferramenta SEEbalance, assim como a Eco-eficiência, foi desenvolvida pela BASF. Ela faz análises considerando os três componentes da sustentabilidade; quais sejam, o ambiental (obtido por meio da ACV), o econômico e o social. O principal objetivo dessa ferramenta é quantificar o desempenho dos três "pilares" da sustentabilidade visando a medição direta do desenvolvimento sustentável dentro das empresas (SALING et al., 2005).

KLOEPFFER (2008) no artigo "Life Cycle Sustainability Assessment of Products" resume o estado da arte da Avaliação da Sustentabilidade do Ciclo de Vida (Life Cycle Sustainability Assessment - LCSA) e propõe um conjunto unificado de métodos que estará qualificado para ser padronizado em um futuro próximo e que servirá para avaliar a sustentabilidade de produtos e serviços. $\mathrm{O}$ autor comenta que o referido conjunto de métodos deve incluir a avaliação de três componentes: o ambiental (por meio da técnica da ACV), o econômico (através do CCV) e o social (por meio da avaliação social do ciclo de vida).

No que diz respeito ao terceiro e último método de avaliação citado, KLOEPFFER (2008) relata que os principais problemas são os seguintes: a relação quantitativa de indicadores sociais com a unidade funcional do estudo; 
a obtenção de dados específicos de uma determinada região para um estudo de avaliação social do ciclo de vida; a quantificação devida de impactos sociais; bem como, a avaliação dos resultados. 


\subsubsection{ACV simplificada}

Para TODD (1996) a meta de simplificar uma ACV é reduzir o tempo e custo de execução de um estudo de ACV sem prejudicar a credibilidade do resultado. TODD; CURRAN (1999) afirmam que os benefícios da simplificação, em termos de economizar recursos, devem ser balanceados em oposição à manutenção da utilidade dos resultados.

As simplificações seguem duas principais categorias:

a) simplificação dentro de uma estrutura existente de ACV

- na metodologia, limitando o escopo do estudo ou simplificando os procedimentos de modelagem, através da limitação da quantidade de dados ou informações necessárias para a avaliação;

- no processo, usando bases de dados incorporadas a programas computacionais.

b) propostas alternativas de simplificação baseada em conceitos de ciclo de vida

- limitar ou eliminar todos ou alguns estágios upstream. Essa simplificação consiste na remoção de estágios antes da manufatura do produto final. A vantagem é a eliminação da necessidade de dados de fornecedores, porém exclui importantes impactos relacionados à extração ou produção de matériaprima;

- limitar ou eliminar estágios downstream, o que corresponde a um estudo de ACV do berço ao portão de saída da fábrica (from the cradle to the gate). Essa proposta consiste na eliminação de todos os estágios após a manufatura do produto. A vantagem é a manutenção da captura de informações para melhoria do produto até a saída da fábrica. Os fornecedores serão forçados a prover materiais de perfis ambientais melhores. Por outro lado, os impactos relacionados ao uso e disposição final são desprezados; 
- limitar ou eliminar estágios upstream e downstream, o que corresponde a uma ACV dentro dos portões da fábrica. Esse tipo de análise é caracterizado como análise ambiental. A vantagem é que os dados podem ser agregados e 0 processo sob estudo pode ser afetado diretamente pelo usuário, a desvantagem é a perda da visão de ciclo de vida (holística) dos materiais;

TODD; CURRAN (1999) concluem que a simplificação da ACV é uma parte do processo de definição da meta e escopo da ACV. 


\subsubsection{Incertezas em estudos de ACV}

A incerteza é uma das questões importantes para os estudos de avaliação do ciclo de vida. $\mathrm{Na}$ literatura, alguns estudos, tais como BJÖRKLUND (2002) e ROSS; EVANS; WEBBER (2002), têm revisado a definição, a classificação e a fonte de incerteza na ACV e também têm explorado a forma de lidar com as incertezas.

A maioria dos estudos teve suas atenções voltadas para diferentes etapas de execução da ACV, como o inventário do ciclo de vida e normalização e ponderação na fase de avaliação de impactos do ciclo de vida. Em particular, no que se refere à etapa de ICV podemos citar os estudos de HUIJBREGTS et al. (2001), SUGIYAMA et al. (2005) e von BAHR; STEEN (2004). A maioria desses estudos considerou para qualidade dos dados do ICV, os critérios qualitativos de indicadores de qualidade dos dados baseados em WEIDEMA; WESNAES (1996). FRISCHKNECHT et al. (2007) posteriormente transformaram os critérios qualitativos em distribuições estatísticas.

Alguns estudos discutiram os resultados na etapa de avaliação de impactos para categorias de impacto afetadas pela incerteza dos resultados de um ICV (GEISLER; HELLWEG; HUNGERBUHLER, 2005). As normas ISO 14040 (ISO, 2006a) e ISO 14044 (ISO, 2006b) citaram os problemas gerados em estudos de ACV devido à incerteza e destacaram que a ausência de dimensões espaciais e temporais nos resultados do ICV irá introduzir incerteza na etapa de avaliação de impactos.

Durante a elaboração de um estudo de ACV podem surgir diferentes tipos de incertezas. Dentre esses, podemos citar: imprecisão na coleta dos dados, ausência de dados; dados não representativos; emprego de dados antigos para representar uma situação atual; emprego de dados de regiões diferentes a do estudo em questão; utilização de modelos impróprios; e escolha das fronteiras do sistema. 
De acordo com JúNIOR (2007), existem diferentes tipos de técnicas que podem ser utilizadas tanto para demonstrar, como reduzir, os possíveis tipos de incerteza encontrados em um estudo de ACV. Podem-se citar: padronização; validação dos dados (que envolve balanços de massa e energia); revisão crítica (para assegurar que o modelo e que os dados utilizados estão de acordo com os objetivos e escopo do estudo); indicadores de qualidade de dados; análise estatística (para determinação de variâncias, médias e desvios no padrão dos dados); medidas adicionais; análise de sensibilidade (que consiste usualmente em alterar os valores dos parâmetros, modelos ou métodos utilizados e observar as alterações ocorridas nos resultados finais, avaliando as alternativas); e simulação probabilística.

WEIDEMA; WESNAES (1996) apud JÚNIOR (2007) definiram alguns indicadores para a qualidade de dados, usados para julgar a relação entre as metas de qualidade de dados especificadas e a atual qualidade dos dados coletados e propuseram uma matriz (matriz pedigree, representação na tabela 12) para avaliar a qualidade dos mesmos.

$\mathrm{Na}$ seqüência, FRISCHKNECHT et al. (2007) incluíram mais um indicador, o número de amostras. Assim, os seguintes indicadores são necessários e suficientes para descrever aqueles aspectos da qualidade do dado, que influenciam a confiança no resultado do estudo: confiança na fonte que foi utilizada para obtenção dos dados relevantes ao estudo; além do método de coleta; completeza; quantidade de amostras coletadas; correlação temporal; correlação geográfica e correlação tecnológica.

Os seis indicadores de qualidade de dados foram expostos em uma matriz de qualidade de dados (tabela 12). Cada indicador recebe uma avaliação de 1 a 5 , sendo que 1 representa o melhor grau de qualidade do indicador e 50 pior caso encontrado.

O uso da matriz de qualidade de dados irá necessariamente envolver julgamentos subjetivos, que irão depender da base de conhecimentos da pessoa realizando a pontuação. 


\begin{tabular}{|c|c|c|c|c|c|}
\hline $\begin{array}{l}\text { Indicador / } \\
\text { pontuação do } \\
\text { indicador }\end{array}$ & 1 & 2 & 3 & 4 & 5 \\
\hline $\begin{array}{l}\text { Confiança na } \\
\text { fonte }\end{array}$ & $\begin{array}{l}\text { Dados verificados } \\
\text { baseados em medidas }\end{array}$ & $\begin{array}{c}\text { Dados verificados } \\
\text { parcialmente baseados } \\
\text { em estimativas ou dados } \\
\text { não verificados baseados } \\
\text { em medidas }\end{array}$ & $\begin{array}{l}\text { Dados não verificados } \\
\text { parcialmente baseados } \\
\text { em estimativas } \\
\text { qualificadas ou } \\
\text { informações teóricas }\end{array}$ & $\begin{array}{l}\text { Estimativa qualificada. } \\
\text { Dados derivados de } \\
\text { informações teóricas }\end{array}$ & $\begin{array}{l}\text { Estimativa não } \\
\text { qualificada }\end{array}$ \\
\hline Completeza & $\begin{array}{l}\text { Dados representativos } \\
\text { de todos os locais } \\
\text { relevantes para o } \\
\text { aspecto e com período } \\
\text { adequado para } \\
\text { compensar flutuações } \\
\text { normais } \\
\end{array}$ & $\begin{array}{c}\text { Dados representativos de } \\
\text { mais de } 50 \% \text { dos locais } \\
\text { relevantes para o } \\
\text { aspecto considerado com } \\
\text { períodos adequados para } \\
\text { compensar flutuações } \\
\text { normais }\end{array}$ & $\begin{array}{c}\text { Dados representativos de } \\
\text { somente alguns locais } \\
(<<50 \%) \text { relevantes para } \\
\text { o aspecto considerado ou } \\
>50 \% \text { dos locais mas } \\
\text { com períodos curtos }\end{array}$ & $\begin{array}{l}\text { Dados representativos } \\
\text { de apenas um local } \\
\text { representativo para o } \\
\text { aspecto considerado } \\
\text { ou alguns locais com } \\
\text { períodos curtos }\end{array}$ & $\begin{array}{l}\text { Representatividade } \\
\text { desconhecida ou } \\
\text { dados de um pequeno } \\
\text { número de locais e } \\
\text { períodos curtos }\end{array}$ \\
\hline $\begin{array}{l}\text { Número de } \\
\text { amostras }\end{array}$ & Maior que 100 & Maior que 20 & Maior que 10 & Maior ou igual a 3 & Desconhecido \\
\hline $\begin{array}{l}\text { Cobertura } \\
\text { geográfica }\end{array}$ & $\begin{array}{c}\text { Dados da região em } \\
\text { estudo }\end{array}$ & $\begin{array}{l}\text { Dados médios de uma } \\
\text { área extensa na qual a } \\
\text { região em estudo está } \\
\text { incluída }\end{array}$ & $\begin{array}{c}\text { Dados de uma área } \\
\text { menor que a do estudo } \\
\text { ou de regiões diferentes } \\
\text { com condições } \\
\text { operacionais similares }\end{array}$ & & $\begin{array}{l}\text { Dados de uma região } \\
\text { desconhecida ou de } \\
\text { uma região com } \\
\text { condições de } \\
\text { operação diferentes }\end{array}$ \\
\hline $\begin{array}{l}\text { Cobertura } \\
\text { temporal }\end{array}$ & $\begin{array}{l}\text { Menos de } 3 \text { anos de } \\
\text { diferença em relação } \\
\text { ao ano em estudo }\end{array}$ & $\begin{array}{c}\text { Menos de } 6 \text { anos de } \\
\text { diferença }\end{array}$ & $\begin{array}{c}\text { Menos de } 10 \text { anos de } \\
\text { diferença }\end{array}$ & $\begin{array}{l}\text { Menos de } 15 \text { de } \\
\text { diferença }\end{array}$ & $\begin{array}{l}\text { Mais de } 15 \text { anos de } \\
\text { diferença ou idade } \\
\text { dos dados } \\
\text { desconhecida }\end{array}$ \\
\hline $\begin{array}{l}\text { Cobertura } \\
\text { tecnológica }\end{array}$ & $\begin{array}{l}\text { Dados de empresas, } \\
\text { processos e materiais } \\
\text { em estudo }\end{array}$ & & $\begin{array}{l}\text { Dados de processos ou } \\
\text { materiais relacionados } \\
\text { mas com mesma } \\
\text { tecnologia ou dados de } \\
\text { processos e materiais em } \\
\text { estudo mas de diferente } \\
\text { tecnologia }\end{array}$ & $\begin{array}{l}\text { Dados de processos e } \\
\text { materiais relacionados } \\
\text { mas de tecnologias } \\
\text { diferentes ou dados de } \\
\text { processos em escala } \\
\text { laboratorial de mesma } \\
\text { tecnologia }\end{array}$ & $\begin{array}{l}\text { Dados de processos } \\
\text { ou materiais } \\
\text { relacionados mas em } \\
\text { escala laboratorial de } \\
\text { tecnologia diferente }\end{array}$ \\
\hline
\end{tabular}

Tabela 12: Matriz de qualidade dos dados (FRISCHKNECHT et al., 2007).

Portanto, as incertezas podem ser caracterizadas por diferentes indicadores. Porém, a matriz de qualidade de dados ainda não determina o grau de incerteza dos dados coletados, apenas gera uma pontuação destes dados. A tabela 13 mostra os fatores de incerteza a serem aplicados na matriz de qualidade de dados:

\begin{tabular}{|l|c|c|c|c|c|}
\hline Pontuação do indicador & $\mathbf{1}$ & $\mathbf{2}$ & $\mathbf{3}$ & $\mathbf{4}$ & $\mathbf{5}$ \\
\hline Confiança na fonte & 1,00 & 1,05 & 1,10 & 1,20 & 1,50 \\
\hline Completeza & 1,00 & 1,02 & 1,05 & 1,10 & 1,20 \\
\hline Número de amostras & 1,00 & 1,02 & 1,05 & 1,10 & 1,20 \\
\hline Correlação temporal & 1,00 & 1,03 & 1,10 & 1,20 & 1,50 \\
\hline Correlação geográfica & 1,00 & 1,01 & 1,02 & - & 1,10 \\
\hline Correlação tecnológica & 1,00 & - & 1,20 & 1,50 & 2,00 \\
\hline
\end{tabular}

Tabela 13: Fatores de incerteza aplicados à pontuação pela qualidade do dado (FRISCHKNECHT et al., 2007). 
FRISCHKNECHT et al. (2007), também baseados em julgamentos feitos por peritos no assunto, criaram fatores básicos de incerteza relativos às entradas e saídas para diferentes aspectos ambientais considerados.

Uma vez avaliada a pontuação do indicador, seu respectivo fator de incerteza e o fator básico de incerteza (entrada ou saída do sistema), então, o respectivo grau de incerteza $\left(S_{D_{995}}\right)$ é calculado através da equação 1 :

$\mathrm{SD}_{995}=\mathrm{e}^{\sqrt{\left[\ln \left(\mathrm{U}_{1}\right)\right]^{2}+\left[\ln \left(\mathrm{U}_{2}\right)\right]^{2}+\left[\ln \left(\mathrm{U}_{3}\right)\right]^{2}+\left[\ln \left(\mathrm{U}_{4}\right)\right]^{2}+\left[\ln \left(\mathrm{U}_{5}\right)\right]^{2}+\left[\ln \left(\mathrm{U}_{6}\right)\right]^{2}+\left[\ln \left(\mathrm{U}_{\mathrm{b}}\right)\right]^{2}}}$ eq. 1

Onde:

$U_{1}=$ fator de incerteza do indicador confiança na fonte;

$\mathrm{U}_{2}=$ fator de incerteza do indicador completeza;

$\mathrm{U}_{3}=$ fator de incerteza do indicador número de amostras;

$U_{4}=$ fator de incerteza do indicador correlação temporal;

$U_{5}=$ fator de incerteza do indicador correlação geográfica;

$U_{6}=$ fator de incerteza do indicador correlação tecnológica; e

$U_{b}=$ fator de incerteza básico, disponível em FRISCHKNECHT et al. (2007).

Um resultado de $\mathrm{SD}_{\text {g95 }}$ igual a 1,53, por exemplo, representa $53 \%$ de incerteza para o aspecto ambiental avaliado (JÚNIOR, 2007).

Uma vez obtido o grau de incerteza dos indicadores (de qualidade dos dados), é então avaliado se a incerteza contida é significativa, ou não, para o estudo de ACV. Caso seja significativa, segue-se para a modelagem estocástica.

Apenas a incerteza relacionada aos indicadores independentes (completeza e número de amostras) pode ser reduzida através de modelagem matemática. Os indicadores de confiança na fonte e de correlações temporal, geográfica e tecnológica dependem de alternativas diferentes à modelagem 
matemática para redução dos erros gerados. Isto porque a redução de essas incertezas está diretamente relacionada à coleta dos dados do ICV e, portanto, não podem ser reduzidas através de simulações (JÚNIOR, 2007).

De acordo com JÚNIOR (2007), a modelagem estocástica (aleatória) tem início com a seleção da distribuição de probabilidade dos dados. São necessários, no mínimo, três valores amostrados para a definição da função de distribuição de probabilidade, a média e o respectivo desvio padrão, necessários a geração de números aleatórios. Caso um estudo não disponha de três valores, ou mais, não há como definir corretamente a base estatística dos dados. 


\subsubsection{Estudos sobre produtos do setor de fertilizantes nitrogenados}

Os fertilizantes de um modo geral, e em particular os fertilizantes nitrogenados, vêm sendo alvos de pesquisas desde suas primeiras aplicações comerciais no que se referem aos consumos de recursos necessários à suas produções, ao uso excessivo e à redução de perdas de estes para o meio ambiente. Nesse sentido comentamos a seguir, de forma resumida, sobre alguns estudos de caso encontrados na literatura para produtos e processos de fabricação presentes na cadeia produtiva de fertilizantes nitrogenados.

Em maio de 2000, o departamento de energia dos Estados Unidos por meio de seu instituto de tecnologias industriais publicou um documento que diz respeito ao perfil energético e ambiental da indústria química do país. Um dos capítulos da publicação é totalmente dedicado aos fertilizantes químicos e contêm descrições dos processos de obtenção e informações sobre os consumos materiais e energéticos, as emissões atmosféricas, os efluentes líquidos e os resíduos sólidos para as produções de: amônia, uréia, ácido nítrico, nitrato de amônio, ácido sulfúrico, sulfato de amônio, ácido fosfórico, fosfatos de amônio e superfosfatos (U.S. DOE, 2000).

Ainda no ano de 2000, a European Fertilizer Manufacturers Association EFMA em conjunto com suas companhias associadas lançou publicações técnicas (Best available techniques for pollution prevention and control in the european fertilizer industry) (EFMA, 2000) que disponibilizam valores de consumo de insumos materiais e energéticos e também de emissões atmosféricas, efluentes líquidos e resíduos sólidos específicos para os seguintes produtos: amônia (processos de reforma catalítica e oxidação parcial); ácido nítrico (obtido da oxidação da amônia); ácido sulfúrico (a partir de enxofre elementar); ácido fosfórico (a partir da rocha fosfática e de ácido sulfúrico); uréia (a partir de amônia e dióxido de carbono); nitrato de amônio (proveniente da reação da amônia com o ácido nítrico) e fertilizantes compostos $(\mathrm{N}-\mathrm{P}-\mathrm{K})$. 
JIMÉNEZ-GONZÁLEZ; KIM; OVERCASH (2000) apresentaram sugestões para geração de informação para um ICV sob o enfoque do ciclo de vida "do portão (de entrada) ao portão (de saída) da fábrica". Os Resultados das informações geradas foram apresentados como um estudo de caso. $O$ estudo de caso apresentado se referiu à produção de amônia através do processo de reforma catalítica com vapor de água. Os insumos materiais considerados no estudo foram são: gás natural (como fonte de hidrogênio); ar (como fonte de nitrogênio) e água. O dióxido de carbono também é produzido como um subproduto. Os autores comentaram o interesse em verificar as diferenças entre os valores estimados para os insumos, os produtos e as emissões atmosféricas e os dados específicos obtidos da indústria. Contudo, uma vez que os dados industriais não estavam disponíveis, foram utilizados, para comparação, dados extraídos da literatura e informações obtidas em bancos de dados comerciais de ACV para o mesmo processo.

KIM; OVERCASH (2000) comentaram e ilustraram procedimentos de alocação, no caso específico da indústria química. A fabricação de amônia, na qual o dióxido de carbono é formado como um subproduto, foi utilizada pelos autores para mostrar um exemplo específico e detalhado do procedimento de alocação baseado em critério físico.

BRENTRUP et al. (2000), selecionaram, a partir de uma revisão da literatura, métodos para estimar as emissões de amônia, de óxido nitroso e de nitratos, durante e após a produção, o armazenamento e a aplicação de fertilizantes orgânicos e minerais.

MENDIVIL et al. (2006) propuseram um método, o qual se baseou na coleta de informações de consumo energético para três matérias-primas diferentes (gás natural, óleo combustível pesado e carvão) ao longo do tempo, em emissões obtidas junto ao programa computacional SimaPro 5.0 para a produção de amônia e na simulação no software Aspen Plus ${ }^{\circledR}$ de parâmetros de processo coletados para o período de 1950 a 2000. Os dados coletados foram transformados em balanços de massa e energia para o processo de 
produção de $1 \mathrm{~kg}$ de amônia sob o contexto "do berço ao portão (da fábrica)". Os dados dos balanços de massa e de energia foram então transformados em indicadores de impactos ambientais, segundo a técnica da ACV. A etapa de avaliação de impactos considerou somente emissões atmosféricas $\left(\mathrm{CO}, \mathrm{CO}_{2}\right.$, $\mathrm{NOx}, \mathrm{SO}_{2}, \mathrm{CH}_{4}$ e $\mathrm{COV}$ ) que foram agregadas apenas na categoria de impacto de potencial de aquecimento global. Por fim, os impactos ambientais resultantes da produção de amônia foram relacionados com a evolução técnica e legislativa do referido processo ao longo do tempo. 


\subsection{Setor de Fertilizantes no Brasil}

\subsubsection{Histórico}

As primeiras fábricas de fertilizantes no Brasil surgiram nos anos 1940, com o processo de industrialização do país. Dedicavam-se exclusivamente à mistura N-P-K com base em fertilizantes simples importados. Isso permitiu que as formulações N-P-K se adaptassem melhor às condições dos solos brasileiros, com as primeiras unidades instaladas próximas a portos marítimos, como Cubatão (SP) e Rio Grande (RS) (MDIC, 2006).

Algumas das grandes empresas do setor já atuavam no mercado no fim da década de 1940 e início da década de 1950, entre elas: TREVO (1930), QUIMBRASIL (1945), IAP (1945), COPAS (1945), MANAH (1947), FERTISUL (1948), ELEKEIROZ (1949) E SOLORRICO (1956) (MDIC, 2006).

Segundo a FUNDAÇÃO INSTITUTO DE ADMINISTRAÇÃO - FIA (2002), no Brasil, a produção de fertilizantes simples, produtos intermediários e matérias-primas foi iniciada na década de 50, quando a indústria era capaz de suprir $8 \%$ da demanda nacional, sendo o restante atendido pelas importações. $\mathrm{Na}$ década de 60, a produção brasileira foi ampliada com a implantação de várias empresas, mas o país ainda possuía forte dependência externa. As importações representavam um pouco mais de um terço da demanda por fosfatados e todo o consumo de potássicos.

A forte intervenção do Estado, a partir de 1974, determinou o surgimento de uma nova fase para o setor de fertilizantes. O Governo criou o Plano Nacional de Fertilizantes e Calcário Agrícola (PNFCA) com o objetivo de aumentar a oferta interna e conseqüentemente a auto-suficiência do país (FIA, 2002).

WONGTSCHOWSKI (2002) destaca que nesse período, após a década de 60 , a indústria de fertilizantes brasileira sofreu um desenvolvimento notável com: 
a) a implantação da ULTRAFERTIL com um complexo de fertilizantes em Cubatão (SP) para a produção de amônia a partir de gases da refinaria Presidente Bernardes, ácido sulfúrico, ácido nítrico, ácido fosfórico, nitrato de amônio, fosfato de diamônio e NPK, por iniciativa do GRUPO ULTRA em associação com a PHILIPS PETROLEUM norte-americana, em 1965;

b) a implantação da VALEFERTIL em Uberaba (MG), com um complexo de grande porte para a produção de ácido sulfúrico, ácido fosfórico, fertilizantes fosfatados de alta e baixa concentração, fosfato de monoamônio e fertilizantes granulados, por iniciativa da COMPANHIA VALE DO RIO DOCE (CVRD);

c) o desenvolvimento e exploração de jazidas de fosfatos nacionais em Jacupiranga (SP) e Araxá (MG) pela SERRANA (pertencente ao GRUPO BUNGE argentino), em Tapira (MG) e Patos de Minas (MG) originalmente da CVRD e atualmente exploradas pela FOSFERTIL, em Ouvidor (GO) e Catalão (GO), originalmente da METAGO (Metais de Goiás S. A., empresa do Governo de Goiás) e atualmente exploradas pela COPEBRÁS e ULTRAFERTIL;

d) o desenvolvimento e exploração de jazidas de sais de potássio (silvinita e carnalita) de Taquari-Vassouras (SE) originalmente pela PETROMIN, que depois se tornou PETROMISA (Petrobras Mineiração S. A.) e atualmente está arrendada à CVRD.

De acordo com a FIA (2002), no começo da década de 80, a indústria já estava consolidada no país. O Governo havia assumido o controle acionário de empresas privadas, como a ULTRAFERTIL, em 1974. A PETROFERTIL (Petrobras Fertilizantes S. A.) foi criada em 1976 e passou a atuar como holding controlando empresas como: ULTRAFERTIL, FOSFERTIL, NITROFERTIL (Fertilizantes Nitrogenados do Nordeste S. A.), ARAFERTIL (Araxá Fertilizantes e Produtos Químicos S. A.), GOIÁSFERTIL (Goiás Fertilizantes S. A.) e a 
INDÚSTRIA CARBOQUÍMICA CATARINENSE (ICC). No fim da década de 80, iniciou-se o processo de liberalização da economia com o fim das restrições quantitativas nas importações de todos os produtos e com a redução das alíquotas de importação.

$\mathrm{Na}$ década de 90, com a abertura econômica, devido à queda das alíquotas de importação e com as privatizações houve uma reestruturação do setor.

Após as privatizações foi desencadeado um processo de fusões e aquisições. No início da década de 90 , havia elevada presença estatal na produção de matérias-primas e fertilizantes simples sendo que após o processo de privatização o controle das duas principais empresas do setor, a FOSFERTIL e a ULTRAFERTIL, passou à FERTIFOS que no ato de sua criação era um consórcio formado por sete empresas (FIA, 2002).

Em 1990, o Governo Federal decidiu pela liquidação das operações da INDÚSTRIA CARBOQUÍMICA CATARINENSE (ICC). A NITROFERTIL foi incorporada a PETROBRAS e ficou fora do processo de privatização (FIA, 2002).

Conforme a FIA (2002), as privatizações do setor de fertilizantes iniciaram-se em 1992. A primeira empresa a ser leiloada foi a INDAG S. A. em janeiro de 1992, passando a IAP (Indústria Agropecuária Paulista S. A.) ser sua maior acionista. Em agosto do mesmo ano a FOSFERTIL foi privatizada. Essa empresa foi adquirida pelo consórcio FERTIFOS que era formado inicialmente por empresas importantes do setor como: SOLORRICO (23,07\%), MANAH (23,07\%), IAP (23,07\%), FERTIBRAS (12,76\%), FERTIZA (10\%), TAKENAKA $(6,17 \%)$ entre outras com pequena participação no capital como: FERTIPAR (1,37\%), CAMPOS GERAIS (0,37\%), HERINGER (0,08\%) e TRIÂNGULO $(0,07 \%)$.

Em outubro de 1992 a GOIÁSFERTIL teve $90 \%$ de seu capital assumido pelo consórcio FERTIFOS. Em julho de 1993, foi realizado o leilão de desestatização da ULTRAFERTIL que teve seu controle adquirido pela 
FOSFERTIL. A ARAFERTIL foi privatizada em abril de 1994, sendo adquirida pela SERRANA (FIA, 2002).

Em 1995 a ULTRAFERTIL é incorporada pela GOIÁSFERTIL, empresa controlada integralmente pela FOSFERTIL. Após a incorporação, a GOIÁSFERTIL assume a razão social ULTRAFERTIL S. A. (FOSFERTIL, 2009).

Segundo WONGTSCHOWSKI (2002), a SERRANA comprou em 1996 a FERTISUL; em 1997 comprou a IAP (e com isso passou a ter $23,06 \%$ das ações da FERTIFOS); em 1998 adquiriu a divisão de fertilizantes da ELEKEIROZ e, também em 1998, em conjunto com a MANAH, comprou a TAKENAKA (adquirindo mais 3,09\% das ações da FERTIFOS). Em 2000 adquiriu o controle da INDÚSTRIA DE FERTILIZANTES MANAH, com isto passando a ter maioria da FERTIFOS, com $52,30 \%$ do capital social da mesma. Surge, então, em agosto, a BUNGE FERTILIZANTES S. A., união da SERRANA, MANAH, IAP e OURO VERDE.

Em julho de 1999, a CARGILL norte-americana (Cargill Agrícola S. A.) adquiriu o controle acionário da SOLORRICO, passando a deter $23,07 \%$ do controle da FERTIFOS, e em outubro de 2000 comprou a FERTIZA, aumentando sua participação na FERTIFOS em mais 10\% (MOSAIC FERTILIZANTES, 2009).

Ainda em 2000 a NORSK HYDRO norueguesa, maior empresa de fertilizantes do mundo, comprou a ADUBOS TREVO (WONGTSCHOWSKI, 2002).

De acordo com a FIA (2002), com a aquisição pelo GRUPO BUNGE da SERRANA e pela CARGILL da SOLORRICO e da FERTIZA, a BUNGE passou a deter $52,30 \%$ da FERTIFOS, a CARGILL $33,07 \%$, a FERTIBRAS $12,76 \%$ e outras $1,89 \%$.

Conforme mostra a tabela 14, a composição societária da FOSFERTIL S. A. não se alterou após o processo de privatização. A FERTIFOS continuou sendo a maior acionista da FOSFERTIL com $56,21 \%$ do capital social, seguida 
pela BUNGE FERTILIZANTES S. A. com 12,23\%, pela FERTIBRAS S. A. com $4,85 \%$, pela BENSPAR S. A. com $3,29 \%$ e por outros acionistas que juntos totalizam 23,42\% (ABIQUIM, 2008a).

No ano de 2004, embora mantendo as razões sociais FERTILIZANTES FOSFATADOS S. A. e ULTRAFERTIL S. A., a empresa passa a adotar uma única identidade corporativa: FOSFERTIL (FOSFERTIL, 2009).

Em outubro de 2004, surgiu a MOSAIC FERTILIZANTES DO BRASIL S. A. da união entre a IMC GLOBAL e a CARGILL FERTILIZANTES (Cargill Crop Nutrition), duas líderes em seus segmentos (MOSAIC FERTILIZANTES, 2009).

Em 2006 a YARA BRASIL incorpora a FERTIBRAS, tornando-se a segunda maior empresa do setor de fertilizantes no país (YARA BRASIL, 2009).

A tabela 14 apresenta as atuais empresas do setor de fertilizantes no Brasil; bem como, suas composições acionárias, seus produtos fertilizantes e a localização de suas unidades industriais. 


\begin{tabular}{|c|c|c|c|}
\hline Empresa & Composição acionária & $\begin{array}{c}\text { Localização das } \\
\text { unidades de operação }\end{array}$ & $\begin{array}{l}\text { Fertilizante } \\
\text { simples }\end{array}$ \\
\hline Braskem S. A. & $\begin{array}{c}\text { Odebrecht S. A. 19,80\%, Belgrávia 12,90\%, } \\
\text { Nordeste Química (Norquisa S. A.) 7,10\%, } \\
\text { Petrobras Química (Petroquisa S. A.) 6,80\%, } \\
\text { Bndespar (Bndes participações) S. A. 6,30\% } \\
\text { e outros 47,10\%. }\end{array}$ & Camaçari (BA) & Sulfato de amônio \\
\hline $\begin{array}{c}\text { Bunge } \\
\text { Fertilizantes S. A. }\end{array}$ & Bunge Brasil S.A. $100 \%$ & $\begin{array}{l}\text { Araxá e Uberaba (MG), } \\
\text { Cajati, Cubatão e Guará } \\
\text { (SP) e Rio Grande (RS) }\end{array}$ & $\begin{array}{l}\text { Sulfato de amônio } \\
\text { e SSP }\end{array}$ \\
\hline $\begin{array}{c}\text { CIBRAFERTIL - } \\
\text { Companhia } \\
\text { Brasileira de } \\
\text { Fertilizantes }\end{array}$ & $\begin{array}{l}\text { Grupo Paranapanema } 98,41 \% \text { e outros } \\
\qquad 1,59 \%\end{array}$ & Camaçari (BA) & SSP \\
\hline $\begin{array}{c}\text { Companhia Vale } \\
\text { do Rio Doce } \\
\text { (CVRD) }\end{array}$ & Holding CVRD $100 \%$ & Rosário do Catete (SE) & $\begin{array}{l}\text { Cloreto de } \\
\text { potássio }\end{array}$ \\
\hline COPEBRAS Ltda. & $\begin{array}{l}\text { Anglo American do Brasil Ltda. } 73 \% \text { e Elko } \\
\text { Chemicals Inc. } 27 \%\end{array}$ & $\begin{array}{l}\text { Catalão (GO) e } \\
\text { Cubatão (SP) }\end{array}$ & SSP, TSP e MAP \\
\hline $\begin{array}{l}\text { Fertilizantes Mitsui } \\
\text { S. A. }\end{array}$ & Mitsui \& Co., LTD. 100\% & Poços de Caldas (MG) & $\begin{array}{l}\text { Termofosfato } \\
\text { magnesiano } \\
\text { fundido }\end{array}$ \\
\hline $\begin{array}{l}\text { FOSFERTIL - } \\
\text { Fertilizantes } \\
\text { Fosfatados S. A. }\end{array}$ & $\begin{array}{c}\text { Fertifos S.A. } 56,21 \%, \\
\text { Bunge Fertilizantes S. A. } 12,23 \% \text {, } \\
\text { Fertibras S. A. 4,85\%, } \\
\text { Benspar S. A. 3,29\% } \\
\text { e outros } 23,42 \%\end{array}$ & $\begin{array}{c}\text { Patos de Minas, Tapira } \\
\text { e Uberaba (MG), } \\
\text { Araucária (PR), } \\
\text { Cubatão (SP) e } \\
\text { Catalão (GO) }\end{array}$ & $\begin{array}{c}\text { SSP, TSP, MAP e } \\
\text { DAP, Uréia e } \\
\text { nitrato de amônio }\end{array}$ \\
\hline $\begin{array}{c}\text { Fertilizantes } \\
\text { Fosfatados do } \\
\text { Paraná - FOSPAR } \\
\text { S. A. }\end{array}$ & Cargill Fertilizantes $100 \%$ & Paranaguá (PR) & SSP \\
\hline $\begin{array}{l}\text { Galvani Indústria, } \\
\text { Comércio e } \\
\text { Serviços Ltda. }\end{array}$ & $\begin{array}{c}\text { Rodolfo Galvani Jr. } 65 \% \text {, } \\
\text { Ronaldo Galvani } 30 \% \text { e } \\
\text { Roberto Galvani } 5 \%\end{array}$ & $\begin{array}{c}\text { Luis Eduardo } \\
\text { Magalhães (BA) e } \\
\text { Paulínia (SP) }\end{array}$ & SSP \\
\hline $\begin{array}{c}\text { Mosaic } \\
\text { Fertilizantes do } \\
\text { Brasil S. A. }\end{array}$ & Mosaic Fertilizantes Ltda. $100 \%$ & Cubatão (SP) & SSP \\
\hline $\begin{array}{c}\text { Petrobras / FAFEN } \\
\text { (Fábrica de } \\
\text { Fertilizantes } \\
\text { Nitrogenados) } \\
\end{array}$ & Petróleo Brasileiro S. A. 100\% & $\begin{array}{l}\text { Camaçari (BA) e } \\
\text { Laranjeiras (SE) }\end{array}$ & Uréia \\
\hline $\begin{array}{l}\text { PROFERTIL - } \\
\text { Produtos Químicos } \\
\text { e Fertilizantes } \\
\text { S. A. }\end{array}$ & $\begin{array}{c}\text { Agrinter Fertilizantes Ltda. 99,99\% e Jean } \\
\text { François Remond } 0,01 \%\end{array}$ & $\begin{array}{l}\text { Candeias - BA e Santa } \\
\text { Luzia do Norte (AL) }\end{array}$ & SSP \\
\hline Roulier Brasil Ltda. & Defer-Roullier $100 \%$ & Rio Grande (RS) & SSP e TSP \\
\hline $\begin{array}{l}\text { Unigel Química S. } \\
\text { A. }\end{array}$ & Unigel S.A. $100 \%$ & Candeias (BA) & Sulfato de amônio \\
\hline Yara Brasil & $\begin{array}{l}\text { Fertilizer Holdings AS } 98,32 \% \\
\text { e outros } 1,68 \% .\end{array}$ & Rio Grande (RS) & SSP e TSP \\
\hline
\end{tabular}

Tabela 14: Empresas do setor de fertilizantes simples no Brasil (ABIQUIM, 2008a). 
Com relação ao ambiente organizacional existem várias organizações de interesse privado, no Brasil, representando os diversos segmentos da cadeia produtiva de fertilizantes entre elas podemos citar: a Associação Nacional para Difusão de Adubos (ANDA), a Associação dos Misturadores de Adubo (AMA), o Sindicato das Indústrias de Adubos e Corretivos Agrícolas do Estado de São Paulo (SIACESP), o Sindicato de Matérias-Primas para Fertilizantes (SIMPRIFERT), entre outros sindicatos estaduais. 


\subsubsection{Produção e importações}

Conforme mostra a tabela 15, em termos mundiais o Brasil foi, no ano de 2007, o quarto maior consumidor de fertilizantes, correspondendo a cerca de $6 \%$ do consumo total. Contudo, o país produziu nesse ano apenas $36 \%$ do necessário ao seu consumo em termos de produtos fertilizantes, um aumento de aproximadamente $12 \%$ em relação ao ano anterior (ANDA, 2008).

\begin{tabular}{|l|c|c|}
\hline \multicolumn{1}{|c|}{ País } & $\begin{array}{c}\text { Consumo em toneladas de nutrientes } \\
\text { (N P K) }\end{array}$ & Participação (\%) \\
\hline China & 51.700 .000 & 30,4 \\
\hline India & 23.490 .000 & 13,8 \\
\hline Estados Unidos & 20.791 .000 & 12,2 \\
\hline Brasil & $\mathbf{1 0 . 5 8 5 . 0 0 0}$ & $\mathbf{6 , 2}$ \\
\hline Indonésia & 4.060 .000 & 2,4 \\
\hline Paquistão & 3.800 .000 & 2,2 \\
\hline França & 3.612 .000 & 2,1 \\
\hline Canadá & 2.700 .000 & 1,6 \\
\hline Alemanha & 2.506 .000 & 1,5 \\
\hline Vietnã & 2.380 .000 & 1,4 \\
\hline Espanha & 2.004 .000 & 1,2 \\
\hline Austrália & 1.979 .000 & 1,2 \\
\hline Turquia & 1.933 .000 & 1,1 \\
\hline Malásia & 1.900 .000 & 1,1 \\
\hline Polônia & 1.865 .000 & 1,1 \\
\hline Egito & 1.814 .000 & 1,1 \\
\hline Irã & 1.800 .000 & 1,1 \\
\hline México & 1.787 .000 & 1,1 \\
\hline Rússia & 1.720 .000 & 1,0 \\
\hline Reino Unido & 1.643 .000 & 1,0 \\
\hline Bangladesh & 1.630 .000 & 1,0 \\
\hline Argentina & 1.581 .000 & 0,9 \\
\hline Tailândia & 1.556 .000 & 0,9 \\
\hline Japão & 1.283 .000 & 0,8 \\
\hline Itália & 1.242 .000 & 0,7 \\
\hline Nova Zelândia & 871.000 & 0,5 \\
\hline Outros & 18.029 .000 & 10,6 \\
\hline Total & $\mathbf{1 7 0 . 2 6 1 . 0 0 0}$ & $\mathbf{1 0 0 , 0 \%}$ \\
\hline Taben & & \\
\hline
\end{tabular}

Tabela 15: Consumo mundial de fertilizantes por país no ano de 2007 (ANDA, 2008). 
A baixa produção no país torna a indústria brasileira de fertilizantes uma das maiores responsáveis pelo déficit do setor químico nacional.

De acordo com a ASSOCIAÇÃO BRASILEIRA DA INDÚSTRIA QUÍMICA - ABIQUIM (2008b) o setor de fertilizantes foi, em 2007, o terceiro maior segmento da indústria química brasileira em termos de faturamento com US\$ 9,0 bilhões no ano, o que correspondeu a apenas $8,7 \%$ do faturamento da indústria química nacional.

O desempenho do setor de fertilizantes está intimamente ligado a variações no desempenho da agricultura. Porém, até os dias atuais, em casos de desempenhos agrícolas elevados a demanda brasileira de fertilizantes químicos só pode ser satisfeita por importações, devido à infra-estrutura deficiente do setor.

As indústrias brasileiras desse setor encontraram nas importações a saída menos onerosa e mais rápida para atender a safras cada vez maiores, ao invés de promoverem investimentos industriais no país. Muitas das instalações industriais do país foram implantadas juntas aos portos, de maneira a operarem com insumos importados.

Conforme pode ser observado na tabela 16, a seguir, as importações brasileiras são intensas nos setores de produção de fertilizantes nitrogenados e potássicos.

No ano de 2007, as importações brasileiras de fertilizantes nitrogenados foram responsáveis por aproximadamente $75 \%$ do consumo aparente desse setor, em termos de nitrogênio (N) (ANDA, 2008).

Segundo Francisco Gros, presidente da FOSFERTIL S. A., no FÓRUM BRASILEIRO DE FERTILIZANTES (2006), os investimentos brasileiros no setor de fertilizantes nitrogenados se tornam complicados devido aos fatores: altíssimo custo inicial; prazo de retorno muito longo; carga tributária elevada; aumento crescente do preço do gás natural no país; tendência preferencial pela utilização do gás natural como recurso energético; e dificuldade de obtenção de licenças ambientais. 
No que diz respeito ao setor brasileiro de fertilizantes potássicos, este atendeu somente cerca de $9 \%$ da demanda nacional, em termos de toneladas de $\mathrm{K}_{2} \mathrm{O}$, em razão da baixa produção nas poucas minas brasileiras (ANDA, 2008).

Quanto ao setor de produção de fertilizantes fosfatados a situação foi bem melhor, pois, a produção brasileira respondeu, no ano de 2007, por aproximadamente $49 \%$ do consumo desse setor em termos de $\mathrm{P}_{2} \mathrm{O}_{5}$ (ANDA, 2008).

\begin{tabular}{|l|c|c|c|}
\cline { 2 - 4 } \multicolumn{1}{c|}{} & $\begin{array}{c}\text { Produção } \\
\mathbf{( 1 )}\end{array}$ & $\begin{array}{c}\text { Importações } \\
\mathbf{( 2 )}\end{array}$ & $\begin{array}{c}\text { Consumo } \\
\text { aparente } \\
\mathbf{2}(\mathbf{1})+(\mathbf{2})\end{array}$ \\
\hline Toneladas de produto fertilizante & $\begin{array}{c}9.815 .709 \\
\mathbf{( 3 6 \% )}\end{array}$ & $\begin{array}{c}17.529 .854 \\
\mathbf{( 6 4 \% )}\end{array}$ & 27.345 .563 \\
\hline Toneladas de $\mathbf{N}$ & $\begin{array}{c}756.519 \\
(\mathbf{2 4 , 6 \% )}\end{array}$ & $\begin{array}{c}2.321 .910 \\
(\mathbf{7 5 , 4 \% )}\end{array}$ & 3.078 .429 \\
\hline Toneladas de $\mathbf{P}_{\mathbf{2}} \mathrm{O}_{5}$ & $\begin{array}{c}2.107 .467 \\
\mathbf{( 4 8 , 8 \% )}\end{array}$ & $\begin{array}{c}2.208 .419 \\
(\mathbf{5 1 , 2 \% )}\end{array}$ & 4.315 .886 \\
\hline Toneladas de $\mathrm{K}_{\mathbf{2}} \mathrm{O}$ & $\begin{array}{c}389.161 \\
(\mathbf{8}, \mathbf{7} \%)\end{array}$ & $\begin{array}{c}4.067 .813 \\
(\mathbf{9 1 , 3 \% )}\end{array}$ & 4.456 .974 \\
\hline
\end{tabular}

Tabela 16: Balanço brasileiro de fertilizantes em 2007 (ANDA, 2008).

A dependência das importações tem a desvantagem de prejudicar o desempenho da balança comercial do país, além de elevar o preço a ser pago pelos formuladores de fertilizantes e por conseqüência pelos agricultores devido ao crescente custo dos fretes marítimos internacionais.

Segundo o Ministério do Desenvolvimento, Indústria e Comércio Exterior - MDIC (2008a), os principais fornecedores brasileiros de fertilizantes, em 2008, foram: Ucrânia (uréia e nitrato de amônio); Federação da Rússia (uréia, nitrato de amônio, MAP, DAP e sulfato de amônio); Estados Unidos (cloreto de potássio, sulfato de amônio, MAP e DAP); Egito (SSP) e Israel (SSP e TSP).

De acordo com a Associação Nacional para Difusão de Adubos - ANDA (2008), atualmente, no Brasil, são produzidos os seguintes fertilizantes nitrogenados: nitrato de amônio; uréia; fosfato de monoamônio (MAP); fosfato de diamônio (DAP) e sulfato de amônio. 
Observa-se na tabela 17 que uréia, fosfato de monoamônio e nitrato de amônio foram os principais fertilizantes nitrogenados produzidos no país, em 2007, correspondendo respectivamente a $54,4 \%, 14,8 \%$ e $14,5 \%$ da produção total do setor (ANDA, 2008).

Conforme dados da tabela 17 , os fertilizantes fosfatados mais produzidos no país no ano de 2007 foram: superfosfato simples, fosfato de monoamônio e superfosfato triplo; que tiveram suas produções respectivamente iguais a $49,9 \%, 26,5 \%$ e $19 \%$ de toda a produção do setor de fosfatados.

Em relação ao setor de fertilizantes potássicos, há apenas um fertilizante sendo produzido atualmente no país, qual seja, o cloreto de potássio (ANDA, 2008).

\begin{tabular}{|l|c|c|c|}
\hline \multicolumn{1}{|c|}{ Fertilizante } & $\begin{array}{c}\text { Toneladas de } \\
\mathbf{N}\end{array}$ & $\begin{array}{c}\text { Toneladas de } \\
\mathbf{P}_{\mathbf{2}} \mathbf{O}_{\mathbf{5}}\end{array}$ & $\begin{array}{c}\text { Toneladas de } \\
\mathbf{K}_{\mathbf{2}} \mathbf{O}\end{array}$ \\
\hline Uréia & 411.471 & & \\
\hline Fosfato de monoamônio (MAP) & 111.912 & 559.302 & \\
\hline Nitrato de amônio & 109.661 & & \\
\hline Complexos & 69.687 & 68.348 & \\
\hline Sulfato de amônio & 53.470 & & \\
\hline Fosfato de diamônio (DAP) & 318 & 813 & \\
\hline Superfosfato simples (SSP) & & 1.052 .400 & \\
\hline Superfosfato triplo (TSP) & & 401.019 & \\
\hline $\begin{array}{l}\text { Termofosfato magnesiano } \\
\text { fundido (FMP) }\end{array}$ & & 15.925 & \\
\hline $\begin{array}{l}\text { Fosfato natural de aplicação } \\
\text { direta }\end{array}$ & & 9.660 & \\
\hline Cloreto de potássio & $\mathbf{7 5 6 . 5 1 9}$ & $\mathbf{2 . 1 0 7 . 4 6 7}$ & $\mathbf{3 8 9 . 1 6 1}$ \\
\hline Total & & & \\
\hline
\end{tabular}

Tabela 17: Produção nacional de fertilizantes em 2007 (ANDA, 2008).

Tal como mostrado na figura 9, a indústria de fertilizantes nitrogenados se baseia no aproveitamento do ar atmosférico como fonte de nitrogênio e do gás natural ou petróleo como fontes de hidrogênio para produção de amônia, o principal insumo desse setor. 
O setor de fertilizantes nitrogenados no Brasil é constituído atualmente por seis empresas, a saber: FAFEN - FÁBRICA DE FERTILIZANTES NITROGENADOS da PETROBRAS (uréia), FOSFERTIL (uréia, nitrato de amônio e fosfatos de amônio - MAP e DAP), BUNGE FERTILIZANTES (sulfato de amônio), BRASKEM (sulfato de amônio), UNIGEL (sulfato de amônio) e COPEBRÁS (MAP).

No que se refere ao setor de fosfatados, existem duas rotas industriais de fabricação dos fertilizantes fosfatados no Brasil: a via úmida e a via térmica (ou seca). A primeira caracteriza-se pelo ataque do ácido sulfúrico ao concentrado fosfático que, dependendo das condições do processo e da relação estequiométrica, pode produzir diretamente superfosfato simples (SSP), fosfato parcialmente acidulado ou, ainda, produzir ácido fosfórico, que origina o superfosfato triplo (TSP).

Os fosfatos de monoamônio e de diamônio são obtidos pela reação entre o ácido fosfórico e a amônia em proporções adequadas. Na solubilização do fósforo pela rota térmica produz-se, a altas temperaturas, o termofosfato por meio do concentrado fosfático e de fontes naturais ou não de magnésio.

De acordo com a figura 9, o setor brasileiro de fertilizantes fosfatados é composto atualmente por dez empresas. São elas: BUNGE FERTILIZANTES (SSP e TSP), CIBRAFERTIL (SSP), COPEBRAS (SSP, TSP e MAP), FERTILIZANTES MITSUI (termofosfato), FOSFERTIL (SSP, TSP, MAP e DAP), FOSPAR (SSP), GALVANI (SSP), MOSAIC FERTILIZANTES (SSP), ROULLIER (SSP e TSP) e YARA BRASIL (SSP e TSP).

A produção de fertilizante potássico no Brasil, iniciada em 1985, está restrita ao complexo mina/usina Taquari-Vassouras, em Sergipe e esteve a cargo da PETROMISA (Petrobras Mineração S. A.) até outubro de 1991.

Em face à extinção da PETROMISA, por força de medidas governamentais e com o fim do processo de liquidação da mesma, todos os direitos de exploração da empresa extinta passaram para a PETROBRAS (Petróleo Brasileiro S. A.), através de cessão de direitos, tendo a PETROBRAS 
arrendado à COMPANHIA VALE DO RIO DOCE (CVRD) os direitos referentes à concessão de lavra, que inclui o complexo mina/usina de Taquari/Vassouras, por um prazo de 25 anos (DNPM, 2008).

Conforme mostrado na figura 9, segundo a ANDA (2008), a indústria brasileira de fertilizantes potássicos é dominada atualmente pela CVRD por meio da produção de cloreto de potássio $(\mathrm{KCl})$ extraído de jazidas de minerais potássicos. Em Sergipe, no município de Rosário do Catete, encontra-se o complexo industrial mina/usina de Taquari/Vassouras onde a CVRD explora as reservas de silvinita $(\mathrm{KCl}$ e $\mathrm{NaCl})$ e carnalita $\left(\mathrm{KCl}\right.$ e $\left.\mathrm{MgCl}_{2}\right)$. Em 2007, a capacidade instalada da CVRD para o fertilizante foi de 850 mil toneladas de $\mathrm{KCl}$. 


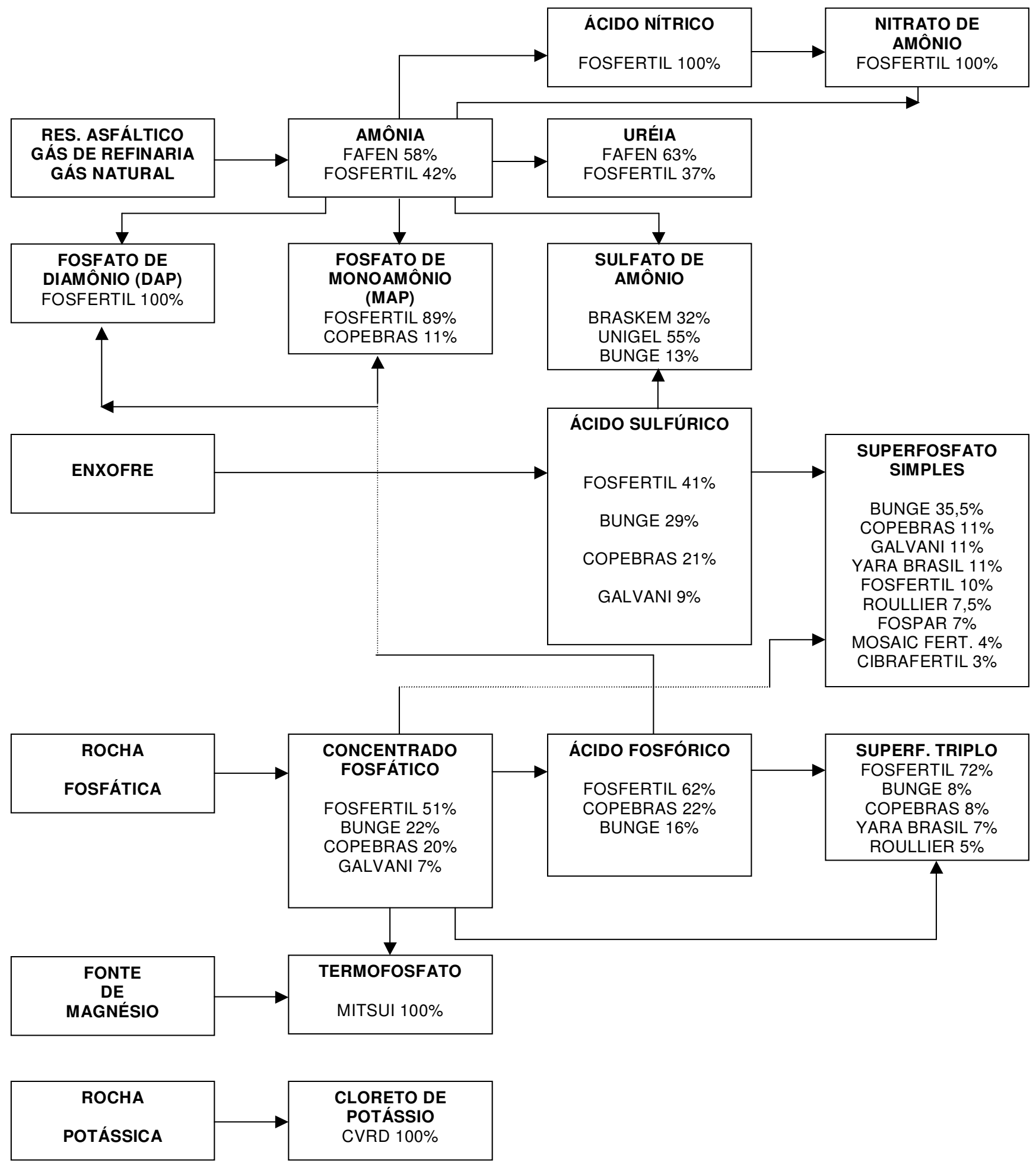

Figura 9: Estrutura do setor de fertilizantes no Brasil em 2007 (ANDA, 2008). 


\subsubsection{Consumo de fertilizantes no país}

Conforme mostra a tabela 18, a soja foi a cultura que mais consumiu fertilizantes no ano de 2007, atingindo $34 \%$ do total de fertilizantes entregue no país. A soja, juntamente com as culturas de milho, cana-de-açúcar e café, atingiram $73 \%$ do total das vendas de fertilizantes no mercado brasileiro de 2007.

\begin{tabular}{|l|c|c|}
\hline \multicolumn{1}{|c|}{ Cultura } & $\begin{array}{c}\text { Consumo em 2007 } \\
\text { (toneladas de fertilizantes) }\end{array}$ & $\begin{array}{c}\text { Participação } \\
(\%)\end{array}$ \\
\hline Soja & 8.344 .000 & 33,9 \\
\hline Milho & 4.761 .000 & 19,3 \\
\hline Cana-de-açúcar & 3.392 .000 & 13,8 \\
\hline Café & 1.564 .000 & 6,4 \\
\hline Algodão & 1.215 .000 & 4,9 \\
\hline Outras & 5.333 .000 & 21,7 \\
\hline Total & $\mathbf{2 4 . 6 0 9 . 0 0 0}$ & $\mathbf{1 0 0 , 0}$ \\
\hline
\end{tabular}

Tabela 18: Consumo de fertilizantes, por cultura, no Brasil no ano de 2007 (ANDA, 2008).

De acordo com os dados da tabela 19, verifica-se que o consumo de fertilizantes no país não está distribuído de forma homogênea. As regiões Sudeste e Centro-Oeste foram, em 2007, os principais pólos agrícolas brasileiros com altas produtividades e muita área disponível para o crescimento. Por conta disso, essas regiões foram as maiores consumidoras de fertilizantes no país.

\begin{tabular}{|l|c|c|}
\hline \multicolumn{1}{|c|}{ Região } & $\begin{array}{c}\text { Consumo em toneladas de produtos } \\
\text { fertilizantes (fertilizantes simples e compostos) }\end{array}$ & $\begin{array}{c}\text { Participação } \\
(\%)\end{array}$ \\
\hline Sudeste & 7.369 .982 & 29,9 \\
\hline Centro-Oeste & 7.315 .391 & 29,7 \\
\hline Sul & 6.781 .735 & 27,6 \\
\hline Nordeste & 2.699 .894 & 11,0 \\
\hline Norte & 441.991 & 1,8 \\
\hline Total Brasil & $\mathbf{2 4 . 6 0 8 . 9 9 3}$ & $\mathbf{1 0 0 , 0}$ \\
\hline
\end{tabular}

Tabela 19: Consumo de fertilizantes por região brasileira em 2007 (ANDA, 2008). 
Em 2007, segundo a ANDA (2008), o estado que mais consumiu fertilizantes no país foi Mato Grosso com um consumo de 4.020.419 toneladas de fertilizantes simples e compostos, seguido pelos estados de São Paulo, Paraná, Minas Gerais, Rio Grande do Sul e de Goiás que tiveram um consumo de $3.848 .884,3.418 .221,3.125 .242,2.701 .277$ e 2.183.066 toneladas de produtos fertilizantes, respectivamente. Nesse mesmo ano, esses seis estados somados representaram $78 \%$ do total do adubo consumido no país. 


\subsection{Indústria brasileira de fertilizantes nitrogenados}

\subsubsection{Principais insumos materiais}

\subsubsection{Recursos naturais}

Os recursos naturais empregados pela indústria de fertilizantes nitrogenados são: ar atmosférico como fonte de nitrogênio, gás natural e petróleo como fontes de hidrogênio para produção de amônia e enxofre para a obtenção de ácido sulfúrico.

Segue uma breve descrição desses recursos utilizados pelas indústrias do setor de fertilizantes nitrogenados:

a) gás natural

De acordo com a AGÊNCIA NACIONAL DO PETRÓLEO, GÁS NATURAL E BIOCOMBUSTÍVEIS - ANP (2008a), em 2007, o Brasil respondeu por $0,2 \%$ das reservas provadas mundiais de gás natural. No que se refere às reservas provadas brasileiras de gás natural, $80,1 \%$ destas estão localizadas em mar. Do total de reservas provadas terrestres, $79 \%$ estão localizadas no estado do Amazonas. Quanto às reservas provadas marítimas, o estado do Rio de Janeiro respondeu, em 2007, por $54,5 \%$ do total nacional. Os estados do Amazonas e Rio de Janeiro contribuíram juntos por $59,4 \%$ do total das reservas provadas de gás natural do país.

Dados coletados junto à ANP (2008a) revelaram que o Brasil respondeu em 2007 por $0,43 \%$ da produção mundial de gás natural, sendo o trigésimo quarto maior produtor. A produção nacional de gás natural em 2007 foi de 18,15 bilhões de $\mathrm{m}^{3}$, o que significou um aumento de $2,5 \%$ em relação ao ano de 2006. Os maiores estados produtores, em 2007, foram: Rio de Janeiro; 
Amazonas e Bahia. Esses três estados juntos responderam por $78,3 \%$ da produção brasileira.

Em 2007, 65,4\% de toda a produção nacional de gás natural foram provenientes de reservas marítimas. No que diz respeito à natureza do gás produzido no país em 2007, constatou-se que $74,4 \%$ foram de origem associada ao petróleo (ANP, 2008a).

No que se referem às importações, estas totalizaram, no ano de 2007, 10,33 bilhões de $\mathrm{m}^{3}$ respondendo por $36,3 \%$ da oferta do mercado interno (ANP, 2008a). Em relação às origens das importações, a Bolívia e a Argentina foram, em 2007, os dois países fornecedores de gás natural para o Brasil. A Bolívia destacou-se como o principal exportador para o Brasil, sendo responsável por $98,4 \%$ da quantidade total importada (MDIC, 2008b). De acordo com MDIC (2008b), verificou-se, em 2007, que as importações brasileiras de gás natural tiveram o estado de Mato Grosso do Sul como seu principal destino.

Segundo o DEPARTAMENTO NACIONAL DE PRODUÇÃO MINERAL DNPM (2008) o consumo de gás natural foi fortemente concentrado na Região Sudeste, sendo este da ordem de $70 \%$ do total.

No que diz respeito ao consumo final energético, de gás natural no país, dados obtidos junto ao MINISTÉRIO DE MINAS E ENERGIA - MME (2008) revelaram que o principal consumidor foi o setor industrial $(56,1 \%$ do total); seguido pela geração e co-geração de energia (24,5\%); pelo setor automotivo (15,6\%); pelo setor comercial/público (2,3\%); e por último, o residencial $(1,5 \%)$.

Conforme o MME (2008), o gás natural respondeu por $9,3 \%$ da matriz energética brasileira em 2007.

O gás natural é um dos recursos naturais utilizados na indústria de fertilizantes nitrogenados como fonte de hidrogênio para a fabricação de amônia.

O uso de gás natural no setor brasileiro de fertilizantes nitrogenados se dá através das unidades industriais da Petrobras/FAFEN, localizadas em 
Camaçari (BA) e Laranjeiras (SE), como recurso material e também como energético.

O gás natural é proveniente dos campos de petróleo situados nos estados da Bahia e Sergipe (SAC PETROBRAS/FAFEN, 2005). No estado da Bahia, o gás encontra-se essencialmente não associado ao petróleo (aproximadamente $82 \%$ da produção do estado em 2007). No estado de Sergipe, em 2007, aproximadamente $53 \%$ do gás produzido encontravam-se associado ao petróleo, sendo que $83 \%$ da produção foram oriundos de reservas marítimas (ANP, 2008a).

De acordo com a PETROBRAS/FAFEN (SAC PETROBRAS/FAFEN, 2005) a distribuição do gás natural é de responsabilidade da Bahia Gás S. A. (BAHIAGÁS) e Sergipe Gás S. A. (SERGÁS) e é realizada através de gasodutos que conectam as Unidades de Processamento de Gás Natural UPGNs até as unidades industriais de Camaçari (BA) e Laranjeiras (SE). Um gasoduto de 14 polegadas de diâmetro e $29 \mathrm{~km}$ de extensão liga a UPGN em Atalaia (Aracajú, SE) até Laranjeiras (SE) onde está localizada a unidade da FAFEN. No estado da Bahia, os gasodutos unem as UPGNs de Catu, em Pojuca (BA) e de Candeias, em Cadeias (BA) até as unidades da FAFEN em Camaçari (BA);

Segue, na tabela 20, a composição típica do gás natural empregado pela PETROBRAS/FAFEN.

\begin{tabular}{|l|c|}
\hline \multicolumn{1}{|c|}{ Constituinte } & \% volumétrica \\
\hline Metano $\left(\mathrm{CH}_{4}\right)$ & 91 \\
\hline Etano $\left(\mathrm{C}_{2} \mathrm{H}_{6}\right)$ & 6,5 \\
\hline Propano $\left(\mathrm{C}_{3} \mathrm{H}_{8}\right)$ & 0,5 \\
\hline Dióxido de carbono $\left(\mathrm{CO}_{2}\right)$ & 0,5 \\
\hline Nitrogênio $\left(\mathrm{N}_{2}\right)$ & 1,5 \\
\hline
\end{tabular}

Tabela 20: Composição aproximada do gás natural empregado pela PETROBRAS / FAFEN (SAC PETROBRAS/FAFEN, 2005). 
b) petróleo

Dados obtidos junto à ANP (2008a) mostraram que em 2007 o Brasil foi o décimo quinto país com maior reserva provada de petróleo no mundo, sendo responsável por $1 \%$ das reservas provadas mundiais.

Segundo a ANP (2008a), as reservas provadas petrolíferas localizadas em terra no Brasil se situam nos estados do Amazonas, Ceará, Rio Grande do Norte, Alagoas, Sergipe, Bahia e Espírito Santo. No mar, as reservas provadas nacionais estão localizadas nos estados de Santa Catarina, Paraná, São Paulo, Rio de Janeiro, Espírito Santo, Bahia, Sergipe, Alagoas, Rio Grande do Norte e Ceará.

Verificou-se em 2007 que 92,9\% do total de reservas provadas brasileiras estão localizadas em mar. O estado do Rio de Janeiro respondeu em 2007 por $87 \%$ das reservas provadas marítimas e por $80,8 \%$ do total de reservas provadas brasileiras. Quanto às reservas provadas terrestres, os estados do Rio Grande do Norte, do Sergipe e da Bahia foram responsáveis em 2007 por $80,3 \%$ do total (ANP, 2008a).

No que diz respeito à produção mundial de petróleo em 2007, o Brasil foi responsável por 2,25\% do total, se tornando o décimo sexto maior produtor. Em 2007 a produção brasileira foi 638 milhões de barris (aumento de 1,5\% em relação a 2006), sendo que $89 \%$ do petróleo extraído no país proveniente de reservas marítimas (ANP, 2008a). O Rio de Janeiro foi o principal estado produtor de petróleo em 2007, sendo responsável por aproximadamente $82 \%$ de toda a produção nacional.

Em relação às importações de petróleo bruto, o Brasil importou em 2007 cerca de 160 milhões de barris o que correspondeu a $20 \%$ da oferta do mercado nacional. Do total de petróleo bruto importado no ano de 2007, 90,3\% foram provenientes de países da África e do Oriente Médio. As exportações brasileiras de petróleo bruto totalizaram, em 2007, cerca de 154 milhões de 
barris representando um aumento de 14,5\% em relação ao ano de 2006 (ANP, 2008a).

De acordo com o MME (2008), o petróleo respondeu por $37,4 \%$ da matriz energética brasileira em 2007.

O petróleo é o recurso natural empregado no setor brasileiro de fertilizantes nitrogenados para gerar matérias-primas como a nafta, o gás de refinaria e o resíduo asfáltico.

A FOSFERTIL S. A. emprega dois derivados do petróleo como fonte de hidrogênio necessário para a produção de amônia: o resíduo asfáltico, na unidade industrial localizada no município de Araucária (PR) e o gás combustível de refinaria, utilizado na unidade industrial de Cubatão (SP). A nafta é utilizada pelas empresas UNIGEL S. A. e BRASKEM S. A. na obtenção de sulfato de amônio obtido como subproduto das fabricações de acrilonitrila, metacrilato de metila (MMA) e caprolactama; e

c) enxofre

Conforme a ANDA (2008), a produção mundial de enxofre em 2006 foi aproximadamente 70,2 milhões de toneladas, sendo $68,2 \%$ da quantidade produzida (47,8 milhões de toneladas) correspondente à obtenção de enxofre elementar.

Os principais países produtores de enxofre elementar em 2006 foram os Estados Unidos (17,6\%), o Canadá (16,6\%), a Rússia (13,3\%) e a Arábia Saudita $(6,2 \%)$ que juntos responderam por $53,7 \%$ da produção mundial (ANDA, 2008).

De acordo com o DNPM (2008), os recursos mundiais de enxofre conhecidos correspondem a pouco mais que 4 bilhões de toneladas e estão contidos em sulfetos metálicos e associados a depósitos de origem vulcânica, petróleo e gás natural. As maiores reservas mundiais estão presentes no 
Iraque, Canadá, Espanha, Polônia, China, Estados Unidos, Arábia Saudita e México.

O Brasil, em 2007, compreendeu apenas $1,2 \%$ das reservas de enxofre conhecidas no mundo, ou seja, cerca de 49 milhões de toneladas (DNPM, 2008).

Segundo o DNPM (2008) as reservas brasileiras de enxofre ocorrem em depósitos da bacia sedimentar de Sergipe, município de Siriri, localidade de Castanhal. Quantidades representativas estão contidas na pirita associada ao carvão da Bacia do Paraná. As reservas oficiais de enxofre no Brasil compreendem: sulfetos de chumbo e de Zinco, que ocorrem em depósitos no Estado de Minas Gerais; a reserva de enxofre associado ao cobre em Jaguararí, na Bahia; e a reserva de enxofre contido no folhelho pirobetuminoso da Formação Iratí.

No que se refere à produção brasileira (480 mil toneladas), esta respondeu por apenas $0,7 \%$ da produção mundial em 2007. As importações brasileiras de enxofre, no referido ano, corresponderam a $82 \%$ do consumo aparente, o qual foi cerca de 2,7 milhões de toneladas (DNPM, 2008).

Conforme o MDIC (2008b), em relação aos países que exportaram para o Brasil em 2007, o Canadá apareceu como o principal fornecedor respondendo por $36 \%$ do total importado.

Quanto às exportações feitas no ano de 2007, a quantidade exportada ficou restrita a 473 toneladas. As exportações de compostos químicos que contém enxofre tiveram a Argentina como principal destino (DNPM, 2008).

$O$ enxofre tem uma variedade muito grande em sua utilização. A principal utilização está em sua transformação a ácido sulfúrico, um dos principais insumos das indústrias de fertilizantes fosfatados e nitrogenados (ABIQUIM, 2008a).

No Brasil, $60,9 \%$ do enxofre é consumido pelas indústrias de papel e celulose, $11,9 \%$ têm aplicação na metalurgia de não ferrosos, $4,1 \%$ é 
assimilado pela indústria de fertilizantes, 7,9\% é usado na indústria de refino do açúcar e 15,2\% se destinam à indústria química (DNPM, 2008).

\subsubsection{Produtos intermediários}

Os produtos intermediários empregados pela indústria brasileira de fertilizantes nitrogenados são: amônia; ácido nítrico para a produção de nitrato de amônio; dióxido de carbono (subproduto da fabricação da amônia) para a produção de uréia; ácido sulfúrico para a obtenção de sulfato de amônio e do ácido fosfórico; e ácido fosfórico para a fabricação dos fosfatos de amônio.

A seguir encontra-se uma breve descrição sobre a utilização desses produtos no setor:

a) amônia

É o principal insumo da indústria de fertilizantes nitrogenados, pois, a partir desse produto obtêm-se todos os fertilizantes desse setor industrial.

Dados coletados junto à INTERNATIONAL FERTILIZER INDUSTRY ASSOCIATION - IFA (2009b) revelaram que 97\% dos fertilizantes nitrogenados produzidos no mundo são obtidos através da amônia pelo processo HaberBosch.

De acordo com KRAMER (2004), a amônia é produzida em cerca de 80 países e $85 \%$ de sua produção mundial são destinados à produção de fertilizantes nitrogenados, sendo que tal percentual já inclui sua aplicação direta como fertilizante.

Segundo a ANDA (2008), a produção mundial de amônia em 2006, em termos do nutriente nitrogênio, foi aproximadamente 121,6 milhões de toneladas e os principais países produtores foram: China (31,7\%); Rússia $(8,8 \%)$; Índia (8,3\%) e Estados Unidos (6,2\%). Esses quatro países juntos foram responsáveis por 55\% da produção mundial do produto em 2006. 
Conforme a IFA (2009b), em relação à capacidade de produção mundial de amônia por matéria-prima, tivemos a seguinte distribuição para o ano de 2007: $67 \%$ para o gás natural; $27 \%$ para o carvão (dos quais $97 \%$ são devidos às unidades industriais na China); 3\% para o óleo combustível; $2 \%$ para a nafta (sendo 92\% empregados na Índia); e 1\% para outros derivados de petróleo.

No Brasil, a produção de amônia em 2007 foi de aproximadamente 590 mil toneladas em termos de nutriente $(\mathrm{N})$ enquanto que as importações totalizaram cerca de 221 mil toneladas em termos de nitrogênio $(N)$ no mesmo ano. Assim sendo, o consumo aparente (soma da produção com importações) desse produto no país teve a seguinte distribuição no ano de 2007: a produção nacional respondeu por $72,7 \%$ e as importações foram responsáveis pelo restante $(27,3 \%)$ do consumo (ANDA, 2008).

Os dois processos de produção de amônia empregados atualmente no Brasil são:

I - reforma catalítica de hidrocarbonetos leves com vapor de água: utilizada nas unidades industriais da PETROBRAS/FAFEN, localizadas em Camaçari (BA) e Laranjeiras (SE), as quais empregam gás natural, e na unidade da FOSFERTIL localizada em Cubatão (SP), que utiliza gás de refinaria como matéria-prima para produção de amônia. Esse processo, segundo a ANDA (2008) respondeu em 2007 por $71 \%$ de toda a capacidade instalada desse produto; e

II - oxidação parcial de hidrocarbonetos pesados: utilizada apenas pela unidade da FOSFERTIL em Araucária (PR) que emprega resíduo asfáltico como fonte de hidrogênio para a obtenção da amônia.

Conforme os dados apresentados na tabela 21 , a seguir, a capacidade instalada de amônia no país no ano de 2007 obedeceu à seguinte distribuição: $58 \%$ correspondendo às instalações da PETROBRAS/FAFEN (58\% utilizando 
gás natural) e $42 \%$ correspondendo às unidades da FOSFERTIL (13\% gás de refinaria e 29\% empregando resíduo asfáltico) (ANDA, 2008).

\begin{tabular}{|c|c|c|c|c|}
\hline Empresa & Localização* $^{*}$ & $\begin{array}{c}\text { Principais } \\
\text { matérias-primas }\end{array}$ & $\begin{array}{c}\text { Concentração (\%) de } \\
\text { nitrogênio (N) }\end{array}$ & $\begin{array}{c}\text { Capacidade } \\
\text { instalada } \\
\text { (t / ano) }\end{array}$ \\
\hline $\begin{array}{c}\text { Petrobras } \\
\text { (Fafen) }\end{array}$ & Camaçari (BA) & Gás natural & 82,2 & 462.000 \\
\hline $\begin{array}{c}\text { Petrobras } \\
\text { (Fafen) }\end{array}$ & Laranjeiras (SE) & Gás natural & 82,2 & 412.500 \\
\hline Fosfertil & Araucária (PR) & Resíduo asfáltico & 82 & 438.000 \\
\hline Fosfertil & Cubatão (SP) & Gás de refinaria & 82 & 191.000 \\
\hline Total & & & $\mathbf{1 . 5 0 3 . 5 0 0}$ \\
\hline
\end{tabular}

Tabela 21: Produtores de amônia do setor de fertilizantes no Brasil *(ANDA, 2008); **(ABIQUIM, 2008a).

Segundo a ABIQUIM (2008c), 63,5\% das vendas nacionais de amônia tiveram como destino a produção de fertilizantes nitrogenados no ano de 2007.

b) ácido nítrico

A utilização de ácido nítrico na indústria brasileira de fertilizantes nitrogenados fica restrita à produção de nitrato de amônio pela FOSFERTIL S. A. na unidade industrial localizada em Cubatão (SP).

Dados apresentados em QUÍMICA INDUSTRIAL (2004) revelaram que o ácido nítrico é produzido comercialmente pela FOSFERTIL S. A. pelo processo de oxidação da amônia anidra em três etapas básicas (processo Ostwald): oxidação da amônia pelo oxigênio do ar em presença de um catalisador de platina e ródio e em altas temperaturas, produzindo monóxido de nitrogênio (NO); oxidação do $\mathrm{NO}$ à dióxido de nitrogênio $\left(\mathrm{NO}_{2}\right)$ pelo oxigênio em excesso presente nos gases; e absorção do $\mathrm{NO}_{2}$ em água, para produzir ácido nítrico $\left(\mathrm{HNO}_{3}\right)$.

De acordo com ABIQUIM (2008c), 100\% das vendas internas de ácido nítrico em 2007 foram destinadas a processos químicos. 
c) ácido sulfúrico

O emprego de ácido sulfúrico pelas indústrias brasileiras de fertilizantes nitrogenados está relacionado às produções de sulfato de amônio e ácido fosfórico.

A produção de ácido sulfúrico pode ser feita através de enxofre elementar, a partir de sulfetos metálicos ou pelo aproveitamento de gases residuais dos processos metalúrgicos que contenham óxidos de enxofre em sua composição. No Brasil, a produção de ácido sulfúrico para a indústria de fertilizantes é feita majoritariamente a partir de enxofre elementar (ABIQUIM, 2008a).

Segundo BRUNO et al. (1985) e CEKINSKI et al. (1990) apud SILVA; KULAY (2003), o processo de produção de ácido sulfúrico a partir de enxofre elementar se inicia com a fusão de este insumo seguida pela filtração do enxofre líquido. O enxofre fundido é queimado em um forno gerando dióxido de enxofre $\left(\mathrm{SO}_{2}\right)$. Na presença do catalisador pentóxido de vanádio $\left(\mathrm{V}_{2} \mathrm{O}_{5}\right)$, o dióxido de enxofre é oxidado a trióxido de enxofre $\left(\mathrm{SO}_{3}\right)$. Finalmente, o trióxido de enxofre é encaminhado a uma torre de absorção onde é absorvido com ácido sulfúrico concentrado recirculado, o qual é mantido na concentração desejada através da adição de água.

A produção mundial de ácido sulfúrico em 2006 foi aproximadamente 191,2 milhões de toneladas. Nesse mesmo ano, a China (25,4\%), os Estados Unidos (15,6\%), o Marrocos (5,9\%), a Rússia (4,9\%) e a Índia (4\%) foram os maiores países produtores, respondendo por $55,8 \%$ da produção mundial de ácido sulfúrico (ANDA, 2008).

Dados coletados junto à ANDA (2008) revelaram que a capacidade de produção de ácido sulfúrico pelas empresas do setor de fertilizantes foi dominada, no ano de 2007, pela FOSFERTIL com $41 \%$ do total instalado. As outras empresas produtoras foram: a BUNGE FERTILIZANTES com 29\%, a 
COPEBRAS com $21 \%$ e a GALVANI respondendo por $9 \%$ de toda a capacidade de produção nacional em 2007.

A produção brasileira de ácido sulfúrico pelas indústrias do setor de fertilizantes no ano de 2007 foi cerca de 5,4 milhões de toneladas do produto, o que correspondeu a $94,4 \%$ do consumo aparente. No que dizem respeito às importações do produto, essas totalizaram aproximadamente 319 mil toneladas no referido ano (ANDA, 2008).

Segundo a ABIQUIM (2008c), as vendas internas de ácido sulfúrico em 2007 tiveram os seguintes destinos: 74,7\% na fabricação de fertilizantes nitrogenados e de fosfatados; $11,1 \%$ para aplicação em processos químicos; $3,4 \%$ no tratamento de metais e metalurgia; e 2,7\% destinadas às indústrias produtoras de papel e celulose.

d) ácido fosfórico

A produção de ácido fosfórico na indústria brasileira de fertilizantes é feita comumente a partir de ácido sulfúrico e concentrado fosfático, pelo processo denominado via úmida. Os produtores de ácido fosfórico do setor de fertilizantes nitrogenados (COPEBRAS E FOSFERTIL) empregam o ácido fosfórico para a obtenção dos fosfatos de amônio (ANDA, 2008).

A capacidade de produção de ácido fosfórico pelas empresas do setor de fertilizantes foi dominada, no ano de 2007 , pela FOSFERTIL com $62 \%$ do total instalado. Também mereceram destaque, a COPEBRAS com $22 \%$ e a BUNGE FERTILIZANTES, que respondeu por $16 \%$ e de toda a capacidade de produção nacional em 2007 (ANDA, 2008).

De acordo com a ANDA (2008) a produção brasileira de ácido fosfórico foi aproximadamente 1,9 milhões de toneladas do produto, sendo responsável por $97,5 \%$ do consumo aparente em 2007. As importações do produto para o Brasil totalizaram pouco mais que 48 mil toneladas no mesmo ano. 
Segundo a ABIQUIM (2008c), 91,4\% das vendas internas de ácido fosfórico foram absorvidas pelas indústrias brasileiras de fertilizantes nitrogenados e fosfatados no ano de 2007.

e) dióxido de carbono

É gerado na produção de amônia e aproveitado pelos fabricantes do setor de fertilizantes nitrogenados (PETROBRAS/FAFEN E FOSFERTIL) apenas para a fabricação de uréia.

Durante a produção de amônia, o dióxido de carbono produzido deve ser removido da mistura de gases para não prejudicar o catalisador da etapa de síntese da amônia.

O dióxido de carbono é removido a baixas temperaturas em um processo de absorção do gás por solventes: metanol, no caso da FOSFERTIL (NEDOCHETKO, 2005) e solução de carbonato de potássio, no processo da PETROBRAS/FAFEN (SAC PETROBRAS/FAFEN, 2005).

O gás extraído como subproduto da unidade de amônia é, posteriormente, empregado na produção de uréia.

\subsubsection{Insumos energéticos}

As indústrias brasileiras do setor de fertilizantes nitrogenados consomem tanto energia térmica como eletricidade em suas unidades de produção.

Em particular, ambas as unidades da PETROBRAS/FAFEN (Camaçari, BA e Laranjeiras, SE) empregam gás natural como matéria-prima e como combustível na seguinte proporção: $65 \%$ de todo o gás natural é empregado como matéria-prima para a obtenção de amônia e 35\% como combustível para gerar, em uma usina termoelétrica própria, eletricidade e vapor (SAC PETROBRAS/FAFEN, 2005). 


\subsubsection{Fertilizantes simples}

De acordo com a ANDA (2008), atualmente, no Brasil, são produzidos os seguintes fertilizantes simples nitrogenados: nitrato de amônio $\left(\mathrm{NH}_{4} \mathrm{NO}_{3}\right)$; uréia [CO $\left.\left(\mathrm{NH}_{2}\right)_{2}\right]$; sulfato de amônio $\left[\left(\mathrm{NH}_{4}\right)_{2} \mathrm{SO}_{4}\right]$; fosfato de monoamônio ou MAP $\left(\mathrm{NH}_{4} \mathrm{H}_{2} \mathrm{PO}_{4}\right)$ e fosfato de diamônio ou DAP $\left[\left(\mathrm{NH}_{4}\right)_{2} \mathrm{HPO}_{4}\right]$.

\subsubsection{Uréia}

De acordo com MALAVOLTA; PIMENTEL-GOMES; ALCARDE (2002), a uréia $\left[\mathrm{CO}\left(\mathrm{NH}_{2}\right)_{2}\right]$ é um fertilizante nitrogenado simples que contém $46 \%$ do nutriente nitrogênio $(\mathrm{N})$ solúvel em água e que absorve com facilidade a umidade existente no ar. No solo, o nitrogênio contido na uréia transforma-se em amônia gasosa $\left(\mathrm{NH}_{3}\right)$ e esta em nitrato $\left(\mathrm{NO}_{3}{ }^{-}\right)$.

Dados coletados junto à Associação Nacional para Difusão de Adubos ANDA (2008), revelaram que a uréia foi o fertilizante nitrogenado mais produzido no país durante o ano de 2007. Segundo a mesma fonte sua produção no referido ano, em termos de nutriente, foi de 411.471 toneladas, o que correspondeu a $54,4 \%$ de toda a produção nacional de fertilizantes nitrogenados.

No que se referem às importações desse fertilizante, essas totalizaram aproximadamente 1,1 milhões de toneladas de nutriente $(\mathrm{N})$ e corresponderam a $44,4 \%$ da quantidade total importada de fertilizantes nitrogenados para 0 Brasil no ano de 2007. Verificou-se ainda que no referido ano as importações foram responsáveis por $73 \%$ do consumo aparente de uréia no país (ANDA, 2008).

A produção brasileira de uréia está restrita a dois fabricantes, quais sejam: a PETROBRAS/FAFEN que responde por $63 \%$ de toda capacidade de produção brasileira de uréia e a FOSFERTIL com apenas uma unidade de produção, que responde por $37 \%$. Tal perfil aparece expressado pelos dados 
que constam da tabela 22. A produção de uréia ocorre a partir da reação de amônia e dióxido de carbono. O dióxido de carbono é suprido pela própria unidade de amônia, da qual é extraído como subproduto.

No que diz respeito às matérias-primas empregadas pelas indústrias produtoras de uréia no país constata-se, conforme a tabela 22 , que todos os produtores utilizam amônia e dióxido de carbono para sua obtenção. Quanto à obtenção destas, verifica-se, na tabela 22 , que $63 \%$ de toda capacidade de produção brasileira de uréia provêm da amônia obtida pelo processo de reforma catalítica de gás natural com vapor de água.

\begin{tabular}{|c|c|c|c|c|c|}
\hline Empresa* & Localização* & $\begin{array}{c}\text { Principais matérias- } \\
\text { primas }^{*}\end{array}$ & $\begin{array}{l}\text { Processo / } \\
\text { acabamento }^{\star *}\end{array}$ & $\begin{array}{c}\text { Concentração } \\
(\%) \text { de } \\
\text { nitrogênio }(\mathrm{N})^{\star}\end{array}$ & $\begin{array}{c}\text { Capacidade } \\
\text { instalada } \\
\text { (t / ano })^{*}\end{array}$ \\
\hline $\begin{array}{l}\text { Petrobras } \\
\text { (Fafen) }\end{array}$ & $\begin{array}{l}\text { Camaçari } \\
\text { (BA) }\end{array}$ & $\begin{array}{c}\text { Amônia (reforma } \\
\text { catalítica de gás natural } \\
\text { com vapor de água) e } \\
\text { dióxido de carbono }\end{array}$ & $\begin{array}{l}\text { Reciclo total da } \\
\text { solução de } \\
\text { carbamato / } \\
\text { perolação }\end{array}$ & 46 & 495.000 \\
\hline $\begin{array}{l}\text { Petrobras } \\
\text { (Fafen) }\end{array}$ & $\begin{array}{l}\text { Laranjeiras } \\
\qquad(\mathrm{SE})\end{array}$ & $\begin{array}{c}\text { Amônia (reforma } \\
\text { catalítica de gás natural } \\
\text { com vapor de água) e } \\
\text { dióxido de carbono }\end{array}$ & $\begin{array}{l}\text { Reciclo total da } \\
\text { solução de } \\
\text { carbamato / } \\
\text { perolação }\end{array}$ & 46 & 594.000 \\
\hline Fosfertil & $\begin{array}{l}\text { Araucária } \\
\quad(\mathrm{PR})\end{array}$ & $\begin{array}{c}\text { Amônia (oxidação } \\
\text { parcial de resíduo } \\
\text { asfáltico) e dióxido de } \\
\text { carbono }\end{array}$ & $\begin{array}{l}\text { Reciclo total da } \\
\text { solução de } \\
\text { carbamato / } \\
\text { perolação }\end{array}$ & 46 & 630.000 \\
\hline \multicolumn{5}{|l|}{ Total } & 1.719 .000 \\
\hline
\end{tabular}

Tabela 22: Empresas produtoras de uréia no Brasil *(ANDA, 2008); **(QUÍMICA INDUSTRIAL, 2004).

Segundo dados obtidos junto à ABIQUIM (2008c), em 2007 as vendas internas de uréia obedeceram à seguinte distribuição: 85\% foram destinadas para uso fertilizante, $13,8 \%$ tiveram seu emprego como intermediário químico e apenas $1,2 \%$ foram empregadas como alimentação animal. 


\subsubsection{Nitrato de amônio}

$\mathrm{O}$ nitrato de amônio $\left(\mathrm{NH}_{4} \mathrm{NO}_{3}\right)$ é um fertilizante nitrogenado simples que contém aproximadamente $35 \%$ do nutriente nitrogênio $(\mathrm{N})$ solúvel em água, metade na forma nítrica e metade na forma amoniacal (MALAVOLTA; PIMENTEL-GOMES; ALCARDE, 2002).

Dados coletados junto à Associação Nacional para Difusão de Adubos ANDA (2008), revelaram que o nitrato de amônio foi o terceiro fertilizante nitrogenado mais produzido no país durante o ano de 2007. Segundo a mesma fonte sua produção no referido ano, em termos de nutriente, foi de 109.661 toneladas, o que correspondeu a $14,5 \%$ de toda a produção nacional de fertilizantes nitrogenados.

As importações desse fertilizante, em 2007, foram responsáveis por apenas $9,7 \%$ de todas as importações de fertilizantes nitrogenados no país. Em termos de nutriente, a quantidade importada de nitrato de amônio foi de 246.427 toneladas (ANDA, 2008).

Levando-se em conta o consumo aparente desse fertilizante de 356.088 toneladas de nutriente, tivemos a seguinte distribuição para o ano de 2007: $31 \%$ do consumo aparente foram oriundos da produção nacional e o restante, $69 \%$, foram provenientes das importações (ANDA, 2008).

Conforme a tabela 23, de acordo com a ANDA (2008), apenas a FOSFERTIL responde, no país pela fabricação de nitrato de amônio, segundo processamento que ocorre em sua unidade industrial de Cubatão (SP). Consiste, basicamente, na neutralização do ácido nítrico por meio de amônia anidra (FOSFERTIL, 2005).

A própria FOSFERTIL produz, além do fertilizante, os insumos necessários (amônia e ácido nítrico) a sua obtenção, também na unidade industrial de Cubatão (SP). A amônia é produzida por meio da reforma catalítica, com vapor de água, de gás de refinaria, o qual é obtido do petróleo refinado na refinaria Presidente Bernardes da PETROBRAS S. A., vizinha à 
unidade industrial da FOSFERTIL em Cubatão (SP). No que diz respeito ao ácido nítrico, este é produzido a partir da amônia gerada e do oxigênio extraído do ar atmosférico (FOSFERTIL, 2005).

\begin{tabular}{|l|c|}
\hline Empresa & Fosfertil S. A. \\
\hline Localização & Cubatão (SP) \\
\hline Principais insumos materiais & Ácido nítrico e amônia \\
\hline Concentração (\%) de nitrogênio (N) & 34 \\
\hline Capacidade instalada (t / ano) & 406.000 \\
\hline
\end{tabular}

Tabela 23: Principais dados para o nitrato de amônio produzido no Brasil (ANDA, 2008).

De acordo com os dados da ABIQUIM (2008c), em 2007, 66\% das vendas internas de nitrato de amônio foram destinadas para uso fertilizante.

\subsubsection{Sulfato de amônio}

Segundo MALAVOLTA; PIMENTEL-GOMES; ALCARDE (2002), o sulfato de amônio $\left[\left(\mathrm{NH}_{4}\right)_{2} \mathrm{SO}_{4}\right]$ é um fertilizante nitrogenado simples que apresenta $21 \%$ de nitrogênio $(\mathrm{N})$ e também $23 \%$ de enxofre $(\mathrm{S})$ solúveis em água.

Dados coletados junto à ABIQUIM (2008a) revelaram que $75 \%$ da capacidade instalada de produção brasileira de sulfato de amônio é baseada na produção residual de: metacrilato de metila - MMA produzido pela UNIGEL S. A. (37\%); acrilonitrila fabricado pela UNIGEL S. A. (6\%); e caprolactama produzida pela BRASKEM S. A. (32\%). O restante da capacidade instalada nacional (25\%) baseia-se na reação da amônia com o ácido sulfúrico, sendo: $13 \%$ para a BUNGE FERTILIZANTES S. A. e $12 \%$ da capacidade para a UNIGEL S. A. (ANDA, 2008).

A tabela 24 mostra a relação de empresas produtoras de sulfato de amônio existentes no setor brasileiro de fertilizantes. 


\begin{tabular}{|c|c|c|c|c|}
\hline Empresa & Localização* & $\begin{array}{l}\text { Principais matérias- } \\
\text { primas (fornecedor) }\end{array}$ & $\begin{array}{l}\text { Concentração (\%) } \\
\text { de nitrogênio }(\mathrm{N})^{\star}\end{array}$ & $\begin{array}{c}\text { Capacidade } \\
\text { instalada } \\
\text { (t / ano })^{\star}\end{array}$ \\
\hline $\begin{array}{c}\text { Bunge } \\
\text { Fertilizantes }\end{array}$ & Cubatão (SP) & $\begin{array}{l}\text { Amônia (FOSFERTIL) e } \\
\text { ácido sulfúrico (próprio) }\end{array}$ & 20,5 & 40.000 \\
\hline Braskem & Camaçari (BA) & $\begin{array}{l}\text { Amônia (FAFEN) e ácido } \\
\text { sulfúrico (Caraíba Metais) }\end{array}$ & 21,2 & 100.000 \\
\hline Unigel & Candeias (BA) & $\begin{array}{l}\text { Amônia (FAFEN) e ácido } \\
\text { sulfúrico (Caraíba Metais) }\end{array}$ & 21 & 170.000 \\
\hline \multicolumn{4}{|l|}{ Total } & 310.000 \\
\hline
\end{tabular}

Conforme dados da tabela 24, a UNIGEL; a BRASKEM e a BUNGE FERTILIZANTES responderam, em 2007, por 55\%, 32\% e $13 \%$, respectivamente, de toda a capacidade de produção brasileira de sulfato de amônio.

A produção nacional de sulfato de amônio no ano de 2007 foi 53.470 toneladas de nutriente $(\mathrm{N})$, quantidade que correspondeu a aproximadamente $7 \%$ de toda produção brasileira de fertilizantes nitrogenados em termos de nutriente (ANDA, 2008).

De acordo com a ANDA (2008), as importações brasileiras de sulfato de amônio em 2007 totalizaram 387.712 toneladas de nutriente $(\mathrm{N})$ e dessa forma, foram responsáveis por $88 \%$ do consumo aparente do fertilizante no país. Tais importações responderam por $15 \%$ da quantidade total importada de fertilizantes nitrogenados em termos de nutriente $(N)$ no ano de 2007.

Segundo dados coletados junto à ABIQUIM (2008c), 98,8\% das vendas internas de sulfato de amônio no ano de 2007 foram destinadas para uso fertilizante. 


\subsubsection{Fosfatos de amônio}

Os fosfatos de amônio são produtos portadores de dois macronutrientes primários: nitrogênio e fósforo. Devido aos teores de nitrogênio e fósforo contidos nesses fertilizantes, diversas referências consideram os fosfatos de amônio como fertilizantes fosfatados.

Dois sais dessa classe são produzidos em escala econômica no país: o fosfato de monoamônio - MAP $\left(\mathrm{NH}_{4} \mathrm{H}_{2} \mathrm{PO}_{4}\right)$ e o fosfato de diamônio - DAP $\left[\left(\mathrm{NH}_{4}\right)_{2} \mathrm{HPO}_{4}\right]$.

No Brasil, a obtenção de MAP e DAP é feita a partir da reação da amônia anidra com o ácido fosfórico (QUÍMICA INDUSTRIAL, 2004).

Segundo CEKINSKI et al. (1990), as equações que expressam as reações envolvidas são:

$\mathrm{NH}_{3}+\mathrm{H}_{3} \mathrm{PO}_{4} \rightarrow \mathrm{NH}_{4} \mathrm{H}_{2} \mathrm{PO}_{4}(\mathrm{MAP})$

eq. 2

$2 \mathrm{NH}_{3}+\mathrm{H}_{3} \mathrm{PO}_{4} \rightarrow\left(\mathrm{NH}_{4}\right)_{2} \mathrm{HPO}_{4}(\mathrm{DAP})$

eq. 3

A tabela 25 apresenta os produtores de MAP no Brasil, bem como a localização das plantas industriais e a capacidade instalada em 2007.

\begin{tabular}{|c|c|c|c|c|c|}
\hline $\begin{array}{c}\text { Empresa } \\
\text { (especificação } \\
\text { do produto) }\end{array}$ & Localização* & $\begin{array}{l}\text { Principais } \\
\text { matérias- } \\
\text { primas }^{\star \star}\end{array}$ & $\begin{array}{c}\text { Concentração } \\
(\%) \text { de } \\
\text { nitrogênio }(\mathrm{N})^{\star}\end{array}$ & $\begin{array}{l}\text { Concentração } \\
\text { de } \mathrm{P}_{2} \mathrm{O}_{5}(\%)^{*}\end{array}$ & $\begin{array}{c}\text { Capacidade } \\
\text { instalada } \\
\text { (t / ano })^{\star}\end{array}$ \\
\hline $\begin{array}{l}\text { Copebrás } \\
\text { (granulado) }\end{array}$ & Catalão (GO) & $\begin{array}{l}\text { Amônia e } \\
\text { ácido } \\
\text { fosfórico }\end{array}$ & 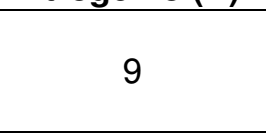 & 48 & 150.000 \\
\hline Fosfertil (pó) & Uberaba (MG) & $\begin{array}{l}\text { Amônia e } \\
\text { ácido } \\
\text { fosfórico }\end{array}$ & 10,5 & 54 & 150.000 \\
\hline $\begin{array}{c}\text { Fosfertil } \\
\text { (granulado) }\end{array}$ & Uberaba (MG) & $\begin{array}{l}\text { Amônia e } \\
\text { ácido } \\
\text { fosfórico }\end{array}$ & 10,5 & 54 & 810.000 \\
\hline $\begin{array}{l}\text { Fosfertil } \\
\text { (granulado) }\end{array}$ & Cubatão (SP) & $\begin{array}{l}\text { Amônia e } \\
\text { ácido } \\
\text { fosfórico }\end{array}$ & 11 & 52,5 & 253.000 \\
\hline \multicolumn{5}{|l|}{ Total } & 1.363 .000 \\
\hline
\end{tabular}

Tabela 25: Relação de produtores de MAP no Brasil ${ }^{*}($ ANDA, 2008); ;*(ABIQUIM, 2008a). 
Conforme pode ser visto na tabela 25 , a capacidade de produção brasileira de MAP é dominada pela FOSFERTIL que responde por $89 \%$ do total, seguida pela Copebrás (11\%).

O MAP foi o segundo fertilizante nitrogenado mais produzido no país em 2007, em termo de nitrogênio. A produção nacional de MAP foi 111.912 toneladas, enquanto que as importações totalizaram 178.230 toneladas de nitrogênio ( $\mathrm{N}$ ) em 2007. As importações de MAP foram responsáveis por $61,4 \%$ do consumo aparente nacional do fertilizante (ANDA, 2008).

Em 2007, 99,9\% das vendas internas de MAP tiveram seu destino para uso fertilizante. No que diz respeito ao DAP, 100\% das vendas internas foram destinadas para uso fertilizante (ABIQUIM, 2008c).

A produção de DAP no país é efetuada apenas pela FOSFERTIL em sua unidade industrial localizada no município de Cubatão (SP). A unidade industrial apresentou em 2007 uma capacidade de produção instalada de 8 mil toneladas do produto fertilizante (ANDA, 2008).

A FOSFERTIL utiliza amônia e ácido fosfórico próprios para a obtenção de DAP. O fertilizante é especificado como granulado e foi comercializado no país em 2007 apresentando os seguintes teores de nitrogênio e fósforo: 18\% de $\mathrm{Ne} 46 \%$ de $\mathrm{P}_{2} \mathrm{O}_{5}$ (ANDA, 2008).

Em 2007 foram produzidas no Brasil 318 toneladas de DAP e aproximadamente 113 mil toneladas foram importadas. Assim sendo, dada a inexpressiva produção nacional, as importações foram responsáveis por 99,7\% do consumo aparente de DAP no país (ANDA, 2008).

A baixa produção de DAP em relação ao MAP se deve, muito provavelmente, ao fato de este último apresentar maiores teores do nutriente fósforo, em termos de $\mathrm{P}_{2} \mathrm{O}_{5}$. 


\section{RESULTADOS}

\subsection{Definição de objetivo e escopo}

\subsubsection{Objetivo}

O objetivo do estudo é o mesmo proposto para o trabalho de doutorado, ou seja, identificar e quantificar os aspectos ambientais associados aos ciclos de vida (sob o enfoque do berço ao portão da fábrica) de três fertilizantes nitrogenados simples no Brasil (uréia, nitrato de amônio e sulfato de amônio), utilizando a técnica da ACV.

\subsubsection{Aplicação pretendida}

Os resultados poderão ser utilizados em estudos de ACV que apresentem na constituição do ciclo de vida os fertilizantes nitrogenados simples (uréia, nitrato de amônio e sulfato de amônio); bem como, os recursos naturais (gás natural, petróleo e ar) e os produtos intermediários (amônia, ácido nítrico, ácido sulfúrico e dióxido de carbono) existentes nas cadeias produtivas desses fertilizantes.

\subsubsection{Razões para condução do estudo}

As razões principais para a realização do estudo são: a necessidade de se disponibilizar dados adequados à realidade nacional e associados aos ciclos de vida dos fertilizantes nitrogenados (uma vez que esses se constituem em um dos elementos comuns ao ciclo de vida de inúmeros produtos); e a necessidade da construção de um banco de dados brasileiro, viabilizando a realização de estudos de ACV no país em termos de tempo e recursos financeiros. 


\subsubsection{Público-alvo}

Usuários da técnica da ACV que utilizem em seus estudos os recursos naturais e produtos intermediários existentes no ciclo de vida dos fertilizantes nitrogenados; além dos próprios fertilizantes nitrogenados simples (uréia, nitrato de amônio e sulfato de amônio) produzidos no Brasil.

\subsubsection{Escopo}

Foram definidos nesta fase, segundo a norma (ISO, 2006a), os itens a seguir.

\subsubsection{Função}

A função definida para os sistemas de produtos dos fertilizantes é a de fornecer o nutriente nitrogênio $(\mathrm{N})$ ao solo.

\subsubsection{Unidade funcional e fluxos de referência}

Adotou-se como unidade funcional para este estudo 1 tonelada do nutriente nitrogênio $(\mathrm{N})$.

Os fluxos de referência, ou seja, as quantidades de cada fertilizante que correspondem à unidade funcional, definidos para o estudo foram: 2,17 toneladas de uréia (para a uréia contendo $46 \%$ de $\mathrm{N}$ ); 2,941 toneladas de nitrato de amônio (para o nitrato de amônio contendo $34 \%$ de N) e 4,717 toneladas de sulfato de amônio (para o sulfato de amônio contendo $21,2 \%$ de N).

Os inventários finais consolidados para cada produto fertilizante serão referidos a essas quantidades mássicas. 
Para este estudo adotou-se, com base em dados coletados junto às empresas brasileiras do setor e à ANDA (2008), que o conteúdo do nutriente nitrogênio de cada fertilizante foi aquele contido nos produtos comercializados no Brasil no ano de 2007.

\subsubsection{Fronteiras iniciais dos sistemas}

Dado o objetivo do trabalho, decidiu-se adotar para a definição dos sistemas de produto de cada fertilizante o enfoque denominado "cradle to gate" (do berço ao portão da fábrica). Essa abordagem considera as etapas dos ciclos de vida dos produtos que são comuns a diversos outros ciclos de vida, quais sejam: extração e beneficiamento de recursos naturais e as etapas de transformação industrial necessárias para a produção do fertilizante.

\subsubsection{Definição dos sistemas de produto}

Serão considerados três sistemas de produto, a saber: uréia, nitrato de amônio e sulfato de amônio. Para garantir uma representatividade adequada aos sistemas e tornar um estudo viável e mais próximo possível do mercado e das tecnologias regionais existentes faz-se necessária a elaboração de um modelo, que apesar de suas limitações permita atingir os objetivos do trabalho.

A elaboração dos modelos representativos dos sistemas de produto de este trabalho levou em conta o número de fabricantes brasileiros, a capacidade instalada (participação no mercado) para o ano de 2007, a localização das unidades de produção, os insumos materiais e energéticos utilizados por cada fabricante; bem como os fornecedores dos produtores brasileiros e as atividades de transporte envolvidas. 


\subsubsection{Sistema de produto da uréia}

O modelo representativo de sistema de produto da uréia produzida no país (figura 10) envolve duas empresas com localidades e insumos distintos para a produção desse fertilizante.

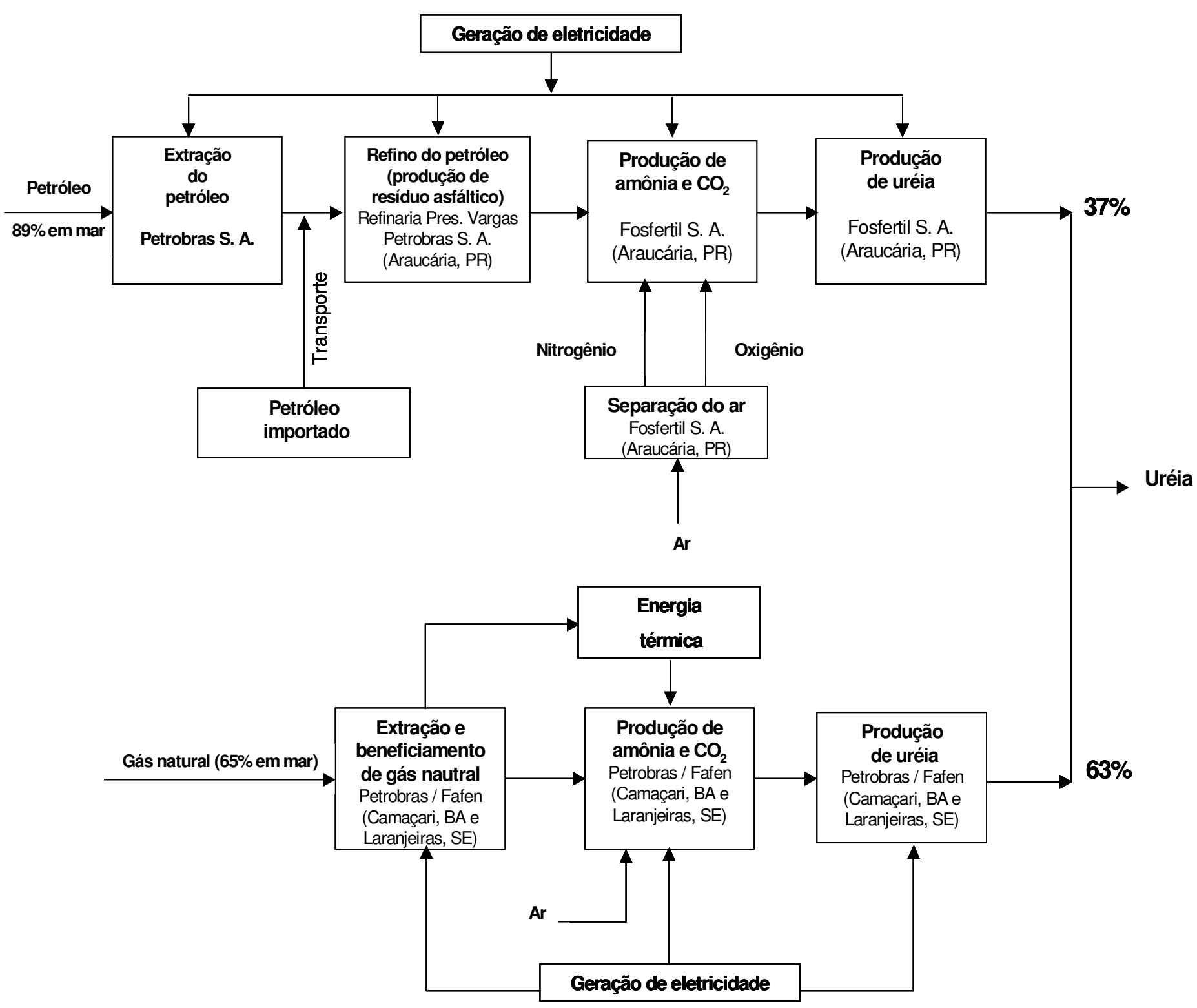

Figura 10: Modelo representativo da uréia produzida no Brasil. 
Os subsistemas que compõem o modelo representativo do sistema de produto da uréia produzida no Brasil são: beneficiamento de gás natural; produção de amônia e $\mathrm{CO}_{2}$ a partir da reforma catalítica de gás natural com vapor de água; produção de uréia a partir da amônia e $\mathrm{CO}_{2}$; geração de energia térmica proveniente da queima de gás natural; extração do petróleo; transporte marítimo do petróleo importado; refino do petróleo - produção de resíduo asfáltico; separação do ar; produção de amônia e $\mathrm{CO}_{2}$ por meio da oxidação parcial de resíduo asfáltico; e geração de eletricidade.

\subsection{Sistema de produto do nitrato de amônio}

Com base nas informações apresentadas no capítulo 4 de este documento, foi possível elaborar o modelo representativo do sistema de produto do nitrato de amônio produzido no Brasil, o qual pode ser observado na figura 11. 


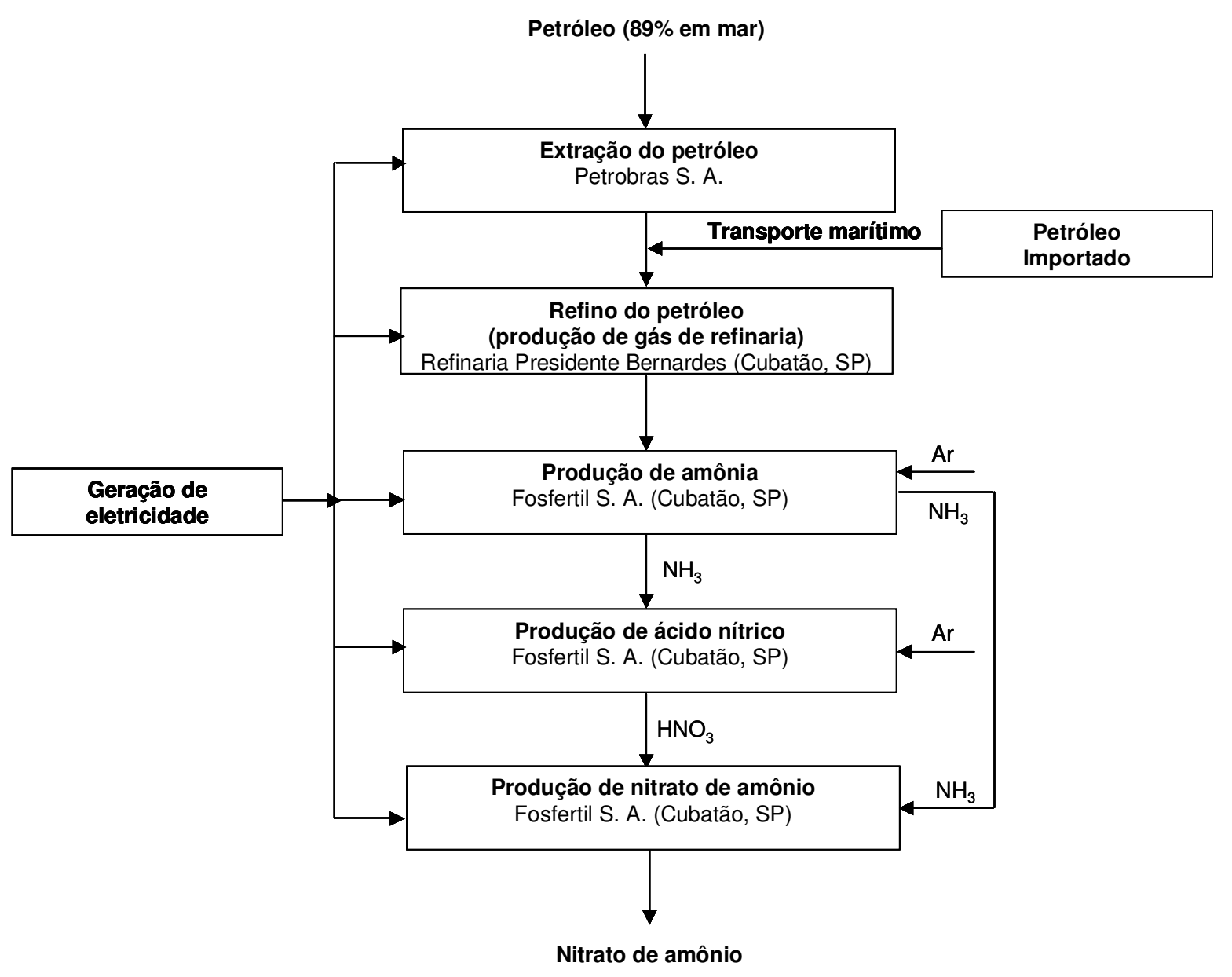

Figura 11: Modelo representativo do nitrato de amônio produzido no país.

Os subsistemas que constituem o modelo representativo do sistema de produto do nitrato de amônio são: extração do petróleo; transporte marítimo do petróleo importado; refino do petróleo - produção de gás de refinaria; produção de amônia a partir da reforma catalítica do gás de refinaria com vapor de água; separação do ar; produção de ácido nítrico a partir da amônia; produção de nitrato de amônio a partir da amônia e ácido nítrico; e geração de eletricidade. 


\subsection{Sistema de produto do sulfato de amônio}

Conforme mencionado no capítulo 4 de este documento e mostrado na figura 12 , a seguir, $75 \%$ de toda a capacidade instalada brasileira de sulfato de amônio é baseada nas produções residuais de metacrilato de metila - MMA, acrilonitrila e caprolactama. O restante $(25 \%)$ baseia-se na reação da amônia com o ácido sulfúrico.

Três empresas compõem o modelo representativo do sulfato de amônio produzido no país: UNIGEL S. A., BRASKEM S. A. e BUNGE FERTILIZANTES S. A.

Segue na figura 12, o modelo representativo do sistema de produto do sulfato de amônio produzido no Brasil. 


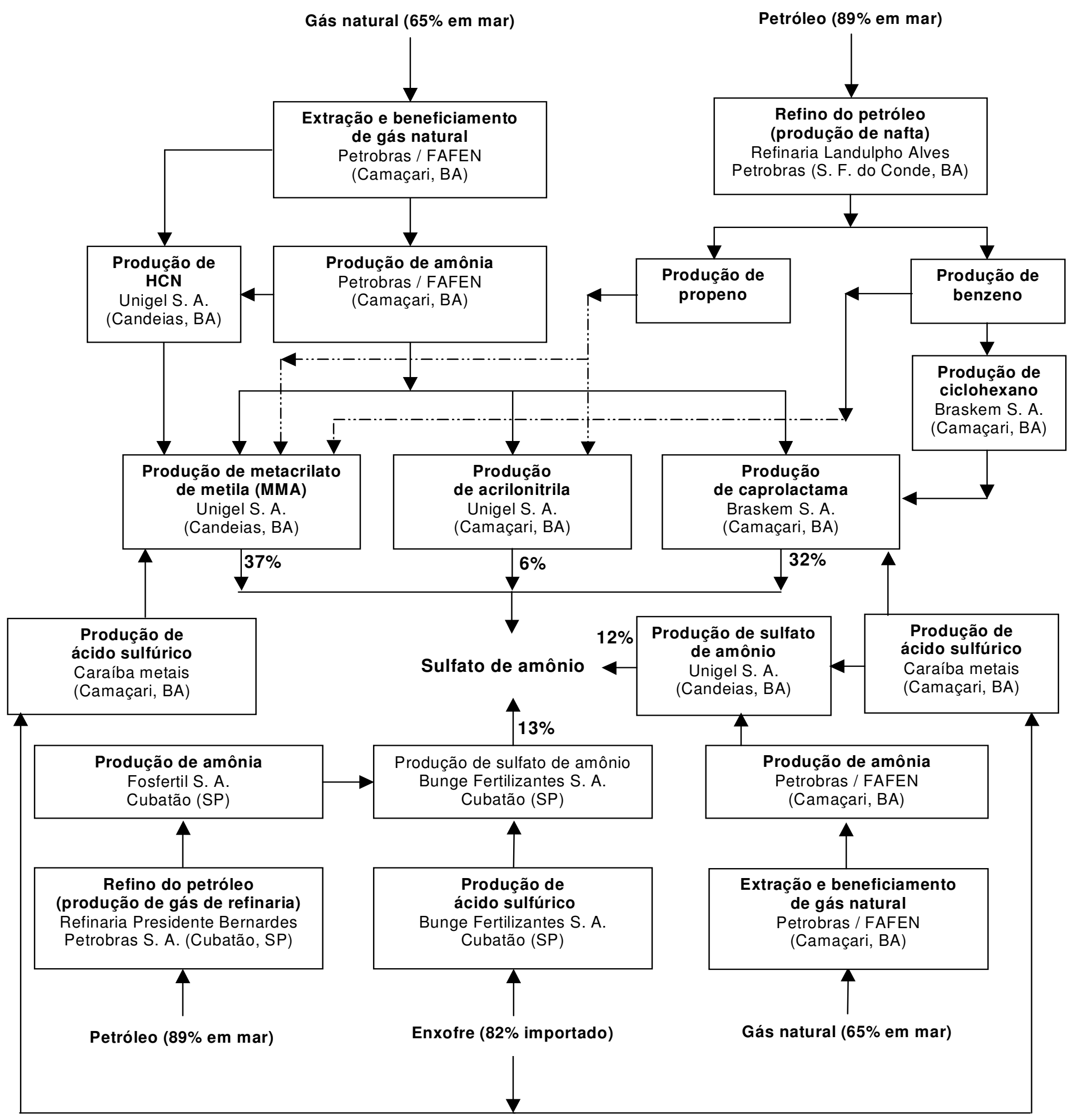

Figura 12: Modelo representativo do sulfato de amônio produzido no país. 
Os subsistemas considerados neste estudo para o sistema de produto do sulfato de amônio são: produção de ácido sulfúrico; extração e beneficiamento de gás natural; geração de energia térmica proveniente da queima de gás natural; produção de amônia a partir do gás de natural; produção de ácido cianídrico - HCN; produção de acrilonitrila; produção de caprolactama; produção de metacrilato de metila - MMA; extração do petróleo (Petrobras S. A.); transporte marítimo de petróleo importado; refino do petróleo - produção de nafta (Petrobras S. A. - São Francisco do Conde, BA); produção de propeno; produção de benzeno; produção de ciclohexano; refino do petróleo - produção de gás de refinaria (Petrobras S. A. - Cubatão, SP); produção de amônia a partir do gás de refinaria; produção de sulfato de amônio via síntese da amônia obtida do gás de refinaria com ácido sulfúrico; e geração de eletricidade.

\subsection{Descrição dos subsistemas}

Para auxiliar a coleta de dados na etapa de análise do inventário apresenta-se, neste item do documento, uma breve descrição dos subsistemas envolvidos nos modelos propostos para este estudo.

a) Extração do petróleo

A operação de extração do petróleo no Brasil é executada pela PETROBRAS (Petróleo Brasileiro S. A.). Segundo a PETROBRAS (2008a), as regiões petrolíferas em terra do país se situam nos estados do Amazonas, Ceará, Rio Grande do Norte, Alagoas, Sergipe, Bahia e Espírito Santo. No mar, a produção é proveniente dos estados do Ceará, Rio Grande do Norte, Alagoas, Sergipe, Bahia, Espírito Santo, Rio de Janeiro e São Paulo. De acordo com a empresa, as plataformas petrolíferas que operam no Brasil são de dois tipos: de perfuração e de produção. 
A exploração do petróleo é a fase que realiza estudos preliminares para a localização de uma jazida, com o intuito de identificar o petróleo nos poros das rochas e decidir a melhor forma de extraí-lo das grandes profundidades na terra e no mar.

De acordo com a PETROBRAS (2008a), o Brasil domina a tecnologia de perfuração submarina em águas profundas (acima de 400 metros) e "ultraprofundas" (acima de 2.000 metros).

As sondas utilizadas na perfuração de poços de petróleo são classificadas de acordo com sua utilização como terrestres ou marítimas.

Se a perfuração ocorrer em terra, conhecida como onshore, 0 equipamento utilizado possui brocas que giram para romper a rocha, trazendo até a superfície o material extraído do subsolo.

O sistema de perfuração marítima, offshore, segue os mesmos moldes da terrestre, contudo, as sondas marítimas diferem entre si por se adequarem às diferentes profundidades em que atuam. Esses equipamentos são instalados em plataformas fixas, móveis (que podem ser posicionadas em locais de diferentes profundidades) ou sobre navios (PETROBRAS, 2008a).

O petróleo que é extraído dos poços, na terra ou no mar, é transportado através de oleodutos ou navios petroleiros até os terminais marítimos, onde ficam estocados. Nesses terminais se encontram instalados diversos tanques que se interligam por meio de tubulações. Em seguida, o petróleo é conduzido por meio de oleodutos dos terminais até as refinarias. A empresa subsidiária TRANSPETRO (Petrobras Transporte S. A.) é a responsável pelo transporte e armazenagem do petróleo e de seus derivados (PETROBRAS, 2008a).

Segundo a PETROBRAS (2008a), a fase de extração do petróleo começa após a avaliação da extensão da jazida. Em cada poço é introduzida uma tubulação de aço na superfície até o fundo, chamada de revestimento. $O$ espaço entre as rochas perfuradas e o revestimento é preenchido com cimento para impedir a comunicação entre as várias zonas porosas que foram atravessadas pelo poço. Uma ferramenta, conhecida por canhão, desce pelo 
interior da tubulação de aço e perfura o revestimento e o cimento criando uma comunicação entre a jazida e o interior do poço. Os fluidos que migram da rocha geradora são extraídos através de uma tubulação de menor diâmetro introduzida no revestimento conhecida como coluna de produção.

Quando o óleo não consegue ser extraído dos poços pelos processos naturais (surgência) e artificiais (elevação artificial, ou seja, bombeamento), é utilizada a recuperação secundária, a qual pode ser efetuada através da injeção de água, de gás natural ou de gás carbônico (PETROBRAS, 2008a).

b) Transporte marítimo do petróleo importado

Para este subsistema é necessário conhecer a origem do petróleo importado pelo Brasil, as distâncias dos países exportadores e as características do meio de transporte.

O petróleo importado é transportado para o Brasil por petroleiros da PETROBRAS, que trabalha com navios de capacidade entre 70.000 e 100.000 toneladas (PETROBRAS, 2004).

De acordo com o Ministério de Desenvolvimento, Indústria e Comércio Exterior - MDIC (2008c) os principais países fornecedores de petróleo para o Brasil, em 2007, foram: Nigéria (42\%); Arábia Saudita (14,5\%); Argélia (13\%); Angola (8\%) e Líbia (8\%). Outros países corresponderam por $14,5 \%$ do total de importações.

Para este estudo, considerou-se uma distância média (tabela 26) obtida pela média ponderada entre as distâncias dos principais portos dos países exportadores de petróleo até o porto da cidade de Santos - SP (PORTWORLD, 2008) e o percentual correspondente às quantidades importadas pelo Brasil dos países exportadores (MDIC, 2008c). A escolha do porto de Santos - SP se deve ao fato de este ser o maior porto brasileiro e latino-americano em termos de movimentações de cargas e de participações na balança comercial do país 
(CODESP, 2008). Calculada a média ponderada, obteve-se uma distância média de $8.457 \mathrm{~km}$ conforme apresentado na tabela 26 , a seguir.

\begin{tabular}{|l|c|c|c|}
\hline \multicolumn{1}{|c|}{ País (porto) } & $\begin{array}{c}\text { Distância* }^{*} \\
\mathbf{( k m )}\end{array}$ & $\begin{array}{c}\text { Participação na } \\
\text { exportação** }\end{array}$ & $\begin{array}{c}\text { Distância média } \\
\mathbf{( k m )}\end{array}$ \\
\hline Nigéria (Lagos) & 6.397 & 42 & $2.686,7$ \\
\hline Argélia (Arzew) & 8.582 & 13 & $1.115,7$ \\
\hline Angola (Luanda) & 6.553 & 8 & 524,2 \\
\hline Líbia (Benghazi) & 10.575 & 8 & 846 \\
\hline Congo (Pointe-Noire) & 6.586 & 3 & 197,6 \\
\hline Arábia Saudita (Yanbu) & 12.757 & 14,5 & $1.849,8$ \\
\hline Iraque (Aden) & 13.616 & 3 & 408,5 \\
\hline Azerbaijão (Ceyhan) & 11.851 & 3 & 355,5 \\
\hline Estados Unidos (Miami) & 8.600 & 5,5 & 473 \\
\hline Total & & $\mathbf{1 0 0}$ & $\mathbf{8 . 4 5 7}$ \\
\hline
\end{tabular}

Tabela 26: Distância e participação na importação brasileira dos países exportares de petróleo para o Brasil *(PORTWORLD, 2008); **(MDIC, 2008c).

c) Refino do petróleo

O petróleo é fracionado em seus diversos componentes através do refino ou destilação fracionada. Este processo aproveita os diferentes pontos de ebulição das substâncias que compõem o petróleo, separando-as e convertendo em produtos finais.

Segundo a PETROBRAS (2008b) os processos normalmente empregados nas refinarias para o processamento do petróleo (óleo cru) são:

- dessalinização e desidratação que consistem, respectivamente, nas remoções de sal e água do óleo cru. Por meio desta estapa o óleo cru é aquecido e recebe um catalisador. A massa resultante é decantada ou filtrada para retirar a água e o sal contidos no óleo;

- dessulfurização, processo utilizado para retirar compostos de enxofre do óleo cru;

- destilação amtosférica e à vácuo, onde o petróleo é aquecido e fracionado incialmente em uma torre que opera à pressão atmosférica. Na etapa de 
destilação atmosférica são extraídos, por ordem crescente de densidade, gases combustíveis, GLP (gás liquefeito de petróleo), gasolina, nafta, solventes e querosenes, óleo diesel e um óleo pesado, chamado resíduo atmosférico, que é extraído do fundo da torre. Esse resíduo é então reaquecido e levado para uma outra torre, onde o seu fracionamento ocorrerá a uma pressão abaixo da pressão atmosférica. Nessa torre serão extraídos mais uma parcela de óleo diesel e um produto chamado genericamente de Gasóleo, o qual servirá como matéria-prima para produção de gases combustíveis, GLP, gasolina e outros;

- craqueamento, processo onde ocorre quebra das moléculas de hidrocarbonetos pesados, convertendo-as em gasolina e outros destilados com maior valor comercial. Os dois principais tipos são o craqueamento térmico e o catalítico. O térmico utiliza calor e altas pressões para efetuar a conversão de moléculas grandes em outras menores e o catalítico utiliza um catalisador para facilitar essa conversão, porém em condições de pressão mais reduzidas. Os catalisadores mais usados são: platina, alumina ou sílica. Em ambos os tipos de craqueamento a utilização de temperaturas relativamente altas é essencial;

- desasfaltação à propano, que tem por objetivo extrair por ação de um solvente, no caso propano líquido a alta pressão, frações de altas viscosidade contidas no resíduo da etapa de destialção à vácuo;

- polimerização, onde ocorre a combinação entre moléculas de hidrocarbonetos mais leves do que a gasolina com moléculas de hidrocarboneto de densidades semelhante. O objetivo do processo é produzir gasolina com alto teor de octano; e

- alquilação, etapa de conversão de moléculas pequenas de hidrocarbonetos em moléculas mais longas e que se obtém gasolina para ser utilizada na produção de gasolina para aviação.

A figura 13 mostra um esquema simplificado das principais operações de refino. 


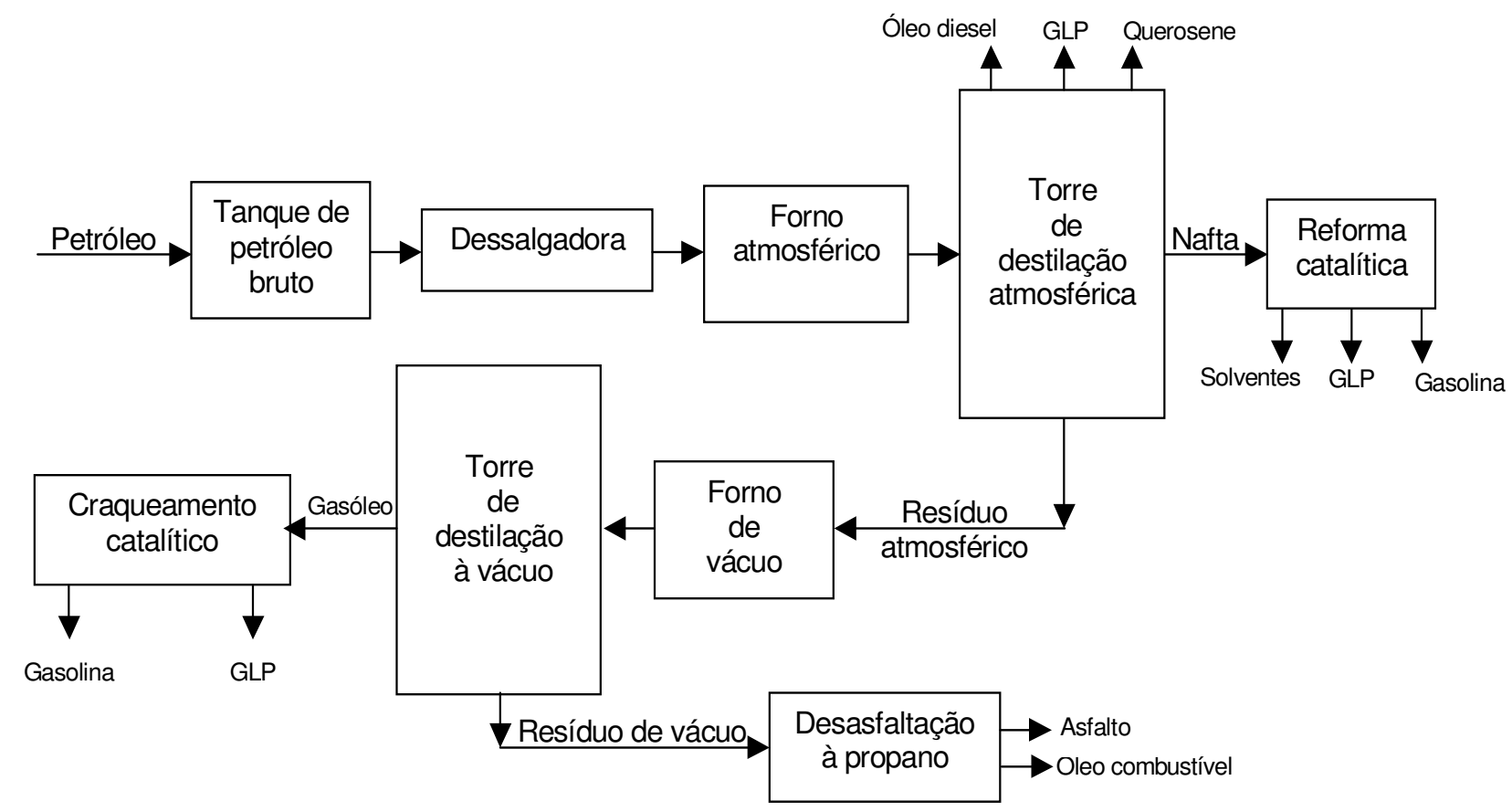

Figura 13: Diagrama de blocos simplificado das operações de refino do petróleo (GARCIA, 2002).

d) Extração e beneficiamento de gás natural

A maior parte do gás natural provém dos campos de petróleo em exploração, onde ele se encontra dissolvido no óleo. A exploração de gás natural é feita de forma semelhante à exploração do petróleo (PETROBRAS, 2008c).

O gás natural antes de ser enviado aos gasodutos de distribuição para os consumidores é beneficiado ou processado nas chamadas UPGNs - Unidades de Processamento de Gás Natural. A função dessas unidades é retirar do gás natural seus componentes indesejáveis e suas frações condensáveis.

De acordo com GARCIA (2002) os componentes indesejáveis existentes no gás natural do Brasil são: sulfeto de hidrogênio $\left(\mathrm{H}_{2} \mathrm{~S}\right)$, dióxido de carbono $\left(\mathrm{CO}_{2}\right)$ e nitrogênio $\left(\mathrm{N}_{2}\right)$. As frações condensáveis são constituídas por: gás 
liquefeito de petróleo (mistura de propano e butanos), nafta leve ou gasolina natural (pentano, hexano e heptano) e água.

Com base nas informações coletadas em PETROBRAS (2008c), podese concluir que o subsistema de beneficiamento ou processamento de gás natural envolve três etapas básicas: dessulfurização (remoção de compostos de enxofre por absorção com soluções de aminas - processo Girbotol); desidratação (remoção de umidade por absorção com glicóis ou por resfriamento e condensação da água) e separação de líquido de gás natural (remoção do gás liquefeito de petróleo e de nafta leve por fracionamento).

O subsistema de processamento de gás natural está representado na figura 14 a seguir.

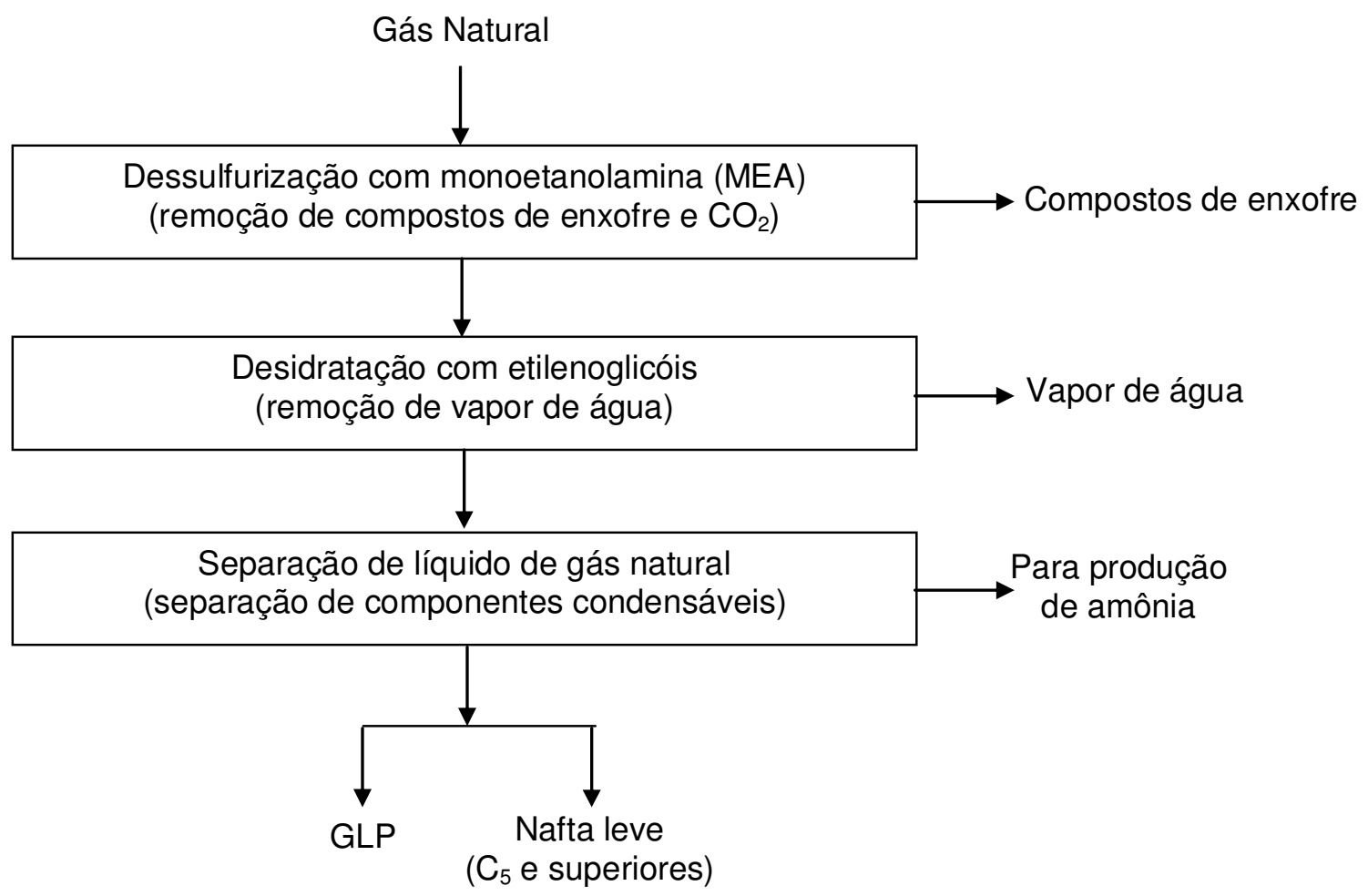

Figura 14: Diagrama de blocos do subsistema de beneficiamento de gás natural adequado às condições brasileiras (GARCIA, 2002). 
e) Geração de energia térmica

O subsistema da geração de energia térmica para o sistema de produto da uréia considera apenas um combustível, a saber: o gás natural.

Dados coletados junto à PETROBRAS/FAFEN (SAC PETROBRAS/FAFEN, 2005) revelaram que as duas unidades industriais da empresa, localizadas em Camaçari (BA) e Laranjeiras (SE), empregam gás natural como matéria-prima e como combustível na seguinte proporção: $65 \%$ de todo o gás natural é empregado como matéria-prima para a obtenção de amônia e 35\% é utilizado como combustível para gerar eletricidade e vapor em usina termoelétrica própria localizada em cada unidade industrial.

Para este subsistema deve-se levar em conta a composição do combustível, a energia térmica gerada na queima do combustível, ou seja, seu poder calorífico e, além disso, as emissões provenientes de sua combustão.

f) Produção de amônia e $\mathrm{CO}_{2}$ a partir da reforma catalítica com vapor de água

Este processo de obtenção de amônia é composto por cinco etapas (QUÍMICA INDUSTRIAL, 2004):

I - reforma catalítica com vapor (ou preparação do gás de síntese): consiste na decomposição endotérmica do hidrocarboneto leve (p. ex. metano) em presença de vapor de água e se faz em dois estágios. No segundo estágio, há presença de um composto de níquel que catalisa a reação entre o vapor de água e o metano.

Em temperaturas da ordem de $820^{\circ} \mathrm{C}$ e pressões de 30 a 50 atm 0 metano é convertido em hidrogênio, monóxido de carbono e dióxido de carbono. As reações que ocorrem estão representadas pelas equações 4 e 5 :

$\mathrm{CH}_{4}+\mathrm{H}_{2} \mathrm{O} \rightarrow \mathrm{CO}+3 \mathrm{H}_{2}$

eq. 4 
$\mathrm{CH}_{4}+2 \mathrm{H}_{2} \mathrm{O} \rightarrow \mathrm{CO}_{2}+4 \mathrm{H}_{2}$

eq. 5

Posteriormente os gases são resfriados, em uma caldeira de recuperação de calor, até aproximadamente $350^{\circ} \mathrm{C}$, mediante a geração de vapor de alta pressão (100 atm) necessário para o acionamento da turbina do compressor de gás de síntese (mistura de $\mathrm{CO}$ e $\mathrm{H}_{2}$ ).

Em seguida, os gases são conduzidos à etapa de conversão do monóxido de carbono com vapor de água em dióxido de carbono e hidrogênio;

II - conversão do monóxido de carbono: etapa na qual o gás de síntese reage com água em dois reatores, o primeiro de alta temperatura e segundo de baixa temperatura, que contêm catalisador de ferro e cromo, respectivamente. A reação que representa esta etapa é:

$\mathrm{CO}+\mathrm{H}_{2} \mathrm{O} \rightarrow \mathrm{H}_{2}+\mathrm{CO}_{2}$ eq. 6

III - remoção do dióxido de carbono $\left(\mathrm{CO}_{2}\right)$ : ao entrar nos dispositivos de purificação o gás contém alta porcentagem de $\mathrm{CO}_{2}$, que é indispensável separar. A separação do $\mathrm{CO}_{2}$ é realizada a baixas temperaturas com o uso de solventes, solução de carbonato de potássio no caso das unidades da PETROBRAS/FAFEN (SAC PETROBRAS/FAFEN, 2005) e metanol na unidade da FOSFERTIL (NEDOCHETKO, 2005);

IV - purificação final do gás de síntese: nesta etapa, o gás ainda contém CO e $\mathrm{CO}_{2}$ e suas concentrações devem ser reduzidas para não prejudicar os catalisadores da síntese da amônia. Isso pode ser feito em uma operação conhecida como "metanação". Nesta operação, os óxidos de carbono são convertidos em um reator catalítico em metano $\left(\mathrm{CH}_{4}\right)$ e água. As reações que ocorrem são: 
$\mathrm{CO}+3 \mathrm{H}_{2} \rightarrow \mathrm{CH}_{4}+\mathrm{H}_{2} \mathrm{O}$

eq. 7

$\mathrm{CO}_{2}+4 \mathrm{H}_{2} \rightarrow \mathrm{CH}_{4}+2 \mathrm{H}_{2} \mathrm{O}$

eq. 8

O metano formado não interfere na síntese da amônia e a água é eliminada na compressão subseqüente do gás. A pressão do gás nesse ponto é da ordem de 23 a 33 atm; e

V - síntese da amônia: independentemente do processo de preparação do gás de síntese (reforma catalítica ou oxidação parcial), para a síntese da amônia é utilizado o processo Haber-Bosch incluindo o sistema de compressão dos gases. Esta etapa consiste, essencialmente, na reação exotérmica entre o hidrogênio e o nitrogênio em presença de catalisador de ferro, segundo a equação de reação:

$\mathrm{N}_{2}+3 \mathrm{H}_{2} \rightarrow 2 \mathrm{NH}_{3}$

eq. 9

A pressão de operação da síntese oscila entre 150 e 230 atm e a reação é processada em dois ou três leitos catalíticos de catalisador de ferro.

No caso das unidades industriais da FOSFERTIL S. A. em Cubatão (SP) e Araucária (PR), as pressões de síntese utilizadas são: 160 e 220 atm, respectivamente (FOSFERTIL, 2005). A pressão de síntese de 150 atm é empregada nas unidades da PETROBRAS / FAFEN (SAC PETROBRAS/FAFEN, 2005).

Após passar pelo reator, os gases quentes são resfriados através de geração de vapor de alta pressão (100 atm). A amônia contida nos gases é condensada e separada através de um ou dois estágios de condensação.

Os gases que não reagiram são reciclados ao reator. Em função do teor das impurezas (metano e argônio) contidas no gás alimentado, que atuam como inertes na reação química, faz-se necessária a realização de uma purga. 
A purga evita a acumulação de inertes, mantendo a pressão nos valores desejados. O gás de purga, que contém metano, nitrogênio, hidrogênio e argônio, é utilizado como combustível no reformador primário.

A figura 15 apresenta o diagrama de blocos para o processo de reforma catalítica com vapor de água de obtenção de amônia. 


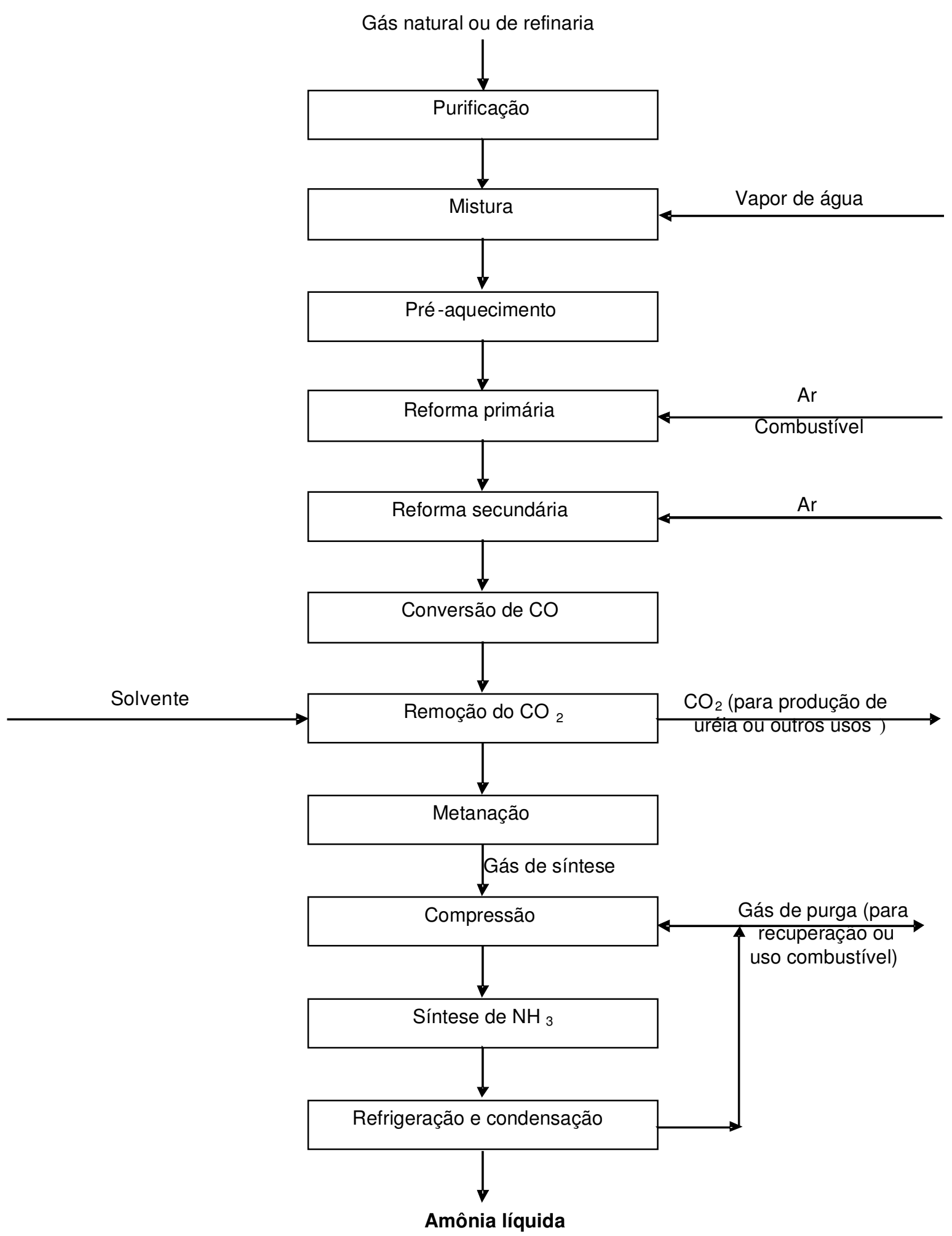

Figura 15: Diagrama de blocos do subsistema de produção de amônia pelo processo de reforma catalítica com vapor de água (CEKINSKI et al., 1990). 
g) Separação do ar

Segundo a FOSFERTIL S. A. (2005), o nitrogênio e o oxigênio são extraídos do ar atmosférico de acordo com o processo Linde efetuado na unidade industrial de Araucária (PR).

Para separar o ar atmosférico em seus maiores constituintes, oxigênio, nitrogênio e argônio, é necessário primeiro comprimi-lo.

O ar é então filtrado para remoção de partículas sólidas. Após a compressão, o ar passa por sistemas de remoção de água, dióxido de carbono e hidrocarbonetos.

Em seguida, o ar é refrigerado até atingir temperaturas extremamente baixas, comprimido para seu estado líquido e separado por destilação fracionada obtendo-se oxigênio, nitrogênio e argônio.

Duas colunas de destilação são necessárias: uma coluna inferior e outra superior. Na coluna inferior, onde a pressão é mais alta, o líquido que vai se separando torna-se progressivamente rico em oxigênio no fundo e o nitrogênio, com alta pureza (em torno de $99 \%$ em volume), é retirado pelo topo dessa coluna.

O oxigênio, proveniente do fundo da coluna inferior, é então encaminhado à coluna superior na qual é purificado e retirado do processo. $\mathrm{O}$ argônio é separado próximo do meio da coluna superior, porém, não com a pureza adequada.

h) Produção de amônia e $\mathrm{CO}_{2}$ por meio de oxidação parcial

Este processo de obtenção baseia-se na oxidação parcial de hidrocarbonetos pesados e difere daquele apresentado no item "e" apenas na etapa de preparação do gás de síntese. A oxidação parcial consiste na combustão regulada e não catalítica de alguns hidrocarbonetos visando à 
formação de hidrogênio $\left(\mathrm{H}_{2}\right)$ (QUÍMICA INDUSTRIAL, 2004). A equação geral é:

$\mathrm{CyHx}+0,5 \mathrm{yO}_{2} \rightarrow \mathrm{yCO}+0,5 \mathrm{xH}_{2}$

eq. 10

No processo empregado na unidade de amônia da FOSFERTIL em Araucária (PR), o resíduo asfáltico, o oxigênio e o vapor de água a uma pressão de $60 \mathrm{~atm}$ e a uma temperatura de $1000^{\circ} \mathrm{C}$ reagem no equipamento conhecido por gaseificador, gerando gases de combustão, que contêm, principalmente, hidrogênio e monóxido de carbono (FOSFERTIL, 2005).

No processo de oxidação parcial de hidrocarbonetos pesados, os gases que saem da seção de gaseificação contêm principalmente hidrogênio e monóxido de carbono com um teor residual de metano e também compostos de enxofre, principalmente na forma de sulfeto de hidrogênio $\left(\mathrm{H}_{2} \mathrm{~S}\right)$.

A etapa de purificação do gás de síntese inclui uma etapa de remoção de $\mathrm{H}_{2} \mathrm{~S}$ com solvente. No caso da fábrica de Araucária (PR) da FOSFERTIL, a remoção se dá por processos físicos a baixas temperaturas utilizando o metanol (FOSFERTIL, 2005).

As etapas que constituem o subsistema de produção de amônia através do processo de oxidação parcial estão representadas pelo diagrama de blocos mostrado na figura 16. 


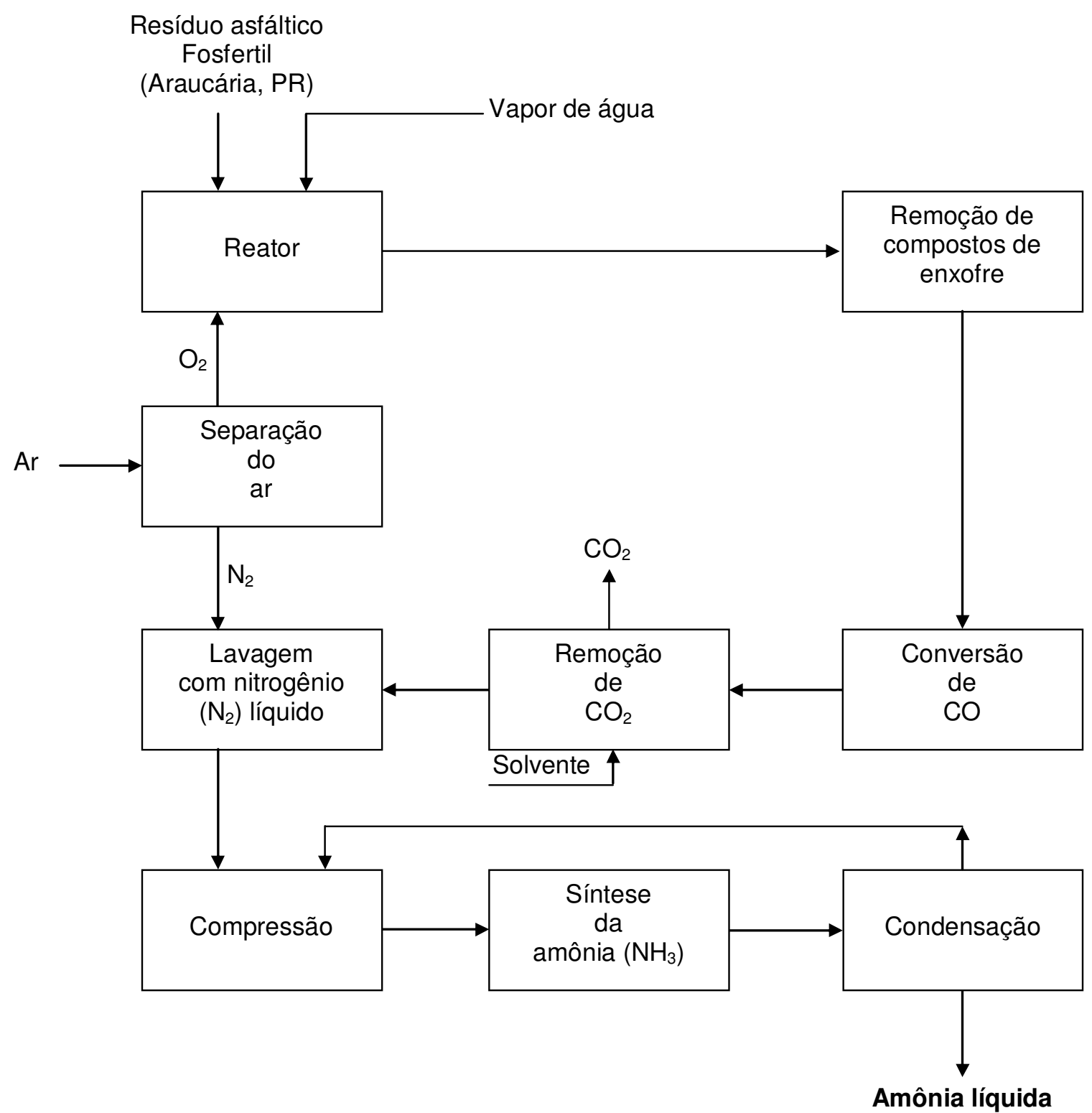

Figura 16: Diagrama de blocos do subsistema de produção de amônia pelo processo de oxidação parcial (CEKINSKI et al., 1990).

i) Produção de uréia

A produção de uréia $\left[\mathrm{CO}\left(\mathrm{NH}_{2}\right)_{2}\right]$ se dá em duas etapas: formação do carbamato de amônio, $\mathrm{NH}_{2} \mathrm{CO}_{2} \mathrm{NH}_{4}$, (reação de amônia e dióxido de carbono extraído como subproduto da unidade de amônia) e desidratação de carbamato 
de amônio para a formação de uréia (QUÍMICA INDUSTRIAL, 2004). As reações são as seguintes:

$2 \mathrm{NH}_{3}+\mathrm{CO}_{2} \rightarrow \mathrm{NH}_{2} \mathrm{CO}_{2} \mathrm{NH}_{4}$ eq. 11

$\mathrm{NH}_{2} \mathrm{CO}_{2} \mathrm{NH}_{4} \rightarrow \mathrm{CO}\left(\mathrm{NH}_{2}\right)_{2}+\mathrm{H}_{2} \mathrm{O}$ eq. 12

Segundo CEKINSKI et al. (1990) a reação representada pela equação 12 é realizada num único reator à pressão mínima de 100 atm, para evitar a decomposição do carbamato de amônio em suas substâncias de origem, e a uma temperatura acima de $160^{\circ} \mathrm{C}$, para garantir uma conversão razoável de carbamato em uréia.

Nos processos não se obtém a conversão total dos reagentes em uréia, sendo necessário o reciclo dos reagentes ao reator. No Brasil as três unidades de fabricação de uréia empregam o processo de reciclo total, no qual toda a mistura de amônia e dióxido de carbono é reciclada ao reator (QUÍMICA INDUSTRIAL, 2004).

Após eliminar o excesso de amônia do efluente, o carbamato é removido da corrente de uréia por decomposição do mesmo em amônia e dióxido de carbono, gerando, assim, uma solução de uréia.

A uréia, produzida sob a forma de uma solução aquosa, pode ser utilizada diretamente para a elaboração de fertilizantes nitrogenados líquidos, ou pode ser concentrada para em seguida ser cristalizada na forma de cristais, pérolas ou grânulos.

$\mathrm{Na}$ cristalização, a solução de uréia é concentrada e passa por um cristalizador onde é evaporado o restante da água, obtendo-se os cristais de uréia. Na perolação, a solução de uréia concentrada é pulverizada sob a forma de pequenas gotículas no topo de uma torre.

Na granulação, a solução de uréia é aspergida sobre grânulos menores em sistemas rotativos ou de leito fluidizado, obtendo-se os grânulos do tamanho 
desejado. Efetua-se, em seguida, a classificação, onde os grânulos foram de especificação retornam para o granulador.

Tradicionalmente, no Brasil, a uréia é comercializada na forma sólida como produto perolado (QUÍMICA INDUSTRIAL, 2004).

A figura 17 apresenta o diagrama de blocos para a produção de solução aquosa de uréia através do processo com reciclo total.

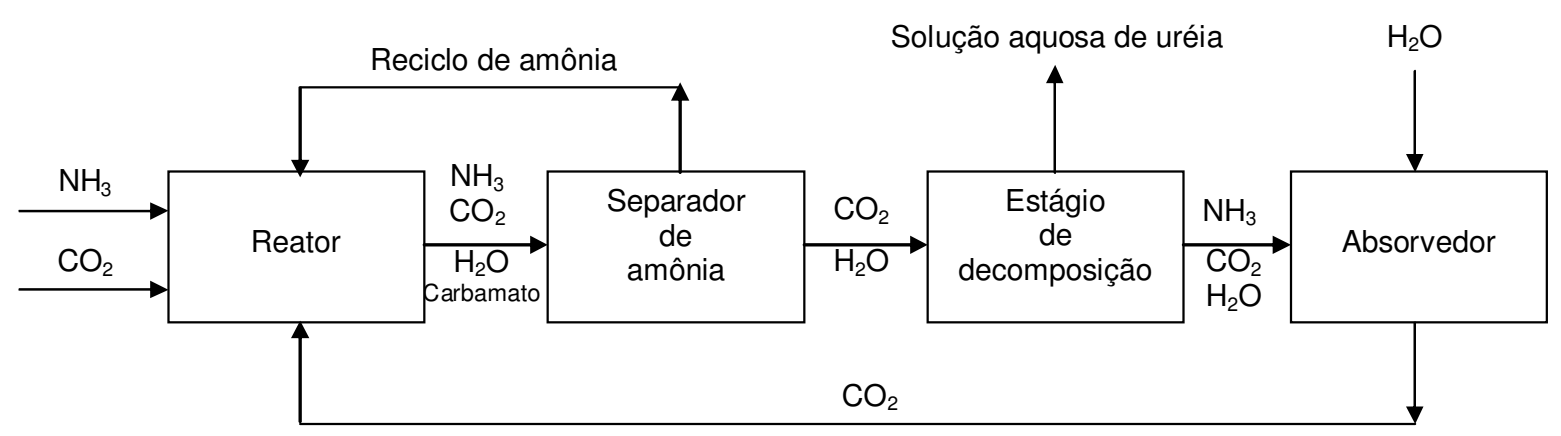

Figura 17: Diagrama de blocos do subsistema de produção de uréia pelo processo de reciclo total (CEKINSKI et al., 1990).

j) Geração de eletricidade

Conforme COLTRO; GARCIA; QUEIROZ (2003), no Brasil a eletricidade é fornecida a várias regiões do país por meio de um sistema interconectado, composto por 418 companhias elétricas, constituindo 389 usinas hidrelétricas (as usinas hidrelétricas respondem por $89 \%$ da energia elétrica total gerada no Brasil) e 29 usinas termoelétricas (10,3\% da energia gerada no país) das quais onze utilizam óleo combustível, seis usam diesel, nove empregam carvão, apenas uma utiliza gás natural e duas empregam urânio como combustível.

De acordo com os mesmos autores $99,9 \%$ de toda a energia elétrica produzida no país é proveniente de três fontes: energia hidrelétrica; termoelétrica e nuclear. 
O fluxograma de este subsistema engloba a geração, distribuição e importação de energia no país, conforme apresentado na figura 18 a seguir.

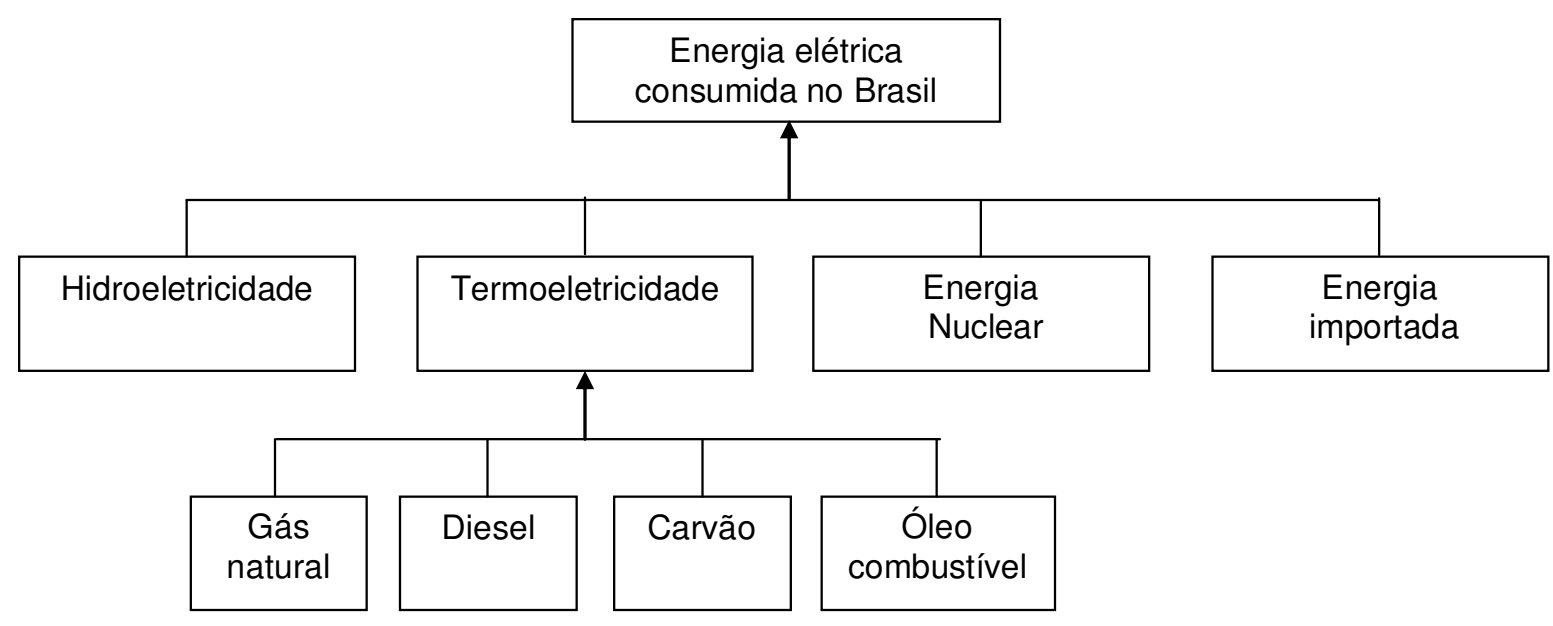

Figura 18: Diagrama de blocos do subsistema de geração, distribuição e importação de energia elétrica no Brasil (COLTRO; GARCIA; QUEIROZ, 2003).

k) Produção de ácido nítrico

Conforme dados apresentados em QUÍMICA INDUSTRIAL (2004) o ácido nítrico é obtido pela reação da amônia com oxigênio atmosférico e pode ser representado pela equação global:

$\mathrm{NH}_{3}+2 \mathrm{O}_{2} \rightarrow \mathrm{HNO}_{3}+\mathrm{H}_{2} \mathrm{O}$

eq. 13

De acordo com QUÍMICA INDUSTRIAL (2004), os processos comerciais de produção de ácido nítrico são classificados de acordo com a pressão utilizada. Assim, têm-se basicamente, os processos de monopressão (que empregam mesma pressão para as etapas de oxidação da amônia, oxidação do monóxido de nitrogênio e absorção de dióxido de nitrogênio) e os de pressão dual (os quais empregam pressões diferentes para as etapas de oxidação da 
amônia, oxidação do monóxido de nitrogênio e absorção de dióxido de nitrogênio).

No que diz respeito ao único fabricante brasileiro (FOSFERTIL) para o setor de fertilizantes, verificou-se que em sua unidade industrial, localizada em Cubatão (SP), emprega-se o processo de monopressão que utiliza pressões elevadas (acima de $7 \mathrm{~atm}$ ) (FOSFERTIL, 2005).

Segundo QUÍMICA INDUSTRIAL (2004), as etapas relacionadas abaixo são comuns a todos os processos:

I - oxidação da amônia para produzir óxidos de nitrogênio, acompanhada da recuperação da energia de combustão: a amônia é oxidada cataliticamente, convertendo-se em monóxido de nitrogênio (representação na equação 14), em reatores com leitos catalíticos de platina-ródio, sob pressão.

A reação é exotérmica e boa parte do calor gerado na reação química é recuperado através da geração de vapor, utilizado geralmente para geração de energia mecânica para acionamento do compressor de ar de combustão, associado ao pré-aquecimento de água de caldeira e ao pré-aquecimento do ar de combustão. A principal reação que representa esta etapa é:

$4 \mathrm{NH}_{3}+5 \mathrm{O}_{2} \rightarrow 4 \mathrm{NO}+6 \mathrm{H}_{2} \mathrm{O}$

eq. 14

II - resfriamento dos gases com oxidação do monóxido de nitrogênio (NO): a mistura de gases que sai do sistema de recuperação de calor segue para posterior processamento por absorção direta nas etapas de combustão da amônia e de absorção do dióxido de nitrogênio $\left(\mathrm{NO}_{2}\right)$.

Os gases são resfriados de forma que a maior parte do monóxido de nitrogênio, formado na etapa anterior, seja oxidado a dióxido de nitrogênio pelo oxigênio remanescente nos gases e pelo oxigênio introduzido no sistema através do ar, gerando, junto com vapor de água condensado, o chamado ácido fraco, o qual é separado dos gases antes de entrar na seção de absorção. A principal reação desta etapa é representa pela equação 15 : 
III - absorção do dióxido de nitrogênio $\left(\mathrm{NO}_{2}\right)$ em água $\left(\mathrm{H}_{2} \mathrm{O}\right)$ : nesta etapa os gases contendo principalmente dióxido de nitrogênio junto com oxigênio, monóxido de nitrogênio e nitrogênio são absorvidos em água, formando o produto final de concentração variável, em função da pressão e da temperatura da coluna de absorção.

$\mathrm{Na}$ coluna absorvedora processam-se simultaneamente as reações de absorção de dióxido de nitrogênio em água (equação 16 ) e a reação de oxidação do monóxido de nitrogênio gerado na reação com o oxigênio residual (equação 14).

$3 \mathrm{NO}_{2}+\mathrm{H}_{2} \mathrm{O} \rightarrow 2 \mathrm{HNO}_{3}+\mathrm{NO}$

Nos sistemas de absorção utilizam-se uma ou duas colunas com pratos perfurados.

Uma vez que a concentração do ácido é favorecida por baixas temperaturas, o resfriamento é obtido nas colunas através de serpentinas localizadas em cada prato.

O líquido mais utilizado para resfriamento é a água (ocasionalmente, pode-se empregar ácido diluído) em diferentes níveis de temperatura; e

IV - sistema de purificação dos gases de exaustão: após a absorção, os gases exaustos contendo principalmente nitrogênio, oxigênio residual e mistura de óxidos de nitrogênio são normalmente aquecidos e expandidos, após passarem pelo sistema de purificação por processos catalíticos ou processos físicos, tais como: combustão catalítica com hidrocarbonetos (como no caso da FOSFERTIL S. A. - FOSFERTIL, 2005); redução seletiva com amônia; e absorção expandida ou à baixa temperatura. 
A figura 19, a seguir, apresenta um diagrama de blocos do subsistema de produção de ácido nítrico que emprega o processo de monopressão.

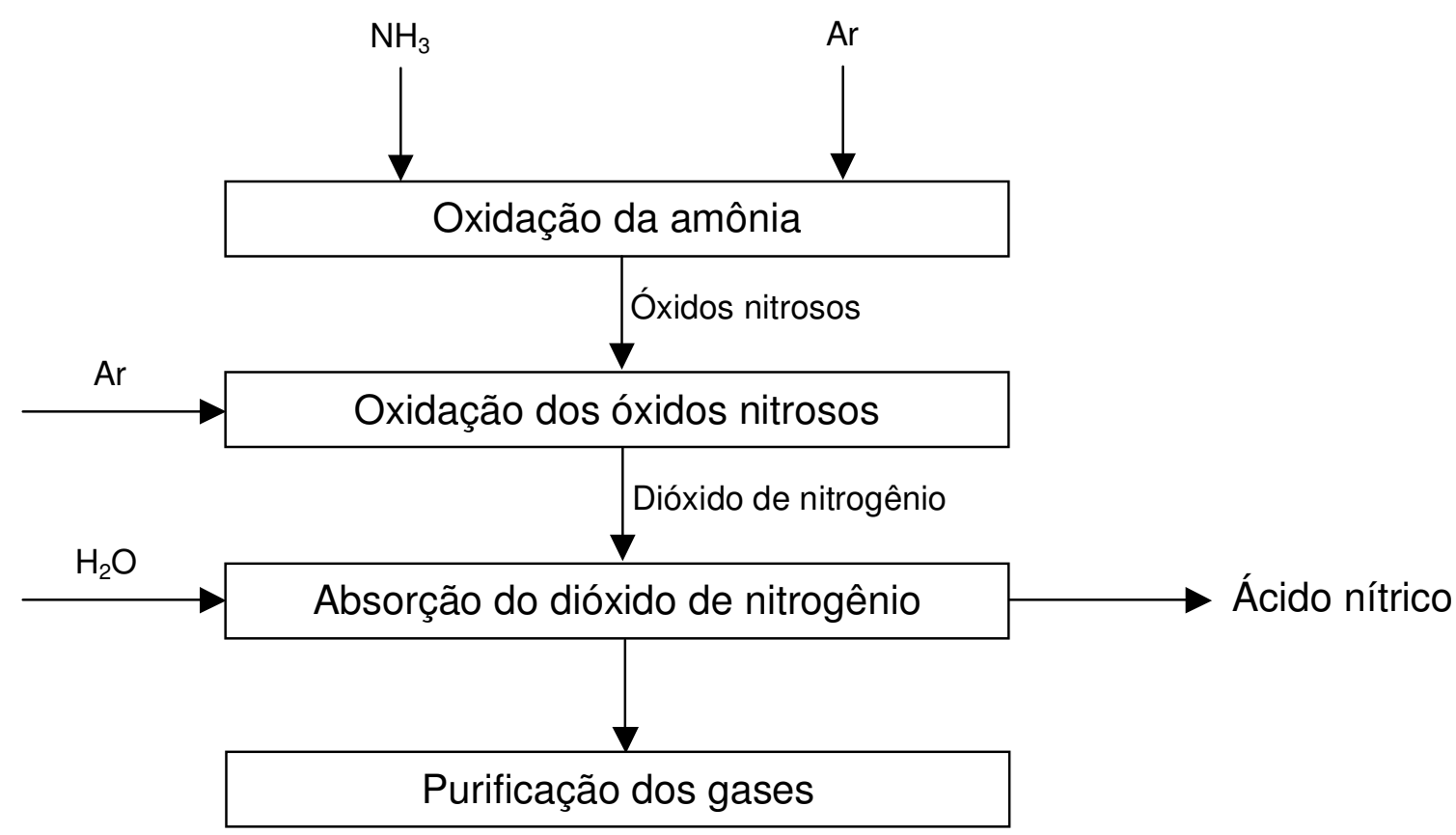

Figura 19: Diagrama de blocos do subsistema de produção de ácido nítrico pelo processo de monopressão (CEKINSKI et al., 1990).

I) Produção de nitrato de amônio

A fabricação do fertilizante consiste, basicamente, na neutralização da solução de ácido nítrico por meio de amônia anidra, segundo a equação geral (QUÍMICA INDUSTRIAL, 2004):

$\mathrm{NH}_{3}+\mathrm{HNO}_{3} \rightarrow \mathrm{NH}_{4} \mathrm{NO}_{3}$ eq. 17

O ácido nítrico é neutralizado com amônia gasosa a pressões variando entre 3 a $6 \mathrm{~atm}$ e temperaturas entre 145 e $190^{\circ} \mathrm{C}$. A reação tem lugar em um ou em dois estágios, em um equipamento ou em vários, e parte da água é removida por evaporação. 
Como a concentração do ácido é de no mínimo $50 \%$ em massa e a neutralização é efetuada sob pressão, gera-se quantidade de vapor suficiente para aquecer o ácido e a amônia que entram no neutralizador, além de concentrar a solução de nitrato de amônio na etapa de evaporação (CEKISNKI et al., 1990).

De acordo com CEKINSKI et al., 1990, a solução aquosa é concentrada na seção de evaporação em um ou em dois estágios.

A complexidade da etapa de concentração é função da concentração da solução que sai da seção de neutralização e do teor de água adequado ao processo de acabamento.

Assim, quando se escolhe a tecnologia de granulação o teor de umidade do nitrato fundido pode ser da ordem de $5 \%$; quando se utiliza tecnologia de perolação, o teor de umidade deve ser da ordem de 0,3 a $0,5 \%$.

O acabamento empregado para o nitrato de amônio produzido em larga escala para uso como fertilizante é a perolação de uma solução concentrada $(99,7 \%)$ de nitrato de amônio em torres de perolação.

O produto perolado é resfriado, peneirado e recoberto com um material inerte para reduzir a tendência ao empedramento durante a estocagem. Em alguns casos, a cobertura sólida é substituída pela adição de agentes químicos antiaglomerantes (QUÍMICA INDUSTRIAL, 2004).

A figura 20 apresenta o diagrama de blocos do processo para a produção de nitrato de amônio. 


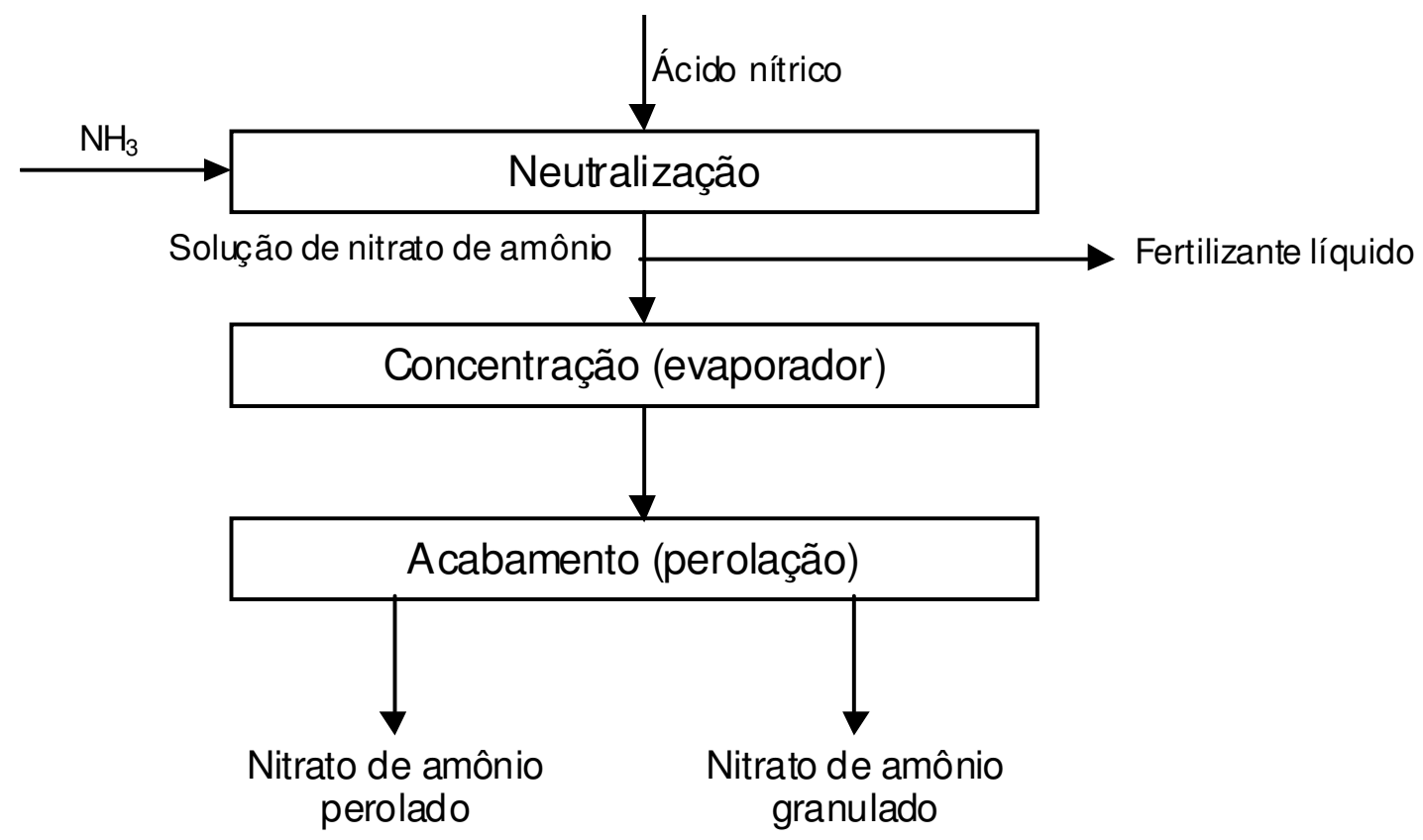

Figura 20: Diagrama de blocos do subsistema da produção de nitrato de amônio (CEKINSKI et al., 1990).

m) Produção de ácido sulfúrico

Segundo BRUNO et al. (1985) apud CEKINSKI et al. (1990), no processo a partir de enxofre elementar, o enxofre sólido é fundido em um tanque dotado de serpentina que usa vapor de baixa pressão como fluído de aquecimento.

O material fundido é levado até a fornalha onde é convertido a dióxido de enxofre $\left(\mathrm{SO}_{2}\right)$, através de combustão com injeção controlada de ar previamente seco.

A temperatura atingida pelos gases de combustão é da ordem de $1000^{\circ} \mathrm{C}$. A reação que representa esta etapa é:

$\mathrm{S}+\mathrm{O}_{2} \rightarrow \mathrm{SO}_{2}$ eq. 18 
Para que haja boa conversão do dióxido a trióxido de enxofre $\left(\mathrm{SO}_{3}\right)$ no conversor, é necessária uma diminuição de temperatura. Esse resfriamento é feito através de geração de vapor em uma caldeira de recuperação de calor.

O vapor, assim gerado, é utilizado para acionamento da turbina do soprador de ar de processo e, quando for o caso, exportado para outras unidades do complexo industrial (CEKINSKI et al., 1990).

A equação 19 representa a conversão do dióxido de carbono:

$2 \mathrm{SO}_{2}+\mathrm{O}_{2} \rightarrow 2 \mathrm{SO}_{3}$ eq. 19

Conforme a mesma fonte, a conversão do $\mathrm{SO}_{2}$ para $\mathrm{SO}_{3}$ é desenvolvida no conversor onde um catalisador apropriado é distribuído em três ou mais leitos, de tal forma que a temperatura em cada leito possa ser controlada para se atingir o ponto ótimo para a conversão.

Para efetuar-se tal controle de temperatura, o gás ao deixar o primeiro leito catalítico deve ser resfriado, o que pode ser feito tanto pela injeção de ar frio, quanto pela troca de calor em caldeira de recuperação, gerando mais vapor. Da mesma forma, o resfriamento é necessário após o segundo e terceiro leitos catalíticos, porém com níveis de temperatura mais baixos.

O gás ao deixar o conversor é ainda resfriado, passando em seguida para a torre de absorção, onde $\mathrm{O}^{\mathrm{SO}_{3}}$ é absorvido por ácido sulfúrico concentrado (em torno de $98 \%$ de $\mathrm{H}_{2} \mathrm{SO}_{4}$ ) recirculado, que é mantido na concentração desejada através da adição de água. A equação 20 representa esta etapa:

$\mathrm{SO}_{3}+\mathrm{H}_{2} \mathrm{O} \rightarrow \mathrm{H}_{2} \mathrm{SO}_{4}$

eq. 20

Parte do ácido, após a torre de absorção, é enviada à torre de secagem de ar de alimentação da fornalha de enxofre e o restante segue para estocagem. 
Nesse tipo de processo, mais conhecido como de simples absorção, a conversão do enxofre elementar para ácido sulfúrico é da ordem de 97 a 98\%, sendo o restante rejeitado para a atmosfera na forma de $\mathrm{SO}_{2}$ (CEKINSKI et al., 1990).

Visando a obtenção de maiores taxas de conversão e a redução da emissão de óxidos de enxofre para o meio ambiente, desenvolveu-se outro processo com uma etapa adicional de absorção, conhecido como processo de dupla absorção. Nesse processo obtêm-se até 99,7\% de rendimento na conversão global (CEKINSKI et al., 1990).

O diagrama de blocos do processo de dupla absorção é mostrado na figura 21 , a seguir. 


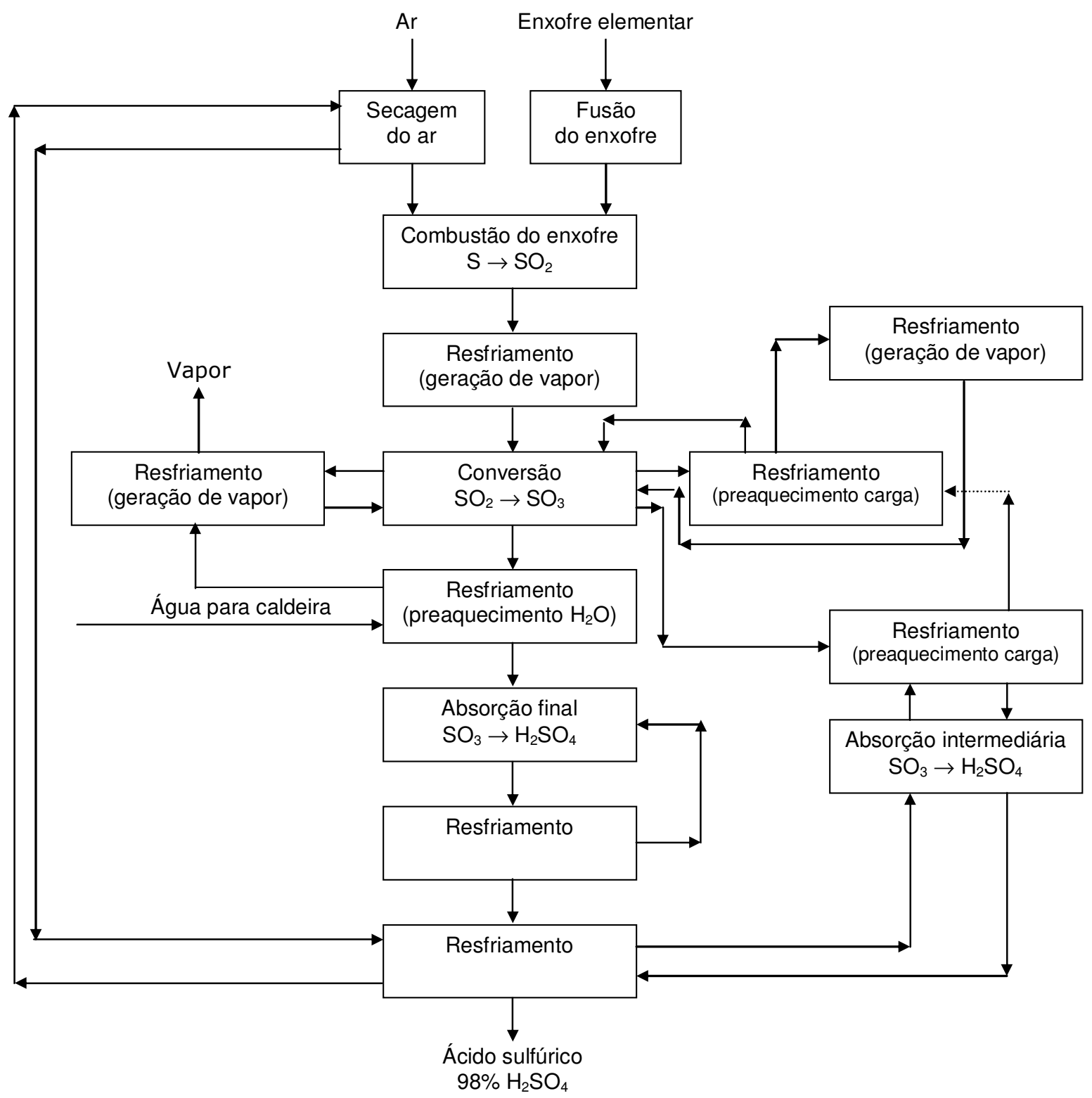

Figura 21: Diagrama de blocos do subsistema da produção de ácido sulfúrico pelo processo de dupla absorção (CEKINSKI et al., 1990). 
n) Produção de sulfato de amônio via síntese

De acordo com QUÍMICA INDUSTRIAL (2004) o processo de obtenção de sulfato de amônio via síntese é conhecido como processo combinado reação-evaporação e consiste basicamente na reação exotérmica entre amônia vaporizada e ácido sulfúrico, segundo a reação representada pela equação 21 :

$2 \mathrm{NH}_{3}+\mathrm{H}_{2} \mathrm{SO}_{4} \rightarrow\left(\mathrm{NH}_{4}\right)_{2} \mathrm{SO}_{4}$

eq. 21

Amônia e ácido sulfúrico são alimentados em um evaporadorcristalizador, dando origem a pequenos cristais de sulfato de amônio. $O$ calor liberado na reação é removido através da evaporação da água presente no ácido sulfúrico ou da água alimentada ao sistema para controle de temperatura.

Após o processamento no evaporador, os cristais de sulfato de amônio seguem para centrifugação, onde os mesmos são removidos. Os cristais passam, então, por um secador rotativo e são classificados, após o que são armazenados (CEKINSKI et al., 1990).

Segue na figura 22 o diagrama de blocos do subsistema de produção de sulfato de amônio via síntese. 


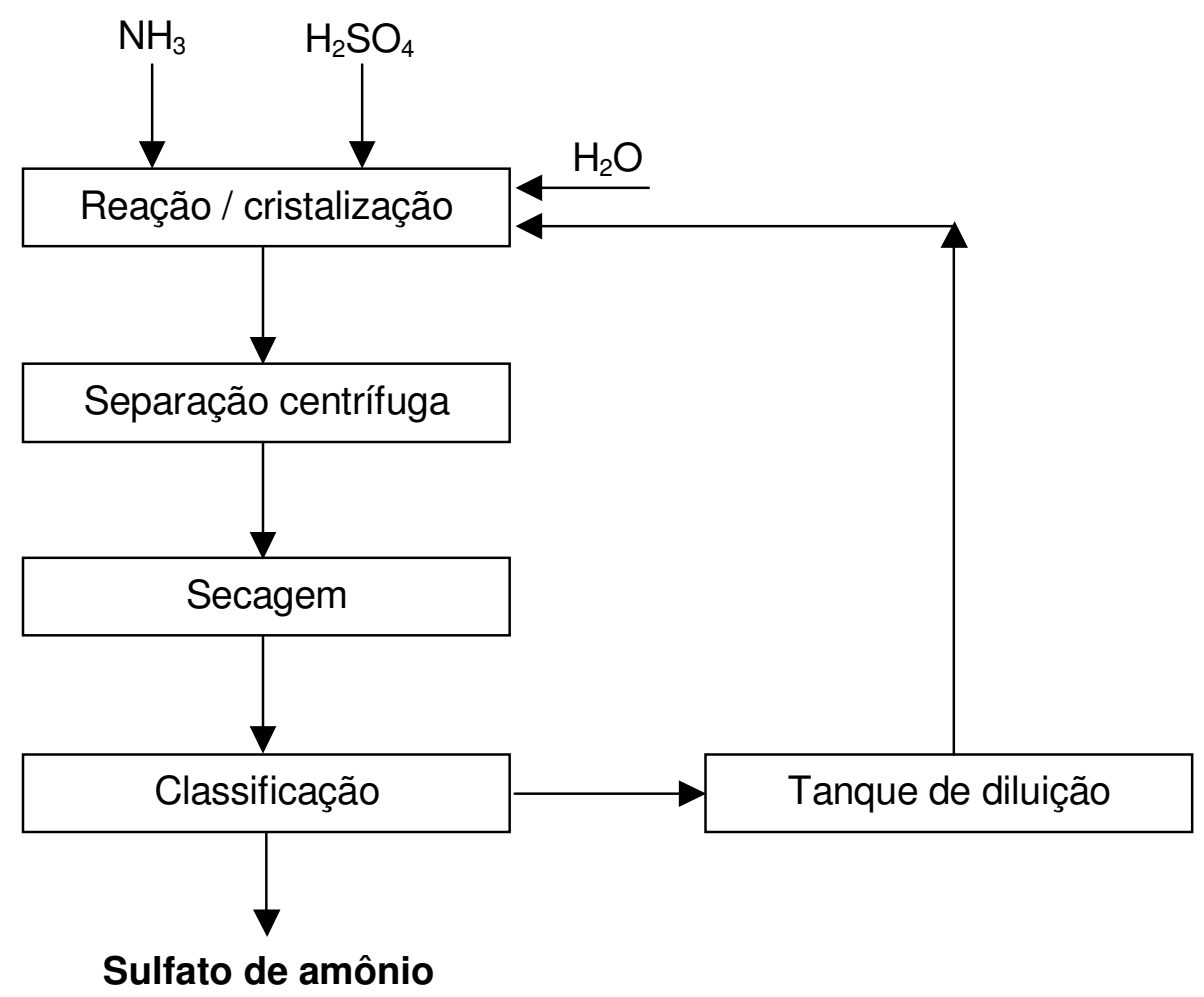

Figura 22: Diagrama de blocos do subsistema da produção de sulfato de amônio pelo processo de síntese (CEKINSKI et al., 1990).

o) Produção de ácido cianídrico

O ácido cianídrico (HCN) é obtido pela UNIGEL S. A., em Candeias (BA), por meio da oxidação catalítica, com platina, da amônia e do metano (provenientes do gás natural) com ar. É empregado na produção de sulfato de amônio e metacrilato de metila (MMA) (UNIGEL, 2006).

O ar filtrado, a amônia e o gás natural são alimentados em um reator e aquecidos até $2.200^{\circ} \mathrm{C}$ na presença de um catalisador de platina. O gás que deixa o reator é resfriado e enviado a uma torre de absorção para remover a amônia não reagida. Água de resfriamento é então adicionada para capturar o 
ácido cianídrico. A mistura de ácido e água é enviada a uma coluna de stripping, na qual se obtêm o ácido cianídrico puro (CHENIER, 1992).

A reação principal desse processo aparece indicada a seguir na equação 22 (CHENIER, 1992):

$2 \mathrm{CH}_{4}+2 \mathrm{NH}_{3}+3 \mathrm{O}_{2} \rightarrow 2 \mathrm{HCN}+6 \mathrm{H}_{2} \mathrm{O}$ eq. 22

p) Produção de benzeno

De acordo com a BRASKEM (2008) o benzeno $\left(\mathrm{C}_{6} \mathrm{H}_{6}\right)$ é produzido através do processo de reforma catalítica da nafta.

A nafta, proveniente do refino do petróleo, é pré-aquecida em presença de hidrogênio até temperaturas entre $450^{\circ} \mathrm{C}$ e $510^{\circ} \mathrm{C}$ e pressões que variam de 17 a 55 atm. Os vapores de nafta quentes são conduzidos, juntamente com o hidrogênio reciclado para o reator que contém um catalisador. Normalmente, o catalisador empregado é de platina. Do reator, os produtos são resfriados em trocadores de calor, onde se obtêm $90 \%$ do hidrogênio. O hidrogênio é então comprimido e reciclado (CHENIER, 1992).

Depois de ter sua temperatura reduzida a um ponto apropriado, em trocadores de calor, o produto principal é encaminhado a uma coluna de fracionamento onde é então fracionado em seus constituintes, por exemplo, em benzeno, tolueno e xilenos.

q) Produção de ciclohexano 
Dados coletados junto a BRASKEM (2008) revelaram que o ciclohexano $\left(\mathrm{C}_{6} \mathrm{H}_{12}\right)$ é obtido pela hidrogenação catalítica do benzeno, de acordo com a reação representada pela equação 23:

$\mathrm{C}_{6} \mathrm{H}_{6}+3 \mathrm{H}_{2} \rightarrow \mathrm{C}_{6} \mathrm{H}_{12}$ eq. 23

O benzeno é alimentado na parte superior do reator onde a temperatura fica em torno de $210^{\circ} \mathrm{C}$, enquanto o hidrogênio é injetado na parte inferior com a temperatura em torno de $150^{\circ} \mathrm{C}$. O reator é provido de um condensador para recuperação dos vapores condensáveis: a fração condensada é misturada à alimentação de benzeno e a fração não-condensada é misturada à alimentação de hidrogênio. A pressão de operação varia entre 24 e 34 atm. O catalisador empregado pode ser níquel ou platina e o rendimento da reação é superior a 99\% (CHENIER, 1992).

r) Produção de propeno ou propileno

O propeno ou propileno $\left(\mathrm{C}_{3} \mathrm{H}_{6}\right)$ é obtido por meio do craqueamento térmico da nafta, proveniente do refino do petróleo, sem presença de catalisadores. A nafta é pré-aquecida, misturada com vapor de água e alimentada a um forno (UNIGEL, 2006).

$\mathrm{O}$ craqueamento da nafta ocorre em temperaturas $\left(815-870^{\circ} \mathrm{C}\right)$ e pressões (41 a 68 atm) elevadas, com um tempo de residência muito curto (no máximo de 1 segundo) e fornece um produto misturado (hidrocarbonetos de moléculas menores e hidrogênio) que deve ser separado nos seus constituintes úteis (CHENIER, 1992).

Os gases são rapidamente resfriados, desidratados e fracionados, a fim de que forneçam os componentes individuais de elevada pureza (p. e.x 
propeno) e também os materiais indesejáveis que são reciclados (CHENIER, 1992).

s) Obtenção de sulfato de amônio como subproduto da produção de acrilonitrila

A UNIGEL obtém sulfato de amônio, em solução, como subproduto da produção de acrilonitrila $\left(\mathrm{C}_{2} \mathrm{H}_{3} \mathrm{CN}\right)$ que consiste em reagir propileno ou propeno (proveniente da nafta do petróleo), amônia e oxigênio com um catalisador (UNIGEL, 2006).

Segundo a UNIGEL (2006), no processo, propileno $\left(\mathrm{C}_{3} \mathrm{H}_{6}\right)$, oxigênio $\left(\mathrm{O}_{2}\right)$, amônia $\left(\mathrm{NH}_{3}\right)$ e água $\left(\mathrm{H}_{2} \mathrm{O}\right)$ são alimentados a um reator de leito fluidizado contendo um catalisador.

Pequenas quantidades de água são alimentadas ao reator para aumentar a seletividade de acrilonitrila e diminuir a temperatura dentro do equipamento. $\mathrm{O}$ reator opera a temperatura compreendida entre $400^{\circ} \mathrm{C}$ e $500^{\circ} \mathrm{C}$ e pressão entre 0,3 e 2 bar. A amônia não convertida é separada dos outros produtos através do emprego de ácido sulfúrico, resultando em uma solução de sulfato de amônio (CHENIER, 1992).

A equação 24 mostra a reação que representa o processo de obtenção de acrilonitrila:

$2 \mathrm{C}_{3} \mathrm{H}_{6}+2 \mathrm{NH}_{3}+3 \mathrm{O}_{2} \rightarrow 2 \mathrm{C}_{2} \mathrm{H}_{3} \mathrm{CN}+6 \mathrm{H}_{2} \mathrm{O}$

t) Obtenção de sulfato de amônio como subproduto da produção de caprolactama

O processo empregado pela BRASKEM que produz sulfato de amônio como subproduto da produção de caprolactama $\left(\mathrm{C}_{6} \mathrm{H}_{11} \mathrm{NO}\right)$ consiste, inicialmente, em reagir ciclohexanona $\left(\mathrm{C}_{6} \mathrm{H}_{10} \mathrm{O}\right)$ com hidroxilamina $\left(\mathrm{NH}_{2} \mathrm{OH}\right)$ 
formando oxima de ciclohexanona - $\mathrm{C}_{6} \mathrm{H}_{10} \mathrm{NOH}$ (equação 27) (BRASKEM, 2008).

A ciclohexanona é proveniente da oxidação do ciclohexano - $\mathrm{C}_{6} \mathrm{H}_{12}$ (equação 25), que por sua vez é obtido do da hidrogenação do benzeno - $\mathrm{C}_{6} \mathrm{H}_{6}$ (equação 23) e a hidroxilamina é preparada mediante a hidrogenação catalítica de óxido nítrico - NO (equação 26), sendo que a obtenção de este último se dá através da oxidação da amônia (equação 14). Seguem as equações:

$\mathrm{C}_{6} \mathrm{H}_{12}+\mathrm{O}_{2} \rightarrow \mathrm{C}_{6} \mathrm{H}_{10} \mathrm{O}+\mathrm{H}_{2} \mathrm{O}$ eq. 25

$2 \mathrm{NO}+3 \mathrm{H}_{2} \rightarrow 2 \mathrm{NH}_{2} \mathrm{OH}$ eq. 26

$\mathrm{C}_{6} \mathrm{H}_{10} \mathrm{O}+\mathrm{NH}_{2} \mathrm{OH} \rightarrow \mathrm{C}_{6} \mathrm{H}_{10} \mathrm{NOH}+\mathrm{H}_{2} \mathrm{O}$

A oxima de ciclohexanona produzida na reação, representada na equação 27, sofre um rearranjo catalítico através da presença de ácido sulfúrico, a temperatura entre $100^{\circ} \mathrm{C}$ e $120^{\circ} \mathrm{C}$. Após a adição de ácido sulfúrico e amônia, obtém-se caprolactama e sulfato de amônio como subproduto (CHENIER, 1992).

A equação 28 mostra a reação que representa a formação de caprolactama e sulfato de amônio:

$\mathrm{C}_{6} \mathrm{H}_{10} \mathrm{NOH}+\mathrm{H}_{2} \mathrm{SO}_{4}+2 \mathrm{NH}_{3} \rightarrow \mathrm{C}_{6} \mathrm{H}_{11} \mathrm{NO}+\left(\mathrm{NH}_{4}\right)_{2} \mathrm{SO}_{4}$

eq. 28

u) Obtenção de sulfato de amônio como subproduto da produção de metacrilato de metila

O sulfato de amônio é obtido pela UNIGEL como subproduto da produção de metacrilato de metila - MMA $\left(\mathrm{C}_{5} \mathrm{H}_{8} \mathrm{O}_{2}\right)$. A obtenção de sulfato de amônio e MMA se inicia com a reação entre acetona $-\mathrm{C}_{3} \mathrm{H}_{6} \mathrm{O}$ (obtida da reação 
entre propeno e benzeno com oxigênio, equação 29) e cianeto de hidrogênio ( $\mathrm{HCN}$ ), produzindo acetona cianidrina $-\mathrm{C}_{3} \mathrm{H}_{6} \mathrm{CNOH}$ (equação 30 ):

$\mathrm{C}_{3} \mathrm{H}_{6}+\mathrm{C}_{6} \mathrm{H}_{6}+\mathrm{O}_{2} \rightarrow \mathrm{C}_{3} \mathrm{H}_{6} \mathrm{O}+\mathrm{C}_{6} \mathrm{H}_{5} \mathrm{OH}$

eq. 29

$\mathrm{C}_{3} \mathrm{H}_{6} \mathrm{O}+\mathrm{HCN} \rightarrow \mathrm{C}_{3} \mathrm{H}_{6} \mathrm{CNOH}$

eq. 30

De acordo com a UNIGEL (2006), a acetona cianidrina obtida é então hidrolisada na presença de ácido sulfúrico formando o sulfato de metacrilamida $\left(\mathrm{C}_{4} \mathrm{H}_{6} \mathrm{ONH}_{2} \mathrm{HSO}_{4}\right)$, de acordo com a equação 31 :

$\mathrm{C}_{3} \mathrm{H}_{6} \mathrm{CNOH}+\mathrm{H}_{2} \mathrm{SO}_{4} \rightarrow \mathrm{C}_{4} \mathrm{H}_{6} \mathrm{ONH}_{2} \mathrm{HSO}_{4}$

eq. 31

O sulfato de metacrilamida é esterificado, reagindo continuamente com metanol $\left(\mathrm{CH}_{3} \mathrm{OH}\right)$, e gerando $\mathrm{MMA}$ e bissulfato de amônio $-\mathrm{NH}_{4} \mathrm{HSO}_{4}$ (equação 32):

$\mathrm{C}_{4} \mathrm{H}_{6} \mathrm{ONH}_{2} \mathrm{HSO}_{4}+\mathrm{CH}_{3} \mathrm{OH} \rightarrow \mathrm{C}_{5} \mathrm{H}_{8} \mathrm{O}_{2}+\mathrm{NH}_{4} \mathrm{HSO}_{4}$

eq. 32

A reação final para a obtenção do sulfato de amônio está representada a seguir na equação 33 (UNIGEL, 2006):

$\mathrm{NH}_{4} \mathrm{HSO}_{4}+\mathrm{NH}_{3} \rightarrow\left(\mathrm{NH}_{4}\right)_{2} \mathrm{SO}_{4}$

eq. 33

\subsubsection{Procedimento de alocação}

Neste estudo, a alocação será necessária no sistema de produto do nitrato de amônio e do sulfato de amônio, para os seguintes subsistemas: refino do petróleo (critério de alocação utilizado: conteúdo energético); produção de amônia e $\mathrm{CO}_{2}$ pelo processo de reforma catalítica (critério: massa); produção 
de metacrilato de metila (critério: massa); de acrilonitrila (critério: massa) e produção de caprolactama (critério: massa).

Os procedimentos de alocação elaborados serão apresentados adiante para os subsistemas mencionados anteriormente.

\subsubsection{Tipos de impacto e metodologia de avaliação de impacto}

Como o trabalho de doutorado pretende disponibilizar inventários de ciclo de vida, não será realizada a etapa de avaliação de impacto.

\subsubsection{Requisitos de qualidade dos dados}

As informações a serem coletadas devem levar em conta as coberturas ou fronteiras temporal, geográfica e tecnológica.

Para este estudo, deu-se preferência à obtenção de dados primários, ou seja, de dados fornecidos pelos fabricantes do setor brasileiro e que pudessem representar da maneira mais fiel possível como os processos industriais ocorrem atualmente no país.

Porém, devido à indisponibilidade de algumas informações atuais precisas e confiáveis, a cobertura temporal adotada para o estudo compreendeu dados a partir do ano de 2003.

Os dados sobre os consumos de recursos materiais e energéticos e de emissões energéticas, empregados neste estudo, foram coletados junto às empresas brasileiras do setor de fertilizantes nitrogenados durante os anos de 2005 e 2008.

Os dados que dizem respeito às emissões atmosféricas, efluentes líquidos e resíduos sólidos foram obtidos de literatura específica e de bancos de dados disponíveis, em ferramentas computacionais, que mais se aproximavam da realidade brasileira a partir do ano de 2003. 
Algumas verificações foram realizadas, quando do uso de informações contidas em bancos de dados, com relação aos dados necessários para o estudo e àqueles oferecidos pelo banco de dados, tais como: as etapas de fabricação envolvidas; os insumos utilizados; a idade dos dados; a matriz energética; o modelo de transporte; etc.

Verificou-se que do total de dados coletados para o estudo, aproximadamente $32 \%$ corresponderam a dados fornecidos pelas empresas.

No que se refere à cobertura geográfica esta envolve o território brasileiro, uma vez que o trabalho se propõe a disponibilizar inventários para as condições brasileiras. Contudo, dada a existência de um insumo importado (petróleo) os aspectos associados a este foram considerados.

Em relação à cobertura tecnológica definida para o estudo, esta representa: a média ponderada obtida das capacidades instaladas dos processos de obtenção de uréia através de amônia obtida tanto por reforma catalítica quanto por oxidação parcial; o único processo existente de fabricação de nitrato de amônio no país; e a média ponderada obtida das capacidades instaladas dos processos de obtenção de sulfato de amônio via síntese direta e via subproduto.

Uma vez que a maioria dos produtores brasileiros do setor de fertilizantes nitrogenados não divulga suas quantidades efetivas de produção, decidiu-se aplicar como fator de ponderação, para os sistemas da uréia e do sulfato de amônio, a contribuição das empresas brasileiras em termos de capacidade instalada de produção no país, para o ano de 2007.

Em pesquisa efetuada em anuários estatísticos da ANDA para a indústria brasileira de fertilizantes, verificou-se que a capacidade instalada de produção das empresas do setor de fertilizantes nitrogenados não sofreu alteração desde o ano de 2003. 


\subsubsection{Tipo de análise crítica}

A norma ISO 14040 (ISO, 2006a) torna obrigatória a análise crítica nos casos em que a ACV tenha sido elaborada para fazer afirmações comparativas entre produtos e que sejam divulgadas ao público. Como este trabalho não se trata de um estudo de ACV comparativo, optou-se pela não realização de sua análise crítica.

\subsubsection{Tipo e formato do relatório final}

Uma vez que o relatório final deve ser elaborado de forma a possibilitar que os resultados da ACV sejam relatados ao público-alvo de forma fiel, completa e exata, pretende-se que o documento gerado em decorrência da tese de doutorado substitua o relatório final previsto pela norma ISO 14040 (ISO, 2006a).

\subsubsection{Suposições e limitações}

Para este estudo adotou-se como critério de exclusão de aspectos ambientais de entrada e saída, que seriam excluídos aqueles cuja porcentagem de contribuição fosse inferior a $1,0 \%$ da soma de todos os aspectos de entrada e saída, respectivamente, exceção feita aos aspectos que reconhecidamente apresentassem potencial de impacto ambiental.

Para o subsistema de transporte marítimo de petróleo importado para o Brasil, adotou-se uma distância média ponderada entre os principais portos dos países exportadores de petróleo para o país e o porto da cidade de Santos. Utilizou-se como fator de ponderação, a contribuição em termos de quantidade de petróleo exportada por cada país para o Brasil no ano de 2007. 
O transporte de petróleo extraído até as refinarias brasileiras é realizado por meio de oleodutos e devido à indisponibilidade de dados nacionais e para a atividade em questão, este não foi considerado no estudo para não prejudicar sua aplicabilidade.

O transporte via duto tem aspectos muito particulares, pois dependem das propriedades físicas dos insumos a serem transportados e das diferenças de relevo na região onde o duto está instalado. Considerando a não disponibilidade desses dados referentes ao transporte via duto pelas empresas do setor de fertilizantes nitrogenados, nenhuma atividade de transporte dutoviário foi considerada neste estudo.

No que se refere aos dados que constituem o subsistema de produção de amônia por reforma catalítica com vapor de água, estes levaram em conta as composições médias dos insumos utilizados pelos fabricantes brasileiros (gás natural e gás de refinaria).

Em relação ao subsistema de produção de amônia por oxidação parcial foi considerado o único insumo utilizado pelo produtor brasileiro, qual seja, resíduo asfáltico.

Para o subsistema separação do ar foram incluídos os aspectos associados às operações do processo Linde, as quais foram descritas anteriormente neste capítulo.

No que diz respeito aos dados que compõe o subsistema de produção de ácido nítrico, estes consideraram as operações que constituem o processo Ostwald, apresentadas anteriormente, por meio da oxidação catalítica da amônia proveniente da reforma de gás de refinaria.

Para o subsistema de produção de ácido sulfúrico, foram considerados dados associados à obtenção do ácido por enxofre elementar e ao processo conhecido como dupla absorção. A adoção do referido processo se deve ao fato de este ser o mais empregado atualmente no país, apresentar maior rendimento e menores emissões de óxidos de enxofre. 
O subsistema de produção de ácido cianídrico considerou aspectos ambientais associados à operação de oxidação catalítica de gás natural e amônia proveniente do processo de reforma de gás natural.

Os dados que compõe o subsistema de produção de nitrato de amônio consideraram que a amônia necessária à sua fabricação foi proveniente do processo de reforma catalítica de gás de refinaria e que o ácido nítrico necessário foi obtido através da referida amônia.

Em relação aos dados que constituem o subsistema de produção de sulfato de amônio via síntese, estes levaram em conta que o ácido sulfúrico foi obtido pelo processo de dupla absorção através de enxofre elementar e de amônia produzida através do processo de reforma catalítica.

Os dados que constituem o subsistema de geração e distribuição de eletricidade no Brasil levaram em conta que a energia elétrica produzida no país foi proveniente de três fontes: hidroelétrica, termoelétrica e nuclear.

Os processos elementares denominados produção de acetona, produção de acetona cianidrina e produção de metanol, compreendidos no sistema de produto do sulfato de amônio obtido como subproduto da produção de metacrilato de metila, não foram incluídos pelo fato de representarem parcelas muito pequenas na quantidade total de materiais que entram no referido sistema.

O enxofre elementar foi considerado neste trabalho como fluxo elementar, ou seja, nenhum aspecto ambiental foi atribuído à atividade de extração deste recurso natural. Pode-se destacar que a não disponibilidade de dados relacionados a tal atividade torna essa consideração necessária, uma vez que $82 \%$ do enxofre elementar consumido no Brasil são de origem importada, o que dificulta a identificação da origem do insumo. Contudo, esta consideração não deixa de ser razoável já que a operação de extração se baseia na fusão do enxofre através do bombeamento de água superaquecida e na injeção de ar comprimido para trazê-lo à superfície. 
Não foram considerados no escopo de este estudo os aspectos ambientais associados ao transporte de enxofre elementar importado para o país.

Nos três sistemas de produto apresentados neste estudo não foram considerados os aspectos ambientais associados à produção de catalisadores $\mathrm{e}$ de solventes.

Os aspectos ambientais associados à obtenção dos recursos necessários para a construção de instalações industriais e de equipamentos de processo; bem como, os aspectos relacionados a derramamentos ou vazamentos acidentais, a efluentes sanitários e ao transporte de funcionários para os locais de trabalho não foram considerados nos inventários apresentados neste estudo. 


\subsection{Análise do inventário}

Esta etapa do projeto constitui-se basicamente: da identificação dos aspectos ambientais associados aos modelos representativos dos sistemas de produto; da quantificação desses aspectos, por meio de uma coleta de dados; e do tratamento ou adequação dos dados obtidos a uma mesma base.

A coleta dos dados necessários para a elaboração dos inventários é constituída essencialmente pelo envio de questionários às empresas brasileiras, do setor de fertilizantes nitrogenados, produtoras de uréia, nitrato de amônio e sulfato de amônio.

Quando da indisponibilidade de dados das empresas, as informações serão obtidas de literatura específica e de bancos de dados que se assemelham às condições brasileiras, guardadas as devidas precauções.

Assim sendo, com o intuito de verificar a disponibilidade de informações de cunho ambiental para os processos de fabricação presentes na cadeia produtiva de fertilizantes nitrogenados efetuou-se uma pesquisa em publicações técnicas (Best available techniques for pollution prevention and control in the european fertilizer industry) da European Fertilizer Manufacturers Association (EFMA), em um banco de dados de periódicos e livros (SpringerLink), em um banco de dados específico de ACV (ECOINVENT CENTRE, 2004) e em bancos de dados contidos em dois programas computacionais de ACV, quais sejam, SimaPro 7.0 (PRé-Consultants, 2006) e GaBi 4 (2004) para suprir uma possível ausência momentânea de dados nacionais.

A seguir são apresentadas informações referentes aos dados coletados e tratados para os subsistemas. 


\subsubsection{Inventário de ciclo de vida do subsistema do petróleo consumido no Brasil}

a) Coleta de dados

Por meio de uma pesquisa realizada por VIANNA (2006) em trabalhos acadêmicos e em bancos de dados de programas computacionais (SimaPro 7.0, PRé-Consultants 2006 e GaBi 4, 2004) encontrou-se, na base de dados $B R$ Crude Oil Mix do software GaBi 4 (2004), o inventário do petróleo consumido no Brasil, o qual inclui aspectos ambientais associados às atividades de extração em terra e em mar no Brasil; bem como o petróleo importado a ser refinado no país.

Os aspectos ambientais associados à infra-estrutura da operação de extração, tanto em terra como em mar, tais como produção de materiais necessários à construção de equipamentos de perfuração e de plataformas não foram incluídos no estudo.

Segundo VIANNA (2006), esse inventário considera que para cada 1 tonelada de petróleo cerca de 0,083 toneladas são perdidos no transporte até a refinaria. Foram incluídas as referidas perdas e, assim sendo, a quantidade necessária de petróleo passou a ser de 1,0905 toneladas.

Segue a tabela 27 referindo-se ao inventário de 1,0905 toneladas de petróleo consumido no Brasil. 


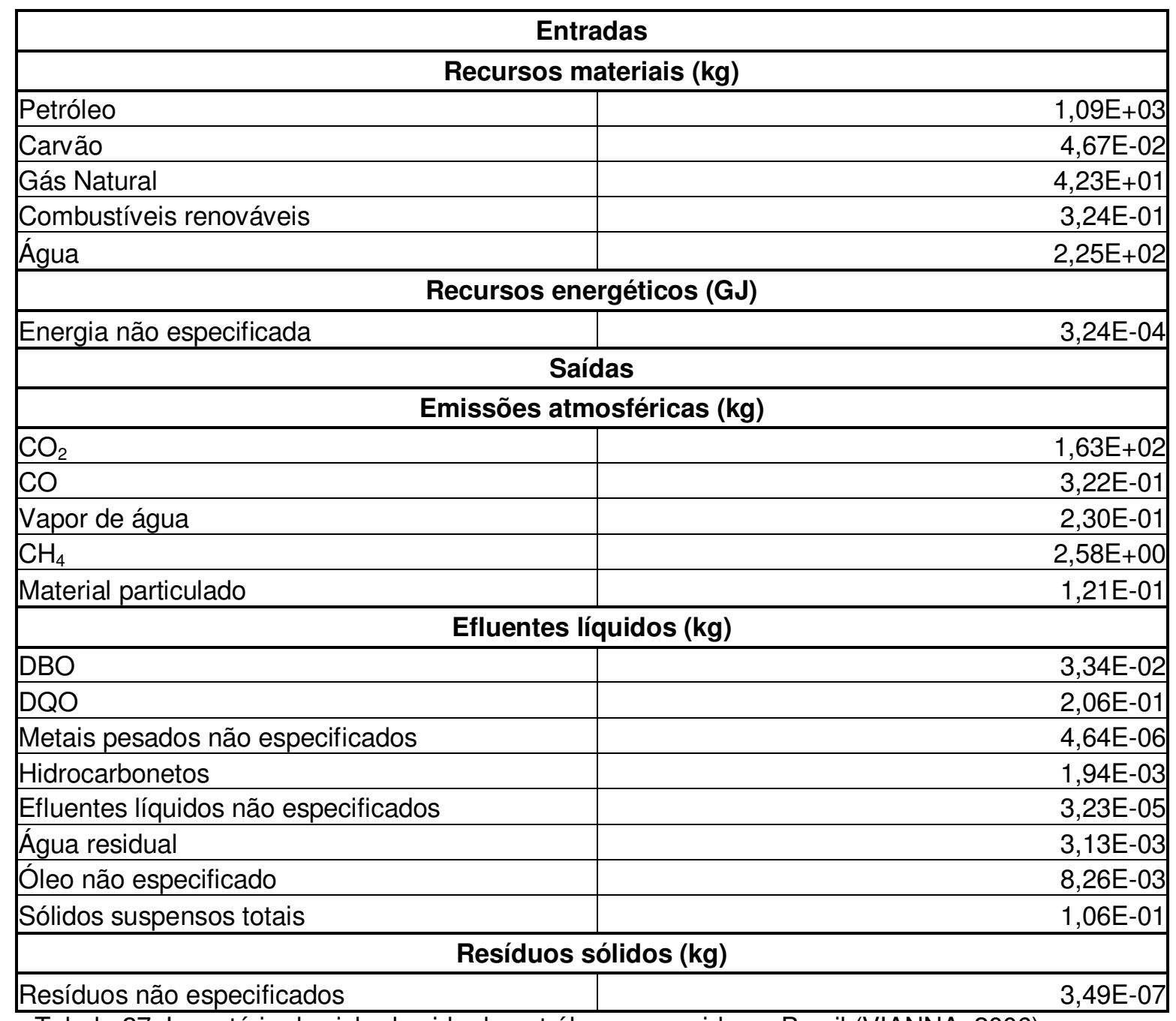

Tabela 27: Inventário de ciclo de vida do petróleo consumido no Brasil (VIANNA, 2006).

b) Tratamento dos dados

Para este trabalho é necessário disponibilizar inventários para três derivados de petróleo: o resíduo asfáltico, produzido na Refinaria Presidente Getúlio Vargas em Araucária - PR (REPAR), o qual faz parte do sistema da uréia brasileira; o gás combustível de refinaria, produzido pela Refinaria Presidente Bernardes em Cubatão - SP (RPBC), contido nos sistemas de produto do nitrato e do sulfato de amônio; e a nafta, produzida na Refinaria 
Landulpho Alves de Mataripe em São Francisco do Conde - BA (RELAM), pertencente ao sistema do sulfato de amônio.

Dados coletados junto à Agência Nacional de Petróleo - ANP (ANP, 2008b) revelaram que o volume de petróleo refinado pela REPAR no ano de 2007 foi de $9.834 .311 \mathrm{~m}^{3}$. Sendo a massa específica média do petróleo processado no país, em 2007, igual a $870 \mathrm{~kg} / \mathrm{m}^{3}$ (MME, 2008), teremos uma massa de petróleo refinado igual a 8.555.850,57 toneladas, a qual correspondeu à produção, de acordo com a tabela 28 , de $227.503,8$ toneladas de resíduo asfáltico. Utilizando-se então as massas citadas de petróleo e de resíduo asfáltico, pode-se concluir que para a obtenção de uma tonelada de resíduo asfáltico são necessárias 37,61 toneladas de petróleo.

Segundo a Fosfertil S. A. (FOSFERTIL, 2005) são necessários $1.083 \mathrm{~kg}$ para se produzir 1,217 toneladas de amônia (2,17 toneladas de uréia). Desse modo, serão necessárias 40,73 toneladas de petróleo para se produzir $1083 \mathrm{~kg}$ de resíduo asfáltico (quantidade para atender ao fluxo de referência de 2,17 toneladas de uréia).

Segue a tabela 28 com os dados da Refinaria Presidente Getúlio Vargas - REPAR para o ano de 2007.

\begin{tabular}{|c|c|c|c|c|c|c|}
\hline $\begin{array}{c}\text { Derivados do } \\
\text { petróleo da REPAR } \\
\text { em Araucária (PR) }\end{array}$ & $\begin{array}{l}\text { (1) Produção } \\
\text { em } 2007\left(m^{3}\right)\end{array}$ & $\begin{array}{c}\text { (2) Massa } \\
\text { específica } \\
\left(\mathrm{kg} / \mathrm{m}^{3}\right)\end{array}$ & $\begin{array}{l}(3)=(1) \times(2) \\
\text { Massa (kg) }\end{array}$ & $\begin{array}{l}\text { (4) Poder } \\
\text { calorífico } \\
\text { (kcal / kg) }\end{array}$ & $\begin{array}{c}(5)=(3) \times(4) \\
\text { Energia (kcal) }\end{array}$ & $\begin{array}{c}\text { Fator de } \\
\text { alocação (\%) }\end{array}$ \\
\hline Gasolina automotiva & 2.574 .400 & 740 & 1905056000 & 10.400 & $1,98126 \mathrm{E}+13$ & 24,05 \\
\hline GLP & 1.013 .625 & 550 & 557493750 & 11.100 & $6,18818 \mathrm{E}+12$ & 7,51 \\
\hline Óleo combustível & 1.239 .816 & 1.000 & 1239816000 & 9.590 & $1,18898 \mathrm{E}+13$ & 14,44 \\
\hline Óleo diesel & 4.363 .242 & 840 & 3665123280 & 10.100 & $3,70177 \mathrm{E}+13$ & 44,94 \\
\hline $\begin{array}{l}\text { Querosene de } \\
\text { aviação }\end{array}$ & 162.527 & 790 & 128396330 & 10.400 & $1,33532 \mathrm{E}+12$ & 1,62 \\
\hline Querosene iluminante & 3.976 & 790 & 3141040 & 10.400 & 32666816000 & 0,04 \\
\hline Asfalto & 255.699 & 1.040 & 265926960 & 9.790 & $2,60342 \mathrm{E}+12$ & 3,16 \\
\hline Nafta & 99.241 & 720 & 71453520 & 10.630 & $7,59551 \mathrm{E}+11$ & 0,92 \\
\hline Solvente & 51.958 & 740 & 38448920 & 10.550 & $4,05636 \mathrm{E}+11$ & 0,49 \\
\hline Resíduo asfáltico & 260.600 & 873 & 227503800 & 10.200 & $2,32054 \mathrm{E}+12$ & 2,82 \\
\hline Total & 10.025 .084 & & 8102359600 & & $8,23655 E+13$ & 100,00 \\
\hline
\end{tabular}

Tabela 28: Dados da refinaria REPAR para o ano de 2007 (1) ANP, 2008c; (2) MME, 2008; (4) MME, 2008. 
No que se refere ao gás combustível de refinaria, este é empregado no sistema de produto do nitrato de amônio e é produzido na Refinaria Presidente Bernardes - RPBC em Cubatão (SP). Desse modo, coletaram-se dados junto à ANP (ANP, 2008b) para a referida refinaria.

Segundo os dados levantados, o volume de petróleo processado pela RPBC em 2007 foi de 8.919.281 $\mathrm{m}^{3}$ e considerando, de acordo com o MME (2008), a massa específica média do petróleo processado no Brasil, em 2007, igual a $870 \mathrm{~kg} / \mathrm{m}^{3}$, calculou-se a massa de petróleo refinado igual a 7.759.774,47 toneladas.

Como a produção de gás de refinaria pela RPBC foi, de acordo com a tabela 29 , de 89.388 toneladas, concluiu-se que para a produção de uma tonelada de gás de refinaria foram necessárias 86,81 toneladas de petróleo.

De acordo com a Fosfertil S. A. (FOSFERTIL, 2005) são necessários $730,2 \mathrm{~kg}$ de gás de refinaria para se produzir 608,6 kg de amônia $(2,941$ toneladas de $\mathrm{NH}_{4} \mathrm{NO}_{3}$ ).

Portanto, para se produzir $730,2 \mathrm{~kg}$ de gás de refinaria (quantidade necessária para atender ao fluxo de referência de 2,941 toneladas de nitrato de amônio) serão necessárias 63,39 toneladas de petróleo da RPBC.

A tabela 29 apresenta os dados da refinaria RPBC para o ano de 2007.

\begin{tabular}{|c|c|c|c|c|c|c|}
\hline $\begin{array}{l}\text { Derivados do petróleo da } \\
\text { RPBC em Cubatão (SP) }\end{array}$ & $\begin{array}{c}(1) \\
\text { Produção } \\
\text { em } 2007 \\
\left(\mathrm{~m}^{3}\right)\end{array}$ & $\begin{array}{l}\text { (2) Massa } \\
\text { específica } \\
\left(\mathrm{kg} / \mathrm{m}^{3}\right)\end{array}$ & $\begin{array}{l}(3)=(1) \times(2) \\
\text { Massa }(\mathrm{kg})\end{array}$ & $\begin{array}{l}\text { (4) Poder } \\
\text { calorífico } \\
\text { (kcal / kg) }\end{array}$ & $\begin{array}{c}(5)=(3) \times(4) \\
\text { Energia } \\
\text { (kcal) }\end{array}$ & $\begin{array}{l}\text { Fator de } \\
\text { alocação } \\
\text { (\%) }\end{array}$ \\
\hline Gasolina automotiva & 2.049 .348 & 740 & 1516517520 & 10.400 & $1,57718 \mathrm{E}+13$ & 22,15 \\
\hline Gasolina de aviação & 62.169 & 720 & 44761680 & 10.600 & $4,74474 \mathrm{E}+11$ & 0,67 \\
\hline GLP & 537.342 & 550 & 295538100 & 11.100 & $3,28047 \mathrm{E}+12$ & 4,61 \\
\hline Óleo combustível & 479.000 & 1.000 & 479000000 & 9.590 & $4,59361 \mathrm{E}+12$ & 6,45 \\
\hline Óleo diesel & 4.410 .507 & 840 & 3704825880 & 10.100 & $3,74187 \mathrm{E}+13$ & 52,54 \\
\hline Coque & 558.556 & 1.041 & 581456796 & 8.390 & $4,87842 \mathrm{E}+12$ & 6,85 \\
\hline Nafta & 192.115 & 720 & 138322800 & 10.630 & $1,47037 \mathrm{E}+12$ & 2,06 \\
\hline Solvente & 195.146 & 740 & 144408040 & 10.550 & $1,5235 \mathrm{E}+12$ & 2,14 \\
\hline Gás combustível de refinaria & 114.600 & 780 & 89388000 & 8.400 & $7,50859 \mathrm{E}+11$ & 1,05 \\
\hline Outros não-energéticos & 118.664 & 873 & 103593672 & 10.200 & $1,05666 \mathrm{E}+12$ & 1,48 \\
\hline Total & 8.717 .447 & & 7097812488 & & $7,12189 E+13$ & 100,00 \\
\hline
\end{tabular}

Tabela 29: Dados da refinaria RPBC para o ano de 2007 (1) ANP, 2008c; (2) MME, 2008; (4) MME, 2008. 
Analogamente, fez-se necessário efetuar os cálculos para outro derivado: a nafta, que compõe o sistema de produto do sulfato de amônio, produzida pela Refinaria Landulpho Alves de Mataripe - RLAM - no Estado da Bahia.

Segundo a ANP (2008b), o volume de petróleo processado na RLAM em 2007 foi de $15.036 .522 \mathrm{~m}^{3}$ e considerando, de acordo com o MME (2008), que a massa específica média do petróleo processado no país, em 2007, foi $870 \mathrm{~kg}$ $/ \mathrm{m}^{3}$, calculou-se a massa de petróleo igual a 13.081.774,14 toneladas.

Conforme pode ser visto na tabela 30 , a produção de nafta na referida refinaria foi de 1.390.772,16 toneladas e assim, foi possível determinar que para a produção de uma tonelada de nafta foram necessárias 9,406 toneladas de petróleo.

A quantidade de nafta necessária para atender ao fluxo de referência de 4,717 toneladas de sulfato de amônio, via subproduto da produção de 2,62 toneladas de caprolactama, é de 11,78 toneladas (BRASKEM, 2008). Por conta disso, para se obter essa massa de nafta serão necessárias 110,8 toneladas de petróleo da RLAM.

Dados coletados junto à UNIGEL (2006), permitiram calcular que as massas necessárias de nafta que correspondem ao fluxo de referência de 4,717 toneladas de sulfato de amônio, obtido como subproduto das fabricações de 29,48 toneladas de acrilonitrila e de 1,57 toneladas de metacrilato de metila são, respectivamente, iguais à 5,798 toneladas e $243,6 \mathrm{~kg}$.

Com base nesses dados, para a obtenção das quantidades de nafta mencionadas serão necessárias 54,54 toneladas e 2,29 toneladas de petróleo da RLAM, respectivamente, para as produções de acrilonitrila e metacrilato de metila.

Seguem na tabela 30 os dados referentes à refinaria RLAM para o ano de 2007. 


\begin{tabular}{|c|c|c|c|c|c|c|}
\hline $\begin{array}{c}\text { Derivados do petróleo } \\
\text { da RLAM (BA) }\end{array}$ & $\begin{array}{l}\text { (1) Produção } \\
\text { em } 2007\left(m^{3}\right)\end{array}$ & $\begin{array}{c}\text { (2) Massa } \\
\text { específica } \\
\left(\mathrm{kg} / \mathrm{m}^{3}\right)\end{array}$ & $\begin{array}{l}(3)=(1) \times(2) \\
\text { Massa }(\mathrm{kg})\end{array}$ & $\begin{array}{l}\text { (4) Poder } \\
\text { calorífico } \\
\text { (kcal / kg) }\end{array}$ & $\begin{array}{c}(5)=(3) \times(4) \\
\text { Energia (kcal) }\end{array}$ & $\begin{array}{c}\text { Fator de } \\
\text { alocação } \\
\text { (\%) }\end{array}$ \\
\hline Gasolina automotiva & 2.533 .878 & 740 & 1875069720 & 10.400 & $1,95007 \mathrm{E}+13$ & 15,34 \\
\hline GLP & 1.112 .471 & 550 & 611859050 & 11.100 & $6,79164 \mathrm{E}+12$ & 5,34 \\
\hline Óleo combustível & 4.058 .697 & 1.000 & 4058697000 & 9.590 & $3,89229 \mathrm{E}+13$ & 30,62 \\
\hline Óleo diesel & 4.520 .810 & 840 & 3797480400 & 10.100 & $3,83546 \mathrm{E}+13$ & 30,17 \\
\hline Querosene de aviação & 270.258 & 790 & 213503820 & 10.400 & $2,22044 \mathrm{E}+12$ & 1,75 \\
\hline Querosene iluminante & 3.668 & 790 & 2897720 & 10.400 & 30136288000 & 0,02 \\
\hline Asfalto & 91.593 & 1.040 & 95256720 & 9.790 & $9,32563 \mathrm{E}+11$ & 0,73 \\
\hline Nafta & 1.931 .628 & 720 & 1390772160 & 10.630 & $1,47839 \mathrm{E}+13$ & 11,63 \\
\hline Solvente & 7.700 & 740 & 5698000 & 10.550 & 60113900000 & 0,05 \\
\hline Lubrificantes & 108.277 & 880 & 95283760 & 10.120 & $9,64272 \mathrm{E}+11$ & 0,76 \\
\hline Parafina & 113.807 & 864 & 98329248 & 10.800 & $1,06196 \mathrm{E}+12$ & 0,84 \\
\hline Outros não energéticos & 392.805 & 873 & 342918765 & 10.200 & $3,49777 \mathrm{E}+12$ & 2,75 \\
\hline Total & 15.145 .592 & & 12587766363 & & 1,27121E+14 & 100,00 \\
\hline
\end{tabular}

Tabela 30: Dados da refinaria RLAM para o ano de 2007 (1) ANP, 2008c; (2) MME, 2008; (4) MME, 2008.

Com os cálculos efetuados, de acordo com as informações anteriores e com o inventário de aspectos associados ao petróleo consumido no Brasil, disponibilizaram-se os inventários de:

I) 40,73 toneladas de petróleo da REPAR necessário à produção de $1083 \mathrm{~kg}$ de resíduo asfáltico utilizado na produção de amônia por oxidação parcial;

II) 63,39 toneladas de petróleo da RPBC necessárias à obtenção de 730,2 kg de gás combustível de refinaria utilizado na fabricação da amônia por reforma catalítica;

II) 110,8 toneladas para produção de 11,78 toneladas de nafta da RLAM necessária à obtenção de caprolactama;

IV) 54,54 toneladas para a produção de 5,798 toneladas de nafta da RLAM necessária à obtenção de acrilonitrila; e

V) 2,29 toneladas de petróleo para a produção de $243,6 \mathrm{~kg}$ de nafta da RLAM consumida na fabricação de metacrilato de metila.

Tais inventários são apresentados no apêndice $A 1$, ao final de este documento. 


\subsubsection{Inventário de ciclo de vida do transporte marítimo de petróleo importado para o Brasil}

a) Coleta de dados

Considerando a ausência momentânea de dados precisos e confiáveis para retratar o perfil de aspectos ambientais associados ao transporte no Brasil e a importância de este subsistema para o modelo ora em desenvolvimento, selecionou-se em SimaPro 7.0 (PRé-CONSULTANTS, 2006), uma base de dados já constituída, que fosse capaz de representar com a maior consistência possível o subsistema de transporte.

Desse modo, para o transporte marítimo de petróleo importado foi empregada a base de dados, Tanker I - IDEMAT 2001, a qual considera um navio de médio porte movido a óleo diesel e a óleo combustível pesado, com capacidade de 88.750 toneladas e que considera o retorno do navio vazio à sua origem (PRé-CONSULTANTS, 2006a).

A adoção da referida base de dados se deve ao fato de essa ser referente ao transporte em um navio que mais se aproximava daqueles utilizados no transporte de petróleo dos países exportadores para o Brasil, em termos de combustíveis e de capacidade, a qual segundo a PETROBRAS (2004) está compreendida entre 70.000 e 100.000 toneladas.

Os dados brutos referentes ao transporte marítimo de $1 \mathrm{t} . \mathrm{km}$ de petróleo importado são apresentados na tabela 31 a seguir. Tais dados são constituídos somente pelas emissões associadas ao transporte em si. Nesses dados não constam os aspectos associados à produção dos combustíveis, bem como os aspectos associados à infra-estrutura do navio. 


\begin{tabular}{|c|c|}
\hline \multicolumn{2}{|c|}{ Entradas (kg) } \\
\hline Óleo combustível pesado & 0,00735 \\
\hline Óleo diesel & 0,00063 \\
\hline \multicolumn{2}{|c|}{ Saídas } \\
\hline \multicolumn{2}{|c|}{ Emissões Atmosféricas (kg) } \\
\hline $\mathrm{SO}_{2}$ & $3,70 \mathrm{E}-04$ \\
\hline $\mathrm{CO}_{2}$ & 2,32E-02 \\
\hline $\mathrm{CO}$ & $7,00 \mathrm{E}-05$ \\
\hline $\mathrm{NOx}$ & $4,40 \mathrm{E}-04$ \\
\hline Hidrocarbonetos (CxHy) & $4,00 \mathrm{E}-05$ \\
\hline
\end{tabular}

Foram considerados no inventário do subsistema de transporte os aspectos ambientais associados à produção dos combustíveis do navio (óleo combustível pesado e óleo diesel).

Tais aspectos foram obtidos das seguintes bases de dados (do mesmo banco de dados - IDEMAT 2001 - que contém a base de dados selecionada para os dados brutos de transporte marítimo), do programa computacional SimaPro 7.0: Diesel I - IDEMAT 2001 (PRé-CONSULTANTS, 2006b) e Heavy fuel oil I - IDEMAT 2001 (PRé-CONSULTANTS, 2006c).

As bases de dados mencionadas admitiram que para as obtenções de 1 $\mathrm{kg}$ de óleo diesel e de $1 \mathrm{~kg}$ de óleo combustível pesado foram necessários 1,032 kg e 1,014 kg de petróleo, respectivamente. Não estavam disponíveis, em tais bases de dados, informações referentes à origem do petróleo extraído, ao critério de alocação aplicado e às operações necessárias a produção dos combustíveis na refinaria.

$\mathrm{Na}$ tabela 32 encontram-se os aspectos ambientais associados às produções dos combustíveis do navio; quais sejam: óleo diesel e óleo combustível pesado. 


\begin{tabular}{|c|c|c|}
\hline & $\begin{array}{c}\text { Produção de } 0,00063 \mathrm{~kg} \text { de } \\
\text { óleo diesel }\end{array}$ & $\begin{array}{l}\text { Produção de } 0,00735 \mathrm{~kg} \text { de } \\
\text { óleo combustivel pesado }\end{array}$ \\
\hline \multicolumn{3}{|c|}{ Entradas } \\
\hline \multicolumn{3}{|c|}{ Recursos materiais (kg) } \\
\hline Petróleo & $6,50 \mathrm{E}-04$ & $7,45 \mathrm{E}-03$ \\
\hline Gás natural & $3,90 \mathrm{E}-05$ & \\
\hline Carvão & $3,21 \mathrm{E}-06$ & \\
\hline Água & $1,32 \mathrm{E}-04$ & \\
\hline \multicolumn{3}{|c|}{ Recursos energéticos (GJ) } \\
\hline Energia não especificada & & $2,78 \mathrm{E}-06$ \\
\hline \multirow{2}{*}{\multicolumn{3}{|c|}{$\begin{array}{c}\text { Saídas } \\
\text { Emissões atmosféricas (kg) }\end{array}$}} \\
\hline & & \\
\hline $\mathrm{CO}_{2}$ & $1,79 \mathrm{E}-04$ & \\
\hline $\mathrm{CO}$ & $5,04 \mathrm{E}-08$ & \\
\hline NOx & $1,83 \mathrm{E}-06$ & \\
\hline Hidrocarbonetos (CxHy) & $1,83 \mathrm{E}-06$ & \\
\hline SOx & $1,13 \mathrm{E}-06$ & \\
\hline Metais & $6,30 \mathrm{E}-10$ & \\
\hline Material particulado & $2,14 \mathrm{E}-07$ & \\
\hline COV - exceto metano & & $1,29 \mathrm{E}-06$ \\
\hline \multicolumn{3}{|c|}{ Efluentes líquidos (kg) } \\
\hline DQO & $6,30 \mathrm{E}-09$ & \\
\hline DBO & $3,15 \mathrm{E}-09$ & \\
\hline İons Metálicos & $3,15 \mathrm{E}-09$ & \\
\hline Cloretos $\left(\mathrm{Cl}^{-}\right)$ & $6,30 \mathrm{E}-09$ & \\
\hline Hidrocarbonetos (CxHy) & $1,26 \mathrm{E}-08$ & \\
\hline Óleo não especificado & & $4,34 \mathrm{E}-08$ \\
\hline \multicolumn{3}{|c|}{ Resíduos sólidos (kg) } \\
\hline Resíduos não especificados & $1,39 \mathrm{E}-06$ & \\
\hline Resíduos sólidos oleosos & & $1,03 \mathrm{E}-04$ \\
\hline
\end{tabular}

Tabela 32: Inventário de ciclo de vida das produções de óleo diesel e óleo combustível pesado (PRé-CONSULTANTS, 2006b; PRé-CONSULTANTS, 2006c).

Segue na tabela 33 o inventário consolidado do transporte marítimo de petróleo, para 1 t.km, com os aspectos associados ao transporte em si e à produção dos combustíveis. Contudo, os aspectos associados à construção do navio não foram considerados devido à indisponibilidade de informações precisas. 


\begin{tabular}{|c|c|}
\hline \multicolumn{2}{|c|}{ Entradas } \\
\hline \multicolumn{2}{|c|}{ Recursos materiais (kg) } \\
\hline Petróleo & $8,10 \mathrm{E}-03$ \\
\hline Carvão & $3,21 \mathrm{E}-06$ \\
\hline Gás natural & $3,90 \mathrm{E}-05$ \\
\hline Água & 1,32E-04 \\
\hline \multicolumn{2}{|c|}{ Recursos energéticos (GJ) } \\
\hline Energia não especificada & $2,78 \mathrm{E}-06$ \\
\hline \multicolumn{2}{|c|}{ Saídas } \\
\hline \multicolumn{2}{|c|}{ Emissões atmosféricas (kg) } \\
\hline $\mathrm{CO}_{2}$ & $2,33 \mathrm{E}-02$ \\
\hline $\mathrm{CO}$ & $7,01 \mathrm{E}-05$ \\
\hline Hidrocarbonetos & $4,18 \mathrm{E}-05$ \\
\hline Metais & $6,30 \mathrm{E}-10$ \\
\hline NOx & $4,42 E-04$ \\
\hline SOx & 3,71E-04 \\
\hline COV - exceto metano & $1,29 \mathrm{E}-06$ \\
\hline Material particulado & $2,14 \mathrm{E}-07$ \\
\hline \multicolumn{2}{|c|}{ Efluentes líquidos (kg) } \\
\hline DBO & $3,15 \mathrm{E}-09$ \\
\hline DQO & $6,30 \mathrm{E}-09$ \\
\hline Hidrocarbonetos & $1,26 \mathrm{E}-08$ \\
\hline Íons metálicos & $3,15 \mathrm{E}-09$ \\
\hline Óleo não especificado & 4,34E-08 \\
\hline Cloretos (Cl-) & $6,30 \mathrm{E}-09$ \\
\hline \multicolumn{2}{|c|}{ Resíduos sólidos (kg) } \\
\hline Resíduos não especificados & 1,39E-06 \\
\hline Resíduos sólidos oleosos & $1,03 E-04$ \\
\hline
\end{tabular}

Tabela 33: Inventário de ciclo de vida do transporte marítimo de 1 t.km de petróleo importado.

O transporte de petróleo extraído até as refinarias brasileiras é realizado por meio de oleodutos e devido à indisponibilidade de dados nacionais e confiáveis para a atividade de transporte em questão, esta não foi considerada no estudo para não prejudicar sua aplicabilidade. 
b) Tratamento dos dados

O tratamento dos dados para o transporte marítimo de petróleo importado para o Brasil consistiu essencialmente: da determinação da distância entre o Brasil e os países exportadores de petróleo; da quantidade total de petróleo importado pelo o Brasil no ano de 2007; do percentual de cada país exportador de petróleo para o Brasil no referido ano; e do percentual total de petróleo importado pelo Brasil em 2007.

A determinação da distância média calculada para este estudo foi apresentada anteriormente no item 5.1.2.4.4 deste documento.

Convém aqui lembrar que para este subsistema, de transporte marítimo de petróleo importado, a quantidade a ser transportada deve ser de $20 \%$ de todo o petróleo consumido no Brasil, uma vez que essa quantidade se refere ao petróleo que foi importado para o país no ano de 2007 (ANP, 2008d).

Assim sendo, para o inventário de transporte marítimo de petróleo importado foram considerados o transporte de 20\% de: 40,73 toneladas de petróleo para a obtenção de resíduo asfáltico (sistema de produto da uréia); 63,39 toneladas de petróleo para o gás de refinaria (sistemas de produto do nitrato de amônio e do sulfato de amônio via síntese); 110,8 toneladas de petróleo para a produção de nafta (sistema de produto do sulfato de amônio via subproduto da produção de caprolactama); 54,54 toneladas de petróleo para a produção de nafta (sistema de produto do sulfato de amônio via subproduto da produção de acrilonitrila); e de 2,29 toneladas de petróleo para a produção de nafta (sistema de produto do sulfato de amônio via subproduto da produção de metacrilato de metila), por $8.457 \mathrm{~km}$ em todos os casos.

Assim sendo, encontramos os seguintes valores para os inventários de transporte: 68.891 t.km para o sistema de produto da uréia; 107.218 t.km para o sistema de produto do nitrato de amônio e também para o sulfato de amônio obtido via síntese; 187.407 t.km para o sulfato de amônio obtido como 
subproduto da produção de caprolactama; 92.249 t.km para o sulfato de amônio obtido como subproduto da produção de acrilonitrila; e 3.874 t.km para o sulfato de amõnio obtido como subproduto da produção de metacrilato de metila.

Esses inventários de transporte encontram-se no apêndice A2, ao final de este documento.

\subsubsection{Inventário de ciclo de vida do subsistema de refino do petróleo}

a) Coleta de dados

O Grupo de Prevenção da Poluição (GP2) já possui um estudo que engloba o subsistema de refino do petróleo. Assim sendo, para retratar o perfil de aspectos ambientais associados à operação de refino do petróleo no Brasil foram coletados dados de VIANNA (2006) que se referem ao refino de 1 tonelada de petróleo em uma refinaria que apresenta as seguintes operações: dessalinização, desidratação, dessulfurização, destilação atmosférica, destilação à vácuo, reforma catalítica e craqueamento.

Admitiu-se para este subsistema que o processo de refino é razoavelmente padronizado entre as refinarias, decidindo-se assim utilizar dados internacionais para a quantificação dos aspectos ambientais de este processo.

O refino de petróleo no Brasil é detido pela PETROBRAS S. A. e segundo a empresa (PETROBRAS, 2008b) as tecnologias utilizadas não se distanciam das utilizadas internacionalmente, mesmo no que se refere ao controle e prevenção da poluição, pois a empresa declara que todos os recursos de engenharia estão sendo adotados para diminuir os impactos do processo de refino sobre o meio ambiente e até por que, a mesma vem atendo às pressões do mercado e exigências ambientais.

Além do mais, segundo informações da PETROBRAS (2008b), o Brasil está entre os países detentores de tecnologia de ponta da indústria do petróleo 
disponível apenas em empresas de países desenvolvidos. O patamar tecnológico alcançado pela empresa, nessa área, já lhe valeu reconhecimento em muitos eventos e premiações internacionais.

A empresa tem acesso à tecnologia de ponta. Os trabalhos da empresa na área se situam na liderança mundial, tanto no segmento exploratório como no desenvolvimento da produção (PETROBRAS, 2008b).

Pode-se concluir, portanto, que os dados utilizados apresentam boa aplicabilidade, uma vez que a tecnologia não se diferencia significativamente para o caso das refinarias brasileiras e, na ausência de dados mais precisos, estes foram aplicados diretamente.

$\mathrm{Na}$ tabela 34 são apresentados os dados brutos para o refino de 1 tonelada de petróleo.

\begin{tabular}{|c|c|}
\hline \multicolumn{2}{|c|}{ Entradas } \\
\hline \multicolumn{2}{|c|}{ Recursos materiais (kg) } \\
\hline Petróleo refinado no Brasil & $1,00 E+03$ \\
\hline \multicolumn{2}{|c|}{ Recursos energéticos (GJ) } \\
\hline Energia elétrica & $1,13 \mathrm{E}-01$ \\
\hline \multicolumn{2}{|c|}{ Saídas } \\
\hline \multicolumn{2}{|c|}{ Emissões atmosféricas (kg) } \\
\hline $\mathrm{CO}_{2}$ & $8,31 E+00$ \\
\hline $\mathrm{CO}$ & 2,63E-02 \\
\hline Hidrocarbonetos & 1,99E-05 \\
\hline $\mathrm{CH}_{4}$ & $3,80 \mathrm{E}-02$ \\
\hline NOx & 5,83E-03 \\
\hline SOx & 4,88E-03 \\
\hline Metil mercarptana & $1,00 \mathrm{E}-05$ \\
\hline $\mathrm{H}_{2} \mathrm{~S}$ & $2,09 \mathrm{E}-04$ \\
\hline COV - exceto metano & 9,56E-01 \\
\hline Material particulado & 1,01E-02 \\
\hline \multicolumn{2}{|c|}{ Efluentes líquidos (kg) } \\
\hline Óleo não especificado & $7,12 \mathrm{E}-03$ \\
\hline $\mathrm{Na}^{+}$ & 1,63E-02 \\
\hline Cloretos $\left(\mathrm{Cl}^{-}\right)$ & $2,43 E-02$ \\
\hline
\end{tabular}

Tabela 34: Inventário do subsistema do refino de $1 \mathrm{t}$ de petróleo (VIANNA, 2006). 
b) Tratamento dos dados

O tratamento dos dados do subsistema do refino do petróleo consistiu da adequação dos dados coletados às quantidades de 40,73 toneladas, 63,39 toneladas, 110,8 toneladas, 54,54 toneladas e 2,29 toneladas de petróleo, necessárias para as produções de: $1.083 \mathrm{~kg}$ de resíduo asfáltico, 730,2 kg de gás combustível de refinaria, 11,78 toneladas de nafta, 5,798 toneladas de nafta e $243,6 \mathrm{~kg}$ de nafta, respectivamente.

Os inventários para o refino de 40,73 toneladas, 63,39 toneladas, 110,8 toneladas, 54,54 toneladas e de 2,29 toneladas de petróleo encontram-se no apêndice $\mathrm{A} 3$ ao final de este documento.

\subsubsection{Inventário consolidado das produções de gás combustível de refinaria, de resíduo asfáltico e de nafta}

a) Coleta de dados

Os dados que constituem os inventários consolidados de aspectos ambientais das produções de gás combustível de refinaria, de resíduo asfáltico e de nafta foram obtidos dos seguintes subsistemas: do petróleo consumido no Brasil, do transporte de marítimo de petróleo importado e do refino do petróleo.

b) Tratamento dos dados

Como o gás combustível de refinaria, o resíduo asfáltico e a nafta não são os únicos produtos obtidos com o refinamento do petróleo, fez-se necessário ratear os aspectos ambientais entre todos os derivados para se obter os dados relativos apenas aos três produtos de interesse. Uma vez que 
os produtos derivados de interesse ao estudo são combustíveis, decidiu-se utilizar como critério a alocação por conteúdo energético.

Os fatores de alocação foram determinados com base nas quantidades produzidas de cada um dos derivados de petróleo no ano de 2007, de acordo com a ANP (2008c) e seus poderes caloríficos (MME, 2008), conforme pode ser observado nas tabelas 28,29 e 30 apresentadas anteriormente.

As quantidades produzidas dos derivados de petróleo utilizados nos sistemas de produto de este estudo forma obtidas das seguintes refinarias da Petrobras: RPBC, a qual produz o gás combustível de refinaria contido nos sistemas do nitrato de amônio e sulfato de amônio (via síntese); a REPAR, que produz o resíduo asfáltico empregado no sistema da uréia; e a RLAM, da qual se obtêm a nafta presente no sistema do sulfato de amônio (via subproduto).

O tratamento de dados consistiu da agregação dos aspectos ambientais dos subsistemas do petróleo consumido no Brasil (petróleo extraído no país e petróleo importado), do transporte de marítimo de petróleo importado e do refino do petróleo; com posterior aplicação dos devidos fatores de alocação (apresentados nas tabelas 28, 29 e 30) correspondentes ao gás de combustível de refinaria $(1,05 \%)$, ao resíduo asfáltico $(2,82 \%)$ e à nafta $(11,63 \%)$.

Assim sendo, obtiveram-se os inventários de aspectos ambientais consolidados para as produções de: $730,2 \mathrm{~kg}$ de gás de refinaria (apresentado no apêndice A4); $1083 \mathrm{~kg}$ de resíduo asfáltico (apêndice A5); 11,78 toneladas de nafta (apêndice A6); 5,798 toneladas de nafta (apêndice A7) e 243,6 kg de nafta (apêndice A8). 


\subsubsection{Inventário de ciclo de vida do subsistema geração e distribuição de energia elétrica no Brasil}

a) Coleta de dados

Os dados que compõem o inventário de ciclo de vida para a energia elétrica gerada e distribuída no país foram obtidos do artigo "Life Cycle Inventory for Eletric Energy in Brazil' (COLTRO; GARCIA; QUEIROZ, 2003), o qual apresenta dados para a geração de $1 \mathrm{GJ}$ de eletricidade no Brasil.

A principal razão da escolha desse inventário para compor os dados de este subsistema se deve ao fato de que, segundo os autores, na construção do modelo de produção de energia foram utilizados dados primários, ou seja, dados coletados diretamente nas companhias elétricas nacionais, combinados com dados do setor de produção.

Os dados que constituem o subsistema de geração e distribuição de eletricidade no Brasil levaram em conta que no país, 99,9\% de toda a energia produzida é proveniente de hidroelétricas, termoelétricas e usinas nucleares, sendo que $89 \%$ são oriundas da primeira fonte. Por essa razão, somente essas fontes foram consideradas neste estudo.

Para este subsistema incluíram-se também os combustíveis (gás natural, óleo diesel, óleo combustível e carvão) para a geração de energia termoelétrica. Os dados consideraram ainda as perdas de energia na transmissão e distribuição e a importação de energia elétrica.

Segue na tabela 35 o inventário do ciclo de vida da geração e distribuição de 1 GJ de eletricidade no Brasil. 


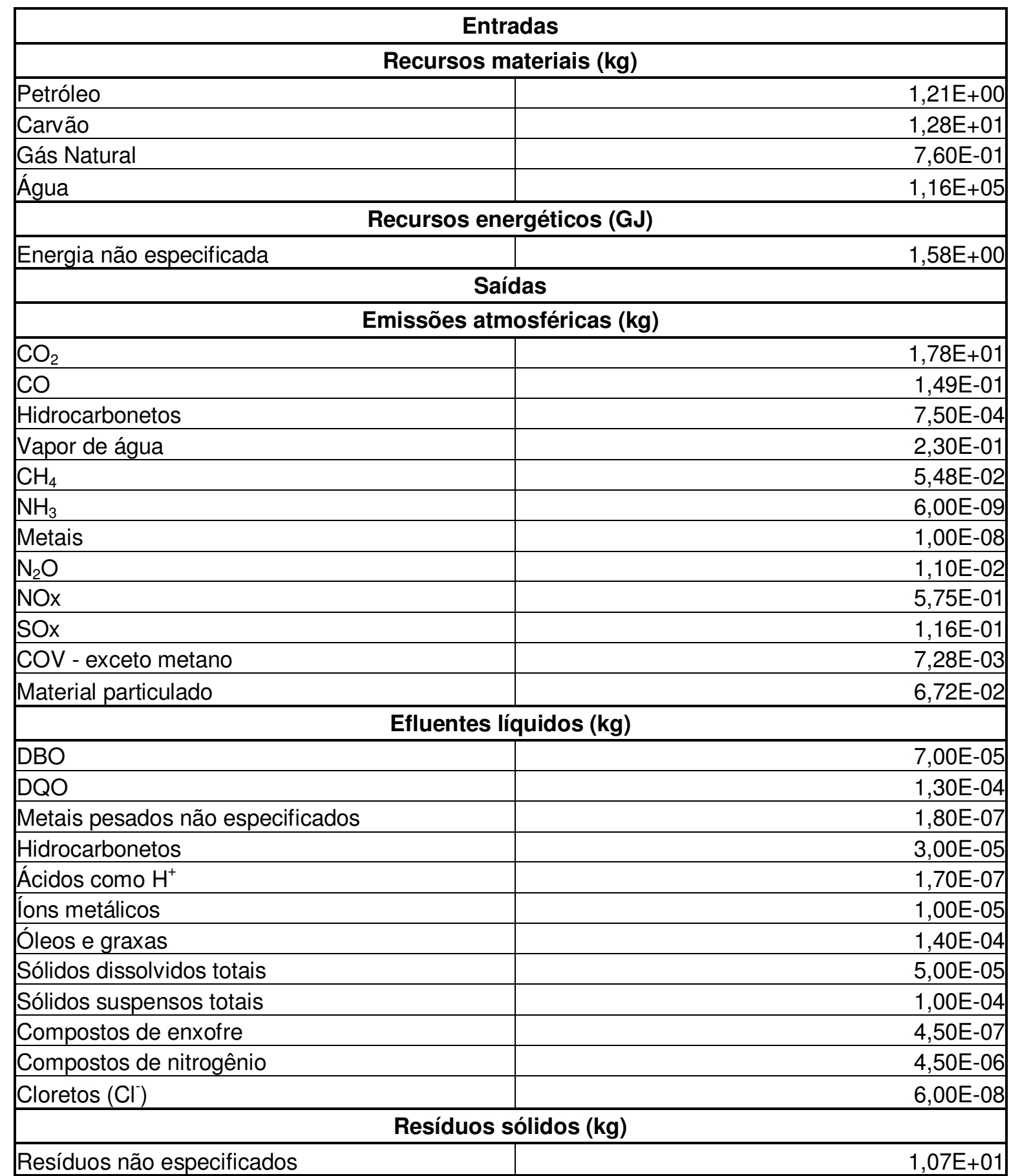

Tabela 35: Inventário de ciclo de vida da geração e distribuição de 1 GJ de energia elétrica no Brasil (COLTRO; GARCIA; QUEIROZ, 2003). 
b) Tratamento dos dados

Os dados que constituem o inventário da geração de energia elétrica no país foram posteriormente tratados e convertidos aos fluxos de referência dos sistemas de produto em estudo.

\subsubsection{Inventário de ciclo de vida da extração e beneficiamento de gás natural}

a) Coleta de dados

Os dados que compõem o inventário de ciclo de vida do beneficiamento de $1 \mathrm{~kg}$ de gás natural foram obtidos de SILVA; RIBEIRO; KULAY (2006) e consideraram a composição média do gás natural utilizado pela PETROBRAS/FAFEN (SAC PETROBRAS/FAFEN, 2005), a qual foi apresentada anteriormente no item 4.3.1.1 deste documento.

O referido inventário considerou que para a obtenção de $1 \mathrm{~kg}$ de gás natural beneficiado foram necessários $1,03 \mathrm{~kg}$ de gás natural bruto a ser extraído. A massa de $1,03 \mathrm{~kg}$ de gás natural bruto incluiu a quantidade de gás natural utilizada para geração de energia necessária às operações.

A referida massa de gás bruto também contabilizou perdas de 2,9\% devido a possíveis vazamentos de gás, no transporte de gás do local da extração até a unidade de processamento e nas etapas de processamento em si.

Para este subsistema, de extração e beneficiamento de gás natural, foram considerados os aspectos ambientais associados à operação de extração em terra e em mar, ao transporte por gasoduto até a UPGN e ao beneficiamento do gás em uma UPGN constituída pelas seguintes operações: separação de petróleo, remoção de compostos de enxofre com solvente; 
remoção de vapor de água com solvente e remoção de hidrocarbonetos condensáveis por fracionamento.

Os bens de capital, ou seja, os dados associados à infra-estrutura de cada operação não foram considerados no inventário. Segue, na tabela 36 , o inventário para $1 \mathrm{~kg}$ de gás natural beneficiado.

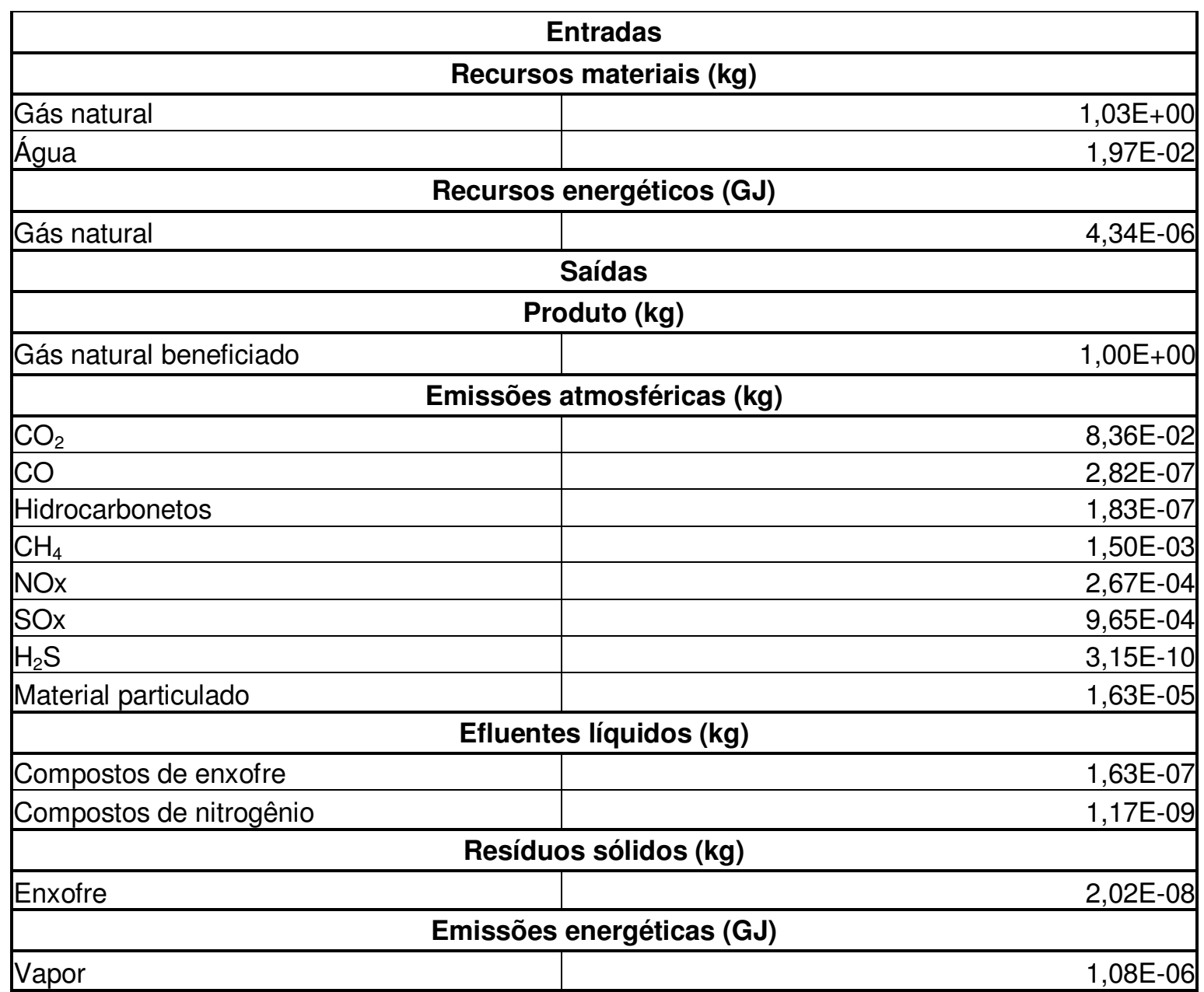

Tabela 36: Inventário de ciclo de vida para $1 \mathrm{~kg}$ de gás natural beneficiado (SILVA; RIBEIRO; KULAY, 2006).

b) Tratamento dos dados

O gás natural é utilizado como recurso material nos sistemas de produto da uréia pela PETROBRAS/FAFEN e do sulfato de amônio. 
No caso do sistema de produto da uréia, dados coletados junto a Fábrica de Fertilizantes Nitrogenados do Nordeste - FAFEN (SAC PETROBRAS/FAFEN, 2005) revelaram que para se produzir 1 tonelada de amônia (ou 0,822 toneladas de N) são necessários $760 \mathrm{~kg}$ de gás natural. Para a produção de 2,17 t (ou 1 tonelada de $\mathrm{N}$ ) de uréia da Fafen são necessários 1,217 toneladas de amônia.

Portanto, para termos 1,217 toneladas de amônia serão necessários 924,92 kg de gás natural. Por conta de essa informação, o tratamento dos dados de este subsistema consistiu da adequação dos valores coletados para a quantidade de 924,92 kg de gás natural.

No que se refere ao sistema de produto do sulfato de amônio, o emprego de gás natural, como recurso material, se dá de duas maneiras distintas:

I) nos subsistemas de produção de sulfato de amônio via síntese (UNIGEL), de produção de sulfato de amônio via subproduto da fabricação de caprolactama (BRASKEM) e de produção via subproduto da fabricação de acrilonitrila (UNIGEL), verificou-se que para a produção de 4,717 toneladas de sulfato de amônio (1 tonelada de $\mathrm{N}$ ) foram necessárias 1,217 toneladas de amônia e, portanto, $924,92 \mathrm{~kg}$ de gás natural. Contudo, como a produção de amônia também gera 1,411 toneladas de dióxido de carbono como subproduto, fez-se necessária à aplicação de um fator de alocação para distribuir os aspectos ambientais entre os produtos no subsistema de extração e beneficiamento de gás natural. Aplicando-se o critério de alocação por massa $\left[\frac{1,217}{(1,217+1,411)} \times 100\right]$ teremos $46,3 \%$ dos aspectos atribuídos à amônia; e

II) no subsistema de produção de sulfato de amônio como subproduto da fabricação de metacrilato de metila - MMA pela UNIGEL, verificou-se na tabela 46 que para a produção de 1,57 toneladas de MMA $(4,717$ toneladas de sulfato de amônio) foram necessárias 3,232 toneladas de ácido cianídrico e, desse modo, 2,456 toneladas de amônia. Logo, para atender à produção desejada foram necessárias 1,87 toneladas de gás natural. Face ao exposto, o 
tratamento dos dados consistiu da adequação dos aspectos apresentados na tabela 34 para 1,87 toneladas de gás natural, com a aplicação do devido fator de alocação para a amônia.

Os inventários de aspectos ambientais para $924,92 \mathrm{~kg}, 924,92 \mathrm{~kg}$ com fator de alocação de $46,3 \%$ e para 1,87 toneladas de gás natural com fator de alocação de $46,3 \%$ estão apresentados no apêndice A9, ao final de este documento.

\subsubsection{Inventário de ciclo de vida da geração de energia térmica através da queima de gás natural}

a) Coleta de dados

Considerando a ausência momentânea de dados genuinamente nacionais capazes de retratar o perfil de aspectos ambientais associados ao inventário desse subsistema, selecionou-se junto ao programa computacional SimaPro 7.0 uma base de dados já constituída, qual seja, Energy gas IDEMAT 2001 (PRé Consultants, 2006d). A base de dados selecionada apresenta os aspectos ambientais associados à geração de $38 \mathrm{MJ}$ de energia térmica por meio da combustão de $1 \mathrm{~kg}$ de gás natural.

Para este subsistema, somente a emissões atmosféricas associadas à geração de energia térmica proveniente da combustão controlada do gás foram consideradas.

Os aspectos ambientais associados à geração de $38 \mathrm{MJ}$ de energia térmica por meio da combustão de $1 \mathrm{~kg}$ de gás natural são apresentados na tabela 37 , a seguir. 


\begin{tabular}{|c|c|}
\hline \multicolumn{2}{|c|}{ Entradas } \\
\hline \multicolumn{2}{|c|}{ Recursos materiais (kg) } \\
\hline Gás natural & $1,00 \mathrm{E}+00$ \\
\hline \multicolumn{2}{|c|}{ Saídas } \\
\hline \multicolumn{2}{|c|}{ Produto (MJ) } \\
\hline Energia térmica & 38 \\
\hline \multicolumn{2}{|c|}{ Emissões atmosféricas (kg) } \\
\hline $\mathrm{CO}_{2}$ & $2,54 \mathrm{E}+00$ \\
\hline $\mathrm{CO}$ & 5,00E-05 \\
\hline NOx & 6,90E-03 \\
\hline SOx & $9,00 \mathrm{E}-05$ \\
\hline
\end{tabular}

Tabela 37: Inventário de ciclo de vida da geração de 38 MJ de energia térmica através da combustão de gás natural (PRé Consultants, 2006d).

b) Tratamento de dados

Das duas empresas produtoras de amônia para fins fertilizantes no Brasil, FOSFERTIL e PETROBRAS/FAFEN, apenas esta última emprega gás natural como fonte de hidrogênio para a produção de amônia e também para geração de energia.

Conforme mencionado no inventário do subsistema anterior, para termos 1,217 toneladas de amônia são necessários 924,92 kg de gás natural. Segundo a Petrobras/Fafen (SAC PETROBRAS/FAFEN, 2005), 65\% dessa quantidade do gás é empregada como matéria-prima e 35\% são usadas como combustível para geração de eletricidade em uma usina termoelétrica própria. A Petrobras/Fafen necessita, portanto, de $323,72 \mathrm{~kg}$ de gás natural para uso como combustível. Considerando, de acordo com o fabricante (SAC PETROBRAS/FAFEN, 2005), que o poder calorífico médio do gás natural utilizado pela empresa seja igual a 47,35 GJ / t, teremos 15,33 GJ de energia disponível para a massa de gás mencionada.

Como o poder calorífico do gás natural do inventário da tabela 26 é 38 GJ / t, para a geração de 15,33 GJ serão necessários 403,42 kg de gás. Desse modo, os aspectos ambientais, contidos na base de dados selecionada, foram 
adequados a essa massa de gás, obtendo-se o inventário de aspectos ambientais para a geração de 15,33 GJ de energia térmica proveniente da combustão do gás natural, o qual é mostrado no apêndice A10.

\subsubsection{Inventário de ciclo de vida do subsistema de separação criogênica do ar}

a) Coleta de dados

A FOSFERTIL S. A. dispõe de uma unidade de separação criogênica do ar na unidade industrial de Araucária, PR. Dessa unidade a empresa aproveita o oxigênio e nitrogênio, separados. De acordo com a FOSFERTIL (2005), o nitrogênio, o oxigênio e o argônio são extraídos do ar atmosférico de acordo com o processo Linde, processo empregado mundialmente.

A razão pela qual os dados que compõem o subsistema da separação criogênica do ar foram obtidos do inventário Air separation unit do documento Life Cycle Inventories of Chemicals do ECOINVENT CENTRE (2004a) é porque este se baseia no processo com operações semelhantes ao empregado pela FOSFERTIL S. A. O referido inventário se refere à separação de $1 \mathrm{~kg}$ de ar em seus maiores constituintes: nitrogênio, oxigênio e argônio.

Para o subsistema separação do ar, foram incluídos os aspectos associados às operações de: filtração do ar; remoção de vapor de água, de dióxido de carbono e de hidrocarbonetos; e à separação criogênica do ar por destilação. Os bens de capital não foram considerados.

Encontra-se na tabela 38, a seguir, o inventário de ciclo de vida para a separação de $1 \mathrm{~kg}$ de ar em seus maiores constituintes: nitrogênio, oxigênio e argônio. 


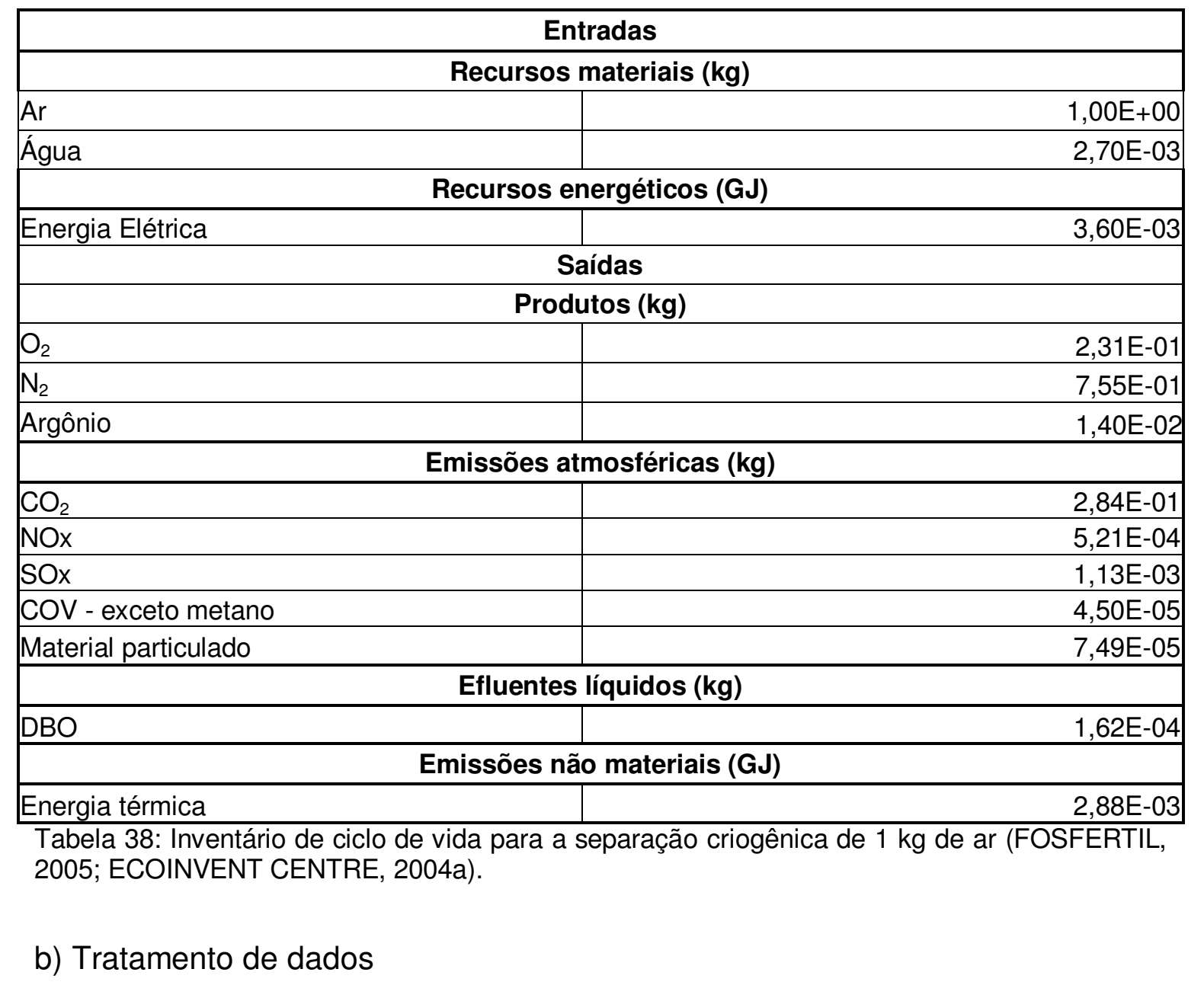

Para a produção de 1 tonelada de amônia pelo processo de oxidação parcial da FOSFERTIL S. A. são necessários $9,64 \mathrm{~kg}$ de ar (FOSFERTIL, 2005). Portanto, para a produção de 1,217 toneladas de amônia ( 1 tonelada de N) são necessários $11,73 \mathrm{~kg}$ de ar a ser separado. Três produtos são gerados na separação do ar, quais sejam: oxigênio, nitrogênio e argônio.

De todo o ar necessário, a empresa aproveita apenas o oxigênio e o nitrogênio nele contidos. $O$ argônio é emitido para a atmosfera.

Por conta de tais informações, o tratamento de dados de este subsistema se constituiu da adequação dos valores do inventário selecionado 
para a quantidade de $11,73 \mathrm{~kg}$ de ar. Tal inventário encontra-se apresentado no apêndice $A 11$, ao final deste documento.

\subsubsection{Inventário de ciclo de vida do subsistema da produção de amônia pelo processo de reforma catalítica de gás natural com vapor de água}

a) Coleta de dados

No que se refere aos dados que constituem o subsistema de produção de amônia por reforma catalítica com vapor de água, estes levaram em conta a composição média do gás natural utilizado pelo fabricante brasileiro e as seguintes operações: reforma catalítica do gás; conversão do monóxido a dióxido de carbono; remoção do dióxido de carbono por solvente; purificação do gás de síntese (metanação); e síntese da amônia.

Os dados de consumo dos recursos materiais e energéticos e de emissões energéticas, que compõem o inventário de dados brutos do subsistema de produção da amônia produzida por meio da reforma catalítica de gás natural com vapor de água, foram obtidos do fabricante (SAC PETROBRAS/FAFEN, 2005) através de contatos realizados via internet e por envio de questionários. As emissões atmosféricas, efluentes líquidos e resíduos sólidos foram obtidos do inventário Ammonia, steam reforming da publicação Life Cycle Inventories of Chemicals do ECOINVENT CENTRE (2004b).

A adoção do referido inventário selecionado para o modelo proposto no estudo se deu pelo motivo de este apresentar dados específicos ao subsistema de produção de amônia por reforma catalítica com vapor; bem como, operações que mais se aproximavam às do processo empregado no país.

O inventário do subsistema da produção de $1 \mathrm{~kg}$ de amônia por reforma catalítica de gás natural com vapor de água é apresentado na tabela 39, a seguir. 


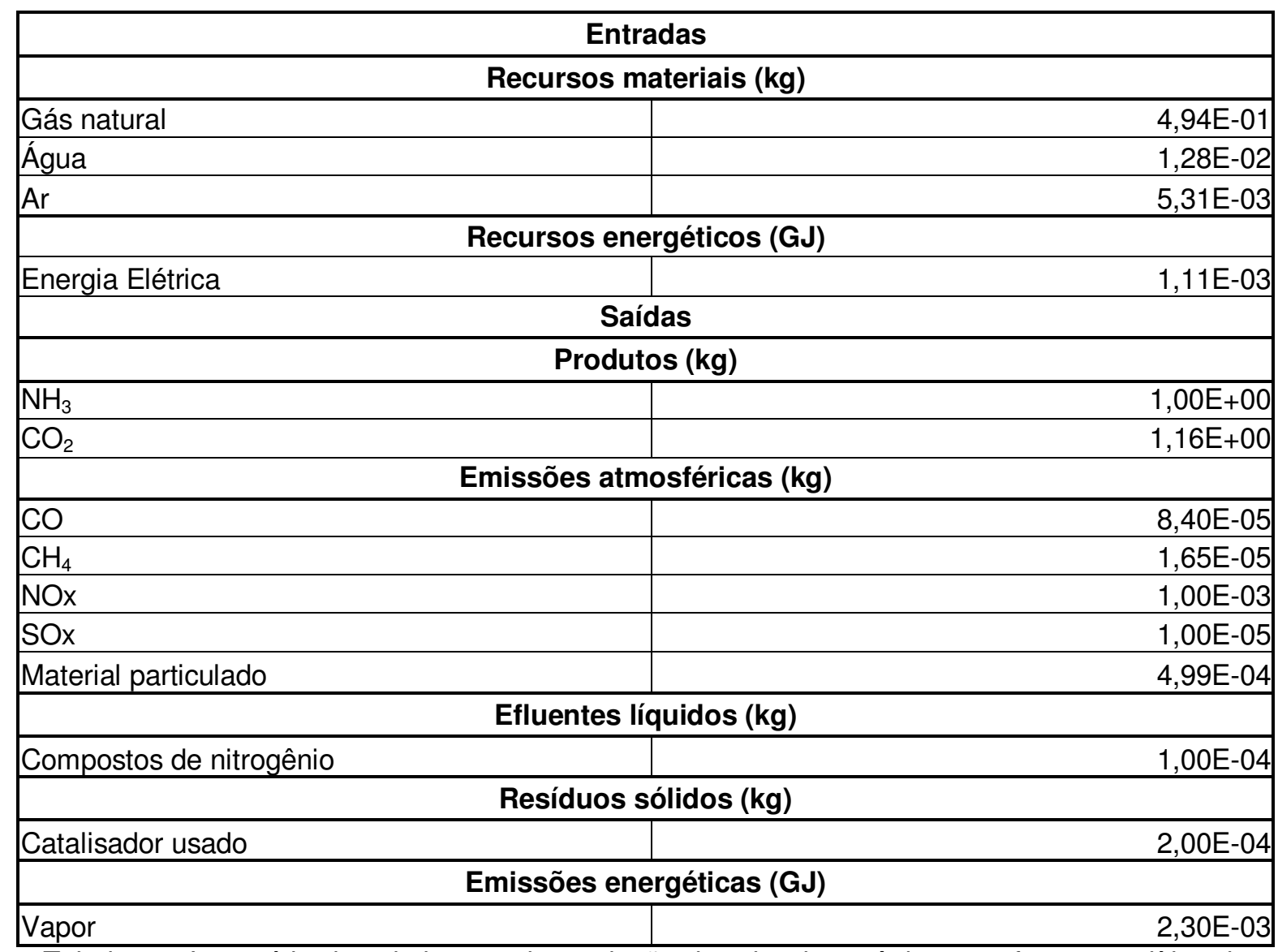

Tabela 39: Inventário do subsistema da produção de $1 \mathrm{~kg}$ de amônia por reforma catalítica de gás natural com vapor de água (SAC PETROBRAS/FAFEN, 2005; ECOINVENT CENTRE; 2004b).

b) Tratamento dos dados

O tratamento dos dados de este subsistema, para o caso do sistema de produto da uréia, consistiu da adequação das informações coletadas à quantidade de 1,217 toneladas de amônia; quantidade necessária para atender ao fluxo de referência de 2,17 toneladas de uréia ( 1 tonelada de $N$ ). Não foi necessário efetuar a alocação entre os dois produtos (amônia e dióxido de carbono) gerados neste subsistema, pois, esses são consumidos no subsistema de produção da uréia. 
Em relação ao sistema de produto do sulfato de amônio, o tratamento dos dados consistiu de duas etapas distintas:

I) para os subsistemas de: produção de sulfato de amônio via síntese da UNIGEL e BUNGE FERTILIZANTES; de produção de sulfato de amônio como subproduto da fabricação de caprolactama; e de produção de sulfato de amônio como subproduto da fabricação de acrilonitrila, foram necessárias 1,217 toneladas de amônia para atender ao fluxo de referência de 4,717 toneladas de sulfato de amônio ( 1 tonelada de N). Como o dióxido de carbono gerado no subsistema de produção da amônia se destina a outro sistema de produto, fezse necessária à aplicação do fator de alocação de 46,3\%, calculado no tratamento dos dados do item 5.2.6, para a amônia.

II) para o subsistema de produção de sulfato de amônio como subproduto da fabricação de metacrilato de metila, o tratamento dos dados consistiu da adequação dos aspectos ambientais da tabela 39 à quantidade de 2,456 toneladas de amônia e da aplicação do fator de alocação mencionado.

Os inventários de aspectos ambientais para 1,217 toneladas de amônia, 1,217 toneladas de amônia com fator de alocação de 46,3\% e para 2,456 toneladas de amônia com fator de alocação de $46,3 \%$ estão apresentados no apêndice $\mathrm{A} 12$.

\subsubsection{Inventário de ciclo de vida do subsistema da produção de amônia pelo processo de oxidação parcial de resíduo asfáltico}

a) Coleta de dados

Em relação ao subsistema de produção de amônia por oxidação parcial, foram consideradas, além do insumo utilizado pelo produtor brasileiro (resíduo asfáltico), as operações de: oxidação parcial; remoção de compostos de enxofre por solvente; conversão do monóxido a dióxido de carbono; remoção do 
dióxido de carbono por solvente; purificação do gás de síntese (metanação); e síntese da amônia.

Os dados de consumo dos recursos materiais e energéticos que compõem o inventário de dados brutos do subsistema de produção da amônia produzida por meio da oxidação parcial de resíduo asfáltico foram obtidos do fabricante (FOSERTIL, 2005) através de contatos realizados via internet e por envio de questionários.

As emissões atmosféricas, efluentes líquidos e resíduos sólidos foram obtidos do inventário Ammonia, partial oxidation da publicação Life Cycle Inventories of Chemicals do ECOINVENT CENTRE (2004c). Mediante uma pesquisa realizada em programas computacionais para apoio à ACV e após serem realizadas devidas verificações, chegou-se a conclusão que os dados contidos no inventário mencionado anteriormente eram os que mais se aproximavam do subsistema de produção de amônia pelo processo de oxidação parcial da FOSFERTIL S. A.

Os dados do inventário para este subsistema contêm os aspectos ambientais associados à produção de amônia propriamente dita, não considerando, portanto, aspectos associados a outras etapas do ciclo de vida do porduto.

O inventário do subsistema da produção de $1 \mathrm{~kg}$ de amônia por oxidação parcial é apresentado na tabela 40, a seguir. 


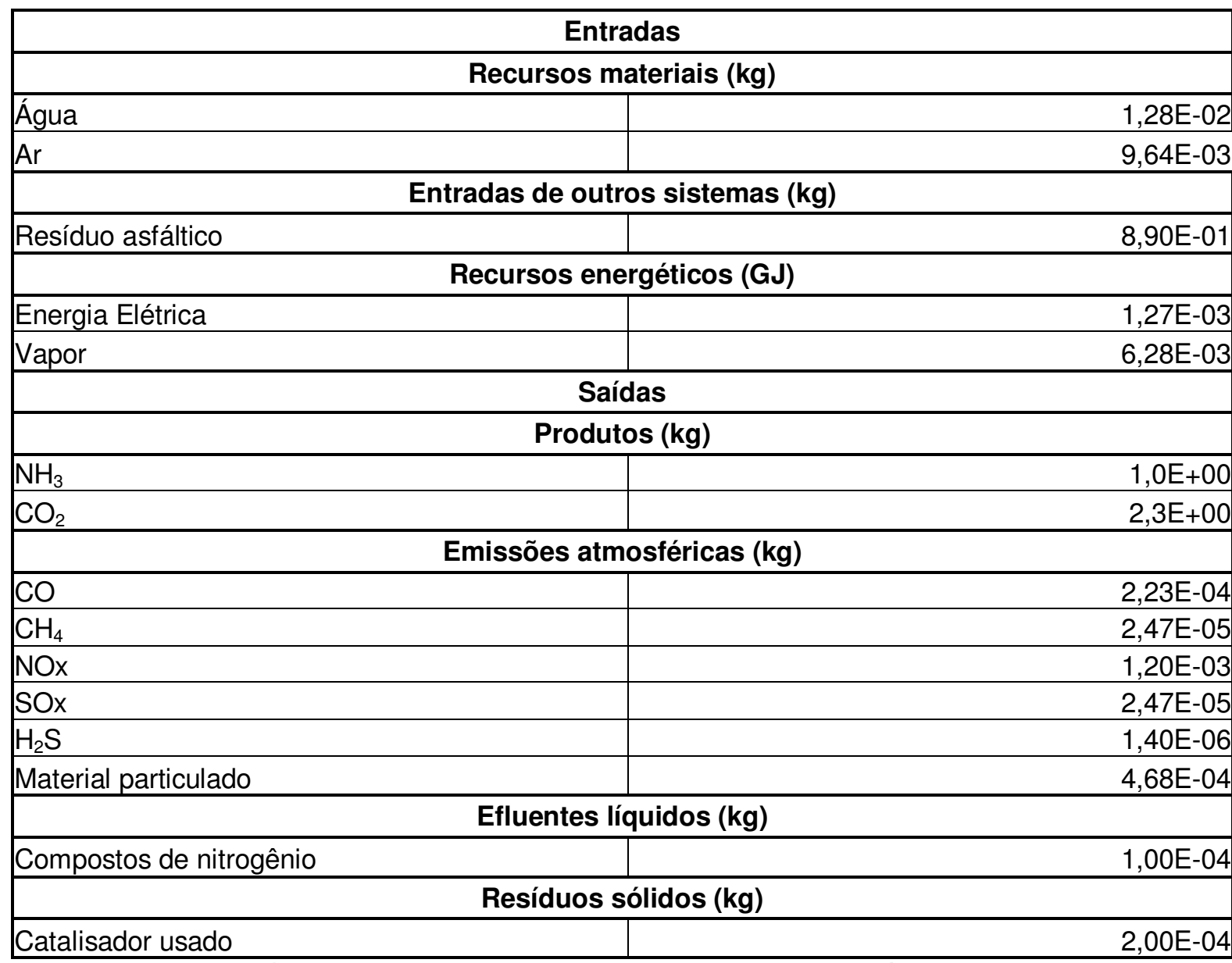

Tabela 40: Inventário do subsistema da produção de $1 \mathrm{~kg}$ de amônia por oxidação parcial (FOSERTIL, 2005; ECOINVENT CENTRE, 2004c).

b) Tratamento dos dados

Para o sistema de produto da uréia e segundo dados coletados junto a FOSFERTIL (2005), são necessários $561 \mathrm{~kg}$ de amônia para se produzir 1 toneladas de uréia. Portanto, para a produção de 2,17 toneladas de uréia (fluxo de referência considerado neste estudo) são necessários 1,217 toneladas de amônia. Desse modo, o tratamento dos dados consistiu da adequação dos aspectos ambientais para 1,217 toneladas de amônia. 
Não houve necessidade de alocar os aspectos ambientais entre os dois produtos gerados neste subsistema, pois, estes (amônia e dióxido de carbono) são consumidos no subsistema de produção da uréia.

O inventário de aspectos ambientais para a produção de 1,217 toneladas de amônia através do processo de oxidação parcial é apresentado no apêndice A13 de este documento.

\subsubsection{Inventário de ciclo de vida do subsistema da produção de amônia pelo processo de reforma catalítica de gás de refinaria com vapor de água}

a) Coleta de dados

No que se refere aos dados que constituem o subsistema de produção de amônia por reforma catalítica com vapor de água, estes levaram em conta as operações de: reforma catalítica do gás; conversão do monóxido a dióxido de carbono; remoção do dióxido de carbono por solvente; purificação do gás de síntese (metanação); e síntese da amônia.

Os dados que compõem o inventário de aspectos ambientais de este subsistema foram extraídos de duas fontes: os consumos de recursos materiais e energéticos e as emissões energéticas foram fornecidos pelo fabricante (FOSFERTIL, 2005) e as emissões atmosféricas, os efluentes líquidos e os resíduos sólidos foram obtidos do inventário Ammonia, steam reforming do documento Life Cycle Inventories of Chemicals do ECOINVENT CENTRE (2004b).

O inventário do subsistema da produção de $1 \mathrm{~kg}$ de amônia por reforma catalítica de gás combustível de refinaria com vapor de água pode ser visto na tabela 41. 


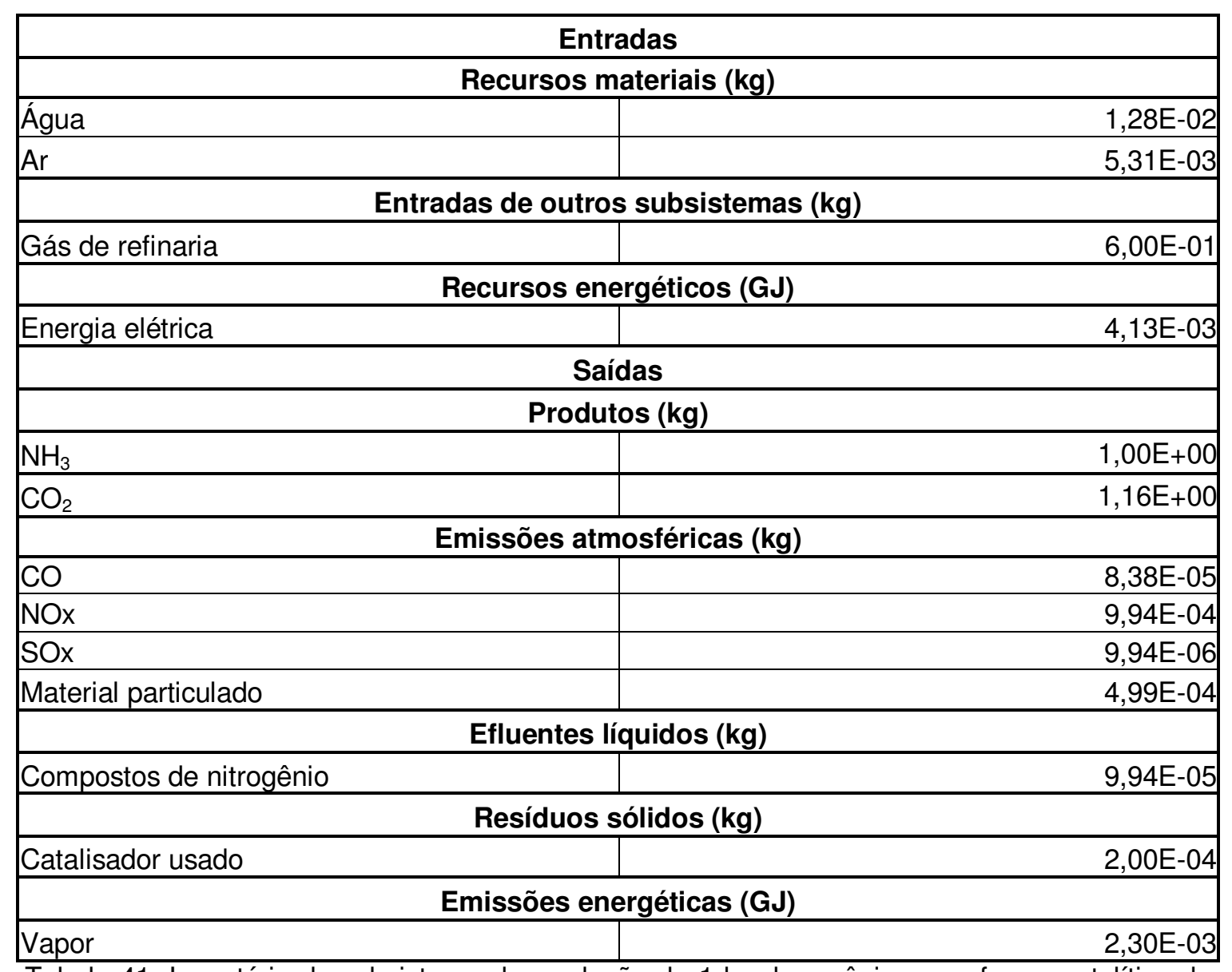

Tabela 41: Inventário do subsistema da produção de $1 \mathrm{~kg}$ de amônia por reforma catalítica de gás combustível de refinaria com vapor de água (FOSFERTIL S. A., 2005; ECOINVENT CENTRE, 2004b).

b) Tratamento dos dados

O tratamento dos dados de este subsistema, para os sistemas de produto do nitrato de amônio (FOSFERTIL) e do sulfato de amônio (em particular para o subsistema de produção de sulfato de amônio via síntese da BUNGE FERTILIZANTES), consistiu de duas etapas.

Primeiramente, fez-se a adequação dos valores do inventário selecionado (tabela 39) para 1,217 toneladas de amônia, quantidade necessária 
para atender aos fluxos de referência de 2,941 toneladas de nitrato de amônio ( 1 tonelada de $N$ ) e 4,717 toneladas de sulfato de amônio (1 tonelada de $N$ ).

$\mathrm{Na}$ segunda etapa, foi necessário alocar os aspectos ambientais para a amônia de acordo com as informações a seguir.

Como a produção de amônia também gera dióxido de carbono como subproduto e este último se destina a outros sistemas de produto (p. ex. uréia), fez-se necessário distribuir os aspectos ambientais entre esses dois produtos.

Sabe-se que na produção de 1,217 toneladas de amônia, 1,411 toneladas de $\mathrm{CO}_{2}$ também são produzidas. Aplicando-se o critério de alocação por massa $\left[\frac{1,217}{(1,217+1,411)} \times 100\right]$ obtêm-se o fator de $46,3 \%$, a ser atribuído à amônia.

O inventário de aspectos ambientais para a produção de 1,217 toneladas de amônia, através do processo de reforma catalítica de gás de refinaria, com aplicação do fator de alocação de 46,3\% encontra-se no apêndice A14.

\subsubsection{Inventário do subsistema da produção de uréia}

a) Coleta de dados

Os dados referentes aos consumos de recursos materiais e energéticos foram obtidos de um dos produtores brasileiro de uréia. Segundo a FOSFERTIL (2005), os consumos para a produção de $1 \mathrm{~kg}$ de uréia são: 0,561 kg de amônia por qualquer um de seus processos de obtenção; 0,65 $\mathrm{kg}$ de dióxido de carbono; 7,61 g de água; 0,54 MJ de eletricidade e 3,5 MJ de vapor.

$\mathrm{Na}$ ausência momentânea de dados genuinamente nacionais para quantificar as emissões atmosféricas, os efluentes líquidos e os resíduos sólidos de este subsistema, selecionou-se no programa computacional SimaPro 7.0 um inventário de aspectos ambientais que fosse capaz de representar da maneira mais adequada possível tais emissões, efluentes e resíduos do 
subsistema de produção da uréia no país a partir de amônia e dióxido de carbono.

Desse modo, disponibilizou-se o inventário Ureum I - IDEMAT 2001 (PRé Consultants, 2006e) para $1 \mathrm{~kg}$ de uréia. Este inventário foi considerado o mais adequado e apresenta dados específicos para o referido subsistema, não considerando outras etapas do ciclo de vida da uréia.

Os dados coletados para o subsistema de produção de uréia levaram em conta as operações de formação de carbamato de amônio, a partir de amônia e dióxido de carbono e de desidratação, por aquecimento, de carbamato para a formação da uréia.

$\mathrm{Na}$ tabela 42, a seguir, são apresentados os dados brutos coletados para a produção de $1 \mathrm{~kg}$ de uréia.

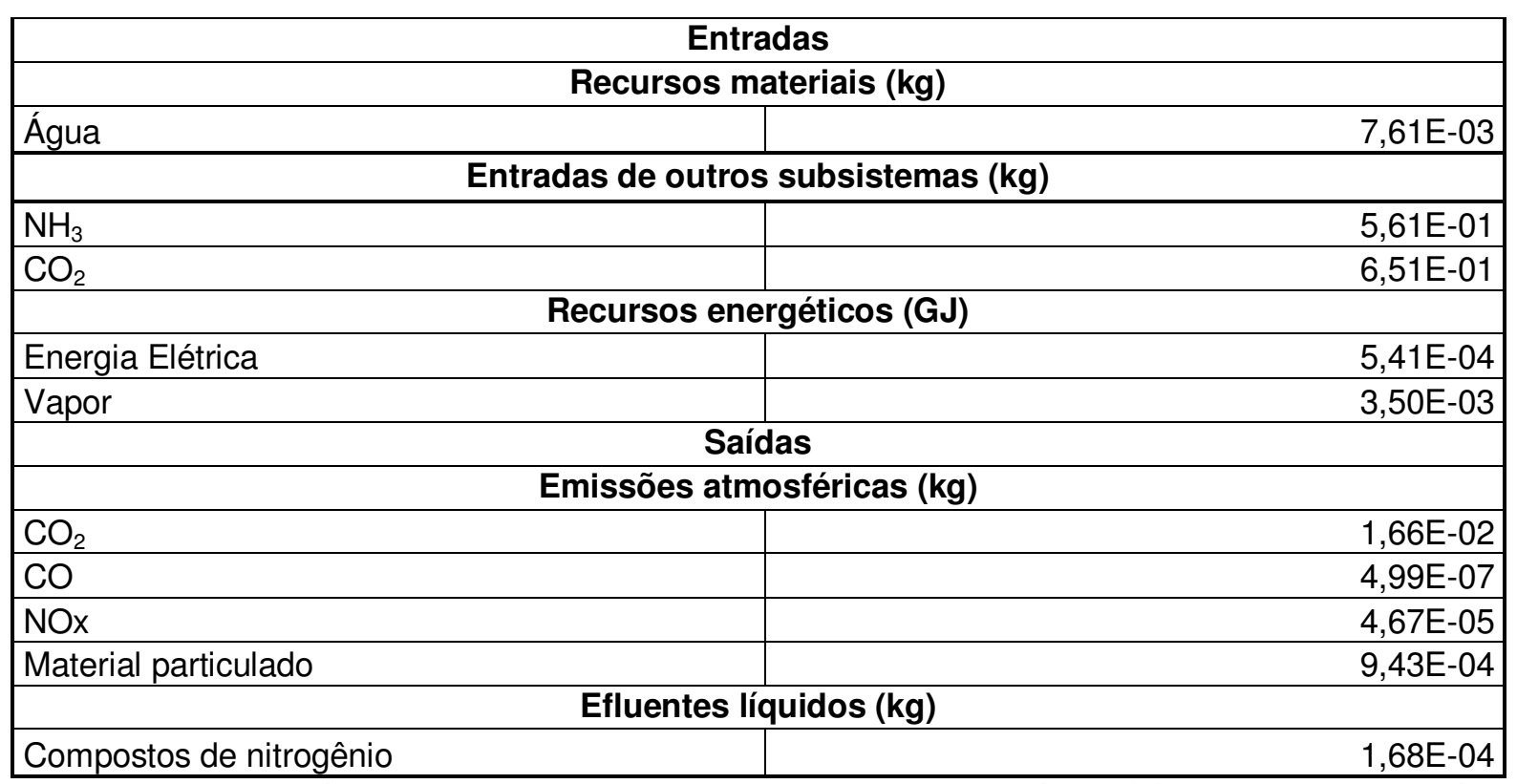

Tabela 42: Inventário do subsistema da produção de 1 kg de uréia (FOSFERTIL, 2005; PRé Consultants, 2006e).

b) Tratamento dos dados

O tratamento dos dados para este subsistema consistiu da adequação dos valores apresentados no inventário para o fluxo de referência de 2,17 
toneladas de uréia ( 1 tonelada de N). Tal inventário é apresentado no apêndice A15, ao final de este documento.

\subsubsection{Inventário do subsistema da produção de ácido nítrico}

a) Coleta de dados

No que diz respeito aos dados que compõe o subsistema de produção de ácido nítrico, estes consideraram as operações de: oxidação catalítica (catalisador de platina - Pt e ródio - Rh) com ar da amônia proveniente da reforma de gás de refinaria; oxidação do monóxido a dióxido de nitrogênio à média pressão (de 3 a 6 atm) e absorção do dióxido de nitrogênio em água para a formação de ácido nítrico à alta pressão (de 7 a 13 atm).

Não foram considerados no inventário de aspectos ambientais de este subsistema os dados associados à produção do catalisador; bem como, os dados relacionados às fabricações dos materiais de construção dos equipamentos e outras infra-estruturas.

Os dados que constituem o inventário de aspectos ambientais de este subsistema foram extraídos de duas fontes: os consumos de recursos materiais e energéticos e as emissões energéticas foram fornecidos pelo fabricante (FOSFERTIL, 2005) e emissões, efluentes e resíduos foram obtidos do inventário Nitric Acid do documento Life Cycle Inventories of Chemicals do ECOINVENT CENTRE (2004d). A razão da escolha do inventário mencionado anteriormente se deu pelo fato de os dados contidos neste serem referentes à obtenção de ácido nítrico pelo processo Ostwald; o qual contém as operações semelhantes àquelas do processo empregado pelo fabricante brasileiro.

De acordo com a FOSFERTIL (2005), para a produção de $1 \mathrm{~kg}$ de ácido nítrico são necessários: $1,5 \mathrm{~kg}$ de $\operatorname{ar} ; 0,27 \mathrm{~kg}$ de amônia e 1,78 MJ de eletricidade. 
$\mathrm{Na}$ tabela 43 encontram-se os dados brutos para a produção de $1 \mathrm{~kg}$ de ácido nítrico.

\begin{tabular}{|c|c|}
\hline \multicolumn{2}{|c|}{ Entradas da natureza } \\
\hline \multicolumn{2}{|c|}{ Recursos materiais (kg) } \\
\hline Ar & $1,50 \mathrm{E}+00$ \\
\hline Água & $6,23 \mathrm{E}-02$ \\
\hline \multicolumn{2}{|c|}{ Entradas de outros subsistemas (kg) } \\
\hline $\mathrm{NH}_{3}$ & $2,70 \mathrm{E}-01$ \\
\hline \multicolumn{2}{|c|}{ Recursos energéticos (GJ) } \\
\hline Energia Elétrica & $1,78 \mathrm{E}-03$ \\
\hline \multicolumn{2}{|c|}{ Saídas } \\
\hline \multicolumn{2}{|c|}{ Emissões atmosféricas (kg) } \\
\hline $\mathrm{NH}_{3}$ & $2,50 \mathrm{E}-03$ \\
\hline $\mathrm{N}_{2} \mathrm{O}$ & $8,39 \mathrm{E}-03$ \\
\hline NOx & $4,71 \mathrm{E}-03$ \\
\hline Material particulado & $2,00 \mathrm{E}-04$ \\
\hline \multicolumn{2}{|c|}{ Efluentes líquidos (kg) } \\
\hline$\overline{\mathrm{DBO}}$ & $1,40 \mathrm{E}-03$ \\
\hline Compostos de nitrogênio & $1,30 \mathrm{E}-04$ \\
\hline \multicolumn{2}{|c|}{ Resíduos sólidos (kg) } \\
\hline Catalisador usado & $3,60 \mathrm{E}-08$ \\
\hline \multicolumn{2}{|c|}{ Emissões energéticas (GJ) } \\
\hline Vapor & $2,25 \mathrm{E}-06$ \\
\hline
\end{tabular}

Tabela 43: Inventário do subsistema da produção de 1 kg de ácido nítrico (FOSFERTIL, 2005; ECOINVENT CENTRE, 2004d).

b) Tratamento dos dados

Segundo a FOSFERTIL (2005) são necessários 765,3 kg de ácido nítrico para a obtenção de 1 tonelada de nitrato de amônio. Assim sendo, para se produzirem 2,941 toneladas de nitrato de amônio (1 tonelada de $N$ ) serão necessários 2,25 toneladas de ácido nítrico. Portanto, o tratamento dos dados para este subsistema consistiu da adequação dos valores coletados para 2,25 toneladas de ácido nítrico. 
O inventário de aspectos ambientais associados à produção de 2,25 toneladas de ácido nítrico encontra-se no apêndice A16, ao final de este documento.

\subsubsection{Inventário do subsistema da produção de nitrato de amônio}

a) Coleta de dados

Os dados que compõe o subsistema de produção de nitrato de amônio consideraram as operações de neutralização do ácido nítrico com amônia, proveniente da reforma de gás de refinaria, e de concentração da solução de nitrato de amônio por evaporação.

Os dados referentes ao consumo de recursos materiais e energéticos forma coletados junto ao fabricante (FOSFERTIL, 2005). Segundo o referido fabricante para a produção de $1 \mathrm{~kg}$ de nitrato de amônio são necessários: 0,207 $\mathrm{kg}$ de amônia, 0,765 kg de ácido nítrico, 0,0595 MJ de energia elétrica e 0,791 MJ de vapor.

No que se referem aos dados das emissões atmosféricas e dos efluentes líquidos, estes foram obtidos do documento Life cycle inventories of agricultural production systems do ECOINVENT CENTRE (2004e). Essa opção se deveu essencialmente a dois fatores: a ausência até o presente momento de dados precisos e confiáveis capazes de retratar o perfil de aspectos ambientais deste subsistema e a importância dele para o modelo em questão.

Seguem na tabela 44 os dados brutos para o subsistema da produção de $1 \mathrm{~kg}$ de nitrato de amônio. 


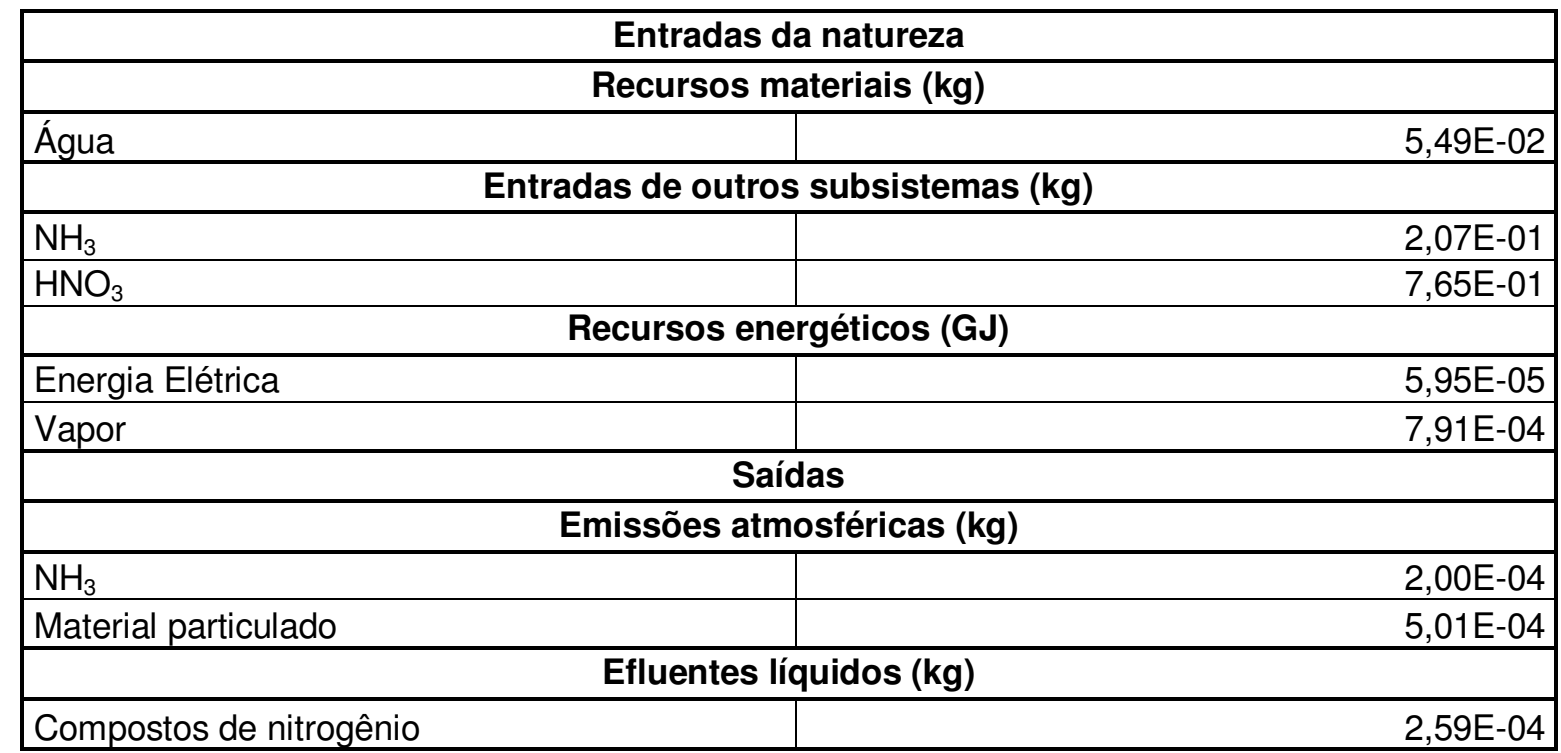

Tabela 44: Inventário do subsistema da produção de $1 \mathrm{~kg}$ de nitrato de amônio (FOSFERTIL, 2005; ECOINVENT CENTRE, 2004e).

b) Tratamento dos dados

O tratamento dos dados consistiu da adequação dos valores coletados ao fluxo de referência de 2,941 toneladas de nitrato de amônio (1 tonelada de N). O inventário de aspectos ambientais associados à produção de 2,941 toneladas de nitrato de amônio é apresentado no apêndice A17.

\subsubsection{Inventário do subsistema da produção de ácido sulfúrico}

a) Coleta de dados

O inventário de aspectos ambientais para o subsistema de produção de ácido sulfúrico foi obtido de SILVA; KULAY (2003) e se refere a 1 tonelada de ácido sulfúrico produzido no Brasil.

Segundo os autores, os dados foram correspondentes à obtenção do ácido por meio de enxofre elementar e pelo processo de dupla absorção, o qual compreendeu as seguintes operações: fusão e filtração do enxofre; combustão 
do enxofre; oxidação catalítica com $\mathrm{V}_{2} \mathrm{O}_{5}$ do dióxido a trióxido de enxofre; e dupla etapa de absorção do trióxido de enxofre em ácido sulfúrico.

O inventário para a produção de 1 tonelada de ácido sulfúrico é mostrado na tabela 45.

\begin{tabular}{|lrr|}
\hline \multicolumn{4}{|c|}{ Entradas } \\
\hline \multicolumn{3}{|c|}{ Recursos materiais (kg) } \\
\hline Enxofre & & $3,30 \mathrm{E}+02$ \\
\hline Água & & $1,45 \mathrm{E}+03$ \\
\hline Ar & \multicolumn{2}{|c|}{ Saídas } \\
\hline \multicolumn{2}{|c|}{ Emissões atmosféricas (kg) } \\
\hline SOx & \\
\hline \multicolumn{2}{|c|}{ Resíduos sólidos (kg) } \\
\hline Enxofre & $2,66 \mathrm{E}+00$ \\
\hline Catalisador usado & $7,59 \mathrm{E}+00$ \\
\hline
\end{tabular}

Tabela 45: Inventário do subsistema da produção de 1 tonelada de ácido sulfúrico (SILVA; KULAY, 2003).

b) Tratamento dos dados

O tratamento dos dados de este subsistema, para o sistema de produto do sulfato de amônio obtido via síntese (BUNGE FERTILIZANTES e UNIGEL) e do sulfato de amônio obtido como subproduto da fabricação de metacrilato de metila (UNIGEL), consistiu de duas etapas.

Primeiramente, de acordo com a UNIGEL (2006), para a produção de 1 tonelada de sulfato de amônio pelo processo de síntese da amônia com o ácido sulfúrico são necessários $742 \mathrm{~kg}$ de ácido sulfúrico.

De posse dessa informação, calculou-se a quantidade de ácido sulfúrico necessária para atender ao fluxo de referência de 4,717 toneladas de sulfato de amônio ( 1 tonelada de N), obtendo-se o valor de 3,5 toneladas do ácido.

$\mathrm{Na}$ segunda etapa, dados coletados junto à UNIGEL (2006) revelaram que para a obtenção de 1,57 toneladas de metacrilato de metila (ou 4,717 toneladas de sulfato de amônio) são necessários $840 \mathrm{~kg}$ de ácido sulfúrico. 
Assim sendo, o tratamento dos dados de este subsistema consistiu da adequação dos valores coletados da tabela 45 às quantidades de 3,5 toneladas e de 840 kg de ácido sulfúrico.

Encontra-se no apêndice A18 o inventário dos aspectos ambientais associados às produções de 3,5 toneladas e de $840 \mathrm{~kg}$ de ácido sulfúrico.

\subsubsection{Inventário do subsistema da produção de sulfato de amônio via síntese}

a) Coleta de dados

Em relação aos dados que constituem o subsistema de produção de sulfato de amônio via síntese, estes levaram em conta as operações de neutralização do ácido sulfúrico proveniente de enxofre elementar com amônia obtida através do processo de reforma catalítica; evaporação da solução de sulfato de amônio obtida; cristalização; e secagem dos cristais formados de sulfato de amônio.

Os dados que compõem o inventário de aspectos ambientais do subsistema da produção de sulfato de amônio pelo processo de síntese foram coletados das seguintes fontes: os consumos de recursos materiais e energéticos foram obtidos junto à empresa UNIGEL (2006); enquanto que as emissões atmosféricas foram extraídas do documento Life cycle inventories of agricultural production systems do ECOINVENT CENTRE (2004e).

Segundo dados fornecidos pela UNIGEL (2006) para a obtenção de 1 tonelada de sulfato de amônio pelo processo de síntese são necessários: 742 kg de ácido sulfúrico, $258 \mathrm{~kg}$ de amônia e 0,589 GJ de eletricidade.

O inventário do subsistema da produção de 1 tonelada de sulfato de amônio é apresentado na tabela 46. 


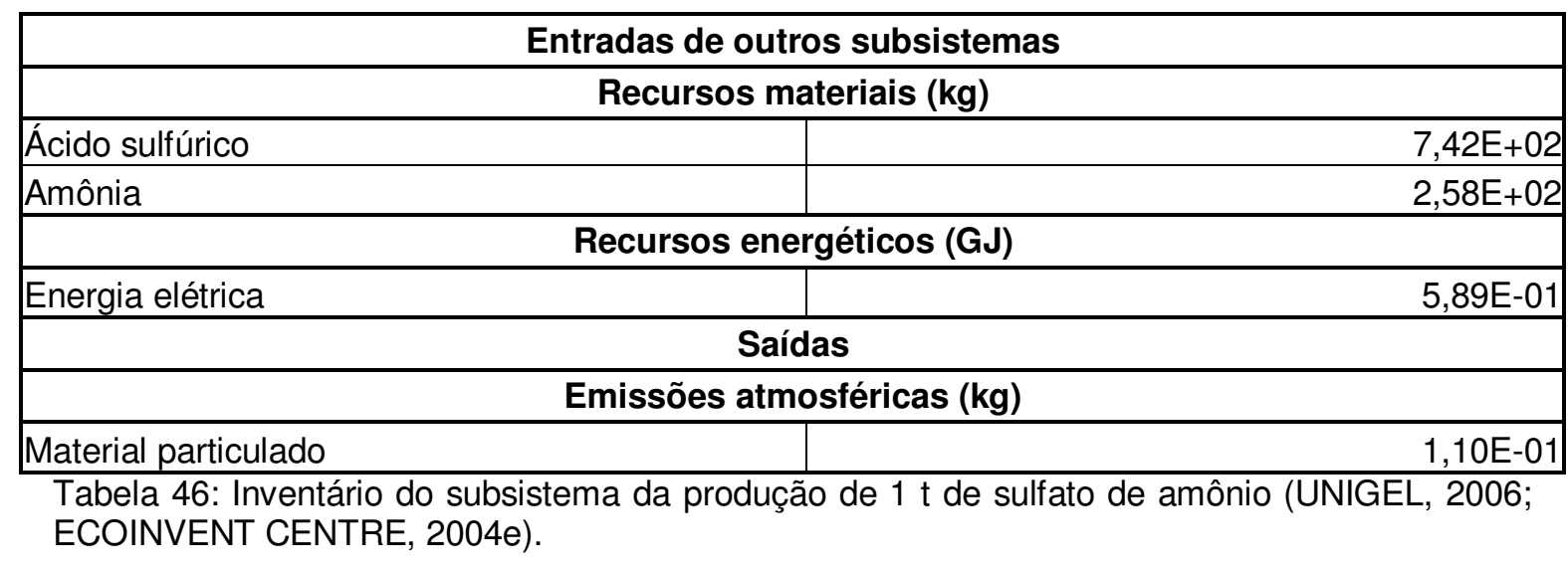

b) Tratamento dos dados

O tratamento dos dados para este subsistema consistiu da adequação dos valores coletados para o fluxo de referência de 4,717 toneladas de sulfato de amônio.

O inventário de aspectos ambientais da produção de 4,717 toneladas de sulfato de amônio, via síntese, é apresentado no apêndice A19, ao final de este documento.

\subsubsection{Inventário do subsistema da produção de benzeno}

a) Coleta de dados

Para a obtenção dos dados referente à produção de benzeno, frente à inexistência de dados nacionais, foi utilizado o inventário Benzene production do banco de dados Data Archive do programa computacional SimaPro 7.0 (PRé CONSULTANTS, 2006f), apresentados na tabela 47. Este inventário se refere aos aspectos ambientais provenientes apenas do processo elementar de obtenção do benzeno e se referem a dados médios de indústrias localizadas na Europa Ocidental. 
Verificou-se a existência de mais bases de dados internacionais disponíveis para o benzeno, porém o Brasil possui características particulares frente a alguns países, pois, utiliza como insumo para este processo a nafta, e não uma mistura de nafta e gás natural. Esse critério foi levado em conta para a seleção da base de dados mencionada. Outro aspecto importante é que esta base se refere à tecnologia média, ou seja, várias empresas foram selecionadas para a coleta de dados, o que diminui a margem de erro ao se comparar, nesse caso, com apenas uma empresa internacional produtora de benzeno.

São apresentados na tabela 47 os dados referentes ao inventário de aspectos ambientais associados à produção de $1 \mathrm{~kg}$ de benzeno.

\begin{tabular}{|c|c|}
\hline \multicolumn{2}{|c|}{ Entradas de outros subsistemas $(\mathbf{k g})$} \\
\hline Nafta & $1,77 \mathrm{E}+00$ \\
\hline \multicolumn{2}{|c|}{ Saídas } \\
\hline \multicolumn{2}{|c|}{ Emissões atmosféricas (kg) } \\
\hline $\mathrm{CO}_{2}$ & $2,46 \mathrm{E}+00$ \\
\hline $\mathrm{CO}$ & $7,28 \mathrm{E}-04$ \\
\hline Hidrocarbonetos & $2,09 \mathrm{E}-03$ \\
\hline NOx & $2,63 \mathrm{E}-03$ \\
\hline SOx & $3,46 \mathrm{E}-04$ \\
\hline Material particulado & $3,99 \mathrm{E}-05$ \\
\hline $\mathrm{H}_{2}$ & $1,00 \mathrm{E}-05$ \\
\hline \multicolumn{2}{|c|}{ Efluentes líquidos (kg) } \\
\hline DQO & $5,32 \mathrm{E}-05$ \\
\hline Hidrocarbonetos & $1,00 \mathrm{E}-05$ \\
\hline Compostos de enxofre & $1,20 \mathrm{E}-04$ \\
\hline $\mathrm{Na}^{+}$ & $4,12 \mathrm{E}-04$ \\
\hline
\end{tabular}

Tabela 47: Inventário do subsistema da produção de $1 \mathrm{~kg}$ de benzeno (PRé Consultants, 2006f).

b) Tratamento dos dados

O tratamento dos dados de este subsistema, para o sistema de produto do sulfato de amônio obtido como subproduto da fabricação de caprolactama (BRASKEM) e do sulfato de amônio obtido como subproduto da fabricação de metacrilato de metila (UNIGEL), foi efetuado conforme as informações a seguir. 
De acordo com a BRASKEM (2008), para a produção de 1 tonelada de ciclohexano são necessárias 1,12 toneladas de benzeno. Sabe-se também, de acordo com a mesma fonte, que para a obtenção de 2,62 toneladas de caprolactama (ou 4,717 toneladas de sulfato de amônio) são necessárias 5,936 toneladas de ciclohexano.

Com base nas informações coletadas, calculou-se a quantidade de benzeno necessária para atender ao fluxo de referência de 4,717 toneladas de sulfato de amônio ( 1 tonelada de N), obtendo-se o valor de 6,66 toneladas do produto.

Dados coletados junto à UNIGEL (2006) revelaram que para a obtenção de 1,57 toneladas de metacrilato de metila (ou 4,717 toneladas de sulfato de amônio) são necessários 68,86 kg de benzeno.

Desse modo, o tratamento dos dados de este subsistema consistiu da adequação dos valores coletados na tabela 47 às quantidades de 6,66 toneladas e de $68,86 \mathrm{~kg}$ de benzeno.

Encontra-se no apêndice A20 o inventário dos aspectos ambientais associados às produções de 6,66 toneladas e de $68,86 \mathrm{~kg}$ de benzeno.

\subsubsection{Inventário do subsistema da produção de ciclohexano}

a) Coleta de dados

Em face da indisponibilidade de dados nacionais, para a obtenção dos aspectos ambeitais referentes à produção de ciclohexano, selecionou-se o inventário Cyclohexane production do banco de dados Data Archive do programa computacional SimaPro 7.0 (PRé Consultants, 2006g).

O critério determinante para a adoção do referido invetário foi baseado no fato de o mesmo apresentar dados referentes ao processo de produção de ciclohexano através da hidrogenação catalítica do benzeno; processo que também é empregado no país. 
O consumo de benzeno necessário à obtenção de ciclohexano foi coletado junto a BRASKEM (2008).

O inventário de aspectos ambientais associados à produção de $1 \mathrm{~kg}$ de ciclohexano é mostrado na tabela 48.

\begin{tabular}{|l|r|}
\hline \multicolumn{2}{|c|}{ Entradas de outros subsistemas $\mathbf{~ k g ) ~}$} \\
\hline \multicolumn{2}{|c|}{ Saídas } \\
\hline \multicolumn{2}{|c|}{ Emissões atmosféricas $\mathbf{~ ( k g ) ~}$} \\
\hline $\mathrm{CO}_{2}$ & $1,12 \mathrm{E}+00$ \\
\hline $\mathrm{CO}$ & $4,28 \mathrm{E}-01$ \\
\hline $\mathrm{Hidrocarbonetos}$ & $1,10 \mathrm{E}-04$ \\
\hline $\mathrm{NOx}$ & $7,00 \mathrm{E}-05$ \\
\hline $\mathrm{COV}$ - exceto metano & $4,10 \mathrm{E}-04$ \\
\hline $\mathrm{H}_{2}$ & $1,60 \mathrm{E}-04$ \\
\hline
\end{tabular}

Tabela 48: Inventário do subsistema da produção de $1 \mathrm{~kg}$ de ciclohexano (PRé Consultants, 2006g).

b) Tratamento dos dados

De acordo com a BRASKEM (2008), para a obtenção de 2,62 toneladas de caprolactama (ou 4,717 toneladas de sulfato de amônio) são necessárias 5,936 toneladas de ciclohexano.

Assim sendo, o tratamento dos dados de este subsistema consistiu da adequação dos valores apresentados na tabela 48 à quantidade de 5,936 toneladas de ciclohenaxo.

O inventário dos aspectos ambientais associados à produção de 5,936 toneladas de ciclohexano encontra-se no apêndice A21.

\subsubsection{Inventário do subsistema da produção de propeno}

a) Coleta de dados

Dada a ausência de dados nacionais para quantificar as emissões atmosféricas, os efluentes líquidos e os resíduos sólidos de este subsistema, 
selecionou-se, o inventário Propene (propylene) production do banco de dados Data Archive do programa computacional SimaPro 7.0 (PRé Consultants, 2006h).

A escolha do referido inventário foi baseada no fato de que o Brasil possui características particulares em relação a alguns países, pois, utiliza como matéria-prima para este processo a nafta e não gás natural, ou uma mistura de nafta e gás natural.

Os dados do inventário se referem à obtenção de $1 \mathrm{~kg}$ de propeno através do craqueamento da nafta com vapor de água, sem presença de catalisadores. Inclui as operações de refrigeração, desidratação e fracionamento.

\begin{tabular}{|c|c|}
\hline \multicolumn{2}{|c|}{ Entradas de outros subsistemas (kg) } \\
\hline Nafta & $1,33 \mathrm{E}+00$ \\
\hline \multicolumn{2}{|c|}{ Saídas (kg) } \\
\hline \multicolumn{2}{|c|}{ Emissões Atmosféricas (kg) } \\
\hline $\mathrm{CO}_{2}$ & $1,06 \mathrm{E}+00$ \\
\hline $\mathrm{CO}$ & 5,40E-04 \\
\hline Hidrocarbonetos & $1,41 \mathrm{E}-03$ \\
\hline NOx & $2,01 E-03$ \\
\hline SOx & $2,00 \mathrm{E}-04$ \\
\hline Material particulado & $3,00 \mathrm{E}-05$ \\
\hline \multicolumn{2}{|c|}{ Efluentes Líquidos (kg) } \\
\hline DQO & $4,00 \mathrm{E}-05$ \\
\hline Compostos de enxofre & $9,00 \mathrm{E}-05$ \\
\hline $\mathrm{Na}^{+}$ & $3,10 \mathrm{E}-04$ \\
\hline
\end{tabular}

Tabela 49: Inventário do subsistema da produção de $1 \mathrm{~kg}$ de propeno (PRé Consultants, 2006h).

b) Tratamento dos dados

O tratamento dos dados de este subsistema, presente no sistema de produto do sulfato de amônio obtido como subproduto da fabricação de acrilonitrila (UNIGEL) e do sulfato de amônio obtido como subproduto da fabricação de metacrilato de metila (UNIGEL), foi realizado de acordo as informações a seguir. 
Dados coletados junto à UNIGEL (2006) revelaram que para a produção de 29,48 toneladas de acrilonitrila (o que corresponde a 4,717 toneladas de sulfato de amônio) são necessárias 4,359 toneladas de propeno.

Ainda segundo a UNIGEL (2006), para a obtenção de 1,57 toneladas de metacrilato de metila (4,717 toneladas de sulfato de amônio) são necessários $91,58 \mathrm{~kg}$ de propeno.

Com base nas informações apresentadas anteirormente, o tratamento dos dados de este subsistema consistiu da adequação dos valores coletados (tabela 49) às quantidades de 4,359 toneladas e de 91,58 $\mathrm{kg}$ de propeno.

Encontra-se no apêndice A22 o inventário dos aspectos ambientais associados às produções de 4,359 toneladas e de 91,58 kg de propeno.

\subsubsection{Inventário do subsistema das produções de caprolactama e sulfato de amônio}

a) Coleta de dados

Os dados que constituem o inventário de aspectos ambientais do subsistema da produção de caprolactama e de sulfato de amônio como subproduto foram coletados das seguintes fontes: os consumos de recursos materiias e energéticos foram obtidos junto a BRASKEM (2008) e devido à ausência de dados nacionais para as emissões atmosféricas, essas foram extraídas do inventário Caprolactam production do banco de dados Data Archive do programa computacional SimaPro 7.0 (PRé-CONSULTANTS, 2006i).

A adoção do referido inventário se deve ao fato de este apresentar dados específicos para a fabricação de caprolactama e sulfato de amônio como subproduto a partir da nafta, mesmo insumo empregado pelo fabricante brasileiro. 
Todos os dados que compõem o inventário de aspectos ambientais de este subsistema se referem a produlção de caprolactama e sulfato de amônio propriamente dita, ou seja, nenhuma outra etapa do ciclo de vida foi considerada.

O inventário das produções de $1 \mathrm{~kg}$ de caprolactama e de $1,8 \mathrm{~kg}$ de sulfato de amônio é apresentado a seguir na tabela 50 .

\begin{tabular}{|c|c|}
\hline \multicolumn{2}{|c|}{ Entradas } \\
\hline \multicolumn{2}{|c|}{ Recursos energéticos (GJ) } \\
\hline Energia elétrica & $8,46 \mathrm{E}-03$ \\
\hline \multicolumn{2}{|c|}{ Entradas de outros subsistemas (kg) } \\
\hline Nafta & $4,46 E+00$ \\
\hline \multicolumn{2}{|c|}{ Saídas } \\
\hline \multicolumn{2}{|c|}{ Produtos (kg) } \\
\hline Sulfato de amônio & $1,80 \mathrm{E}+00$ \\
\hline Caprolactama & $1,00 \mathrm{E}+00$ \\
\hline \multicolumn{2}{|c|}{ Emissões atmosféricas (kg) } \\
\hline $\mathrm{CO}_{2}$ & $4,45 \mathrm{E}+00$ \\
\hline Hidrocarbonetos & $1,04 \mathrm{E}-03$ \\
\hline $\mathrm{NH}_{3}$ & $2,10 \mathrm{E}-04$ \\
\hline NOx & $3,70 \mathrm{E}-03$ \\
\hline SOx & $1,00 \mathrm{E}-04$ \\
\hline
\end{tabular}

Tabela 50: Inventário do subsistema da produção de $1 \mathrm{~kg}$ de caprolactama (BRASKEM, 2008; PRé Consultants, 2006i).

b) Tratamento dos dados

Segundo a BRASKEM S. A. (BRASKEM, 2008) para cada tonelada de caprolactama gerada, 1,8 toneladas de sulfato de amônio também são produzidas. De posse dessa informação, pode-se concluir que para atender ao fluxo de referência de 4,717 toneladas de sulfato de amônio ( 1 tonelada de $N$ ) definido neste estudo, serão necessárias 2,62 toneladas de caprolactama.

Assim sendo, o tratamento dos dados do subsistema de produção de caprolactama e sulfato de amônio como subproduto consistiu da adequação dos valores coletados à quantidade de 2,62 toneladas de caprolactama (ou 4,717 toneladas de sulfato de amônio).

Os dados tratados para o inventário de este subsistema são apresentados no apêndice A23. 


\subsubsection{Inventário do subsistema da produção de ácido cianídrico}

a) Coleta de dados

Os dados que constituem o inventário de aspectos ambientais de este subsistema foram extraídos de duas fontes: os consumos de recursos materiais e energéticos foram fornecidos pelo fabricante nacional (UNIGEL, 2006) e os dados de emissões atmosféricas e de efluentes líquidos foram obtidos do inventário Hydrogen Cyanide do documento Life Cycle Inventories of Chemicals do ECOINVENT CENTRE (2004f).

Para este subsistema utilizaram-se dados que mais se aproximavam do processo empregado pela UNIGEL para a obtenção do ácido. Tais dados se basearam nas seguintes operações: filtração do ar e oxidação catalítica com platina da amônia e do metano, provenientes do gás natural, com ar.

Os dados associados à produção do catalisador e às infra-estruturas necessárias ao processo de produção do ácido não foram considerados no inventário.

O inventário da produção de $1 \mathrm{~kg}$ de ácido cianídrico $(\mathrm{HCN})$ é apresentado a seguir na tabela 51 . 


\begin{tabular}{|c|c|}
\hline \multicolumn{2}{|c|}{ Entradas } \\
\hline \multicolumn{2}{|c|}{ Recursos materiais (kg) } \\
\hline Gás Natural & $6,80 \mathrm{E}-01$ \\
\hline \multicolumn{2}{|c|}{ Entradas de outros subsistemas $(\mathrm{kg})$} \\
\hline Amônia & $7,60 \mathrm{E}-01$ \\
\hline \multicolumn{2}{|c|}{ Recursos energéticos (GJ) } \\
\hline Energia elétrica & $3,94 \mathrm{E}-04$ \\
\hline \multicolumn{2}{|c|}{ Saídas } \\
\hline \multicolumn{2}{|c|}{ Emissões atmosféricas (kg) } \\
\hline $\mathrm{CO}_{2}$ & $2,47 \mathrm{E}+00$ \\
\hline $\mathrm{CO}$ & $1,08 \mathrm{E}-03$ \\
\hline Hidrocarbonetos & $6,39 \mathrm{E}-07$ \\
\hline $\mathrm{CH}_{4}$ & $9,80 \mathrm{E}-04$ \\
\hline $\mathrm{NH}_{3}$ & $9,67 \mathrm{E}-05$ \\
\hline $\mathrm{N}_{2} \mathrm{O}$ & $2,39 \mathrm{E}-07$ \\
\hline NOx & $9,30 \mathrm{E}-03$ \\
\hline sox & $1,88 \mathrm{E}-02$ \\
\hline Cianetos (CN) & $4,80 \mathrm{E}-05$ \\
\hline COV - exceto metano & $1,93 \mathrm{E}-03$ \\
\hline Material Particulado & $1,01 \mathrm{E}-03$ \\
\hline \multicolumn{2}{|c|}{ Efluentes líquidos (kg) } \\
\hline DBO & $6,14 \mathrm{E}-05$ \\
\hline $\mathrm{DQO}$ & $1,96 \mathrm{E}-04$ \\
\hline Metais pesados não especificados & $2,03 \mathrm{E}-06$ \\
\hline Hidrocarbonetos & $4,50 \mathrm{E}-05$ \\
\hline Ácidos como $\mathrm{H}^{+}$ & $1,18 \mathrm{E}-04$ \\
\hline Íons metálicos & $7,56 \mathrm{E}-06$ \\
\hline Óleo não especificado & $2,40 \mathrm{E}-05$ \\
\hline Sólidos dissolvidos totais & $6,39 \mathrm{E}-04$ \\
\hline Sólidos suspensos totais & $1,09 \mathrm{E}-03$ \\
\hline Compostos de enxofre & $2,43 \mathrm{E}-03$ \\
\hline Compostos de nitrogênio & $5,68 \mathrm{E}-04$ \\
\hline $\mathrm{Na}^{+}$ & $1,33 \mathrm{E}-03$ \\
\hline Cloretos $\left(\mathrm{Cl}^{-}\right)$ & $4,68 \mathrm{E}-03$ \\
\hline
\end{tabular}

Tabela 51: Inventário do subsistema da produção de 1 kg de ácido cianídrico (UNIGEL, 2006; ECOINVENT CENTRE, 2004f). 
b) Tratamento dos dados

Dados coletados junto à UNIGEL (2006) revelaram que para cada tonelada de metacrilato de metila (MMA) produzida, 3 toneladas de sulfato de amônio são geradas.

Portanto, para atender ao fluxo de referência de 4,717 toneladas de sulfato de amônio ( 1 tonelada de N) definido neste estudo, serão necessárias 1,57 toneladas de metacrilato de metila.

A mesma fonte também forneceu a quantidade de ácido cianídrico necessária para a produção de 1 tonelada de MMA, sendo esta igual a 2,059 toneladas de ácido.

Desse modo, para se obterem 1,57 toneladas de MMA (ou 4,717 toneladas de sulfato de amônio) o conusmo de ácido cianídrico será igual a 3,232 toneladas.

Logo, o tratamento dos dados para este subsistema consistiu da adequação dos valores apresentados na tabela 51 à 3,232 toneladas de ácido cianídrico.

O inventário de aspectos ambientais para a produção de 3,232 toneladas de ácido cianídrico pode ser visto no apêndice A24, ao final de este documento.

\subsubsection{Inventário do subsistema das produções de acrilonitrila e sulfato de amônio}

a) Coleta de dados

Para o subsistema de produção de acrilonitrila e de sulfato de amônio como subproduto, os dados de consumo de recursos materiais e energéticos foram coletados junto à UNIGEL (2006) e no que se referem às emissões atmosféricas, dada a ausência de dados nacionais, estas foram extraídas do 
inventário Acrylonitril da base de dados IDEMAT do programa computacional SimaPro 7.0 (PRé-CONSULTANTS, 2006j).

O inventário selecionado é o que mais se aproxima do processo de obtenção do produtor brasileiro e se refere à obtenção de acrilonitra através da nafta, o mesmo insumo utilizado pela UNIGEL.

$\mathrm{Na}$ tabela 52, a seguir, é apresentado o inventário das produções de $1 \mathrm{~kg}$ de acrilonitrila e $0,16 \mathrm{~kg}$ de sulfato de amônio.

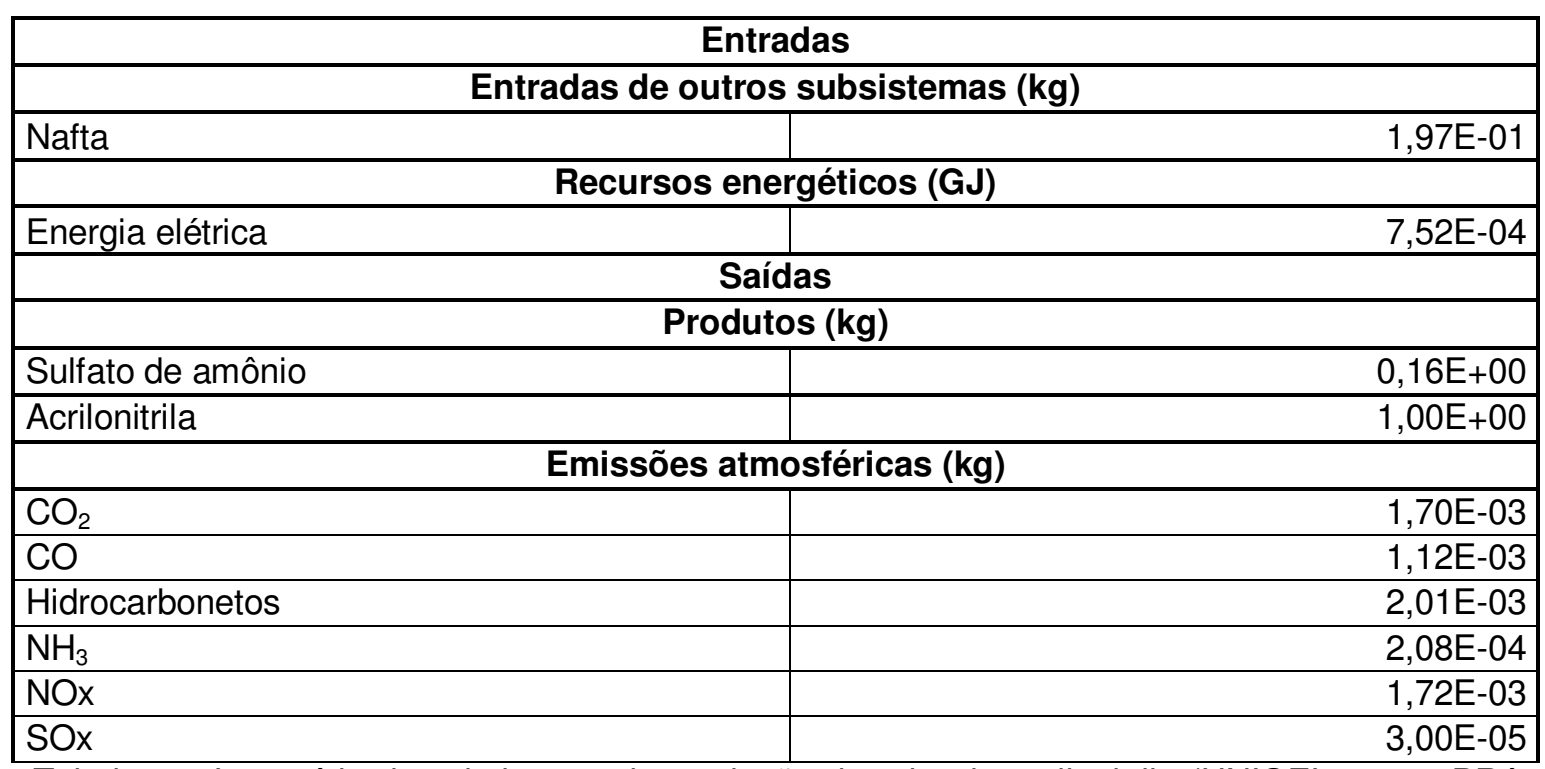

Tabela 52: Inventário do subsistema da produção de 1 kg de acrilonitrila (UNIGEL, 2006; PRé Consultants, 2006j).

b) Tratamento dos dados

De acordo com as informações obtidas junto à UNIGEL (2006), para cada tonelada de acrilonitrila gerada, 160 kg de sulfato de amônio também são produzidos.

De posse dessa informação, concluiu-se que para atender ao fluxo de referência de 4,717 toneladas de sulfato de amônio ( 1 tonelada de N) definido neste estudo, serão necessárias 29,48 toneladas de acrilonitrila. 
Assim sendo, o tratamento dos dados para este subsistema consistiu da adequação dos valores coletados à quantidade de 29,48 toneladas de acrilonitrila (ou 4,717 toneladas de sulfato de amônio).

O inventário de aspectos ambientais para a produção de 29,48 toneladas de acrilonitrila é apresentado no apêndice A25.

\subsubsection{Inventário do subsistema das produções de metacrilato de metila e sulfato de amônio}

a) Coleta de dados

Para este subsistema, devido à ausência de alguns dados nacionais, foram utilizados dados que mais se aproximavam do processo empregado pela UNIGEL para a obtenção do monômero de metacrilato de metila (MMA), a partir da nafta, e de sulfato de amônio como subproduto.

Os dados que constituem o inventário de aspectos ambientais de este subsistema foram extraídos de duas fontes: os consumos de recursos materiais e energéticos foram fornecidos pelo fabricante (UNIGEL, 2006) e as emissões atmosféricas, efluentes líquidos e resíduos sólidos foram obtidos do inventário MMA - Methyl Methacrylate Monomer da base de dados IDEMAT do programa computacional SimaPro 7.0 (PRé-CONSULTANTS, 2006k).

Segue, na tabela 53, o inventário das produções de $1 \mathrm{~kg}$ de metacrilato de metila e $3 \mathrm{~kg}$ de sulfato de amônio. 


\begin{tabular}{|c|c|}
\hline \multicolumn{2}{|c|}{ Entradas } \\
\hline \multicolumn{2}{|c|}{ Entradas de outros subsistemas $(\mathrm{kg})$} \\
\hline Nafta & $7,76 \mathrm{E}-02$ \\
\hline \multicolumn{2}{|c|}{ Recursos energéticos (GJ) } \\
\hline Energia elétrica & $1,41 \mathrm{E}-02$ \\
\hline \multicolumn{2}{|c|}{ Saídas } \\
\hline \multicolumn{2}{|c|}{ Produtos (kg) } \\
\hline Sulfato de amônio & $3,00 \mathrm{E}+00$ \\
\hline Metacrilato de metila & $1,00 \mathrm{E}+00$ \\
\hline \multicolumn{2}{|c|}{ Emissões atmosféricas (kg) } \\
\hline $\mathrm{CO}_{2}$ & $5,50 \mathrm{E}+00$ \\
\hline $\mathrm{CO}$ & $5,80 \mathrm{E}-03$ \\
\hline Hidrocarbonetos & $6,70 \mathrm{E}-03$ \\
\hline $\mathrm{CH}_{4}$ & $2,80 \mathrm{E}-02$ \\
\hline $\mathrm{NH}_{3}$ & $3,40 \mathrm{E}-05$ \\
\hline Íons metálicos & $1,00 \mathrm{E}-05$ \\
\hline NOx & $2,40 \mathrm{E}-02$ \\
\hline SOx & $2,60 \mathrm{E}-02$ \\
\hline Cianetos (CN) & $1,60 \mathrm{E}-05$ \\
\hline COV - exceto metano & $2,91 \mathrm{E}-03$ \\
\hline Material Particulado & $5,70 \mathrm{E}-03$ \\
\hline \multicolumn{2}{|c|}{ Efluentes líquidos (kg) } \\
\hline DBO & $2,30 \mathrm{E}-04$ \\
\hline DQO & $9,90 \mathrm{E}-04$ \\
\hline Hidrocarbonetos & $5,80 \mathrm{E}-05$ \\
\hline Ácidos como $\mathrm{H}^{+}$ & $2,50 \mathrm{E}-04$ \\
\hline Íons metálicos & $3,01 \mathrm{E}-04$ \\
\hline Óleo não especificado & $6,10 \mathrm{E}-05$ \\
\hline Sólidos dissolvidos totais & $5,40 \mathrm{E}-04$ \\
\hline Sólidos suspensos totais & $1,40 \mathrm{E}-03$ \\
\hline Compostos de enxofre & $3,00 \mathrm{E}-02$ \\
\hline Compostos de nitrogênio & $3,01 \mathrm{E}-03$ \\
\hline $\mathrm{Na}^{+}$ & $1,40 \mathrm{E}-02$ \\
\hline Cloretos $\left(\mathrm{Cl}^{-}\right)$ & $8,50 \mathrm{E}-03$ \\
\hline \multicolumn{2}{|c|}{ Resíduos sólidos (kg) } \\
\hline Resíduos processuais & $1,03 \mathrm{E}-01$ \\
\hline
\end{tabular}

Tabela 53: Inventário do subsistema da produção de $1 \mathrm{~kg}$ de metacrilato de metila (UNIGEL, 2006; PRé Consultants, 2006k). 
b) Tratamento dos dados

Segundo a UNIGEL (2006) na obtenção de 1 tonelada de MMA, são produzidas também 3 toneladas de sulfato de amônio. Assim sendo, para atender ao fluxo de referência de 4,717 toneladas de sulfato de amônio (1 tonelada de $\mathrm{N}$ ) definido neste estudo, serão necessárias 1,57 toneladas de MMA.

Desse modo, o tratamento dos dados do subsistema de produção de MMA e sulfato de amônio como subproduto consistiu da adequação dos valores da tabela 53 à quantidade de 1,57 toneladas de MMA (ou 4,717 toneladas de sulfato de amônio).

Encontra-se no apêndice A26 o inventário de aspectos ambientais para a produção de 1,57 toineladas de MMA.

\subsubsection{Inventário consolidado da uréia produzida pela Petrobras/Fafen}

a) Coleta de dados

Os dados que compõem o inventário consolidado da uréia produzida pela PETROBRAS/FAFEN foram provenientes dos subsistemas: extração e beneficiamento de gás natural, energia térmica gerada na queima de gás natural, produção de amônia por reforma catalítica de gás natural com vapor de água e produção de uréia; além dos aspetos ambientais da geração e distribuição de eletricidade no país.

b) Tratamento dos dados

O tratamento dos dados consistiu da agregação dos aspectos ambientais dos subsistemas, previamente adequados ao fluxo de referência de 2,17 
toneladas de uréia ( 1 tonelada de $\mathrm{N}$ ). Assim sendo, foram obtidos os valores: 2,53 GJ de eletricidade; extração e beneficiamento de 924,92 kg de gás natural (apêndice A9); 15,33 GJ de energia térmica proveniente da queima de gás natural (apêndice A10); produção de 1,217 toneladas de amônia por reforma catalítica de gás natural (apêndice A12); e produção de 2,17 toneladas de uréia (apêndice A15).

O inventário consolidado da produção de uréia da PETROBRAS/FAFEN encontra-se no apêndice B1 de este documento.

\subsubsection{Inventário consolidado da uréia produzida pela Fosfertil S. A.}

a) Coleta de dados

Para este inventário foram utilizados os dados: da produção de resíduo asfáltico; separação do ar; produção de amônia por oxidação parcial; produção de uréia; além dos aspectos associados à geração e distribuição de eletricidade no país.

b) Tratamento dos dados

Os aspectos ambientais dos subsistemas de produção de resíduo asfáltico; da separação do ar; da produção de amônia por oxidação parcial; da produção de uréia e da geração de eletricidade; foram devidamente ajustados ao fluxo de referência de 2,17 toneladas de uréia e posteriormente agregados para constituir o inventário consolidado da uréia produzida no país pela FOSFERTIL S. A.

Os inventários dos seguintes subsistemas foram agregados para compor o inventário final consolidado: produção de $1.083 \mathrm{~kg}$ de resíduo asfáltico com fator de alocação de 2,82\% (apêndice A5); separação de $11,73 \mathrm{~kg}$ de ar (apêndice A11); produção de 1,217 toneladas de amônia por oxidação parcial 
(apêndice A13); produção de 2,17 toneladas de uréia (apêndice A15) e geração e distribuição de 2,15 GJ de eletricidade. O inventário final é apresentado no apêndice B2.

\subsubsection{Inventário consolidado da uréia adequada às condições brasileiras}

a) Coleta de dados

Os dados que constituem o inventário consolidado da uréia produzida no Brasil foram coletados dos apêndices B1 e B2 de este documento.

b) Tratamento dos dados

O tratamento dos dados para este inventário consistiu da ponderação dos aspectos ambientais da uréia produzida pela PETROBRAS/FAFEN (apêndice B1) com os aspectos ambientais da uréia produzida pela FOSFERTIL (apêndice B2) e posterior agregação dos mesmos.

O fator de ponderação foi obtido por meio da distribuição dos dados de capacidade instalada das duas empresas, para o ano de 2007, de acordo com as informações da tabela 22, do capítulo 4, de este documento. Assim, atribuíram-se $63 \%$ dos aspectos ambientais para a PETROBRAS/FAFEN e $37 \%$ para a FOSFERTIL.

O inventário final consolidado da uréia produzida no país é apresentado no apêndice B3. 


\subsubsection{Inventário consolidado do nitrato de amônio adequado às condições brasileiras}

a) Coleta de dados

Os dados que compõem o inventário consolidado do nitrato de amônio produzido no país pela FOSFERTIL foram coletados dos seguintes subsistemas: produção de gás combustível de refinaria; produção de amônia via reforma catalítica de gás de refinaria; produção de ácido nítrico; produção de nitrato de amônio; além dos aspectos ambientais associados à geração e distribuição de eletricidade no país.

b) Tratamento dos dados

O tratamento dos dados envolveu a aplicação do fator de alocação em massa, calculado para a amônia, de $46,3 \%$ aos aspectos associados à produção de gás de refinaria (do apêndice A4) e a agregação dos aspectos ambientais já previamente ajustados ao fluxo de referência de 2,941 toneladas de nitrato de amônio dos seguintes subsistemas: produção de 730,2 kg de gás de refinaria com fator de alocação de 1,05\% (apêndice A4); produção de 1,217 toneladas de amônia via reforma catalítica de gás de refinaria com fator de alocação de 46,3\% (apêndice A14); produção de 2,25 toneladas de ácido nítrico (apêndice A16); produção de 2,94 toneladas de nitrato de amônio (apêndice A17) e geração e distribuição de 6,534 GJ de eletricidade.

O inventário consolidado do nitrato de amônio produzido no país pela FOSFERTIL é apresentado no apêndice B4 ao final de este documento. 


\subsubsection{Inventário consolidado do sulfato de amônio produzido pelo processo de síntese pela Unigel S. A.}

a) Coleta de dados

Para compor os dados do inventário consolidado do sulfato de amônio produzido pela UNIGEL, por síntese da amônia com ácido sulfúrico, foram utilizados os seguintes subsistemas: extração e beneficiamento de gás natural; energia térmica proveniente da queima do gás natural; produção de amônia via reforma catalítica de gás natural com vapor de água; produção de ácido sulfúrico; produção de sulfato de amônio e os aspectos ambientais da geração e distribuição de eletricidade no Brasil.

b) Tratamento dos dados

Os dados que constituem o inventário consolidado do sulfato de amônio produzido pela UNIGEL S. A. foram tratados conforme as informações a seguir: uma vez que os aspectos ambientais dos subsistemas de extração e beneficiamento de gás natural $(924,92 \mathrm{~kg}$ - apêndice A9), da energia térmica proveniente da queima do gás natural (15,33 GJ - apêndice A 10) e da produção de amônia por reforma catalítica de gás natural (1,217 toneladas apêndice A12) já se encontravam ajustados ao fluxo de referência de 4,717 toneladas de sulfato de amônio, aplicou-se a todos os aspectos o fator de alocação em massa igual a 46,3\% calculado para a amônia.

Posteriormente, agregaram-se os aspectos ambientais associados aos subsistemas da produção de ácido sulfúrico (3,5 toneladas - apêndice A18); da produção de sulfato de amônio (4,717 toneladas - apêndice A19) e da geração e distribuição de eletricidade (3,406 GJ); sendo que todos estes já estavam adequados ao fluxo de referência mencionado. 
O inventário consolidado do sulfato de amônio produzido no país pela UNIGEL pelo processo de síntese da amônia com o ácido sulfúrico encontra-se no apêndice B5 ao final de este documento.

\subsubsection{Inventário consolidado do sulfato de amônio produzido pelo processo de síntese pela Bunge fertilizantes S. A.}

a) Coleta de dados

Os dados que compõem este inventário consolidado foram coletados dos seguintes subsistemas: produção de gás combustível de refinaria com fator de alocação de 1,05\%; produção de amônia via reforma catalítica de gás de refinaria com fator de alocação de 46,3\%; produção de ácido sulfúrico; produção de sulfato de amônio; além dos aspectos ambientais associados à geração e distribuição de eletricidade no país.

b) Tratamento dos dados

O tratamento dos dados envolveu a aplicação do fator de alocação em massa calculado para a amônia de $46,3 \%$ aos aspectos associados à produção de gás de refinaria; e a agregação dos aspectos ambientais já previamente ajustados ao fluxo de referência de 4,717 toneladas de sulfato de amônio dos seguintes subsistemas: produção de gás de refinaria (730,2 kg - apêndice A4); produção de amônia via reforma catalítica (1,217 toneladas - apêndice A14); produção de ácido sulfúrico (3,5 toneladas - apêndice A18); produção de sulfato de amônio (4,717 toneladas - apêndice A19) e geração e distribuição de eletricidade (5,14 GJ).

O inventário consolidado do sulfato de amônio produzido no país pela BUNGE FERTILIZANTES é mostrado no apêndice B6 de este documento. 


\subsubsection{Inventário consolidado do sulfato de amônio obtido como subproduto da produção de caprolactama pela Braskem S. A.}

a) Coleta de dados

Os dados que compõem o inventário consolidado do sulfato de amônio obtido como subproduto da fabricação de caprolactama foram coletados dos seguintes subsistemas: produção de nafta; extração e beneficiamento de gás natural; geração de energia térmica proveniente da queima de gás natural; produção de amônia via reforma catalítica de gás natural; produção de ácido sulfúrico; produção de benzeno; produção de ciclohexano; produção de caprolactama e sulfato de amônio; e geração e distribuição de eletricidade.

b) Tratamento dos dados

O tratamento de dados foi efetuado em três etapas. Primeiramente, os aspectos ambientais dos seguintes subsistemas foram adequados ao fluxo de referência de 4,717 toneladas de sulfato de amônio: produção de 11,78 toneladas de nafta com fator de alocação de 11,63\% (apêndice A6); extração e beneficiamento de 924,92 kg de gás natural (apêndice A9); geração de 15,33 GJ de energia térmica proveniente da queima de gás natural (apêndice A10); produção de 1,217 toneladas de amônia via reforma catalítica de gás natural (apêndice A12); produção de 3,5 toneladas de ácido sulfúrico (apêndice A18); produção de 6,66 toneladas de benzeno (apêndice A20); produção de 5,936 toneladas de ciclohenxano (apêndice A21); produção de 2,62 toneladas de caprolactama e 4,717 toneladas de sulfato de amônio (apêndice A23) e geração e distribuição de 24,28 GJ de eletricidade.

Posteriormente, aplicou-se o fato de alocação, calculado para amônia obtida por reforma catalítica, de $46,3 \%$ aos dados dos subsistemas de extração 
e beneficiamento de gás natural, geração de energia térmica e produção de amônia.

Uma vez que os aspectos ambientais dos subsistemas citados já se encontravam ajustados ao fluxo de referência e com os devidos fatores de alocação aplicados, a terceira etapa consistiu da agregação dos aspectos contidos em cada um deles.

O inventário consolidado do sulfato de amônio obtido como subproduto da produção de caprolactama pela BRASKEM pode ser visto no apêndice B7.

\subsubsection{Inventário consolidado do sulfato de amônio obtido como subproduto da produção de acrilonitrila pela Unigel S. A.}

a) Coleta de dados

Os dados que compõem o inventário consolidado do sulfato de amônio obtido como subproduto da fabricação de acrilonitrila foram coletados dos seguintes subsistemas: produção de nafta; extração e beneficiamento de gás natural; geração de energia térmica proveniente da queima de gás natural; produção de amônia via reforma catalítica de gás natural; produção de propeno; produção de acrilonitrila e sulfato de amônio; e geração e distribuição de eletricidade.

b) Tratamento dos dados

Os dados que constituem o inventário consolidado do sulfato de amônio, produzido pela UNIGEL, obtido como subproduto da fabricação de acrilonitrila foram tratados conforme as informações a seguir: uma vez que os aspectos ambientais dos subsistemas de extração e beneficiamento de $924,92 \mathrm{~kg}$ de gás natural (apêndice A9), da geração de 15,33 GJ de energia térmica proveniente da queima do gás natural (apêndice A10) e da produção de 1,217 toneladas de 
amônia por reforma catalítica de gás natural (apêndice A12) já se encontravam ajustados ao fluxo de referência de 4,717 toneladas de sulfato de amônio, aplicou-se a todos os aspectos o fator de alocação em massa igual a 46,3\% calculado para a amônia.

Posteriormente, agregaram-se os aspectos ambientais associados aos subsistemas da produção de 5,798 toneladas de nafta com alocação de 11,63\% (apêndice A7), da produção de 4,359 toneladas de propeno (apêndice A22), da produção de 4,717 toneladas de sulfato de amônio e 29,48 toneladas de acrilonitrila (apêndice A25) e da geração de eletricidade (23,54 GJ); sendo que todos estes já estavam adequados ao fluxo de referência mencionado.

O inventário consolidado do sulfato de amônio obtido como subproduto da produção de acrilonitrila produzido no país pela UNIGEL pode ser visto no apêndice B8 ao final de este documento.

\subsubsection{Inventário consolidado do sulfato de amônio obtido como subproduto da produção de metacrilato de metila pela Unigel S. A.}

a) Coleta de dados

Os dados que compõem o inventário consolidado do sulfato de amônio obtido como subproduto da fabricação de MMA foram coletados dos seguintes subsistemas: produção de nafta; extração e beneficiamento de gás natural; geração de energia térmica proveniente da queima de gás natural; produção de amônia via reforma catalítica de gás natural; produção de benzeno; produção de propeno; produção de ácido cianídrico; produção de MMA e sulfato de amônio; e geração e distribuição de eletricidade. 
b) Tratamento dos dados

Os dados que constituem o inventário consolidado do sulfato de amônio, produzido pela UNIGEL, obtido como subproduto da fabricação de MMA foram tratados conforme as informações a seguir: uma vez que os aspectos ambientais dos subsistemas de extração e beneficiamento de 1,87 toneladas de gás natural (apêndice A9), da geração de 15,33 GJ de energia térmica proveniente da queima do gás natural (apêndice A10) e da produção de 2,456 toneladas de amônia por reforma catalítica de gás natural (apêndice A12) já se encontravam ajustados ao fluxo de referência de 4,717 toneladas de sulfato de amônio, aplicou-se a todos os aspectos o fator de alocação em massa igual a $46,3 \%$ calculado para a amônia.

Posteriormente, agregaram-se os aspectos ambientais associados aos subsistemas da produção de $243,6 \mathrm{~kg}$ de nafta com alocação de 11,63\% (apêndice A8), da produção de 68,86 $\mathrm{kg}$ de benzeno (apêndice A20), da produção de $91,58 \mathrm{~kg}$ de propeno (apêndice A22), da produção de 3,232 toneladas de ácido cianídrico (apêndice A24), da produção de 4,717 toneladas de sulfato de amônio e 1,57 toneladas de MMA (apêndice A26) e da geração de eletricidade (24,667 GJ); sendo que todos estes já estavam adequados ao fluxo de referência mencionado.

O inventário consolidado do sulfato de amônio obtido como subproduto da produção de MMA pela UNIGEL é apresentado no apêndice B9 ao final de este documento. 


\subsubsection{Inventário consolidado do sulfato de amônio adequado às condições brasileiras}

a) Coleta de dados

Os dados que constituem o inventário consolidado do sulfato de amônio produzido no Brasil foram coletados dos apêndices B5, B6, B7, B8 e B9 de este documento.

b) Tratamento dos dados

O tratamento dos dados para este inventário consistiu inicialmente da aplicação de fatores de alocação, baseados em critério físico (massa), para o sulfato de amônio obtido como subproduto das fabricações de caprolactama, acrilonitrila e metacrilato de metila.

Conforme apresentado anteriormente, em este mesmo capítulo, para o atendimento do fluxo de referência de 4,717 toneladas de sulfato de amônio, são produzidas também, em cada processo: 2,62 toneladas de caprolactama; 29,48 toneladas de acrilonitrila e 1,57 toneladas de metacrilato de metila.

Face ao exposto, foram obtidos então os seguintes fatores de alocação em massa para o sulfato de amônio produzido como subproduto das fabricações de caprolactama, acrilonitrila e metacrilato de metila: $64,3 \% ; 13,8 \%$ e $75 \%$, respectivamente. Desse modo, aplicaram-se os fatores de alocação de $64,3 \%, 13,8 \%$ e $75 \%$ aos dados finais dos apêndices B7, B8 e B9, respectivamente.

O tratamento dos dados consistiu ainda da ponderação e posterior agregação dos aspectos ambientais do sulfato de amônio obtido: pelo processo de síntese da UNIGEL (apêndice B5); pelo processo de síntese da BUNGE FERTILIZANTES (apêndice B6); como subproduto da fabricação de caprolactama da BRASKEM (apêndice B7); como subproduto da fabricação de 
acrilonitrila da UNIGEL (apêndice B8); e como subproduto da fabricação de MMA da UNIGEL (apêndice B9).

O fator de ponderação foi obtido por meio da distribuição dos dados de capacidade instalada das duas empresas, para o ano de 2007, de acordo com as informações do item 4.3.3.3 do capítulo 4 de este documento.

Assim, atribuíram-se: $12 \%$ dos aspectos ambientais para o processo de síntese da UNIGEL, 13\% para o processo de síntese da BUNGE FERTILIZANTES, 32\% para o processo de obtenção de sulfato de amônio como subproduto da fabricação de caprolactama da BRASKEM; $6 \%$ para o processo de obtenção de sulfato de amônio como subproduto da fabricação de acrilonitrila da UNIGEL; e 37\% para o processo de obtenção de sulfato de amônio como subproduto da fabricação de MMA da UNIGEL.

O inventário final consolidado do sulfato de amônio produzido no país é apresentado no apêndice B10. 


\section{DISCUSSÃO DOS RESULTADOS, CONCLUSÕES E RECOMENDAÇÕES}

Uma vez que o objetivo inicialmente proposto foi atendido, ou seja, que os resultados dos inventários do ciclo de vida da uréia, do nitrato de amônio e do sulfato de amônio foram obtidos e apresentados, este último capítulo do documento têm o intuito de apresentar alguns comentários e conclusões a esse respeito.

Ao final, encerra-se o trabalho com comentários sobre o atendimento aos objetivos e com algumas recomendações para futuros estudos relacionados a este projeto.

Os dados obtidos no inventário consolidado do ciclo de vida da uréia revelaram 45 aspectos ambientais, assim distribuídos: seis recursos materiais, quatro recursos energéticos, quatorze emissões atmosféricas, quinze efluentes líquidos, quatro resíduos sólidos e duas emissões energéticas.

O gás natural é o recurso energético responsável pela geração de energia térmica no subsistema de produção da amônia por reforma catalítica e pela geração de energia elétrica do subsistema beneficiamento de gás natural.

O consumo de gás natural empregado como matéria-prima no sistema foi igual a $653 \mathrm{~kg}$ / t de N. As etapas de extração e beneficiamento de gás natural e de produção da amônia por reforma catalítica foram as principais responsáveis pelo seu consumo.

$\mathrm{O}$ ar consumido pelo sistema foi de $8,40 \mathrm{~kg} / \mathrm{t}$ de $\mathrm{N}$ e teve nos subsistemas de separação criogênica do ar e de produção de amônia por ambos os processos seus destinos.

O consumo total de energia do sistema foi de 25,16 GJ, já descontadas as quantidades de vapor liberadas nos subsistemas de extração e beneficiamento de gás natural, separação do ar e de produção de amônia por reforma catalítica e teve a seguinte distribuição: 10,6\% corresponderam à 
eletricidade, $34,4 \%$ ao emprego de vapor; $38,4 \%$ ao uso do gás natural para geração de energias térmica e elétrica e $16,6 \%$ a energia necessária para a geração de eletricidade.

Os dados obtidos no inventário do ciclo de vida da uréia revelaram ainda potencial contribuição do sistema ao aquecimento global devido a elevadas emissões de dióxido de carbono $\left(\mathrm{CO}_{2}\right)$ presentes nas duas cadeias produtivas (FOSFERTIL e PETROBRAS/FAFEN). Verificou-se, de acordo com os dados do apêndice B3, que o dióxido de carbono foi responsável por $98,3 \%$ de todas as emissões atmosféricas do sistema; sendo este seguido por: 0,59\% referente aos óxidos de nitrogênio (NOx), 0,24\% devido às emissões de $\mathrm{CH}_{4}, 0,13 \%$ referente às emissões de óxidos de enxofre (SOx) e $0,74 \%$ correspondente às emissões de outros gases.

Convém aqui ressaltar, como não poderia deixar de ser, a presença de compostos nitrogenados nos efluentes líquidos gerados pelo sistema. Os compostos nitrogenados corresponderam a $73,5 \%$ de todos os efluentes líquidos gerados e foram oriundos, em sua totalidade, de quatro subsistemas: produção de amônia por oxidação parcial, produção de amônia por reforma catalítica, produção de uréia e geração e distribuição de eletricidade. Do total gerado desses compostos, $63 \%$ foram emitidos na cadeia produtiva de produção da uréia da PETROBRAS/FAFEN.

No que se referem aos resíduos sólidos, esses foram gerados principalmente nos subsistemas de: transporte marítimo de petróleo importado, refino do petróleo, produção de amônia (catalisador usado) e geração e distribuição de eletricidade.

Os resultados obtidos no inventário de ciclo de vida consolidado do nitrato de amônio revelaram 42 aspectos ambientais sendo seis recursos materiais, três recursos energéticos, quatorze emissões atmosféricas, quinze efluentes líquidos, três resíduos sólidos e uma emissão energética. 
O consumo total de água pelo sistema foi igual a 763 toneladas, quantidade que respondeu por $99,5 \%$ do total de recursos materiais consumidos.

O consumo energético total do sistema foi de 17,98 GJ, já descontadas as quantidades de vapor liberadas nos subsistemas da produção de amônia e da produção de ácido nítrico. O consumo de eletricidade do sistema foi de 6,55 GJ e teve a seguinte distribuição: $61,2 \%$ foi consumido no subsistema da produção de ácido nítrico; 35,6\% teve seu consumo na produção de amônia; $2,7 \%$ na produção de nitrato de amônio e $0,5 \%$ no subsistema da produção de gás de refinaria.

No que diz respeito às emissões atmosféricas, verificou-se que o dióxido de carbono $\left(\mathrm{CO}_{2}\right)$ foi responsável por $79 \%$ de todas as emissões do sistema, seguido por $8,2 \%$ referente à emissão de $\mathrm{N}_{2} \mathrm{O}, 6,6 \%$ referente às emissões dos óxidos de nitrogênio (NOx), 2,7\% devido às emissões de $\mathrm{NH}_{3}$ e por 3,5\% correspondente às emissões de outros gases.

No que se referem aos efluentes líquidos gerados pelo sistema, destacase a presença de compostos nitrogenados. Os compostos de nitrogênio corresponderam a $25,3 \%$ de todos os efluentes líquidos gerados e foram oriundos, em sua totalidade, de quatro subsistemas: produção de amônia, produção de ácido nítrico, produção de nitrato de amônio e geração e distribuição de eletricidade.

Em relação aos resíduos sólidos, esses foram gerados principalmente nos subsistemas de refino do petróleo e da geração de eletricidade.

Os dados obtidos no inventário de ciclo de vida consolidado do sulfato de amônio revelaram 46 aspectos ambientais distribuídos em: sete recursos materiais, três recursos energéticos, dezesseis emissões atmosféricas, quinze efluentes líquidos, quatro resíduos sólidos e uma emissão energética.

O consumo energético total do sistema foi de 36,91 GJ, já descontadas as quantidades de vapor liberadas nos subsistemas de extração e beneficiamento de gás de natural e da produção de amônia. 
O consumo de eletricidade do sistema foi de 13,11 GJ e teve a seguinte distribuição: $8,2 \%$ foram consumidos na obtenção do sulfato de amônio via síntese e o restante, $91,8 \%$, na obtenção do sulfato de amônio como subproduto das produções de: caprolactama $(38,1 \%)$, acrilonitrila $(1,5 \%)$ e metacrilato de metila $(52,2 \%)$.

No que diz respeito às emissões atmosféricas, verificou-se que o dióxido de carbono $\left(\mathrm{CO}_{2}\right)$ foi responsável por $99 \%$ de todas as emissões do sistema, seguido por $0,3 \%$ devido às emissões dos óxidos de enxofre (SOx), 0,3\% correspondente às emissões dos óxidos de nitrogênio (NOx), 0,18\% devido às emissões de metano $\left(\mathrm{CH}_{4}\right)$ e por $0,22 \%$ referente às emissões de outros gases.

Em relação aos efluentes líquidos gerados pelo sistema merecem destaque as contribuições de compostos nitrogenados e de compostos de enxofre.

Os compostos de enxofre foram responsáveis por $41 \%$ da massa total de efluentes líquidos do sistema e foram provenientes dos subsistemas de: extração e beneficiamento de gás natural, geração e distribuição de eletricidade, produção de ácido cianídrico e produção de metacrilato de metila.

Os compostos nitrogenados corresponderam a $5 \%$ de todos os efluentes líquidos gerados e foram oriundos, em sua totalidade, de cinco subsistemas: extração e beneficiamento de gás natural, produção de amônia, produção de ácido cianídrico, produção de metacrilato de metila e geração e distribuição de eletricidade.

No que se referem aos resíduos sólidos, esses foram gerados principalmente nos subsistemas de extração e de refino do petróleo e da geração de eletricidade. Merece destaque, a presença de enxofre nos resíduos sólidos do sistema, sendo correspondente a 4,5\% da massa total de resíduos gerada e proveniente dos subsistemas de extração e beneficiamento de gás natural e produção de ácido sulfúrico.

Como conclusão final constata-se, para os três sistemas de produto inventariados, o alto consumo de água e de recursos energéticos; bem como as 
elevadas emissões atmosféricas de dióxido de carbono e a presença de compostos de nitrogênio nos efluentes líquidos, evidenciando potenciais de impactos ambientais.

O projeto prestou-se à identificação e quantificação dos principais aspectos ambientais associados aos ciclos de vida dos fertilizantes nitrogenados no país. Muito embora as limitações ainda existentes em relação ao uso da técnica de ACV, decorrentes, principalmente, da falta de uma metodologia universal consolidada e da inexistência, particularmente no Brasil, de bancos de dados regionalizados, não prejudicaram o atendimento dos objetivos propostos por este trabalho.

Nesse contexto, a busca de resultados para este estudo baseou-se principalmente nas etapas do sistema de produto nacional que se diferenciam de outros, tais como: atividades de transporte, insumos e processos de fabricação utilizados e geração de eletricidade.

Portanto, recomenda-se para o aprimoramento do trabalho a substituição dos dados coletados de fontes secundárias por dados primários, obtidos das empresas envolvidas no sistema de produto.

Recomenda-se ainda que sejam conduzidos estudos visando melhorias de processo no que dizem respeito à otimização dos consumos de recursos materiais e energéticos e à redução de rejeitos. 


\section{REFERÊNCIAS BIBLIOGRÁFICAS}

ABIQUIM - ASSOCIAÇÃO BRASILEIRA DA INDÚSTRIA QUÍMICA. Guia da indústria química brasileira 2008. São Paulo, 2008, ano 16. 504p. ISSN $0102-$ 5368. 2008a.

ABIQUIM - ASSOCIAÇÃO BRASILEIRA DA INDÚSTRIA QUÍMICA. A indústria química: estatísticas. 2008. Disponível em: $<$ http://www.abiquim.org.br/conteudo.asp?princ=ain\&pag=estat>. Acesso em 21 jan. 08. 2008b.

ABIQUIM - ASSOCIAÇÃO BRASILEIRA DA INDÚSTRIA QUÍMICA. Anuário da indústria química brasileira 2008. São Paulo, 2008, ano 35. 264p. ISSN 0102-5341. 2008c.

ABNT - ASSOCIAÇÃO BRASILEIRA DE NORMAS TÉCNICAS. Sistemas de gestão ambiental - Especificações e diretrizes para uso - NBR ISO 14001. Rio de Janeiro, 1996.

ABNT - ASSOCIAÇÃO BRASILEIRA DE NORMAS TÉCNICAS. Gestão Ambiental - Avaliação do ciclo de vida - Princípios e estrutura - NBR ISO 14040. Rio de Janeiro, 2001.

ABNT - ASSOCIAÇÃO BRASILEIRA DE NORMAS TÉCNICAS. Gestão Ambiental - Avaliação do ciclo de vida - Definição de objetivo e escopo e análise de inventário - NBR ISO 14041. Rio de Janeiro, 2004a.

ABNT - ASSOCIAÇÃO BRASILEIRA DE NORMAS TÉCNICAS. Gestão Ambiental - Avaliação do ciclo de vida - Avaliação do impacto do ciclo de vida - NBR ISO 14042. Rio de Janeiro, 2004b. 
ANDA - ASSOCIAÇÃO NACIONAL PARA DIFUSÃO DE ADUBOS. Anuário estatístico do setor de fertilizantes 2007. São Paulo, 2008. 160p. ISSN 01034790.

ANDA - ASSOCIAÇÃO NACIONAL PARA DIFUSÃO DE ADUBOS. Publicações. Boletins técnicos. 2009. O uso de fertilizantes minerais e o meio ambiente. Disponível em: $<$ http://www.anda.org.br/boletins/fertilizantes_meio_ambiente.pdf>. Acesso em 27 fev. 09.

ANP - AGÊNCIA NACIONAL DO PETRÓLEO, GÁS NATURAL E BIOCOMBUSTÍVEIS. Conheça a ANP. Publicações ANP. Anuário estatístico brasileiro do petróleo, gás natural e biocombustíveis 2008. 2008a. Disponível em: <http://www.anp.gov.br/conheca/anuario_2008.asp>. Acesso em: 11 mar. 09

ANP - AGÊNCIA NACIONAL DO PETRÓLEO, GÁS NATURAL E BIOCOMBUSTÍVEIS. Volume de petróleo refinado nas refinarias nacionais. 2008b. Disponível em: <http://www.anp.gov.br/dados_estatisticos/Producao_de_Derivados_m3.xls>. Acesso em 01 jul. 2008.

ANP - AGÊNCIA NACIONAL DO PETRÓLEO, GÁS NATURAL E BIOCOMBUSTÍVEIS. Produção nacional de derivados de petróleo. 2008c. Disponível em: $<$ http://www.anp.gov.br/dados_estatisticos/Producao_de_Derivados_m3.xls>. Acesso em 01 jul. 2008. 
ANP - AGÊNCIA NACIONAL DO PETRÓLEO, GÁS NATURAL E BIOCOMBUSTÍVEIS. Importações e exportações. 2008d. Disponível em: <http://www.anp.gov.br/doc/dados_estatisticos/Importacoes_e_Exportacoes_m3 .xls>. Acesso em 01 jul. 2008.

BAUMANN, H.; TILLMAN, A. M. The Hitch Hiker's guide to LCA - An orientation in life cycle assessment methodology and application. Studentlitteratur, 2004. 543p.

BENJAMIN, A. K. Desenvolvimento de modelo para avaliação de softwares de apoio à análise de ciclo de vida. 128p. Dissertação (Mestrado). Escola Politécnica da Universidade de São Paulo. São Paulo, 2001.

BJÖRKLUND, A. E. Survey of approaches to improve reliability in LCA. The International Journal of Life Cycle Assessment. V. 7, n. 2, p. 64 - 72. 2002.

BORGES, F. J. Inventário do ciclo de vida do PVC produzido no Brasil. 174p. Dissertação (Mestrado). Escola Politécnica da Universidade de São Paulo. São Paulo, 2004.

BRASKEM S. A. Informações sobre a produção. [mensagem enviada por Portal Braskem - Contato]. Mensagem recebida por <paulo.henrique@poli.usp.br> em 15 de ago. 08.

BRENTRUP, F.; KIISTERS, J.; LAMMEL, J.; KUHLMANN, H. Methods to estimate on-field nitrogen emissions from crop production as an input to LCA studies in the agricultural sector. The International Journal of Life Cycle Assessment. V. 5, n. 6, p. $349-357.2000$. 
BRUNO, M. A. C. (Coord.); PRESSINOTTI, A. F.; CAMARGO, C. A.; BARRAL, M. F.; VERTIOLA, S. R. R.; MARTINS, W. Conservação de energia na indústria de fertilizantes: manual de recomendações. São Paulo: IPT, 1985. 487p. Publicação IPT n. 1632.

CAPES. Coordenação de Aperfeiçoamento de Pessoal de Nível Superior. Banco de teses. 2008. Disponível em: <http://servicos.capes.gov.br/capesdw>. Acesso em 22 dez. 08.

CEKINSKI, E. (Coord.); CALMANOVICI, C. E.; BICHARA, J. M.; FABIANI, M.; GIULIETTI, M.; CASTRO, M. L. M.; SILVEIRA, P. B. M.; PRESSINOTTI, Q. S. H. C.; GUARDANI, R. Tecnologia de produção de fertilizantes. Instituto de Pesquisas Tecnológicas. São Paulo, 1990. 237p. Publicação IPT n. 1816.

CHEHEBE, J. R. B. Análise do Ciclo de Vida de Produtos - Ferramenta gerencial da ISO 14.000. Rio de Janeiro: Qualitymark. Ed., 1998. 120p.

CHENIER, P. J. Survey of industrial chemistry. $2^{\text {nd }}$ revised ed. New York: VCH Publishers Inc., 1992. 527p. ISBN 1-56081-082-3.

CHRISTIANSEN, K.; JENSEN, A. A.; ELKINGTON, J.; HOFFMANN, L.; MOLLER, B. T.; SCHMIDT, A.; DIJK, F. Life cycle assessment (LCA) a guide to approaches, experiences and information sources. Final report. Soborg: dk-TEKNIK Energy \& Environment, 1997.

CODESP - Companhia Docas do Estado de São Paulo. Porto de Santos. Disponível em: <http://www.portodesantos.com/doc/>. Acesso em 31 jul. 2008. 
COLTRO, L.; GARCIA, E. E. C.; QUEIROZ, G. C. Life cycle inventory for electric energy system in Brazil. The International Journal of Life Cycle Assessment. Landsberg, v. 8, n. 5, p. 290-296, 2003.

CONSOLI, F. (Ed.); ALLEN, D.; BOUSTEAD, I.; FAVA, J.; FRANKLIN, W.; JENSEN, A. A.; OUDE, N.; PARRISH, R.; PERRIMAN, R.; POSTLETHWAITE, D.; QUAY, B.; SÉGUIN, J.; VIGON, B. Guidelines for Life-Cycle Assessment: A "Code of Practice". $1^{\text {st }}$. ed. Pensacola: Society of Environmental Toxicology and Chemistry (SETAC) and SETAC Foundation for Environmental Education, 1993. 73p.

CURRAN, M. A. (Ed.). Environmental life-cycle assessment. New York: McGraw-Hill, 1996. 432p.

CURRAN, M. A. Report on activity of task force 1 in the life cycle inventory programme: data registry - global life cycle inventory data resources. The International Journal of Life Cycle Assessment V. 11, n. 4, p. 284 - 289. 2006.

DECRETO № 4.954 DE 14 DE JANEIRO DE 2004. Disponível em: <http://www.planalto.gov.br/ccivil/_Ato2004-2006/2004/Decreto/D4954.htm>. Acesso em 01 mar. 09.

DEDALUS. Banco de dados bibliográficos da Universidade de São Paulo. $2008 . \quad$ Disponível em: <http://dedalus.usp.br:4500/ALEPH/por/USP/USP/DEDALUS/START>. Acesso em: 22 dez. 08. 
DNPM - DEPARTAMENTO NACIONAL DE PRODUÇÃO MINERAL. Sumário mineral brasileiro 2008.2 Disponível em: $<$ http://www.dnpm.gov.br/conteudo.asp?IDSecao=68\&IDPagina=1165>. Acesso em: 09 mar. 09.

DREYER, L. C.; HAUSCHILD, M. Z.; SCHIERBECK, J. A framework for social life cycle impact assessment. The International Journal of Life Cycle Assessment. V. 11, n. 2, p. $88-97.2006$.

ECOINVENT CENTRE - Swiss Centre for Life Cycle Inventories. Life cycle inventories of chemicals. Air Separation unit. Ecoinvent report n. 08. Dübendorf, 2004a.

ECOINVENT CENTRE - Swiss Centre for Life Cycle Inventories. Life cycle inventories of chemicals. Ammonia, steam reforming. Ecoinvent report $n$. 08. Dübendorf, 2004b.

ECOINVENT CENTRE - Swiss Centre for Life Cycle Inventories. Life cycle inventories of chemicals. Ammonia, partial oxidation. Ecoinvent report $\mathrm{n}$. 08. Dübendorf, 2004c.

ECOINVENT CENTRE - Swiss Centre for Life Cycle Inventories. Life cycle inventories of chemicals. Nitric Acid. Ecoinvent report n. 08. Dübendorf, 2004d.

ECOINVENT CENTRE - Swiss Centre for Life Cycle Inventories. Life cycle inventories of agricultural production systems. Life cycle inventories of mineral fertilisers. Ecoinvent report n. 15. Dübendorf, 2004e. 
ECOINVENT CENTRE - Swiss Centre for Life Cycle Inventories. Life cycle inventories of chemicals. Hydrogen Cyanide. Ecoinvent report n. 08. Dübendorf, $2004 \mathrm{f}$.

EFMA - EUROPEAN FERTILIZER MANUFACTURERS ASSOCIATION. Publications. Best Avaiable Techniques 2000. Disponível em: $<$ http://www.efma.org/EPUB/easnet.dll/ExecReq/Page?eas:template_im=000BC 2\&eas:dat_im=000EAE>. Acesso em 30 jun. 08.

EPLCA - EUROPEAN PLATFORM ON LIFE CYCLE ASSESSMENT. List of tools. Disponível em: <http://lca.jrc.ec.europa.eu/lcainfohub/toolList.vm>. Acesso em 17 jan. 07.

FAVA, J. A. (Ed.); DENISON, R.; JONES, B.; CURRAN, M. A.; VIGON, B.; SELKE, S.; BARNUM, J. A technical framework for life-cycle assessment. Washington, DC: Society of Environmental Toxicology and Chemistry (SETAC) and SETAC Foundation for Environmental Education, Inc. 1991. 134p.

FAVA, J. A. (Ed.); BARNTHOUSE, L.; HUMPHREYS, K.; HUNT, R.; LAIBSON, L.; NOESEN, S.; NORRIS, G.; OWENS, J.; TODD, J.; VIGON, B.; WEITZ, K.; YOUNG, J. Life-cycle impact assessment: The state-of-the-art. $2^{\text {nd }}$ ed. Pensacola: Society of Environmental Toxicology and Chemistry (SETAC) and SETAC Foundation for Environmental Education, 1998.

FERREIRA, S. R.; PIRES, A. C.; CASTANHO, C. D.; LAMB, C. M. S. R.; BRASHER, M.; FERNANDEZ, J. H. C. Trajetória do projeto: "Inventário do ciclo de vida para competitividade ambiental da industria brasileira" - ICV. In: Conferência Internacional sobre Avaliação de Ciclo de Vida - CILCA 2007, anais. São Paulo, 2007. 1 CD-ROM. 
FIA - FUNDAÇÃO INSTITUTO DE ADMINISTRAÇÃO. Complemento do relatório sobre o setor de fertilizantes. São Paulo, 2002. 31p.

FINKBEINER, M.; INABA, A.; TAN, R. B. H.; CHRISTIANSEN, K.; KLUPPEL, H. $J$. The new international standards for life cycle assessment: ISO 14040 and ISO 14044. The International Journal of Life Cycle Assessment. V. 22, n. 2, p. 80-85. 2006.

FÓRUM BRASILEIRO DE FERTILIZANTES. São Paulo, 2006. Novos investimentos para matérias-primas nitrogenadas. São Paulo: Instituto de Pesquisas Tecnológicas do Estado de São Paulo, 2006. 1 CD-ROM.

FOSFERTIL - FERTILIZANTES FOSFATADOS S. A. Informações sobre a produção. 2005. [mensagem enviada por COMUNICA comunica@fosfertil.com.br]._Mensagem <paulo.henrique@poli.usp.br>em 21 de mar. 05.

FOSFERTIL. A Fosfertil. Histórico. 2009. Disponível em: <http://www.fosfertil.com.br/>. Acesso em 02 fev. 09.

FRISCHKNECHT, R.; JUNGBLUTH, N.; ALTHAUS, H.; DOKA, G.; DONES, R.; HECK, T.; HELLWEG, S; HISCHIER, R.; NEMECEK, T.; REBITZER, G.; SPIELMANN, M. The ecoinvent Database: overview and methodological framework. The International Journal of Life Cycle Assessment. V. 10, n. 1, p. 3 - 9. 2005. 
FRISCHKNECHT, R. (Ed.); JUNGBLUTH, N.; ALTHAUS, H.-J.; DOKA, G.; DONES, R.; HECK, T.; HELLWEG, S.; HISCHIER, R.; NEMECEK, T.; REBITZER, G.; SPIELMANN, M.; WERNET, G. Overview and Methodology. Ecoinvent report n. 01. Swiss Centre for Life Cycle Inventories. 77 p. Dübendorf, 2007.

GABI 4. The software system for Life Cycle Engineering: PE Europe GMBH Life Cycle Engineering. 1 CD-ROM: GABI extension Database II. BR Crude oil mix (1995). Stuttgart, 2004.

GARCIA, R. Combustíveis e combustão industrial. Ed. Interciência. Rio de Janeiro, 2002. 202p.

GEISLER, G.; HELLWEG, S.; HUNGERBUHLER, K. Uncertainty analysis in life cycle assessment (LCA): case study on plant-protection products and implications for decision making. The International Journal of Life Cycle Assessment. V. 10, n. 3, p. $184-192.2005$.

GOLDSMITH, E.; ALLEN, R.; ALLABY, M.; DAVOLL, J.; LAWRENCE, S. A Blueprint for Survival. The Ecologist. V. 2, n. 1. 1972.

GRAEDEL, T. E. Streamlined Life Cycle Assessment. By Bell Laboratories, Lucent Technologies. Published by Pretice Hall, Inc. New Jersey. 1998.

GUINÉE, J. B. (Ed.); GORRÉE, M.; HEIJUNGS, R.; HUPPES, G.; KLEIJN, R.; KOMING, A.; OERS, L.; SLEESWIJK, W.; SUH, S. W.; UDO de HAES, H. A.; BRUIJN, H.; DUIN, R.; HUIJBREGTS, M. A. J. Life cycle assessment: an operational guide to the ISO standards. Final Report. Leiden University, 2001. Part 1-3. 
HUIJBREGTS, M. A. J.; NORRIS, G.; BRETZ, R.; CIROTH, A.; MAURICE, B.; von BAHR, B.; WEIDEMA, B.; de BEAUFORT, A. S. H. Framework for modelling data uncertainty in life cycle inventories. The International Journal of Life Cycle Assessment. V. 6, n. 3, p. 127 -132. 2001.

HUNKELER, D. Societal LCA methodology and case study. The International Journal of Life Cycle Assessment. V. 11, n. 6, p. 371 -382. 2006.

HUNKELER, D.; REBITZER, G. The future of life cycle assessment. The International Journal of Life Cycle Assessment. V. 10, n. 5, p. 305 - 308. 2005.

IFA - INTERNATIONAL FERTILIZER INDUSTRY ASSOCIATON. Fertilizers \& the industry. What are fertilizers? 2009a. Disponível em: $<$ <ttp://www.fertilizer.org/ifa/Home-Page/FERTILIZERS-THE-INDUSTRY/Whatare-fertilizers>. Acesso em 09 mar. 09.

IFA - INTERNATIONAL FERTILIZER INDUSTRY ASSOCIATION. Statistics. Production and trade statistics. Ammonia, Urea, AN, AS. 2009b. Disponível em: $\quad<$ http://www.fertilizer.org/ifa/Home-Page/STATISTICS/Production-andtrade-statistics>. Acesso em 10 mar. 09.

ISO 14040 - INTERNATIONAL ORGANIZATION FOR STANDARDIZATION. Environmental Management - life cycle assessment - principles and framework. Genève, 1997. 12p.

ISO 14041 - INTERNATIONAL ORGANIZATION FOR STANDARDIZATION. Environmental Management - life cycle assessment - goal and scope definition and inventory analysis. Genève, 1998. 22p. 
ISO 14042 - INTERNATIONAL ORGANIZATION FOR STANDARDIZATION. Environmental Management - life cycle assessment - life cycle impact assessment. Genève, 2000a. 16p.

ISO 14043 - INTERNATIONAL ORGANIZATION FOR STANDARDIZATION. Environmental Management - life cycle assessment - life cycle interpretation. Genève, 2000b.

ISO/TR 14049 - $\quad$ INTERNATIONAL ORGANIZATION FOR STANDARDIZATION. Environmental Management - life cycle assessment Examples of application of ISO 14041 to goal and scope definition and inventory analysis. Genève, 2000c (Technical report). 43p.

ISO/DTR 14047 - INTERNATIONAL ORGANIZATION FOR STANDARDIZATION. Illustrative examples on how to apply ISO 14042 Life cycle assessment - Life cycle impact assessment. Kuala Lumpur, 2001 (Draft Technical Report). 86p.

ISO/DTR 14048 - INTERNATIONAL ORGANIZATION FOR STANDARDIZATION. Environmental Management - Life cycle assessment - LCA data documentation format. Kuala Lumpur, 2002 (Draft Technical Report). 52p.

ISO/FDIS 14040 - INTERNATIONAL ORGANIZATION FOR STANDARDIZATION. Environmental Management - Life cycle assessment - Principles and framework. 2006a (Final Draft International Standard). 20p. 
ISO/DIS $14044 \quad-\quad$ INTERNATIONAL ORGANIZATION FOR STANDARDIZATION.

Environmental Management - Life cycle assessment - Requirements and guidelines. 2006b (Draft International Standard). 46p.

ISO 14025 - INTERNATIONAL ORGANIZATION FOR STANDARDIZATION. Environmental labels and declarations - Type III environmental declarations - Principles and procedures. 2006c (Final Draft International Standard). 25p.

JENSEN, A. A.; ELKINGTON, J.; CHRISTIANSEN, K.; HOFFMANN, L.; MOLLER, B. T.; SCHMIDT, A.; van DIJK, F. Life cycle assessment (LCA) - A guide to approaches, experiences and information sources. Copenhagen: European Environmental Agency, 1997. 159p. ISBN: 92-9167-079-0

JIMÉNEZ-GONZÁLEZ, C.; KIM, S.; OVERCASH, M. R. Methodology for developing gate-to-gate life cycle inventory information. The International Journal of Life Cycle Assessment. V. 5, n. 3, p. 153 - 159. .2000.

JOLLIET, O. Emergence and Future of Life Cycle Impact Assessment: Good science comes from good people. The International Journal of Life Cycle Assessment. V. 11, Special Issue 1, p. 9-10. 2006.

JORGENSEN, A.; LE BOCQ, A.; NAZARKINA, L.; HAUSCHILD, M. Methodologies for social life cycle assessment. The International Journal of Life Cycle Assessment. V. 13, n. 2, p. 96 - 103. 2008.

JÚNIOR, G. B. Avaliação de incertezas em inventários do ciclo de vida. 90p. Dissertação (Mestrado). Centro Tecnológico da Universidade Federal de Santa Catarina. Florianópolis, 2007. 
KIM, S.; OVERCASH, M. R. Allocation procedure in multi-output process: an illustration of ISO 14041. The International Journal of Life Cycle Assessment. V. 5, n. 4, p. $221-228.2000$.

KLOEPfFER, W. Life Cycle Sustainability Assessment of Products. The International Journal of Life Cycle Assessment. V. 13 n. 2. p. 89 - 95. 2008.

KRAMER, D. A. Nitrogen. Mineral Commodity Profiles. United States Geological Survey (USGS), 2004. Open-File Report 2004-1290.

KULAY, L. A. Desenvolvimento de modelo de análise de ciclo de vida adequado às condições brasileiras: aplicação ao caso do superfosfato simples. 141p. Dissertação (Mestrado). Escola Politécnica da Universidade de São Paulo. São Paulo, 2000.

KULAY, L. A. Uso da análise de ciclo de vida para a comparação do desempenho ambiental das rotas úmida e térmica de produção de fertilizantes fosfatados. 314p. Tese (Doutorado). Escola Politécnica da Universidade de São Paulo. São Paulo, 2004.

LIFE CYCLE INITIATIVE. International life cycle partnership for a sustainable world. Life Cycle Initiative Background. 2009a. Disponível em:

$<$ http://jp1.estis.net/sites/lcinit/default.asp?site=Icinit\&page_id=E657318B-B78C471A-AEC6-58CF17ECA26B>. Acesso em 05 jan 2009.

LIFE CYCLE INITIATIVE. International Life cycle partnership for a sustainable world. Life Cycle Impact Assessment Programme. Summary list of the LCIA methods. 2009b. Disponível em: $<$ http://jp1.estis.net/sites//cinit/default.asp?site=Icinit\&page_id=67F5A66D-9EB84E75-B663-297B7FD626B6>. Acesso em 06 jan. 2009. 
MALAVOLTA, E. Manual de química agrícola: adubos e adubações. 3.ed. São Paulo: Ed. Agronômica Ceres, 1981. 596p.

MALAVOLTA, E.; PIMENTEL-GOMES, F.; ALCARDE, J. C. Adubos e adubações. São Paulo: Ed. Nobel, 2002. 200p. ISBN 85-213-1074-9.

MAPA - MINISTÉRIO DA AGRICULTURA, PECUÁRIA E ABASTECIMENTO. Estatísticas. Agronegócio brasileiro. 2009. Agronegócio Brasileiro: uma oportunidade de investimentos. Disponível em: $<$ http://www.agricultura.gov.br/>. Acesso em: 27 fev. 09.

MARIOTONI, C. A.; CUNHA, M. E. G.; BAPTISTELA, R. Z. Uma discussão de diferentes softwares visando a aplicação da técnica Avaliação do Cicio de Vida (ACV) em indústrias. In: Conferência Internacional sobre Avaliação de Ciclo de Vida - CILCA 2007, anais. São Paulo, 2007. 1 CD-ROM.

MDIC - MINISTÉRIO DO DESENVOLVIMENTO, INDÚSTRIA E COMÉRCIO EXTERIOR. Estudos e publicações. Publicações BNDES. BNDES Setorial. DIAS, V. P.; FERNANDES, E. Fertilizantes: uma visão global sintética. Rio de Janeiro, 2006. n. 24, p. 97 - 138. Disponível em: <http://www.bndes.gov.br/conhecimento/bnset/set2404.pdf>. Acesso em: 27 fev. 09.

MDIC - MINISTÉRIO DO DESENVOLVIMENTO, INDÚSTRIA E COMÉRCIO EXTERIOR. Alice Web. Importações de uréia, nitrato de amônio, sulfato de amônio, MAP e DAP. 2008a. Disponível em: <http://aliceweb.desenvolvimento.gov.br>. Acesso em 26 jun. 08. 
MDIC - MINISTÉRIO DO DESENVOLVIMENTO, INDÚSTRIA E COMÉRICO EXTERIOR. Alice Web. Importações de gás natural e enxofre. 2008b. Disponível em: <http://aliceweb.desenvolvimento.gov.br>. Acesso em 11 mar. 09.

MDIC - MINISTÉRIO DO DESENVOLVIMENTO, INDÚSTRIA E COMÉRCIO EXTERIOR. Alice Web. Importações de petróleo. 2008c. Disponível em: $<$ http://aliceweb.desenvolvimento.gov.br>. Acesso em 31 jun. 08.

MEADOWS, D. H.; MEADOWS, D. L.; RANDERS, J.; BEHRENS, W. W. The Limits to Growth: A Report for the Club of Rome's Project on the Predicament of Mankind. Universe Books, New York. 1972. 205p.

MELO, G. S. de; LEÃO, M. M. D.; SOUZA, D. M. de. Metodologias de avaliação de impacto do ciclo de vida - um estudo comparativo. In: I Congresso Brasileiro em Gestão do Ciclo de Vida. Curitiba, 2008. 1 CD-ROM.

MENDIVIL, R.; FISCHER, U.; HIRAO, M.; HUNGERBÜHLER, K. A new LCA methodology of technology evolution (TE-LCA) and its application to the production of ammonia (1950-2000). The International Journal of Life Cycle Assessment. V. 11, n. 2, p. $98-105.2006$.

MILLET, D.; BISTAGNINO, L.; LANZAVECCHIA, C.; CAMOUS, R.; TIIU POLDMA. Does the potencial of the use of LCA match the design team needs? Journal of Cleaner Production. V. 15, p. $335-346.2007$. 
MME - MINISTÉRIO DE MINAS E ENERGIA. Publicações. Balanço energético nacional 2008: ano base 2007. Disponível em: <http://www.mme.gov.br/site/menu/select_main_menu_item.do?channelld=1432 \&pageld=17029>. Acesso em 11 mar. 09.

MOSAIC FERTILIZANTES. Empresa. História. 2009. Disponível em: $<$ http://www.mosaicco.com.br/Default.aspx?wcmp=23>. Acesso em 02 fev. 09.

MOURAD, A. L.; GARCIA, E. E. C.; VILHENA, A. (Coord.) Avaliação do ciclo de vida: Princípios e Aplicações. Campinas: CETEA/CEMPRE, 2002. 92p.

NEDOCHETKO, J. R. Informações sobre o solvente empregado para remover o $\mathbf{C O}_{2}$. 2005. [mensagem enviada por joserenato@fosfertil.com.br]. Mensagem recebida por <paulo.henrique@poli.usp.br> em 21 de mar. 2005.

PEGORARO, L. A.; GOEDKOOP, M.; UGAYA, C. M. L.; TADANO, Y. S. The life cycle impact assessment (LCIA) and some important considerations to Brazil. In: Conferência Internacional do Ciclo de Vida - CILCA 2007. São Paulo, 2007. 1 CD-ROM.

PETROBRAS - PETRÓLEO BRASILEIRO S. A. Dúvidas mais freqüentes. $2004 . \quad$ Disponível em: <http://www2.petrobras.com.br/minisite/duvidas/faq/portugues/exploracao/>. Acesso em 10 nov. 04.

PETROBRAS - PETRÓLEO BRASILEIRO S. A. Espaço conhecer. Sobre o petróleo. Exploração e produção. 2008a. Disponível em: <http://www2.petrobras.com.br/espacoconhecer/sobrepetroleo/ExploracaoProdu cao_extracao.asp>. Acesso em 11 ago. 08. 
PETROBRAS - PETRÓLEO BRASILEIRO S. A. Espaço conhecer. Sobre o petróleo. Refino. 2008b. Disponível em: <http://www2.petrobras.com.br/espacoconhecer/sobrepetroleo/Refino.asp>. Acesso em 11 ago. 08.

PETROBRAS - PETRÓLEO BRASILEIRO S. A. Espaço conhecer. Sobre o gás natural. Processamento. 2008c. Disponível em: <http://www2.petrobras.com.br/espacoconhecer/SobreGas/processamento.asp> Acesso em 11 ago. 08.

PIRES, A. C.; PAULA, M. C. S.; VILLAS BOAS, R. C. (Org.) Avaliação do ciclo de vida: a ISO 14040 na América Latina. Brasília: Abipti, 2005. 337p.

PORTWORLD. Distâncias entre portos internacionais. Disponível em <http://www.portworld.com/map/>. Acesso em 02 jul. 2008.

PRÉ-CONSULTANTS. SimaPro. Versão 7.0. PRé Consultants, Amsterdam, 2006.

PRÉ-CONSULTANTS. IDEMAT 2001. Tanker I. SimaPro. Versão 7.0. 2006a.

PRÉ-CONSULTANTS. IDEMAT 2001. Diesel I. SimaPro. Versão 7.0. 2006b.

PRÉ-CONSULTANTS. IDEMAT 2001. Heavy fuel oil I. SimaPro. Versão 7.0. 2006c.

PRÉ-CONSULTANTS. IDEMAT 2001. Energy gas. SimaPro. Versão 7.0. 2006d.

PRÉ-CONSULTANTS. IDEMAT 2001. Ureum I. SimaPro. Versão 7.0. 2006e. 
PRÉ-CONSULTANTS. Data Archive. Benzene production. SimaPro. Versão 7.0. $2006 f$.

PRÉ-CONSULTANTS. Data Archive. Cyclohexane production. SimaPro. Versão 7.0. 2006g.

PRÉ-CONSULTANTS. Data Archive. Propene (propylene) production. SimaPro. Versão 7.0. 2006h.

PRÉ-CONSULTANTS. Data Archive. Caprolactam production. SimaPro. Versão 7.0. 2006i.

PRÉ-CONSULTANTS. IDEMAT. Acrylonitril. SimaPro. Versão 7.0. 2006j.

PRÉ-CONSULTANTS. IDEMAT. MMA - Methyl Methacrylate Monomer. SimaPro. Versão 7.0. 2006k.

QUÍMICA INDUSTRIAL. Edição especial - As maiores empresas do setor químico. São Paulo: Signus Editora, n. 96, jul. 2004. 56p. Bimestral. ISSN 0103-2836.

REAP, J.; ROMAN, F.; DUNCAN, S.; BRAS, B. A survey of unresolved problems in life cycle assessment. Part 1: goal and scope and inventory analysis. The International Journal of Life Cycle Assessment. V. 13, p. $290-$ 300. 2008.

RIBEIRO, P. H. Modelagem de sistemas de produto em estudos de avaliação do ciclo de vida - ACV. 135p. Dissertação (Mestrado). Escola Politécnica da Universidade de São Paulo. São Paulo, 2004. 
ROSS, S.; EVANS, D.; WEBBER, M. How LCA studies deal with uncertaity. The International Journal of Life Cycle Assessment. V. 7, n. 1, p. 47 - 52. 2002.

SABER. O Portal do Conhecimento da Universidade de São Paulo. Biblioteca digital de teses e dissertações da USP. 2008. Disponível em: $<w w w . t e s e s . u s p . b r>$. Acesso em 22 dez. 08.

SAC PETROBRAS/FAFEN - Assistência técnica e serviço de atendimento ao cliente petrobras. 2005. Informações sobre a produção. [mensagem enviada por_sac@petrobras.com.br]. Mensagem recebida por <paulo.henrique@poli.usp.br> em 03 de fev. 2005.

SALING, P.; MAISCH, R.; SILVAN, M.; KONIG, N. Assessing the environmental-hazard potencial for life cycle assessment, Eco-eficiency and SEEbalance. The International Journal of Life Cycle Assessment. V. 10, n. 5 , p. $364-371.2005$.

SCHMIDT, I.; MEURER, M.; SAILING, P.; KICHERER, A.; REUTER, W.; GENSH, C. SEEbalance - Managing sustainability of products and process with the socio-eco-efficiency analysis by BASF. Greener Management International. V. 45, p. $79-84.2004$.

SILVA, G.A. Disciplina AQ - 012: Análise de Ciclo de Vida de Processos Industriais. Módulo de Gestão e Tecnologias Ambientais - Programa de Educação Continuada em Engenharia - PECE. Universidade de São Paulo. São Paulo, 2003 [notas de aula]. 
SILVA, G. A. Panorama da avaliação do Ciclo de Vida (ACV) no Brasil. In: Seminário Avaliação do Ciclo de Vida de Produto e Ecodesign, São Paulo. São Paulo, 2006. Disponível em: $<$ http://www.fiesp.com.br/download/publicacoes_meio_ambiente/apres_gil_ande ri.pdf>. Acesso em 27 jan. 09.

SILVA, G. A.; KULAY, L. A. Application of life cycle assessment to the LCA case studies single superphosphate production. The International Journal of Life Cycle Assessment. Landsberg, v. 8, n. 4, p. 209 -214. 2003.

SILVA, G. A.; KULAY, L. A. Avaliação do ciclo de vida. In: JÚNIOR, A. V.; DEMAJOROVIC, J. (Org.) Modelos e ferramentas de gestão ambiental: desafios e perspectivas para as organizações. São Paulo: Editora Senac, 2006. p. 313 336.

SILVA, G.A.; RIBEIRO, P.H.; KULAY, L.A. Avaliação do Desempenho Ambiental dos Fertilizantes Químicos no Brasil. In: XVI Congresso Brasileiro de Engenharia Química, 2006, Santos. Anais. São Paulo, 2006. 12 p.

SILVA, G. A.; YOKOTE, A. Y.; RIBEIRO, P. H. Desenvolvimento de banco de dados brasileiro para avaliação de ciclo de vida. In: Global Conference building a sustainable world, São Paulo. São Paulo, 2002. 5p. 1 CD-ROM.

SONNEMANN, G.; CASTELLS, F.; SCHUHMACHER, M. Integrated life-cycle and risk assessment for industrial processes. Tarragona, Spain: CRC Press Llc, 2004. 392p. 
SOUZA, D. M.; SOARES, S. R.; SOUSA, S. R. A life cycle impact assessment method for the Brazilian context. In: Conferência Internacional sobre Avaliação de Ciclo de Vida - CILCA 2007, anais. São Paulo, 2007. 1 CDROM.

SPILLEMAECKERS, S.; VANHOUTTE, G.; TAVERNIERS, L.; van BRAECKEL, D.; MAZZIJN, B.; RIVERA, J. D. Integrated product assessment - The development of the label sustainable development for products ecological, social and economical aspects of integrated product policy. Belgian Science Policy, Belgium. 2004.

SpringerLink Database. The International Journal of Life Cycle Assessment. 2008.

Disponível

em:

<http://www.springerlink.com/content/112849/?p=45a4f4712faa4af8baea82fe5e 94897f\&pi=108>. Acesso em 21 dez. 08.

SUGIYAMA, $\quad H_{\text {.; }}$ FUKUSHIMA, Y.; HIRAO, M.; HELLWEG, S.; HUNGERBUHLER, K. Using standard statistics to consider uncertainty in industry-based life cycle inventory databases. The International Journal of Life Cycle Assessment. V. 10, n. 6, p. 399 - 405. 2005.

TILLMAN, A. M.; BAUMANN, H. General description of life cycle assessment methodology. Chalmers University of Technology: 1995 (Report 1995:5).

TODD, J. A. Cp.4 : Streamlining. In: CURRAN, M. A. (Ed.) Environmental lifecycle assessment. EUA: McGraw-Hill, 1996. p. 4.1-4.17. 
TODD, J. A. ; CURRAN, M. A. (Ed.) Streamlined life-cycle assessment: A final report from the SETAC North America streamlined LCA workgroup. Society of Environmental Toxicology and Chemistry (SETAC) and SETAC Foundation for Environmental Education, 1999.

UGAYA, C. M. L.; MACHADO, M. A.; JUNIOR, A. C. Avaliação social do ciclo de vida: estudos de caso. In: Conferência Internacional sobre Avaliação de Ciclo de Vida - CILCA 2005, anais. San José, 2005.

UGAYA, C. M. L.; JUNIOR, A. C. Incorporação de indicadores sociais na avaliação de ciclo de vida. In: Conferência Internacional sobre Avaliação de Ciclo de Vida - CILCA 2007, anais. São Paulo, 2007. 1 CD-ROM.

UNEP - UNITED NATIONS ENVIRONMENT PROGRAMME. Life cycle assessment: what it is and how to do it. $1^{\text {st }}$ ed. Paris: United Nations Publication, 1996. 92p. ISBN: 92-807-1546-1.

UNEP - UNITED NATIONS ENVIRONMENT PROGRAMME. Towards the global use of life cycle assessment. $1^{\text {st }}$ ed. Paris: United Nations Publication, 1999. 71p. ISBN: 92-807-1740-5.

UNIGEL. Informações sobre a produção. [mensagem enviada por THIEME, M. <marcelo.thieme@unigel.com.br>.]. Mensagem recebida por <paulo.henrique@poli.usp.br> em 04 de jul. 06.

U. S. DOE - United States Department of Energy. Energy and environmental profile of the U.S. chemical industry. Office of Industrial Technologies. Columbia: Energetics, Inc., 2000. 215p. 
USEPA - UNITED STATES ENVIRONMENTAL PROTECTION AGENCY. Life Cycle Assessment: principles and practice. Scientific Applications International Corporation (SAIC), 2006. Disponível em: <http://www.epa.gov/nrmrl/lcaccess/pdfs/chapter1_frontmatter_Ica101.pdf>. Acesso em 22 jan. 09.

USEPA - UNITED STATES ENVIRONMENTAL PROTECTION AGENCY. LifeCycle Assessment Research. 2007. Disponível em: $<$ http://www.epa.gov/NRMRL/lcaccess/resources.html\#Software>. Acesso em 17 jan. 07.

USEPA - UNITED STATES ENVIRONMENTAL PROTECTION AGENCY. LCA Resources. 2009. Disponível em:

<http://74.125.47.132/search?q=cache:P5j7ZabkrdlJ:www.epa.gov/nrmrl/lcacce ss/resources.html+CURRAN+\%22environmental+life+cycle+assessment\%22\&h $\mathrm{l}=\mathrm{pt}-\mathrm{BR} \& \mathrm{ct}=\mathrm{clnk} \& \mathrm{~cd}=7 \& \mathrm{gl}=\mathrm{br}>$. Acesso em 22 jan. 09 .

VALT, R. B. G. Ciclo de vida de embalagens para bebidas no Brasil. Brasília: Thesaurus Editora, 2007. 224p. ISBN 978857062644-8.

VIGON, B. W. (Coord); TOLLE, D. A.; CORNABY, B. W.; LATHAN, H. C.; HARRISON, C. L.; BOGUSHI, T. L.; HUNT, R. G.; SELLERS, J. D. Life-cycle assessment: inventory guidelines and principles. Cincinnati: EPA, 1993. 108p. EPA/600/R-92/245.

VIANNA, F. C. Análise de ecoeficiência: avaliação do desempenho econômico-ambiental do biodiesel e petrodiesel. 182p. Dissertação (Mestrado). Escola Politécnica da Universidade de São Paulo. São Paulo, 2006. 
von BAHR, B.; STEEN, B. Reducing epistemological uncertainty in life cycle inventory. Journal of Cleaner Production. V. 12, n. 4, p. 369 - 388. 2004.

WANG, X. W.; HUA, B. Global scope assessment: a novel method and its application to the Chinese paper industry. Energy Police. V. 35, p. 16101615. 2007.

WEIDEMA, B. P. ISO 14044 also applies to social LCA. The International Journal of Life Cycle Assessment. V. 10, n. 6, p. 381-381. 2005.

WEIDEMA, B. P.; WESNAES, M. S. Data quality management for life cycle inventories - an example of using data quality indicators. Journal of Cleaner Production. V. 4, n. 3-4, p. 167-174. 1996.

WENZEL, H.; HAUSCHILD, M.; ALTING, L. Environmental Assessment of Products Volume 1: Methodology, tools and case studies in product development. USA: Chapman \& Hall, $2^{\text {nd }}$ printing by KAP, 2000. 543p.

WONGTSCHOWSKI, P. Indústria química riscos e oportunidades. Edgard Blücher Ltda. Ed. $2^{a}$ edição. São Paulo, 2002. 215p.

YARA BRASIL. Sobre a Yara. Histórico. 2009. Disponível em: $<$ http://www.yarabrasil.com.br/pt/about_yara/history/index.html>. Acesso em 02 fev. 09. 


\section{GLOSSÁRIO}

Alocação: repartição dos fluxos de entrada e saída de um processo ou sistema de produto sob estudo (ISO, 2006a).

Aspecto ambiental: elemento das atividades, produtos ou serviços de uma organização que pode interagir com o meio ambiente (ISO, 2006a). Exemplo de aspecto ambiental: emissão de $\mathrm{CO}_{2}$.

Avaliação do ciclo de vida - ACV: compilação e avaliação das entradas, das saídas e dos impactos ambientais potenciais de um sistema de produto ao longo do seu ciclo de vida (ISO, 2006a).

Categoria de impacto: classe que representa as questões ambientais relevantes às quais os resultados do ICV podem ser associados (ISO, 2006a). Exemplos são: aquecimento global, acidificação (do solo, do ar ou da água), toxicidade humana, consumo de recursos naturais, redução da camada de ozônio, etc.

Ciclo de vida: estágios sucessivos e encadeados de um sistema de produto, desde a aquisição da matéria-prima ou geração de recursos naturais à disposição final (ISO, 2006a).

Entrada: material ou energia que entra em um processo elementar (ISO, 2006a).

Fluxo elementar: material ou energia que (1) entra no sistema sob estudo, que foi retirado do meio ambiente sem transformação humana prévia; (2) deixa o sistema sob estudo, que é descartado no meio ambiente sem transformação subseqüente por interferência humana (ISO, 2006a).

Fluxo de referência: medida das saídas de processos em um dado sistema de produto requeridas para realizar a função expressa pela unidade funcional (ISO, 2006a).

Fronteira do sistema: conjunto de critérios que especificam quais processos elementares fazem parte de um sistema de produto (ISO, 2006a). 
Impacto ambiental: qualquer modificação adversa do meio ambiente, que resulte, no todo ou em parte, das atividades, produtos ou serviços de uma organização (ABNT, 1996). Exemplo de impacto ambiental: aquecimento global (efeito estufa).

Indicador de categoria de impacto: representação quantificável de uma categoria de impacto (ISO, 2006a).

Processo elementar: menor elemento considerado na análise do inventário do ciclo vida para o qual dados de entrada e saída são quantificados (ISO, 2006a).

Produto: matéria ou energia gerada por um sistema, a qual é o objeto do estudo de uma ACV que tem um valor ou uso potencial (SILVA, 2003).

Rejeito: material ou energia que sai de um sistema e é lançada para o meio ambiente através do ar, água e/ou solo (SILVA, 2003).

Saída: material ou energia que deixa um processo elementar (ISO, 2006a).

Sistema de produto: conjunto de processos elementares, desempenhando uma ou mais funções definidas e que modela o ciclo de vida de um produto (ISO, 2006a).

Subproduto: material ou energia gerada por sistema, a qual não é o objeto de estudo de uma ACV, que pode encontrar utilização em outros sistemas (SILVA, 2003).

Subsistema: conjunto de processos elementares que é uma parte do sistema definido (VIGON et al., 1993).

Unidade funcional: desempenho quantificado de um sistema de produto para uso como uma unidade de referência num estudo de ACV (ISO, 2006a). 


\section{ANEXO A - Estudos acadêmicos de ACV publicados no Brasil}

\begin{tabular}{|c|c|c|c|c|}
\hline Autor & $\begin{array}{r}\text { Título } \\
\end{array}$ & Instituição / Área & Ano & Observação \\
\hline $\begin{array}{l}\text { 1- Adriana } \\
\text { Karaver } \\
\text { Benjamin }\end{array}$ & $\begin{array}{l}\text { Desenvolvimento de modelo para } \\
\text { avaliação de softwares de apoio à } \\
\text { análise de ciclo de vida }\end{array}$ & $\begin{array}{l}\text { Universidade de São Paulo } \\
\text { - Engenharia Química }\end{array}$ & 2002 & Mestrado \\
\hline $\begin{array}{l}\text { 2- Angela Maria } \\
\text { Ferreira Lima }\end{array}$ & $\begin{array}{l}\text { Avaliação do ciclo de vida no Brasil: } \\
\text { inserção e perspectivas }\end{array}$ & $\begin{array}{l}\text { Universidade Federal da } \\
\text { Bahia - Escola Politécnica }\end{array}$ & 2007 & Mestrado \\
\hline $\begin{array}{l}\text { 3- Aldo Roberto } \\
\text { Ometto }\end{array}$ & $\begin{array}{l}\text { Avaliação do ciclo de vida do álcool } \\
\text { etílico hidratado combustível pelos } \\
\text { métodos edip, exergia e emergia }\end{array}$ & $\begin{array}{l}\text { Universidade de São Paulo } \\
\text { / São Carlos - Engenharia } \\
\text { Hidráulica e Saneamento }\end{array}$ & 2005 & Doutorado \\
\hline $\begin{array}{l}\text { 4- Alexandre } \\
\text { Yoshikazu } \\
\text { Yokote }\end{array}$ & $\begin{array}{llll}\text { Inventário de ciclo de vida da } & \text { de } \\
\text { distribuição de energia elétrica no } & \text { no } \\
\text { Brasil } & & & \\
\end{array}$ & $\begin{array}{l}\text { Universidade de São Paulo } \\
\text { - Engenharia Química }\end{array}$ & 2003 & Mestrado \\
\hline $\begin{array}{l}\text { 5- Ana Carolina } \\
\text { Badalotti } \\
\text { Passuello }\end{array}$ & $\begin{array}{l}\text { Aplicação da avaliação de ciclo de } \\
\text { vida em embalagens descartáveis } \\
\text { para frutas: estudo de caso }\end{array}$ & $\begin{array}{lll}\text { Universidade } & \text { Federal do } \\
\text { Rio Grande do Sul } & - \\
\text { Recursos Hídricos } & \text { e } \\
\text { Saneamento Ambiental } & \\
\end{array}$ & 2007 & Mestrado \\
\hline $\begin{array}{l}\text { 6- André Critchii } \\
\text { Junior }\end{array}$ & $\begin{array}{l}\text { Incorporação de indicadores sociais } \\
\text { relacionados ao trabalho à Avaliação } \\
\text { de Ciclo de Vida: estudo de caso em } \\
\text { uma indústria metal-mecânica }\end{array}$ & $\begin{array}{l}\text { Universidade Tecnológica } \\
\text { Federal do Paraná - } \\
\text { Engenharia Mecânica e de } \\
\text { Materiais }\end{array}$ & 2007 & Mestrado \\
\hline $\begin{array}{l}\text { 7- André Moreira } \\
\text { de Camargo }\end{array}$ & $\begin{array}{l}\text { Inventário do ciclo de vida do metanol } \\
\text { para as condições brasileiras }\end{array}$ & $\begin{array}{l}\text { Universidade de São Paulo } \\
\text { - Engenharia Química }\end{array}$ & 2007 & Mestrado \\
\hline $\begin{array}{l}\text { 8- André Silva } \\
\text { Oliveira }\end{array}$ & $\begin{array}{l}\text { Análise ambiental da viabilidade de } \\
\text { seleção de produtos da construção } \\
\text { civil através da ACV e do software } \\
\text { Bees } 3.0\end{array}$ & $\begin{array}{l}\text { Universidade Federal do } \\
\text { Rio Grande do Sul - } \\
\text { Engenharia Civil }\end{array}$ & 2007 & Mestrado \\
\hline $\begin{array}{l}\text { 9- Andréa } \\
\text { Rodrigues Fabi }\end{array}$ & $\begin{array}{l}\text { Comparação do consumo de energia } \\
\text { e emissão de } \mathrm{CO}_{2} \text { entre garrafas de } \\
\text { PET e de vidro, utilizando análise } \\
\text { ambiental de ciclo de vida }\end{array}$ & $\begin{array}{l}\text { Universidade Estadual de } \\
\text { Campinas - Planejamento } \\
\text { de Sistemas Energéticos }\end{array}$ & 2004 & Mestrado \\
\hline $\begin{array}{l}\text { 10- Antonio dos } \\
\text { Santos }\end{array}$ & $\begin{array}{l}\text { Análise das potencialidades da } \\
\text { avaliação do ciclo de vida de produto } \\
\text { como instrumento de apoio à gestão } \\
\text { ambiental }\end{array}$ & $\begin{array}{l}\text { Universidade Metodista de } \\
\text { Piracicaba - Engenharia de } \\
\text { Produção }\end{array}$ & 1998 & Mestrado \\
\hline $\begin{array}{l}\text { 11- Arimar Leal } \\
\text { Vieira }\end{array}$ & $\begin{array}{l}\text { Análise do Ciclo de vida: uma } \\
\text { avaliação social e econômica da } \\
\text { reciclagem das latas de alumínio da } \\
\text { cidade de Belém }\end{array}$ & $\begin{array}{l}\text { Universidade } \text { Federal do } \\
\text { Pará - Desenvolvimento } \\
\text { Sustentável do Trópico } \\
\text { Úmido }\end{array}$ & 2004 & Doutorado \\
\hline $\begin{array}{l}\text { 12- Breno de } \\
\text { Almeida Marques }\end{array}$ & $\begin{array}{l}\text { Considerações ambientais e } \\
\text { exergéticas na fase de pós-colheita de } \\
\text { grãos. Estudo de caso do Estado do } \\
\text { Paraná }\end{array}$ & $\begin{array}{lcr}\text { Universidade } & \text { Federal } & \text { do } \\
\text { Paraná - } & \text { Engenharia } & \text { de } \\
\text { Recursos } & \text { Hídricos } & \text { e } \\
\text { Ambiental } & & \\
\end{array}$ & 2006 & Mestrado \\
\hline $\begin{array}{l}\text { 13- Carlos } \\
\text { Vicente John dos } \\
\text { Santos }\end{array}$ & $\begin{array}{l}\text { Tecnologias de produção mais limpas } \\
\text { e análise de ciclo de vida na indústria } \\
\text { da construção civil - estudos de casos }\end{array}$ & $\begin{array}{lll}\text { Universidade } & \text { Federal do } \\
\text { Rio Grande do Sul } & - \\
\text { Recursos Hídricos } & \text { e } \\
\text { Saneamento Ambiental } & \end{array}$ & 2000 & Mestrado \\
\hline $\begin{array}{l}\text { 14- Cássia Maria } \\
\text { Lie Ugaya }\end{array}$ & $\begin{array}{l}\text { Análise de Ciclo de Vida: estudo de } \\
\text { caso para materiais e componentes } \\
\text { automotivos }\end{array}$ & $\begin{array}{l}\text { Universidade } \begin{array}{r}\text { Estadual de } \\
\text { Campinas - } \\
\text { Mecânica }\end{array} \\
\end{array}$ & 2001 & Doutorado \\
\hline
\end{tabular}




\begin{tabular}{|c|c|c|c|c|}
\hline $\begin{array}{l}\text { 15- Claudio de } \\
\text { Campos }\end{array}$ & $\begin{array}{l}\text { Avaliação de desempenho ambiental } \\
\text { em projetos: procedimentos e } \\
\text { ferramentas }\end{array}$ & $\begin{array}{l}\text { Universidade de São Paulo } \\
\text { - Arquitetura e Urbanismo }\end{array}$ & 2007 & Mestrado \\
\hline $\begin{array}{l}\text { 16- Claudio Elias } \\
\text { Carvalho }\end{array}$ & $\begin{array}{l}\text { A análise do ciclo de vida e os custos } \\
\text { completos no planejamento energético }\end{array}$ & $\begin{array}{l}\text { Universidade de São Paulo } \\
\text { - Engenharia Elétrica }\end{array}$ & 2000 & Mestrado \\
\hline $\begin{array}{l}\text { 17- Celso } \\
\text { Munhoz Ribeiro }\end{array}$ & $\begin{array}{l}\text { Ciclo de vida de seringa para injeção } \\
\text { odontológica no Brasil: inventário e } \\
\text { análise de melhorias }\end{array}$ & $\begin{array}{l}\text { Universidade Paulista - } \\
\text { Engenharia de Produção }\end{array}$ & 2004 & Mestrado \\
\hline $\begin{array}{l}\text { 18- Constance } \\
\text { Manfredini }\end{array}$ & $\begin{array}{l}\text { Identificação dos impactos ambientais } \\
\text { causados pelas indústrias de } \\
\text { cerâmica vermelha no Rio Grande do } \\
\text { Sul - }\end{array}$ & $\begin{array}{l}\text { Universidade Federal do } \\
\text { Rio Grande do Sul - } \\
\text { Engenharia Civil }\end{array}$ & 2003 & Mestrado \\
\hline $\begin{array}{l}\text { 19- Cristiane } \\
\text { Ferreira Eder }\end{array}$ & $\begin{array}{l}\text { Método para a escolha de processos } \\
\text { considerando os impactos ambientais: } \\
\text { uma aplicação para processos de } \\
\text { decapagem }\end{array}$ & $\begin{array}{l}\text { Universidade Federal do } \\
\text { Rio Grande do Sul - } \\
\text { Engenharia de Produção }\end{array}$ & 2005 & Mestrado \\
\hline $\begin{array}{l}\text { 20- Cristiane } \\
\text { Sandes Tosta }\end{array}$ & $\begin{array}{l}\text { Inserção da análise de ciclo de vida } \\
\text { no Estado da Bahia, através da } \\
\text { atuação do órgão ambiental }\end{array}$ & $\begin{array}{l}\text { Universidade Federal da } \\
\text { Bahia - Gerenciamento e } \\
\text { Tecnologia Ambiental no } \\
\text { Processo Produtivo }\end{array}$ & 2003 & Mestrado \\
\hline $\begin{array}{l}\text { 21- Deise Viana } \\
\text { Mastella }\end{array}$ & $\begin{array}{l}\text { Comparação entre os processos de } \\
\text { produção de blocos cerâmicos e de } \\
\text { concreto para alvenaria estrutural, } \\
\text { através da análise do ciclo de vida }\end{array}$ & $\begin{array}{l}\text { Universidade Federal de } \\
\text { Santa Catarina } \\
\text { Engenharia Civil }\end{array}$ & 2002 & Mestrado \\
\hline $\begin{array}{l}\text { 22- Eden Roberto } \\
\text { Cavalcante } \\
\text { Souza }\end{array}$ & $\begin{array}{l}\text { Estudo quantitativo } \text { do impacto } \\
\text { ambiental na produção industrial do } \\
\text { polietileno }\end{array}$ & $\begin{array}{l}\text { Universidade de São Paulo } \\
\text { - Engenharia Química }\end{array}$ & 2004 & Mestrado \\
\hline $\begin{array}{l}\text { 23- Emitério da } \\
\text { Rosa Neto }\end{array}$ & $\begin{array}{l}\text { Uso de inventário do ciclo de vida } \\
\text { como ferramenta auxiliar na tomada } \\
\text { de decisões no sistema de } \\
\text { gerenciamento de resíduos sólidos } \\
\text { urbanos em São Luiz Gonzaga - Rio } \\
\text { Grande do Sul }\end{array}$ & $\begin{array}{l}\text { Universidade de Santa } \\
\text { Cruz do Sul - Tecnologia } \\
\text { Ambiental }\end{array}$ & 2007 & Mestrado \\
\hline $\begin{array}{l}\text { 24- Érica Márcia } \\
\text { Leite Barros }\end{array}$ & $\begin{array}{l}\text { Avaliação de desempenho ambiental } \\
\text { de edifícios: percepções de alguns } \\
\text { agentes do construbusiness no estado } \\
\text { do Espirito Santo. }\end{array}$ & $\begin{array}{l}\text { Universidade Federal do } \\
\text { Espírito Santo - Engenharia } \\
\text { Civil }\end{array}$ & 2005 & Mestrado \\
\hline $\begin{array}{l}\text { 25- Flávio de } \\
\text { Miranda Ribeiro }\end{array}$ & $\begin{array}{l}\text { Inventário de ciclo de vida da geração } \\
\text { hidrelétrica no Brasil - Usina de Itaipú: } \\
\text { primeira aproximação }\end{array}$ & $\begin{array}{l}\text { Universidade de São Paulo } \\
\text { - Programa Interunidades } \\
\text { de Pós-Graduação em } \\
\text { Energia }\end{array}$ & 2004 & Mestrado \\
\hline $\begin{array}{l}\text { 26- Flávio Lúcio } \\
\text { Nunes de Lima }\end{array}$ & $\begin{array}{l}\text { Proposição de metodologia de } \\
\begin{array}{l}\text { avaliação do impacto ambiental no } \\
\text { desenvolvimento de projetos } \\
\text { arquitetônicos }\end{array}\end{array}$ & $\begin{array}{l}\text { Universidade Federal de } \\
\text { Minas Gerais - Arquitetura }\end{array}$ & 2006 & Mestrado \\
\hline $\begin{array}{l}\text { 27- Felipe } \\
\text { Moreton Chohfi }\end{array}$ & 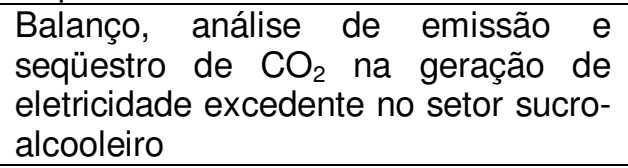 & $\begin{array}{l}\text { Universidade Federal de } \\
\text { Itajubá - Engenharia de } \\
\text { Energia }\end{array}$ & 2004 & Mestrado \\
\hline $\begin{array}{l}\text { 28- Fernanda } \\
\text { Cristina Milanin } \\
\text { Bido }\end{array}$ & $\begin{array}{l}\text { Aplicação da metodologia de } \\
\text { avaliação do ciclo de vida no setor } \\
\text { farmoquímico: comparação dos } \\
\text { processos produtivos da heparina de }\end{array}$ & $\begin{array}{l}\text { Instituto de } \\
\text { Tecnológicas do Estado de } \\
\text { São Paulo - Processos } \\
\text { Industriais }\end{array}$ & 2007 & Mestrado \\
\hline
\end{tabular}




\begin{tabular}{|c|c|c|c|c|}
\hline & origem suína e bovina & & & \\
\hline $\begin{array}{l}\text { 29- Fernanda } \\
\text { Cristina Vianna }\end{array}$ & $\begin{array}{l}\text { Análise de ecoeficiência: avaliação do } \\
\text { desempenho econômico-ambiental do } \\
\text { biodiesel e petrodiesel }\end{array}$ & $\begin{array}{l}\text { Universidade de São Paulo } \\
\text { - Engenharia Química }\end{array}$ & 2006 & Mestrado \\
\hline $\begin{array}{l}\text { 30- Fúlvia Jung } \\
\text { Borges }\end{array}$ & $\begin{array}{l}\text { Inventário do ciclo de vida do PVC } \\
\text { produzido no Brasil }\end{array}$ & $\begin{array}{l}\text { Universidade de São Paulo } \\
\text { - Engenharia Química }\end{array}$ & 2004 & Mestrado \\
\hline $\begin{array}{l}\text { 31- Gabriela } \\
\text { Delgado Ibrahim }\end{array}$ & $\begin{array}{l}\text { Aplicação da metodologia de ACV } \\
\text { como apoio para avaliação do } \\
\text { desempenho operacional na produção } \\
\text { de sacos plásticos usando material } \\
\text { reciclado: um estudo de caso }\end{array}$ & $\begin{array}{lr}\text { Centro } & \text { Federal de } \\
\text { Educação } & \text { Tecnológica } \\
\text { Celso Suckow da Fonseca } \\
\text { - Tecnologia }\end{array}$ & 2007 & Mestrado \\
\hline $\begin{array}{l}\text { 32- George Luiz } \\
\text { Bleyer Ferreira }\end{array}$ & $\begin{array}{l}\text { Utilização da ACV (Avaliação do Ciclo } \\
\text { de Vida) e do DFE (Design for } \\
\text { Environment) como subsídio em } \\
\text { processos decisórios na avaliação da } \\
\text { melhor opção de projeto do produto } \\
\text { objetivando a redução dos custos } \\
\text { ambientais nas empresas }\end{array}$ & $\begin{array}{l}\text { Universidade Regional de } \\
\text { Blumenau - Administração }\end{array}$ & 1999 & Mestrado \\
\hline $\begin{array}{l}\text { 33- Gilberto } \\
\text { Benedet Júnior }\end{array}$ & $\begin{array}{l}\text { Avaliação de incertezas } \\
\text { inventários de ciclo de vida }\end{array}$ & $\begin{array}{lr}\text { Universidade Federal de } \\
\text { Santa Catarina } & - \\
\text { Engenharia Ambiental } & \end{array}$ & 2007 & Mestrado \\
\hline $\begin{array}{l}\text { 34- Giovanno } \\
\text { Pretto }\end{array}$ & $\begin{array}{l}\text { Técnica de análise do ciclo de vida } \\
\text { para gerenciamento ambiental de } \\
\text { propriedades produtoras de suínos }\end{array}$ & $\begin{array}{lr}\text { Universidade } & \text { Federal de } \\
\text { Viçosa } & \text { Economia } \\
\text { Aplicada } & \end{array}$ & 2003 & Mestrado \\
\hline $\begin{array}{l}\text { 35- Gisela de } \\
\text { Andrade } \\
\text { Brugnara }\end{array}$ & $\begin{array}{l}\text { Florestas, madeira e habitações: } \\
\text { análise energética e ambiental da } \\
\text { produção e uso de madeira como uma } \\
\text { contribuição para o desafio da } \\
\text { valorização da floresta amazônica }\end{array}$ & $\begin{array}{l}\text { Universidade Estadual de } \\
\text { Campinas - Planejamento } \\
\text { de Sistemas Energéticos }\end{array}$ & 2001 & Mestrado \\
\hline $\begin{array}{l}\text { 36- Guilherme de } \\
\text { Paula Galdiano }\end{array}$ & $\begin{array}{l}\text { Inventário do ciclo de vida do papel } \\
\text { offset produzido no Brasil }\end{array}$ & $\begin{array}{l}\text { Universidade de São Paulo } \\
\text { - Engenharia Química }\end{array}$ & 2006 & Mestrado \\
\hline $\begin{array}{l}\text { 37- Gustavo } \\
\text { Filice de Barros }\end{array}$ & $\begin{array}{l}\text { Gestão do Ciclo de Vida (GCV) como } \\
\text { auxílio à ciência e tecnologia para a } \\
\text { gestão ambiental: o caso do óleo } \\
\text { lubrificante automotivo usado }\end{array}$ & $\begin{array}{l}\text { Universidade de Brasília - } \\
\text { Desenvolvimento } \\
\text { Sustentável }\end{array}$ & 2005 & Mestrado \\
\hline $\begin{array}{l}\text { 38- Harryson Luiz } \\
\text { da Silva }\end{array}$ & 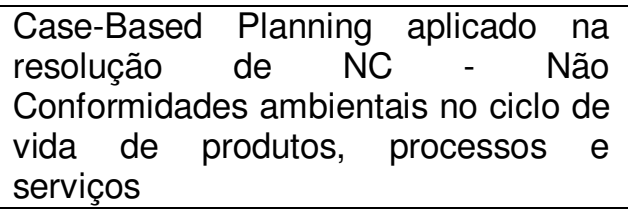 & $\begin{array}{l}\text { Universidade Federal de } \\
\text { Santa Catarina - } \\
\text { Engenharia de Produção }\end{array}$ & 1997 & Doutorado \\
\hline $\begin{array}{l}\text { 39- Husein Husni } \\
\text { Caldeira Husein }\end{array}$ & $\begin{array}{l}\text { Análise de ciclo de vida na fabricação } \\
\text { de reservatórios de água de fibra de } \\
\text { vidro }\end{array}$ & $\begin{array}{l}\text { Universidade } \text { Federal de } \\
\text { Santa Maria - Engenharia } \\
\text { de Produção }\end{array}$ & 2004 & Mestrado \\
\hline $\begin{array}{l}\text { 40- Isis Samara } \\
\text { Ruschel Pasquali }\end{array}$ & $\begin{array}{l}\text { ACV em auxílio ao gerenciamento } \\
\text { ambiental dos resíduos sólidos de } \\
\text { construção e demolição civil de Santa } \\
\text { Maria/RS }\end{array}$ & $\begin{array}{l}\text { Universidade Federal de } \\
\text { Santa Maria - Engenharia } \\
\text { de Produção }\end{array}$ & 2005 & Mestrado. \\
\hline $\begin{array}{l}\text { 41- Janine } \\
\text { Gomes da Silva }\end{array}$ & $\begin{array}{l}\text { Análise do ciclo de vida de tijolos } \\
\text { prensados de escória de alto-forno }\end{array}$ & $\begin{array}{l}\text { Universidade Federal do } \\
\text { Espírito Santo - Engenharia } \\
\text { Civil }\end{array}$ & 2005 & Mestrado \\
\hline $\begin{array}{l}\text { 42- Jean Carlo } \\
\text { Camasmie de } \\
\text { Paola }\end{array}$ & Análise ambiental de aços forjados & $\begin{array}{l}\text { Universidade de São Paulo } \\
\text { - Engenharia Metalúrgica }\end{array}$ & 2004 & Doutorado \\
\hline
\end{tabular}




\begin{tabular}{|c|c|c|c|c|}
\hline $\begin{array}{l}\text { 43- João Carlos } \\
\text { Boyadjan }\end{array}$ & $\begin{array}{l}\text { Análise do ciclo de vida de projetos } \\
\text { industriais: estudo de caso }\end{array}$ & $\begin{array}{l}\text { Universidade de São Paulo } \\
-\quad \text { Engenharia Naval e } \\
\text { Oceânica }\end{array}$ & 2007 & Mestrado \\
\hline $\begin{array}{l}\text { 44- João Carlos } \\
\text { de Almeida Mieli }\end{array}$ & $\begin{array}{l}\text { Sistemas de avaliação ambiental na } \\
\text { indústria de celulose e papel }\end{array}$ & $\begin{array}{l}\text { Universidade Federal de } \\
\text { Viçosa - Ciência Florestal }\end{array}$ & 2007 & Doutorado \\
\hline $\begin{array}{l}\text { 45- Jose } \\
\text { Humberto } \\
\text { Valadares Xavier }\end{array}$ & $\begin{array}{l}\text { Analise de Ciclo de Vida (ACV) da } \\
\text { produção agrícola familiar em Unai- } \\
\text { MG: resultados econômicos e } \\
\text { impactos ambientais }\end{array}$ & $\begin{array}{l}\text { Universidade de Brasília - } \\
\text { Desenvolvimento } \\
\text { Sustentável }\end{array}$ & 2003 & Mestrado \\
\hline $\begin{array}{l}\text { 46- Juliana Cintra } \\
\text { da Silva }\end{array}$ & $\begin{array}{l}\text { Análise do impacto ambiental do } \\
\text { processo de produção de hidrogênio }\end{array}$ & $\begin{array}{l}\text { Universidade Estadual de } \\
\text { Campinas - Engenharia } \\
\text { Química }\end{array}$ & 2005 & Mestrado \\
\hline $\begin{array}{l}\text { 47- Juliana de } \\
\text { Carvalho }\end{array}$ & $\begin{array}{l}\text { Análise de ciclo de vida ambiental } \\
\text { aplicada à construção civil - Estudo } \\
\text { de caso: comparação entre cimentos } \\
\text { Portland com adição de resíduos }\end{array}$ & $\begin{array}{l}\text { Universidade de São Paulo } \\
\text { - Engenharia Civil }\end{array}$ & 2002 & Mestrado \\
\hline $\begin{array}{l}\text { 48- Katia } \\
\text { Schoeps de } \\
\text { Oliveira }\end{array}$ & $\begin{array}{l}\text { Avaliação do ciclo de vida das telhas } \\
\text { ecológicas }\end{array}$ & $\begin{array}{l}\text { Universidade de São Paulo } \\
\text { - Engenharia Metalúrgica }\end{array}$ & 2004 & Mestrado \\
\hline $\begin{array}{l}\text { 49- Lara Leite } \\
\text { Barbosa }\end{array}$ & $\begin{array}{l}\text { [Re] design: uma aproximação à } \\
\text { abordagem transdisciplinar da } \\
\text { sustentabilidade através do mobiliário } \\
\text { contemporâneo }\end{array}$ & $\begin{array}{l}\text { Universidade de São Paulo } \\
\text { / São Carlos - Arquitetura e } \\
\text { Urbanismo }\end{array}$ & 2003 & Mestrado \\
\hline $\begin{array}{l}\text { 50- Leandro } \\
\text { Alberto Novak }\end{array}$ & $\begin{array}{l}\text { Redução dos impactos ambientais por } \\
\text { meio do consumo sustentável }\end{array}$ & $\begin{array}{l}\text { Universidade Tecnológica } \\
\text { Federal do Paraná - } \\
\text { Engenharia Mecânica e de } \\
\text { Materiais }\end{array}$ & 2006 & Mestrado \\
\hline $\begin{array}{l}\text { 51- Leandro Jose } \\
\text { Morilhas }\end{array}$ & $\begin{array}{l}\text { O estágio emergente das práticas } \\
\text { ambientais no desenvolvimento de } \\
\text { produto das organizações inovadoras: } \\
\text { um estudo exploratório }\end{array}$ & $\begin{array}{l}\text { Universidade de São Paulo } \\
\text { - Faculdade de Economia, } \\
\text { Administração } \\
\text { Contabilidade }\end{array}$ & 2007 & Mestrado \\
\hline $\begin{array}{l}\text { 52- Leica } \\
\text { Kotsuko Kajino }\end{array}$ & $\begin{array}{l}\text { Estudo da viabilidade de implantação, } \\
\text { operação e monitoramento de aterros } \\
\text { sanitários: uma abordagem } \\
\text { econômica }\end{array}$ & $\begin{array}{l}\text { Universidade } r \text { Estadual } \\
\text { Paulista Júlio de Mesquita } \\
\text { Filho / Bauru - Engenharia } \\
\text { Mecânica }\end{array}$ & 2005 & Mestrado \\
\hline $\begin{array}{l}\text { 53- Lienne Carla } \\
\text { Pires }\end{array}$ & $\begin{array}{l}\text { Análise de ciclo de vida como } \\
\text { ferramenta para a identificação de } \\
\text { impactos ambientais na cadeia } \\
\text { produtiva da cerveja }\end{array}$ & $\begin{array}{l}\text { Universidade de São Paulo } \\
\text { - Engenharia Civil }\end{array}$ & 2005 & Doutorado \\
\hline $\begin{array}{l}\text { 54- Lino José } \\
\text { Cardoso Santos }\end{array}$ & $\begin{array}{l}\text { Avaliação do ciclo de vida e custeio do } \\
\text { ciclo de vida de evaporadores para } \\
\text { usinas de açúcar }\end{array}$ & $\begin{array}{l}\text { Universidade de São Paulo } \\
\text { - Engenharia Metalúrgica }\end{array}$ & 2007 & Doutorado \\
\hline $\begin{array}{l}\text { 55- Lúcia Helena } \\
\text { da Silva Maciel } \\
\text { Xavier }\end{array}$ & $\begin{array}{l}\text { Sistemas logísticos e a gestão } \\
\text { ambiental no gerenciamento do ciclo } \\
\text { de vida de embalagens plásticas }\end{array}$ & $\begin{array}{lll}\text { Universidade } & \text { Federal do } \\
\text { Rio de } & \text { Janeiro } & - \\
\text { Engenharia de Produção } & \end{array}$ & 2005 & Doutorado \\
\hline $\begin{array}{l}\text { 56- Luciane } \\
\text { Poleto Gatto }\end{array}$ & $\begin{array}{l}\text { Programa de gestão ambiental para o } \\
\text { processo de mineração no município } \\
\text { de São Domingos do Sul - RS }\end{array}$ & $\begin{array}{l}\text { Universidade Federal de } \\
\text { Santa Maria - Engenharia } \\
\text { de Produção }\end{array}$ & 2003 & Mestrado \\
\hline $\begin{array}{l}\text { 57- Luciane } \\
\text { Sartori }\end{array}$ & $\begin{array}{l}\text { Avaliação comparativa de } \\
\text { desempenho ambiental de duas } \\
\text { caixas de carga de semi-reboque } \\
\text { bitrem graneleiro: compósito natural } \\
\text { versus compósito sintético }\end{array}$ & $\begin{array}{l}\text { Universidade de Caxias do } \\
\text { Sul - Programa de pós- } \\
\text { graduação em materiais }\end{array}$ & 2007 & Mestrado \\
\hline
\end{tabular}




\begin{tabular}{|c|c|c|c|c|}
\hline $\begin{array}{l}\text { 58- Luciano } \\
\text { Miguel Moreira } \\
\text { dos Santos }\end{array}$ & $\begin{array}{l}\text { Desenvolvimento de uma metodologia } \\
\text { e um software para avaliação } \\
\text { ambiental de processos metalúrgicos }\end{array}$ & $\begin{array}{l}\text { Universidade Federal de } \\
\text { Minas Gerais - Engenharia } \\
\text { Metalúrgica e de Minas }\end{array}$ & 2001 & Doutorado \\
\hline $\begin{array}{l}\text { 59- Luiz } \\
\text { Alexandre Kulay }\end{array}$ & $\begin{array}{l}\text { Desenvolvimento de modelo de } \\
\text { análise de ciclo de vida adequado às } \\
\text { condições brasileiras - aplicação ao } \\
\text { caso do superfosfato simples }\end{array}$ & $\begin{array}{l}\text { Universidade de São Paulo } \\
\text { - Engenharia Química }\end{array}$ & 2000 & Mestrado \\
\hline $\begin{array}{l}\text { 60- Luiz } \\
\text { Alexandre Kulay }\end{array}$ & $\begin{array}{l}\text { Uso da análise de ciclo de vida para a } \\
\text { comparação do desempenho } \\
\text { ambiental das rotas úmida e térmica } \\
\text { de produção de fertilizantes fosfatados }\end{array}$ & $\begin{array}{l}\text { Universidade de São Paulo } \\
\text { - Engenharia Química }\end{array}$ & 2004 & Doutorado \\
\hline $\begin{array}{l}\text { 61- Luiz Antonio } \\
\text { Viegas da Silva }\end{array}$ & $\begin{array}{l}\text { Proposta de sistema de gestão } \\
\text { integrada de meio ambiente, } \\
\text { segurança e saúde no trabalho (SGl- } \\
\text { MSS) para empresas: metodologia de } \\
\text { implantação prática com ferramentas } \\
\text { de validação e controle }\end{array}$ & $\begin{array}{l}\text { Universidade } \quad \text { Federal } \\
\text { Fluminense - Geociências } \\
\text { (Geoquímica) }\end{array}$ & 2007 & Doutorado \\
\hline $\begin{array}{l}\text { 62- Luiza Carla } \\
\text { Girard Teixeira } \\
\text { Machado }\end{array}$ & $\begin{array}{l}\text { Análise de ciclo de vida aplicada ao } \\
\text { gerenciamento de resíduos: o caso da } \\
\text { ETA Bolonha - RMB }\end{array}$ & $\begin{array}{l}\text { Universidade Federal do } \\
\text { Pará }\end{array}$ & 2003 & Doutorado \\
\hline $\begin{array}{l}\text { 63- Manuela } \\
\text { Fontana Alves }\end{array}$ & $\begin{array}{l}\text { A evolução de materiais na indústria } \\
\text { automobilística: o caso Volkswagen } \\
\text { caminhões e ônibus }\end{array}$ & $\begin{array}{l}\text { Universidade } \begin{array}{r}\text { Federal } \\
\text { Fluminense - Engenharia } \\
\text { de Produção }\end{array} \\
\end{array}$ & 2006 & Mestrado \\
\hline $\begin{array}{l}\text { 64- Marcelo } \\
\text { Costa Almeida }\end{array}$ & $\begin{array}{l}\text { Estudo do ciclo de vida do pneu } \\
\text { automotivo e oportunidades para a } \\
\text { disposição final de pneus inservíveis }\end{array}$ & $\begin{array}{l}\text { Universidade Federal de } \\
\text { São Carlos - Ciência e } \\
\text { Engenharia dos Materiais }\end{array}$ & 2002 & Mestrado \\
\hline $\begin{array}{l}\text { 65- Marcelo } \\
\text { Geraldo Teixeira }\end{array}$ & $\begin{array}{l}\text { Aplicação de conceitos da ecologia } \\
\text { industrial para a produção de } \\
\text { materiais ecológicos: o exemplo do } \\
\text { resíduo de madeira }\end{array}$ & $\begin{array}{l}\text { Universidade Federal da } \\
\text { Bahia - Gerenciamento e } \\
\text { Tecnologia Ambiental no } \\
\text { Processo Produtivo }\end{array}$ & 2005 & Mestrado \\
\hline $\begin{array}{l}\text { 66- Marcelo } \\
\text { Mendes Viana }\end{array}$ & $\begin{array}{l}\text { Inventário do ciclo de vida do biodiesel } \\
\text { etílico do óleo de girassol }\end{array}$ & $\begin{array}{l}\text { Universidade de São Paulo } \\
\text { - Engenharia Química }\end{array}$ & 2008 & Mestrado \\
\hline $\begin{array}{l}\text { 67- Marcelo Real } \\
\text { Prado }\end{array}$ & $\begin{array}{l}\text { Análise de fluxos de materiais e } \\
\text { energia do ciclo de vida de } \\
\text { embalagens para indústria de } \\
\text { refrigerantes no Brasil } \\
\end{array}$ & $\begin{array}{l}\text { Universidade Federal do } \\
\text { Paraná - Tecnologia de } \\
\text { Alimentos }\end{array}$ & 2007 & Doutorado \\
\hline $\begin{array}{l}\text { 68- Marcio de } \\
\text { Almeida } \\
\text { D'Agosto }\end{array}$ & $\begin{array}{l}\text { Análise da eficiência da cadeia } \\
\text { energética para as principais fontes de } \\
\text { energia utilizadas em veículos } \\
\text { rodoviários no Brasil }\end{array}$ & $\begin{array}{ll}\text { Universidade } & \text { Federal do } \\
\text { Rio de Janeiro - } \\
\text { Engenharia de Transportes }\end{array}$ & 2004 & Doutorado \\
\hline $\begin{array}{l}\text { 69- Marcos Fruet } \\
\text { Palhares }\end{array}$ & $\begin{array}{l}\text { O impacto do marketing "verde" nas } \\
\text { decisões sobre embalagens das } \\
\text { cervejarias que operam no Brasil }\end{array}$ & $\begin{array}{l}\text { Universidade de São Paulo } \\
\text { - Faculdade de Economia, } \\
\text { Administração e } \\
\text { Contabilidade (FEA) }\end{array}$ & 2003 & Mestrado \\
\hline $\begin{array}{l}\text { 70- Marcus } \\
\text { Vinicius Pereira } \\
\text { Remédio }\end{array}$ & $\begin{array}{l}\text { Avaliação de ciclo de vida de garrafas } \\
\text { PET: materiais, energia e emissões }\end{array}$ & $\begin{array}{l}\text { Universidade } \text { Federal de } \\
\text { São Carlos - Ciência e } \\
\text { Engenharia dos Materiais }\end{array}$ & 2004 & Doutorado \\
\hline $\begin{array}{l}\text { 71- Margareth } \\
\text { Lafin }\end{array}$ & $\begin{array}{l}\text { Aplicação da avaliação do ciclo de } \\
\text { vida do produto pelas organizações } \\
\text { com sistema de gestão ambiental e } \\
\text { certificado }\end{array}$ & $\begin{array}{l}\text { Universidade } \quad \text { Federal } \\
\text { Fluminense - Sistemas de } \\
\text { Gestão }\end{array}$ & 2004 & Mestrado \\
\hline $\begin{array}{l}\text { 72- Marilí de } \\
\text { Lima Ferreira }\end{array}$ & $\begin{array}{l}\text { Design sustentável: o uso da matéria } \\
\text { prima renovável um estudo de caso }\end{array}$ & $\begin{array}{l}\text { Universidade de São Paulo } \\
\text { - Arquitetura e Urbanismo }\end{array}$ & 2007 & Mestrado \\
\hline
\end{tabular}




\begin{tabular}{|c|c|c|c|c|}
\hline Brandão & $\begin{array}{l}\text { da produção do couro vegetal no norte } \\
\text { do Brasil }\end{array}$ & & & \\
\hline $\begin{array}{l}\text { 73- Marília Stella } \\
\text { Vaz Costa }\end{array}$ & $\begin{array}{l}\text { O enfoque de ciclo de vida como } \\
\text { estratégia para a gestão ambiental: } \\
\text { um estudo sobre pneus }\end{array}$ & $\begin{array}{ll}\text { Universidade } & \text { Federal do } \\
\text { Rio de Janeiro } & - \\
\text { Engenharia de Produção } & \end{array}$ & 2007 & Mestrado \\
\hline $\begin{array}{l}\text { 74- Maristela de } \\
\text { Cássia F. Ramos } \\
\text { Oliveira }\end{array}$ & $\begin{array}{l}\text { Estudo comparativo de tintas } \\
\text { utilizando a análise do ciclo de vida }\end{array}$ & $\begin{array}{l}\text { Centro Universitário do } \\
\text { Instituto Mauá de } \\
\text { Tecnologia - Engenharia de } \\
\text { Processos Químicos e } \\
\text { Bioquímicos }\end{array}$ & 2006 & Mestrado \\
\hline $\begin{array}{l}\text { 75- Michelli } \\
\text { Cristina Marcante }\end{array}$ & $\begin{array}{l}\text { Projeto de produto sustentável: um } \\
\text { estudo de caso das embalagens de } \\
\text { papel da empresa Natura Cosméticos }\end{array}$ & $\begin{array}{l}\text { Instituto de Pesquisas } \\
\text { Tecnológicas do Estado de } \\
\text { São Paulo - Tecnologia } \\
\text { Ambiental }\end{array}$ & 2007 & Mestrado \\
\hline 76- Omar Seye & $\begin{array}{l}\text { Análise de ciclo de vida aplicada ao } \\
\text { processo de cerâmica tendo como } \\
\text { insumo energético capim elefante }\end{array}$ & $\begin{array}{l}\text { Universidade Estadual de } \\
\text { Campinas - Planejamento } \\
\text { de Sistemas Energéticos }\end{array}$ & 2003 & Doutorado \\
\hline $\begin{array}{l}\text { 77- Osvaldo } \\
\text { Stella Martins }\end{array}$ & $\begin{array}{l}\text { Análise de ciclos de vida como } \\
\text { contribuição à gestão ambiental de } \\
\text { processos produtivos } \\
\text { empreendimentos energéticos }\end{array}$ & $\begin{array}{l}\text { Universidade de São Paulo } \\
\text { - Programa Interunidades } \\
\text { de Pós-Graduação em } \\
\text { Energia }\end{array}$ & 1999 & Mestrado \\
\hline $\begin{array}{l}\text { 78- Paulo Ernani } \\
\text { Bauer }\end{array}$ & $\begin{array}{l}\text { Metodologia e procedimentos para a } \\
\text { consideração ambiental no projeto de } \\
\text { processos químicos }\end{array}$ & 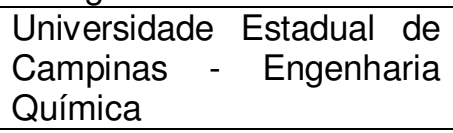 & 2003 & Doutorado \\
\hline $\begin{array}{l}\text { 79- Paulo } \\
\text { Henrique Ribeiro }\end{array}$ & $\begin{array}{l}\text { Modelagem de sistemas de produto } \\
\text { em estudos de Avaliação do Ciclo de } \\
\text { Vida (ACV) }\end{array}$ & $\begin{array}{l}\text { Universidade de São Paulo } \\
\text { - Engenharia Química }\end{array}$ & 2004 & Mestrado \\
\hline $\begin{array}{l}\text { 80- Paulo } \\
\text { Ricardo Santos } \\
\text { da Silva }\end{array}$ & $\begin{array}{l}\text { Avaliação de impactos e custos } \\
\text { ambientais em processos industriais - } \\
\text { uma abordagem metodológica }\end{array}$ & $\begin{array}{l}\text { Universidade Federal do } \\
\text { Rio Grande do Sul - } \\
\text { Engenharia de Produção }\end{array}$ & 2003 & Mestrado \\
\hline $\begin{array}{l}\text { 81- Paulo Sergio } \\
\text { Moreira Soares }\end{array}$ & $\begin{array}{l}\text { Avaliação do desempenho ambiental } \\
\text { de um sistema de produto para } \\
\text { geração de energia elétrica a partir do } \\
\text { carvão }\end{array}$ & $\begin{array}{l}\text { Universidade Federal do } \\
\text { Rio de Janeiro - Tecnologia } \\
\text { de Processos Químicos e } \\
\text { Bioquímicos }\end{array}$ & 2006 & Doutorado \\
\hline $\begin{array}{l}\text { 82- Rafael Justus } \\
\text { Barreto }\end{array}$ & $\begin{array}{l}\text { Incorporação da avaliação do ciclo de } \\
\text { vida ao processo de desenvolvimento } \\
\text { de produtos }\end{array}$ & $\begin{array}{l}\text { Universidade Tecnológica } \\
\text { Federal do Paraná - } \\
\text { Engenharia Mecânica e de } \\
\text { Materiais }\end{array}$ & 2007 & Mestrado \\
\hline $\begin{array}{l}\text { 83- Regina Célia } \\
\text { Zimmermann }\end{array}$ & $\begin{array}{l}\text { O PVC e a sustentabilidade ambiental: } \\
\text { marcos históricos e o caso Amanco } \\
\text { Brasil }\end{array}$ & $\begin{array}{lr}\text { Universidade Federal de } \\
\text { Santa Catarina } & - \\
\text { Engenharia Ambiental } & \end{array}$ & 2004 & Mestrado \\
\hline $\begin{array}{l}\text { 84- Reinaldo } \\
\text { Toshiyuki } \\
\text { Tateyama }\end{array}$ & $\begin{array}{l}\text { Softwares de análise do ciclo de vida: } \\
\text { uma contribuição à difusão da } \\
\text { ferramenta no Brasil }\end{array}$ & 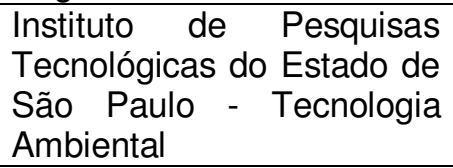 & 2007 & Mestrado \\
\hline $\begin{array}{l}\text { 85- Renata } \\
\text { Bachmann } \\
\text { Guimaraes Valt }\end{array}$ & $\begin{array}{l}\text { Análise do ciclo de vida de } \\
\text { embalagens de PET, de alumínio e de } \\
\text { vidro para refrigerantes no Brasil } \\
\text { variando a taxa de reciclagem dos } \\
\text { materiais }\end{array}$ & 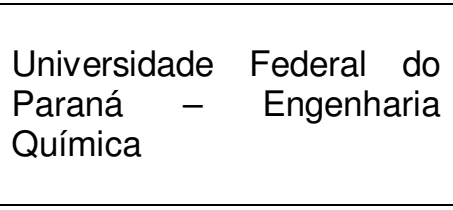 & 2004 & Mestrado \\
\hline $\begin{array}{l}\text { 86- Renata } \\
\text { Maery de Lima } \\
\text { Mendonça }\end{array}$ & $\begin{array}{l}\text { Avaliação do ciclo de vida do carbono } \\
\text { na queima de biodiesel à base de óleo } \\
\text { de soja }\end{array}$ & $\begin{array}{l}\text { Universidade de Brasília - } \\
\text { Ciências Mecânicas }\end{array}$ & 2007 & Mestrado \\
\hline
\end{tabular}




\begin{tabular}{|c|c|c|c|c|}
\hline $\begin{array}{l}\text { 87- Renato Paula } \\
\text { de Andrade }\end{array}$ & $\begin{array}{l}\text { Delineamento de metodologias de } \\
\text { gestão ambiental para execução de } \\
\text { teste hidrostático em dutos de gás } \\
\text { natural }\end{array}$ & $\begin{array}{l}\text { Universidade Federal de } \\
\text { Santa Maria - Engenharia } \\
\text { de Produção }\end{array}$ & 2004 & Mestrado \\
\hline $\begin{array}{l}\text { 88- Ricardo } \\
\text { Barreto Moraes }\end{array}$ & $\begin{array}{l}\text { O designer e a avaliação do ciclo de } \\
\text { vida dos produtos: análise do uso das } \\
\text { ferramentas }\end{array}$ & $\begin{array}{l}\text { Pontifícia Universidade } \\
\text { Católica do Rio de Janeiro - } \\
\text { Design }\end{array}$ & 2005 & Mestrado \\
\hline $\begin{array}{l}\text { 89- Rita de } \\
\text { Cássia Monteiro } \\
\text { Marzullo }\end{array}$ & $\begin{array}{l}\text { Análise de ecoeficiência dos óleos } \\
\text { vegetais oriundos da soja e palma } \\
\text { visando a produção de biodiesel }\end{array}$ & $\begin{array}{l}\text { Universidade de São Paulo } \\
\text { - Engenharia Química }\end{array}$ & 2007 & Mestrado \\
\hline $\begin{array}{l}\text { 90- Rita Mello } \\
\text { Magalhães }\end{array}$ & $\begin{array}{l}\text { Análise de ciclo de vida orientada para } \\
\text { o meio ambiente, uma revisão crítica }\end{array}$ & $\begin{array}{lll}\text { Universidade } & \text { Federal do } \\
\text { Rio de } & \text { Janeiro } & \text { - } \\
\text { Engenharia de } & \text { Produção } & \end{array}$ & 1998 & Mestrado \\
\hline $\begin{array}{lr}\text { 91- } & \text { Roberta } \\
\text { Tomasi } & \text { Pires } \\
\text { Hinz } & \end{array}$ & $\begin{array}{l}\text { Aspectos e impactos ambientais } \\
\text { associados ao processo de injeção da } \\
\text { blenda PPO/PSAl através do } \\
\text { inventário do ciclo de vida }\end{array}$ & $\begin{array}{l}\text { Universidade do Estado de } \\
\text { Santa Catarina - Ciência e } \\
\text { Engenharia de Materiais }\end{array}$ & 2007 & Mestrado \\
\hline $\begin{array}{l}\text { 92- Rogério } \\
\text { Ferraz Garcia de } \\
\text { Andrade }\end{array}$ & $\begin{array}{l}\text { Evidenciação dos gastos ambientais } \\
\text { do ciclo de vida do produto: uma } \\
\text { aplicação do custeio baseado em } \\
\text { atividades na indústria eletrônica }\end{array}$ & $\begin{array}{l}\text { Universidade de São Paulo } \\
\text { / São Carlos - Engenharia } \\
\text { de Produção }\end{array}$ & 2006 & Mestrado \\
\hline $\begin{array}{l}\text { 93- Rosane } \\
\text { Rodrigues Pagno }\end{array}$ & $\begin{array}{l}\text { ACV (Análise do Ciclo de Vida), como } \\
\text { ferramenta de decisão para diminuir o } \\
\text { passivo ambiental numa indústria } \\
\text { moveleira. }\end{array}$ & $\begin{array}{l}\text { Universidade Federal de } \\
\text { Santa Maria - Engenharia } \\
\text { de Produção }\end{array}$ & 2003 & Mestrado \\
\hline $\begin{array}{l}\text { 94- Rose Maria } \\
\text { Arantes Santos }\end{array}$ & $\begin{array}{l}\text { Implantação da norma ISO } 14040 \\
\text { numa indústria de vidro plano }\end{array}$ & $\begin{array}{l}\text { Universidade de Taubaté - } \\
\text { Ciências Ambientais }\end{array}$ & 2004 & Mestrado \\
\hline $\begin{array}{l}\text { 95- Roselis Ester } \\
\text { da Costa }\end{array}$ & $\begin{array}{l}\text { Inventário do ciclo de vida do biodiesel } \\
\text { obtido a partir do óleo de palma para } \\
\text { as condições do Brasil e da Colômbia }\end{array}$ & $\begin{array}{l}\text { Universidade Federal de } \\
\text { Itajubá - Engenharia de } \\
\text { Energia }\end{array}$ & 2007 & Mestrado \\
\hline $\begin{array}{l}\text { 96- Sandra } \\
\text { Harumi } \\
\text { Fukurozaki }\end{array}$ & $\begin{array}{l}\text { Análise ambiental da célula a } \\
\text { combustível de membrana trocadora } \\
\text { de prótons sob o enfoque da } \\
\text { avaliação do ciclo de vida }\end{array}$ & $\begin{array}{l}\text { Universidade de São Paulo } \\
\text { - Tecnologia Nuclear }\end{array}$ & 2006 & Mestrado \\
\hline $\begin{array}{l}\text { 97- Sérgio } \\
\text { Fernando } \\
\text { Tavares }\end{array}$ & $\begin{array}{l}\text { Metodologia para análise do ciclo de } \\
\text { vida energético de edificações } \\
\text { residenciais brasileiras }\end{array}$ & $\begin{array}{l}\text { Universidade Federal de } \\
\text { Santa Catarina } \\
\text { Engenharia Civil }\end{array}$ & 2006 & Doutorado \\
\hline $\begin{array}{l}\text { 98- Sérgio Luiz } \\
\text { Puff }\end{array}$ & $\begin{array}{l}\text { Avaliação de ciclo de vida de produtos } \\
\text { metalúrgicos }\end{array}$ & $\begin{array}{l}\text { Universidade } \\
\text { Blumenau - Engional de } \\
\text { Ambiental }\end{array}$ & 2003 & Mestrado \\
\hline $\begin{array}{l}\text { 99- Sheila Elisa } \\
\text { Scheidemantel } \\
\text { Klein }\end{array}$ & $\begin{array}{llll}\text { Diretrizes de } & \text { gestão ambiental na } \\
\text { indústria da } & \text { construção civil de } \\
\text { edificações } & & & \\
\end{array}$ & $\begin{array}{l}\text { Universidade } \\
\text { Blumenau - Engional de } \\
\text { Ambiental }\end{array}$ & 2002 & Mestrado \\
\hline $\begin{array}{l}\text { 100- Sibeli } \\
\text { Warmling }\end{array}$ & $\begin{array}{l}\text { Análise ambiental do processo } \\
\text { produtivo de pisos cerâmicos. } \\
\text { Aplicação de avaliação do ciclo de } \\
\text { vida }\end{array}$ & $\begin{array}{l}\text { Universidade Federal de } \\
\text { Santa Catarina } \\
\text { Engenharia Ambiental }\end{array}$ & 2004 & Mestrado \\
\hline $\begin{array}{l}\text { 101- Sílvio José } \\
\text { Jacovelli }\end{array}$ & $\begin{array}{l}\text { Projeto para o meio ambiente } \\
\text { (Ecodesign) na indústria de máquinas- } \\
\text { ferramenta - elementos para uma } \\
\text { proposta de implantação nas } \\
\text { indústrias Romi S/A }\end{array}$ & $\begin{array}{l}\text { Universidade Metodista de } \\
\text { Piracicaba - Engenharia de } \\
\text { Produção }\end{array}$ & 2005 & Mestrado \\
\hline 102- Stella Maris & Estudo da técnica de análise do ciclo & Universidade & 1998 & Mestrado \\
\hline
\end{tabular}




\begin{tabular}{|c|c|c|c|c|}
\hline $\begin{array}{l}\text { Gomes de } \\
\text { Almeida }\end{array}$ & $\begin{array}{l}\text { de vida e sua aplicação como } \\
\text { ferramenta de gestão ambiental nas } \\
\text { empresas }\end{array}$ & $\begin{array}{l}\text { Rio de Janeiro } \\
\text { Planejamento Energético }\end{array}$ & & \\
\hline $\begin{array}{l}\text { 103- Stelvia } \\
\text { Vigolvino Matos }\end{array}$ & $\begin{array}{l}\text { Seleção de fronteiras para análise de } \\
\text { ciclo de vida de sistemas que emitem } \\
\text { poluentes tóxicos de chaminés }\end{array}$ & $\begin{array}{l}\text { Universidade de São Paulo } \\
\text { / São Carlos - Engenharia } \\
\text { Hidráulica e Saneamento }\end{array}$ & 2002 & Doutorado \\
\hline $\begin{array}{l}\text { 104- Telmo Luiz } \\
\text { Bruson }\end{array}$ & $\begin{array}{l}\text { O fator higiene ocupacional, dentro da } \\
\text { análise do ciclo de vida de um } \\
\text { produto: proposta para abordagem }\end{array}$ & $\begin{array}{l}\text { Universidade de São Paulo } \\
\text { - Saúde Pública }\end{array}$ & 2001 & Mestrado \\
\hline $\begin{array}{l}\text { 105- Thiago } \\
\text { Guilherme } \\
\text { Ferreira Prado }\end{array}$ & $\begin{array}{l}\text { Externalidades do ciclo produtivo da } \\
\text { cana-de-açúcar com ênfase na } \\
\text { produção de energia elétrica }\end{array}$ & $\begin{array}{l}\text { Universidade de São Paulo } \\
\text { - Programa Interunidades } \\
\text { de Pós-Graduação em } \\
\text { Energia }\end{array}$ & 2007 & Mestrado \\
\hline $\begin{array}{l}\text { 106- Thiago José } \\
\text { Millani }\end{array}$ & $\begin{array}{l}\text { Subsídios à avaliação do ciclo de vida } \\
\text { do pescado: avaliação ambiental das } \\
\text { atividades de piscicultura e pesque- } \\
\text { pague, estudo de caso na bacia } \\
\text { hidrográfica do rio Mogi-Guaçu }\end{array}$ & $\begin{array}{l}\text { Universidade de São Paulo } \\
\text { - Escola de Engenharia de } \\
\text { São Carlos }\end{array}$ & 2007 & Mestrado \\
\hline $\begin{array}{l}\text { 107- Vanessa } \\
\text { Gomes da Silva }\end{array}$ & $\begin{array}{l}\text { Avaliação da sustentabilidade de } \\
\text { edifícios de escritórios brasileiros: } \\
\text { diretrizes e base metodológica }\end{array}$ & $\begin{array}{l}\text { Universidade de São Paulo } \\
\text { - Engenharia Civil }\end{array}$ & 2003 & Doutorado \\
\hline $\begin{array}{l}\text { 108- Valdélis } \\
\text { Fernandes de } \\
\text { Andrade }\end{array}$ & $\begin{array}{l}\text { Análise do ciclo de vida das } \\
\text { embalagens de cerveja em Portugal }\end{array}$ & $\begin{array}{l}\text { Instituto de Pesquisas } \\
\text { Tecnológicas do Estado de } \\
\text { São Paulo - Tecnologia } \\
\text { Ambiental }\end{array}$ & 2007 & Mestrado \\
\hline $\begin{array}{l}\text { 109- Wady } \\
\text { Facury Victorino }\end{array}$ & $\begin{array}{l}\text { Inventário de ciclo de vida do sistema } \\
\text { de transmissão de energia elétrica }\end{array}$ & $\begin{array}{l}\text { Universidade de São Paulo } \\
\text { - Engenharia Química }\end{array}$ & 2004 & Mestrado \\
\hline $\begin{array}{l}\text { 110- Yane } \\
\text { Ribeiro de } \\
\text { Oliveira Lobo }\end{array}$ & $\begin{array}{l}\text { Proposta de metodologia de } \\
\text { concepção e projeto do produto } \\
\text { considerando aspectos ambientais no } \\
\text { ciclo de vida }\end{array}$ & $\begin{array}{l}\text { Universidade } \text { Estadual de } \\
\text { Campinas - Engenharia } \\
\text { Mecânica }\end{array}$ & 2000 & Doutorado \\
\hline $\begin{array}{l}\text { 111- Zeila } \\
\text { Chittolina Piotto }\end{array}$ & $\begin{array}{l}\text { Eco-eficiência na indústria de celulose } \\
\text { e papel }\end{array}$ & $\begin{array}{l}\text { Universidade de São Paulo } \\
\text { - Engenharia Civil }\end{array}$ & 2003 & Doutorado \\
\hline
\end{tabular}




\section{APÊNDICE A1 - Inventários do subsistema de petróleo a ser consumido no Brasil nas produções de resíduo asfáltico, gás de refinaria e nafta}

\begin{tabular}{|c|c|c|c|c|c|}
\hline & \begin{tabular}{|l|}
\multicolumn{1}{|c|}{40,73 t de } \\
petróleo \\
consumido no \\
Brasil (para o \\
resíduo asf.)
\end{tabular} & $\begin{array}{c}63,39 \text { t de } \\
\text { petróleo } \\
\text { consumido } \\
\text { no Brasil } \\
\text { (para o gás } \\
\text { de refinaria) } \\
\end{array}$ & $\begin{array}{c}110,8 \text { t de } \\
\text { petróleo } \\
\text { consumido } \\
\text { no Brasil } \\
\text { (para a nafta) }\end{array}$ & $\begin{array}{c}54,54 \text { t de } \\
\text { petróleo } \\
\text { consumido no } \\
\text { Brasil (para a } \\
\quad \text { nafta) }\end{array}$ & $\begin{array}{c}2,29 \text { t de } \\
\text { petróleo } \\
\text { consumido } \\
\text { no Brasil } \\
\text { (para a } \\
\text { nafta) } \\
\end{array}$ \\
\hline \multicolumn{6}{|c|}{ Entradas } \\
\hline \multicolumn{6}{|c|}{ Recursos materiais (kg) } \\
\hline Petróleo & $4,44 \mathrm{E}+04$ & $6,91 \mathrm{E}+04$ & $1,21 \mathrm{E}+05$ & $5,95 \mathrm{E}+04$ & $2,50 \mathrm{E}+03$ \\
\hline Carvão & $1,90 \mathrm{E}+00$ & $2,96 \mathrm{E}+00$ & $5,18 \mathrm{E}+00$ & $2,55 \mathrm{E}+00$ & 1,07E-01 \\
\hline Gás Natural & $1,72 \mathrm{E}+03$ & $2,68 \mathrm{E}+03$ & $4,69 \mathrm{E}+03$ & $2,31 \mathrm{E}+03$ & $9,69 \mathrm{E}+01$ \\
\hline Combustíveis renováveis & $1,32 \mathrm{E}+01$ & $2,05 \mathrm{E}+01$ & $3,59 \mathrm{E}+01$ & $1,77 \mathrm{E}+01$ & 7,42E-01 \\
\hline Água & $9,15 \mathrm{E}+03$ & $1,42 \mathrm{E}+04$ & $2,49 \mathrm{E}+04$ & $1,22 \mathrm{E}+04$ & $5,14 \mathrm{E}+02$ \\
\hline \multicolumn{6}{|c|}{ Recursos energéticos (GJ) } \\
\hline Energia não especificada & 1,32E-02 & $2,05 \mathrm{E}-02$ & 3,59E-02 & 1,77E-02 & 7,42E-04 \\
\hline \multicolumn{6}{|c|}{ Saídas } \\
\hline \multicolumn{6}{|c|}{ Emissões atmosféricas (kg) } \\
\hline $\mathrm{CO}_{2}$ & \begin{tabular}{|c|}
$6,62 \mathrm{E}+03$ \\
\end{tabular} & $1,03 \mathrm{E}+04$ & $1,80 \mathrm{E}+04$ & $8,87 \mathrm{E}+03$ & $3,72 \mathrm{E}+02$ \\
\hline $\mathrm{CO}$ & $1,31 \mathrm{E}+01$ & $2,04 \mathrm{E}+01$ & $3,57 \mathrm{E}+01$ & $1,76 \mathrm{E}+01$ & $7,38 \mathrm{E}-01$ \\
\hline Vapor de água & $9,35 \mathrm{E}+00$ & $1,46 \mathrm{E}+01$ & $2,54 \mathrm{E}+01$ & $1,25 \mathrm{E}+01$ & $5,26 \mathrm{E}-01$ \\
\hline $\mathrm{CH}_{4}$ & $1,05 \mathrm{E}+02$ & $1,64 \mathrm{E}+02$ & $2,86 \mathrm{E}+02$ & $1,41 \mathrm{E}+02$ & $5,91 \mathrm{E}+00$ \\
\hline Material particulado & $4,92 \mathrm{E}+00$ & $7,66 \mathrm{E}+00$ & $1,34 \mathrm{E}+01$ & $6,59 \mathrm{E}+00$ & $2,77 \mathrm{E}-01$ \\
\hline \multicolumn{6}{|c|}{ Efluentes líquidos (kg) } \\
\hline DBO & $1,36 \mathrm{E}+00$ & $2,12 \mathrm{E}+00$ & $3,70 \mathrm{E}+00$ & $1,82 \mathrm{E}+00$ & $7,65 E-02$ \\
\hline DQO & $8,39 \mathrm{E}+00$ & $1,31 \mathrm{E}+01$ & $2,28 \mathrm{E}+01$ & $1,12 \mathrm{E}+01$ & $4,72 \mathrm{E}-01$ \\
\hline Metais pesados não especificados & $1,89 \mathrm{E}-04$ & 2,94E-04 & $5,14 \mathrm{E}-04$ & $2,53 \mathrm{E}-04$ & $1,06 \mathrm{E}-05$ \\
\hline Hidrocarbonetos & $7,90 \mathrm{E}-02$ & 1,23E-01 & $2,15 \mathrm{E}-01$ & $1,06 \mathrm{E}-01$ & 4,44E-03 \\
\hline Efluentes líquidos não especificados & 1,31E-03 & $2,05 E-03$ & $3,58 \mathrm{E}-03$ & 1,76E-03 & $7,39 \mathrm{E}-05$ \\
\hline Água residual & 1,27E-01 & $1,98 \mathrm{E}-01$ & $3,46 \mathrm{E}-01$ & $1,71 \mathrm{E}-01$ & $7,16 \mathrm{E}-03$ \\
\hline Óleo não especificado & 3,37E-01 & $5,24 \mathrm{E}-01$ & $9,16 \mathrm{E}-01$ & $4,51 \mathrm{E}-01$ & $1,89 \mathrm{E}-02$ \\
\hline Sólidos suspensos totais & $4,32 \mathrm{E}+00$ & $6,72 \mathrm{E}+00$ & $1,17 \mathrm{E}+01$ & $5,78 \mathrm{E}+00$ & $2,43 E-01$ \\
\hline \multicolumn{6}{|c|}{ Resíduos sólidos (kg) } \\
\hline Resíduos processuais não especificados & $1,42 \mathrm{E}-05$ & 2,21E-05 & 3,86E-05 & $1,90 \mathrm{E}-05$ & $7,99 \mathrm{E}-07$ \\
\hline
\end{tabular}




\section{APÊNDICE A2 - Inventários do subsistema de transporte marítimo de petróleo importado necessário às produções de resíduo asfáltico, gás de refinaria e nafta}

\begin{tabular}{|c|c|c|c|c|c|}
\hline & \begin{tabular}{|c|} 
Transporte \\
marítimo de \\
$68.891 \mathrm{t.km}$ \\
(para o \\
resíduo asf.) \\
\end{tabular} & \begin{tabular}{|c|} 
Transporte \\
marítimo: \\
$107.218 \mathrm{t} . \mathrm{km}$ \\
(para o gás \\
de refinaria) \\
\end{tabular} & $\begin{array}{c}\text { Transporte } \\
\text { marítimo: } \\
187.407 \text { t.km } \\
\text { (para a nafta) }\end{array}$ & $\begin{array}{c}\text { Transporte } \\
\text { marítimo: } \\
92.249 \text { t.km } \\
\text { (para a } \\
\text { nafta) } \\
\end{array}$ & $\begin{array}{l}\text { Transporte } \\
\text { marítimo: } \\
3.874 \text { t.km } \\
\text { (para a } \\
\text { nafta) } \\
\end{array}$ \\
\hline \multicolumn{6}{|c|}{ Entradas } \\
\hline \multicolumn{6}{|c|}{ Recursos materiais (kg) } \\
\hline Petróleo & $5,58 \mathrm{E}+02$ & $8,69 \mathrm{E}+02$ & $1,52 \mathrm{E}+03$ & $7,47 \mathrm{E}+02$ & $3,14 \mathrm{E}+01$ \\
\hline Carvão & $2,21 \mathrm{E}-01$ & $3,44 \mathrm{E}-01$ & $6,02 \mathrm{E}-01$ & $2,96 \mathrm{E}-01$ & 1,24E-02 \\
\hline Gás Natural & $2,68 \mathrm{E}+00$ & $4,18 \mathrm{E}+00$ & $7,30 \mathrm{E}+00$ & $3,59 \mathrm{E}+00$ & $1,51 \mathrm{E}-01$ \\
\hline Água & $9,11 \mathrm{E}+00$ & $1,42 \mathrm{E}+01$ & $2,48 \mathrm{E}+01$ & $1,22 \mathrm{E}+01$ & $5,13 E-01$ \\
\hline \multicolumn{6}{|c|}{ Recursos energéticos (GJ) } \\
\hline Energia não especificada & $1,91 \mathrm{E}-01$ & $2,98 \mathrm{E}-01$ & $5,21 \mathrm{E}-01$ & 2,56E-01 & 1,08E-02 \\
\hline \multicolumn{6}{|c|}{ Saídas } \\
\hline \multicolumn{6}{|c|}{ Emissões atmosféricas (kg) } \\
\hline $\mathrm{CO}_{2}$ & $1,61 \mathrm{E}+03$ & $2,50 \mathrm{E}+03$ & $4,37 \mathrm{E}+03$ & $2,15 \mathrm{E}+03$ & $9,04 \mathrm{E}+01$ \\
\hline $\mathrm{CO}$ & $4,83 \mathrm{E}+00$ & $7,51 \mathrm{E}+00$ & $1,31 \mathrm{E}+01$ & $6,46 \mathrm{E}+00$ & 2,71E-01 \\
\hline Hidrocarbonetos & $2,88 \mathrm{E}+00$ & $4,48 \mathrm{E}+00$ & $7,84 \mathrm{E}+00$ & $3,86 \mathrm{E}+00$ & $1,62 \mathrm{E}-01$ \\
\hline Metais & 4,34E-05 & $6,75 \mathrm{E}-05$ & $1,18 \mathrm{E}-04$ & $5,81 \mathrm{E}-05$ & $2,44 \mathrm{E}-06$ \\
\hline NOx & $3,04 \mathrm{E}+01$ & $4,74 \mathrm{E}+01$ & $8,28 \mathrm{E}+01$ & $4,08 \mathrm{E}+01$ & $1,71 \mathrm{E}+00$ \\
\hline SOx & $2,56 \mathrm{E}+01$ & $3,98 \mathrm{E}+01$ & $6,96 \mathrm{E}+01$ & $3,42 \mathrm{E}+01$ & $1,44 \mathrm{E}+00$ \\
\hline COV - exceto metano & 8,91E-02 & 1,39E-01 & $2,42 \mathrm{E}-01$ & 1,19E-01 & 5,01E-03 \\
\hline Material particulado & $1,48 \mathrm{E}-02$ & 2,30E-02 & 4,01E-02 & $1,98 \mathrm{E}-02$ & $8,30 \mathrm{E}-04$ \\
\hline \multicolumn{6}{|c|}{ Efluentes líquidos $(\mathrm{kg})$} \\
\hline $\mathrm{DBO}$ & $2,17 \mathrm{E}-04$ & 3,38E-04 & 5,90E-04 & $2,91 \mathrm{E}-04$ & 1,22E-05 \\
\hline DQO & 4,34E-04 & $6,75 \mathrm{E}-04$ & $1,18 \mathrm{E}-03$ & $5,81 \mathrm{E}-04$ & $2,44 \mathrm{E}-05$ \\
\hline Hidrocarbonetos & $8,68 \mathrm{E}-04$ & 1,35E-03 & $2,36 \mathrm{E}-03$ & $1,16 \mathrm{E}-03$ & $4,88 \mathrm{E}-05$ \\
\hline Ílons metálicos & $2,17 \mathrm{E}-04$ & $3,38 \mathrm{E}-04$ & $5,90 \mathrm{E}-04$ & 2,91E-04 & $1,22 \mathrm{E}-05$ \\
\hline Óleo não especificado & $2,99 \mathrm{E}-03$ & $4,65 \mathrm{E}-03$ & $8,13 E-03$ & $4,00 \mathrm{E}-03$ & 1,68E-04 \\
\hline Cloretos $\left(\mathrm{Cl}^{-}\right)$ & 4,34E-04 & 6,75E-04 & $1,18 \mathrm{E}-03$ & 5,81E-04 & $2,44 \mathrm{E}-05$ \\
\hline \multicolumn{6}{|c|}{ Resíduos sólidos $(\mathrm{kg})$} \\
\hline Resíduos não especificados & $9,55 \mathrm{E}-02$ & 1,49E-01 & $2,60 \mathrm{E}-01$ & $1,28 \mathrm{E}-01$ & 5,37E-03 \\
\hline Resíduos sólidos oleosos & $7,09 \mathrm{E}+00$ & $1,10 \mathrm{E}+01$ & $1,93 \mathrm{E}+01$ & $9,49 \mathrm{E}+00$ & 3,99E-01 \\
\hline
\end{tabular}




\section{APÊNDICE A3 - Inventários do subsistema de refino do petróleo para as produções de resíduo asfáltico, gás de refinaria e nafta}

\begin{tabular}{|c|c|c|c|c|c|}
\hline & $\begin{array}{c}\text { Refino de } \\
40,73 \text { t de } \\
\text { petróleo } \\
\text { (para o } \\
\text { resíduo asf.) }\end{array}$ & $\begin{array}{c}\text { Refino de } \\
63,39 \text { t de } \\
\text { petróleo } \\
\text { (para o gás } \\
\text { de refinaria) } \\
\end{array}$ & $\begin{array}{c}\text { Refino de } \\
110,8 \text { t de } \\
\text { petróleo } \\
\text { (para a } \\
\text { nafta) } \\
\end{array}$ & $\begin{array}{c}\text { Refino de } \\
54,54 \text { t de } \\
\text { petróleo } \\
\text { (para a } \\
\text { nafta) } \\
\end{array}$ & $\begin{array}{c}\text { Refino de } \\
2,29 \text { t de } \\
\text { petróleo } \\
\text { (para a } \\
\text { nafta) }\end{array}$ \\
\hline \multicolumn{6}{|c|}{ Entradas } \\
\hline \multicolumn{6}{|c|}{ Recursos materiais (kg) } \\
\hline Petróleo refinado no Brasil & $4,07 \mathrm{E}+04$ & $6,34 \mathrm{E}+04$ & $1,11 \mathrm{E}+05$ & $5,45 \mathrm{E}+04$ & $2,29 E+03$ \\
\hline \multicolumn{6}{|c|}{ Recursos energéticos (GJ) } \\
\hline Energia Elétrica & $4,58 \mathrm{E}+00$ & $7,13 \mathrm{E}+00$ & $1,25 \mathrm{E}+01$ & $6,14 \mathrm{E}+00$ & $2,58 \mathrm{E}-01$ \\
\hline \multicolumn{6}{|c|}{ Saídas } \\
\hline \multicolumn{6}{|c|}{ Emissões atmosféricas (kg) } \\
\hline $\mathrm{CO}_{2}$ & $3,38 \mathrm{E}+02$ & $5,26 \mathrm{E}+02$ & $9,20 \mathrm{E}+02$ & $4,53 \mathrm{E}+02$ & $1,90 \mathrm{E}+01$ \\
\hline $\mathrm{CO}$ & $1,07 \mathrm{E}+00$ & 1,67E+00 & $2,92 \mathrm{E}+00$ & $1,44 \mathrm{E}+00$ & 6,03E-02 \\
\hline Hidrocarbonetos & $8,12 \mathrm{E}-04$ & 1,26E-03 & 2,21E-03 & 1,09E-03 & 4,56E-05 \\
\hline $\mathrm{CH}_{4}$ & $1,55 \mathrm{E}+00$ & $2,41 \mathrm{E}+00$ & $4,21 \mathrm{E}+00$ & $2,07 \mathrm{E}+00$ & 8,69E-02 \\
\hline NOx & $2,37 E-01$ & $3,70 \mathrm{E}-01$ & 6,46E-01 & $3,18 \mathrm{E}-01$ & 1,34E-02 \\
\hline SOx & $1,99 \mathrm{E}-01$ & 3,09E-01 & $5,41 \mathrm{E}-01$ & $2,66 \mathrm{E}-01$ & $1,12 \mathrm{E}-02$ \\
\hline Metil mercarptana & 4,07E-04 & 6,34E-04 & 1,11E-03 & $5,45 \mathrm{E}-04$ & $2,29 \mathrm{E}-05$ \\
\hline $\mathrm{H}_{2} \mathrm{~S}$ & 8,53E-03 & 1,33E-02 & 2,32E-02 & 1,14E-02 & $4,80 \mathrm{E}-04$ \\
\hline COV - exceto metano & $3,89 \mathrm{E}+01$ & $6,06 \mathrm{E}+01$ & $1,06 \mathrm{E}+02$ & $5,21 \mathrm{E}+01$ & $2,19 \mathrm{E}+00$ \\
\hline Material particulado & $4,13 \mathrm{E}-01$ & $6,42 \mathrm{E}-01$ & $1,12 \mathrm{E}+00$ & $5,53 \mathrm{E}-01$ & $2,32 \mathrm{E}-02$ \\
\hline \multicolumn{6}{|c|}{ Efluentes líquidos $(\mathrm{kg})$} \\
\hline Óleo não especificado & $2,90 \mathrm{E}-01$ & $4,51 \mathrm{E}-01$ & $7,89 \mathrm{E}-01$ & $3,88 \mathrm{E}-01$ & $1,63 \mathrm{E}-02$ \\
\hline $\mathrm{Na}^{+}$ & 6,64E-01 & $1,03 \mathrm{E}+00$ & $1,81 \mathrm{E}+00$ & 8,89E-01 & 3,73E-02 \\
\hline Cloretos $\left(\mathrm{Cl}^{-}\right)$ & 9,91E-01 & $1,54 \mathrm{E}+00$ & $2,70 \mathrm{E}+00$ & $1,33 \mathrm{E}+00$ & 5,57E-02 \\
\hline
\end{tabular}




\section{APÊNDICE A4 - Inventário consolidado da produção $730,2 \mathrm{~kg}$ de gás de refinaria}

\begin{tabular}{|c|c|c|c|c|}
\hline & $\begin{array}{c}63,39 \text { t de } \\
\text { petróleo nacional } \\
\text { e importado }\end{array}$ & $\begin{array}{l}\text { Transporte } \\
\text { marítimo: } \\
107.218 \text { t.km }\end{array}$ & Refino: $63,39 \mathrm{t}$ & $\begin{array}{c}\text { Produção de } \\
730,2 \text { kg de gás } \\
\text { de refinaria } \\
\text { (alocação de } \\
1,05 \%) \\
\end{array}$ \\
\hline & Apêndice A1 & Apêndice A2 & Apêndice A3 & $\begin{array}{l}\text { Soma com } \\
\text { alocação }\end{array}$ \\
\hline \multicolumn{5}{|c|}{ Entradas } \\
\hline \multicolumn{5}{|c|}{ Recursos materiais (kg) } \\
\hline Petróleo refinado no Brasil & & & $6,34 \mathrm{E}+04$ & \\
\hline Petróleo & $6,91 \mathrm{E}+04$ & $8,69 \mathrm{E}+02$ & & $7,35 \mathrm{E}+02$ \\
\hline Carvão & $2,96 \mathrm{E}+00$ & $3,44 \mathrm{E}-01$ & & 3,47E-02 \\
\hline Gás Natural & $2,68 \mathrm{E}+03$ & $4,18 \mathrm{E}+00$ & & $2,82 \mathrm{E}+01$ \\
\hline Combustíveis renováveis & $2,05 \mathrm{E}+01$ & & & $2,16 \mathrm{E}-01$ \\
\hline Água & $1,42 \mathrm{E}+04$ & $1,42 \mathrm{E}+01$ & & $1,50 \mathrm{E}+02$ \\
\hline \multicolumn{5}{|c|}{ Recursos energéticos (GJ) } \\
\hline Energia Elétrica & & & $7,13 \mathrm{E}+00$ & 7,49E-02 \\
\hline Energia não especificada & $2,05 \mathrm{E}-02$ & 2,98E-01 & & 3,34E-03 \\
\hline \multicolumn{5}{|c|}{ Saídas } \\
\hline \multicolumn{5}{|c|}{ Emissões atmosféricas (kg) } \\
\hline $\mathrm{CO}_{2}$ & $1,03 \mathrm{E}+04$ & $2,50 \mathrm{E}+03$ & $5,26 \mathrm{E}+02$ & $1,40 \mathrm{E}+02$ \\
\hline $\mathrm{CO}$ & $2,04 \mathrm{E}+01$ & $7,51 \mathrm{E}+00$ & $1,67 \mathrm{E}+00$ & $3,11 \mathrm{E}-01$ \\
\hline Hidrocarbonetos & & $4,48 \mathrm{E}+00$ & $1,26 \mathrm{E}-03$ & $4,71 \mathrm{E}-02$ \\
\hline Vapor de água & $1,46 \mathrm{E}+01$ & & & $1,53 \mathrm{E}-01$ \\
\hline $\mathrm{CH}_{4}$ & $1,64 \mathrm{E}+02$ & & $2,41 \mathrm{E}+00$ & $1,74 \mathrm{E}+00$ \\
\hline Íons metálicos & & 6,75E-05 & & 7,09E-07 \\
\hline NOx & & $4,74 \mathrm{E}+01$ & $3,70 \mathrm{E}-01$ & $5,01 \mathrm{E}-01$ \\
\hline SOx & & $3,98 \mathrm{E}+01$ & $3,09 E-01$ & $4,21 \mathrm{E}-01$ \\
\hline Metil mercarptana & & & 6,34E-04 & 6,66E-06 \\
\hline $\mathrm{H}_{2} \mathrm{~S}$ & & & 1,33E-02 & 1,39E-04 \\
\hline COV - exceto metano & & 1,39E-01 & $6,06 \mathrm{E}+01$ & $6,38 \mathrm{E}-01$ \\
\hline Material particulado & $7,66 \mathrm{E}+00$ & $2,30 \mathrm{E}-02$ & $6,42 \mathrm{E}-01$ & $8,75 \mathrm{E}-02$ \\
\hline \multicolumn{5}{|c|}{ Efluentes líquidos $(\mathrm{kg})$} \\
\hline DBO & $2,12 \mathrm{E}+00$ & $3,38 \mathrm{E}-04$ & & $2,23 E-02$ \\
\hline DQO & $1,31 \mathrm{E}+01$ & $6,75 \mathrm{E}-04$ & & $1,37 \mathrm{E}-01$ \\
\hline Metais pesados não especificados & $2,94 \mathrm{E}-04$ & & & 3,09E-06 \\
\hline Hidrocarbonetos & $1,23 E-01$ & 1,35E-03 & & $1,31 \mathrm{E}-03$ \\
\hline Efluentes líquidos não especificados & $2,05 E-03$ & & & $2,15 \mathrm{E}-05$ \\
\hline Água residual & $1,98 \mathrm{E}-01$ & & & $2,08 \mathrm{E}-03$ \\
\hline Ílons metálicos & & $3,38 E-04$ & & $3,55 E-06$ \\
\hline Óleo não especificado & $5,24 \mathrm{E}-01$ & $4,65 \mathrm{E}-03$ & 4,51E-01 & 1,03E-02 \\
\hline
\end{tabular}




\begin{tabular}{|c|c|c|c|c|}
\hline Sólidos suspensos totais & $6,72 \mathrm{E}+00$ & & & $7,06 \mathrm{E}-02$ \\
\hline $\mathrm{Na}^{+}$ & & & $1,03 E+00$ & 1,09E-02 \\
\hline Cloretos $\left(\mathrm{Cl}^{-}\right)$ & & $6,75 \mathrm{E}-04$ & $1,54 \mathrm{E}+00$ & 1,62E-02 \\
\hline \multicolumn{5}{|c|}{ Resíduos sólidos (kg) } \\
\hline Resíduos não especificados & $2,21 \mathrm{E}-05$ & $1,49 \mathrm{E}-01$ & & $1,56 \mathrm{E}-03$ \\
\hline Resíduos sólidos oleosos & & $1,10 \mathrm{E}+01$ & & $1,16 \mathrm{E}-01$ \\
\hline
\end{tabular}




\section{APÊNDICE A5 - Inventário consolidado da produção de 1.083 $\mathrm{kg}$ de resíduo asfáltico}

\begin{tabular}{|c|c|c|c|c|}
\hline & $\begin{array}{c}40,73 \text { t de } \\
\text { petróleo } \\
\text { nacional e } \\
\text { importado } \\
\end{array}$ & $\begin{array}{l}\text { Transporte } \\
\text { marítimo: } \\
68.891 \text { t.km }\end{array}$ & $\begin{array}{l}\text { Refino de } \\
40,73 \text { t de } \\
\text { petróleo }\end{array}$ & $\begin{array}{c}\text { Produção de } 1.083 \\
\text { kg de resíduo } \\
\text { asfáltico (alocação } \\
\text { de } 2,82 \% \text { ) } \\
\end{array}$ \\
\hline & Apêndice A1 & Apêndice A2 & Apêndice A3 & $\begin{array}{c}\text { Soma com } \\
\text { alocação }\end{array}$ \\
\hline \multicolumn{5}{|c|}{ Entradas } \\
\hline \multicolumn{5}{|c|}{ Recursos materiais (kg) } \\
\hline Petróleo refinado no Brasil & & & $4,07 \mathrm{E}+04$ & \\
\hline Petróleo & $4,44 \mathrm{E}+04$ & $5,58 \mathrm{E}+02$ & & 1,27E+03 \\
\hline Carvão & $1,90 \mathrm{E}+00$ & $2,21 \mathrm{E}-01$ & & 5,99E-02 \\
\hline Gás Natural & $1,72 \mathrm{E}+03$ & $2,68 \mathrm{E}+00$ & & $4,87 \mathrm{E}+01$ \\
\hline Combustíveis renováveis & $1,32 \mathrm{E}+01$ & & & $3,72 \mathrm{E}-01$ \\
\hline Água & $9,15 \mathrm{E}+03$ & $9,11 \mathrm{E}+00$ & & $2,58 \mathrm{E}+02$ \\
\hline \multicolumn{5}{|c|}{ Recursos energéticos (GJ) } \\
\hline Energia Elétrica & & & $4,58 \mathrm{E}+00$ & $1,29 \mathrm{E}-01$ \\
\hline Energia não especificada & $1,32 \mathrm{E}-02$ & $1,91 \mathrm{E}-01$ & & 5,77E-03 \\
\hline \multicolumn{5}{|c|}{ Saídas } \\
\hline \multicolumn{5}{|c|}{ Emissões atmosféricas (kg) } \\
\hline $\mathrm{CO}_{2}$ & $6,62 \mathrm{E}+03$ & $1,61 \mathrm{E}+03$ & $3,38 \mathrm{E}+02$ & $2,42 \mathrm{E}+02$ \\
\hline $\mathrm{CO}$ & $1,31 \mathrm{E}+01$ & $4,83 \mathrm{E}+00$ & $1,07 \mathrm{E}+00$ & $5,37 E-01$ \\
\hline Hidrocarbonetos & & $2,88 \mathrm{E}+00$ & $8,12 \mathrm{E}-04$ & $8,13 E-02$ \\
\hline Vapor de água & $9,35 \mathrm{E}+00$ & & & $2,64 \mathrm{E}-01$ \\
\hline $\mathrm{CH}_{4}$ & $1,05 \mathrm{E}+02$ & & $1,55 \mathrm{E}+00$ & $3,01 \mathrm{E}+00$ \\
\hline Metais & & 4,34E-05 & & $1,22 \mathrm{E}-06$ \\
\hline $\mathrm{NOx}$ & & $3,04 \mathrm{E}+01$ & 2,37E-01 & $8,65 E-01$ \\
\hline SOx & & $2,56 \mathrm{E}+01$ & 1,99E-01 & 7,27E-01 \\
\hline Metil mercarptana & & & 4,07E-04 & 1,15E-05 \\
\hline $\mathrm{H}_{2} \mathrm{~S}$ & & & $8,53 \mathrm{E}-03$ & $2,41 \mathrm{E}-04$ \\
\hline COV - exceto metano & & $8,91 \mathrm{E}-02$ & $3,89 \mathrm{E}+01$ & $1,10 \mathrm{E}+00$ \\
\hline Material particulado & $4,92 \mathrm{E}+00$ & 1,48E-02 & $4,13 \mathrm{E}-01$ & $1,51 \mathrm{E}-01$ \\
\hline \multicolumn{5}{|c|}{ Efluentes líquidos (kg) } \\
\hline DBO & $1,36 \mathrm{E}+00$ & $2,17 E-04$ & & 3,84E-02 \\
\hline DQO & $8,39 \mathrm{E}+00$ & $4,34 \mathrm{E}-04$ & & $2,37 \mathrm{E}-01$ \\
\hline Metais pesados não especificados & 1,89E-04 & & & $5,33 E-06$ \\
\hline Hidrocarbonetos & 7,90E-02 & $8,68 E-04$ & & $2,25 E-03$ \\
\hline Efluentes líquidos não especificados & $1,31 \mathrm{E}-03$ & & & $3,71 \mathrm{E}-05$ \\
\hline Água residual & $1,27 \mathrm{E}-01$ & & & 3,59E-03 \\
\hline Íons metálicos & & $2,17 \mathrm{E}-04$ & & $6,12 \mathrm{E}-06$ \\
\hline Óleo não especificado & $3,37 E-01$ & $2,99 \mathrm{E}-03$ & $2,90 \mathrm{E}-01$ & $1,78 \mathrm{E}-02$ \\
\hline Sólidos suspensos totais & $4,32 \mathrm{E}+00$ & & & $1,22 \mathrm{E}-01$ \\
\hline $\mathrm{Na}^{+}$ & & & 6,64E-01 & 1,87E-02 \\
\hline
\end{tabular}




\begin{tabular}{|l|c|c|c|c|}
\hline Cloretos $\left(\mathrm{Cl}^{-}\right)$ & & $4,34 \mathrm{E}-04$ & $9,91 \mathrm{E}-01$ & $2,80 \mathrm{E}-02$ \\
\hline \multicolumn{3}{|c|}{ Resíduos sólidos (kg) } \\
\hline Resíduos não especificados & $1,42 \mathrm{E}-05$ & $9,55 \mathrm{E}-02$ & & $2,69 \mathrm{E}-03$ \\
\hline Resíduos sólidos oleosos & & $7,09 \mathrm{E}+00$ & & $2,00 \mathrm{E}-01$ \\
\hline
\end{tabular}




\section{APÊNDICE A6 - Inventário consolidado da produção de 11,78 toneladas de nafta}

\begin{tabular}{|c|c|c|c|c|}
\hline & $\begin{array}{l}110,8 \text { t de } \\
\text { petróleo } \\
\text { nacional e } \\
\text { importado }\end{array}$ & $\begin{array}{c}\text { Transporte } \\
\text { marítimo: } \\
187.407 \\
\text { t.km } \\
\end{array}$ & $\begin{array}{l}\text { Refino: } \\
110,8 \mathrm{t}\end{array}$ & $\begin{array}{c}\text { Produção de } \\
11,78 \mathrm{t} \text { de nafta } \\
\text { (alocação de } \\
11,63 \% \text { ) }\end{array}$ \\
\hline & $\begin{array}{c}\text { Apêndice } \\
\text { A1 }\end{array}$ & $\begin{array}{l}\text { Apêndice } \\
\text { A2 }\end{array}$ & $\begin{array}{l}\text { Apêndice } \\
\text { A3 }\end{array}$ & $\begin{array}{c}\text { Soma com } \\
\text { alocação }\end{array}$ \\
\hline \multicolumn{5}{|c|}{ Entradas } \\
\hline \multicolumn{5}{|c|}{ Recursos materiais (kg) } \\
\hline Petróleo refinado no Brasil & & & $1,11 \mathrm{E}+05$ & \\
\hline Petróleo & $1,21 \mathrm{E}+05$ & $1,52 \mathrm{E}+03$ & & $1,42 \mathrm{E}+04$ \\
\hline Carvão & $5,18 \mathrm{E}+00$ & $6,02 \mathrm{E}-01$ & & $6,72 \mathrm{E}-01$ \\
\hline Gás Natural & $4,69 \mathrm{E}+03$ & $7,30 \mathrm{E}+00$ & & $5,46 \mathrm{E}+02$ \\
\hline Combustíveis renováveis & $3,59 \mathrm{E}+01$ & & & $4,18 \mathrm{E}+00$ \\
\hline Água & $2,49 \mathrm{E}+04$ & $2,48 \mathrm{E}+01$ & & $2,90 \mathrm{E}+03$ \\
\hline \multicolumn{5}{|c|}{ Recursos energéticos (GJ) } \\
\hline Energia Elétrica & & & $1,25 \mathrm{E}+01$ & $1,45 \mathrm{E}+00$ \\
\hline Energia não especificada & 3,59E-02 & $5,21 \mathrm{E}-01$ & & $6,47 \mathrm{E}-02$ \\
\hline \multicolumn{5}{|c|}{ Saídas } \\
\hline \multicolumn{5}{|c|}{ Emissões atmosféricas (kg) } \\
\hline $\mathrm{CO}_{2}$ & $1,80 \mathrm{E}+04$ & $4,37 \mathrm{E}+03$ & $9,20 \mathrm{E}+02$ & $2,71 \mathrm{E}+03$ \\
\hline $\mathrm{CO}$ & $3,57 \mathrm{E}+01$ & $1,31 \mathrm{E}+01$ & $2,92 \mathrm{E}+00$ & $6,02 \mathrm{E}+00$ \\
\hline Hidrocarbonetos & & $7,84 \mathrm{E}+00$ & $2,21 \mathrm{E}-03$ & $9,12 \mathrm{E}-01$ \\
\hline Vapor de água & $2,54 \mathrm{E}+01$ & & & $2,96 \mathrm{E}+00$ \\
\hline $\mathrm{CH}_{4}$ & $2,86 \mathrm{E}+02$ & & $4,21 \mathrm{E}+00$ & $3,37 \mathrm{E}+01$ \\
\hline Íons metálicos & & $1,18 \mathrm{E}-04$ & & 1,37E-05 \\
\hline NOx & & $8,28 \mathrm{E}+01$ & $6,46 \mathrm{E}-01$ & $9,70 \mathrm{E}+00$ \\
\hline SOx & & $6,96 \mathrm{E}+01$ & $5,41 \mathrm{E}-01$ & $8,15 \mathrm{E}+00$ \\
\hline Metil mercarptana & & & $1,11 \mathrm{E}-03$ & 1,29E-04 \\
\hline $\mathrm{H}_{2} \mathrm{~S}$ & & & $2,32 \mathrm{E}-02$ & $2,70 \mathrm{E}-03$ \\
\hline COV - exceto metano & & $2,42 \mathrm{E}-01$ & $1,06 \mathrm{E}+02$ & $1,23 \mathrm{E}+01$ \\
\hline Material particulado & $1,34 \mathrm{E}+01$ & 4,01E-02 & $1,12 \mathrm{E}+00$ & $1,69 \mathrm{E}+00$ \\
\hline \multicolumn{5}{|c|}{ Efluentes líquidos (kg) } \\
\hline DBO & $3,70 \mathrm{E}+00$ & $5,90 \mathrm{E}-04$ & & 4,31E-01 \\
\hline $\mathrm{DQO}$ & $2,28 \mathrm{E}+01$ & $1,18 \mathrm{E}-03$ & & $2,65 \mathrm{E}+00$ \\
\hline Metais pesados não especificados & $5,14 \mathrm{E}-04$ & & & 5,98E-05 \\
\hline Hidrocarbonetos & $2,15 E-01$ & $2,36 \mathrm{E}-03$ & & $2,53 \mathrm{E}-02$ \\
\hline Efluentes líquidos não especificados & 3,58E-03 & & & 4,16E-04 \\
\hline Água residual & $3,46 \mathrm{E}-01$ & & & 4,03E-02 \\
\hline Íons metálicos & & $5,90 \mathrm{E}-04$ & & $6,87 E-05$ \\
\hline Óleo não especificado & $9,16 \mathrm{E}-01$ & 8,13E-03 & 7,89E-01 & $1,99 \mathrm{E}-01$ \\
\hline Sólidos suspensos totais & $1,17 \mathrm{E}+01$ & & & 1,37E+00 \\
\hline $\mathrm{Na}^{+}$ & & & $1,81 \mathrm{E}+00$ & $2,10 \mathrm{E}-01$ \\
\hline
\end{tabular}




\begin{tabular}{|l|c|c|c|c|}
\hline Cloretos $\left(\mathrm{Cl}^{-}\right)$ & & $1,18 \mathrm{E}-03$ & $2,70 \mathrm{E}+00$ & $3,14 \mathrm{E}-01$ \\
\hline \multicolumn{4}{|c|}{ Resíduos sólidos (kg) } \\
\hline Resíduos não especificados & $3,86 \mathrm{E}-05$ & $2,60 \mathrm{E}-01$ & & $3,02 \mathrm{E}-02$ \\
\hline Resíduos sólidos oleosos & & $1,93 \mathrm{E}+01$ & & $2,24 \mathrm{E}+00$ \\
\hline
\end{tabular}




\section{APÊNDICE A7 - Inventário consolidado da produção de 5,798 toneladas de nafta}

\begin{tabular}{|c|c|c|c|c|}
\hline & \\
\hline & $\begin{array}{c}54,54 \mathrm{t} \text { de } \\
\text { petróleo } \\
\text { nacional e } \\
\text { importado }\end{array}$ & \begin{tabular}{|c|} 
Transporte \\
marítimo: \\
92.249 \\
t.km \\
\end{tabular} & $\begin{array}{l}\text { Refino: } \\
54,54 \mathrm{t}\end{array}$ & $\begin{array}{c}\text { Produção de } 5,798 \text { t } \\
\text { de nafta (alocação } \\
\text { de } 11,63 \%)\end{array}$ \\
\hline & Apêndice A1 & $\begin{array}{c}\text { Apêndice } \\
\text { A2 }\end{array}$ & $\begin{array}{c}\text { Apêndice } \\
\text { A3 }\end{array}$ & Soma com alocação \\
\hline \multicolumn{5}{|c|}{ Entradas } \\
\hline \multicolumn{5}{|c|}{ Recursos materiais (kg) } \\
\hline Petróleo refinado no Brasil & & & $5,45 E+04$ & \\
\hline Petróleo & $5,95 \mathrm{E}+04$ & $7,47 \mathrm{E}+02$ & & $7,00 \mathrm{E}+03$ \\
\hline Carvão & $2,55 \mathrm{E}+00$ & $2,96 \mathrm{E}-01$ & & 3,31E-01 \\
\hline Gás Natural & $2,31 \mathrm{E}+03$ & $3,59 \mathrm{E}+00$ & & $2,69 \mathrm{E}+02$ \\
\hline Combustíveis renováveis & $1,77 \mathrm{E}+01$ & & & $2,06 \mathrm{E}+00$ \\
\hline Água & $1,22 E+04$ & $1,22 \mathrm{E}+01$ & & $1,43 E+03$ \\
\hline \multicolumn{5}{|c|}{ Recursos energéticos (GJ) } \\
\hline Energia Elétrica & & & $6,14 \mathrm{E}+00$ & $7,14 \mathrm{E}-01$ \\
\hline Energia não especificada & $1,77 \mathrm{E}-02$ & 2,56E-01 & & $3,19 \mathrm{E}-02$ \\
\hline \multicolumn{5}{|c|}{ Saídas } \\
\hline \multicolumn{5}{|c|}{ Emissões atmosféricas (kg) } \\
\hline $\mathrm{CO}_{2}$ & $8,87 \mathrm{E}+03$ & $2,15 \mathrm{E}+03$ & $4,53 \mathrm{E}+02$ & $1,33 \mathrm{E}+03$ \\
\hline $\mathrm{CO}$ & $1,76 \mathrm{E}+01$ & $6,46 \mathrm{E}+00$ & $1,44 \mathrm{E}+00$ & $2,96 \mathrm{E}+00$ \\
\hline Hidrocarbonetos & & $3,86 \mathrm{E}+00$ & 1,09E-03 & 4,49E-01 \\
\hline Vapor de água & $1,25 \mathrm{E}+01$ & & & $1,46 \mathrm{E}+00$ \\
\hline $\mathrm{CH}_{4}$ & $1,41 \mathrm{E}+02$ & & $2,07 \mathrm{E}+00$ & $1,66 \mathrm{E}+01$ \\
\hline Ílons metálicos & & 5,81E-05 & & $6,76 \mathrm{E}-06$ \\
\hline NOx & & $4,08 \mathrm{E}+01$ & $3,18 \mathrm{E}-01$ & $4,78 \mathrm{E}+00$ \\
\hline SOx & & $3,42 \mathrm{E}+01$ & $2,66 \mathrm{E}-01$ & $4,01 \mathrm{E}+00$ \\
\hline Metil mercarptana & & & $5,45 \mathrm{E}-04$ & 6,34E-05 \\
\hline $\mathrm{H}_{2} \mathrm{~S}$ & & & $1,14 \mathrm{E}-02$ & $1,33 \mathrm{E}-03$ \\
\hline COV - exceto metano & & $1,19 \mathrm{E}-01$ & $5,21 \mathrm{E}+01$ & $6,08 \mathrm{E}+00$ \\
\hline Material particulado & $6,59 \mathrm{E}+00$ & 1,98E-02 & $5,53 \mathrm{E}-01$ & 8,33E-01 \\
\hline \multicolumn{5}{|c|}{ Efluentes líquidos (kg) } \\
\hline DBO & $1,82 \mathrm{E}+00$ & $2,91 \mathrm{E}-04$ & & $2,12 \mathrm{E}-01$ \\
\hline DQO & $1,12 \mathrm{E}+01$ & $5,81 E-04$ & & $1,31 \mathrm{E}+00$ \\
\hline Metais pesados não especificados & $2,53 \mathrm{E}-04$ & & & 2,94E-05 \\
\hline Hidrocarbonetos & $1,06 \mathrm{E}-01$ & 1,16E-03 & & $1,24 \mathrm{E}-02$ \\
\hline Efluentes líquidos não especificados & 1,76E-03 & & & 2,05E-04 \\
\hline Água residual & $1,71 \mathrm{E}-01$ & & & $1,98 \mathrm{E}-02$ \\
\hline Ílons metálicos & & 2,91E-04 & & 3,38E-05 \\
\hline Óleo não especificado & $4,51 \mathrm{E}-01$ & $4,00 \mathrm{E}-03$ & $3,88 \mathrm{E}-01$ & $9,80 \mathrm{E}-02$ \\
\hline Sólidos suspensos totais & $5,78 \mathrm{E}+00$ & & & $6,72 \mathrm{E}-01$ \\
\hline $\mathrm{Na}^{+}$ & & & 8,89E-01 & $1,03 \mathrm{E}-01$ \\
\hline
\end{tabular}




\begin{tabular}{|l|c|c|c|c|} 
Cloretos $\left(\mathrm{Cl}^{-}\right)$ & & $5,81 \mathrm{E}-04$ & $1,33 \mathrm{E}+00$ & $1,54 \mathrm{E}-01$ \\
\hline \multicolumn{3}{|c|}{ Resíduos sólidos $\mathbf{( k g})$} \\
\hline Resíduos não especificados & $1,90 \mathrm{E}-05$ & $1,28 \mathrm{E}-01$ & & $1,49 \mathrm{E}-02$ \\
\hline Resíduos sólidos oleosos & & $9,49 \mathrm{E}+00$ & & $1,10 \mathrm{E}+00$ \\
\hline
\end{tabular}




\section{APÊNDICE A8 - Inventário consolidado da produção de 243,6 kg de nafta}

\begin{tabular}{|c|c|c|c|c|}
\hline & $\begin{array}{l}2,29 \text { t de } \\
\text { petróleo } \\
\text { nacional e } \\
\text { importado }\end{array}$ & $\begin{array}{l}\text { Transporte } \\
\text { marítimo: } \\
3.874 \text { t.km }\end{array}$ & $\begin{array}{c}\text { Refino: } 2,29 \\
\text { toneladas }\end{array}$ & $\begin{array}{c}\text { Produção de } \\
243,6 \text { kg de } \\
\text { nafta (alocação } \\
\text { de } 11,63 \% \text { ) }\end{array}$ \\
\hline & Apêndice A1 & Apêndice A2 & Apêndice A3 & $\begin{array}{c}\text { Soma com } \\
\text { alocação }\end{array}$ \\
\hline \multicolumn{5}{|c|}{ Entradas } \\
\hline \multicolumn{5}{|c|}{ Recursos materiais (kg) } \\
\hline Petróleo refinado no Brasil & & & $2,29 \mathrm{E}+03$ & \\
\hline Petróleo & $2,50 \mathrm{E}+03$ & $3,14 \mathrm{E}+01$ & & $2,94 \mathrm{E}+02$ \\
\hline Carvão & 1,07E-01 & 1,24E-02 & & 1,39E-02 \\
\hline Gás Natural & $9,69 \mathrm{E}+01$ & 1,51E-01 & & $1,13 \mathrm{E}+01$ \\
\hline Combustíveis renováveis & $7,42 \mathrm{E}-01$ & & & $8,64 \mathrm{E}-02$ \\
\hline Água & $5,14 \mathrm{E}+02$ & $5,13 E-01$ & & $5,99 \mathrm{E}+01$ \\
\hline \multicolumn{5}{|c|}{ Recursos energéticos (GJ) } \\
\hline Energia Elétrica & & & $2,58 \mathrm{E}-01$ & $3,00 \mathrm{E}-02$ \\
\hline Energia não especificada & $7,42 E-04$ & 1,08E-02 & & 1,34E-03 \\
\hline \multicolumn{5}{|c|}{ Saídas } \\
\hline \multicolumn{5}{|c|}{ Emissões atmosféricas (kg) } \\
\hline $\mathrm{CO}_{2}$ & $3,72 \mathrm{E}+02$ & $9,04 \mathrm{E}+01$ & $1,90 \mathrm{E}+01$ & $5,60 \mathrm{E}+01$ \\
\hline $\mathrm{CO}$ & $7,38 \mathrm{E}-01$ & $2,71 \mathrm{E}-01$ & $6,03 \mathrm{E}-02$ & $1,25 \mathrm{E}-01$ \\
\hline Hidrocarbonetos & & $1,62 \mathrm{E}-01$ & $4,56 \mathrm{E}-05$ & $1,89 \mathrm{E}-02$ \\
\hline Vapor de água & $5,26 \mathrm{E}-01$ & & & $6,12 \mathrm{E}-02$ \\
\hline $\mathrm{CH}_{4}$ & $5,91 \mathrm{E}+00$ & & 8,69E-02 & $6,98 \mathrm{E}-01$ \\
\hline Metais & & $2,44 \mathrm{E}-06$ & & $2,84 \mathrm{E}-07$ \\
\hline $\mathrm{NOx}$ & & $1,71 \mathrm{E}+00$ & 1,34E-02 & $2,01 \mathrm{E}-01$ \\
\hline SOx & & $1,44 \mathrm{E}+00$ & $1,12 \mathrm{E}-02$ & $1,69 \mathrm{E}-01$ \\
\hline Metil mercarptana & & & $2,29 \mathrm{E}-05$ & $2,66 \mathrm{E}-06$ \\
\hline $\mathrm{H}_{2} \mathrm{~S}$ & & & $4,80 \mathrm{E}-04$ & 5,58E-05 \\
\hline COV - exceto metano & & $5,01 \mathrm{E}-03$ & $2,19 \mathrm{E}+00$ & $2,55 \mathrm{E}-01$ \\
\hline Material particulado & $2,77 \mathrm{E}-01$ & $8,30 \mathrm{E}-04$ & 2,32E-02 & $3,50 \mathrm{E}-02$ \\
\hline \multicolumn{5}{|c|}{ Efluentes líquidos (kg) } \\
\hline DBO & 7,65E-02 & $1,22 \mathrm{E}-05$ & & $8,91 \mathrm{E}-03$ \\
\hline DQO & $4,72 \mathrm{E}-01$ & $2,44 \mathrm{E}-05$ & & $5,49 \mathrm{E}-02$ \\
\hline Metais pesados não especificados & $1,06 \mathrm{E}-05$ & & & $1,24 \mathrm{E}-06$ \\
\hline Hidrocarbonetos & 4,44E-03 & 4,88E-05 & & $5,23 E-04$ \\
\hline Efluentes líquidos não especificados & 7,39E-05 & & & $8,60 \mathrm{E}-06$ \\
\hline Água residual & $7,16 \mathrm{E}-03$ & & & $8,33 \mathrm{E}-04$ \\
\hline Íons metálicos & & 1,22E-05 & & $1,42 \mathrm{E}-06$ \\
\hline Óleos e graxas & 1,89E-02 & $1,68 \mathrm{E}-04$ & 1,63E-02 & $4,12 \mathrm{E}-03$ \\
\hline Sólidos suspensos totais & $2,43 \mathrm{E}-01$ & & & $2,82 \mathrm{E}-02$ \\
\hline $\mathrm{Na}^{+}$ & & & 3,73E-02 & $4,34 \mathrm{E}-03$ \\
\hline
\end{tabular}




\section{APÊNDICE A9 - Inventários do subsistema de extração e beneficiamento de gás natural}

\begin{tabular}{|c|c|c|c|}
\hline & \begin{tabular}{|c|} 
924,92 kg de gás \\
natural \\
beneficiado (sem \\
alocação) \\
\end{tabular} & \begin{tabular}{|c|}
$924,92 \mathrm{~kg}$ de gás \\
natural \\
beneficiado com \\
alocação de $46,3 \%$
\end{tabular} & $\begin{array}{c}1,87 \text { toneladas de } \\
\text { gás natural } \\
\text { beneficiado com } \\
\text { alocação de } 46,3 \%\end{array}$ \\
\hline \multicolumn{4}{|c|}{ Entradas } \\
\hline \multicolumn{4}{|c|}{ Recursos materiais (kg) } \\
\hline Gás natural & $9,53 \mathrm{E}+02$ & $4,41 \mathrm{E}+02$ & $8,92 \mathrm{E}+02$ \\
\hline Água & $1,82 \mathrm{E}+01$ & $8,54 \mathrm{E}+00$ & $1,71 E+01$ \\
\hline \multicolumn{4}{|c|}{ Recursos energéticos (GJ) } \\
\hline Energia (gás natural) & $4,01 \mathrm{E}-03$ & $1,86 \mathrm{E}-03$ & 3,75E-03 \\
\hline \multicolumn{4}{|c|}{ Saídas } \\
\hline \multicolumn{4}{|c|}{ Emissões atmosféricas (kg) } \\
\hline $\mathrm{CO}_{2}$ & $7,73 \mathrm{E}+01$ & $3,58 \mathrm{E}+01$ & $7,24 \mathrm{E}+01$ \\
\hline $\mathrm{CO}$ & $2,61 \mathrm{E}-04$ & $1,21 \mathrm{E}-04$ & $2,44 \mathrm{E}-04$ \\
\hline Hidrocarbonetos & 1,69E-04 & 7,84E-05 & 1,59E-04 \\
\hline $\mathrm{CH}_{4}$ & $1,38 \mathrm{E}+00$ & $6,41 \mathrm{E}-01$ & $1,29 \mathrm{E}+00$ \\
\hline NOx & 2,47E-01 & $1,14 \mathrm{E}-01$ & $2,31 \mathrm{E}-01$ \\
\hline SOx & 8,92E-01 & $4,13 \mathrm{E}-01$ & $8,35 \mathrm{E}-01$ \\
\hline $\mathrm{H}_{2} \mathrm{~S}$ & $2,92 \mathrm{E}-07$ & 1,35E-07 & $2,73 \mathrm{E}-07$ \\
\hline Material particulado & 1,50E-02 & 6,96E-03 & 1,41E-02 \\
\hline \multicolumn{4}{|c|}{ Efluentes líquidos (kg) } \\
\hline Compostos de enxofre & 1,50E-04 & 6,96E-05 & 1,41E-04 \\
\hline Compostos de nitrogênio & $1,08 \mathrm{E}-06$ & 5,01E-07 & 1,01E-06 \\
\hline \multicolumn{4}{|c|}{ Resíduos sólidos (kg) } \\
\hline Enxofre & $1,86 \mathrm{E}-05$ & $8,63 E-06$ & $1,75 E-05$ \\
\hline \multicolumn{4}{|c|}{ Emissões não materiais (GJ) } \\
\hline Vapor & $1,00 \mathrm{E}-03$ & 4,64E-04 & 9,38E-04 \\
\hline
\end{tabular}




\section{APÊNDICE A10 - Inventário do subsistema de geração de energia térmica proveniente da combustão do gás natural}

\begin{tabular}{|c|c|c|}
\hline & $\begin{array}{c}\text { Geração de 15,33 GJ } \\
\text { de energia (sem } \\
\text { alocação) }\end{array}$ & $\begin{array}{c}\text { Geração de 15,33 GJ } \\
\text { de energia (com } \\
\text { alocação de } 46,3 \%) \\
\end{array}$ \\
\hline \multicolumn{3}{|c|}{ Entradas } \\
\hline \multicolumn{3}{|c|}{ Recursos materiais $(\mathbf{k g})$} \\
\hline Gás natural & $4,03 \mathrm{E}+02$ & $1,87 \mathrm{E}+02$ \\
\hline \multicolumn{3}{|c|}{ Saídas } \\
\hline \multicolumn{3}{|c|}{ Produto (GJ) } \\
\hline Energia térmica & $1,53 \mathrm{E}+01$ & $7,10 \mathrm{E}+0 \mathrm{C}$ \\
\hline \multicolumn{3}{|c|}{ Emissões atmosféricas $(\mathrm{kg})$} \\
\hline $\mathrm{CO}_{2}$ & $1,02 \mathrm{E}+03$ & $4,74 \mathrm{E}+02$ \\
\hline $\mathrm{CO}$ & $2,02 \mathrm{E}-02$ & $9,34 \mathrm{E}-03$ \\
\hline NOx & $2,78 \mathrm{E}+00$ & $1,29 \mathrm{E}+0 \mathrm{C}$ \\
\hline SOx & $3,63 \mathrm{E}-02$ & $1,68 \mathrm{E}-02$ \\
\hline
\end{tabular}




\section{APÊNDICE A11 - Inventário do subsistema de separação criogênica de $11,73 \mathrm{~kg}$ de ar}

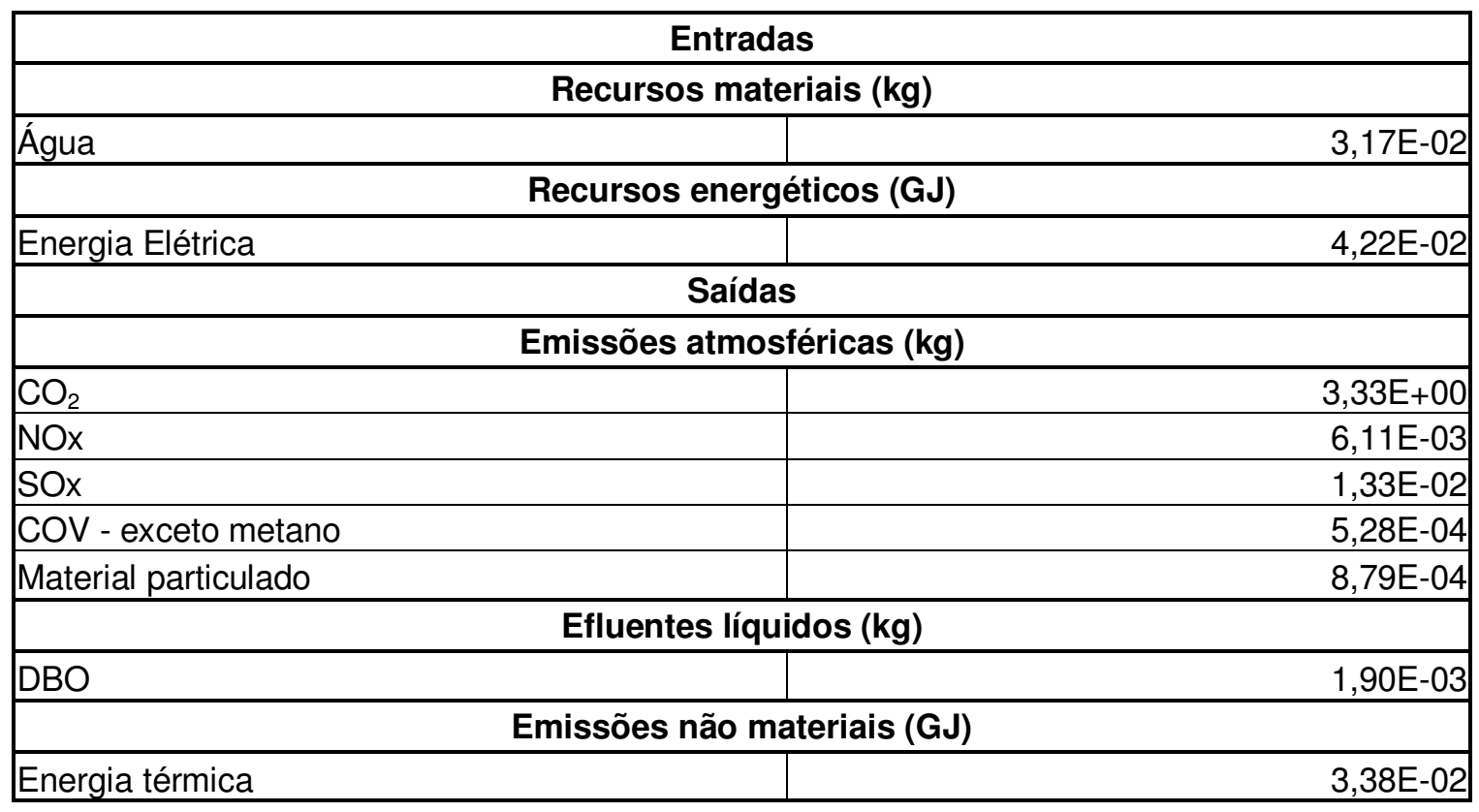




\section{APÊNDICE A12 - Inventários do subsistema da produção de amônia por reforma catalítica de gás natural}

\begin{tabular}{|c|c|c|c|}
\hline & $\begin{array}{l}\text { Produção de } 1,217 \\
\text { toneladas de } \mathrm{NH}_{3}\end{array}$ & \begin{tabular}{|c|} 
Produção de 1,217 \\
toneladas de $\mathrm{NH}_{3}$ com \\
alocação de $46,3 \%$
\end{tabular} & $\begin{array}{c}\text { Produção de } 2,456 \\
\text { toneladas de } \mathrm{NH}_{3} \\
\text { com alocação de } \\
46,3 \%\end{array}$ \\
\hline \multicolumn{4}{|c|}{ Entradas } \\
\hline \multicolumn{4}{|c|}{ Recursos materiais (kg) } \\
\hline Gás natural & $6,01 \mathrm{E}+02$ & $2,78 \mathrm{E}+02$ & $5,61 \mathrm{E}+02$ \\
\hline Água & $1,56 \mathrm{E}+01$ & $7,24 \mathrm{E}+00$ & $1,46 \mathrm{E}+01$ \\
\hline Ar & $6,46 \mathrm{E}+00$ & $2,99 \mathrm{E}+00$ & $6,04 \mathrm{E}+00$ \\
\hline \multicolumn{4}{|c|}{ Recursos energéticos (GJ) } \\
\hline Energia Elétrica & $1,35 \mathrm{E}+00$ & $6,26 \mathrm{E}-01$ & $1,26 \mathrm{E}+00$ \\
\hline \multicolumn{4}{|c|}{ Saídas } \\
\hline \multicolumn{4}{|c|}{ Emissões atmosféricas (kg) } \\
\hline $\mathrm{CO}$ & 1,02E-01 & 4,72E-02 & $9,53 \mathrm{E}-02$ \\
\hline $\mathrm{CH}_{4}$ & $2,00 \mathrm{E}-02$ & $9,28 \mathrm{E}-03$ & 1,87E-02 \\
\hline NOx & $1,22 \mathrm{E}+00$ & $5,60 \mathrm{E}-01$ & $1,13 E+00$ \\
\hline SOx & 1,22E-02 & $5,60 \mathrm{E}-03$ & $1,13 \mathrm{E}-02$ \\
\hline Material particulado & 6,07E-01 & $2,81 \mathrm{E}-01$ & 5,67E-01 \\
\hline \multicolumn{4}{|c|}{ Efluentes líquidos (kg) } \\
\hline Compostos de nitrogênio & 1,22E-01 & 5,60E-02 & $1,13 \mathrm{E}-01$ \\
\hline \multicolumn{4}{|c|}{ Resíduos sólidos (kg) } \\
\hline Catalisador usado & $2,43 \mathrm{E}-01$ & $1,13 \mathrm{E}-01$ & $2,28 \mathrm{E}-01$ \\
\hline \multicolumn{4}{|c|}{ Emissões não materiais (GJ) } \\
\hline Vapor & $2,80 \mathrm{E}+00$ & $1,30 \mathrm{E}+00$ & $2,62 \mathrm{E}+00$ \\
\hline
\end{tabular}




\section{APÊNDICE A13 - Inventário do subsistema da produção de 1,217 toneladas de amônia por oxidação parcial de resíduo asfáltico}

\begin{tabular}{|c|c|}
\hline \multicolumn{2}{|c|}{ Entradas } \\
\hline \multicolumn{2}{|c|}{ Recursos materiais (kg) } \\
\hline Água & $1,56 \mathrm{E}+01$ \\
\hline $\mathrm{Ar}$ & $1,17 \mathrm{E}+01$ \\
\hline \multicolumn{2}{|c|}{ Recursos energéticos (GJ) } \\
\hline Energia Elétrica & $1,54 \mathrm{E}+00$ \\
\hline Energia (vapor) & $7,64 \mathrm{E}+00$ \\
\hline \multicolumn{2}{|c|}{ Saídas } \\
\hline \multicolumn{2}{|c|}{ Emissões atmosféricas (kg) } \\
\hline $\mathrm{CO}$ & $2,71 \mathrm{E}-01$ \\
\hline $\mathrm{CH}_{4}$ & $3,01 \mathrm{E}-02$ \\
\hline NOx & $1,46 \mathrm{E}+00$ \\
\hline SOx & $3,01 \mathrm{E}-02$ \\
\hline $\mathrm{H}_{2} \mathrm{~S}$ & 1,70E-03 \\
\hline Material particulado & 5,69E-01 \\
\hline \multicolumn{2}{|c|}{ Efluentes líquidos (kg) } \\
\hline Compostos de nitrogênio & 1,22E-01 \\
\hline \multicolumn{2}{|c|}{ Resíduos sólidos $(\mathrm{kg})$} \\
\hline Catalisador usado & $2,43 \mathrm{E}-01$ \\
\hline
\end{tabular}




\section{APÊNDICE A14 - Inventário do subsistema da produção de 1,217 toneladas de amônia, por reforma catalítica de gás de refinaria, com fator de alocação de $46,3 \%$}

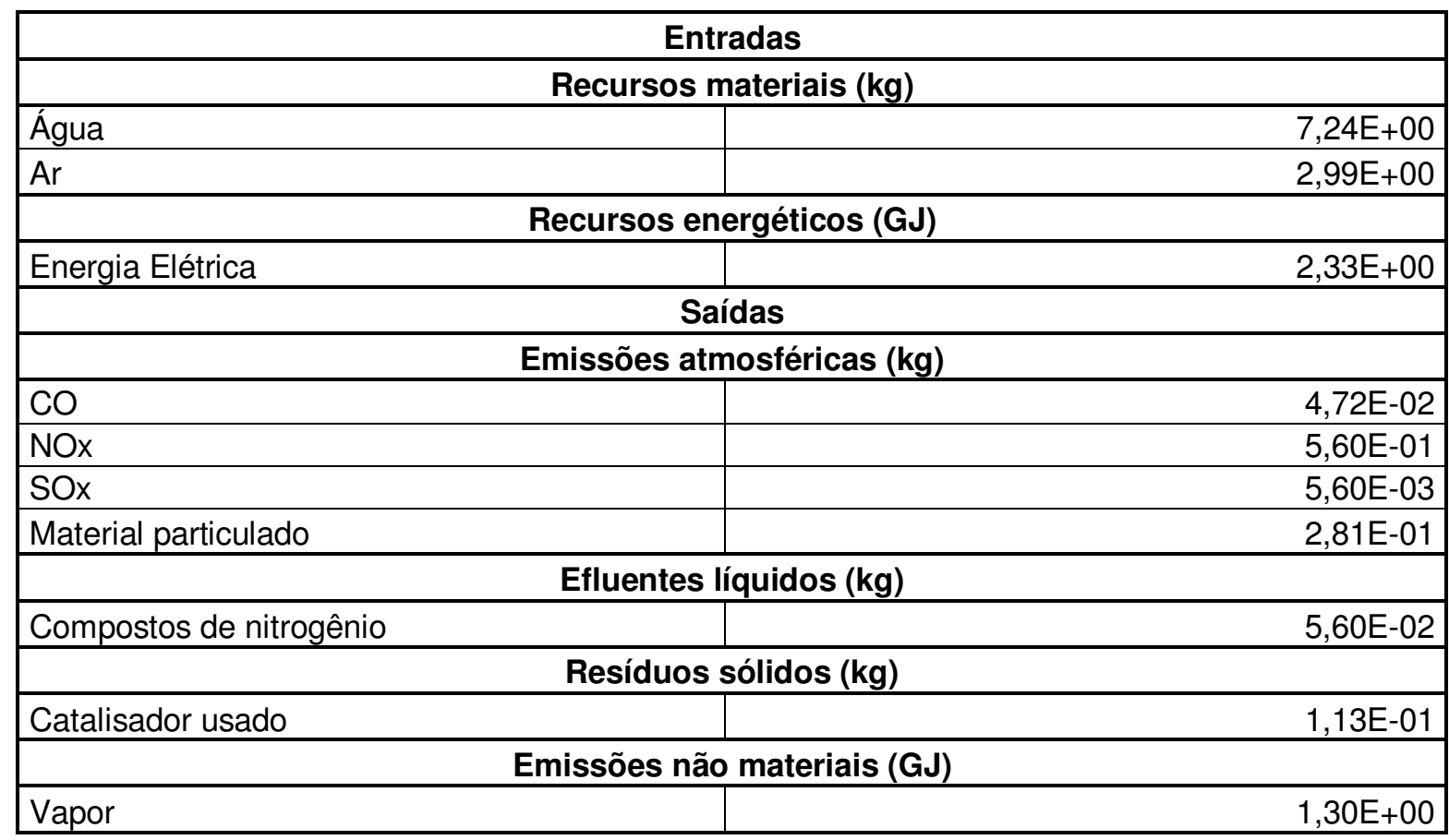




\section{APÊNDICE A15 - Inventário do subsistema da produção de 2,17 toneladas de uréia}

\begin{tabular}{|c|c|}
\hline \multicolumn{2}{|c|}{ Entradas } \\
\hline \multicolumn{2}{|c|}{ Recursos materiais (kg) } \\
\hline Água & $1,65 E+01$ \\
\hline \multicolumn{2}{|c|}{ Recursos energéticos (GJ) } \\
\hline Energia Elétrica & $1,17 \mathrm{E}+00$ \\
\hline Energia (vapor) & $7,60 \mathrm{E}+00$ \\
\hline \multicolumn{2}{|c|}{ Saídas } \\
\hline \multicolumn{2}{|c|}{ Emissões atmosféricas (kg) } \\
\hline $\mathrm{CO}_{2}$ & $3,61 \mathrm{E}+01$ \\
\hline $\mathrm{CO}$ & $1,08 \mathrm{E}-03$ \\
\hline NOx & $1,01 \mathrm{E}-01$ \\
\hline Material particulado & $2,05 E+00$ \\
\hline \multicolumn{2}{|c|}{ Efluentes líquidos (kg) } \\
\hline Compostos de nitrogênio & $3,65 \mathrm{E}-01$ \\
\hline
\end{tabular}




\section{APÊNDICE A16 - Inventário do subsistema da produção de 2,25 toneladas de ácido nítrico}

\begin{tabular}{|c|c|}
\hline \multicolumn{2}{|c|}{ Entradas } \\
\hline \multicolumn{2}{|c|}{ Recursos materiais (kg) } \\
\hline $\mathrm{Ar}$ & $3,38 \mathrm{E}+03$ \\
\hline Água & $1,40 E+02$ \\
\hline \multicolumn{2}{|c|}{ Recursos energéticos (GJ) } \\
\hline Energia Elétrica & $4,01 E+00$ \\
\hline \multicolumn{2}{|c|}{ Saídas } \\
\hline \multicolumn{2}{|c|}{ Emissões atmosféricas (kg) } \\
\hline $\mathrm{NH}_{3}$ & $5,63 E+00$ \\
\hline $\mathrm{N}_{2} \mathrm{O}$ & $1,89 \mathrm{E}+01$ \\
\hline NOx & $1,06 \mathrm{E}+01$ \\
\hline Material particulado & $4,50 \mathrm{E}-01$ \\
\hline \multicolumn{2}{|c|}{ Efluentes líquidos (kg) } \\
\hline DBO & $3,15 E+00$ \\
\hline Compostos de nitrogênio & 2,92E-01 \\
\hline \multicolumn{2}{|c|}{ Resíduos sólidos (kg) } \\
\hline Catalisador usado & $8,10 \mathrm{E}-05$ \\
\hline \multicolumn{2}{|c|}{ Emissões não materiais (GJ) } \\
\hline Vapor & $5,06 \mathrm{E}-03$ \\
\hline
\end{tabular}




\section{APÊNDICE A17 - Inventário do subsistema da produção de 2,941 toneladas de nitrato de amônio}

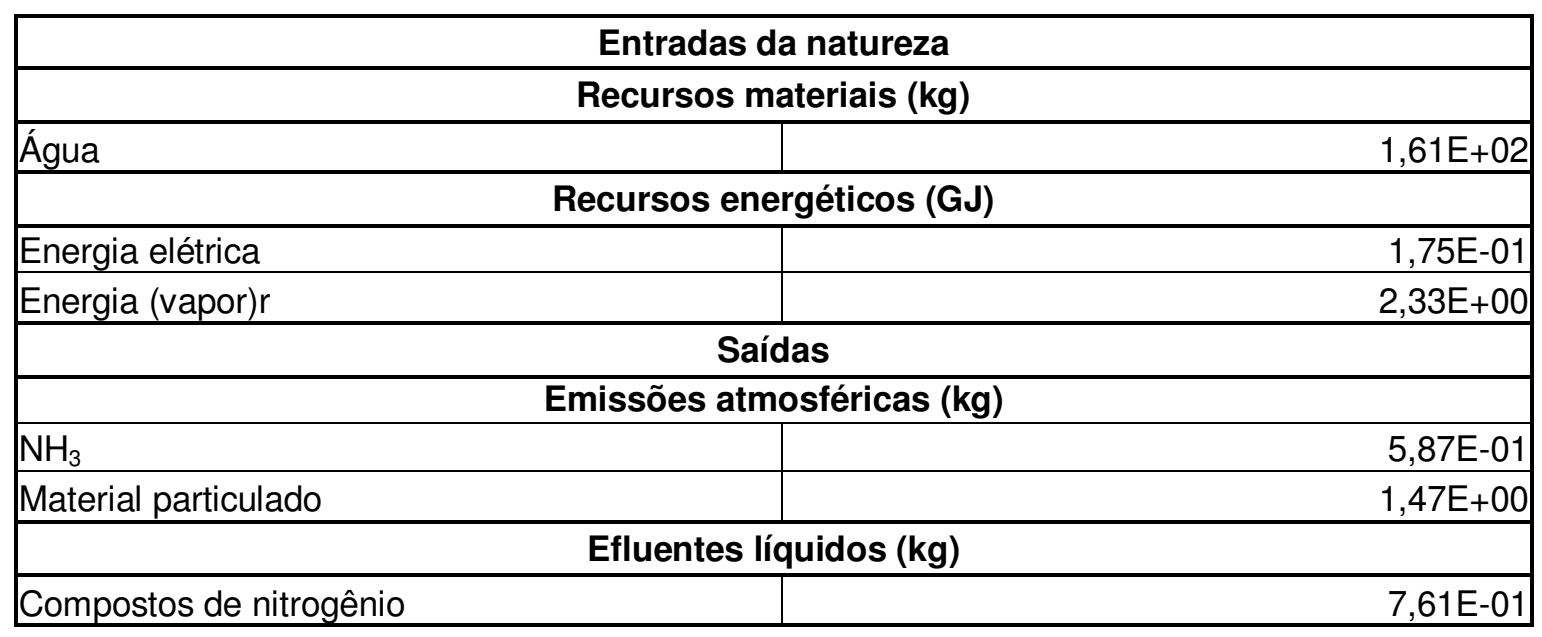




\section{APÊNDICE A18 - Inventário do subsistema da produções de} $840 \mathrm{~kg}$ e 3,5 toneladas de ácido sulfúrico

\begin{tabular}{|c|c|c|}
\hline & 840 kg de ácido sulfúrico & $\begin{array}{c}3,5 \text { toneladas de ácido } \\
\text { sulfúrico }\end{array}$ \\
\hline \multicolumn{3}{|c|}{ Entradas } \\
\hline \multicolumn{3}{|c|}{ Recursos materiais $(\mathbf{k g})$} \\
\hline Enxofre & $2,77 \mathrm{E}+02$ & $1,16 \mathrm{E}+03$ \\
\hline Água & $1,22 \mathrm{E}+03$ & $5,08 \mathrm{E}+03$ \\
\hline Ar & $4,12 \mathrm{E}+00$ & $1,72 \mathrm{E}+01$ \\
\hline \multicolumn{3}{|c|}{ Saídas } \\
\hline \multicolumn{3}{|c|}{ Emissões atmosféricas (kg) } \\
\hline SOx & $2,23 \mathrm{E}+00$ & $9,30 \mathrm{E}+00$ \\
\hline \multicolumn{3}{|c|}{ Resíduos sólidos (kg) } \\
\hline Enxofre & $6,38 \mathrm{E}+00$ & $2,66 \mathrm{E}+01$ \\
\hline Catalisador usado & $4,88 \mathrm{E}+01$ & $2,03 \mathrm{E}+02$ \\
\hline
\end{tabular}




\section{APÊNDICE A19 - Inventário do subsistema da produção de 4,717 toneladas de sulfato de amônio via síntese}

\begin{tabular}{|l|r|}
\hline \multicolumn{2}{|c|}{ Entradas } \\
\hline \multicolumn{2}{|c|}{ Recursos energéticos (GJ) } \\
\hline Energia elétrica & \\
\hline \multicolumn{2}{|c|}{ Saídas } \\
\hline & $2,78 \mathrm{E}+00$ \\
\hline Material particulado & \\
\hline
\end{tabular}




\section{APÊNDICE A20 - Inventário do subsistema das produções de $68,86 \mathrm{~kg}$ e 6,66 toneladas de benzeno}

\begin{tabular}{|c|c|c|}
\hline & $68,86 \mathrm{~kg}$ de benzeno & 6,66 toneladas de benzeno \\
\hline \multicolumn{3}{|c|}{ Entradas de outros subsistemas (kg) } \\
\hline Nafta & $1,22 \mathrm{E}+02$ & $11,78 \mathrm{E}+03$ \\
\hline \multicolumn{3}{|c|}{ Saídas } \\
\hline \multicolumn{3}{|c|}{ Emissões atmosféricas (kg) } \\
\hline $\mathrm{CO}_{2}$ & $1,69 \mathrm{E}+02$ & $1,64 \mathrm{E}+04$ \\
\hline $\mathrm{CO}$ & 5,01E-02 & $4,85 E+00$ \\
\hline Hidrocarbonetos & $1,44 \mathrm{E}-01$ & $1,39 \mathrm{E}+01$ \\
\hline NOx & $1,81 \mathrm{E}-01$ & $1,75 E+01$ \\
\hline SOx & $2,38 \mathrm{E}-02$ & $2,30 \mathrm{E}+00$ \\
\hline Material particulado & $2,75 E-03$ & 2,66E-01 \\
\hline $\mathrm{H}_{2}$ & 6,89E-04 & $6,66 \mathrm{E}-02$ \\
\hline \multicolumn{3}{|c|}{ Efluentes líquidos (kg) } \\
\hline DQO & $3,66 \mathrm{E}-03$ & $3,54 \mathrm{E}-01$ \\
\hline Hidrocarbonetos & $6,89 \mathrm{E}-04$ & $6,66 \mathrm{E}-02$ \\
\hline Compostos de enxofre & $8,24 \mathrm{E}-03$ & 7,97E-01 \\
\hline $\mathrm{Na}^{+}$ & $2,84 \mathrm{E}-02$ & $2,75 E+00$ \\
\hline
\end{tabular}




\section{APÊNDICE A21 - Inventário do subsistema da produção de 5,936 toneladas de ciclohexano}

\begin{tabular}{|c|c|}
\hline \multicolumn{2}{|c|}{ Entradas de outros subsistemas (kg) } \\
\hline Benzeno & $6,66 \mathrm{E}+03$ \\
\hline \multicolumn{2}{|c|}{ Saídas } \\
\hline \multicolumn{2}{|c|}{ Emissões atmosféricas (kg) } \\
\hline $\mathrm{CO}_{2}$ & $2,54 \mathrm{E}+03$ \\
\hline $\mathrm{CO}$ & 6,53E-01 \\
\hline Hidrocarbonetos & 4,16E-01 \\
\hline $\mathrm{NOx}$ & $2,43 E+00$ \\
\hline COV - exceto metano & 9,50E-01 \\
\hline $\mathrm{H}_{2}$ & 2,37E-01 \\
\hline
\end{tabular}




\section{APÊNDICE A22 - Inventário do subsistema das produções de $91,58 \mathrm{~kg}$ e 4,359 toneladas de propeno}

\begin{tabular}{|c|c|c|}
\hline & $91,58 \mathrm{~kg}$ de propeno & 4,359 toneladas de propeno \\
\hline \multicolumn{3}{|c|}{ Entradas de outros subsistemas (kg) } \\
\hline Nafta & $1,22 \mathrm{E}$ & $5,80 \mathrm{E}+03$ \\
\hline \multicolumn{3}{|c|}{ Saídas } \\
\hline \multicolumn{3}{|c|}{ Emissões atmosféricas (kg) } \\
\hline $\mathrm{CO}_{2}$ & $9,66 \mathrm{E}$ & $4,60 \mathrm{E}+03$ \\
\hline $\mathrm{CO}$ & $4,95 \mathrm{E}$ & $2,35 \mathrm{E}+00$ \\
\hline Hidrocarbonetos & 1,291 & $6,15 \mathrm{E}+00$ \\
\hline NOx & 1,84 & $8,76 \mathrm{E}+00$ \\
\hline SOx & $1,83 !$ & $8,72 \mathrm{E}-01$ \\
\hline Material particulado & 2,75 & $1,31 \mathrm{E}-01$ \\
\hline \multicolumn{3}{|c|}{ Efluentes líquidos (kg) } \\
\hline $\mathrm{DQO}$ & 3,66 & $1,74 \mathrm{E}-01$ \\
\hline Compostos de enxofre & $8,24 \mathrm{l}$ & $3,92 \mathrm{E}-01$ \\
\hline $\mathrm{Na}^{+}$ & $2,84 \mathrm{t}$ & $1,35 \mathrm{E}+00$ \\
\hline
\end{tabular}




\section{APÊNDICE A23 - Inventário do subsistema da produção de 2,62 toneladas de caprolactama e 4,717 toneladas de sulfato de amônio}

\begin{tabular}{|c|c|}
\hline \multicolumn{2}{|c|}{ Entradas } \\
\hline \multicolumn{2}{|c|}{ Recursos energéticos (GJ) } \\
\hline Energia elétrica & $2,22 E+01$ \\
\hline \multicolumn{2}{|c|}{ Saídas } \\
\hline \multicolumn{2}{|c|}{ Emissões atmosféricas (kg) } \\
\hline $\mathrm{CO}_{2}$ & $1,17 \mathrm{E}+04$ \\
\hline Hidrocarbonetos & $2,72 \mathrm{E}+00$ \\
\hline $\mathrm{NH}_{3}$ & $5,50 \mathrm{E}-01$ \\
\hline NOx & $9,69 \mathrm{E}+00$ \\
\hline SOx & $2,62 \mathrm{E}-01$ \\
\hline
\end{tabular}




\section{APÊNDICE A24 - Inventário do subsistema da produção de 3,232 toneladas de ácido cianídrico}

\begin{tabular}{|c|c|}
\hline \multicolumn{2}{|c|}{ Entradas } \\
\hline \multicolumn{2}{|c|}{ Recursos materiais $(\mathbf{k g})$} \\
\hline Gás Natural & $2,20 \mathrm{E}+03$ \\
\hline \multicolumn{2}{|c|}{ Recursos energéticos (GJ) } \\
\hline Energia Elétrica & $1,27 \mathrm{E}+00$ \\
\hline \multicolumn{2}{|c|}{ Saídas } \\
\hline \multicolumn{2}{|c|}{ Emissões atmosféricas (kg) } \\
\hline $\mathrm{CO}_{2}$ & $7,99 \mathrm{E}+03$ \\
\hline $\mathrm{CO}$ & $3,49 \mathrm{E}+00$ \\
\hline Hidrocarbonetos & $2,07 \mathrm{E}-03$ \\
\hline $\mathrm{CH}_{4}$ & $3,17 \mathrm{E}+00$ \\
\hline $\mathrm{NH}_{3}$ & $3,13 \mathrm{E}-01$ \\
\hline $\mathrm{N}_{2} \mathrm{O}$ & $7,72 \mathrm{E}-04$ \\
\hline NOx & $3,01 \mathrm{E}+01$ \\
\hline SOx & $6,08 \mathrm{E}+01$ \\
\hline Cianetos $(\mathrm{CN})$ & $1,55 \mathrm{E}-01$ \\
\hline COV - exceto metano & $6,24 \mathrm{E}+00$ \\
\hline Material particulado & $3,26 \mathrm{E}+00$ \\
\hline \multicolumn{2}{|c|}{ Efluentes líquidos (kg) } \\
\hline DBO & $1,98 \mathrm{E}-01$ \\
\hline $\mathrm{DQO}$ & $6,33 \mathrm{E}-01$ \\
\hline Metais pesados não especificados & $6,57 \mathrm{E}-03$ \\
\hline Hidrocarbonetos & $1,45 \mathrm{E}-01$ \\
\hline Ácidos como H ${ }^{+}$ & $3,81 \mathrm{E}-01$ \\
\hline Íons metálicos & $2,44 \mathrm{E}-02$ \\
\hline Óleo não especificado & $7,76 \mathrm{E}-02$ \\
\hline Sólidos dissolvidos totais & $2,07 \mathrm{E}+00$ \\
\hline Sólidos suspensos totais & $3,52 \mathrm{E}+00$ \\
\hline Compostos de enxofre & $7,85 \mathrm{E}+00$ \\
\hline Compostos de nitrogênio & $1,84 \mathrm{E}+00$ \\
\hline $\mathrm{Na}^{+}$ & $4,30 \mathrm{E}+00$ \\
\hline Cloretos $\left(\mathrm{Cl}^{-}\right)$ & $1,51 \mathrm{E}+01$ \\
\hline
\end{tabular}


APÊNDICE A25 - Inventário do subsistema da produção de 29,48 toneladas de acrilonitrila e 4,717 toneladas de sulfato de amônio

\begin{tabular}{|l|r|}
\hline \multicolumn{2}{|c|}{ Entradas } \\
\hline \multicolumn{2}{|c|}{ Recursos energéticos (GJ) } \\
\hline Energia Elétrica & \multicolumn{2}{c|}{ Saídas } \\
\hline \multicolumn{2}{|c|}{ Emissões atmosféricas (kg) } \\
\hline \multicolumn{2}{|c|}{} \\
\hline $\mathrm{CO}_{2}$ & $5,01 \mathrm{E}+01$ \\
\hline $\mathrm{CO}$ & $3,30 \mathrm{E}+01$ \\
\hline $\mathrm{Hidrocarbonetos}$ & $5,92 \mathrm{E}+01$ \\
\hline $\mathrm{NH}_{3}$ & $6,13 \mathrm{E}+00$ \\
\hline $\mathrm{NOx}$ & $5,07 \mathrm{E}+01$ \\
\hline $\mathrm{SOx}$ & $8,84 \mathrm{E}-01$ \\
\hline
\end{tabular}




\section{APÊNDICE A26 - Inventário do subsistema da produção de 1,57 toneladas de MMA e 4,717 toneladas de sulfato de amônio}

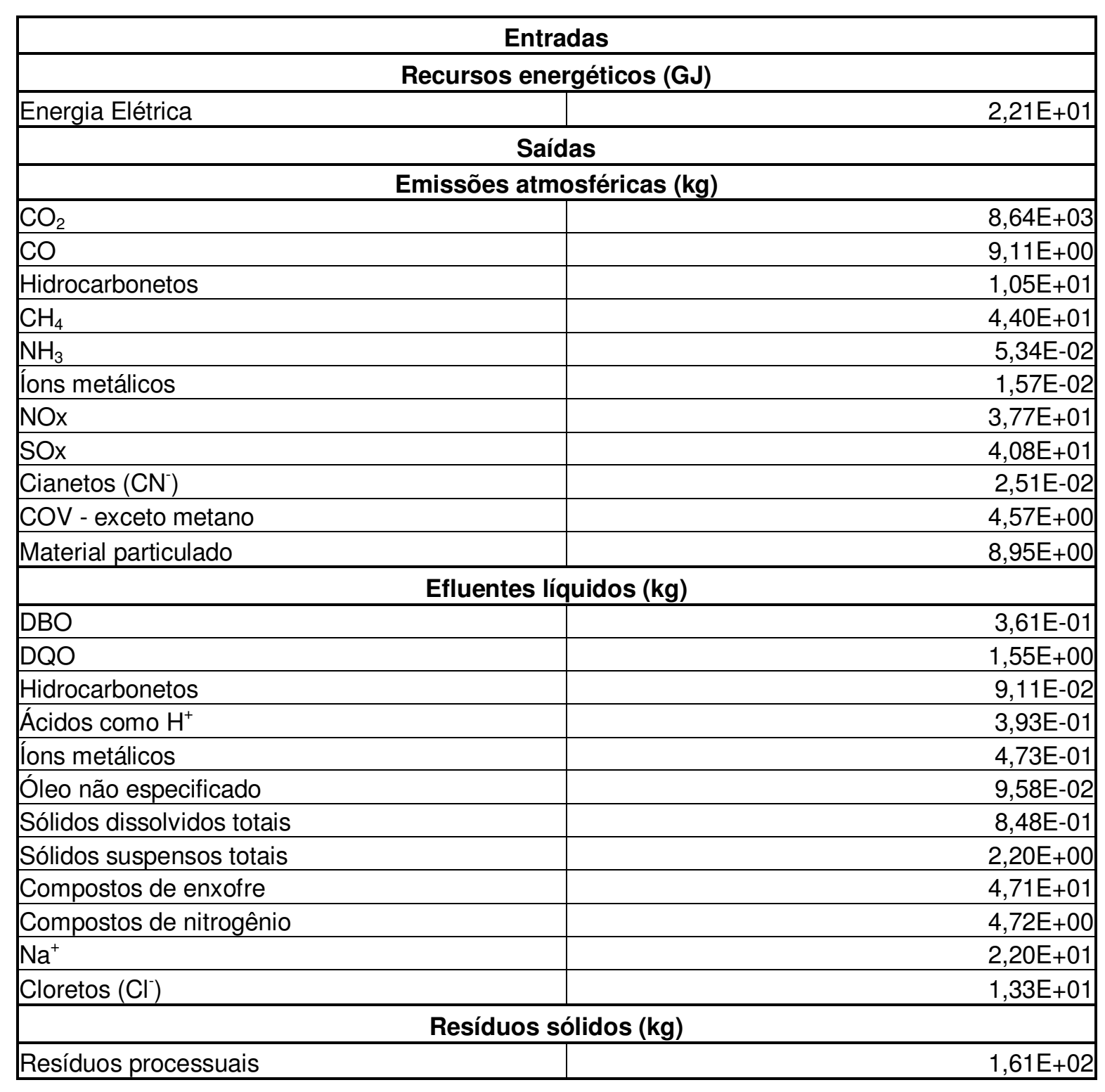




\section{APÊNDICE B1 - Inventário consolidado da uréia produzida pela Petrobras/Fafen}

\begin{tabular}{|c|c|c|c|c|c|c|}
\hline & Apêndice A9 & Apêndice A10 & Apêndice A12 & Apêndice A15 & $\begin{array}{c}\text { Tabela } 35 \\
\text { para 2,52 GJ }\end{array}$ & Soma \\
\hline & $\begin{array}{c}\text { Beneficiamento } \\
\text { de } 924,92 \mathrm{~kg} \text { de } \\
\text { gás natural }\end{array}$ & $\begin{array}{c}\text { Energia } \\
\text { térmica prov. } \\
\text { da queima do } \\
\text { gás natural: } \\
15,33 \text { GJ }\end{array}$ & $\begin{array}{c}\text { Produção de } \\
1,217 \text { t de } \\
\text { amônia via } \\
\text { reforma } \\
\text { catalítica }\end{array}$ & $\begin{array}{l}\text { Produção de } \\
2,17 \text { t de uréia }\end{array}$ & $\begin{array}{c}\text { Eletricidade: } \\
2,52 \mathrm{GJ}\end{array}$ & $\begin{array}{c}\text { Uréia } \\
\text { Fafen (por } \\
\text { t de } N \text { ou } \\
2,17 t \text { de } \\
\text { uréia) }\end{array}$ \\
\hline \multicolumn{7}{|c|}{ Entradas } \\
\hline \multicolumn{7}{|c|}{ Recursos materiais (kg) } \\
\hline Petróleo & & & & & $3,05 \mathrm{E}+00$ & $3,05 E+00$ \\
\hline Carvão & & & & & $3,24 \mathrm{E}+01$ & $3,24 \mathrm{E}+01$ \\
\hline Gás Natural & $9,53 \mathrm{E}+02$ & $4,03 \mathrm{E}+02$ & $6,01 \mathrm{E}+02$ & & $1,92 \mathrm{E}+00$ & $1,01 E+03$ \\
\hline Água & $1,82 \mathrm{E}+01$ & & $1,56 \mathrm{E}+01$ & $1,65 \mathrm{E}+01$ & $2,93 E+05$ & $2,93 E+05$ \\
\hline $\mathrm{Ar}$ & & & $6,46 \mathrm{E}+00$ & & & $6,46 \mathrm{E}+00$ \\
\hline \multicolumn{7}{|c|}{ Recursos energéticos (GJ) } \\
\hline Energia Elétrica & & & $1,35 \mathrm{E}+00$ & $1,17 \mathrm{E}+00$ & & $2,52 \mathrm{E}+00$ \\
\hline Energia (vapor) & & & & $7,60 \mathrm{E}+00$ & & $7,60 \mathrm{E}+00$ \\
\hline Energia não especificada & & & & & $3,99 \mathrm{E}+00$ & $3,99 \mathrm{E}+00$ \\
\hline Energia (gás natural) & $4,01 \mathrm{E}-03$ & $1,53 \mathrm{E}+01$ & & & & $1,53 E+01$ \\
\hline \multicolumn{7}{|c|}{ Saídas } \\
\hline \multicolumn{7}{|c|}{ Emissões atmosféricas (kg) } \\
\hline $\mathrm{CO}_{2}$ & $7,73 \mathrm{E}+01$ & $1,02 \mathrm{E}+03$ & & $3,61 \mathrm{E}+01$ & $4,49 \mathrm{E}+01$ & $1,18 \mathrm{E}+03$ \\
\hline $\mathrm{CO}$ & $2,61 \mathrm{E}-04$ & 2,02E-02 & 1,02E-01 & 1,08E-03 & $3,76 \mathrm{E}-01$ & $5,00 \mathrm{E}-01$ \\
\hline Hidrocarbonetos & 1,69E-04 & & & & 1,89E-03 & $2,06 \mathrm{E}-03$ \\
\hline Vapor de água & & & & & $5,80 \mathrm{E}-01$ & $5,80 \mathrm{E}-01$ \\
\hline $\mathrm{CH}_{4}$ & $1,38 \mathrm{E}+00$ & & $2,00 \mathrm{E}-02$ & & $1,38 \mathrm{E}-01$ & $1,54 \mathrm{E}+00$ \\
\hline $\mathrm{NH}_{3}$ & & & & & $1,51 \mathrm{E}-08$ & 1,51E-08 \\
\hline Metais & & & & & 2,52E-08 & 2,52E-08 \\
\hline $\mathrm{N}_{2} \mathrm{O}$ & & & & & 2,77E-02 & 2,77E-02 \\
\hline NOx & 2,47E-01 & $2,78 \mathrm{E}+00$ & $1,22 \mathrm{E}+00$ & $1,01 \mathrm{E}-01$ & $1,45 \mathrm{E}+00$ & $5,80 \mathrm{E}+00$ \\
\hline SOx & 8,92E-01 & 3,63E-02 & $1,22 \mathrm{E}-02$ & & 2,93E-01 & $1,23 E+00$ \\
\hline $\mathrm{H}_{2} \mathrm{~S}$ & 2,92E-07 & & & & & 2,92E-07 \\
\hline COV - exceto metano & & & & & $1,83 \mathrm{E}-02$ & 1,83E-02 \\
\hline Material particulado & $1,50 \mathrm{E}-02$ & & $6,07 \mathrm{E}-01$ & $2,05 \mathrm{E}+00$ & $1,69 \mathrm{E}-01$ & $2,84 \mathrm{E}+00$ \\
\hline \multicolumn{7}{|c|}{ Efluentes líquidos (kg) } \\
\hline DBO & & & & & $1,76 \mathrm{E}-04$ & $1,76 \mathrm{E}-04$ \\
\hline DQO & & & & & $3,28 \mathrm{E}-04$ & 3,28E-04 \\
\hline Metais pesados não especificados & & & & & 4,54E-07 & 4,54E-07 \\
\hline Hidrocarbonetos & & & & & $7,56 \mathrm{E}-05$ & 7,56E-05 \\
\hline Ácidos como $\mathrm{H}^{+}$ & & & & & $4,28 \mathrm{E}-07$ & 4,28E-07 \\
\hline Íons metálicos & & & & & 2,52E-05 & 2,52E-05 \\
\hline Óleos e graxas & & & & & 3,53E-04 & 3,53E-04 \\
\hline
\end{tabular}




\begin{tabular}{|c|c|c|c|c|c|}
\hline Sólidos dissolvidos totais & & & & $1,26 \mathrm{E}-04$ & 1,26E-04 \\
\hline Sólidos suspensos totais & & & & 2,52E-04 & 2,52E-04 \\
\hline Compostos de enxofre & $1,50 \mathrm{E}-04$ & & & $1,13 \mathrm{E}-06$ & 1,52E-04 \\
\hline Compostos de nitrogênio & $1,08 \mathrm{E}-06$ & $1,22 \mathrm{E}-01$ & $3,65 \mathrm{E}-01$ & $1,13 \mathrm{E}-05$ & 4,86E-01 \\
\hline Cloretos $\left(\mathrm{Cl}^{-}\right)$ & & & & $1,51 \mathrm{E}-07$ & 1,51E-07 \\
\hline \multicolumn{6}{|c|}{ Resíduos sólidos (kg) } \\
\hline $\begin{array}{l}\text { Resíduos processuais não } \\
\text { especificados }\end{array}$ & & & & $2,70 \mathrm{E}+01$ & $2,70 \mathrm{E}+01$ \\
\hline Enxofre & $1,86 \mathrm{E}-05$ & & & & 1,86E-05 \\
\hline Catalisador usado & & 2,43E-01 & & & 2,43E-01 \\
\hline \multicolumn{6}{|c|}{ Emissões energéticas (GJ) } \\
\hline Vapor & $1,00 \mathrm{E}-03$ & $2,80 E+00$ & & & $2,80 \mathrm{E}+00$ \\
\hline
\end{tabular}




\section{APÊNDICE B2 - Inventário consolidado da uréia produzida pela Fosfertil}

\begin{tabular}{|c|c|c|c|c|c|c|}
\hline & Apêndice A5 & Apêndice A11 & Apêndice A13 & Apêndice A15 & $\begin{array}{c}\text { Tabela 35 } \\
\text { para } 2,88 \text { GJ }\end{array}$ & Soma \\
\hline & $\begin{array}{l}\text { Produção de } \\
1083 \text { kg de } \\
\text { resíduo } \\
\text { asfáltico } \\
\text { (alocação de } \\
2,82 \% \text { ) }\end{array}$ & $\begin{array}{l}\text { Separação de } \\
11,73 \mathrm{~kg} \text { de ar }\end{array}$ & $\begin{array}{c}\text { Produção de } \\
1,217 \text { t de } \\
\text { amônia via } \\
\text { oxidação } \\
\text { parcial }\end{array}$ & $\begin{array}{l}\text { Produção de } \\
2,17 \mathrm{t} \text { de uréia }\end{array}$ & $\begin{array}{l}\text { Eletricidade: } \\
2,88 \mathrm{GJ}\end{array}$ & $\begin{array}{c}\text { Uréia } \\
\text { Fosfertil } \\
\text { (por } t \text { de } \\
\mathrm{N} \text { ou } \\
2,17 \mathrm{t} \text { de } \\
\text { uréia) }\end{array}$ \\
\hline \multicolumn{7}{|c|}{ Entradas } \\
\hline \multicolumn{7}{|c|}{ Recursos materiais $(\mathbf{k g})$} \\
\hline Petróleo & $1,27 \mathrm{E}+03$ & & & & $3,48 \mathrm{E}+00$ & $1,27 E+03$ \\
\hline Carvão & $5,99 \mathrm{E}-02$ & & & & $3,70 \mathrm{E}+01$ & $3,70 \mathrm{E}+01$ \\
\hline Gás Natural & $4,87 \mathrm{E}+01$ & & & & $2,19 \mathrm{E}+00$ & $5,09 E+01$ \\
\hline Combustíveis renováveis & $3,72 \mathrm{E}-01$ & & & & & 3,72E-01 \\
\hline Água & $2,58 \mathrm{E}+02$ & $3,17 \mathrm{E}-02$ & $1,56 \mathrm{E}+01$ & $1,65 \mathrm{E}+01$ & $3,35 \mathrm{E}+05$ & $3,35 \mathrm{E}+05$ \\
\hline $\mathrm{Ar}$ & & & $1,17 \mathrm{E}+01$ & & & $1,17 \mathrm{E}+01$ \\
\hline \multicolumn{7}{|c|}{ Recursos energéticos (GJ) } \\
\hline Energia Elétrica & $1,29 \mathrm{E}-01$ & 4,22E-02 & $1,54 \mathrm{E}+00$ & $1,17 \mathrm{E}+00$ & & $2,88 \mathrm{E}+00$ \\
\hline Energia (vapor) & & & $7,64 \mathrm{E}+00$ & $7,60 \mathrm{E}+00$ & & $1,52 \mathrm{E}+01$ \\
\hline Energia não especificada & $5,77 \mathrm{E}-03$ & & & & $4,56 \mathrm{E}+00$ & $4,57 \mathrm{E}+00$ \\
\hline \multicolumn{7}{|c|}{ Saídas } \\
\hline \multicolumn{7}{|c|}{ Emissões atmosféricas (kg) } \\
\hline $\mathrm{CO}_{2}$ & $2,42 \mathrm{E}+02$ & $3,33 \mathrm{E}+00$ & & $3,61 \mathrm{E}+01$ & $5,14 \mathrm{E}+01$ & $3,32 \mathrm{E}+02$ \\
\hline $\mathrm{CO}$ & $5,37 \mathrm{E}-01$ & & $2,71 \mathrm{E}-01$ & $1,08 \mathrm{E}-03$ & $4,30 \mathrm{E}-01$ & $1,24 E+00$ \\
\hline Hidrocarbonetos & $8,13 \mathrm{E}-02$ & & & & $2,16 \mathrm{E}-03$ & 8,34E-02 \\
\hline Vapor de água & 2,64E-01 & & & & $6,63 \mathrm{E}-01$ & 9,27E-01 \\
\hline $\mathrm{CH}_{4}$ & $3,01 \mathrm{E}+00$ & & 3,01E-02 & & $1,58 \mathrm{E}-01$ & $3,20 \mathrm{E}+00$ \\
\hline $\mathrm{NH}_{3}$ & & & & & 1,73E-08 & 1,73E-08 \\
\hline Metais & $1,22 \mathrm{E}-06$ & & & & $2,88 \mathrm{E}-08$ & 1,25E-06 \\
\hline $\mathrm{N}_{2} \mathrm{O}$ & & & & & $3,17 \mathrm{E}-02$ & 3,17E-02 \\
\hline $\mathrm{NOx}$ & 8,65E-01 & $6,11 \mathrm{E}-03$ & $1,46 \mathrm{E}+00$ & $1,01 \mathrm{E}-01$ & $1,66 \mathrm{E}+00$ & $4,09 E+00$ \\
\hline SOx & 7,27E-01 & 1,33E-02 & 3,01E-02 & & $3,35 \mathrm{E}-01$ & $1,11 E+00$ \\
\hline Metil mercarptana & $1,15 \mathrm{E}-05$ & & & & & 1,15E-05 \\
\hline $\mathrm{H}_{2} \mathrm{~S}$ & $2,41 \mathrm{E}-04$ & & $1,70 \mathrm{E}-03$ & & & $1,94 \mathrm{E}-03$ \\
\hline COV - exceto metano & $1,10 \mathrm{E}+00$ & $5,28 \mathrm{E}-04$ & & & $2,10 \mathrm{E}-02$ & $1,12 \mathrm{E}+00$ \\
\hline Material particulado & $1,51 \mathrm{E}-01$ & $8,79 \mathrm{E}-04$ & $5,69 \mathrm{E}-01$ & $2,05 \mathrm{E}+00$ & $1,94 \mathrm{E}-01$ & $2,96 \mathrm{E}+00$ \\
\hline \multicolumn{7}{|c|}{ Efluentes líquidos (kg) } \\
\hline DBO & 3,84E-02 & $1,90 \mathrm{E}-03$ & & & $2,02 \mathrm{E}-04$ & 4,05E-02 \\
\hline DQO & 2,37E-01 & & & & $3,74 \mathrm{E}-04$ & 2,37E-01 \\
\hline Metais pesados não especificados & 5,33E-06 & & & & $5,18 \mathrm{E}-07$ & 5,85E-06 \\
\hline Hidrocarbonetos & 2,25E-03 & & & & 8,64E-05 & 2,34E-03 \\
\hline Ácidos como H ${ }^{+}$ & & & & & $4,90 \mathrm{E}-07$ & 4,90E-07 \\
\hline Efluentes líquidos não especificados & $3,71 \mathrm{E}-05$ & & & & & 3,71E-05 \\
\hline
\end{tabular}




\begin{tabular}{|c|c|c|c|c|c|c|}
\hline Água residual & 3,59E-03 & & & & & 3,59E-03 \\
\hline Íons metálicos & $6,12 \mathrm{E}-06$ & & & & $2,88 \mathrm{E}-05$ & 3,49E-05 \\
\hline Óleos e graxas & $1,78 \mathrm{E}-02$ & & & & 4,03E-04 & 1,82E-02 \\
\hline Sólidos dissolvidos totais & & & & & $1,44 \mathrm{E}-04$ & 1,44E-04 \\
\hline Sólidos suspensos totais & $1,22 \mathrm{E}-01$ & & & & 2,88E-04 & 1,22E-01 \\
\hline Compostos de enxofre & & & & & $1,30 \mathrm{E}-06$ & $1,30 \mathrm{E}-06$ \\
\hline Compostos de nitrogênio & & & $1,22 \mathrm{E}-01$ & $3,65 \mathrm{E}-01$ & $1,30 \mathrm{E}-05$ & 4,87E-01 \\
\hline $\mathrm{Na}^{+}$ & 1,87E-02 & & & & & 1,87E-02 \\
\hline Cloretos $\left(\mathrm{Cl}^{-}\right)$ & $2,80 \mathrm{E}-02$ & & & & $1,73 \mathrm{E}-07$ & 2,80E-02 \\
\hline \multicolumn{7}{|c|}{ Resíduos sólidos (kg) } \\
\hline Resíduos processuais não especificados & 2,69E-03 & & & & $3,08 \mathrm{E}+01$ & $3,08 \mathrm{E}+01$ \\
\hline Resíduos sólidos oleosos & $2,00 \mathrm{E}-01$ & & & & & $2,00 \mathrm{E}-01$ \\
\hline Catalisador usado & & & $2,43 \mathrm{E}-01$ & & & 2,43E-01 \\
\hline \multicolumn{7}{|c|}{ Emissões energéticas (GJ) } \\
\hline Energia térmica & & 3,38E-02 & & & & 3,38E-02 \\
\hline
\end{tabular}




\section{APÊNDICE B3 - Inventário consolidado da uréia adequada às condições brasileiras}

\begin{tabular}{|c|c|c|c|}
\hline & & & \\
\hline & Apêndice B1 & Apêndice B2 & Soma \\
\hline & $\begin{array}{c}\text { Uréia Fosfertil - } \\
37 \%\end{array}$ & Uréia Fafen - 63\% & Total \\
\hline \multicolumn{4}{|c|}{ Entradas } \\
\hline \multicolumn{4}{|c|}{ Recursos materiais (kg) } \\
\hline Petróleo & $4,71 \mathrm{E}+02$ & $1,92 \mathrm{E}+00$ & $4,72 E+02$ \\
\hline Carvão & $1,37 \mathrm{E}+01$ & $2,04 \mathrm{E}+01$ & $3,41 E+01$ \\
\hline Gás Natural & $1,88 \mathrm{E}+01$ & $6,34 \mathrm{E}+02$ & $6,53 \mathrm{E}+02$ \\
\hline Combustíveis renováveis & $1,38 \mathrm{E}-01$ & & 1,38E-01 \\
\hline Água & $1,24 \mathrm{E}+05$ & $1,85 \mathrm{E}+05$ & $3,09 \mathrm{E}+05$ \\
\hline $\mathrm{Ar}$ & $4,33 \mathrm{E}+00$ & $4,07 \mathrm{E}+00$ & $8,40 \mathrm{E}+00$ \\
\hline \multicolumn{4}{|c|}{ Recursos energéticos (GJ) } \\
\hline Energia elétrica & $1,07 \mathrm{E}+00$ & $1,59 \mathrm{E}+00$ & $2,66 \mathrm{E}+00$ \\
\hline Energia (vapor) & $5,64 \mathrm{E}+00$ & $4,79 \mathrm{E}+00$ & $1,04 \mathrm{E}+01$ \\
\hline Energia não especificada & $1,69 \mathrm{E}+00$ & $2,51 \mathrm{E}+00$ & $4,20 \mathrm{E}+00$ \\
\hline Energia (gás natural) & & $9,66 \mathrm{E}+00$ & $9,66 \mathrm{E}+00$ \\
\hline \multicolumn{4}{|c|}{ Saídas } \\
\hline \multicolumn{4}{|c|}{ Emissões atmosféricas (kg) } \\
\hline $\mathrm{CO}_{2}$ & $1,23 \mathrm{E}+02$ & $7,45 \mathrm{E}+02$ & $8,68 \mathrm{E}+02$ \\
\hline $\mathrm{CO}$ & $4,58 \mathrm{E}-01$ & $3,15 \mathrm{E}-01$ & 7,73E-01 \\
\hline Hidrocarbonetos & 3,09E-02 & $1,30 \mathrm{E}-03$ & 3,22E-02 \\
\hline Vapor de água & $3,43 E-01$ & $3,66 \mathrm{E}-01$ & 7,09E-01 \\
\hline $\mathrm{CH}_{4}$ & $1,18 \mathrm{E}+00$ & $9,71 \mathrm{E}-01$ & $2,15 \mathrm{E}+00$ \\
\hline $\mathrm{NH}_{3}$ & 6,39E-09 & 9,53E-09 & 1,59E-08 \\
\hline Metais & 4,64E-07 & $1,59 \mathrm{E}-08$ & 4,79E-07 \\
\hline $\mathrm{N}_{2} \mathrm{O}$ & 1,17E-02 & $1,74 \mathrm{E}-02$ & 2,92E-02 \\
\hline NOx & $1,51 \mathrm{E}+00$ & $3,65 \mathrm{E}+00$ & $5,17 \mathrm{E}+00$ \\
\hline SOx & 4,09E-01 & 7,77E-01 & $1,19 E+00$ \\
\hline Metil mercarptana & $4,25 \mathrm{E}-06$ & & 4,25E-06 \\
\hline $\mathrm{H}_{2} \mathrm{~S}$ & $7,20 \mathrm{E}-04$ & $1,84 \mathrm{E}-07$ & 1,23E-02 \\
\hline COV - exceto metano & $4,15 \mathrm{E}-01$ & $1,16 \mathrm{E}-02$ & $2,20 \mathrm{E}+00$ \\
\hline Material particulado & $1,10 \mathrm{E}+00$ & $1,79 \mathrm{E}+00$ & $2,88 \mathrm{E}+00$ \\
\hline \multicolumn{4}{|c|}{ Efluentes líquidos (kg) } \\
\hline DBO & $1,50 \mathrm{E}-02$ & $1,11 \mathrm{E}-04$ & 1,51E-02 \\
\hline DQO & 8,76E-02 & $2,06 \mathrm{E}-04$ & 8,79E-02 \\
\hline Metais pesados não especificados & $2,16 \mathrm{E}-06$ & $2,86 \mathrm{E}-07$ & 2,45E-06 \\
\hline Hidrocarbonetos & $8,66 \mathrm{E}-04$ & 4,76E-05 & 9,13E-04 \\
\hline Ácidos como $\mathrm{H}^{+}$ & $1,81 \mathrm{E}-07$ & $2,70 \mathrm{E}-07$ & 4,51E-07 \\
\hline Efluentes líquidos não especificados & 1,37E-05 & & 1,37E-05 \\
\hline Água residual & 1,33E-03 & & 1,33E-03 \\
\hline
\end{tabular}




\begin{tabular}{|c|c|c|c|}
\hline Íons metálicos & $1,29 \mathrm{E}-05$ & $1,59 \mathrm{E}-05$ & 2,88E-05 \\
\hline Óleos e graxas & $6,72 \mathrm{E}-03$ & 2,22E-04 & $6,94 \mathrm{E}-03$ \\
\hline Sólidos dissolvidos totais & 5,33E-05 & 7,94E-05 & 1,33E-04 \\
\hline Sólidos suspensos totais & $4,52 \mathrm{E}-02$ & $1,59 \mathrm{E}-04$ & 4,53E-02 \\
\hline Compostos de enxofre & $4,80 \mathrm{E}-07$ & 9,54E-05 & 9,59E-05 \\
\hline Compostos de nitrogênio & $1,80 \mathrm{E}-01$ & $3,06 \mathrm{E}-01$ & 4,87E-01 \\
\hline $\mathrm{Na}^{+}$ & 6,93E-03 & & 6,93E-03 \\
\hline Cloretos $\left(\mathrm{Cl}^{-}\right)$ & $1,03 \mathrm{E}-02$ & 9,53E-08 & 1,03E-02 \\
\hline \multicolumn{4}{|c|}{ Resíduos sólidos (kg) } \\
\hline Resíduos processuais não especificados & $1,14 \mathrm{E}+01$ & $1,70 \mathrm{E}+01$ & $2,84 \mathrm{E}+01$ \\
\hline Resíduos sólidos oleosos & 7,40E-02 & & 7,40E-02 \\
\hline Enxofre & & 1,17E-05 & 1,17E-05 \\
\hline Catalisador usado & 8,99E-02 & $1,53 \mathrm{E}-01$ & 2,43E-01 \\
\hline \multicolumn{4}{|c|}{ Emissões energéticas (GJ) } \\
\hline Vapor & & $1,76 \mathrm{E}+00$ & $1,76 \mathrm{E}+00$ \\
\hline Energia térmica não especificada & $1,25 \mathrm{E}-02$ & & $1,25 \mathrm{E}-02$ \\
\hline
\end{tabular}




\section{APÊNDICE B4 - Inventário consolidado do nitrato de amônio adequado às condições brasileiras}

\begin{tabular}{|c|c|c|c|c|c|c|}
\hline & $\begin{array}{c}\text { Produção de } \\
730,2 \mathrm{~kg} \text { de } \\
\text { gás de refinaria } \\
\text { (alocação de } \\
1,05 \% \text { e } \\
46,3 \% \text { ) }\end{array}$ & $\begin{array}{l}\text { Produção de } \\
1,217 \text { t de } \mathrm{NH}_{3} \\
\text { (alocação de } \\
46,3 \%)\end{array}$ & $\begin{array}{l}\text { Produção de } \\
2,25 \text { t de ácido } \\
\text { nítrico }\left(\mathrm{HNO}_{3}\right)\end{array}$ & $\begin{array}{c}\text { Produção de } \\
2,941 \text { t de } \\
\text { nitrato de } \\
\text { amônio } \\
\left(\mathrm{NH}_{4} \mathrm{NO}_{3}\right)\end{array}$ & $\begin{array}{l}\text { Eletricidade: } \\
\text { 6,55 GJ }\end{array}$ & $\begin{array}{c}\text { Total (por t de } \mathrm{N} \\
\text { ou } 2,941 \mathrm{t} \text { de } \\
\mathrm{NH}_{4} \mathrm{NO}_{3} \text { ) }\end{array}$ \\
\hline & Apêndice A4 & Apêndice A14 & Apêndice A16 & Apêndice A17 & $\begin{array}{c}\text { Tabela 35 } \\
\text { para 6,55 GJ }\end{array}$ & Soma \\
\hline \multicolumn{7}{|c|}{ Entradas } \\
\hline \multicolumn{7}{|c|}{ Recursos materiais (kg) } \\
\hline Petróleo & $3,40 \mathrm{E}+02$ & & & & $7,94 \mathrm{E}+00$ & $3,48 \mathrm{E}+02$ \\
\hline Carvão & 1,61E-02 & & & & $8,42 \mathrm{E}+01$ & $8,42 E+01$ \\
\hline Gás Natural & $1,31 \mathrm{E}+01$ & & & & $4,99 \mathrm{E}+00$ & $1,81 \mathrm{E}+01$ \\
\hline Combustíveis renováveis & 9,99E-02 & & & & & 9,99E-02 \\
\hline $\operatorname{Ar}$ & & $2,99 \mathrm{E}+00$ & $3,38 \mathrm{E}+03$ & & & $3,38 \mathrm{E}+03$ \\
\hline Água & $6,93 \mathrm{E}+01$ & $7,24 \mathrm{E}+00$ & $1,40 \mathrm{E}+02$ & $1,61 \mathrm{E}+02$ & $7,62 \mathrm{E}+05$ & $7,63 \mathrm{E}+05$ \\
\hline \multicolumn{7}{|c|}{ Recursos energéticos (GJ) } \\
\hline Energia Elétrica & 3,47E-02 & $2,33 \mathrm{E}+00$ & $4,01 \mathrm{E}+00$ & $1,75 \mathrm{E}-01$ & & $6,55 \mathrm{E}+00$ \\
\hline Energia não especificada & $1,55 \mathrm{E}-03$ & & & & $1,04 \mathrm{E}+01$ & $1,04 \mathrm{E}+01$ \\
\hline Energia (vapor) & & & & $2,33 \mathrm{E}+00$ & & $2,33 \mathrm{E}+00$ \\
\hline \multicolumn{7}{|c|}{ Saídas } \\
\hline \multicolumn{7}{|c|}{ Emissões atmosféricas (kg) } \\
\hline $\mathrm{CO}_{2}$ & $6,48 \mathrm{E}+01$ & & & & $1,17 \mathrm{E}+02$ & $1,82 E+02$ \\
\hline $\mathrm{CO}$ & $1,44 \mathrm{E}-01$ & 4,72E-02 & & & $9,78 \mathrm{E}-01$ & $1,17 \mathrm{E}+00$ \\
\hline Hidrocarbonetos & $2,18 \mathrm{E}-02$ & & & & 4,91E-03 & 2,67E-02 \\
\hline Vapor de água & 7,08E-02 & & & & $1,51 \mathrm{E}+00$ & $1,58 \mathrm{E}+00$ \\
\hline $\mathrm{CH}_{4}$ & 8,07E-01 & & & & $3,59 \mathrm{E}-01$ & $1,17 \mathrm{E}+00$ \\
\hline $\mathrm{NH}_{3}$ & & & $5,63 \mathrm{E}+00$ & 5,87E-01 & $3,93 \mathrm{E}-08$ & $6,21 E+00$ \\
\hline Metais & $3,28 \mathrm{E}-07$ & & & & $6,55 \mathrm{E}-08$ & 3,94E-07 \\
\hline $\mathrm{N}_{2} \mathrm{O}$ & & & $1,89 \mathrm{E}+01$ & & $7,18 \mathrm{E}-02$ & $1,89 \mathrm{E}+01$ \\
\hline NOx & 2,32E-01 & $5,60 \mathrm{E}-01$ & $1,06 \mathrm{E}+01$ & & $3,77 \mathrm{E}+00$ & $1,52 \mathrm{E}+01$ \\
\hline SOx & 1,95E-01 & $5,60 \mathrm{E}-03$ & & & $7,62 \mathrm{E}-01$ & 9,63E-01 \\
\hline Metil mercarptana & $3,08 \mathrm{E}-06$ & & & & & $3,08 \mathrm{E}-06$ \\
\hline $\mathrm{H}_{2} \mathrm{~S}$ & $6,46 \mathrm{E}-05$ & & & & & $6,46 \mathrm{E}-05$ \\
\hline COV - exceto metano & 2,95E-01 & & & & 4,75E-02 & 3,43E-01 \\
\hline Material particulado & 4,05E-02 & 2,81E-01 & 4,50E-01 & $1,47 \mathrm{E}+00$ & 4,39E-01 & $2,68 \mathrm{E}+00$ \\
\hline \multicolumn{7}{|c|}{ Efluentes líquidos (kg) } \\
\hline DBO & 1,03E-02 & & $3,15 \mathrm{E}+00$ & & 4,59E-04 & $3,16 \mathrm{E}+00$ \\
\hline DQO & $6,35 \mathrm{E}-02$ & & & & $8,50 \mathrm{E}-04$ & 6,43E-02 \\
\hline Metais pesados não especificados & $1,43 \mathrm{E}-06$ & & & & $1,18 \mathrm{E}-06$ & 2,61E-06 \\
\hline Hidrocarbonetos & $6,05 \mathrm{E}-04$ & & & & 1,96E-04 & 8,01E-04 \\
\hline Ácidos como $\mathrm{H}^{+}$ & & & & & 1,11E-06 & 1,11E-06 \\
\hline
\end{tabular}




\begin{tabular}{|c|c|c|c|c|c|c|}
\hline Efluentes líquidos não especificados & 9,95E-06 & & & & & 9,95E-06 \\
\hline Água residual & 9,63E-04 & & & & & 9,63E-04 \\
\hline Íons metálicos & 1,64E-06 & & & & $6,55 \mathrm{E}-05$ & 6,71E-05 \\
\hline Óleos e graxas & 4,76E-03 & & & & $9,18 \mathrm{E}-04$ & $5,68 \mathrm{E}-03$ \\
\hline Sólidos dissolvidos totais & & & & & $3,28 \mathrm{E}-04$ & 3,28E-04 \\
\hline Sólidos suspensos totais & 3,27E-02 & & & & $6,55 \mathrm{E}-04$ & 3,33E-02 \\
\hline Compostos de enxofre & & & & & 2,95E-06 & 2,95E-06 \\
\hline Compostos de nitrogênio & & $5,60 \mathrm{E}-02$ & 2,92E-01 & 7,61E-01 & 2,95E-05 & $1,11 E+00$ \\
\hline $\mathrm{Na}^{+}$ & $5,02 \mathrm{E}-03$ & & & & & $5,02 \mathrm{E}-03$ \\
\hline Cloretos $\left(\mathrm{Cl}^{-}\right)$ & $7,50 \mathrm{E}-03$ & & & & $3,93 \mathrm{E}-07$ & 7,50E-03 \\
\hline \multicolumn{7}{|c|}{ Resíduos sólidos (kg) } \\
\hline Resíduos processuais não especificados & $7,23 \mathrm{E}-04$ & & & & $7,02 \mathrm{E}+01$ & $7,03 \mathrm{E}+01$ \\
\hline Resíduos sólidos oleosos & 5,36E-02 & & & & & 5,36E-02 \\
\hline Catalisador usado & & $1,13 \mathrm{E}-01$ & $8,10 \mathrm{E}-05$ & & & 1,13E-01 \\
\hline \multicolumn{7}{|c|}{ Emissões energéticas (GJ) } \\
\hline Vapor & & $1,30 \mathrm{E}+00$ & 5,06E-03 & & & $1,30 \mathrm{E}+00$ \\
\hline
\end{tabular}




\section{APÊNDICE B5 - Inventário consolidado do sulfato de amônio produzido pelo processo de síntese pela Unigel}

\begin{tabular}{|c|c|c|c|c|c|c|c|}
\hline & Apêndice A9 & Apêndice A10 & $\begin{array}{c}\text { Apêndice } \\
\text { A12 }\end{array}$ & $\begin{array}{c}\text { Apêndice } \\
\text { A18 }\end{array}$ & $\begin{array}{c}\text { Apêndice } \\
\text { A19 }\end{array}$ & $\begin{array}{c}\text { Tabela 35 } \\
\text { para 3,406 GJ }\end{array}$ & Soma \\
\hline & $\begin{array}{c}\text { Beneficiamento } \\
\text { de } 924,92 \text { kg de } \\
\text { gás natural } \\
\text { (alocação: } \\
46,3 \%)\end{array}$ & $\begin{array}{c}\text { Energia térmica } \\
\text { prov. do gás } \\
\text { natural: } 15,33 \\
\text { GJ (alocação: } \\
46,3 \%)\end{array}$ & $\begin{array}{c}\text { Produção } \\
\text { de } 1,217 \text { t de } \\
\text { amônia via } \\
\text { reforma } \\
\text { catalítica } \\
\text { (alocação: } \\
46,3 \% \text { ) }\end{array}$ & $\begin{array}{l}\text { Produção de } \\
3,5 \text { t de ácido } \\
\text { sulfúrico } \\
\left(\mathrm{H}_{2} \mathrm{SO}_{4}\right)\end{array}$ & $\begin{array}{c}\text { Produção de } \\
4,717 \mathrm{t} \text { de } \\
\left(\mathrm{NH}_{4}\right)_{2} \mathrm{SO}_{4}\end{array}$ & $\begin{array}{l}\text { Eletricidade: } \\
\text { 3,406 GJ }\end{array}$ & $\begin{array}{l}\text { Total (por t de } \mathrm{N} \\
\text { ou } 4,717 \mathrm{t} \text { de } \\
\text { sulfato de amônio) }\end{array}$ \\
\hline \multicolumn{8}{|c|}{ Entradas } \\
\hline \multicolumn{8}{|c|}{ Recursos materiais (kg) } \\
\hline Petróleo & & & & & & $4,12 \mathrm{E}+00$ & $4,12 \mathrm{E}+00$ \\
\hline Enxofre & & & & $1,16 \mathrm{E}+03$ & & & $1,16 \mathrm{E}+03$ \\
\hline Carvão & & & & & & $4,37 \mathrm{E}+01$ & $4,37 \mathrm{E}+01$ \\
\hline Gás Natural & $4,41 \mathrm{E}+02$ & $1,87 \mathrm{E}+02$ & $2,78 \mathrm{E}+02$ & & & $2,59 \mathrm{E}+00$ & $9,09 \mathrm{E}+02$ \\
\hline Água & $8,45 \mathrm{E}+00$ & & $7,24 \mathrm{E}+00$ & $5,08 \mathrm{E}+03$ & & $3,96 \mathrm{E}+05$ & $4,01 \mathrm{E}+05$ \\
\hline $\mathrm{Ar}$ & & & $2,99 \mathrm{E}+00$ & $1,72 \mathrm{E}+01$ & & & $2,01 \mathrm{E}+01$ \\
\hline \multicolumn{8}{|c|}{ Recursos energéticos (GJ) } \\
\hline Energia Elétrica & & & $6,26 \mathrm{E}-01$ & & $2,78 \mathrm{E}+00$ & & $3,41 E+00$ \\
\hline Energia não especificada & & & & & & $5,40 \mathrm{E}+00$ & $5,40 \mathrm{E}+00$ \\
\hline Energia (gás natural) & $1,86 \mathrm{E}-03$ & $7,10 \mathrm{E}+00$ & & & & & $7,10 \mathrm{E}+00$ \\
\hline \multicolumn{8}{|c|}{ Saídas } \\
\hline \multicolumn{8}{|c|}{ Emissões atmosféricas (kg) } \\
\hline $\mathrm{CO}_{2}$ & $3,58 \mathrm{E}+01$ & $4,74 \mathrm{E}+02$ & & & & $6,07 \mathrm{E}+01$ & $5,71 \mathrm{E}+02$ \\
\hline $\mathrm{CO}$ & $1,21 \mathrm{E}-04$ & $9,34 \mathrm{E}-03$ & 4,72E-02 & & & $5,09 \mathrm{E}-01$ & $5,66 \mathrm{E}-01$ \\
\hline Hidrocarbonetos & 7,84E-05 & & & & & $2,55 \mathrm{E}-03$ & 2,63E-03 \\
\hline Vapor de água & & & & & & 7,85E-01 & $7,85 \mathrm{E}-01$ \\
\hline $\mathrm{CH}_{4}$ & 6,41E-01 & & $9,28 \mathrm{E}-03$ & & & 1,87E-01 & $8,36 \mathrm{E}-01$ \\
\hline $\mathrm{NH}_{3}$ & & & & & & $2,04 \mathrm{E}-08$ & $2,04 \mathrm{E}-08$ \\
\hline Metais & & & & & & $3,41 \mathrm{E}-08$ & $3,41 \mathrm{E}-08$ \\
\hline $\mathrm{N}_{2} \mathrm{O}$ & & & & & & $3,74 \mathrm{E}-02$ & $3,74 \mathrm{E}-02$ \\
\hline NOx & $1,14 \mathrm{E}-01$ & $1,29 \mathrm{E}+00$ & $5,60 \mathrm{E}-01$ & & & $1,96 \mathrm{E}+00$ & $3,92 \mathrm{E}+00$ \\
\hline SOx & 4,13E-01 & $1,68 \mathrm{E}-02$ & $5,60 \mathrm{E}-03$ & $9,30 \mathrm{E}+00$ & & $3,96 \mathrm{E}-01$ & $1,01 \mathrm{E}+01$ \\
\hline $\mathrm{H}_{2} \mathrm{~S}$ & $1,35 \mathrm{E}-07$ & & & & & & $1,35 \mathrm{E}-07$ \\
\hline COV - exceto metano & & & & & & $2,48 \mathrm{E}-02$ & $2,48 \mathrm{E}-02$ \\
\hline Material particulado & 6,96E-03 & & 2,81E-01 & & $5,20 \mathrm{E}-01$ & $2,29 \mathrm{E}-01$ & $1,04 \mathrm{E}+00$ \\
\hline \multicolumn{8}{|c|}{ Efluentes líquidos (kg) } \\
\hline DBO & & & & & & $2,38 \mathrm{E}-04$ & 2,38E-04 \\
\hline DQO & & & & & & 4,43E-04 & 4,43E-04 \\
\hline $\begin{array}{l}\text { Metais pesados não } \\
\text { especificados }\end{array}$ & & & & & & $6,13 \mathrm{E}-07$ & 6,13E-07 \\
\hline Hidrocarbonetos & & & & & & $1,02 E-04$ & $1,02 E-04$ \\
\hline
\end{tabular}




\begin{tabular}{|c|c|c|c|c|c|}
\hline Ácidos como $\mathrm{H}^{+}$ & & & & 5,79E-07 & 5,79E-07 \\
\hline Ílons metálicos & & & & 3,41E-05 & 3,41E-05 \\
\hline Óleos e graxas & & & & 4,77E-04 & 4,77E-04 \\
\hline Sólidos dissolvidos totais & & & & $1,70 \mathrm{E}-04$ & $1,70 \mathrm{E}-04$ \\
\hline Sólidos suspensos totais & & & & 3,41E-04 & 3,41E-04 \\
\hline Compostos de enxofre & $6,96 \mathrm{E}-05$ & & & $1,53 \mathrm{E}-06$ & 7,12E-05 \\
\hline Compostos de nitrogênio & $5,01 \mathrm{E}-07$ & $5,60 \mathrm{E}-02$ & & 1,53E-05 & $5,60 \mathrm{E}-02$ \\
\hline Cloretos $\left(\mathrm{Cl}^{-}\right)$ & & & & 2,04E-07 & 2,04E-07 \\
\hline \multicolumn{6}{|c|}{ Resíduos sólidos (kg) } \\
\hline $\begin{array}{l}\text { Resíduos processuais não } \\
\text { especificados }\end{array}$ & & & & $3,64 \mathrm{E}+01$ & $3,64 E+01$ \\
\hline Enxofre & 8,63E-06 & & $2,66 \mathrm{E}+01$ & & $2,66 \mathrm{E}+01$ \\
\hline Catalisador usado & & 1,13E-01 & $2,03 \mathrm{E}+02$ & & $2,03 E+02$ \\
\hline \multicolumn{6}{|c|}{ Emissões energéticas (GJ) } \\
\hline Vapor & 4,64E-04 & $1,30 \mathrm{E}+00$ & & & $1,30 \mathrm{E}+00$ \\
\hline
\end{tabular}




\section{APÊNDICE B6 - Inventário consolidado do sulfato de amônio produzido pelo processo de síntese pela Bunge fertilizantes}

\begin{tabular}{|c|c|c|c|c|c|c|}
\hline & $\begin{array}{c}\text { Produção de } \\
730,2 \text { kg de gás } \\
\text { de refinaria } \\
\text { (alocação de } \\
1,05 \% \text { e } 46,3 \% \text { ) }\end{array}$ & $\begin{array}{c}\text { Produção de } \\
\text { 1,217 } \mathrm{t} \text { de } \mathrm{NH}_{3} \\
\text { (alocação de } \\
46,3 \% \text { ) }\end{array}$ & $\begin{array}{c}\text { Produção de } 3,5 \\
\text { t de } \mathrm{H}_{2} \mathrm{SO}_{4}\end{array}$ & $\begin{array}{c}\text { Produção de } \\
4,717 \mathrm{tde} \\
\left(\mathrm{NH}_{4}\right)_{2} \mathrm{SO}_{4}\end{array}$ & $\begin{array}{l}\text { Eletricidade: } \\
5,14 \mathrm{GJ}\end{array}$ & $\begin{array}{c}\text { Total (por } t \text { de } \\
\mathrm{N} \text { ou } 4,717 \mathrm{t} \\
\text { de sulfato de } \\
\text { amônio) }\end{array}$ \\
\hline & Apêndice A4 & Apêndice A14 & Apêndice A18 & Apêndice A19 & $\begin{array}{c}\text { Tabela } 35 \text { para } \\
5,14 \mathrm{GJ}\end{array}$ & Soma \\
\hline \multicolumn{7}{|c|}{ Entradas } \\
\hline \multicolumn{7}{|c|}{ Recursos materiais (kg) } \\
\hline Petróleo & $3,40 \mathrm{E}+02$ & & & & $6,23 \mathrm{E}+00$ & $3,47 E+02$ \\
\hline Enxofre & & & $1,16 \mathrm{E}+03$ & & & $1,16 \mathrm{E}+03$ \\
\hline Carvão & 1,61E-02 & & & & $6,61 \mathrm{E}+01$ & $6,61 \mathrm{E}+01$ \\
\hline Gás Natural & $1,31 \mathrm{E}+01$ & & & & $3,92 \mathrm{E}+00$ & $1,70 \mathrm{E}+01$ \\
\hline Combustíveis renováveis & 9,99E-02 & & & & & 9,99E-02 \\
\hline Água & $6,93 \mathrm{E}+01$ & $7,24 \mathrm{E}+00$ & $5,08 \mathrm{E}+03$ & & $5,98 \mathrm{E}+05$ & $6,03 E+05$ \\
\hline Ar & & $2,99 \mathrm{E}+00$ & $1,72 \mathrm{E}+01$ & & & 2,01E+01 \\
\hline \multicolumn{7}{|c|}{ Recursos energéticos (GJ) } \\
\hline Energia Elétrica & 3,47E-02 & $2,33 \mathrm{E}+00$ & & $2,78 \mathrm{E}+00$ & & $5,14 \mathrm{E}+00$ \\
\hline Energia não especificada & $1,55 \mathrm{E}-03$ & & & & $8,14 \mathrm{E}+00$ & $8,15 E+00$ \\
\hline \multicolumn{7}{|c|}{ Saídas } \\
\hline \multicolumn{7}{|c|}{ Emissões atmosféricas (kg) } \\
\hline $\mathrm{CO}_{2}$ & $6,48 \mathrm{E}+01$ & & & & $9,18 \mathrm{E}+01$ & 1,57E+02 \\
\hline $\mathrm{CO}$ & $1,44 \mathrm{E}-01$ & $4,72 \mathrm{E}-02$ & & & 7,67E-01 & 9,59E-01 \\
\hline Hidrocarbonetos & $2,18 \mathrm{E}-02$ & & & & 3,85E-03 & 2,57E-02 \\
\hline Vapor de água & $7,08 \mathrm{E}-02$ & & & & $1,18 \mathrm{E}+00$ & $1,25 \mathrm{E}+00$ \\
\hline $\mathrm{CH}_{4}$ & 8,07E-01 & & & & 2,82E-01 & $1,09 \mathrm{E}+00$ \\
\hline $\mathrm{NH}_{3}$ & & & & & $3,09 \mathrm{E}-08$ & 3,09E-08 \\
\hline Metais & $3,28 \mathrm{E}-07$ & & & & $5,14 \mathrm{E}-08$ & 3,80E-07 \\
\hline $\mathrm{N}_{2} \mathrm{O}$ & & & & & $5,64 \mathrm{E}-02$ & 5,64E-02 \\
\hline NOx & 2,32E-01 & $5,60 \mathrm{E}-01$ & & & $2,96 \mathrm{E}+00$ & $3,75 \mathrm{E}+00$ \\
\hline SOx & 1,95E-01 & $5,60 \mathrm{E}-03$ & $9,30 \mathrm{E}+00$ & & 5,98E-01 & $1,01 \mathrm{E}+01$ \\
\hline Metil mercarptana & $3,08 \mathrm{E}-06$ & & & & & 3,08E-06 \\
\hline $\mathrm{H}_{2} \mathrm{~S}$ & 6,46E-05 & & & & & 6,46E-05 \\
\hline COV - exceto metano & 2,95E-01 & & & & 3,73E-02 & 3,33E-01 \\
\hline Material particulado & 4,05E-02 & 2,81E-01 & & $5,20 \mathrm{E}-01$ & $3,45 \mathrm{E}-01$ & $1,19 \mathrm{E}+00$ \\
\hline \multicolumn{7}{|c|}{ Efluentes líquidos (kg) } \\
\hline DBO & 1,03E-02 & & & & $3,60 \mathrm{E}-04$ & 1,07E-02 \\
\hline DQO & $6,35 \mathrm{E}-02$ & & & & 6,67E-04 & 6,41E-02 \\
\hline Metais pesados não especificados & $1,43 \mathrm{E}-06$ & & & & $9,24 \mathrm{E}-07$ & 2,35E-06 \\
\hline Hidrocarbonetos & $6,05 \mathrm{E}-04$ & & & & $1,54 \mathrm{E}-04$ & 7,59E-04 \\
\hline Ácidos como $\mathrm{H}^{+}$ & & & & & 8,74E-07 & 8,74E-07 \\
\hline
\end{tabular}




\begin{tabular}{|c|c|c|c|c|c|}
\hline Efluentes líquidos não especificados & $9,95 \mathrm{E}-06$ & & & & 9,95E-06 \\
\hline Água residual & 9,63E-04 & & & & 9,63E-04 \\
\hline Ílons metálicos & 1,64E-06 & & & $5,14 \mathrm{E}-05$ & $5,30 \mathrm{E}-05$ \\
\hline Óleos e graxas & 4,76E-03 & & & $7,20 \mathrm{E}-04$ & $5,48 \mathrm{E}-03$ \\
\hline Sólidos dissolvidos totais & & & & 2,57E-04 & 2,57E-04 \\
\hline Sólidos suspensos totais & 3,27E-02 & & & $5,14 \mathrm{E}-04$ & 3,32E-02 \\
\hline Compostos de enxofre & & & & 2,31E-06 & 2,31E-06 \\
\hline Compostos de nitrogênio & & $5,60 \mathrm{E}-02$ & & 2,31E-05 & $5,60 \mathrm{E}-02$ \\
\hline $\mathrm{Na}^{+}$ & $5,02 \mathrm{E}-03$ & & & & $5,02 \mathrm{E}-03$ \\
\hline Cloretos $\left(\mathrm{Cl}^{-}\right)$ & $7,50 \mathrm{E}-03$ & & & $3,09 \mathrm{E}-07$ & $7,50 \mathrm{E}-03$ \\
\hline \multicolumn{6}{|c|}{ Resíduos sólidos (kg) } \\
\hline Resíduos processuais não especificados & $7,23 \mathrm{E}-04$ & & & $5,51 \mathrm{E}+01$ & $5,51 E+01$ \\
\hline Resíduos sólidos oleosos & $5,36 \mathrm{E}-02$ & & & & 5,36E-02 \\
\hline Enxofre & & & $2,66 \mathrm{E}+01$ & & $2,66 \mathrm{E}+01$ \\
\hline Catalisador usado & & $1,13 \mathrm{E}-01$ & $2,03 \mathrm{E}+02$ & & $2,03 E+02$ \\
\hline \multicolumn{6}{|c|}{ Emissões energéticas (GJ) } \\
\hline Vapor & & $1,30 \mathrm{E}+00$ & & & $1,30 \mathrm{E}+00$ \\
\hline
\end{tabular}




\section{APÊNDICE B7 - Inventário consolidado do sulfato de amônio obtido como subproduto da produção de caprolactma pela Braskem}

\begin{tabular}{|c|c|c|c|c|c|c|c|c|c|c|}
\hline & $\begin{array}{l}\text { Produção } \\
\text { de 11,78 t } \\
\text { de nafta } \\
\text { (alocação } \\
\text { de 11,63\%) }\end{array}$ & \begin{tabular}{|c|} 
Produção de \\
$6,66 \mathrm{t}$ de \\
benzeno
\end{tabular} & $\begin{array}{l}\text { Produção de } \\
5,936 \text { t de } \\
\text { ciclohexano }\end{array}$ & $\begin{array}{c}\text { Beneficiamento } \\
\text { de } 924,92 \mathrm{~kg} \text { de } \\
\text { gás natural } \\
\text { (alocação de } \\
46,3 \%)\end{array}$ & \begin{tabular}{|c|} 
Energia \\
térmica do \\
gás natural: \\
15,33 GJ \\
(alocação de \\
$46,3 \%)$ \\
\end{tabular} & $\begin{array}{l}\text { Produção } \\
\text { de } 1,217 \mathrm{t} \\
\text { de } \mathrm{NH}_{3} \\
\text { (alocação } \\
\text { de 46,3\%) }\end{array}$ & $\begin{array}{c}\text { Produção } \\
\text { de } 3,5 \mathrm{tde} \\
\mathrm{H}_{2} \mathrm{SO}_{4}\end{array}$ & \begin{tabular}{|c|} 
Produção de \\
$2,62 \mathrm{t}$ de \\
caprolactama e \\
$4,717 \mathrm{t}$ de sulfato \\
de amônio
\end{tabular} & $\begin{array}{l}\text { Eletricidade: } \\
\text { 24,28 GJ }\end{array}$ & $\begin{array}{l}\text { Total por t de } \\
\text { N sem } \\
\text { alocação }\end{array}$ \\
\hline & $\begin{array}{c}\text { Apêndice } \\
\text { A6 }\end{array}$ & $\begin{array}{l}\text { Apêndice } \\
\text { A20 }\end{array}$ & $\begin{array}{l}\text { Apêndice } \\
\text { A21 }\end{array}$ & Apêndice A9 & $\begin{array}{l}\text { Apêndice } \\
\text { A10 }\end{array}$ & $\begin{array}{l}\text { Apêndice } \\
\text { A12 }\end{array}$ & $\begin{array}{l}\text { Apêndice } \\
\text { A18 }\end{array}$ & Apêndice A23 & $\begin{array}{c}\text { Tabela 35 para } \\
24,28 \text { GJ }\end{array}$ & Soma \\
\hline \multicolumn{11}{|c|}{ Entradas } \\
\hline \multicolumn{11}{|c|}{ Recursos materiais $(\mathrm{kg})$} \\
\hline Petróleo & $1,42 \mathrm{E}+04$ & & & & & & & & $2,94 \mathrm{E}+01$ & $1,43 E+04$ \\
\hline Enxofre & & & & & & & $1,16 \mathrm{E}+03$ & & & $1,16 \mathrm{E}+03$ \\
\hline Carvão & $6,72 \mathrm{E}-01$ & & & & & & & & $3,12 \mathrm{E}+02$ & $3,12 \mathrm{E}+02$ \\
\hline Gás Natural & $5,46 \mathrm{E}+02$ & & & $4,41 \mathrm{E}+02$ & $1,87 E+02$ & $2,78 \mathrm{E}+02$ & & & $1,85 \mathrm{E}+01$ & $1,47 \mathrm{E}+03$ \\
\hline Combustíveis renováveis & $4,18 \mathrm{E}+00$ & & & & & & & & & $4,18 \mathrm{E}+00$ \\
\hline Água & $2,90 \mathrm{E}+03$ & & & $8,45 \mathrm{E}+00$ & & $7,24 \mathrm{E}+00$ & $5,08 \mathrm{E}+03$ & & $2,82 E+06$ & $2,83 E+06$ \\
\hline Ar & & & & & & $2,99 \mathrm{E}+00$ & $1,72 \mathrm{E}+01$ & & & $2,01 E+01$ \\
\hline \multicolumn{11}{|c|}{ Recursos energéticos (GJ) } \\
\hline Energia Elétrica & $1,45 \mathrm{E}+00$ & & & & & $6,26 \mathrm{E}-01$ & & $2,22 \mathrm{E}+01$ & & $2,43 E+01$ \\
\hline Energia não especificada & $6,47 \mathrm{E}-02$ & & & & & & & & $3,85 \mathrm{E}+01$ & $3,85 \mathrm{E}+01$ \\
\hline Energia (gás natural) & & & & $1,86 \mathrm{E}-03$ & $7,10 \mathrm{E}+00$ & & & & & $7,10 \mathrm{E}+00$ \\
\hline \multicolumn{11}{|c|}{ Saídas } \\
\hline \multicolumn{11}{|c|}{ Emissões atmosféricas (kg) } \\
\hline $\mathrm{CO}_{2}$ & $2,71 \mathrm{E}+03$ & $1,64 \mathrm{E}+04$ & $2,54 \mathrm{E}+03$ & $3,58 \mathrm{E}+01$ & $4,74 \mathrm{E}+02$ & & & $1,17 \mathrm{E}+04$ & $4,33 \mathrm{E}+02$ & $3,43 \mathrm{E}+04$ \\
\hline $\mathrm{co}$ & $6,02 \mathrm{E}+00$ & $4,85 \mathrm{E}+00$ & $6,53 \mathrm{E}-01$ & $1,21 \mathrm{E}-04$ & $9,34 \mathrm{E}-03$ & $4,72 \mathrm{E}-02$ & & & $3,63 \mathrm{E}+00$ & $1,52 \mathrm{E}+01$ \\
\hline Hidrocarbonetos & $9,12 \mathrm{E}-01$ & $1,39 \mathrm{E}+01$ & $4,16 \mathrm{E}-01$ & $7,84 \mathrm{E}-05$ & & & & $2,72 \mathrm{E}+00$ & $1,82 \mathrm{E}-02$ & $1,80 \mathrm{E}+01$ \\
\hline
\end{tabular}




\begin{tabular}{|c|c|c|c|c|c|c|c|c|c|c|}
\hline Vapor de água & $2,96 \mathrm{E}+00$ & & & & & & & & $5,59 \mathrm{E}+00$ & $8,55 \mathrm{E}+00$ \\
\hline $\mathrm{CH}_{4}$ & $3,37 \mathrm{E}+01$ & & & $6,41 \mathrm{E}-01$ & & $9,28 \mathrm{E}-03$ & & & $1,33 \mathrm{E}+00$ & $3,57 \mathrm{E}+01$ \\
\hline $\mathrm{NH}_{3}$ & & & & & & & & $5,50 \mathrm{E}-01$ & $1,46 \mathrm{E}-07$ & $5,50 \mathrm{E}-01$ \\
\hline Metais & $1,37 \mathrm{E}-05$ & & & & & & & & $2,43 \mathrm{E}-07$ & $1,40 \mathrm{E}-05$ \\
\hline $\mathrm{N}_{2} \mathrm{O}$ & & & & & & & & & $2,67 \mathrm{E}-01$ & $2,67 \mathrm{E}-01$ \\
\hline NOx & $9,70 \mathrm{E}+00$ & $1,75 \mathrm{E}+01$ & $2,43 \mathrm{E}+00$ & $1,14 \mathrm{E}-01$ & $1,29 \mathrm{E}+00$ & $5,60 \mathrm{E}-01$ & & $9,69 \mathrm{E}+00$ & $1,40 \mathrm{E}+01$ & $5,53 \mathrm{E}+01$ \\
\hline Sox & $8,15 \mathrm{E}+00$ & $2,30 E+00$ & & 4,13E-01 & $1,68 \mathrm{E}-02$ & $5,60 \mathrm{E}-03$ & $9,30 \mathrm{E}+00$ & 2,62E-01 & $2,82 E+00$ & $2,33 \mathrm{E}+01$ \\
\hline Metil mercarptana & $1,29 \mathrm{E}-04$ & & & & & & & & & $1,29 \mathrm{E}-04$ \\
\hline $\mathrm{H}_{2} \mathrm{~S}$ & $2,70 \mathrm{E}-03$ & & & $1,35 \mathrm{E}-07$ & & & & & & $2,70 \mathrm{E}-03$ \\
\hline COV - exceto metano & $1,23 \mathrm{E}+01$ & & $9,50 \mathrm{E}-01$ & & & & & & $1,77 \mathrm{E}-01$ & $1,35 \mathrm{E}+01$ \\
\hline Material particulado & $1,69 \mathrm{E}+00$ & $2,66 \mathrm{E}-01$ & & $6,96 \mathrm{E}-03$ & & 2,81E-01 & & & $1,63 \mathrm{E}+00$ & $3,88 E+00$ \\
\hline $\mathrm{H}_{2}$ & & 6,66E-02 & $2,37 \mathrm{E}-01$ & & & & & & & $3,04 \mathrm{E}-01$ \\
\hline \multicolumn{11}{|c|}{ Efluentes líquidos (kg) } \\
\hline DBO & 4,31E-01 & & & & & & & & $1,70 \mathrm{E}-03$ & 4,32E-01 \\
\hline DQO & $2,65 \mathrm{E}+00$ & $3,54 \mathrm{E}-01$ & & & & & & & $3,16 \mathrm{E}-03$ & $3,01 E+00$ \\
\hline Metais pesados não especificados & $5,98 \mathrm{E}-05$ & & & & & & & & $4,37 \mathrm{E}-06$ & 6,42E-05 \\
\hline Hidrocarbonetos & $2,53 \mathrm{E}-02$ & $6,66 \mathrm{E}-02$ & & & & & & & $7,28 \mathrm{E}-04$ & $9,26 \mathrm{E}-02$ \\
\hline Ácidos como H ${ }^{+}$ & & & & & & & & & $4,13 \mathrm{E}-06$ & 4,13E-06 \\
\hline Efluentes líquidos não especificados & $4,16 \mathrm{E}-04$ & & & & & & & & & 4,16E-04 \\
\hline Água residual & 4,03E-02 & & & & & & & & & 4,03E-02 \\
\hline Íns metálicos & $6,87 \mathrm{E}-05$ & & & & & & & & 2,43E-04 & $3,11 \mathrm{E}-04$ \\
\hline Óleos e graxas & $1,99 \mathrm{E}-01$ & & & & & & & & $3,40 \mathrm{E}-03$ & 2,03E-01 \\
\hline Sólidos dissolvidos totais & & & & & & & & & $1,21 \mathrm{E}-03$ & $1,21 \mathrm{E}-03$ \\
\hline Sólidos suspensos totais & $1,37 \mathrm{E}+00$ & & & & & & & & $2,43 \mathrm{E}-03$ & $1,37 \mathrm{E}+00$ \\
\hline Compostos de enxofre & & 7,97E-01 & & $6,96 \mathrm{E}-05$ & & & & & $1,09 \mathrm{E}-05$ & 7,97E-01 \\
\hline Compostos de nitrogênio & & & & $5,01 \mathrm{E}-07$ & & $5,60 \mathrm{E}-02$ & & & $1,09 \mathrm{E}-04$ & $5,61 \mathrm{E}-02$ \\
\hline $\mathrm{Na}^{+}$ & $2,10 \mathrm{E}-01$ & $2,75 \mathrm{E}+00$ & & & & & & & & $2,96 \mathrm{E}+00$ \\
\hline Cloretos $(\mathrm{Cl})$ & $3,14 \mathrm{E}-01$ & & & & & & & & $1,46 \mathrm{E}-06$ & $3,14 \mathrm{E}-01$ \\
\hline \multicolumn{11}{|c|}{ Resíduos sólidos (kg) } \\
\hline Resíduos processuais não especificados & 3,02E-02 & & & & & & & & $2,60 \mathrm{E}+02$ & $2,60 \mathrm{E}+02$ \\
\hline Resíduos sólidos oleosos & $2,24 \mathrm{E}+00$ & & & & & & & & & $2,24 E+00$ \\
\hline
\end{tabular}




\begin{tabular}{|c|c|c|c|c|}
\hline Enxofre & $8,63 \mathrm{E}-06$ & & $2,66 \mathrm{E}+01$ & $2,66 \mathrm{E}+01$ \\
\hline Catalisador usado & & $1,13 \mathrm{E}-01$ & $2,03 E+02$ & $2,03 E+02$ \\
\hline \multicolumn{5}{|c|}{ Emissões energéticas (GJ) } \\
\hline Vapor & 4,64E-04 & $1,30 \mathrm{E}+00$ & & $1,30 \mathrm{E}+00$ \\
\hline
\end{tabular}




\section{APÊNDICE B8 - Inventário consolidado do sulfato de amônio obtido como subproduto da produção de acrilonitrila pela Unigel}

\begin{tabular}{|c|c|c|c|c|c|c|c|c|}
\hline & $\begin{array}{l}\text { Produção de } \\
5,798 \mathrm{t} \text { de } \\
\text { nafta } \\
\text { (alocação de } \\
11,63 \% \text { ) }\end{array}$ & $\begin{array}{l}\text { Produção de } \\
4,359 \text { t de } \\
\text { propeno }\end{array}$ & $\begin{array}{c}\text { Beneficiamento } \\
\text { de } 924,92 \mathrm{~kg} \text { de } \\
\text { gás natural } \\
\text { (alocação de } \\
46,3 \%)\end{array}$ & \begin{tabular}{|c|} 
Energia \\
térmica do \\
gás natural: \\
15,33 GJ \\
(alocação de \\
$46,3 \%$ ) \\
\end{tabular} & \begin{tabular}{|c|} 
Produção de \\
$1,217 \mathrm{t}$ de \\
$\mathrm{NH}_{3}$ \\
(alocação de \\
$46,3 \%$ ) \\
\end{tabular} & $\begin{array}{l}\text { Produção de } \\
29,48 \text { t de } \\
\text { acrilonitrila }\end{array}$ & $\begin{array}{c}\text { Eletricidade: } \mathbf{2 3 , 5 4} \\
\text { GJ }\end{array}$ & $\begin{array}{l}\text { Total por } t \text { de } N \text { sem } \\
\text { alocação }\end{array}$ \\
\hline & Apêndice A7 & Apêndice A22 & Apêndice A9 & Apêndice A10 & Apêndice A12 & Apêndice A25 & $\begin{array}{c}\text { Tabela } 35 \text { para } 23,54 \\
\text { GJ }\end{array}$ & Soma \\
\hline \multicolumn{9}{|c|}{ Entradas } \\
\hline \multicolumn{9}{|c|}{ Recursos materiais $(\mathrm{kg})$} \\
\hline Petróleo & $7,00 \mathrm{E}+03$ & & & & & & $2,85 \mathrm{E}+01$ & $7,03 E+03$ \\
\hline Carvão & 3,31E-01 & & & & & & $3,02 \mathrm{E}+02$ & $3,03 E+02$ \\
\hline Gás Natural & $2,69 \mathrm{E}+02$ & & $4,41 \mathrm{E}+02$ & $1,87 \mathrm{E}+02$ & $2,78 \mathrm{E}+02$ & & $1,79 \mathrm{E}+01$ & $1,19 \mathrm{E}+03$ \\
\hline Combustíveis renováveis & $2,06 \mathrm{E}+00$ & & & & & & & $2,06 \mathrm{E}+00$ \\
\hline Água & $1,43 \mathrm{E}+03$ & & $8,45 \mathrm{E}+00$ & & $7,24 \mathrm{E}+00$ & & $2,74 \mathrm{E}+06$ & $2,74 \mathrm{E}+06$ \\
\hline $\operatorname{Ar}$ & & & & & $2,99 \mathrm{E}+00$ & & & $2,99 \mathrm{E}+00$ \\
\hline \multicolumn{9}{|c|}{ Recursos energéticos (GJ) } \\
\hline Energia Elétrica & $7,14 \mathrm{E}-01$ & & & & $6,26 \mathrm{E}-01$ & $2,22 \mathrm{E}+01$ & & $2,35 \mathrm{E}+01$ \\
\hline Energia não especificada & $3,19 \mathrm{E}-02$ & & & & & & $3,73 \mathrm{E}+01$ & $3,73 E+01$ \\
\hline Energia (gás natural) & & & 1,86E-03 & $7,10 \mathrm{E}+00$ & & & & $7,10 \mathrm{E}+00$ \\
\hline \multicolumn{9}{|c|}{ Saídas } \\
\hline \multicolumn{9}{|c|}{ Emissões atmosféricas (kg) } \\
\hline $\mathrm{CO}_{2}$ & $1,33 \mathrm{E}+03$ & $4,60 \mathrm{E}+03$ & $3,58 \mathrm{E}+01$ & $4,74 \mathrm{E}+02$ & & $5,01 \mathrm{E}+01$ & $4,20 \mathrm{E}+02$ & $6,91 \mathrm{E}+03$ \\
\hline $\mathrm{CO}$ & $2,96 \mathrm{E}+00$ & $2,35 \mathrm{E}+00$ & 1,21E-04 & 9,34E-03 & 4,72E-02 & $3,30 \mathrm{E}+01$ & $3,52 \mathrm{E}+00$ & $4,19 \mathrm{E}+01$ \\
\hline Hidrocarbonetos & 4,49E-01 & $6,15 \mathrm{E}+00$ & 7,84E-05 & & & $5,92 \mathrm{E}+01$ & 1,77E-02 & $6,58 \mathrm{E}+01$ \\
\hline Vapor de água & $1,46 \mathrm{E}+00$ & & & & & & $5,42 \mathrm{E}+00$ & $6,88 \mathrm{E}+00$ \\
\hline $\mathrm{CH}_{4}$ & $1,66 \mathrm{E}+01$ & & $6,41 \mathrm{E}-01$ & & $9,28 \mathrm{E}-03$ & & $1,29 E+00$ & $1,85 \mathrm{E}+01$ \\
\hline
\end{tabular}




\begin{tabular}{|c|c|c|c|c|c|c|c|c|}
\hline $\mathrm{NH}_{3}$ & & & & & & $6,13 \mathrm{E}+00$ & $1,41 \mathrm{E}-07$ & $6,13 E+00$ \\
\hline Metais & $6,76 \mathrm{E}-06$ & & & & & & 2,35E-07 & $6,99 \mathrm{E}-06$ \\
\hline $\mathrm{N}_{2} \mathrm{O}$ & & & & & & & 2,59E-01 & 2,59E-01 \\
\hline NOx & $4,78 \mathrm{E}+00$ & $8,76 \mathrm{E}+00$ & 1,14E-01 & $1,29 \mathrm{E}+00$ & $5,60 \mathrm{E}-01$ & $5,07 \mathrm{E}+01$ & $1,35 \mathrm{E}+01$ & 7,97E+01 \\
\hline SOx & $4,01 \mathrm{E}+00$ & $8,72 \mathrm{E}-01$ & 4,13E-01 & $1,68 \mathrm{E}-02$ & $5,60 \mathrm{E}-03$ & $8,84 \mathrm{E}-01$ & $2,74 \mathrm{E}+00$ & $8,94 \mathrm{E}+00$ \\
\hline Metil mercarptana & $6,34 \mathrm{E}-05$ & & & & & & & 6,34E-05 \\
\hline $\mathrm{H}_{2} \mathrm{~S}$ & 1,33E-03 & & 1,35E-07 & & & & & 1,33E-03 \\
\hline COV - exceto metano & $6,08 \mathrm{E}+00$ & & & & & & 1,71E-01 & $6,25 \mathrm{E}+00$ \\
\hline Material particulado & $8,33 \mathrm{E}-01$ & $1,31 \mathrm{E}-01$ & $6,96 \mathrm{E}-03$ & & 2,81E-01 & & $1,58 \mathrm{E}+00$ & $2,83 E+00$ \\
\hline \multicolumn{9}{|c|}{ Efluentes líquidos $(\mathrm{kg})$} \\
\hline DBO & $2,12 \mathrm{E}-01$ & & & & & & $1,65 \mathrm{E}-03$ & $2,14 \mathrm{E}-01$ \\
\hline DQO & $1,31 \mathrm{E}+00$ & 1,74E-01 & & & & & $3,06 \mathrm{E}-03$ & $1,48 \mathrm{E}+00$ \\
\hline Metais pesados não especificados & $2,94 \mathrm{E}-05$ & & & & & & 4,24E-06 & $3,37 \mathrm{E}-05$ \\
\hline Hidrocarbonetos & $1,24 \mathrm{E}-02$ & & & & & & 7,06E-04 & 1,32E-02 \\
\hline Ácidos como $\mathrm{H}^{+}$ & & & & & & & 4,00E-06 & 4,00E-06 \\
\hline Efluentes líquidos não especificados & $2,05 \mathrm{E}-04$ & & & & & & & 2,05E-04 \\
\hline Água residual & $1,98 \mathrm{E}-02$ & & & & & & & $1,98 \mathrm{E}-02$ \\
\hline Íons metálicos & 3,38E-05 & & & & & & 2,35E-04 & 2,69E-04 \\
\hline Óleos e graxas & $9,80 \mathrm{E}-02$ & & & & & & $3,30 \mathrm{E}-03$ & 1,01E-01 \\
\hline Sólidos dissolvidos totais & & & & & & & $1,18 \mathrm{E}-03$ & 1,18E-03 \\
\hline Sólidos suspensos totais & $6,72 \mathrm{E}-01$ & & & & & & $2,35 \mathrm{E}-03$ & $6,75 \mathrm{E}-01$ \\
\hline Compostos de enxofre & & 3,92E-01 & 6,96E-05 & & & & 1,06E-05 & 3,92E-01 \\
\hline Compostos de nitrogênio & & & $5,01 \mathrm{E}-07$ & & $5,60 \mathrm{E}-02$ & & 1,06E-04 & 5,61E-02 \\
\hline $\mathrm{Na}^{+}$ & 1,03E-01 & $1,35 \mathrm{E}+00$ & & & & & & $1,45 \mathrm{E}+00$ \\
\hline Cloretos $\left(\mathrm{Cl}^{-}\right)$ & $1,54 \mathrm{E}-01$ & & & & & & 1,41E-06 & $1,54 \mathrm{E}-01$ \\
\hline \multicolumn{9}{|c|}{ Resíduos sólidos (kg) } \\
\hline Resíduos processuais não especificados & $1,49 \mathrm{E}-02$ & & & & & & $2,52 \mathrm{E}+02$ & $2,52 \mathrm{E}+02$ \\
\hline Resíduos sólidos oleosos & $1,10 \mathrm{E}+00$ & & & & & & & $1,10 \mathrm{E}+00$ \\
\hline Enxofre & & & 8,63E-06 & & & & & $8,63 \mathrm{E}-06$ \\
\hline Catalisador usado & & & & & $1,13 \mathrm{E}-01$ & & & 1,13E-01 \\
\hline
\end{tabular}


Emissões energéticas (GJ)

\begin{tabular}{|c|c|c|c|}
\hline \multicolumn{4}{|c|}{ Emissões energéticas (GJ) } \\
\hline Vapor & 4,64E-04 & $1,30 \mathrm{E}+00$ & $1,30 \mathrm{E}+00$ \\
\hline
\end{tabular}




\section{APÊNDICE B9 - Inventário consolidado do sulfato de amônio obtido como subproduto da produção de MMA pela Unigel}

\begin{tabular}{|c|c|c|c|c|c|c|c|c|c|c|c|}
\hline & \begin{tabular}{|c|} 
Produção \\
de $243,6 \mathrm{~kg}$ \\
de nafta \\
(alocação \\
de 11,63\%)
\end{tabular} & $\begin{array}{c}\text { Produção } \\
\text { de } 91,58 \mathbf{~ k g} \\
\text { de propeno }\end{array}$ & $\begin{array}{l}\text { Produção } \\
\text { de } 68,86 \mathrm{~kg} \\
\text { de benzeno }\end{array}$ & $\begin{array}{c}\text { Beneficiamento } \\
\text { de } 1,87 \mathrm{t} \text { de gás } \\
\text { natural } \\
\text { (alocação de } \\
46,3 \% \text { ) }\end{array}$ & $\begin{array}{c}\text { Produção } \\
\text { de } 2,456 \mathrm{t} \\
\text { de } \mathrm{NH}_{3} \\
\text { (alocação } \\
\text { de } 46,3 \% \text { ) }\end{array}$ & $\begin{array}{l}\text { Produção } \\
\text { de } 3,232 \mathrm{t} \\
\text { de } \mathrm{HCN}\end{array}$ & \begin{tabular}{|c|} 
Energia \\
térmica do \\
gás natural: \\
$15,33 \mathrm{GJ}$ \\
(alocação \\
de $46,3 \%)$ \\
\end{tabular} & $\begin{array}{l}\text { Produção } \\
\text { de } 840 \mathrm{~kg} \\
\text { de } \mathrm{H}_{2} \mathrm{SO}_{4}\end{array}$ & $\begin{array}{c}\text { Produção } \\
\text { de } 1,57 \text { t de } \\
\text { MMA }\end{array}$ & $\begin{array}{l}\text { Eletricidade: } \\
24,667 \text { GJ }\end{array}$ & $\begin{array}{l}\text { Total por } \mathrm{t} \\
\text { de } \mathrm{N} \text { (sem } \\
\text { alocação) }\end{array}$ \\
\hline & $\begin{array}{c}\text { Apêndice } \\
\text { A8 }\end{array}$ & $\begin{array}{l}\text { Apêndice } \\
\text { A22 }\end{array}$ & $\begin{array}{l}\text { Apêndice } \\
\text { A20 }\end{array}$ & Apêndice A9 & $\begin{array}{l}\text { Apêndice } \\
\text { A12 }\end{array}$ & $\begin{array}{l}\text { Apêndice } \\
\text { A24 }\end{array}$ & $\begin{array}{l}\text { Apêndice } \\
\text { A10 }\end{array}$ & $\begin{array}{c}\text { Apêndice } \\
\text { A18 }\end{array}$ & $\begin{array}{c}\text { Apêndice } \\
\text { A26 }\end{array}$ & \begin{tabular}{|c|} 
Tabela 35 para \\
24,667 GJ \\
\end{tabular} & Soma \\
\hline \multicolumn{12}{|c|}{ Entradas } \\
\hline \multicolumn{12}{|c|}{ Recursos materiais $(\mathrm{kg})$} \\
\hline Petróleo & $2,94 \mathrm{E}+02$ & & & & & & & & & $2,98 \mathrm{E}+01$ & $3,24 \mathrm{E}+02$ \\
\hline Enxofre & & & & & & & & 2,77E+02 & & & 2,77E+02 \\
\hline Carvão & 1,39E-02 & & & & & & & & & $3,17 \mathrm{E}+02$ & 3,17E+02 \\
\hline Gás Natural & $1,13 \mathrm{E}+01$ & & & $8,92 E+02$ & $5,61 \mathrm{E}+02$ & $2,20 \mathrm{E}+03$ & $1,87 \mathrm{E}+02$ & & & $1,87 \mathrm{E}+01$ & $3,87 \mathrm{E}+03$ \\
\hline Combustíveis renováveis & 8,64E-02 & & & & & & & & & & 8,64E-02 \\
\hline Água & $5,99 \mathrm{E}+01$ & & & $1,71 \mathrm{E}+01$ & $1,46 \mathrm{E}+01$ & & & $1,22 \mathrm{E}+03$ & & $2,87 \mathrm{E}+06$ & $2,87 \mathrm{E}+06$ \\
\hline $\operatorname{Ar}$ & & & & & $6,04 \mathrm{E}+00$ & & & $4,12 \mathrm{E}+00$ & & & $1,02 E+01$ \\
\hline \multicolumn{12}{|c|}{ Recursos energéticos (GJ) } \\
\hline Energia Elétrica & $3,00 \mathrm{E}-02$ & & & & $1,26 \mathrm{E}+00$ & $1,27 \mathrm{E}+00$ & & & $2,21 \mathrm{E}+01$ & & $2,47 E+01$ \\
\hline Energia não especificada & 1,34E-03 & & & & & & & & & $3,91 \mathrm{E}+01$ & $3,91 \mathrm{E}+01$ \\
\hline Energia (gás natural) & & & & 3,75E-03 & & & $7,10 \mathrm{E}+00$ & & & & $7,10 \mathrm{E}+00$ \\
\hline \multicolumn{12}{|c|}{ Saídas } \\
\hline \multicolumn{12}{|c|}{ Emissões atmosféricas $(\mathrm{kg})$} \\
\hline $\mathrm{CO}_{2}$ & $5,60 \mathrm{E}+01$ & $9,66 \mathrm{E}+01$ & $1,69 \mathrm{E}+02$ & $7,24 \mathrm{E}+01$ & & $7,99 \mathrm{E}+03$ & $4,74 \mathrm{E}+02$ & & $8,64 \mathrm{E}+03$ & $4,40 \mathrm{E}+02$ & $1,79 E+04$ \\
\hline $\mathrm{CO}$ & $1,25 \mathrm{E}-01$ & 4,95E-02 & $5,01 \mathrm{E}-02$ & 2,44E-04 & 9,53E-02 & $3,49 \mathrm{E}+00$ & 9,34E-03 & & $9,11 \mathrm{E}+00$ & $3,69 \mathrm{E}+00$ & $1,66 \mathrm{E}+01$ \\
\hline Hidrocarbonetos & 1,89E-02 & $1,29 \mathrm{E}-01$ & 1,44E-01 & $1,59 \mathrm{E}-04$ & & 2,07E-03 & & & $1,05 E+01$ & 1,85E-02 & $1,08 E+01$ \\
\hline Vapor de água & $6,12 \mathrm{E}-02$ & & & & & & & & & $5,68 \mathrm{E}+00$ & $5,74 \mathrm{E}+00$ \\
\hline
\end{tabular}




\begin{tabular}{|c|c|c|c|c|c|c|c|c|c|c|c|}
\hline $\mathrm{CH}_{4}$ & $6,98 \mathrm{E}-01$ & & & $1,29 \mathrm{E}+00$ & $1,87 \mathrm{E}-02$ & $3,17 \mathrm{E}+00$ & & & $4,40 \mathrm{E}+01$ & $1,35 \mathrm{E}+00$ & $5,05 \mathrm{E}+01$ \\
\hline $\mathrm{NH}_{3}$ & & & & & & $3,13 \mathrm{E}-01$ & & & $5,34 \mathrm{E}-02$ & $1,48 \mathrm{E}-07$ & $3,66 \mathrm{E}-01$ \\
\hline Metais & $2,84 \mathrm{E}-07$ & & & & & & & & $1,57 \mathrm{E}-02$ & 2,47E-07 & $1,57 \mathrm{E}-02$ \\
\hline $\mathrm{N}_{2} \mathrm{O}$ & & & & & & $7,72 \mathrm{E}-04$ & & & & $2,71 \mathrm{E}-01$ & $2,72 \mathrm{E}-01$ \\
\hline NOx & $2,01 \mathrm{E}-01$ & $1,84 \mathrm{E}-01$ & $1,81 \mathrm{E}-01$ & $2,31 \mathrm{E}-01$ & $1,13 \mathrm{E}+00$ & $3,01 \mathrm{E}+01$ & $1,29 \mathrm{E}+00$ & & $3,77 \mathrm{E}+01$ & $1,42 E+01$ & $8,51 \mathrm{E}+01$ \\
\hline SOx & $1,69 \mathrm{E}-01$ & 1,83E-02 & $2,38 \mathrm{E}-02$ & $8,35 \mathrm{E}-01$ & $1,13 \mathrm{E}-02$ & $6,08 \mathrm{E}+01$ & $1,68 \mathrm{E}-02$ & $2,23 \mathrm{E}+00$ & $4,08 \mathrm{E}+01$ & $2,87 \mathrm{E}+00$ & $1,08 \mathrm{E}+02$ \\
\hline Metil mercarptana & $2,66 \mathrm{E}-06$ & & & & & & & & & & $2,66 \mathrm{E}-06$ \\
\hline $\mathrm{H}_{2} \mathrm{~S}$ & $5,58 \mathrm{E}-05$ & & & 2,73E- 07 & & & & & & & $5,61 \mathrm{E}-05$ \\
\hline Cianetos $(\mathrm{CN})$ & & & & & & $1,55 \mathrm{E}-01$ & & & $2,51 \mathrm{E}-02$ & & $1,80 \mathrm{E}-01$ \\
\hline COV - exceto metano & 2,55E-01 & & & & & $6,24 \mathrm{E}+00$ & & & $4,57 \mathrm{E}+00$ & $1,80 \mathrm{E}-01$ & $1,12 \mathrm{E}+01$ \\
\hline Material particulado & $3,50 \mathrm{E}-02$ & $2,75 \mathrm{E}-03$ & $2,75 \mathrm{E}-03$ & $1,41 \mathrm{E}-02$ & $5,67 \mathrm{E}-01$ & $3,26 \mathrm{E}+00$ & & & $8,95 \mathrm{E}+00$ & $1,66 \mathrm{E}+00$ & $1,45 \mathrm{E}+01$ \\
\hline $\mathrm{H}_{2}$ & & & $6,89 \mathrm{E}-04$ & & & & & & & & $6,89 \mathrm{E}-04$ \\
\hline \multicolumn{12}{|c|}{ Efluentes líquidos $(\mathrm{kg})$} \\
\hline DBO & $8,91 \mathrm{E}-03$ & & & & & $1,98 \mathrm{E}-01$ & & & $3,61 \mathrm{E}-01$ & $1,73 \mathrm{E}-03$ & $5,70 \mathrm{E}-01$ \\
\hline $\mathrm{DQO}$ & $5,49 \mathrm{E}-02$ & $3,66 \mathrm{E}-03$ & $3,66 \mathrm{E}-03$ & & & 6,33E-01 & & & $1,55 \mathrm{E}+00$ & $3,21 \mathrm{E}-03$ & $2,25 \mathrm{E}+0 \mathrm{C}$ \\
\hline Metais pesados não especificados & $1,24 \mathrm{E}-06$ & & & & & 6,57E-03 & & & & 4,44E-06 & $6,58 \mathrm{E}-03$ \\
\hline Hidrocarbonetos & $5,23 \mathrm{E}-04$ & & $6,89 \mathrm{E}-04$ & & & $1,45 \mathrm{E}-01$ & & & $9,11 \mathrm{E}-02$ & $7,40 \mathrm{E}-04$ & $2,38 \mathrm{E}-01$ \\
\hline Ácidos como H & & & & & & $3,81 \mathrm{E}-01$ & & & 3,93E-01 & $4,19 \mathrm{E}-06$ & $7,74 \mathrm{E}-01$ \\
\hline Efluentes líquidos não especificados & $8,60 \mathrm{E}-06$ & & & & & & & & & & $8,60 \mathrm{E}-06$ \\
\hline Água residual & $8,33 \mathrm{E}-04$ & & & & & & & & & & $8,33 \mathrm{E}-04$ \\
\hline Íons metálicos & $1,42 \mathrm{E}-06$ & & & & & $2,44 \mathrm{E}-02$ & & & $4,73 \mathrm{E}-01$ & 2,47E-04 & 4,97E-01 \\
\hline Óleos e graxas & $4,12 \mathrm{E}-03$ & & & & & $7,76 \mathrm{E}-02$ & & & $9,58 \mathrm{E}-02$ & $3,45 \mathrm{E}-03$ & $1,81 \mathrm{E}-01$ \\
\hline Sólidos dissolvidos totais & & & & & & $2,07 \mathrm{E}+00$ & & & $8,48 \mathrm{E}-01$ & $1,23 \mathrm{E}-03$ & $2,91 \mathrm{E}+0 \mathrm{C}$ \\
\hline Sólidos suspensos totais & $2,82 \mathrm{E}-02$ & & & & & $3,52 \mathrm{E}+00$ & & & $2,20 \mathrm{E}+00$ & $2,47 \mathrm{E}-03$ & $5,75 \mathrm{E}+0 \mathrm{C}$ \\
\hline Compostos de enxofre & & $8,24 \mathrm{E}-03$ & $8,24 \mathrm{E}-03$ & $1,41 \mathrm{E}-04$ & & $7,85 \mathrm{E}+00$ & & & $4,71 \mathrm{E}+01$ & $1,11 \mathrm{E}-05$ & $5,50 \mathrm{E}+01$ \\
\hline Compostos de nitrogênio & & & & $1,01 \mathrm{E}-06$ & 1,13E-01 & $1,84 \mathrm{E}+00$ & & & $4,72 \mathrm{E}+00$ & $1,11 \mathrm{E}-04$ & $6,67 \mathrm{E}+0 \mathrm{C}$ \\
\hline $\mathrm{Na}^{+}$ & 4,34E-03 & $2,84 \mathrm{E}-02$ & $2,84 \mathrm{E}-02$ & & & $4,30 \mathrm{E}+00$ & & & $2,20 \mathrm{E}+01$ & & $2,63 E+01$ \\
\hline Cloretos $\left(\mathrm{Cl}^{-}\right)$ & $6,49 \mathrm{E}-03$ & & & & & $1,51 \mathrm{E}+01$ & & & $1,33 \mathrm{E}+01$ & $1,48 \mathrm{E}-06$ & $2,85 \mathrm{E}+01$ \\
\hline \multicolumn{12}{|c|}{ Resíduos sólidos (kg) } \\
\hline Resíduos processuais não especificados & $6,25 \mathrm{E}-04$ & & & & & & & & $1,61 \mathrm{E}+02$ & $2,64 E+02$ & $4,25 \mathrm{E}+02$ \\
\hline
\end{tabular}




\begin{tabular}{|c|c|c|c|c|c|}
\hline Resíduos sólidos oleosos & $4,64 \mathrm{E}-02$ & & & & 4,64E-02 \\
\hline Enxofre & & $1,75 \mathrm{E}-05$ & & $6,38 \mathrm{E}+00$ & $6,38 \mathrm{E}+00$ \\
\hline Catalisador usado & & & $2,28 \mathrm{E}-01$ & $4,88 \mathrm{E}+01$ & $4,90 \mathrm{E}+01$ \\
\hline \multicolumn{6}{|c|}{ Emissões energéticas (GJ) } \\
\hline Vapor & & $9,38 \mathrm{E}-04$ & $2,62 \mathrm{E}+00$ & & $2,62 E+00$ \\
\hline
\end{tabular}




\section{APÊNDICE B10 - Inventário consolidado do sulfato de amônio adequado às condições brasileiras}

\begin{tabular}{|c|c|c|c|c|c|c|}
\hline & \begin{tabular}{|c|} 
Produção de \\
sulfato de \\
amônio e \\
caprolactama: \\
$32 \%$ (alocação \\
de $64,3 \%)$ \\
\end{tabular} & \begin{tabular}{|c|} 
Produção de \\
sulfato de \\
amônio e \\
acrilonitrila: \\
$6 \%$ (alocação \\
de $13,8 \%$ ) \\
\end{tabular} & \begin{tabular}{|c|} 
Produção de \\
sulfato de \\
amônio e \\
MMA: $37 \%$ \\
(alocação de \\
$75 \%$ ) \\
\end{tabular} & \begin{tabular}{|c|} 
Produção de \\
sulfato de \\
amônio via \\
síntese \\
(Bunge): \\
$13 \%$ \\
\end{tabular} & \begin{tabular}{|c|} 
Produção de \\
sulfato de \\
amônio via \\
síntese \\
(Unigel): \\
$12 \%$ \\
\end{tabular} & $\begin{array}{c}\text { Sulfato de } \\
\text { amônio } \\
\text { produzido } \\
\text { no Brasil }\end{array}$ \\
\hline & Apêndice B7 & Apêndice B8 & Apêndice B9 & Apêndice B6 & Apêndice B5 & Soma \\
\hline \multicolumn{7}{|c|}{ Entradas } \\
\hline \multicolumn{7}{|c|}{ Recursos materiais (kg) } \\
\hline Petróleo & $2,93 \mathrm{E}+03$ & $5,82 \mathrm{E}+01$ & $8,99 \mathrm{E}+01$ & $4,50 \mathrm{E}+01$ & 4,95E-01 & $3,13 E+03$ \\
\hline Enxofre & $2,38 \mathrm{E}+02$ & & $7,69 \mathrm{E}+01$ & $1,50 \mathrm{E}+02$ & $1,39 \mathrm{E}+02$ & $6,03 E+02$ \\
\hline Carvão & $6,43 \mathrm{E}+01$ & $2,51 \mathrm{E}+00$ & $8,79 \mathrm{E}+01$ & $8,59 \mathrm{E}+00$ & $5,25 \mathrm{E}+00$ & $1,69 \mathrm{E}+02$ \\
\hline Gás Natural & $3,03 \mathrm{E}+02$ & $9,88 \mathrm{E}+00$ & $1,07 \mathrm{E}+03$ & $2,21 \mathrm{E}+00$ & $1,09 \mathrm{E}+02$ & $1,50 \mathrm{E}+03$ \\
\hline Combustíveis renováveis & 8,59E-01 & $1,70 \mathrm{E}-02$ & $2,40 \mathrm{E}-02$ & $1,30 \mathrm{E}-02$ & & 9,13E-01 \\
\hline Água & $5,83 \mathrm{E}+05$ & $2,27 \mathrm{E}+04$ & 7,97E+05 & $7,84 \mathrm{E}+04$ & $4,82 \mathrm{E}+04$ & $1,53 \mathrm{E}+06$ \\
\hline $\mathrm{Ar}$ & $4,14 \mathrm{E}+00$ & 2,48E-02 & $2,82 \mathrm{E}+00$ & $2,62 \mathrm{E}+00$ & $2,42 \mathrm{E}+00$ & $1,20 \mathrm{E}+01$ \\
\hline \multicolumn{7}{|c|}{ Recursos energéticos (GJ) } \\
\hline Energia Elétrica & $5,00 \mathrm{E}+00$ & \begin{tabular}{|l|}
$1,95 \mathrm{E}-01$ \\
\end{tabular} & $6,85 \mathrm{E}+00$ & $6,68 \mathrm{E}-01$ & 4,09E-01 & $1,31 \mathrm{E}+01$ \\
\hline Energia não especificada & $7,93 \mathrm{E}+00$ & $3,09 \mathrm{E}-01$ & $1,08 \mathrm{E}+01$ & $1,06 \mathrm{E}+00$ & $6,47 \mathrm{E}-01$ & $2,08 \mathrm{E}+01$ \\
\hline Energia (gás natural) & $1,46 \mathrm{E}+00$ & $5,88 \mathrm{E}-02$ & $1,97 \mathrm{E}+00$ & & 8,52E-01 & $4,34 \mathrm{E}+00$ \\
\hline \multicolumn{7}{|c|}{ Saídas } \\
\hline \multicolumn{7}{|c|}{ Emissões atmosféricas (kg) } \\
\hline $\mathrm{CO}_{2}$ & $7,05 \mathrm{E}+03$ & $5,72 \mathrm{E}+01$ & $4,98 \mathrm{E}+03$ & $2,04 \mathrm{E}+01$ & $6,85 \mathrm{E}+01$ & $1,22 \mathrm{E}+04$ \\
\hline $\mathrm{CO}$ & $3,13 \mathrm{E}+00$ & 3,47E-01 & $4,61 \mathrm{E}+00$ & $1,25 \mathrm{E}-01$ & 6,79E-02 & $8,28 \mathrm{E}+00$ \\
\hline Hidrocarbonetos & $3,70 \mathrm{E}+00$ & $5,45 \mathrm{E}-01$ & $3,01 \mathrm{E}+00$ & 3,34E-03 & $3,16 \mathrm{E}-04$ & $7,25 \mathrm{E}+00$ \\
\hline Vapor de água & $1,76 \mathrm{E}+00$ & $5,70 \mathrm{E}-02$ & $1,59 \mathrm{E}+00$ & $1,63 \mathrm{E}-01$ & $9,41 \mathrm{E}-02$ & $3,67 E+00$ \\
\hline $\mathrm{CH}_{4}$ & $7,35 \mathrm{E}+00$ & $1,54 \mathrm{E}-01$ & $1,40 \mathrm{E}+01$ & 1,42E-01 & $1,00 \mathrm{E}-01$ & $2,18 E+01$ \\
\hline $\mathrm{NH}_{3}$ & $1,13 \mathrm{E}-01$ & $5,08 \mathrm{E}-02$ & $1,02 \mathrm{E}-01$ & 4,01E-09 & $2,45 \mathrm{E}-09$ & $2,66 \mathrm{E}-01$ \\
\hline Metais & 2,88E-06 & 5,79E-08 & 4,36E-03 & 4,94E-08 & 4,09E-09 & 4,36E-03 \\
\hline $\mathrm{N}_{2} \mathrm{O}$ & 5,49E-02 & $2,14 \mathrm{E}-03$ & 7,54E-02 & 7,33E-03 & 4,49E-03 & $1,44 \mathrm{E}-01$ \\
\hline NOx & $1,14 \mathrm{E}+01$ & 6,60E-01 & $2,36 \mathrm{E}+01$ & 4,87E-01 & 4,71E-01 & $3,66 \mathrm{E}+01$ \\
\hline SOx & $4,79 \mathrm{E}+00$ & 7,40E-02 & $2,99 \mathrm{E}+01$ & $1,31 \mathrm{E}+00$ & $1,22 \mathrm{E}+00$ & $3,73 E+01$ \\
\hline Metil mercarptana & $2,65 \mathrm{E}-05$ & $5,25 \mathrm{E}-07$ & 7,39E-07 & 4,01E-07 & & 2,82E-05 \\
\hline $\mathrm{H}_{2} \mathrm{~S}$ & 5,55E-04 & $1,10 \mathrm{E}-05$ & 1,56E-05 & 8,39E-06 & $1,62 \mathrm{E}-08$ & $5,90 \mathrm{E}-04$ \\
\hline Cianetos $\left(\mathrm{CN}^{-}\right)$ & & & $5,00 \mathrm{E}-02$ & & & $5,00 \mathrm{E}-02$ \\
\hline COV - exceto metano & $2,77 \mathrm{E}+00$ & 5,17E-02 & $3,12 \mathrm{E}+00$ & 4,32E-02 & 2,98E-03 & $5,99 \mathrm{E}+00$ \\
\hline Material particulado & 7,98E-01 & 2,35E-02 & $4,02 \mathrm{E}+00$ & $1,54 \mathrm{E}-01$ & $1,24 \mathrm{E}-01$ & $5,12 \mathrm{E}+00$ \\
\hline $\mathrm{H}_{2}$ & $6,25 \mathrm{E}-02$ & & 1,91E-04 & & & 6,27E-02 \\
\hline \multicolumn{7}{|c|}{ Efluentes líquidos (kg) } \\
\hline
\end{tabular}




\begin{tabular}{|c|c|c|c|c|c|c|}
\hline DBO & 8,90E-02 & 1,77E-03 & $1,58 \mathrm{E}-01$ & 1,39E-03 & 2,86E-05 & 2,50E-01 \\
\hline DQO & $6,19 \mathrm{E}-01$ & 1,23E-02 & $6,25 \mathrm{E}-01$ & 8,34E-03 & 5,31E-05 & $1,27 E+00$ \\
\hline Metais pesados não especificados & $1,32 \mathrm{E}-05$ & 2,79E-07 & 1,82E-03 & $3,06 \mathrm{E}-07$ & 7,36E-08 & 1,84E-03 \\
\hline Hidrocarbonetos & 1,91E-02 & $1,09 E-04$ & 6,62E-02 & 9,86E-05 & 1,23E-05 & 8,54E-02 \\
\hline Ácidos como $\mathrm{H}^{+}$ & $8,49 \mathrm{E}-07$ & $3,31 \mathrm{E}-08$ & $2,15 \mathrm{E}-01$ & $1,14 \mathrm{E}-07$ & $6,95 \mathrm{E}-08$ & $2,15 \mathrm{E}-01$ \\
\hline Efluentes líquidos não especificados & 8,56E-05 & $1,70 \mathrm{E}-06$ & $2,39 \mathrm{E}-06$ & 1,29E-06 & & 9,10E-05 \\
\hline Água residual & 8,29E-03 & $1,64 \mathrm{E}-04$ & 2,31E-04 & $1,25 E-04$ & & 8,81E-03 \\
\hline Íons metálicos & 6,41E-05 & 2,23E-06 & $1,38 \mathrm{E}-01$ & $6,89 \mathrm{E}-06$ & $4,09 \mathrm{E}-06$ & 1,38E-01 \\
\hline Óleos e graxas & 4,17E-02 & 8,39E-04 & 5,02E-02 & 7,13E-04 & 5,72E-05 & 9,35E-02 \\
\hline Sólidos dissolvidos totais & $2,50 \mathrm{E}-04$ & $9,75 E-06$ & 8,09E-01 & 3,34E-05 & 2,04E-05 & 8,09E-01 \\
\hline Sólidos suspensos totais & 2,82E-01 & $5,59 \mathrm{E}-03$ & $1,60 \mathrm{E}+00$ & 4,31E-03 & 4,09E-05 & $1,89 \mathrm{E}+00$ \\
\hline Compostos de enxofre & $1,64 \mathrm{E}-01$ & $3,25 \mathrm{E}-03$ & $1,53 \mathrm{E}+01$ & $3,01 \mathrm{E}-07$ & $8,54 \mathrm{E}-06$ & $1,54 \mathrm{E}+01$ \\
\hline Compostos de nitrogênio & $1,15 \mathrm{E}-02$ & $4,65 \mathrm{E}-04$ & $1,85 \mathrm{E}+00$ & 7,29E-03 & $6,72 \mathrm{E}-03$ & $1,88 \mathrm{E}+00$ \\
\hline $\mathrm{Na}^{+}$ & $6,09 E-01$ & $1,20 \mathrm{E}-02$ & $7,31 \mathrm{E}+00$ & $6,53 \mathrm{E}-04$ & & $7,93 \mathrm{E}+00$ \\
\hline Cloretos $\left(\mathrm{Cl}^{-}\right)$ & $6,46 \mathrm{E}-02$ & $1,28 \mathrm{E}-03$ & $7,90 \mathrm{E}+00$ & $9,76 \mathrm{E}-04$ & $2,45 \mathrm{E}-08$ & $7,97 \mathrm{E}+00$ \\
\hline \multicolumn{7}{|c|}{ Resíduos sólidos (kg) } \\
\hline Resíduos processuais não especificados & $5,35 \mathrm{E}+01$ & $2,09 \mathrm{E}+00$ & $1,18 \mathrm{E}+02$ & $7,17 \mathrm{E}+00$ & $4,37 \mathrm{E}+00$ & $1,85 E+02$ \\
\hline Resíduo sólidos oleosos & 4,61E-01 & $9,14 \mathrm{E}-03$ & 1,29E-02 & 6,97E-03 & & $4,90 \mathrm{E}-01$ \\
\hline Enxofre & $5,47 \mathrm{E}+00$ & $7,15 \mathrm{E}-08$ & $1,77 \mathrm{E}+00$ & $3,45 \mathrm{E}+00$ & $3,19 \mathrm{E}+00$ & $1,39 \mathrm{E}+01$ \\
\hline Catalisador usado & $4,19 \mathrm{E}+01$ & $9,32 \mathrm{E}-04$ & $1,36 \mathrm{E}+01$ & $2,65 E+01$ & $2,44 \mathrm{E}+01$ & $1,06 \mathrm{E}+02$ \\
\hline \multicolumn{7}{|c|}{ Emissões energéticas (GJ) } \\
\hline Vapor & 2,67E-01 & 1,07E-02 & 7,26E-01 & 1,69E-01 & $1,56 \mathrm{E}-01$ & $1,33 E+00$ \\
\hline
\end{tabular}

